The Interplay Between Chemistry and Transport $P$ henomena During the Fast Pyrolysis of Cellulose, Lignin and Biomass

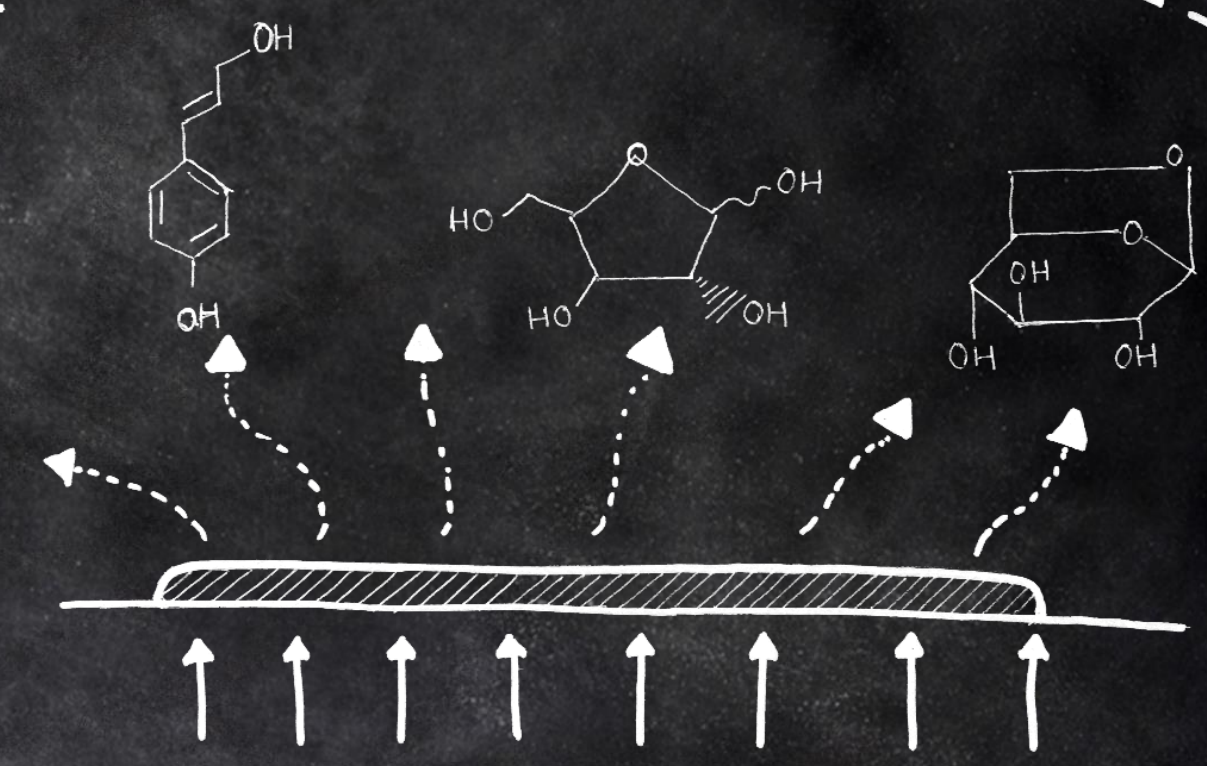

Pushkar Salish Marathe 



\title{
THE INTERPLAY BETWEEN CHEMISTRY AND TRANSPORT PHENOMENA DURING THE FAST PYROLYSIS OF CELLULOSE, LIGNIN AND BIOMASS
}

\author{
Pushkar Satish Marathe
}





\title{
THE INTERPLAY BETWEEN CHEMISTRY AND TRANSPORT PHENOMENA DURING THE FAST PYROLYSIS OF CELLULOSE, LIGNIN AND BIOMASS
}

\author{
DISSERTATION
}

\author{
to obtain \\ the degree of doctor at the University of Twente, \\ on the authority of the rector magnificus, \\ prof.dr. T.T.M. Palstra, \\ on account of the decision of the Doctorate Board, \\ to be publicly defended \\ on Friday the $13^{\text {th }}$ of September 2019 at 16:45 hours \\ by
}

Pushkar Satish Marathe

born on the $16^{\text {th }}$ August 1988

in Mumbai, India 
This dissertation has been approved by:

Supervisor:

prof.dr. S.R.A. Kersten

The research described in this thesis was conducted in the Sustainable Process Technology (SPT) group at the University of Twente, The Netherlands. This work is financially supported by the Netherlands Organisation for Scientific Research (NWO); Project number - 717-014-006.

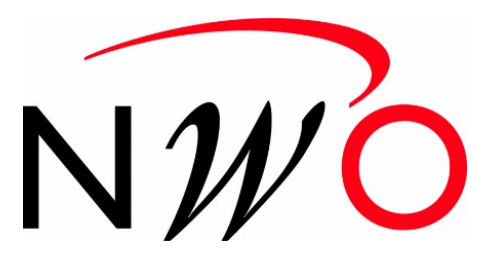

\section{UNIVERSITY OF TWENTE.}

Cover design: Prachi P. Buche Marathe and Pushkar S. Marathe

Printed by: Gildeprint

Lay-out: in $\mathrm{AT}_{\mathrm{E}} \mathrm{X}$ by Pushkar S. Marathe

ISBN: 978-90-365-4845-8

DOI: $10.3990 / 1.9789036548458$

(C) 2019 Pushkar S. Marathe, The Netherlands. All rights reserved. No parts of this thesis may be reproduced, stored in a retrieval system or transmitted in any form or by any means without permission of the author. 


\section{GRADUATION COMMITTEE:}

Chairman:

Secretary:

Supervisor:

Referee:

Members: prof.dr J.L. Herek

prof.dr J.L. Herek

prof.dr. S.R.A. Kersten

dr.ir. R.J.M. Westerhof

prof.dr.ir. G. Brem

prof.dr. K. Seshan

prof.dr.ir. W. Prins

prof.dr. M. Garcia Perez
University of Twente

University of Twente

University of Twente

Suster BV

University of Twente, ET

University of Twente, TNW

Ghent University

Washington State University 

Dedicated to my father 

... If I have seen further it is by standing on the shoulders of Giants.

- Sir Isaac Newton (5 ${ }^{\text {th }}$ February 1676) 
Summary (xiii)

Samenvatting (xvii)

सारांश ( $x$ i)

Evaluating quantitative

determination of levoglucosan and hydroxyacetaldehyde in bio-oils by gas and liquid chromatography

$$
\text { (39) }
$$

Materials and methods

General introduction

(1)

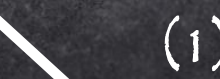

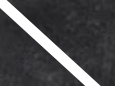

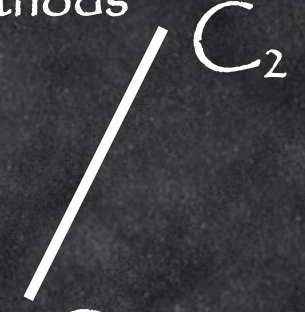

Fast pyrolysis of cellulose: interaction

between chemistry and transport phenomena in the absence and presence of potassium

(51)

Appendices: A(161), B (201), C (207), D (233)

References (259) 


\section{ontents}

Fast pyrolysis of lignins with different molecular weight: experiments and modelling

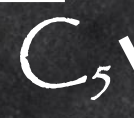

(91)

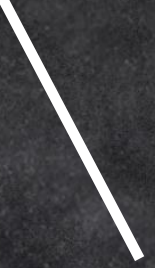

On the effect of ether linkages in lignin

Con the product yields and the molecular

$\mathrm{C}_{6}$ weight of pyrolysis oils using $\mathrm{HSQC}$ NMR

Effect of pressure on the fast pyrolysis of acid-leached bagasse and pine wood: experiments and modelling

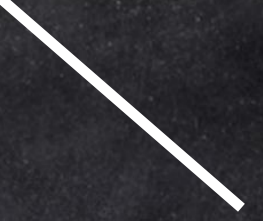

(139)

$C_{8}$ Conclusions and outlook (153)

Acknowledgements (287), List of publications (293)

About the author (295) 



\section{Summary}

Depleting fossil energy resources and the changes in climatic conditions have propelled humanity to find alternative sustainable resources to satisfy the increasing demand. Lignocellulosic biomass is one of the carbon-based renewable resources which can be used to produce fuels and chemicals. Fast pyrolysis is one of the promising technologies in which lignocellulosic biomass is decomposed at $\sim 500{ }^{\circ} \mathrm{C}$ and in the absence of oxygen, to produce oil $(\sim 75 \%)$, char $(\sim 12 \%)$ and gas $(\sim 13 \%)$. Pyrolysis oil can be upgraded to fuel or platform chemicals via downstream processing.

Literature suggests that the yields of products and their composition obtained during the pyrolysis are affected by the competition between transport phenomena and chemistry. The research described in this thesis aims at advancing the current understanding of the three simultaneously occurring processes, viz. chemical reactions (decomposition, cracking, polymerisation), heat transfer and mass transfer (evaporation, sublimation, random ejection), and their interplay during the fast pyrolysis of cellulose, lignin and lignocellulosic biomass.

For that, a dedicated screen-heater reactor was used, which was designed: 1) to minimise non-isothermality (heating rate: $\sim 5000^{\circ} \mathrm{C} \mathrm{s}^{-1}$ ), 2) to control the reaction time inside the reacting particle by the escape rate of compounds from the reaction zone by variation of the pressure, and 3) to minimise reactions outside the reacting particle by minimising hot vapour residence time $(\sim 20 \mathrm{~ms})$ and fast quenching of the products ( $180{ }^{\circ} \mathrm{C}$ ). Experiments were also carried out in a bench-scale $1 \mathrm{~kg} \mathrm{~h}^{-1}$ fluidised bed unit equipped with a fractional condensation system to investigate the effect of hot vapour residence time $(\sim 2 s)$.

Qualitative and quantitative characterisation of pyrolysis products was done using various analytical tools. In order to understand the reaction mechanisms, quantitative analysis of species present in pyrolysis oil is necessary. The suitability of gas chromatography (GC) and liquid chromatography (LC) for the quantification of levoglucosan (LG) and hydroxyacetaldehyde (HA) was evaluated. It was found that both GC and LC can principally determine LG quantitatively in pyrolysis oils. However, depolymerisation of oligo-anhydrosugars in GC owns a risk of overestimation of the LG yields. HA can only be determined quantitatively by LC because of its reactions during the high temperature $\left(\sim 250^{\circ} \mathrm{C}\right)$ injection in GC.

It was found that in the absence of potassium salts, cellulose could almost entirely be converted to anhydrosugars while producing hardly any gas $(<1 \%)$ and char $(<1 \%)$ in 
a wide temperature range of 450 to $765^{\circ} \mathrm{C}$. Depolymerisation of cellulose to anhydrosugars was identified to be a true primary reaction; gas and char formation secondary. Mathematical models were developed, including the interaction between chemistry, heat transfer and mass transfer. The escape rate of products from the hot reacting particle was identified as a crucial process affecting the DP distribution of anhydrosugars.

The potassium concentration in cellulose was varied to mimic the mineral-rich and pre-treated feedstock and subsequently pyrolysed at $530^{\circ} \mathrm{C}$ in screen-heater and fluidised bed. Potassium was found to be catalytically active even when the escape rate of the product away from the reaction front was extremely high (milliseconds). The yields of oil and anhydrosugars decreased significantly as a function of potassium concentration, while the production of other products (water, gases, light oxygenated compounds) was enhanced. The production of char was found to be independent of the escape rate of products at any given potassium concentration. It could be concluded that pyrolysis at reduced pressure, i.e. by fast removal of products from the hot reaction zone, can improve the oil and sugar yields, but only for low alkali and alkaline earth metals content feedstock.

The effect of molecular weight on the competing physio-chemical processes was investigated by pyrolysing 14 lignins $(350-1900 \mathrm{Da})$ in the screen-heater at $0.5 \mathrm{kPa}$ and $100 \mathrm{kPa}$. A population balance model was developed, which includes simultaneously occurring cracking reactions, polymerisation reactions and mass transport away from the reaction zone. The model was able to predict all experimentally observed trends after parametrisation. The molecular weight distribution was found to be one of the crucial characteristics of the lignin feedstock, which has a significant influence on the pyrolysis product distribution. Upwards $530{ }^{\circ} \mathrm{C}$, the temperature turned out to have only a minor influence on the yields and composition of the oils produced, whereas the system pressure was identified as the main steering wheel to manipulate the product yields and the molecular weight of the oils. HSQC NMR analysis of lignins and its oils showed that the yields of oil and char and the number average molecular weight of oils were found to be independent of the number of ether linkages in the lignin feedstock.

Fast pyrolysis of acid-leached bagasse was carried out in the pressure range of 0.005 to $100 \mathrm{kPa}$ in screen-heater. At the lowest pressure, the total yield of $\mathrm{C}_{6}$-anhydrosugars (sum of $D P_{1}$ to $D P_{6}$ ) was as high as $73 \%$ of the poly- $\mathrm{C}_{6}$-sugars in the feedstock. A mathematical model, including again reaction and mass transfer away from the reaction zone, was able to predict the measured decrease in a total yield of $\mathrm{C}_{6}$-anhydrosugars and the shift to lighter $\mathrm{C}_{6}$-anhydrosugars as a function of increasing pressure. At identical pressure and temperature, the total yield of $\mathrm{C}_{6}$-anhydrosugars obtained from acid-leached 
pinewood was the same for the screen-heater and fluidised bed. As a result of the longer hot vapour residence time in the fluidised bed, $D P_{\geq 2} \mathrm{C}_{6}$-anhydrosugars depolymerised towards $D P_{1}$.

In nutshell, besides the heating rate of sample, hot vapour residence time of products and the temperature during the pyrolysis, the system pressure is the key parameter, which alters the residence time of products in/on the hot reacting particle, thereby, providing a means to steer the yields and composition of the products of pyrolysis. 



\section{Samenvatting}

Het uitputten van fossiele energiebronnen en de klimaatveranderingen hebben de mensheid ertoe aangezet om alternatieve duurzame bronnen te vinden om aan de toenemende vraag te voldoen. Lignocellulose biomassa is een van de hernieuwbare bronnen op basis van koolstof die kunnen worden gebruikt om brandstoffen en chemicaliën te produceren. Snelle pyrolyse is een van de veelbelovende technologieën waarbij lignocellulosische biomassa wordt afgebroken bij $\sim 500{ }^{\circ} \mathrm{C}$ en in afwezigheid van zuurstof, om olie $(\sim 75 \%)$, kool $(\sim 12 \%)$ en gas $(\sim 13 \%)$ te produceren. Pyrolyse-olie kan worden opgewaardeerd tot brandstof of platformchemicaliën via vervolgstappen in het proces.

In de literatuur wordt gesuggereerd dat de opbrengsten en de samenstelling van producten verkregen tijdens de pyrolyse, worden beïnvloed door een samenhang vantransportverschijnselen en chemie. Het onderzoek dat in dit proefschrift beschreven wordt, is gericht op het bevorderen van het huidige begrip van de drie gelijktijdig optredende processen. Deze drie processen zijn: chemische reacties (ontleding, kraken en polymerisatie), warmte- en massaoverdracht (verdamping, sublimatie en willekeurige uitstoot) en hun wisselwerking tijdens de snelle pyrolyse van cellulose, lignine en lignocellulose biomassa.

Voor het onderzoek werd een speciale screen-heater reactor gebruikt, die ontworpen was om: 1) niet-isotherm gedrag te minimaliseren (verwarmingssnelheid: $\sim 5000{ }^{\circ} \mathrm{C}$ $\left.\mathrm{s}^{-1}\right), 2$ ) de reactietijd in het reagerende deeltje door de ontsnappingsnelheid van componenten uit de reactiezone te controleren door variatie van de druk, en 3)reacties buiten het reagerende deeltje te minimaliseren door de verblijftijd van hete damp te minimaliseren $(\sim 20 \mathrm{~ms})$ en de producten snel af te koelen $\left(\sim-180^{\circ} \mathrm{C}\right)$. Er werden ook experimenten uitgevoerd in een $1 \mathrm{~kg} \mathrm{~h}^{-1}$ wervelbed opstelling uitgerust met een fractioneel condensatiesysteem om het effect van de verblijftijd ( $\sim 2 s)$ van de hete damp te onderzoeken.

Kwalitatieve en kwantitatieve karakterisering van pyrolyseproducten werd uitgevoerd met behulp van verschillende analytische hulpmiddelen. Om de reactiemechanismen te begrijpen, is kwantitatieve analyse van de in pyrolyse-olie aanwezige componenten noodzakelijk. De geschiktheid van gaschromatografie (GC) en vloeistofchromatografie (LC) voor de kwantificering van levoglucosaan (LG) en hydroxyacetaldehyde (HA) werd geëvalueerd. Zowel GC als LC kunnen in principe LG kwantitatief bepalen in pyrolyse-oliën. Echter, depolymerisatie van oligo-anhydrosuikers in GC kan resulteren in een overschatting van de LG opbrengsten. HA kan alleen kwantitatief worden bepaald door middel van $\mathrm{LC}$ vanwege reacties tijdens de injectie op hoge temperatuur $\left(\sim 250^{\circ} \mathrm{C}\right)$ in GC. 
Cellulose kon bij afwezigheid van kaliumzouten vrijwel volledig worden omgezet in anhydrosuikers, terwijl er nauwelijks gas $(<1 \%)$ en kool $(<1 \%)$ werd geproduceerd over een breed temperatuurbereik van 450 tot $765^{\circ} \mathrm{C}$. Depolymerisatie van cellulose naar anhydrosuikers werd geïdentificeerd als een primaire reactie; gas- en koolvorming als secondaire reacties. Wiskundige modellen werden ontwikkeld, inclusief de interactie tussen chemie, warmte-t en massaoverdracht. De ontsnappingssnelheid van producten uit het verwarmde reagerende deeltje werd geïdentificeerd als een cruciaal proces dat de $D P$-verdeling van anhydrosuikers beïnvloedde.

De kaliumconcentratie in cellulose werd gevarieerd om de mineraalrijke en voorbehandelde biomassa na te bootsen en vervolgens werd de cellulose bij $530{ }^{\circ} \mathrm{C}$ in de screen-heater en wervelbedreactor gepyrolyseerd. Kalium bleek katalytisch actief te zijn, zelfs wanneer de ontsnappingssnelheid van het product van de reactie zone af extreem hoog was (milliseconden). De opbrengsten van olie en anhydrosuikers namen aanzienlijk af als functie van de kaliumconcentratie, terwijl de productie van andere producten (water, gassen en kleine geoxygeneerde verbindingen) was toegenomen. De productie van kool bleek onafhankelijk te zijn van de ontsnappingssnelheid van producten bij elke gegeven kaliumconcentratie. Er zou kunnen worden geconcludeerd dat pyrolyse bij verlaagde druk, d.w.z. door snelle verwijdering van producten uit de hete reactiezone, de olie- en suikeropbrengsten kan verbeteren, maar alleen voor biomassa met een laag gehalte alkali- en aardalkalimetaal.

Het effect van het molecuulgewicht op de competitie tussen fysisch-chemische processen werd onderzocht d.m.v. het pyrolyseren van 14 lignines (350 - $1900 \mathrm{Da})$ in de screen-heater bij $0.5 \mathrm{kPa}$ en $100 \mathrm{kPa}$. Er is een populatiebalansmodel ontwikkeld dat gelijktijdig optredende kraakreacties, polymerisatiereacties en massatransport uit de reactiezone omvat. Het model was in staat om, na parametrisatie, alle experimenteel waargenomen trends te voorspellen. De molecuulgewichtsverdeling bleek een van de cruciale kenmerken van de lignine-grondstof te zijn, en heeft een significante invloed op de distributie van pyrolyseproducten. Een temperatuur groter dan $530{ }^{\circ} \mathrm{C}$ bleek slechts een geringe invloed te hebben op de opbrengsten en samenstelling van de geproduceerde oliën, terwijl de systeemdruk werd geïdentificeerd als de belangrijkste variabele om de productopbrengsten en het molecuulgewicht van de oliën te manipuleren. HSQC NMRanalyse van lignines en bijbehorende oliën toonde aan dat de opbrengsten van olie en kool en de getalgemiddelde molecuulmassa van oliën onafhankelijk zijn van het aantal etherbindingen in de lignine-grondstof.

Snelle pyrolyse van zuur-uitgeloogde bagasse werd uitgevoerd in het drukbereik van 0.005 tot $100 \mathrm{kPa}$ in de screen-heater. Bij de laagste druk was de totale opbrengst 
aan C6-anhydrosuikers (som van $D P_{1}$ tot $D P_{6}$ ) maximaal $73 \%$ van de poly-C6-suikers in de voeding. Een wiskundig model, dat opnieuw reactie en massaoverdracht van de reactiezone af omvat, was in staat om de gemeten afname in een totale opbrengst aan C6-anhydrosuikers en de verschuiving naar lichtere C6-anhydrosuikers als een functie van toenemende druk te voorspellen. Bij identieke druk en temperatuur was de totale opbrengst aan C6-anhydrosuikers, verkregen uit met zuur uitgeloogd dennenhout, hetzelfde voor de screen-heater en de wervelbedreactor. Als gevolg van de langere verblijftijd van hete damp in het wervelbed werden $D P_{\geq 2} \mathrm{C}_{6}$-anhydrosuikers gedepolymeriseerd naar $D P_{1}$.

Kortom de systeemdruk is de belangrijkste parameter die de verblijftijd van producten in/op het heet reagerende deeltje verandert, waardoor de opbrengsten en samenstelling van de producten van pyrolyse gestuurd kunnen worden. Andere parameters zijn de verwarmingssnelheid van het sample, de verblijftijd van warme dampen van producten en de temperatuur tijdens de pyrolyse. 



\section{सारांश}

जीवाश्म उर्जा संसाधनांतील सततची होणारी घट आणि हवामानात होणारी स्थित्यंतरे या बाबींमुळे मानवाला, उर्जेचे पर्यायी स्त्रोत शोधण्याची गरज निर्माण झाली आहे. या पार्श्वभूमीवर लिग्रोसेल्युलोसिक बायोमास (उदा. उसाची चिपाडे, वाळलेले गवत) हा एक कार्बन आधारित उर्जेचा स्त्रोत आहे ज्याचा उपयोग इंधन तसेच रसायने तयार करण्यासाठी होऊ शकतो. फास्ट पायारोलीसीस (Fast Pyrolysis) हे एक असामान्य तंत्रज्ञान आहे ज्याद्वारे लिग्रोसेल्युलोसिक बायोमासचे रुपांतर, ५०० डी. से.ला आणि प्राणवायूच्या अनुपस्थितीत, तेल (७५\%), कोळसा (१२\%) व इंधन-वायूत (१३\%) असे करता येते.

पायारोलीसीस तंत्रज्ञाना दरम्यान तयार होणारी उत्पादने आणि त्यांची घटक रचना ही उष्णता हस्तांतरण, वस्तुमान हस्तांतरण व रसायन शास्त्र ह्यांच्या मधील स्पर्धेने प्रभावित होते. प्रस्तुत प्रबंधात केलेले व मांडलेले संशोधन एकाच वेळी होणन्या रासायनिक अभिक्रिया, वस्तुमान हस्तांतरण आणि उष्णता हस्तांतरण यावर प्रकाश टाकते. सेल्युलोस, लिग्रिन आणि लिग्रोसेल्युलोसिक बायोमास यांच्या पायारोलीसीस मध्ये असलेल्या स्पर्धेचा अभ्यास या प्रबंधात सादर केला आहे.

या संशोधनामध्ये स्क्रीन-हिटर रीअक्टरचा वापर केला गेला आहे. त्याची प्रमुख वैशिष्ट्ये पुढील प्रमाणे आहेत. (9)उष्णता हस्तांतरण दर ५००० डी.से. प्रति सेकंद (२) रीअक्टर मधील दाबात बदल करून लिग्रोसेल्युलोसिक बायोमास अंतर्गत व बाह्य अश्या दोन्ही रासायनिक अभिक्रियांना लागणारा वेळ नियंत्रित करता येतो. (३) रासायनिक अभिक्रियांमधून तयार झालेली उत्पादने द्रावित नायट्रोजन (- १९६ डी.से.) वापरून थंड केली जातात.

सेल्युलोस, लिग्रिन आणि लिग्रोसेल्युलोसिक बायोमास चा फास्ट पायारोलीसीस निःसन्देहपणे एकाच वेळी होणन्या रासायनिक अभिक्रिया, वस्तुमान हस्तांतरण आणि उष्णता हस्तांतरण यांच्यातील आंतरक्रियेद्वारा नियंत्रित होतो. आधीपासूनच माहित असल्याप्रमाणे, उच उष्णता हस्तांतरण दर तेलाचे उत्पादन वाढविण्यासाठी आवश्यक आहे. बायोमास बाहेरील घडणान्या रासायनिक अभिक्रियांच्या वेळेचा ( 9 - २सेकंद) साखर उत्पादानावारती नाममात्र परिणाम घडतो. लिग्रिनचे आण्विक वजन (वितरण) हा एक महत्त्वाचा गुणधर्म असून त्याचा पायारोलीसीसच्या उत्पादनांच्या वितरणावर महत्त्वपूर्ण प्रभाव पडतो. पायारोलीसीसचे तापमान ५०० डी. से. पेक्षा कमी असल्यास तेल उत्पादनावर लक्षणीय प्रभाव पडतो. $4 ५ 0$ डी.से. च्यावर पायारोलीसीसचे तापमान गेल्यास रासायनिक अभिक्रियांचा दर हा उष्मा हस्तांतरण दरापेक्षा जास्त होतो ज्या परत्वे पायारोलीसीसचे तापमान न वाढता स्थिर रहाते. या सर्वांव्यतिरिक्त पायारोलीसीस दरम्यान असलेला वायूचा दाब हा महत्त्वाचे परिमाण असून त्याचा उपयोग तेलाचे उत्पादन आणि त्यातील घटकांची संरचना नियंत्रित करण्यासाठी करता येऊ शकतो. 


\section{$C_{1}$}

\section{General introduction}

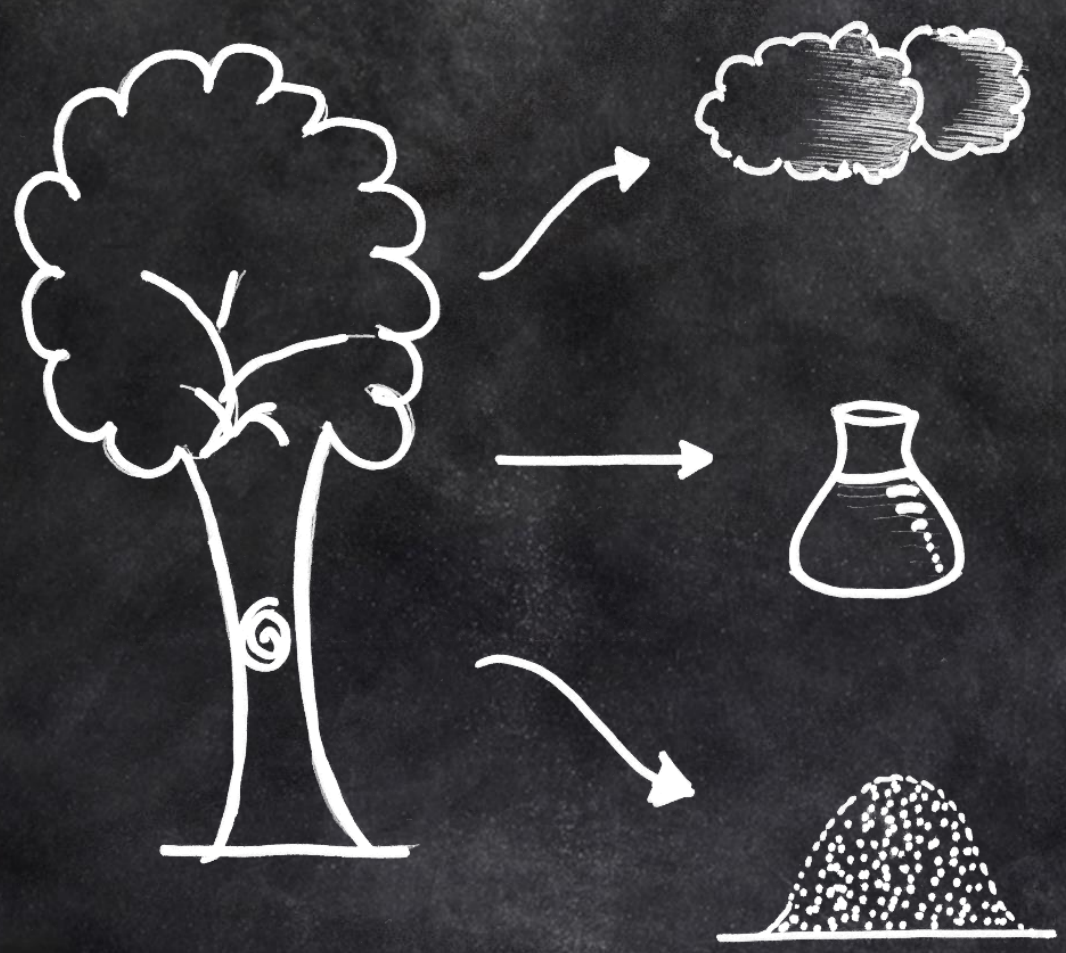




\subsection{Motivation}

The world population is estimated to reach 9.15 billion by the end of 2040, and with that, the energy demand is expected to grow annually at a rate of $1 \%$. 1 . Currently, fossil fuels are the primary energy sources, and their extensive use has resulted in the emission of greenhouse gases and particulate matter, causing air pollution and global warming. Uneven distribution of fossil energy resources across the globe and geopolitics dictates the supply and price of energy. Climatic change and energy security, primarily, have stimulated the search for the alternative, $\mathrm{CO}_{2}$ neutral (or negative), energy sources to meet the growing energy demand and to mitigate the carbon footprint.

Solar energy, wind energy, hydropower, geothermal and biomass have been identified as renewable resources. Among these, the availability of the first four energy sources is very much dependent on the geographical locations 233 . Biomass, being the only renewable carbon source ( $\sim 5 \%$ C on dry ash free basis 4 ), may fit into the existing fossil infrastructure ${ }^{5}$, and could partially replace crude oil derived fuels and materials. Also, biomass energy is essentially $\mathrm{CO}_{2}$ neutral, if none or little fossil energy is used for its production and processing since it is based on a short carbon cycle ${ }^{5}$. Currently, 12 $13 \%$ of the total world energy demand is satisfied by biomass 5 . However, biomass is often available as low bulk density solids, especially agricultural/forestry waste, and it needs a processing step before it can be transported and used.

\subsection{Lignocellulosic biomass}

The $1^{\text {st }}$ generation biofuels (bio-diesel, bio-ethanol), produced from food crops, have been commercialised to mature technologies. In the EU alone, the production

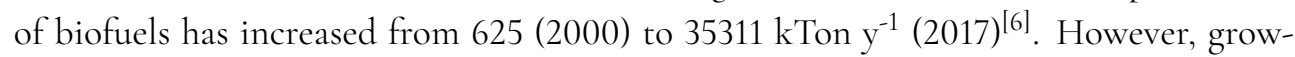
ing concern about the competition between the increasing demand for food and fuel has shifted the focus towards the $2^{\text {nd }}$ generation biomass feedstock, i.e. lignocellulosic biomass. It can be subdivided into three types namely; softwood (e.g. pine, spruce, cedar), hardwoods (e.g. oak, beech, maple.) and grasses (e.g. miscanthus, switchgrass, reed canary). Lignocellulosic biomass is composed of cellulose, hemicellulose, lignin, extractives and inorganics. They are discussed briefly hereafter since next to biomass their pyrolysis behaviour is investigated in this thesis.

Cellulose: Cellulose, an essential structural component of the primary cell wall, accounts for 35 to $50 \mathrm{wt}$. \% of dry lignocellulosic biomass. It is the most abundant, naturally occurring polymer in the biosphere ${ }^{7}$. It is a linear polymer composed of anhydroglucopyranose units connected by $\beta-(1-4)$ glycosidic bond 8 . The degree of polymerisation 
of native cellulose is between 10000 to 14000 , whereas it is much lower $(200-3000)$ in microcrystalline cellulose (isolated via a pulping process) 7 .

Hemicellulose: A second major component of lignocellulosic biomass is hemicellulose. It accounts for $\sim 28 \%$ and $~ 35 \%$ of dry lignocellulosic biomass in softwoods and hardwoods, respectively 9 . Hemicellulose is composed of three hexoses (glucose, mannose and galactose) and two pentoses (xylose and arabinose), together with some uronic acids 8 , which makes it a hetero-polysaccharide. Softwood hemicelluloses are rich in galacto-glucomannan, and hardwood hemicelluloses are rich in xylans 9 . Unlike cellulose, it is a branched polymer and has a degree of polymerisation in the range 50 to 20079 .

Lignin: Lignin is a three dimensional, highly cross-linked, hydrophobic, heteropolymer 10 . It is the most abundant naturally occurring aromatic polymer and accounts for up to $35 \%$ of dry lignocellulosic biomass. Coumaryl-, coniferyl- and sinapyl alcohols, the precursors of lignin, are interconnected by various linkages, which are broadly classified as ether linkages and carbon linkages 11 13. During the isolation process (e.g. kraft, organosolv 14 15), native lignin undergoes structural changes, and the extent to which the structure of native lignin is preserved is controlled by the severity of the isolation method 1516 . Note that milled wood lignin, obtained by Björkman's method, is considered to represent native lignin most accurately 17.

Extractives: In addition to the above three main constituents, extractives are present in the biomass ( $\sim 5 \%$ on dry mass). They are low molecular weight species, including fats, waxes, alkaloids, proteins, phenolics and essential oils 79 . Extractives act as intermediates in plant metabolism, energy reserves, and defences against microbial threats 9 . These can be extracted by using polar (e.g. water, alcohols) or non-polar (e.g. toluene, hexane) solvents 79 .

Inorganics: The content of inorganic species (also known as ash) in biomass varies significantly as a result of soil and climate conditions $\sqrt{18}$. In woody biomass, it is typically in the range between 0.1 to $7.1 \mathrm{wt}$. \%, while in grasses, it can be as high as $42 \mathrm{wt}$. $\% \frac{18}{18}$. Following are commonly found elements in woody biomass: calcium (Ca), potassium $(\mathrm{K})$, sodium $(\mathrm{Na})$, silicon $(\mathrm{Si})$, magnesium $(\mathrm{Mg})$, aluminium $(\mathrm{Al})$, sulphur $(\mathrm{S})$, iron $(\mathrm{Fe})$, phosphorous $(\mathrm{P})$, manganese $(\mathrm{Mn})$ 18/19. These minerals are attached to the biomass matrix by an ionic or a covalent bond 19 . The content of alkali and alkaline earth metals (AAEMs), i.e. $\mathrm{Na}, \mathrm{K}, \mathrm{Ca}, \mathrm{Mg}$, in biomass is especially of importance for thermo-chemical conversion process 20 . 


\subsection{Biomass conversion routes}

Figure 1.1 shows an overview of different conversion processes to convert lignocellulosic biomass to fuels and chemicals. Direct combustion of biomass to produce energy has been the first step in the history of human civilisation. Worldwide, in large scale plants, direct combustion of biomass is carried out in a fixed bed reactor or grate furnace 21 24. The main processes and routes depected in Figure 1.1 are briefly discussed here. In gasification, biomass is converted to $\mathrm{CO}, \mathrm{CO}_{2}, \mathrm{H}_{2}$, and $\mathrm{CH}_{4}$ at high temperatures $\left(>900^{\circ} \mathrm{C}\right)$ in the presence of air, oxygen or steam. Depending on the relative composition of these gasses, they are referred to as synthesis gas or producer gas 25 . In the liquefaction process, biomass is converted in a temperature range of $150-360{ }^{\circ} \mathrm{C}$ and at elevated pressures $(90-250$ bar) to yield two main products, liquid (organic + aqueous) and gas 2627 . The organic fraction is considered as the targeted product of liquefaction and has a significantly lower oxygen content than the feedstock $(10-25$ wt. \% in organic phase vs $45 \mathrm{wt}$. \% in feed) 28 . The organic part of the liquid can be upgraded into diesel/gasoline range fuels by catalytic hydrocracking in the presence of a solvent ${ }^{27}$. In the following section, pyrolysis technology, being the focus of this thesis, is elaborated in detail. 


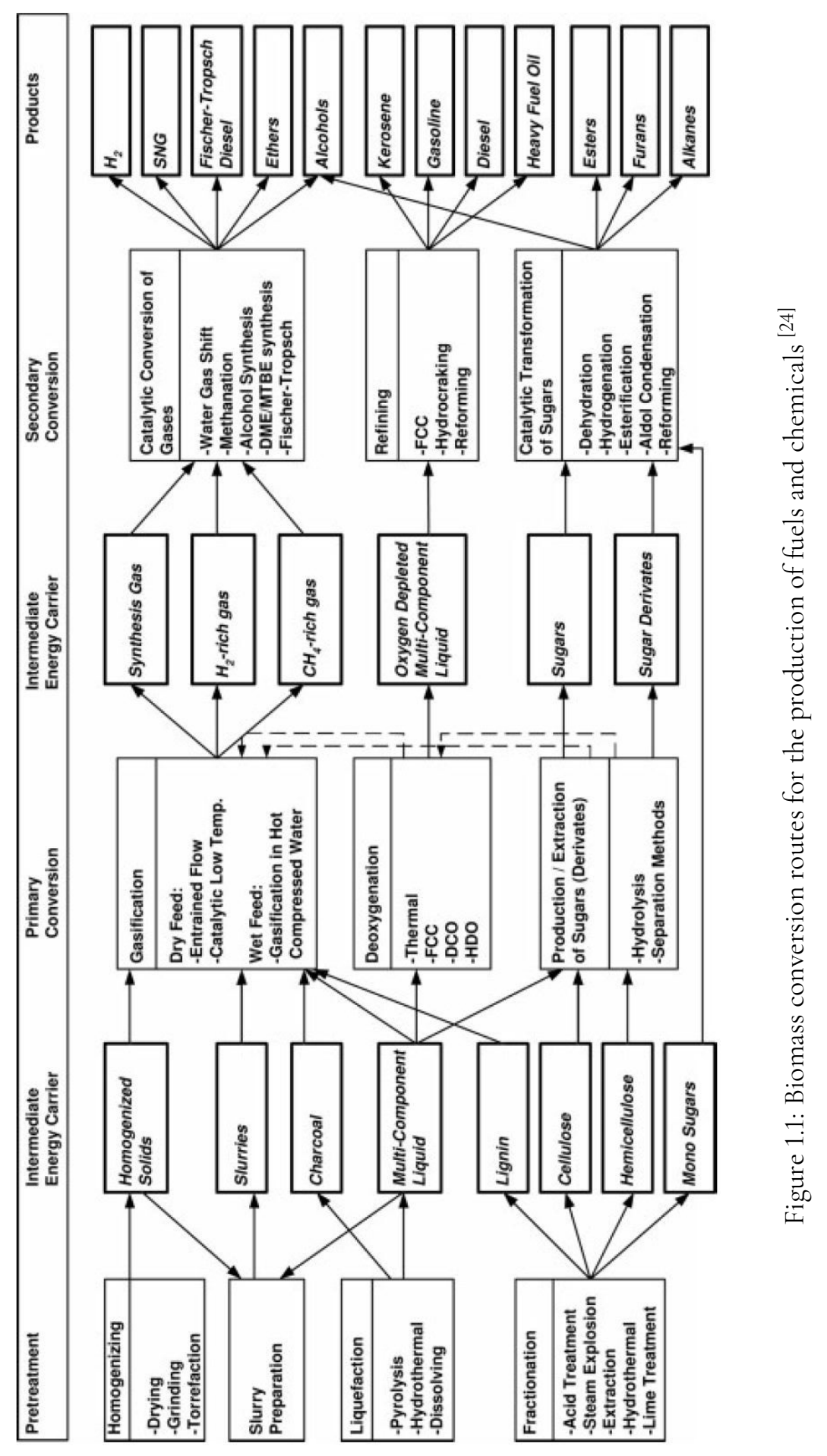




\subsection{Pyrolysis}

The word pyrolysis is based on Greek-derived elements; Pyr $(\pi v \rho)$ implies fire and Lysi $(\lambda v \sigma \eta)$ implies releasing, meaning releasing by fire. In pyrolysis lignocellulosic biomass is converted in the absence of oxygen, to form char, gas, and oil. The yields of these lumped products are affected by the type of feedstock, its ash content, reactor type, heating rate, operating conditions, (hot) vapour residence time of the products 4 . Various pyrolysis modes are available to selectively maximise the yield of the product(s) of interest, i.e. char (charcoal), oil or gas 2930 . These modes are differentiated based on the size of particles, temperature, heating rate and, most importantly, the vapour residence time of products, as shown in Table 1.1

Table 1.1: Typical product yields (dry wood basis) obtained by different modes of pyrolysis 2930

\begin{tabular}{lllllll}
\hline Mode & Temperature & RT $^{\mathrm{a}}$ & HVRT $^{\mathrm{b}}$ & Oil & Char & Gas \\
\hline Torrefaction & $\sim 290{ }^{\circ} \mathrm{C}$ & $\sim 10-60 \mathrm{~min}$ & - & $0-5 \%$ & $80 \%$ & $15-20 \%$ \\
Intermediate & $\sim 500{ }^{\circ} \mathrm{C}$ & $\sim 20 \mathrm{~min}$ & $10-30 \mathrm{~s}$ & $50 \%$ & $25 \%$ & $25 \%$ \\
Fast & $\sim 500^{\circ} \mathrm{C}$ & $\sim 10 \mathrm{~s}$ & $1-2 \mathrm{~s}$ & $75 \%$ & $12 \%$ & $13 \%$ \\
Gasification & $750-900{ }^{\circ} \mathrm{C}$ & seconds & $\sim 5 \mathrm{~s}$ & $5 \%$ & $10 \%$ & $85 \%$ \\
\hline
\end{tabular}

${ }^{a}$ Reaction time

${ }^{\mathrm{b}}$ Hot vapour residence time

The char, black carbonaceous material rich in minerals, is widely used for the combined heat and power (CHP) generation or as an additive to soil as a fertiliser and carbon sequestration agent 31 . The gas produced during pyrolysis is mainly composed of $\mathrm{CO}$, $\mathrm{CO}_{2}$ and light hydrocarbons, and can be burned to produce process heat. Oil (or biooil or pyrolysis oil) is a complex mixture of organic compounds of different chemical classes such as acids, aldehydes, ketones and anhydrosugars, which are generally present in low concentrations. As an example, typical properties and composition of the fast pyrolysis oil derived from wood are presented in Table 1.2 Compared to crude oil, the composition of pyrolysis oil differs significantly. The relatively high oxygen content in pyrolysis oil makes it thermally unstable, making its direct use as a fuel in CHP systems, burners/engines difficult $32[33$. However, significant efforts have been made to upgrade pyrolysis oil (catalytically) to transportation fuel 34 and use as a source for the production of chemicals 38,40 . 
Table 1.2: Typical composition of pinewood derived pyrolysis oil and its properties 32

\begin{tabular}{lll}
\hline Chemical class & Unit & Value \\
\hline Water & wt. \% & 24 \\
Acids & wt. \% & 4 \\
Alcohols & wt. \% & 2 \\
Aldehydes and ketones & wt. \% & 15 \\
Sugars & wt. \% & 34 \\
LMM lignin & wt. \% & 13 \\
HMM lignin & wt. \% & 2 \\
Extractives & wt. \% & 4 \\
\hline Property & Unit & Value \\
\hline pH & & 2.5 \\
Specific gravity & & 1.2 \\
Elemental composition & wt. \% & \\
C & & $54-58$ \\
H & & $5.5-7$ \\
O & & $35-40$ \\
N & & $0-0.2$ \\
Ash & & $0-0.2$ \\
HHV & MJ kg-1 & $16-19$ \\
Viscosity (at 42 ${ }^{\circ} \mathrm{C}$ ) & cP & $25-1000$ \\
Solids & wt. \% & $0.2-1$ \\
Distillation residue & wt. \% & up to 50 \\
\hline & &
\end{tabular}

\subsubsection{Pyrolysis reactors}

The historical developments in the fields of pyrolysis reactors have been summarised by Garcia-Nunez et al. 42 . Reviews of Butler et al. 43 and Venderbosch et al. 41 have summarised the commercial scale efforts in the fast pyrolysis of biomass. Different fast pyrolysis reactor configurations have been implemented on commercial scale: bubbling fluidised bed reactor (Dynamotive (Canada) 200 tpd, Biomass Engineering Ltd. (UK) 4.8 tpd, Agri-Therm (Canada) 1 - 10 tpd), circulating fluidised bed reactor (Ensyn (Canada) 100 tpd, Metso Consortium (Finland) 7.2 tpd), rotating cone reactor (BTG (Netherlands) 120 tpd, Bio-oil Holding N.V. (Belgium/Netherlands) 12 tpd), auger reactor (KIT-Lurgi (Germany) 12 tpd, ARBI-Tech (Canada) 50 tpd, Renewable Oil International LLC (USA) 4.8 tpd), ablative reactor (PyTec (Germany) 6 tpd). At the time of writing this thesis, a consortium of TechnipFMC, BTG-BTL and Green Fuel Nordic Oy has decided to build four 120 tpd pyrolysis units in Finland 44 . Although fast pyrolysis technology is close to commercialisation, the following are the main chal- 
lenges: 1) scale-up of the technology from laboratory scale concepts/setups to commercial plants, 2) design and operational difficulties, 3) flexibility to accommodate different feedstock (wet/dry, high ash content), and 4) production of quality product to find suitable applications 4143 .

Table 1.3: Characteristics of various laboratory-scale setups used for pyrolysis

\begin{tabular}{|c|c|c|c|c|c|}
\hline $\begin{array}{l}\text { Reactor } \\
-\end{array}$ & $\begin{array}{l}\text { Heating rate } \\
{ }^{\circ} \mathrm{C} \mathrm{s}^{-1}\end{array}$ & $\begin{array}{l}\text { Temperature } \\
{ }^{\circ} \mathrm{C}\end{array}$ & $\begin{array}{l}\text { Pressure } \\
\mathrm{kPa}\end{array}$ & $\begin{array}{l}\text { HVRT }^{\mathrm{a}} \\
-\end{array}$ & $\begin{array}{l}\text { Analysis }{ }^{\mathrm{b}} \\
-\end{array}$ \\
\hline TGA & $\sim 3$ & $30-900$ & 100 & seconds & Online \\
\hline Tubular & 10 & $200-900$ & 100 & milliseconds & $\begin{array}{l}\text { Online/ } \\
\text { offline }\end{array}$ \\
\hline Micro-pyrolyser & $\sim 200$ & $400-600$ & 100 & seconds & Online \\
\hline PHASR $^{c}$ & 11800 & $400-500$ & - & $\sim 10 \mathrm{~ms}$ & Online \\
\hline Screen-heater & 5000 & $320-800$ & $0.005-100$ & $\sim 20 \mathrm{~ms}$ & Offline \\
\hline
\end{tabular}

${ }^{a}$ Hot vapour residence time of products

b Possibility of analysing pyrolysis products

${ }^{c}$ Pulse heated analysis of solid reactions

In laboratories, mainly, thermogravimetric analyser (TGA), tubular reactor, micropyrolyser, PHASR reactor and screen-heater reactor (also called wiremesh) are used: 1) to study the yield of lumped products (gas, char, oil) and their composition of varies types of biomass, 2) to measure (lumped) reaction kinetics, and 3) to investigate ongoing physio-chemical processes and primary/early stage reactions of biomass pyrolysis 45 . The main characteristics of various reactors types used in laboratories are as follows; sample heating rate, operating conditions, (hot) vapour residence time of products and the possibility of analysing formed pyrolysis products, see Table 1.3 For further reading on these reactors, the reader is referred to the review of Sribala et al. ${ }^{45}$. It is important to note that, especially in TGA and micropyrolysers, the actual heating rate of the sample can be significantly different from the one claimed by the machine manufacturer 46,49 .

In the screen-heater, nearly isothermal operation is achieved by applying a high heating rate $\left(5000{ }^{\circ} \mathrm{C} \mathrm{s}^{-1}\right)$. Other important characteristics of the screen-heater are: 1 ) the escape rate of products, away from the hot reacting particle, can be controlled by manipulating pressure during the pyrolysis, 2) rapid quenching of products is achieved by a liquid nitrogen bath to minimize outside the reacting particle, and 3) importantly, not only light but also heavy species in the oil are collected and can subsequently be analysed. For example, compounds having a molecular weight up to $30000 \mathrm{Da}$ and anhydrosugars with a degree of polymerisation up to 11 can be analysed by using GPC and 
LC/MS, respectively. The combination of these characteristics can be achieved using the screen-heater, making it suitable for studying primary reaction products.

\subsubsection{Chemical and physical processes during pyrolysis}

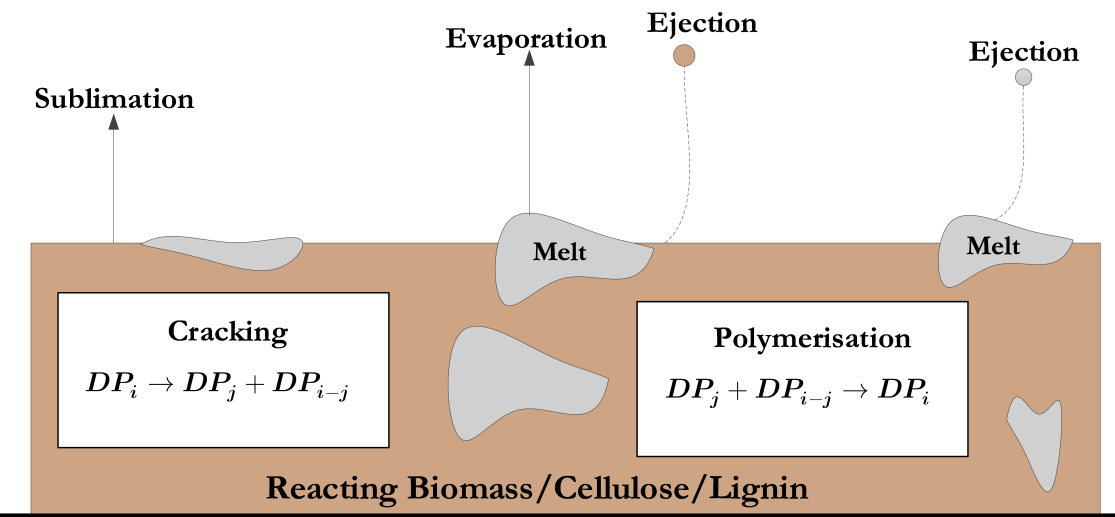

Heat source

Figure 1.2: Schematic representation of chemical and physical processes occurring during pyrolysis

Lédé 47 suggested that the pyrolysis of biomass and its building blocks is governed by the competition between physical and chemical processes. During pyrolysis, a fraction of lignocellulosic biomass passes through a liquid intermediate (Figure 1.2), also called a melt, which has a lower degree of polymerisation compared to that of the original polymers. In the case of cellulose, this intermediate liquid is termed the active cellulose $\frac{50}{\text {. }}$ At the reacting particle and/or within this liquid intermediate 51, a large number of chemical reactions take place, which are broadly classified into cracking reactions to form volatiles and gases, and polymerisation reactions to produce char.

Volatile products are transported away from the hot reaction front not only by evaporation but also by random ejection in the form of aerosols $52 \sqrt[55]{5}$ or by sublimation 56 . The mass transport rate of products depends on two factors, i.e. the molecular weight of species and the operating conditions during the pyrolysis. At a constant pyrolysis temperature, smaller molecules have higher vapour pressure due to which they can escape the hot reaction front easily. On the contrary, because of the lower mass transport rates, bigger molecules spend a longer time at the hot reaction front, where they consequently undergo cracking as well as polymerisation reactions. Once escaped from the hot reaction front, products may undergo secondary reactions in/on the surface of 
nascent char (containing AAEMs) or in the hot vapour phase before condensation. Secondary reactions of the vapours facilitate the formation of gasses and light oxygenated compounds. The extent of secondary reactions depends on the hot vapour residence time ${ }^{5758}$, temperature 58 and the presence of AAEMs 58 .

Next to the mass transport of species, the supply of energy to drive the pyrolysis reactions is of equal importance. The heat transfer is strongly influenced by the size of the biomass particle, surrounding temperature and the transfer mechanism59. Pyle et al. have identified the following three regimes, based on Biot number (Bi) and Pyrolysis $\left(\mathrm{Py}_{1}\right.$ and $\left.\mathrm{Py}_{2}\right)$ numbers $\frac{60}{6}$, in which pyrolysis reactions are controlled by: 1) kinetics (reactions taking place at the surrounding temperature), 2) External heat transfer (absence of heat carrier from the heat source to the particle), and 3) Internal heat transfer (big particles). In essence, the heating rate of the lignocellulosic biomass predominantly affects the set of pyrolysis reactions it will undergo, resulting in a different outcome.

Collectively, the yields and the distribution of pyrolysis products are influenced by the interplay between reaction rates, the heating rate of the particle and the rate of mass transport of species/products away from the hot reaction front.

\subsubsection{Role of AAEMs during pyrolysis}

The AAEMs, present in the biomass matrix, reportedly affect the carbohydrate fraction (cellulose and hemicellulose) of the biomass by catalysing ring-fragmentation and dehydration reactions $\frac{6162}{2}$. As a result of that, the yields of anhydrosugars and organics decrease while facilitating the production of light oxygenated compounds, water and gaseous species (e.g. $\mathrm{CO}, \mathrm{CO}_{2}, \mathrm{CH}_{4}$ ). The yields of organics and anhydrosugars can be improved by: 1) minimising AAEMs content by pre-treating the lignocellulosic biomass with (hot) water ${ }^{63}$ or by acid-water mixture (mineral acid [616465] or organic acid $(2[66[67)$, and 2) by ceasing the catalytic activity of AAEMs by passivating them by strong acids $\left(\mathrm{H}_{2} \mathrm{SO}_{4}, \mathrm{H}_{3} \mathrm{PO}_{4}\right)$ to form stable salts which are catalytically less active 68 .70 However, it is unknown to what extent the destructive effects of AAEMs on sugar production can be minimised by maximising the product removal rate.

In the literature, Oudenhoven et al. 71 have reported the maximum sugar yields of $30 \%$ on acid-leached pinewood basis in a fluidised bed, whereas others have reported the sugar yields in the range between $8 \%$ and $22 \% 6164 / 72,75$. Pyrolytic sugars can be upgraded to monosaccharides (e.g. glucose, xylose, mannose) via hydrolysis followed by fermentation and catalytic processing to produce bio-ethanol and platform chemicals $\frac{76}{}$, respectively. 


\subsubsection{Analytical techniques}

A combined use of qualitative and quantitative analysis of pyrolysis oil is needed: 1) in understanding its composition, 2) for proposing reaction mechanisms, 3) for optimising process conditions to maximise the production of the targeted product(s), and 4) for determining its physical properties for downstream applications such as catalytic upgrading. Reviews 77,79 available in the literature, provide a detailed overview of analytical techniques and strategies used for the characterisation of pyrolysis oils. Gas chromatography (GC) with mass spectrometry (MS) is used to analyse the volatile fraction ( $\mathrm{T}_{\text {boiling }} \sim 320^{\circ} \mathrm{C}$ ) of pyrolysis oil. In principle, whole pyrolysis oil, i.e. water-soluble (e.g. sugars, acids, aldehydes) and water-insoluble (e.g. mono-, oligo-phenolics), can be characterised by liquid chromatography (LC) with MS. Gel permeation chromatography (GPC) or size exclusion chromatography (SEC) provides a molecular weight distribution of pyrolysis oil. Additionally, different spectroscopic (e.g. NMR, ESR) and spectrometric (e.g. mass, UV-vis, FTIR) techniques are used extensively to characterise pyrolysis oil. 


\subsubsection{Modelling}

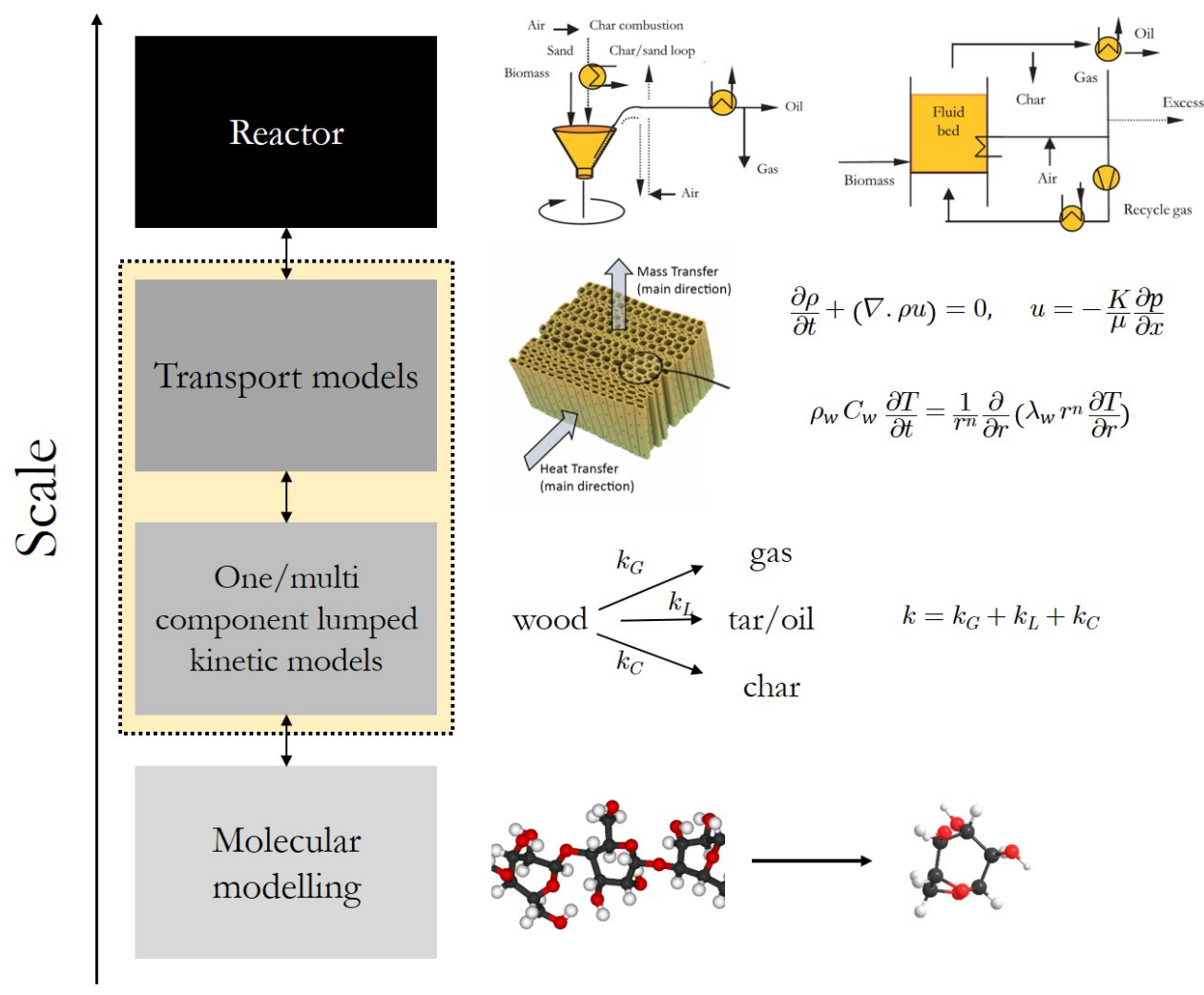

Figure 1.3: Multi-scale modelling for the pyrolysis of biomass

Mathematical modelling proves to be a useful tool for process design, development and optimisation, and predicting reactor performance and product yields 4 . In a few extensive reviews 45900 , 82 , efforts of biomass pyrolysis modelling have been summarised. Pyrolysis of biomass is a multi-scale modelling problem (Figure 1.3, encompassing reactions at the molecular level to the hydrodynamics in the reactor. One/multi component (lumped) kinetic models are based on the weight loss profiles of biomass (or its building blocks) measured under slow pyrolysis conditions 83 [1]. In transport models, the physical processes (mass, heat and momentum transfer) are taken into account across the biomass particle where volume and the physical properties vary with the degree of conversion and temperature 92,100 . Next, reactor models, a combination of previous two models and hydrodynamics, are available in the literature for fixed bed reactor 101102, rotating cone reactor 103 , fluidised bed reactor $\frac{104105}{}$. More recently, density functional 
theory (DFT) based calculation methods have been exploited to understand and describe the pyrolysis reaction mechanisms of cellulose $\frac{106}{108}$, hemicellulose $109 / 110$ and lignin pyrolysis 111 .113.

Independently developed lumped reaction kinetics models and transport models, when combined, can be used to predict the trends of the yields of oil, char and gas 4 . However, they possess limited prediction power due to the wide variation in the reported kinetics $\frac{114}{}$. Also, these combined models, except those of Solomon et al.115]116, do not take into account the effect of molecular weight on the mass transport rate of species. The macroscopic structures of microcrystalline cellulose ${ }^{[117}$ and lignin 118 are significantly different from that of lignocellulosic biomass 7 , hence, restricting the applicability of transport models to biomass. Most importantly, as described in Section 1.4.2 of this introduction, the mass transport rate dependent likelihood of chemical reactions occurring at the hot reaction front, is not included in the combined lumped reaction kinetics-transport models. Therefore, in the author's point of view, a unified mechanistic model (yellow shaded area in Figure 1.3) incorporating a simultaneous competition/interaction between chemistry (cracking and polymerisation reactions), heat transfer (sample heating rate) and mass transport of products (by sublimation, evaporation and random ejection) away from the hot reaction front is needed to describe the pyrolysis of biomass and/or its building blocks more accurately. 


\subsection{Outline of the thesis}

As mentioned in preceding sections, the yields of products and their distribution obtained during pyrolysis are affected by the relative rates of reactions (cracking and polymerisation), heat transfer and mass transfer. The work presented in this thesis aims at advancing the current understanding of these chemical and physical processes and their interplay during fast pyrolysis of biomass, cellulose and lignin. For that, a significant part of the experimental work was done using a previously developed 119 and characterised ${ }^{120}$ screen-heater. It is designed to obtain insights into primary (or early stage) reactions of pyrolysis by minimising non-isothermality by employing high heating rates $\left(\sim 5000^{\circ} \mathrm{C} \mathrm{s}^{-1}\right)$. In addition, mass transfer limitations of products were minimised (hot vapour residence time $\sim 20 \mathrm{~ms}$ ) by reducing pressure during pyrolysis in combination with rapid quenching of products $\left(\sim-180{ }^{\circ} \mathrm{C}\right)$, thereby, minimising secondary reactions outside the reacting particle. The work presented in the subsequent chapters is as follows.

Chapter 2. A detailed overview of materials, experimental procedures, experimental setups, and analytical techniques that are used in this thesis is provided in this chapter. Product definitions, yield calculations and mass balances are also described.

Chapter 3. This chapter evaluates the pitfalls of using gas chromatography and liquid chromatography in the quantification of levoglucosan (LG) and hydroxyacetaldehyde (HA) in biomass and cellulose derived pyrolysis oils. For that, pyrolysis oil samples infused with known amounts of LG and HA were analysed using both techniques.

Chapter 4. This chapter deals with fast pyrolysis of microcrystalline cellulose (Avicel PH 101) in the dedicated screen-heater to study the primary pyrolysis reactions and products. Under these conditions, the effect of temperature on the product yields and the distribution of anhydrosugars in oil is studied. Two mathematical models are developed to interpret and predict experimentally observed trends and to investigate if the pyrolysis is kinetically controlled or if there is an interplay between heat, mass transfer and chemistry. Based on the experimental observations and modelling results, the most prevailing parameters influencing the $D P$ distribution of anhydrosugars are identified.

It is widely accepted that the AAEMs have a destructive effect on the production of anhydrosugars. However, it is unknown to what extent this effect can be minimised by maximising the product removal rate from the reacting particle. For that, potassium infused cellulose (concentration: 1 to $10000 \mathrm{mg} \mathrm{kg}^{-1}$ ) samples were pyrolysed, and the effect of potassium on the yields of oil, char, gas and sugars is investigated. The conditions applied in the screen-heater $(0.5 \mathrm{kPa}$ and $\sim 20 \mathrm{~ms}$ hot vapour residence time) 
are challenging to replicate in an industrial scale reactor. Hence, results obtained from screen-heater are compared with a bench scale fluidised bed.

Chapter 5. In this chapter, the interplay of chemistry and mass transfer will be studied using 14 lignins having number average molecular weights between $350 \mathrm{Da}$ and $1900 \mathrm{Da}$. These lignins were characterised and subsequently pyrolysed in a wide range of operating conditions (Temperature: 425 to $793^{\circ} \mathrm{C}$; Pressure: $0.5 \mathrm{kPa}$ and $100 \mathrm{kPa}$ ). Experimentally obtained oil and char yields and the molecular weight (distribution) of oils are interpreted as a function of molecular weight of the feedstock. A population balance model, including three concurrently occurring processes, viz. cracking reactions, polymerisation reactions and mass transport (molecular weight dependent) from the hot reacting particle, was developed. Based on the experimental observations and the modelling results, the most crucial process parameter to steer the yields of oil and char, and the molecular weight of the oil was identified.

Chapter 6. Next to the molecular weight of the feedstock lignin, its chemical structure may influence the pyrolysis outcome as well. Five lignins, isolated via three different methods, and their oils (Temperature: $530{ }^{\circ} \mathrm{C}$; Pressure: $0.5 \mathrm{kPa}$ and $100 \mathrm{kPa}$ ) are characterised by HSQC NMR to elucidate structural changes. Three main ether linkages, namely, $\beta$-aryl ether $(\beta-O-4)$, phenylcoumaran $\left(\beta-5^{\prime}\right)$ and resinol $(\beta-\beta)$, were detected and quantified. In this appendix, the influence of these ether linkages on the yields of oil and char, and the molecular weight of products is studied.

Chapter 7. Finally, fast pyrolysis of acid-leached biomass is studied by varying the system pressure ( 0.005 to $100 \mathrm{kPa}$ ) in order to investigate the relative effects between the reaction rate and the escape rate of products. The total yield of anhydrosugars and their DP distribution is obtained as a function of pressure. A mathematical model, including the competition between (depolymerisation and decomposition) reactions and mass transport of anhydrosugars, is used to interpret and predict experimentally observed trends. Additionally, the effect of hot vapour residence time on the DP distribution of anhydrosugars is investigated by pyrolysing acid-leached biomass in a fluidised bed reactor. Additionally, a mathematical model is developed to interpret experimentally observed influence of hot vapour residence time on the DP distribution of anhydrosugars.

Chapter 8. The main conclusions of this thesis with the outlook are presented in this chapter. 
Appendix A. Supporting information for chapter 3. Appendix B. Supporting information for chapter 4. Appendix C. Supporting information for chapter 5. Appendix D. Supporting information for chapter 7 . 


\section{Nomenclature}

Bi Biot number

Py1 Pyrolysis number 1

$\mathrm{Py}_{2} \quad$ Pyrolysis number 2 $\frac{h R}{\lambda}=\frac{\text { External heat transfer rate }}{\text { Internal heat transfer rate }}$

$\frac{\lambda}{k \rho c_{p} R^{2}}=\frac{\text { Internal heat transfer rate }}{\text { Reaction rate }}$

$\frac{h}{k \rho c_{p} R}=\frac{\text { External heat transfer rate }}{\text { Reaction rate }}$ 
$\mathrm{C}_{2}$ 


\section{$C_{2}$}

Materials and methods

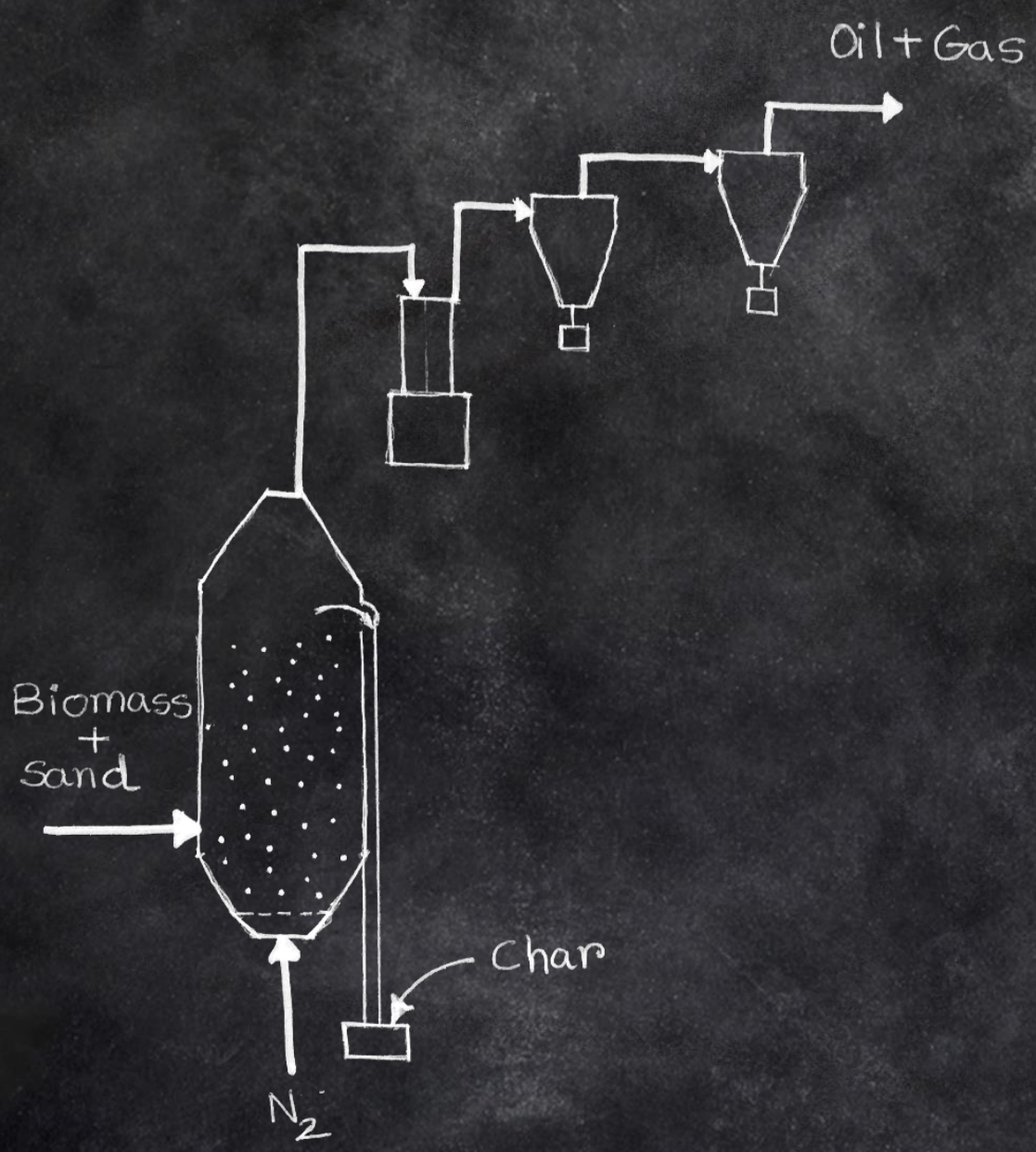




\begin{abstract}
This chapter provides an overview of the materials, experimental procedures and setups, and analytical techniques used in this thesis. Short, but adequate, descriptions are given and for details the reader is directed to relevant publications.
\end{abstract}




\subsection{Chemicals and Materials}

All chemicals and materials used in the experiments performed in this thesis are listed in Table 2.1 and Table 2.2 respectively.

Table 2.1: Chemicals used in the experiment

\begin{tabular}{lll}
\hline Compound & $\begin{array}{l}\text { Purity } \\
\%\end{array}$ & Supplier \\
\hline Acetol (1-Hydroxy-2-propanone) & $>89$ & Sigma Aldrich \\
Barium carbonate $\left(\mathrm{BaCO}_{3}\right)$ & $>99$ & Sigma-Aldrich \\
Cellobiosan (1,6-Anhydro- $\beta$-cellobiose) & $>95$ & Carbosynth Ltd. \\
Cellotriosan (1,6-Anhydro- $\beta$-D-cellotriose) & $>98$ & LC Scientific \\
Cellotetrasan (1,6-Anhydro- $\beta$-D-cellotetrose) & $>98$ & LC Scientific \\
Dichloromethane (DCM) & $\geq 99.8$ & Merck \\
Glucose & $>99.99$ & Sigma-Aldrich \\
Hydroxyacetaldehyde (as glycolaldehyde dimer) & $>99$ & Sigma-Aldrich \\
Levoglucosan (1,6-Anhydro- $\beta$-D-glucopyranose) & $>98$ & Carbosynth Ltd. \\
Levoglucosenone & $>95$ & Carbosynth Ltd. \\
(1,6-anhydro-3,4-dideoxyhex-3-enopyran-2-ulose) & & \\
Potassium carbonate $\left(\mathrm{K}_{2} \mathrm{CO} \mathrm{O}_{3}\right)$ & $>99$ & Sigma-Aldrich \\
Potassium chloride $(\mathrm{KCl})$ & $>99$ & Sigma-Aldrich \\
Potassium hydroxide $(\mathrm{KOH})$ & $>98$ & Sigma-Aldrich \\
Sulfuric acid ( $\left.\mathrm{H}_{2} \mathrm{SO}_{4}\right)$ & $>99.99$ & Sigma-Aldrich \\
\hline
\end{tabular}




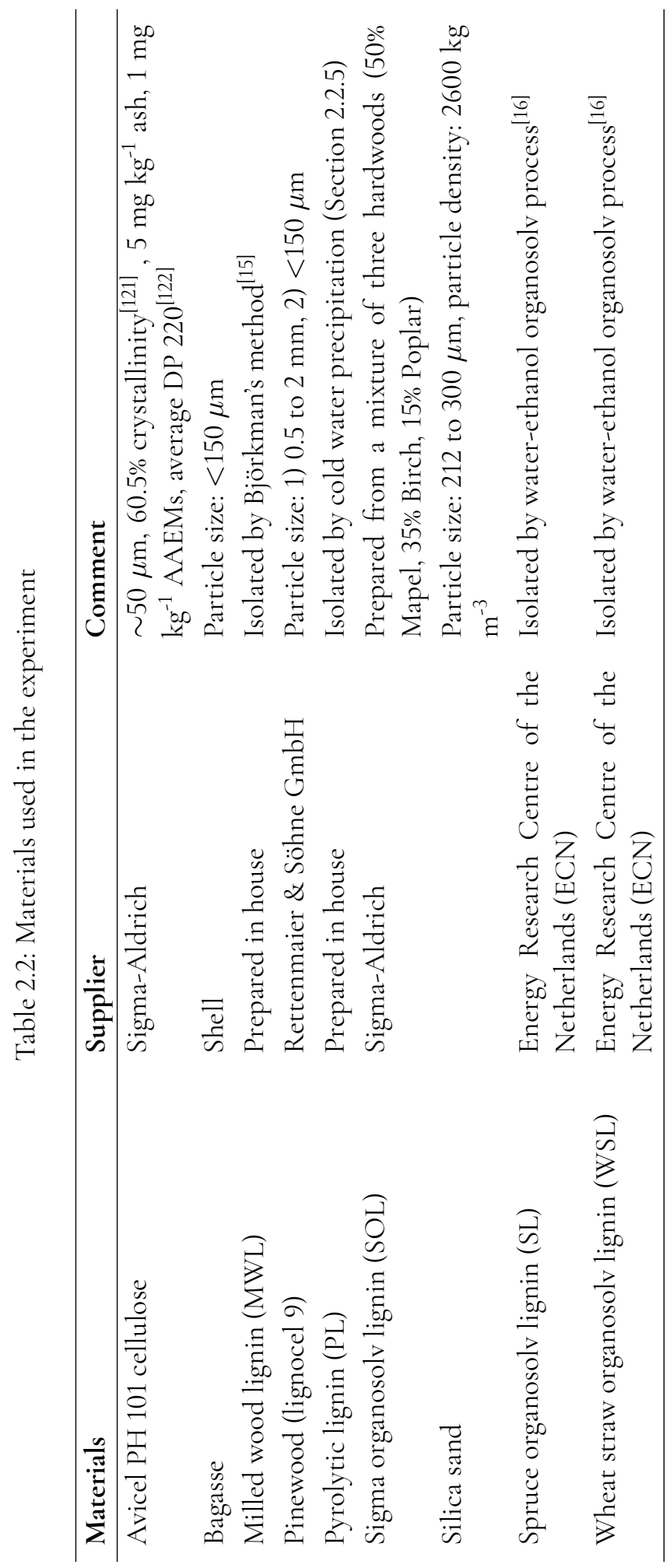




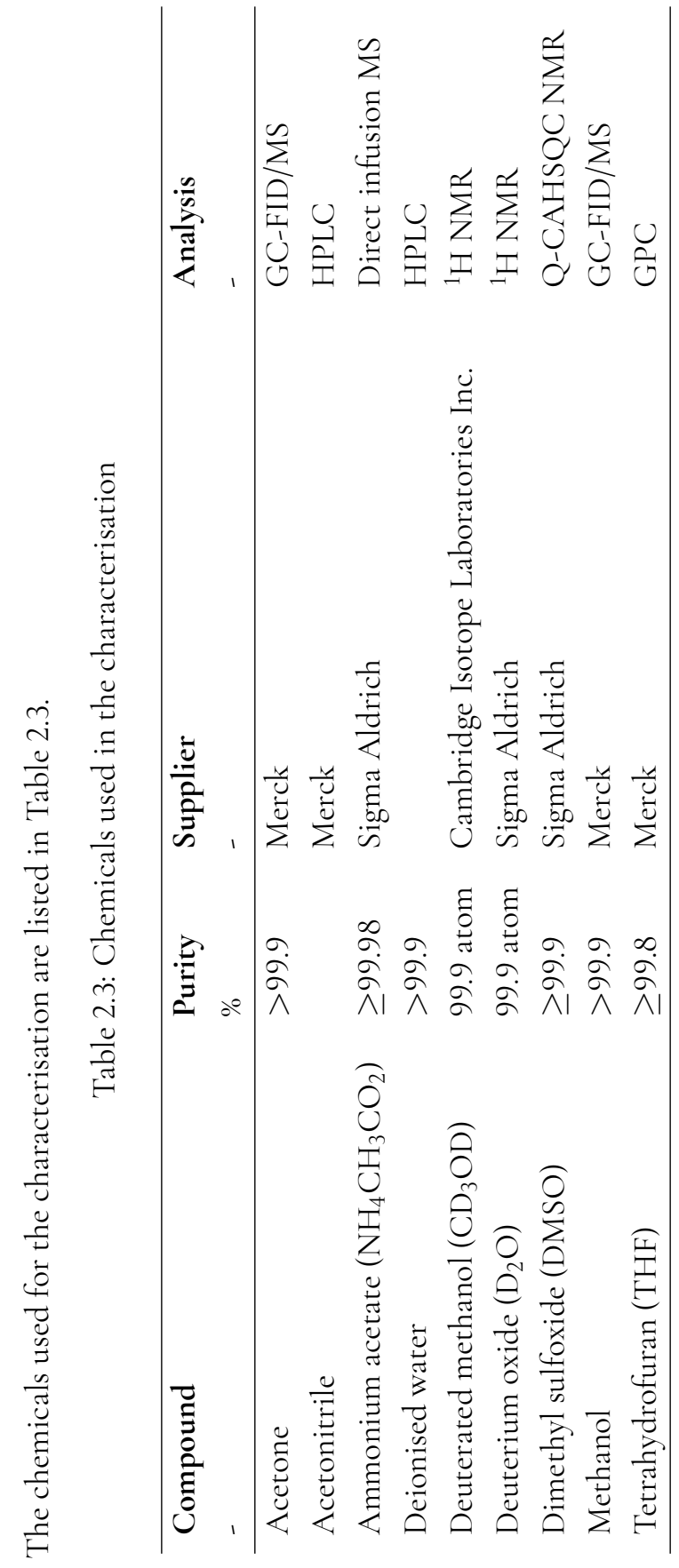




\subsection{Methods}

\subsubsection{Impregnation of salts in cellulose and levoglucosan}

$\mathrm{K}_{2} \mathrm{CO}_{3}, \mathrm{KCl}$ or $\mathrm{KOH}$ was dissolved in deionised water, and then dry cellulose was added to the mixture. The potassium (source: $\mathrm{K}_{2} \mathrm{CO}_{3}$ ) concentration in cellulose was varied between $100 \mathrm{mg} \mathrm{kg}^{-1}$ and $10000 \mathrm{mg} \mathrm{kg}^{-1}$. For $\mathrm{KCl}$ and $\mathrm{KOH}$, the concentration of potassium was $1000 \mathrm{mg} \mathrm{kg}^{-1}$. The water-salt-cellulose mixtures were thoroughly mixed $\left(\mathrm{T}=20^{\circ} \mathrm{C}\right)$ in a round bottom flasks for $1 \mathrm{~h}$. After mixing, deionised water was removed using a rotary evaporator (BÜCHI Rotavapor $\mathrm{R}-200, \mathrm{~T}=65^{\circ} \mathrm{C}, \mathrm{P}=10 \mathrm{kPa}, \sim 1 \mathrm{~h}$ ), and wet cellulose samples were dried for $24 \mathrm{~h}$ using a vacuum oven (Heraeus FVT420, $\mathrm{T}=20$ $\left.{ }^{\circ} \mathrm{C}, \mathrm{P}=0.5 \mathrm{kPa}\right)$.

Potassium (source: $\mathrm{K}_{2} \mathrm{CO}_{3}$ ) was impregnated in levoglucosan to have a concentration of $1000 \mathrm{mg} \mathrm{kg}^{-1}$. Unlike cellulose, levoglucosan readily dissolved in a water- $\mathrm{K}_{2} \mathrm{CO}_{3}$ mixture. Deionised water was slowly removed using the same method as for cellulose, while the mixture is continuously stirred to ensure uniform distribution of potassium. Gradual precipitation of sugar and salt, from the saturated aqueous solution, ensured a homogeneous distribution of potassium in levoglucosan.

\subsubsection{Acid Leaching}

The acid leaching of biomass samples was carried out in a $1 \mathrm{~L}$ round bottom glass reactor. For acid leaching of biomass, a synthetic mixture mimicking $2^{\text {nd }}$ condenser liquid (aqueous acidic solution) from the pyrolysis process was used, of which the composition is presented in Table 2.4 For details, readers are kindly referred to the literature $62[6671$. The glass reactor, filled with the leaching solution, was preheated to $90{ }^{\circ} \mathrm{C}$. A watercooled condenser was used to condense the volatile compounds. Biomass was added to the reactor, once the desired temperature was reached, in a mass ratio of $0.1 \mathrm{~g}$ of dry biomass to $1 \mathrm{~g}$ of the leaching solution. The mixture was thoroughly mixed by a magnetic stirrer (Magneetroerder X-1250) at $600 \mathrm{rpm}$ for $2 \mathrm{~h}$. After that, biomass slurry was vacuum filtered through a $6 \mu \mathrm{m}$ filter (Whatman quantitative filter paper, ashless, grade 42). The biomass was rinsed with the deionised water, to remove the leaching solution from the pores of the particle, until the $\mathrm{pH}$ of the effluent liquid was higher than 6 . Acid pre-treated biomass was dried in a vacuum oven (Heraeus FVT420, $\mathrm{P}<0.5 \mathrm{kPa}$ ) at room temperature for $24 \mathrm{~h}$. 
Table 2.4: Chemical composition of synthetic mixture mimicking $2^{\text {nd }}$ condenser liquid

\begin{tabular}{ll}
\hline Component & $\begin{array}{l}\text { Mass percentage } \\
\%\end{array}$ \\
\hline Acetic acid & 10 \\
Ethanol & 3.75 \\
Acetone & 3.75 \\
Propionic acid & 1.5 \\
Guaiacol & 1.5 \\
Deionised water & 79.5 \\
\hline
\end{tabular}

\subsubsection{Ash content determination}

The ash content of a sample was determined by using a dry oxidation method 123 . A crucible was rinsed with deionised water followed by dilute nitric acid $(0.1 \mathrm{M})$. The crucible was dried at $105^{\circ} \mathrm{C}$ and stored in a desiccator at room temperature. The weight of the crucible was measured three times with and without sample on a weighing balance (Mettler Toledo AX205, max $220 \mathrm{~g}$, precision $0.01 \mathrm{mg}$ ) and the average weight was recorded. Next, the crucible containing the sample was kept in a muffle furnace at 575 $\pm 5^{\circ} \mathrm{C}$ for $24 \mathrm{~h}$. After that, it was cooled down to room temperature in a desiccator and weighted again using the same balance. The ash content of the sample was determined by subtracting the weight of the empty crucible from the crucible including ash, and the weight difference is divided by the sample weight Eq. 2.1.

$$
Y_{\text {Ash }}=\frac{M_{\text {crucible }+ \text { ash }}-M_{\text {crucible }}}{M_{\text {crucible+sample }}-M_{\text {crucible }}} \times 100
$$

\subsubsection{Acid hydrolysis}

The total amount of anhydrosugars present in pyrolysis oils were determined by acid hydrolysis. For that, the NREL LAP method "Determination of sugars, by-products, and degradation products in liquid fraction process samples" was used 124 . Approximately $40 \mathrm{mg}$ of pyrolysis oil was dissolved in $10 \mathrm{~g}$ of deionised water. $350 \mu \mathrm{L}$ of concentrated $\mathrm{H}_{2} \mathrm{SO}_{4}(72 \mathrm{wt} . \%)$ was added to the diluted oil sample. The mixture was heated in an autoclave at $120^{\circ} \mathrm{C}$ for $1 \mathrm{~h}$ and was allowed to reach the room temperature. The mixture was transferred to a centrifuge tube, and $\mathrm{BaCO}_{3}$ was added to the mixture to neutralise $\mathrm{H}_{2} \mathrm{SO}_{4}$. Precipitated barium sulphate $\left(\mathrm{BaSO}_{4}\right)$ was separated by centrifuge (Eppendorf centrifuge 5804, $9000 \mathrm{rpm}, 5 \mathrm{~min}$ ). 


\subsubsection{Cold Water Precipitation}

Pyrolytic lignin was produced by cold water precipitation as described in the literature $\frac{125 / 126}{\text {. }}$ Pinewood-derived pyrolysis oils were added dropwise to ice-cold water while being stirred continuously. The precipitated powder was recovered by vacuum filtration followed by drying in a vacuum oven (Heraeus FVT420, $\mathrm{P}<0.5 \mathrm{kPa}$ ) at room temperature for $24 \mathrm{~h}$. Dry pyrolytic lignin was stored in a freezer maintained at $-25^{\circ} \mathrm{C}$.

\subsubsection{Lignin fractionation}

Lignins were fractionated into low and high molecular weight fractions by solvent extraction $[27 \mid 128$. A lignin sample was added to DCM in a weight ratio of 1 to 10. The DCM insoluble fraction, referred to as the heavy fraction $(\mathrm{H})$, was separated from the soluble fraction by filtration. The DCM soluble fraction, referred to as the light fraction (L), was recovered by evaporating DCM. See Figure 2.1 for the schematics.

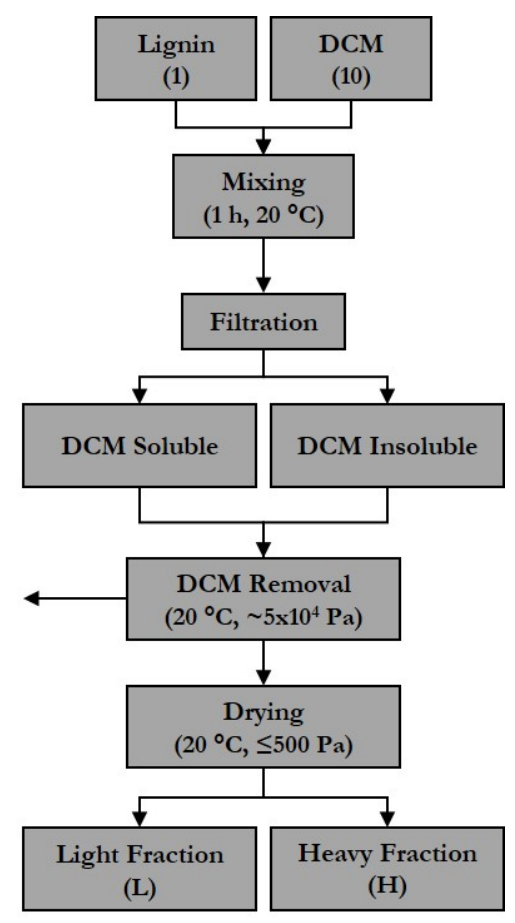

Figure 2.1: Lignin fractionation procedure 


\subsection{Fast pyrolysis setups}

\subsubsection{Screen-heater}

Fast pyrolysis of cellulose, lignin and biomass was carried out in the screen-heater setup. The schematic representation of screen-heater is shown in Figure 2.2 The screenheater setup and its main characteristics, sample preparation, and the operating procedure is described here.

1 Vessel (glass)

2 Mesh/Sample

3 Pyrometer spot

4 Liquid nitrogen bath (glas)

5 Copper electrode/clamp

6 Tape

7 Thermocouple connection

8 Syringe connection (gas sample)

9 Pressure sensor

10 Vacuum pump

11 Nitrogen gas

12 Pyrometer

13 Tube (glass)

14 Silicon sealing

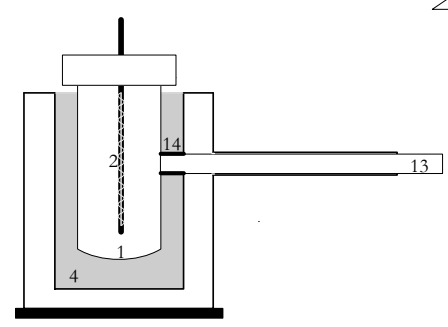

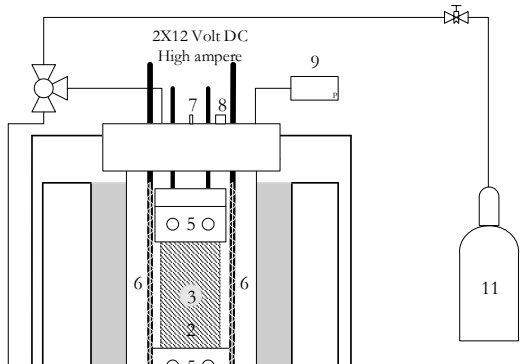

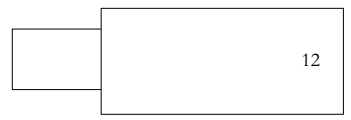

Figure 2.2: Schematics of the screen-heater setup

\section{Sample preparation and setup}

A uniformly distributed sample ( $\sim 50 \mathrm{mg})$ was pressed between the two catalytically inactive ${ }^{120}$ screens ( $\# 2$, thickness: $\sim 45 \mu \mathrm{m} \frac{119}{}$ ) using a 16-tonne hydraulic press. The pressed screens were clamped between two copper electrodes with bolts (\#5). The electrodes, clamps and bolts (\#5) were covered with tape (\#6). A glass vessel (\#1, Duran $250 \mathrm{~mL}$ centrifuge tube, round bottom, $147 \mathrm{~mm} \times 56 \mathrm{~mm}$ ) was installed around the copper electrodes $(\# 5)$ and screens $(\# 2)$ as shown in Figure 2.2 The reactor with the glass 
vessel was placed in the liquid nitrogen $\left(-196^{\circ} \mathrm{C}\right)$ bath $(\# 4)$ to achieve quick quenching of the produced vapours/aerosols.

The glass vessel was purged with the dry nitrogen gas (\#11) to remove air from the vessel before each experiment. Vacuum $(\leq 0.5 \mathrm{kPa})$ was achieved by an inline vacuum pump (\#10). In case of atmospheric pressure experiments (referred to as $100 \mathrm{kPa}$ experiment), a nitrogen atmosphere of $\sim 100 \mathrm{kPa}$ was maintained in the glass vessel after flushing the air out. The pressure inside the glass vessel was $0.5 \mathrm{kPa}$ or $100 \mathrm{kPa}$ and was monitored by two high-speed pressure sensors (\#9, Heise DXD3765 and Druck PTX 520). The vapour phase temperature was recorded by using a K-type thermocouple (diameter $0.025 \mathrm{~mm}$ connected to a Weidmuller MAS K-type thermocouple signal conditioner, recording every $16 \mathrm{~ms}$ ), introduced from $\#$, placed at $15 \mathrm{~mm}$ distance from the screens. The temperature of screens was measured with a pyrometer (\#12, Kleiber KGA 730). The detailed calibration procedure of the pyrometer is described elsewhere ${ }^{120}$. The optical beam of pyrometer was focused at the centre of the screens (\#3) via a glass tube (\#13) and silicon sealing (\#14) to avoid the disturbance of the temperature measurement by the liquid nitrogen.

The temperature measured at the pyrometer spot was termed as the final temperature of the screens $\left(\mathrm{T}_{\mathrm{FS}}\right.$ ), and to reach $\mathrm{T}_{\mathrm{FS}}$ the screens were heated at a rate of $5000^{\circ} \mathrm{C} \mathrm{s}^{-1}$ approaching as close as possible to isothermal measurements $119 \mid 120$. The temperature of the screens was measured and regulated by a calibrated pyrometer 120 and a PID control routine programmed in LabVIEW, respectively. The holding time of the screens at a given $\mathrm{T}_{\mathrm{FS}}$ was set at $5 \mathrm{~s}$ unless otherwise mentioned, and after that, they were cooled at a rate of $\sim 60^{\circ} \mathrm{C} \mathrm{s}^{-1}$. Experiments were performed at $0.5 \mathrm{kPa}$ and $100 \mathrm{kPa}$ unless otherwise mentioned. It was estimated that for both pressures the quenching rate of the formed products was very fast (hot vapour residence time in order of $20 \mathrm{~ms}$ ), which ruled out a significant effect of reactions outside the reacting sample (minimised vapour phase reactions) 120 .

\section{Product recovery and mass balance determination}

At the end of each experiment, the reactor was allowed to reach room temperature. In reduced pressure experiments, the reactor was filled with dry nitrogen gas before taking a gas sample from the glass vessel (\#8), and for $100 \mathrm{kPa}$ experiments, a sample was taken from a gas bag. The composition of gases, determined by using gas chromatography, was used to calculate the gas yield ( $\mathrm{kg} \mathrm{gas} \mathrm{kg}^{-1}$ feedstock), as given by Eq. 2.2 The char yield ( $\mathrm{kg}$ char $\mathrm{kg}^{-1}$ feedstock) was estimated from the difference between the weights of the screens before (with feedstock), and after (with char) the experiment Eq. 


$$
\begin{array}{r}
Y_{\text {Gas }}=\frac{\frac{P_{\text {sample }} f_{v, i}\left(V_{\text {vessel }}+V_{\text {bag }}\right) M_{w, i}}{R T_{\text {ambient }}}}{M_{\text {feedstock }}\left(1-f_{w}-f_{\text {ash }}\right)} \\
Y_{\text {Char }}=\frac{M_{\text {screens }+ \text { char }}-M_{\text {screens }}}{M_{\text {feedstock }}\left(1-f_{w}-f_{\text {ash }}\right)}
\end{array}
$$

Oil was condensed primarily on the interiors of the glass vessel and to a minor extent on the electrodes, clamps and bolts. The weights of the tape, wrapped around the electrodes, clamps and bolts, and the glass vessel were recorded before and after the experiment and used to calculate the oil yield ( $\mathrm{kg}$ oil kg-1 feedstock), see Eq. 2.4 Independently determined oil, char, and gas yields were summed together to determine the overall mass balance closure of the experiment Eq. 2.5.

$$
\begin{gathered}
Y_{\text {Oil }}=\frac{\left(M_{\text {vessel }+ \text { oil }}-M_{\text {vessel }}\right)+\left(M_{c+b+t+o i l}-M_{c+b+t}\right)}{M_{\text {feedstock }}\left(1-f_{w}-f_{\text {ash }}\right)} \\
\text { Mass balance }=Y_{\text {Gas }}+Y_{\text {Char }}+Y_{\text {Oil }}
\end{gathered}
$$

\subsubsection{Fluidised bed}

\section{Bench-scale fluidised bed}

Cellulose samples (pure, $100 \mathrm{mg} \mathrm{kg}^{-1}$ and $1000 \mathrm{mg} \mathrm{kg}^{-1}$ potassium impregnated) were pyrolysed in a bench scale fluidised bed reactor at a temperature of $530{ }^{\circ} \mathrm{C}$. Silica sand was used as bed material and preheated nitrogen as the fluidisation gas. During each experiment, $\sim 100 \mathrm{~g}$ of cellulose was fed manually to the reactor in batches of 2 to $5 \mathrm{~g}$ together with 4 to $8 \mathrm{~g}$ of sand. The feeding system consisted of two valves which functioned as a gas lock. The experimental time was 25 min. Produced char was separated from the outgoing gas/vapour stream leaving the reactor by using a wire-mesh filter (opening size $9 \mu \mathrm{m}$ ). Almost all char, including potassium, was collected on the filter. This filter cake, with varying amounts of potassium, was used as a tool to study the secondary vapour phase reactions. The estimated vapour residence time of products in the hot zone of the setup, including reactor and tubing, was always kept around 1.6 s. About $95 \%$ of the produced vapours were condensed by an electrostatic precipitator 
(ESP) operated at $20^{\circ} \mathrm{C}$ (outgoing gas temperature). The remaining vapours were condensed in a double-walled glass condenser operated at $-5{ }^{\circ} \mathrm{C}$ (outgoing gas temperature). Both fractions were considered for the mass balance. The char yield was determined by weighing the char/sand mixture and char/filter after the experiment and subtracting the initial weight of the sand and filter plus the sand fed during the experiment. The gas yield was determined by difference.

\section{Pilot plant - continuous fluidised bed}

Fast pyrolysis of (untreated and acid-leached) pinewood, under atmospheric and reduced pressure, was carried out in the continuous fluidised bed, with a capacity of 1 $\mathrm{kg} \mathrm{h}^{-1}$ biomass. The schematic representation of the setup is shown in Figure 2.3 All experiments were carried out in a nitrogen atmosphere. The pilot plant included two hoppers each with $4 \mathrm{~kg}$ capacity, of which one is used for storing pinewood (\#1) and second for the sand (\#5). The feeding rates of pinewood and sand screws were calibrated and controlled by two different systems. A mixture of pinewood and sand was fed to the fluidised bed reactor by using a third screw (\#3). The temperatures of two hot zones, i.e. fluidised bed reactor (\#6) and char separation section, were controlled independently. In all experiments, the temperature of the fluidised bed reactor was maintained at $\sim 485$ ${ }^{\circ} \mathrm{C}$. The operational conditions are summarised in Table 2.5

An overflow vessel (\#7), connected at the bottom of the reactor, was used to collect sand and char particles from the reaction zone. Solid particles, entrained with gas/vapours, were removed by a knocked out vessel (\#8) and cyclones (\#9). The outlet of cyclones was connected to the jacketed electrostatic precipitator (ESP, \#10), where the temperature of the ESP condenser was maintained at $20^{\circ} \mathrm{C}$ (outgoing gas temperature). The products, which could not be condensed in ESP, were sent to a second condenser,

Table 2.5: Summary of the experimental conditions of reactor and condenser

\begin{tabular}{lcccc}
\hline Parameter & Unit & Normal operation & Reduced pressure operation \\
\hline Run time & $\min$ & & 90 & \\
$\mathrm{M}_{\text {sand,initial }}$ & $\mathrm{kg}$ & $\sim 2$ & $\sim 2$ & $\sim 4$ \\
$\mathrm{U} / \mathrm{U}_{\mathrm{mf}}$ & - & & 20 & \\
$\mathrm{~T}_{\mathrm{ESP}}$ & ${ }^{\circ} \mathrm{C}$ & & -10 & \\
$\mathrm{~T}_{\mathrm{IC}}$ & ${ }^{\circ} \mathrm{C}$ & 100 & & 55 \\
$\mathrm{P}_{\text {Reactor }}$ & $\mathrm{kPa}$ & 1.9 & & 1 \\
$\tau_{\text {vapors }}$ & $\mathrm{s}$ & & & \\
\hline
\end{tabular}



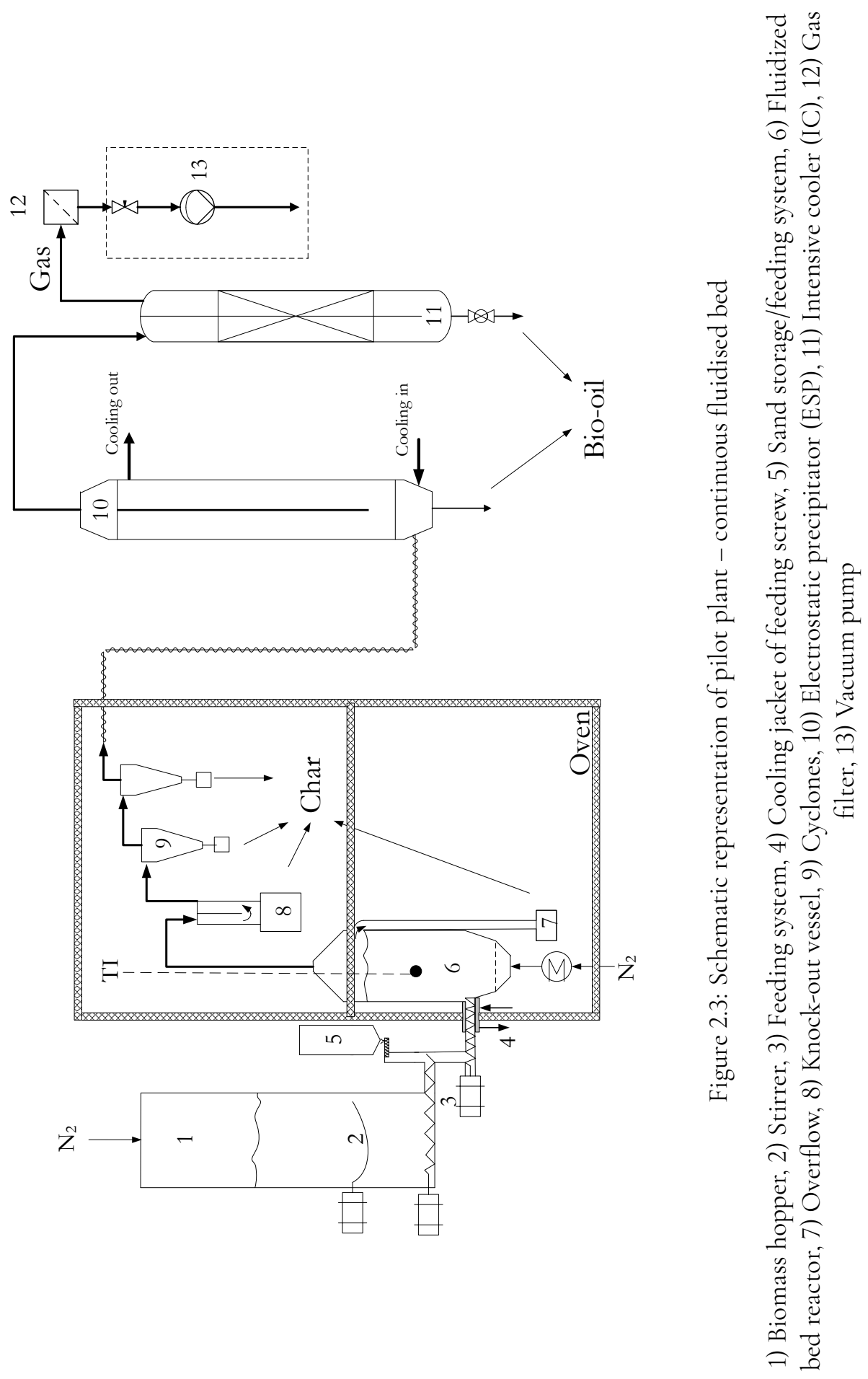
also called as an intensive cooler (IC, \#11), operated at $-10^{\circ} \mathrm{C}$. The permanent gases passed through a gas filter (\#12) to collect the remaining liquid. The vacuum in the pilot plant was achieved by using a vacuum pump (\#13) connected at the outlet of the gas filter (\#12). A needle valve was used at the inlet of the vacuum pump to control the pressure in the pilot plant. The volumetric flow rate of the outgoing gas was measured by using a dry gas meter. At every $10 \mathrm{~min}$, a gas sample was taken from the outgoing gas stream.

\section{Mass balance determination}

After each experiment, oil, char and gas yields were individually determined as follows. The char present in the reactor, the overflow vessel, the knock out vessel and the cyclones was collected to determine the char yield (Eq. 2.6). Based on the gas composition and the flowrate of nitrogen gas fed to the fluidised bed, the gas yield Eq. 2.7 was calculated. The mass of oil collected in ESP and IC were added together to determine the total yield of (wet) pyrolysis oil Eq. 2.8. The yields of oil, char and gas were summed together to determine the overall mass balance of the experiment Eq. 2.5.

$$
\begin{gathered}
Y_{\text {Char }}=\frac{M_{C, R}+M_{C, O}+M_{C, K D}+M_{C, C}}{M_{\text {biomass }}\left(1-f_{w}-f_{\text {ash }}\right)} \\
Y_{\text {Gas }}=\frac{\int_{t=0}^{t=t_{\text {end }}}\left\{\frac{\phi_{\text {out }} P_{\text {sample }}}{R T_{\text {ambient }}}-\frac{\phi_{\text {in }} P_{\text {sample }}}{R T_{\text {ambient }}}\right\} \sum_{i=1}^{n} f_{v, i} M_{w, i} d t}{M_{\text {biomass }}\left(1-f_{w}-f_{\text {ash }}\right)} \\
Y_{\text {Oil }}=\frac{M_{O, E S P}+M_{O, I C}}{M_{\text {biomass }}\left(1-f_{w}-f_{\text {ash }}\right)}
\end{gathered}
$$




\subsection{Analytical techniques}

\subsubsection{Gas Chromatography (GC)}

Micro-GC

A gas chromatograph (Varian MicroGC CP4900, 2 analytical columns: $10 \mathrm{~m}$ Molsieve 5A, $10 \mathrm{~m} P P Q$, carrier gas: $\mathrm{He}$ ) was used for analysing gas samples of screen-heater experiments for $\mathrm{N}_{2}, \mathrm{O}_{2}, \mathrm{CO}, \mathrm{CO}_{2}, \mathrm{CH}_{4}, \mathrm{C}_{2} \mathrm{H}_{6}, \mathrm{C}_{2} \mathrm{H}_{4}, \mathrm{C}_{3} \mathrm{H}_{6}$ and $\mathrm{C}_{3} \mathrm{H}_{8}$. The samples were analysed twice to ensure the reproducibility.

\section{Refinery GC}

The gas composition of the samples, collected during the pilot plant experiments, was determined using gas chromatography (Varian 450-RGA). The GC was equipped with three channels. Channel 1 equipped with two columns (Hayesep Q - Agilent CP1305 and Molsieve 5A - Agilent CP1306) detected $\mathrm{H}_{2}$ using thermal conductivity detector (TCD) with $\mathrm{N}_{2}$ as a carrier gas. $\mathrm{N}_{2}, \mathrm{O}_{2}, \mathrm{CO}$ and $\mathrm{CO}_{2}$ were separated by three columns (Hayesep Q - Varian CP1308, Hayesep N - Varian CP1307, Molsieve 13X - Varian CP1309), and were detected by channel 2 using TCD with He as a carrier gas. In channel 3, equipped with two columns (CP-Sil 5CB - Varian CP1310 and $\mathrm{Al}_{2} \mathrm{O}_{3} / \mathrm{MAPD}$ - Varian CP7433), hydrocarbons $\left(\mathrm{CH}_{4}, \mathrm{C}_{2} \mathrm{H}_{6}, \mathrm{C}_{2} \mathrm{H}_{4}, \mathrm{C}_{3} \mathrm{H}_{6}, \mathrm{C}_{3} \mathrm{H}_{8}\right)$ were detected using a flame ionisation detector (FID) with $\mathrm{He}$ as a carrier gas.

\subsubsection{Gas Chromatography-Mass Spectrometry}

Pyrolysis oils were diluted with a solvent in a mass ratio of 1:20 and were filtered with a $0.45 \mu \mathrm{m}$ Whatman RC Agilent filter, and subsequently analysed by using GCFID/MS (GC - 7890A, MS - 5975C Agilent Technologies system) equipped with a Agilent HP-5Ms HP19091S-433 capillary column (60 m, ID 0.25 mm, Film thickness: 0.25 $\mu \mathrm{m})$. The column is packed with (5\%-Phenyl)-methylpolysiloxane. Helium was used as carrier gas with a constant flow of $1.95 \mathrm{~mL} \mathrm{~min}^{-1}$. The oven temperature was programmed from $45^{\circ} \mathrm{C}(4 \mathrm{~min})$ to $280^{\circ} \mathrm{C}(20 \mathrm{~min})$ at a heating rate of $3{ }^{\circ} \mathrm{C} \mathrm{min}^{-1}$. The injector and the column to MS interface were maintained at a constant temperature of $250{ }^{\circ} \mathrm{C}$ and $280{ }^{\circ} \mathrm{C}$, respectively. A sample of $1 \mu \mathrm{L}$ was injected into the GC. The deactivated inlet liner (Agilent part no: 5183-4711) was regularly replaced to eliminate the influence of non-volatile (inorganic) species deposited on the glass wool. The MS was operated in electron ionisation mode, and ions were scanned in a $\mathrm{m} / \mathrm{z}$ range from 15 to 500. The identification of the peaks was made by matching its mass spectra with the NIST and Wood library or on the retention times of standards of known compounds 
injected in the column. The limit of detection for a given species was $0.008 \mathrm{wt} . \%$, while 0.01 wt. \% was the limit of quantification. The quantification was performed based on the FID.

\subsubsection{Ion chromatography}

The content of AAEMs $\left(\mathrm{Na}^{+}, \mathrm{K}^{+}, \mathrm{Ca}^{2+}, \mathrm{Mg}^{2+}\right)$ present in a sample was determined by using ion chromatography (IC). The water-soluble fraction of the sample was dissolved in $8 \mathrm{~g}$ of deionised water. The samples were filtered (Whatman RC Agilent 0.2 $\mu \mathrm{m}$ filter) before the IC analysis. The IC (Metrosep 850 Professional IC) was equipped with a cation column (Metrosep C6 - 150/4.0) and Metrohm 732 IC detector coupled to an IC Separation Centre. The analysis was performed at room temperature and with eluent (1.7 mM nitric acid $+1.7 \mathrm{mM}$ dipicolinic acid) flow rate of $1 \mathrm{~mL} \mathrm{~min}{ }^{-1}$. The quantification was done based on four point calibration of each cation.

\subsubsection{High-pressure liquid chromatography}

Liquid phase analysis of pyrolysis oils was performed by using HPLC (Agilent 1200 series). The system was equipped with Hi-Plex Pb column $(7.7$ x $300 \mathrm{~mm}, 8 \mu \mathrm{m})$, and refractive index detector (RID, $\mathrm{T}=55^{\circ} \mathrm{C}$ ) and variable wavelength detector (VWD, $\lambda$ $=254 \mathrm{~nm}$ ). The column was packed with a strong cation-exchange resin consisting of sulfonated crosslinked styrene/divinylbenzene copolymer in lead $(\mathrm{Pb})$ form. Deionised water was used as a mobile phase at a flowrate of $0.6 \mathrm{~mL} \mathrm{~min}^{-1}$. Pyrolysis oils (watersoluble fraction) were diluted in deionised water in a mass ratio of 1:20 and were filtered with $0.2 \mu \mathrm{m}$ Whatman RC Agilent filter. During analysis temperature of the column was maintained at $70{ }^{\circ} \mathrm{C}$ and $10 \mu \mathrm{L}$ of sample volume was injected into the system at room temperature. The limit of detection for a given species is $0.002 \mathrm{wt}$. \%, while 0.008 wt. \% is the limit of quantification. Quantification was performed based on the RID.

Analysis of model compound pyrolysis oils was performed on LC-UV (UHPLC 3000 Thermo Fisher Scientific) system, equipped with Kinetex F5 core-shell LC column by phenomenex operated at $35^{\circ} \mathrm{C}$. A mixture of acetonitrile and water was used as eluent $\left(0.2 \mathrm{~mL} \mathrm{~min}^{-1}\right)$, where the concentration of acetonitrile was gradually increased from 10 vol. \% to 90 vol. \% over $60 \mathrm{~min}$. During the analysis, VWD was set at $254 \mathrm{~nm}$ and it was used for the quantification.

\subsubsection{Direct infusion mass spectrometry}

The pyrolysis oils (water-soluble fraction) were diluted with deionised water to a concentration of $\sim 150 \mathrm{mg} \mathrm{kg}^{-1}$. Ammonium acetate was added to the diluted oil- 
water mixture as an ionisation agent 129/130. A $1 \mathrm{~mL}$ Hamilton syringe loaded onto a syringe pump was used to infuse diluted samples directly into the ESI chamber at a rate of $0.01 \mathrm{~mL} \mathrm{~min}^{-1}$. The instrument used was an ESI Ion-Trap mass spectrometer (Bruker amaZon SL, Germany). The ESI MS analysis was accomplished in manual mode using drying temperature of $200{ }^{\circ} \mathrm{C}, \mathrm{N}_{2}$ flowrate and nebulizer pressure of $6 \mathrm{~L} \mathrm{~min}^{-1}$ and 10 psi, respectively. Full scan mass spectra were acquired over the $\mathrm{m} / \mathrm{z}$ range of $50-2000$. For $\mathrm{MS}^{2}$ experiments, helium gas was used as a collision gas with a fragmentation amplitude voltage of $1 \mathrm{~V}$ and a mass window was $1.5 \mathrm{Da}$.

\subsubsection{Gel permeation chromatography (GPC)}

The molecular weight distribution $\left(\mathrm{M}_{W} \mathrm{D}\right)$ of lignin and pyrolysis oils was determined by using GPC (Agilent Technologies 1200) equipped with three columns (7.5 $\mathrm{mm}$ x $300 \mathrm{~mm}$, particle size $3 \mu \mathrm{m}$ ) placed in series packed with highly cross-linked polystyrene-divinylbenzene copolymer gel (Varian PLgelMIXED E). The column temperature was maintained at $40{ }^{\circ} \mathrm{C}$ during analysis. Samples were dissolved in tetrahydrofuran (THF) in a 1:100 mass ratio and were filtered through a $0.45 \mu \mathrm{m}$ Whatman RC Agilent filter. THF was used as a mobile phase at a flowrate of $1 \mathrm{~mL} \mathrm{~min}^{-1}$. A RID and $\operatorname{VWD}(\lambda=254 \mathrm{~nm})$ were installed. The calibration line was made with 10 polystyrene standards with molecular weights ranging from 162 Da to $29510 \mathrm{Da}$, which was used for the conversion of elution volume to molecular weight.

\subsubsection{Nuclear magnetic resonance (NMR)}

\section{D NMR: ${ }^{1} \mathrm{H}$}

${ }^{1} \mathrm{H}$ NMR spectra were recorded on a Bruker Avance II $600 \mathrm{MHz}$ NMR spectrometer $(14.1 \mathrm{~T})$, using a $5 \mathrm{~mm}$ triple nucleus TXI ${ }^{1} \mathrm{H}-{ }^{13} \mathrm{C} /{ }^{15} \mathrm{~N} /{ }^{2} \mathrm{H}$ probe and Avance III 400 MHz NMR spectrometer $(9.4 \mathrm{~T})$ provided with a broadband BBFO probe. Both spectrometers are equipped a with $z$ gradient coil producing a maximum gradient strength of 50 gauss $\mathrm{cm}^{-1}$.

\section{D NMR: Q-CAHSQC}

2D Q-CAHSQC NMR spectra were acquired on a Bruker Avance II $600 \mathrm{MHz}$ spectrometer $(14.1 \mathrm{~T})$, using a $5 \mathrm{~mm}$ triple nucleus TXI ${ }^{1} \mathrm{H}-{ }^{13} \mathrm{C} /{ }^{15} \mathrm{~N} /{ }^{2} \mathrm{H}$ probe, equipped at $25^{\circ} \mathrm{C}$ without sample spinning using the Q-CAHSQC pulse program $\frac{131}{1}$. Matrices of 2048 data points for the $1 \mathrm{H}$-dimension and 256 data points for the $13 \mathrm{C}$-dimension were collected with a relaxation delay of $6 \mathrm{~s}$ and spectral widths from 14 to -1 ppm and from 
200 to $0 \mathrm{ppm}$ for the ${ }^{1} \mathrm{H}$ and ${ }^{13} \mathrm{C}$ dimensions, respectively. The samples were dissolved in DMSO-d $\mathrm{d}_{6}$ (Concentration: $0.1 \mathrm{mg} \mu \mathrm{L}^{-1}$ ), and chemical shifts were referenced to the solvent signal (2.5/39.5 ppm). The spectra were processed using MestReNova.

\subsubsection{Karl-Fischer Titration (KFT)}

The water content of pyrolysis oils was determined by Karl-Fischer titration using a Metrohm 787 KF Titrino. Hydranal Composite 5 was used as a titrant and a solution of methanol : dichloromethane (3:1 in volume) was used as a solvent.

\subsubsection{Elemental analysis}

A Perkin-Elmer elemental analyser (Thermo scientific Flash 2000) was used for the ultimate analysis $(\mathrm{C}, \mathrm{H}, \mathrm{N})$ of the samples. The analyser was equipped with a column of two reactive beds, i.e. copper oxide and electrolyte copper. The column temperature was maintained at $900{ }^{\circ} \mathrm{C}$. Argon $\left(140 \mathrm{~mL} \mathrm{~min}^{-1}\right)$ and $\mathrm{O}_{2}\left(250 \mathrm{~mL} \mathrm{~min}^{-1}\right)$ were used as a carrier and reactive gases, respectively. TCD was used for the detection of 29 gases. Tin cups loaded with the sample ( $\sim 3 \mathrm{mg}$ ) were inserted into the column by an autosampler. The weight fraction of $\mathrm{C}, \mathrm{H}$ and $\mathrm{N}$ were calculated based on the amount of $\mathrm{H}_{2} \mathrm{O}, \mathrm{CO}_{2}$ and $\mathrm{N}_{2}$ evolved from the decomposition of the samples. The oxygen fraction was calculated by difference. 


\section{Nomenclature}

$i$

$M_{\text {feedstock }}$

$M_{\text {screens }}$

$M_{\text {screens+residue }}$

$M_{\text {vessel }}$

$M_{\text {vessel+oil }}$

$M_{c+b+t}$

$M_{c+b+t+o i l}$

$M_{\text {crucible }}$

$M_{\text {crucible+sample }}$

$M_{\text {crucible+ash }}$

$M_{\text {biomass }}$

$M_{C, R}$

$M_{C, O}$

$M_{C, K D}$

$M_{C, C}$

$M W_{i}$

Psample

R

$T_{\text {ambient }}$

$f_{v, i}$

$f_{w}$

$f_{\text {ash }}$

$V_{\text {vessel }}$

$V_{b a g}$

$Y_{\text {Ash }}$

$Y_{\text {Gas }}$

$Y_{\text {Char }}$

$Y_{\text {Oil }}$

$\phi_{\text {out }}$

$\phi_{\text {in }}$ $k g$

$k g$

$k g$

$k g$

$k g$

$k g$

$k g$

$k g$

$k g$

$k g$

$k g$

$k g$

$k g$

$k g$

$k g$

kg mole $e^{-1}$

$\mathrm{Pa}$

$J$ mole ${ }^{-1} K^{-1}$

K

$-$

-

$m^{3}$

$m^{3}$

$k g k g^{-1}$

$k g k g^{-1}$

$k g k g^{-1}$

$k g k g^{-1}$

$m^{3} s^{-1}$

$m^{3} s^{-1}$
Number of components detected in the gas sample

Dry mass of feedtsock

Mass of the screens before experiment

Mass of the screens with char

Mass of the vessel before experiment

Mass of the vessel with oil

Mass of the clamps (c), bolts (b) and tape (t) before experiment

Mass of the clamps (c), bolts (b) and tape (t) with oil

Mass of the empty crucible

Mass of the empty crucible and sample

Mass of the empty crucible and ash

Mass of biomass pyrolysed in fluidised bed

Mass of char collected from the fluidised bed reactor

Mass of char collected from the overflow vessel

Mass of char collected from the knock out vessel

Mass of char collected from the cyclones

Molecular weight of component $i$

Pressure at which the gas sample was taken

Universal gas constant

Temperature at which the gas sample was taken

Volume fraction of component $i$ in the gas sample

Mass fraction of moisture in feedstock

Mass fraction of ash in feedstock

Volume of the vessel

Volume of the gas bag; for vacuum experiment $V_{b a g}$ was zero

Ash yield

Gas yield, dry ash free basis

Char yield, dry ash free basis

Oil yield, dry ash free basis

Total flowrate of gas measured by the gas meter

Total flowrate of nitrogen added to the fluidised bed reactor 


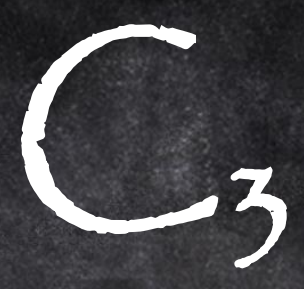

\section{Evaluating quantitative}

determination of levoglucosan and hydroxyacetaldehyde in bio-oils by gas and liquid chromatography

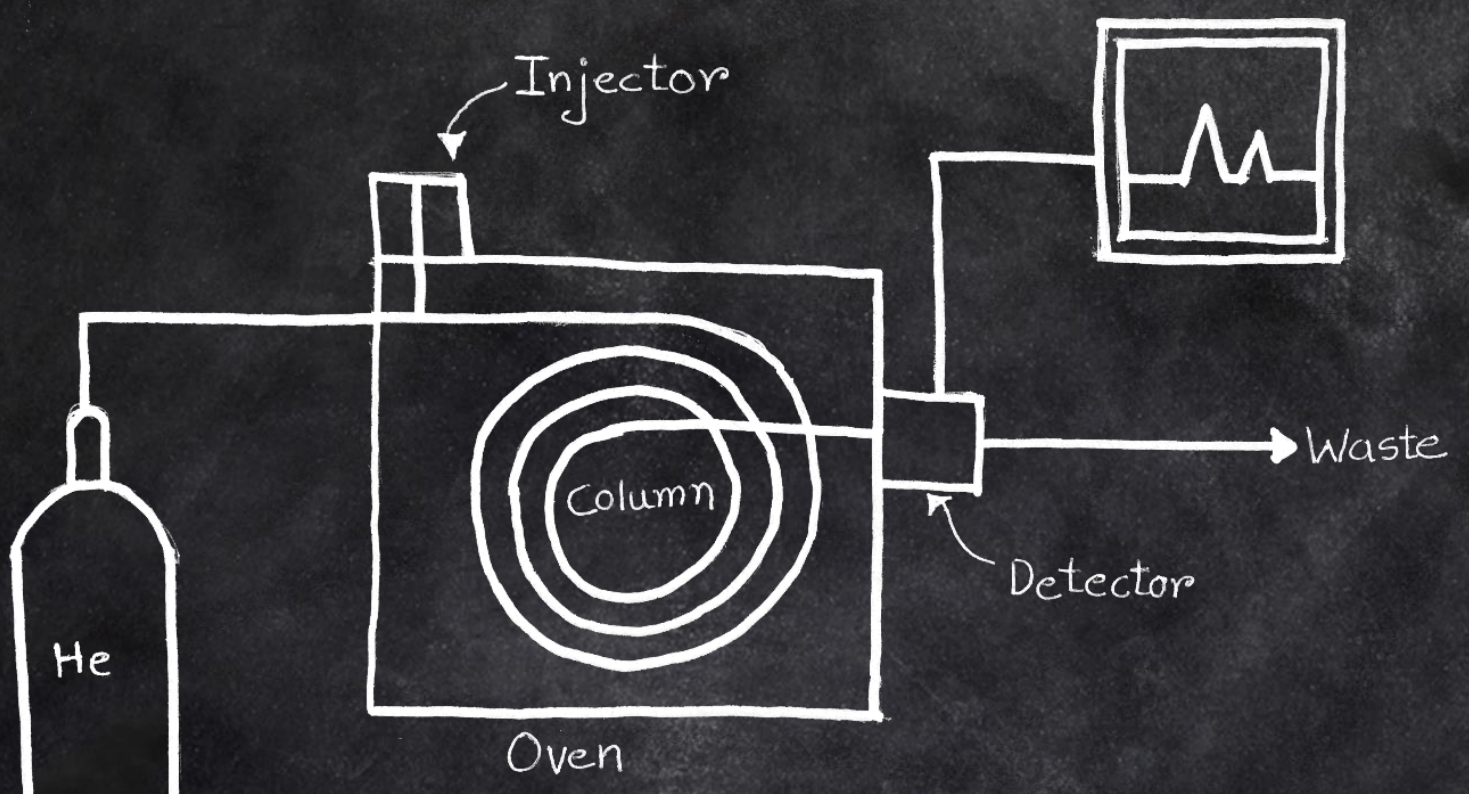




\begin{abstract}
This chapter evaluates the suitability of gas and liquid chromatography for the quantification of levoglucosan and hydroxyacetaldehyde in bio-oils. It was found that both techniques can principally determine levoglucosan quantitatively in cellulose/biomass derived bio-oils. However, it is also shown that oligo-anhydrosugars present in the biooils undergo depolymerisation to levoglucosan during gas chromatography, resulting in an overestimation of the concentration of levoglucosan. Hydroxyacetaldehyde can only be determined quantitatively by liquid chromatography. Presented experimental evidence shows that the high temperature $\left(200-320^{\circ} \mathrm{C}\right)$ of injection in gas chromatography is a key factor causing oligo-anhydrosugars and hydroxyacetaldehyde to react during analysis, which may lead to flawed results.
\end{abstract}

This chapter is based on:

P.S. Marathe, A. Juan, X. Hu, R.J.M. Westerhof, S.R.A. Kersten, Evaluating quantitative determination of levoglucosan and hydroxyacetaldehyde in bio-oils by gas and liquid chromatography, J. Anal. Appl. Pyrolysis (2019). 


\subsection{Introduction}

This chapter deals with the quantitative determination of levoglucosan (LG) and hydroxyacetaldehyde (HA) in bio-oils by gas (GC) and liquid (LC) chromatography, being the most frequently used analytical techniques. In the literature, a limited number of studies deal with the GC analysis of silylated of bio-oils (e.g. $132+138$ ), whereas $>100$ research articles report GC analysis of non-silylated bio-oils. Therefore, in this work, GC analysis of only non-silylated bio-oils is considered.

The motivation for this work is our observation that analysing the same oil on our GC and LC instrument resulted in different concentrations of LG and HA in the samples. In order to rule out the artefacts of our equipment and methods, LG and HA yields reported in the literature were examined. 65 papers $48|49| 61|64| 66|72| 75|107| 130|136| 139|-191|$, including 6 66|130|154|174|181/185 of our own, reporting on different biomasses, reactors, operating conditions and analytical techniques were evaluated. All data used are listed in Table A.1 to A.4 in Appendix A Aligning the LG (or HA) yields obtained under different conditions and by different measurement techniques is rather difficult. However, the statistical analysis of these data shows that the influence of measurement (analytical) technique used on the reported yields of LG is significant and for HA yields cannot be excluded. This statement is substantiated below in more detail. Table 3.1 shows the range and average of LG and HA yields reported, for cellulose and lignocellulosic biomass pyrolysis, in the temperature range between 300 and $650{ }^{\circ} \mathrm{C}$. This table also lists standard deviations, $p$-values and the results of the principal component analysis (PCA).

The $p$-values indicate that for LG there is a difference between the population means of the sets with a different analytical technique, i.e. reported yields by GC and LC are statistically different. This is not the case for HA, although PCA indicates that for HA the analytical technique is the $3^{\text {rd }}$ (biomass) and the $4^{\text {th }}$ (cellulose) principle component out of six. This suggests that there may be an effect of the analytical technique. Wang et al. 174 reported the LG yields determined by GC and LC, in which they report higher LG yields by GC than by LC for cellulose-derived oils, and vice-versa for pyrolysis oils obtained from biomass. No study in the literature reports HA yields measured by both GC and LC.

Based on our observations and analysis of literature data, we decided to investigate the suitability of GC and LC for the quantification of LG and HA in bio-oils systematically. To the best of our knowledge, no such study is available in literature. Conducting such a study would be of significant importance for obtaining the correct information about the true yields of LG and HA. These are two important compounds derived from 
Table 3.1: Reported yields of levoglucosan (LG) and hydroxyacetaldehyde (HA): minimum, maximum, mean $(\mu)$, standard deviation $(\sigma)$, number of data points, number of papers, $p$-values (Welch test), and principal components

\begin{tabular}{|c|c|c|c|c|c|c|c|}
\hline \multirow{2}{*}{$\begin{array}{c}\text { Compound } \\
\text { Unit } \\
\text { Analytical technique } \\
\text { Feedstock }\end{array}$} & \multicolumn{3}{|c|}{$\begin{array}{c}\text { LG } \\
\text { wt. \% on cellulose/biomass }\end{array}$} & \multicolumn{4}{|c|}{$\begin{array}{c}\text { HA } \\
\text { wt. \% on cellulose/biomass }\end{array}$} \\
\hline & $\begin{array}{l}\text { GC LC } \\
\text { Cellulose }\end{array}$ & $\begin{array}{r}\text { GC } \\
\text { Bis }\end{array}$ & $\begin{array}{l}\text { LC } \\
\text { hass }\end{array}$ & $\begin{array}{l}\mathrm{GC} \\
\mathrm{Cel}\end{array}$ & $\begin{array}{l}\text { LC } \\
\text { lose }\end{array}$ & $\begin{array}{r}\text { GC } \\
\text { Bi }\end{array}$ & Biomass \\
\hline nr of data points & 26 & 97 & 32 & 16 & 6 & 55 & 22 \\
\hline nr of papers & 12 & 33 & 12 & 9 & 3 & 19 & 8 \\
\hline minimum & 0.5 & 0.0 & 0.0 & 1.6 & 0.0 & 0.0 & 0.0 \\
\hline maximum & 63.5 & 23.5 & 22.1 & 16.0 & 15.3 & 12.7 & 17.1 \\
\hline$\mu$ & 36.7 & 3.6 & 5.3 & 6.8 & 9.8 & 4.5 & 5.7 \\
\hline$\sigma$ & $20.4 \quad 13.1$ & 4.3 & 5.7 & 4.0 & 5.2 & 3.6 & 4.6 \\
\hline AT being PC nr..$^{a}$ & $2^{b}$ & \multicolumn{2}{|c|}{2} & \multicolumn{2}{|c|}{4} & \multicolumn{2}{|c|}{3} \\
\hline$p$-value & 0.003 & \multicolumn{2}{|c|}{0.037} & \multicolumn{2}{|c|}{0.278} & \multicolumn{2}{|c|}{0.302} \\
\hline
\end{tabular}

a The following 6 principal components (PC) were used: Y: yield; A: ash content; R: reactor type; T: temperature; P: pressure; AT: analytical technique. In Section A.3 of Appendix A the complete output of the PCA is presented.

${ }^{\mathrm{b}}$ For example, AT being PC number means analytical technique is $2^{\text {nd }}$ principal component

cellulose via pyrolysis, which is a prerequisite for understanding the composition of biooil and for understanding the mechanism for pyrolysis cellulose or biomass.

\subsection{Bio-oils}

Bio-oils used in this chapter were derived from cellulose and pinewood. Cellulose samples (pure and $1000 \mathrm{mg} \mathrm{kg}^{-1}$ potassium infused) were pyrolysed in a screen-heater $(0.5$ $\mathrm{kPa})$ and fluidised bed reactor $(100 \mathrm{kPa})$ at $530{ }^{\circ} \mathrm{C}$. Pinewood was pyrolysed in a continuous fluidised bed reactor, (two separate experiments) at $530{ }^{\circ} \mathrm{C}$. For the details of pyrolysis experiments and the discussion about experimentally observed trends, refer to Chapter 4 and the work of Oudenhoven et al. 62. The oil yields observed for pure cellulose in screen-heater $\left(0.96 \mathrm{~kg} \mathrm{~kg}^{-1}\right)$ and fluidised bed $\left(0.73 \mathrm{~kg} \mathrm{~kg}^{-1}\right)$ were higher compared to the oil yields obtained for $1000 \mathrm{mg} \mathrm{kg}^{-1}$ potassium infused cellulose (screen-heater: $0.52 \mathrm{~kg} \mathrm{~kg}^{-1}$ and fluidised bed: $0.6 \mathrm{~kg} \mathrm{~kg}^{-1}$ ) (see Chapter 4). For pinewood, $0.55 \mathrm{~kg} \mathrm{~kg}^{-1}$ oil yields, excluding water, were obtained in the work of Oudenhoven et al.62. All bio-oils were stored at $-25^{\circ} \mathrm{C}$ in the absence of light before analysis.

Note that, because of the limited quantity ( $30 \mathrm{mg}$ ) of oil collected from a single 
screen-heater experiment, it was not possible to analyse the same oil by GC and LC. Therefore, both cellulose samples were pyrolysed, in the screen-heater eight times, under identical experimental conditions, of these four oils were analysed individually by either GC or LC. The error bars in Figure 3.1 and 3.3 represent the standard deviations on the mean. Contrary, the quantity of oil obtained from a single fluidised bed experiment was sufficient for both analysis techniques. Thus, for each fluidised bed oil, three separate samples (for each analysis technique) were prepared and were subsequently analysed. The LG (and HA) yield values are averages of three separate analyses. The standard deviation on the mean, for the LG (and HA) yields obtained (in GC and LC) from three injections (per oil) was $<1 \%$ for LG (and HA). Hence, to avoid the confusion between LG (and HA) yields from four experiments (in screen-heater) and three separate samples (of a single fluidised oil), the error bars for latter were not included in Figure 3.1 and 3.3

\subsection{A note on GC and LC settings reported in literature}

GC: Table A.5 in the Appendix A presents the summary of GC settings, i.e. solvent, injection temperature, column, oven temperature program, reported in the literature. Methanol and acetone are the commonly used solvents for diluting bio-oils before GC analysis. Diluted oils are subsequently introduced into GC via an injection port/section, of which temperature ranges between 200 to $320^{\circ} \mathrm{C}$. It is important to note that during (high temperature) injection, solvent and species present in the pyrolysis oil matrix are present together. In the literature, 20 different chromatographic columns varying in polarity are reported. Typically, the GC oven temperature increases with a low heating rate of 3 to $5^{\circ} \mathrm{C} \mathrm{min}^{-1}$.

LC: Table A.6 in the Appendix A presents the summary of LC settings, i.e. mobile phase and its flowrate, column, and the temperature at which the separation takes place, reported in the literature. Different mobile phases, from acidic to basic in nature, are used to separate the species present in the pyrolysis oil, and its flowrate ranges from 0.4 $\min ^{-1}$ to $2 \mathrm{~min}^{-1}$. In literature, 8 different LC columns are reported, and their operation temperature lies in between 25 to $85^{\circ} \mathrm{C}$.

It is worth mentioning that the GC and LC settings used in this work do not deviate from the ones reported in the literature. 


\subsection{Results and discussion}

\subsubsection{Levoglucosan}

Figure 3.1 shows that LG yields determined by GC were consistently higher than that by LC. The difference was most noticeable for the pyrolysis oil obtained from pure cellulose and was smaller for oils obtained from $1000 \mathrm{mg} \mathrm{kg}^{-1}$ potassium infused cellulose. Note, the effect of potassium on cellulose pyrolysis has been elaborated in Chapter 4, and hence it is not discussed here.

Literature shows that the pyrolysis of oligo-anhydrosugars (e.g. cellobiosan) results in the production of $\mathrm{LG}^{130 / 174}$. Based on these findings, it has been proposed, by us, that the oligo-anhydrosugars present in the pyrolysis oil partially depolymerise to LG at the injection temperature of $250{ }^{\circ} \mathrm{C}$ of a GC. To validate this hypothesis, a cellobiosan solution (of known concentration) diluted in methanol was injected into the GC and it was confirmed that the only observed peak in the chromatogram of cellobiosan was of LG (RT $=55.5 \mathrm{~min}$ ), see Figure A.3 in Appendix A Based on the recovery of LG calculated from the chromatogram, the estimated conversion, based on the assumption that cellobiosan only reacts to levoglucosan, was $28 \%$. On the other hand, cellobiosan analysed by LC showed no evidence of decomposition. Accordingly, it can be concluded that the oligo-anhydrosugars partially depolymerise to smaller anhydrosugar(s) at the temperatures as low as $250{ }^{\circ} \mathrm{C}$ during GC analysis.

It has been shown in literature that pyrolysis oil obtained from pure cellulose is comprised of oligo-anhydrosugars with a degree of polymerisation up to 11 130|178|187|192/193 . Therefore, it is argued that the higher LG yields (by GC) observed (in Figure 3.1), in the case of pure cellulose oils, is a result of the partial depolymerisation of oligo-anhydrosugars taking place in GC. In the case of $1000 \mathrm{mg} \mathrm{kg}^{-1}$ potassium impregnated cellulose pyrolysis, the majority of oligo-anhydrosugars were destroyed during pyrolysis (Chapter 4); consequently, the difference in the LG yields determined by the two analytical techniques was smaller.

Figure 3.2 shows the LG yields, obtained from unspiked and spiked cellulose oils (fluidised bed), determined by GC and LC. The oils were spiked with $0.07 \mathrm{~kg} \mathrm{~kg}^{-1} \mathrm{LG}$ (on cellulose basis). Hereafter, original bio-oils and bio-oils doped with extra LG (or HA in Section 3.4.2 are referred to as unspiked and spiked oils, respectively. The additional LG was recovered completely by both analytical techniques. These findings suggest that quantification of LG is not affected by the analytical techniques self, even when present in the matrix of other chemical species. In conclusion, to avoid the over-estimation of the LG yield caused by depolymerisation of oligo-anhydrosugars and for precise quan- 


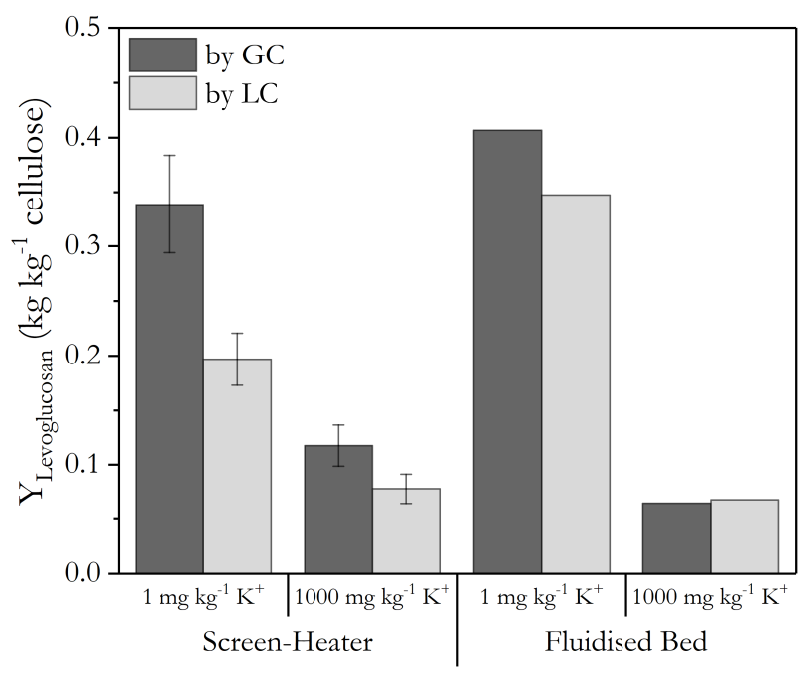

Figure 3.1: LG yield measured by GC and LC

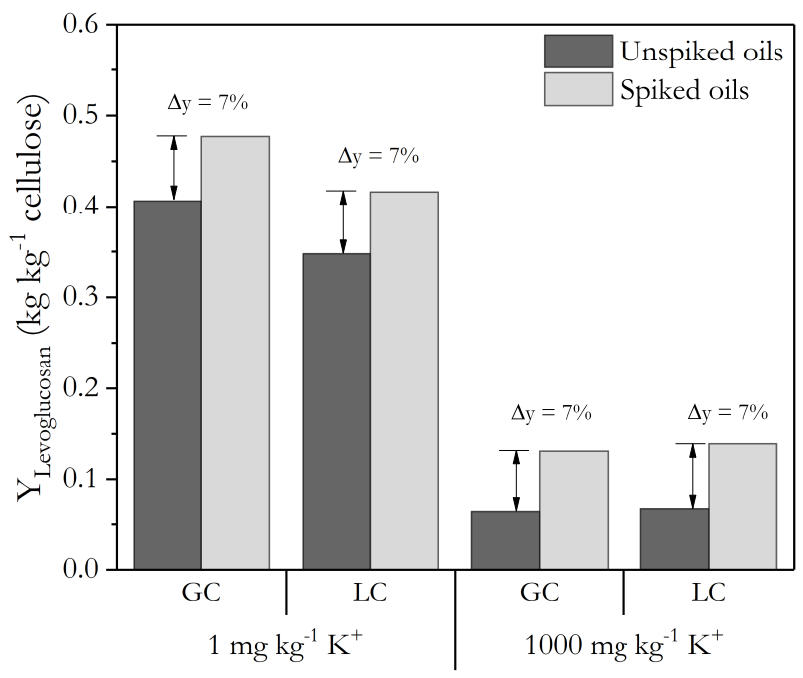

Figure 3.2: LG yield, obtained from unspiked and spiked cellulose bio-oils (fluidised bed), determined by GC and LC 
tification of LG yield, liquid chromatography is recommended. If in case, a GC system is used for the quantification of LG, careful interpretation of the LG yield is essential.

\subsubsection{Hydroxyacetaldehyde}

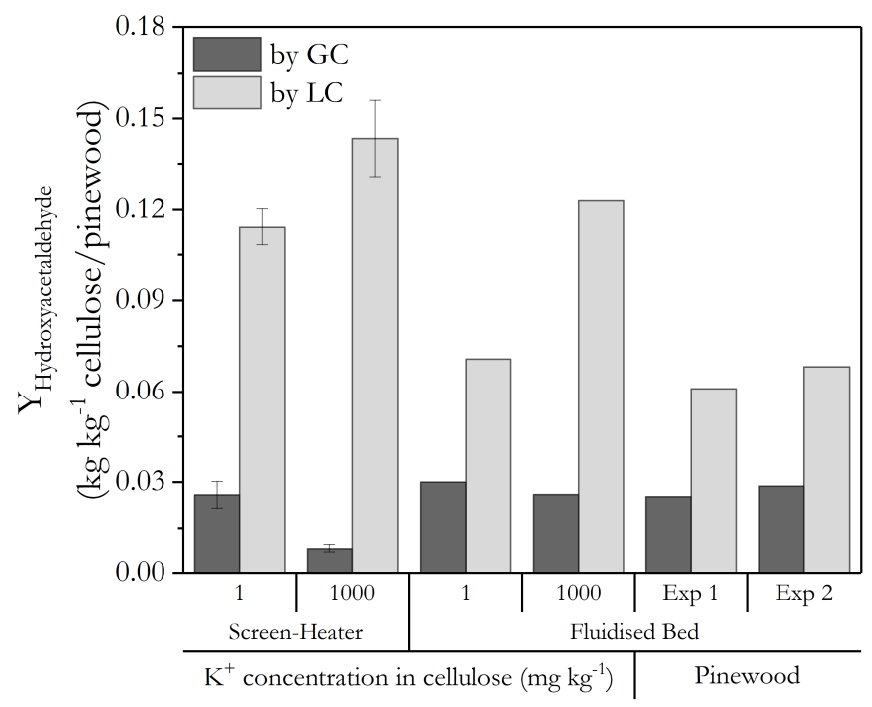

Figure 3.3: HA yield measured by GC and LC

Figure 3.3 compares the HA yield determined by GC and LC. It can be seen that the yield of HA measured by GC is lower than by LC. This observed trend is independent of feedstock and the experimental setup. Note, for the details about the isolation, identification and quantification of the HA, Section A.6 of Appendix A can be referred.

In order to understand the discrepancy in HA yields, bio-oils spiked with $0.07 \mathrm{~kg}$ $\mathrm{kg}^{-1} \mathrm{HA}$ (on cellulose basis) were analysed by GC and LC. Figure $3.4 \mathrm{~A}$ and $3.4 \mathrm{~B}$ present the HA yields, obtained from unspiked and spiked cellulose oils determined by GC and LC. The difference between the HA yields obtained from unspiked and spiked oils, determined by GC analysis, was smaller than the spiked amount, while it was $0.07 \mathrm{~kg} \mathrm{~kg}^{-1}$ for both oils when determined by LC. This observed trend is independent of the solvent used for dilution of oils prior to GC analysis, see Figure $3.4 \mathrm{~A}$ (methanol) and $3.4 \mathrm{~B}$ (acetone).

These results suggest that HA undergoes reactions during GC analysis, while it does not react during LC analysis. One of the decomposition products, glycolaldehyde dimethyl acetal, was detected in the GC chromatograms. Glycolaldehyde dimethyl ac- 


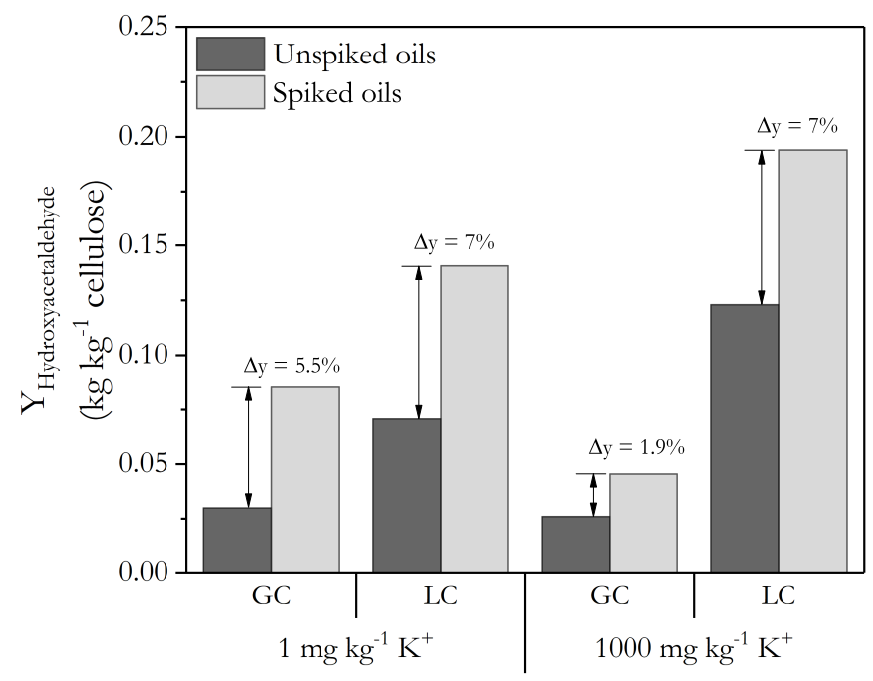

Figure 3.4A: HA yield, obtained from unspiked and spiked cellulose bio-oils (fluidised bed), determined by GC and LC; solvent: Methanol

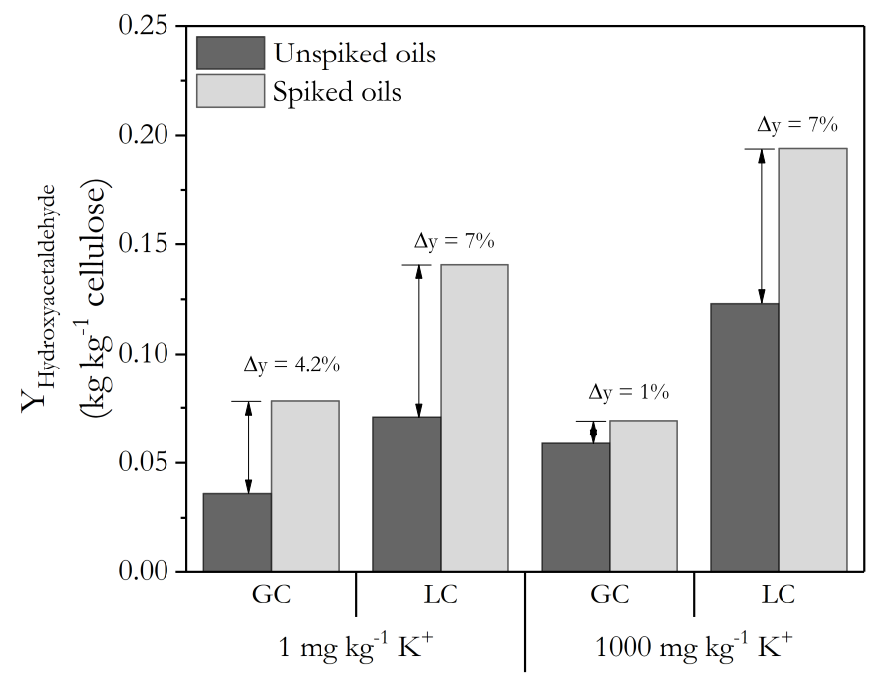

Figure 3.4B: HA yield, obtained from unspiked and spiked cellulose bio-oils (fluidised bed), determined by GC and LC; solvent: Acetone 
etal is a product of the reaction between HA and methanol. A similar decomposition product, namely glycolaldehyde methyl acetal, was observed by Stassinopoulou et al. 194 in deuterated methanol, which was used for dilution. Shen et al. .195 have proposed that $\mathrm{HA}$ can decompose thermally to form permeant gases (e.g. $\mathrm{CO}, \mathrm{CH}_{4}, \mathrm{H}_{2}$ ) and other species (e.g. methanol, acetic acid, pyruvaldehyde). Diebold 196 has identified the reactions between saturated aldehydes, present in pyrolysis oil, with methanol at low temperatures. Similarly, Patwardhan et al. ${ }^{148}$ have reported interactions between methanol and aldehydes during the GC analysis. Interestingly, for pure cellulose (spiked and unspiked) oils (diluted in methanol), the difference in the HA yield is $0.055 \mathrm{~kg} \mathrm{~kg}^{-1}$, while it is only $0.019 \mathrm{~kg} \mathrm{~kg}^{-1}$ for oils (spiked and unspiked) obtained from potassium infused cellulose. Although, Stassinopoulou et al. .194 found no decomposition products of glycolaldehyde in acetone at room temperature, incomplete recovery of the spiked HA was observed by us, when acetone was used as a diluent. Hence, in the view of these results, the possibility of thermal degration of HA, and reactions between HA and other species present in the bio-oils cannot be neglected. Nevertheless, further experimental investigation is needed to understand the reactions of HA at the GC injection temperature.

In summary: during injection of the sample in GC, HA - 1) might react with the solvent in which oil is diluted, 2) decomposes, and 3) might undergo reactions with other species present in the pyrolysis oil, on the other hand, during liquid chromatography it does not react. Therefore, liquid chromatography is recommended for determining the yield of HA present in the bio-oils. 


\subsection{Conclusions}

In this chapter, the suitability of gas chromatography and liquid chromatography for the quantification of levoglucosan and hydroxyacetaldehyde was investigated. Levoglucosan can be quantified with gas chromatography, but there is a risk of overestimation due to its production out of oligo-anhydrosugars. For ash rich feedstock ( $>0.1 \mathrm{wt} . \%$ ), this effect is minor. Hydroxyacetaldehyde can decompose, and react with compounds in the matrix and solvent used during gas chromatography. Liquid chromatography does not suffer from these shortcomings and allows for the quantitative determination of levoglucosan and hydroxyacetaldehyde in bio-oils. Generalising, the high injection temperature of gas chromatography analysis leads to a flawed quantitative analysis of reactive components. 
$\mathrm{C}_{4}$ 


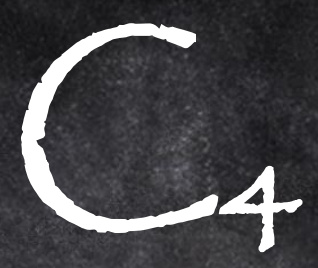

\section{Fast pyrolysis of cellulose:}

interaction between chemistry and transport phenomena in the absence and presence of potassium

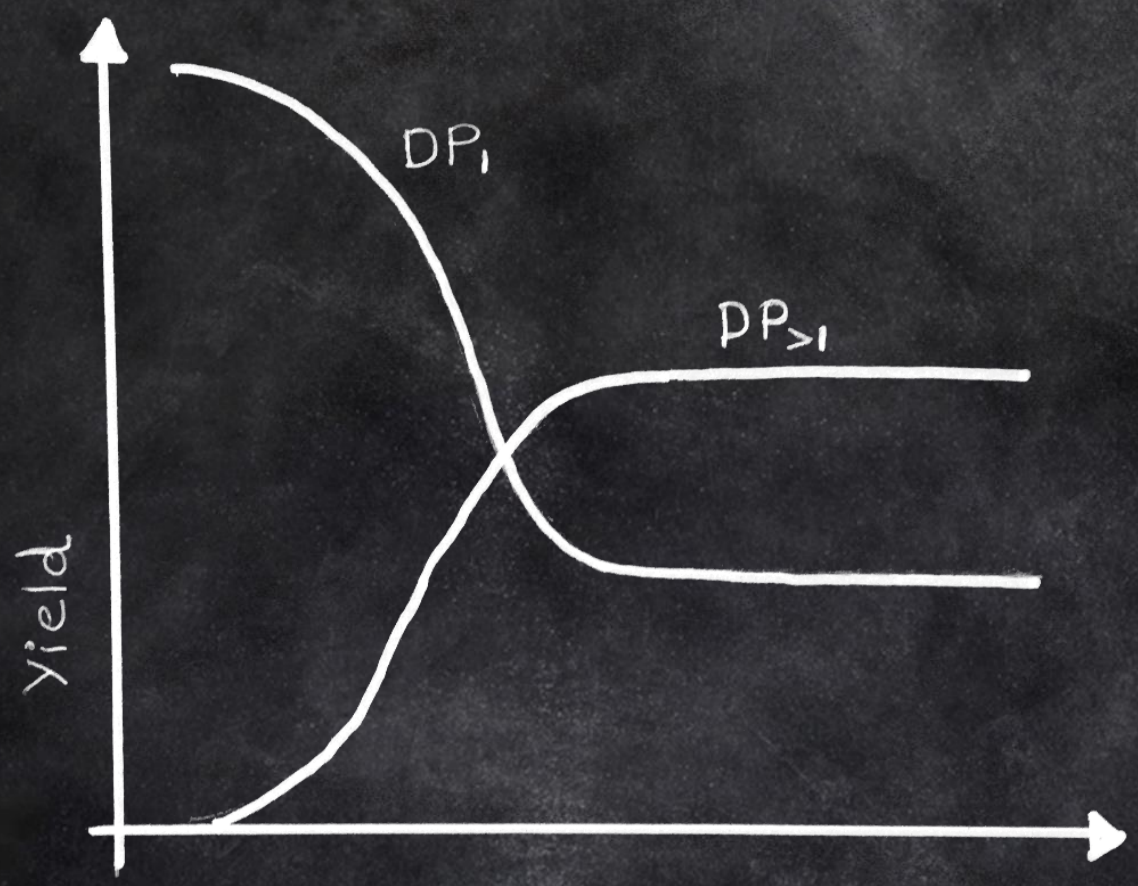

Temperature 


\begin{abstract}
The interplay between chemistry and transport processes in the pyrolysis of cellulose has been investigated in the presence and absence of potassium salts. For this, a dedicated screen-heater set-up has been used that combines a high heating rate of the sample with fast removal and quenching of reaction products. In the absence of potassium salts, cellulose can almost entirely be converted to anhydrosugars while producing hardly any gas $(<1 \%)$ and char $(<1 \%)$ in a wide temperature range of 450 to $765^{\circ} \mathrm{C}$. The obtained product yields and the degree of polymerisation $(D P)$ distribution of anhydrosugars as a function of process and pyrolysis conditions are presented and interpreted, also using two mathematical models, on the level of chemistry, heat transfer, mass transfer and their interplay. In addition to the heating rate of sample and the hot vapour residence time, the escape rate of products from the hot reacting particle has been identified as a crucial process determining the mass loss rate and the $D P$ distribution of anhydrosugars. Next, the potassium concentration in cellulose is varied to mimic the mineral-rich and pre-treated feedstock. Potassium has been found to be catalytically active even when the escape rate (milliseconds) of the product from the reaction front is extremely high. The yields of oil and anhydrosugars decrease significantly as a function of potassium concentration, while the production of other products (water, gases, light oxygenated compounds) is enhanced as a result of potassium catalysed dehydration and ring opening reactions. The production of char is found to be independent of escape rate of products at a given potassium concentration. Pyrolysis at reduced pressure, i.e. by fast removal of products from the hot reaction zone, can improve the oil and sugar yields, especially for low alkali and alkaline earth metals (AAEMs) content feedstock.
\end{abstract}

This chapter is based on:

R.J.M. Westerhof, S.R.G. Oudenhoven, P.S. Marathe, M. Engelen, M. Garcia-Perez, Z. Wang, S.R.A. Kersten, The interplay between chemistry and heat/mass transfer during the fast pyrolysis of cellulose, Reaction Chemistry \& Engineering 1 (2016) 555-566

P.S. Marathe, S.R.G. Oudenhoven, P.W. Heerspink, S.R.A. Kersten, R.J.M. Westerhof, Fast pyrolysis of cellulose in vacuum: The effect of potassium salts on the primary reactions, Chem. Eng. J. (Lausanne) 329 (2017) 187-197 


\subsection{Introduction}

Pyrolysis oil is a complex mixture of organic compounds, with different chemi-

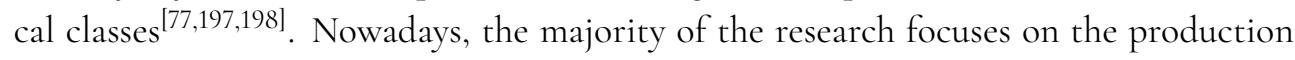
of targeted compounds (e.g. mono-phenols, sugars) at high yields. Especially the production of anhydrosugars from lignocellulosic biomass seems to be a promising route. These pyrolytic sugars can be converted to monosaccharides (e.g. glucose, xylose, mannose) via acid hydrolysis, and subsequently upgraded to bio-ethanol 199/200 by fermentation or catalytically to platform chemicals $32201-204$. In literature, sugar yields up to 30 wt. \% have been reported 2271 . Pyrolysis of cellulose, being one of the major building blocks of lignocellulosic biomass, has been studied, over a century 205. Recent reviews of Lédé have summarised the primary reactions of cellulose pyrolysis 50206 , and others have identified the gaps in the knowledge and challenges 9 |207208. From these reviews, it can be concluded that although progress is still made in the detailed understanding, predictive models of the chemistry and transport processes (mass and energy) lack at molecular, cell, particle and reactor level.

The first part of this chapter aims at advancing the understanding of reactions and transport phenomena by pyrolysing cellulose, under the conditions that are nearly isothermal, maximise the escape rate of volatile products from the reacting cellulose particles and maximise the rate of the subsequent quenching of these products. High escape rates will minimise, on/in the hot reacting particle, the secondary reactions of the volatile products. Rapid quenching ensures minimal reactions in the vapour phase and the ejected fragments (e.g. aerosols). In order to be able to draw conclusions without being hindered by uncontrollable and poorly understood phenomena, such as the effects of AAEMs $140[209 \mid 210$ and interactions between the biomass' building blocks 211212, it was decided to start with Avicel PH 101 (very pure) cellulose. Additionally, two mathematical models, which include reactions and heat transfer, were developed to -1) interpret and predict experimentally observed trends, and 2) to investigate if the pyrolysis is kinetically controlled $\frac{60}{60}$ if there is an interplay between heat, mass transfer and chemistry.

The second part of the chapter is dedicated to understanding the effects of AAEMs on the early stage products of cellulose pyrolysis. It is well known that the presence of AAEMs has an adverse effect on the production of anhydrosugars. Although, several methods exist to remove (or passivate) the AAEMs from (or in) biomass, complete removal of the AAEMs is impossible in practice. Moreover, it is unknown to what extent the destructive effects of AAEMs (in low concentration), on sugar production, can be minimised by manipulating -1) operating conditions, 2) short hot vapour residence time, and 3) rapid quenching. Therefore, potassium, being naturally present in the 
biomass 1819 , was selected as a model cation representing other AAEMs and was infused in Avicel PH 101 cellulose. The following concentrations were chosen: $1 \mathrm{mg} \mathrm{kg}{ }^{-1}$ was selected as a lower boundary, 100 and $1000 \mathrm{mg} \mathrm{kg}^{-1}$ because it is typically achievable after acid leaching $\frac{6162}{6}$, and $10000 \mathrm{mg} \mathrm{kg}^{-1}$ representing untreated biomass $\frac{19}{19}$. It is worth mentioning that $100 \mathrm{mg} \mathrm{kg}^{-1}$ corresponds to a single potassium molecule per $\sim 2500$ glucose units (in cellulose) and $1000 \mathrm{mg} \mathrm{kg}^{-1}$ to a single potassium molecule per $\sim 250$ glucose units (in cellulose). Additionally, the catalytic effect of different anions $\left(\mathrm{CO}_{3}{ }^{2-}, \mathrm{Cl}^{-}, \mathrm{OH}^{-}\right)$on pyrolysis products was studied by infusing different potassium salts in cellulose.

The experiments were carried out in a screen-heater and a bench scale fluidised bed reactor. The screen-heater is designed to combine the high heating rate of the sample with fast removal and rapid quenching of reaction products 119 . The effect of vapour residence time on the pyrolysis products was studied by comparing the results from the screen-heater experiments ( $\sim 20 \mathrm{~ms})$ with fluidised bed experiments $(\sim 1.6 \mathrm{~s})$. Oils were analysed to identify and quantify light oxygenated compounds (e.g. levoglucosenone, acetol, hydroxyacetaldehyde) and levoglucosan as well as the yield of bigger anhydrosugars $\left(D P_{>1}\right)$, lumped as glucose after acid hydrolysis. 


\subsection{Interpretation models}

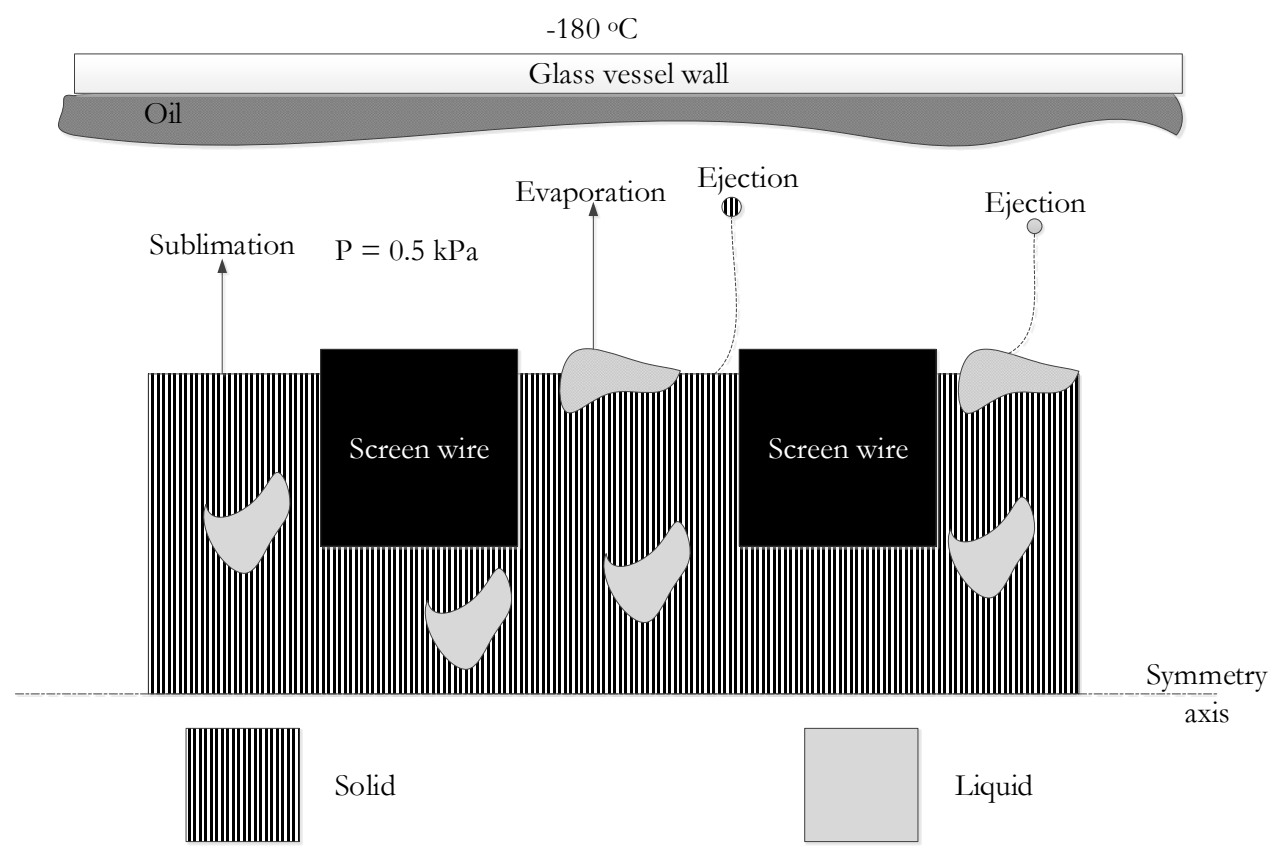

Cross sectional view

Figure 4.1: Schematic representation of the mass and heat transport processes

To support the analysis of the experimental data, two interpretation models were used. The models are schematically visualised in Figure 4.1 Heat is transferred via direct contact with the wires to the sample. The wires have a heating rate of approx. $5000{ }^{\circ} \mathrm{C}$ $\mathrm{s}^{-1} 120$. At elevated temperatures, chemical reactions will start to proceed in the solid cellulose sample. The temperature of the reacting sample can be lower than the temperature of the wires due to endothermic reactions and a finite heat transfer coefficient between sample and wires. Some decay products leave the solid matrix via sublimation. Other smaller products can form liquid regions locally inside the solid matrix. Such liquids have been observed in pyrolysing biomass 213 . In the liquid pools, reactions can continue, and products can evaporate from it. Evaporation of smaller products (e.g. $D P_{1}$ ) may be turbulent as the vapour pressure can be much higher than the prevailing pressure in the vessel. The work of Teixeira et al. $\stackrel{54}{~ h a s ~ s h o w n ~ t h a t ~ i t ~ i s ~ a l s o ~ p o s s i b l e ~ t h a t ~}$ aerosols are ejected from reacting cellulose samples. Summarising, products can escape from the pyrolysing particle via sublimation, evaporation and aerosol ejection. 


\section{Model I}

To describe the weight loss and temperature of the cellulose sample, a modified version of the model as described by Boutin et al. $\stackrel{214}{ }$ was used, in combination with the

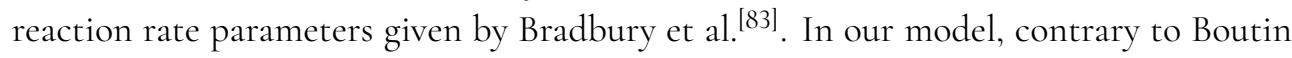
et al.'s, the sample has a spatially uniform temperature, and the state of the intermediate/active cellulose is not defined (can be liquid and/or solid). The purpose of this model is to predict the conversion (mass loss) as a function of the temperature (of the screens) and holding time for comparison with the measured data. Also the average reaction temperature $\left(T_{r}\right)$, defined as the mean temperature of the sample between $10 \%$ and 90 $\%$ conversion as a function of the final temperature of the screens can be calculated. The following lumped reaction pathways shown in Figure 4.2 are used.

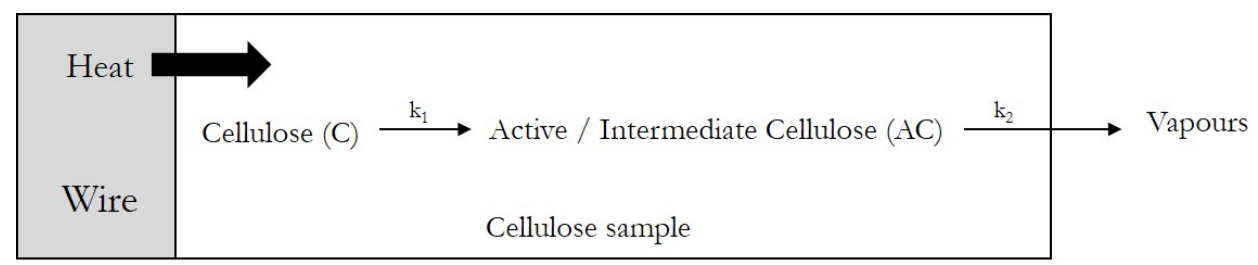

Figure 4.2: Schematic representation of interpretation model I

The vapours were recovered on the cold glass vessel as oil. The reaction rate constant $k_{2}$ describes both chemical reactions and the escape rate of products from the reacting sample $\underline{83}$. Both reactions, i.e. 1 (Cellulose to intermediates) and 2 (Intermediates to vapours), are described by first order rate equations and the Arrhenius temperature dependency. Mass balance equations are solved for cellulose (C) and active/intermediate cellulose (AC). Symmetry is assumed, thus, only one side of the sample is modelled.

$$
\begin{gathered}
\frac{d M_{C}}{d t}=-k_{1}\left(T_{C}\right) M_{C} \\
\frac{d M_{A C}}{d t}=k_{1}\left(T_{C}\right) M_{C}-k_{2}\left(T_{C}\right) M_{A C} \\
M_{S}=M_{C}+M_{A C} \\
X=1-\frac{M_{S}}{M_{S, 0}}
\end{gathered}
$$


The following energy balance is solved assuming that the heat of reaction of the $1^{\text {st }}$ reaction is negligible:

$$
\frac{d T_{C}}{d t}=\frac{A \alpha\left(T_{S}-T_{C}\right)-k_{2}\left(T_{C}\right) M_{A C} \Delta H_{2}}{M_{S} C_{p}}
$$

The temperature of the screens is modelled by:

$$
\frac{d T_{S}}{d t}=\left\{\begin{array}{lll}
B & \text { if } & T_{S}<T_{\text {set }} \wedge t \leq t_{h} \\
0 & \text { if } & T_{S}=T_{\text {set }} \wedge 0 \leq t \leq t_{h}+\frac{T_{\text {set }}}{B} \\
-B^{\prime} & \text { if } & t>t_{h}+\frac{T_{\text {set }}}{B}
\end{array}\right.
$$

For the calculation of the char yield (Figure 4.5A the cooling period was taken into account. For the calculation of $T_{r}$, given by Eq. 4.7, the cooling period was not taken into account; after heating, the screens remain at the set-point temperature.

$$
T_{r}=\frac{\int_{X=0.1}^{X=0.9} T_{S}(X) d X}{\int_{X=0.1}^{X=0.9} d X}
$$

The initial conditions are:

$$
\begin{gathered}
M_{S, 0}\left(M_{C, 0}\right)=2.5 \times 10^{-5} \mathrm{~kg} \\
M_{A C, 0}=0 \\
T_{C, 0}=T_{S, 0}=298 \mathrm{~K}
\end{gathered}
$$




\section{Model II}

To predict the trend of the product distribution as a function of the temperature, model I has been extended by -1$)$ an intermediate / active cellulose phase that consists of heavies $\left(D P_{\geq 2}\right)$ and $\left.D P_{1}, 2\right)$ a reaction of heavies to compounds of lower $D P$ that takes place on the sample and 3) lower escape rates of heavies compared to lights. This is shown schematically in Figure 4.3

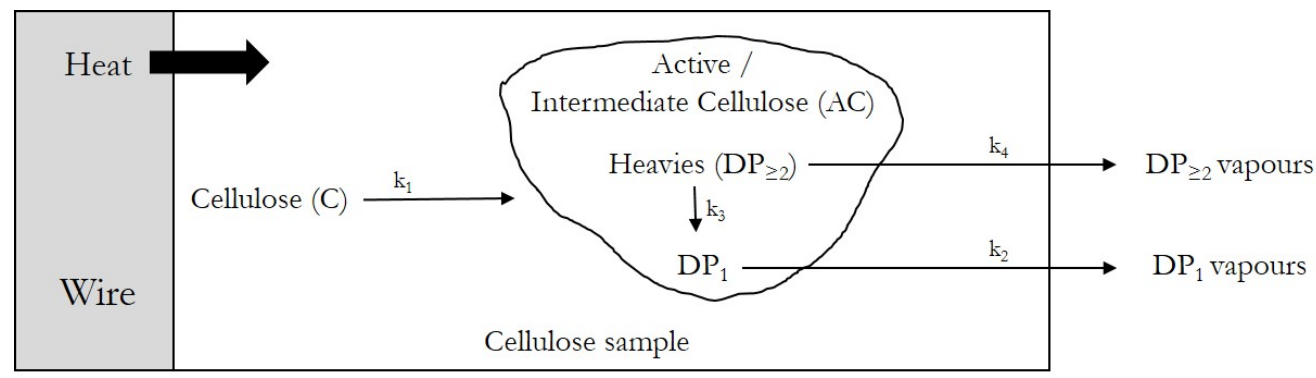

Figure 4.3: Schematic representation of interpretation model II

The vapours were recovered on the cold glass vessel as oil. In this model, the rate constants $k_{2}$ and $k_{4}$ only describe the escape rate of the products from the sample which is assumed to be a first order process. $k_{4}$ is chosen to be smaller than $k_{2}$ in order to show that the larger sugars have a lower escape rate compared to $D P_{1} . k_{3}$ is chosen/set arbitrary to be $10 \%$ of the value of $k_{2} . k_{1}$ and $k_{2}$ are the constants derived by Bradbury et al. 83 . Note, the purpose of the model is to investigate if a model, including chemical reactions and mass transfer, can predict the experimentally observed trends, i.e. the $D P$-distribution in the oil as a function of the temperature of the screens, and not for any quantitative prediction. The latter would need a model that includes independently measured or disentangled values for the rate constants of the chemical reactions on the particle and escape rates (velocity) of products from the sample. The mass balances are:

$$
\begin{gathered}
\frac{d M_{C}}{d t}=-k_{1}\left(T_{C}\right) M_{C} \\
\frac{d M_{D P_{\geq 2}}}{d t}=k_{1}\left(T_{C}\right) M_{C}-\left(k_{3}\left(T_{C}\right)+k_{4}\left(T_{C}\right)\right) M_{D P_{\geq 2}} \\
\frac{d M_{D P_{1}}}{d t}=k_{3}\left(T_{C}\right) M_{D P_{\geq 2}}-k_{2}\left(T_{C}\right) M_{D P_{1}}
\end{gathered}
$$




$$
\begin{gathered}
M_{S}=M_{C}+M_{D P_{1}}+M_{D P_{\geq 2}} \\
X=1-\frac{M_{S}}{M_{S, 0}}
\end{gathered}
$$

The following energy balance is solved assuming that the heat of reaction of the $1^{\text {st }}$ reaction (cellulose to intermediates) is negligible and that the heat effect involved with the escape of (evaporation of) $D P_{1}$ and $D P_{\geq 2}$ from the particle is equal on a mass basis:

$$
\frac{d T_{C}}{d t}=\frac{A \alpha\left(T_{S}-T_{C}\right)-\left(k_{2}\left(T_{C}\right) M_{D P_{1}}+k_{4}\left(T_{C}\right) M_{D P_{\geq 2}}\right) \Delta H}{M_{S} C_{p}}
$$

The temperature of the screens is modelled using the same procedure as for Model I Eq. 4.6. The yields of $D P_{1}$ and $D P_{\geq 2}$ in the condensed product are calculated by:

$$
\begin{gathered}
Y_{D P_{1}}=\frac{\int_{t=0}^{t=\infty} k_{2}\left(T_{C}\right) M_{D P_{1}} d t}{M_{S, 0}} \\
Y_{D P_{\geq 2}}=\frac{\int_{t=0}^{t=\infty} k_{4}\left(T_{C}\right) M_{D P_{\geq 2}} d t}{M_{S, 0}}
\end{gathered}
$$

The initial conditions are:

$$
\begin{gathered}
M_{S, 0}\left(M_{C, 0}\right)=2.5 \times 10^{-5} \mathrm{~kg} \\
M_{D P_{1}, 0}=M_{D P_{\geq 2}, 0}=0 \\
T_{C, 0}=T_{S, 0}=298 \mathrm{~K}
\end{gathered}
$$

\section{Numerical method}

Model I and Model II equations were solved in the coding environment of Mat-

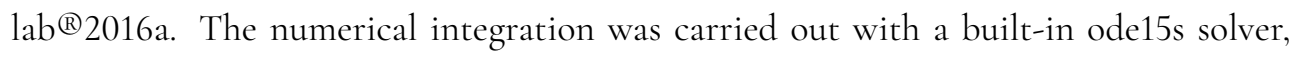
especially suited for a system of differential algebraic equations (DAE). In Table 4.1 the numerical values of the parameters used in model I and model II are listed. 
Table 4.1: Constants used for pyrolysis model I and model II

\begin{tabular}{|c|c|c|c|}
\hline Parameter & Unit & Value & Comment \\
\hline$B$ & ${ }^{\circ} \mathrm{C} s^{-1}$ & $5000(10000)$ & $\begin{array}{l}\text { The heating rate of the screens. } 5000{ }^{\circ} \mathrm{C} s^{-1} \text { was the ex- } \\
\text { perimentally determined value. In the sensitivity analysis } \\
\text { also } 10000{ }^{\circ} \mathrm{C} \mathrm{s}^{-1} \text { was used. }\end{array}$ \\
\hline$B^{\prime}$ & ${ }^{\circ} \mathrm{C} s^{-1}$ & 60 & $\begin{array}{l}\text { Cooling rate (measured) of the screens after the holding } \\
\text { time. }\end{array}$ \\
\hline$k_{1,0}$ & $s^{-1}$ & $2.8 \times 10^{19}$ & Pre-exponential constant of reaction 183 \\
\hline$E_{1}$ & $J m o l^{-1}$ & $2.42 \times 10^{5}$ & Activation energy of reaction $1 \underline{83}$ \\
\hline$k_{2,0}$ & $s^{-1}$ & $3.2 \times 10^{14}$ & Pre-exponential constant of reaction 2 \\
\hline$E_{2}$ & $J m o l^{-1}$ & $1.98 \times 10^{5}$ & Activation energy of reaction $2 \underline{83}$ \\
\hline$k_{3,0}$ & $s^{-1}$ & $3.2 \times 10^{13}$ & $10 \%$ of $k_{2,0}$ (arbitrary choice) \\
\hline$E_{3}$ & $J m o l^{-1}$ & $1.98 \times 10^{5}$ & Equal to $E_{2}$ (arbitrary choice) \\
\hline$k_{4,0}$ & $s^{-1}$ & $10 \times 10^{20}$ & Overall k lower than $k_{2}$ (arbitrary choice) \\
\hline$E_{4}$ & $J m o l^{-1}$ & $3.0 \times 10^{5}$ & Overall k lower than $k_{2}$ (arbitrary choice) \\
\hline$C p$ & $J k g^{-1} K^{-1}$ & 1500 & Specific heat capacity cellulose $\underline{215}$ \\
\hline$A$ & $m^{2}$ & 0.003 & $\begin{array}{l}\text { Area, Estimated based on the porosity of the screens } \\
(\sim 0.25) \text {, the diameter of the wires }\left(6 \times 10^{-5} \mathrm{~m}\right) \text { and the fill- } \\
\text { ing of the cellulose between the wires. }\end{array}$ \\
\hline$\alpha$ & $W m^{-2} K^{-1}$ & 1000 to $\infty$ & $\begin{array}{l}\text { A low estimate of the heat transfer coefficient and infi- } \\
\text { nite. (Model I) }\end{array}$ \\
\hline$\alpha$ & $W m^{-2} K^{-1}$ & $1 \times 10^{4}$ & Good contact between sample and wires (Model II) \\
\hline$\Delta H_{2}$ & $J k g^{-1}$ & $\begin{array}{l}-0.25 \times 10^{6} \text { to } \\
0.7 \times 10^{6}\end{array}$ & $\begin{array}{l}\text { Slightly exothermic reaction till the heat of evaporation } \\
\text { of levoglucosan. }\end{array}$ \\
\hline$\Delta H$ & $J k g^{-1}$ & $0.7 \times 10^{6}$ & Heat of evaporation of levoglucosan 216 . \\
\hline
\end{tabular}




\subsection{Results and discussion}

\subsubsection{Screen-heater and fluidised bed characteristics}

The characteristics of the screen-heater have been discussed in detail by Hoekstra et al. 119 and Oudenhoven $\frac{120}{12}$. Here, the characteristics are briefly discussed and summarised in Table 4.2 The cellulose sample is distributed evenly between the two screens to achieve nearly uniform heating. The heating rate of the screens is $\sim 5000{ }^{\circ} \mathrm{C} \mathrm{s}^{-1}$. The temperature difference over the screen was $\pm 15^{\circ} \mathrm{C}$. The screens were held at the $\mathrm{T}_{\mathrm{FS}}$ for $5 \mathrm{~s}$. The cooling rate of the screens was $\sim 60^{\circ} \mathrm{C} \mathrm{s}^{-1}$. A detailed validation of the temperature profiles and measurements can be found elsewhere $\frac{120}{}$. It has been shown that the pyrolysis time, i.e. the time to reach full conversion, at $610^{\circ} \mathrm{C}$ and $0.5 \mathrm{kPa}$ is around 121 $\mathrm{ms}$ for pure cellulose $\mathrm{e}^{120}$. The pyrolysis time was also checked for cellulose impregnated with potassium $\left(10000 \mathrm{mg} \mathrm{kg}^{-1}\right)$ at $530^{\circ} \mathrm{C}$ and $0.5 \mathrm{kPa}$, see Figure 4.4 This figure shows screenshots of a movie recorded with a high-speed camera. It can be seen that the first products were condensed on the cold glass vessel after $63 \mathrm{~ms}$. After that, no change in the shape of the black material present between the screens and the appearance of the oil on the glass vessel (see red arrows), between $79 \mathrm{~ms}$ and $304 \mathrm{~ms}$, implied that the pyrolysis reactions were finished.

The time difference between the escape of vapours or aerosols from the reacting particle until quenching is defined as the hot vapour residence time. At $0.5 \mathrm{kPa}$, the vapours/aerosols are rapidly quenched at the glass vessel, which was surrounded by the liquid nitrogen $\left(-196{ }^{\circ} \mathrm{C}\right)$ bath, equilibrated at $-180^{\circ} \mathrm{C}$. It was estimated that for both pressures $(0.5$ and $100 \mathrm{kPa}$ ) hot vapour residence time is in order of $\sim 20 \mathrm{~ms}$, which ruled out a significant effect of reactions outside the reacting cellulose particle $\frac{120}{2}$. The most significant difference between the screen-heater and the bench-scale fluidised bed is the hot vapour residence time $\left(\sim 20 \mathrm{~ms} \stackrel{120}{ }\right.$ vs $1.6 \mathrm{~s} \frac{\sqrt[66]{6}}{)}$, see Table 4.2 In the screen-heater at $0.5 \mathrm{kPa}$, the escape rate of the $D P_{1}$ anhydrosugar (levoglucosan) is a factor 10 higher compared to $100 \mathrm{kPa}$, see Table 4.2 As a consequence, the residence time of the products on the hot reacting particle was considerably lower in the case of vacuum. 

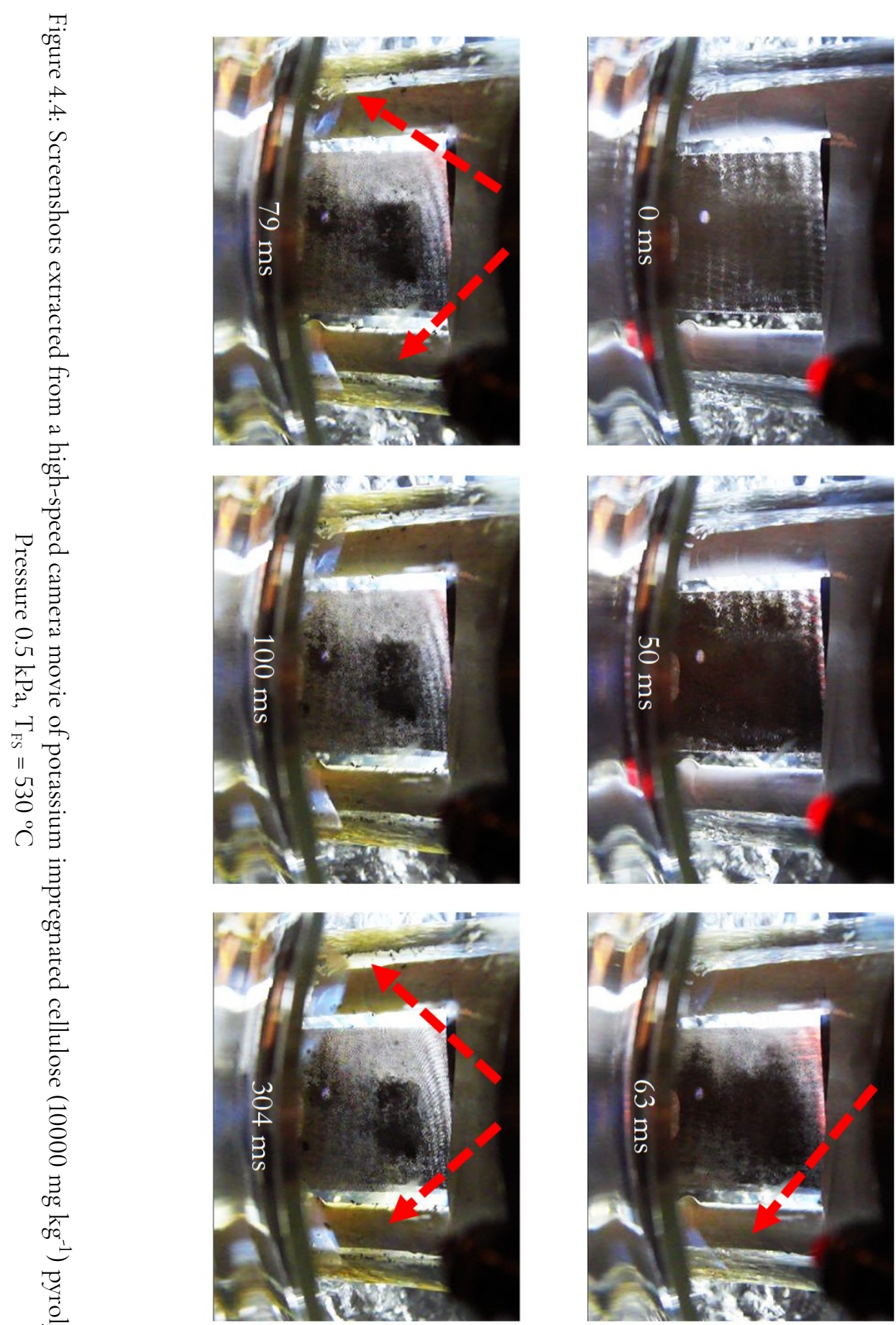
Table 4.2: Summary of experimental conditions in screen-heater and fluidised bed

\begin{tabular}{llll}
\hline & Screen-heater & Screen-heater & Fluidised bed \\
\hline Temperature, ${ }^{\circ} \mathrm{C}$ & 530 & 530 & 530 \\
Pressure, $\mathrm{kPa}$ & 0.5 & 100 & 100 \\
Heating rate, ${ }^{\circ} \mathrm{C} \mathrm{s}^{-1}$ & 5000 & 5000 & 5000 \\
Hot vapour residence time, s & 0.02 & $\sim 0.02$ & 1.6 \\
Vapour Temperature, ${ }^{\circ} \mathrm{C}$ & N.A. & $80^{\mathrm{a}}$ & 530 \\
Levoglucosan evaporation time, s & 0.03 & $<0.3$ & $<0.3$ \\
\hline
\end{tabular}

${ }^{a}$ Temperature measured $1.5 \mathrm{~cm}$ away from the screens

\subsubsection{Identification and hydrolysis of anhydrosugars}

The anhydrosugars $D P_{1}$ (levoglucosan), $D P_{1-2}$ (compounds identified between $D P_{1}$ and $D P_{2}$ ), $D P_{2}$ (cellobiosan), $D P_{3}$ (cellotriosan), $D P_{4+5}$ (sum of $D P_{4}$ (cellotetrasan) and $D P_{5}$ (cellopentosan)) and $D P_{>5}$ were analyzed using HPLC (see Section 2.4.4 of Chapter 2) and obtained chromatograms were integrated by following the procedure described by Oudenhoven $\frac{120}{2}$. LC/MS analysis was used to identify the degree of polymerization of compounds referred to as $D P_{>5}$ and to obtain information on the composition of compounds termed $D P_{1-2}{ }^{120}$. Hydrolysis of anhydrosugars to glucose was done by the procedure described in Section 2.2.4 of Chapter 2. Oudenhoven $\frac{120}{2}$ has shown that the hydrolysis efficiency decreases with an increase in the degree of polymerisation of anhydrosugars; $D P_{1}(\sim 93 \%)$ and $D P_{2}(\sim 84 \%)$. Therefore, the glucose yields reported in this chapter were corrected as described by Oudenhoven $\frac{120}{}$.

\subsubsection{Effect of $\mathrm{T}_{\mathrm{FS}}$ on the pyrolysis of pure cellulose}

\section{Mass balance closure}

The mass balance closure of the 37 reported cellulose screen-heater experiments at the level of gas, oil and char was in the range of $0.87 \mathrm{~kg} \mathrm{~kg}^{-1}$ to $1.01 \mathrm{~kg} \mathrm{~kg}^{-1}$ with a median of $0.94 \mathrm{~kg} \mathrm{~kg}^{-1}$. Reproducibility was checked by taking into account 5 measurements in the range of 520 to $540{ }^{\circ} \mathrm{C}$ (a single constant temperature was not possible due to control issues). The standard deviation in the yields of oil, gas and char were $0.03 \mathrm{~kg} \mathrm{~kg}^{-1}, 0.005$ $\mathrm{kg} \mathrm{kg}^{-1}$ and $0.002 \mathrm{~kg} \mathrm{~kg}^{-1}$, respectively. The standard deviation in the yields of $D P_{1}$ to $D P_{>5}$ was $0.02 \mathrm{~kg} \mathrm{~kg}^{-1}$ (average value of the standard deviations of the individual $D P s$ ). Taking into account the small amount of sample, the tedious recovery and the analysis procedure these numbers were considered quite satisfactory. 


\section{Lumped product yields}

In Figure $4.5 \mathrm{~A}$ and $4.5 \mathrm{~B}$ the yields of char and oil are plotted versus the final temperature of the screens $\left(\mathrm{T}_{\mathrm{FS}}\right)$. The presented experimental data was measured by four different experimenters. Note that experiments were performed with a holding time of $1 \mathrm{~s}$ and $5 \mathrm{~s}$. Over the whole temperature range of $\mathrm{T}_{\mathrm{FS}}\left(330\right.$ to $\left.765^{\circ} \mathrm{C}\right)$, the gas yield was below $0.01 \mathrm{~kg} \mathrm{~kg}^{-1} 120$. This absence of gas at temperatures as high as $750{ }^{\circ} \mathrm{C}$ further supports the conclusion that gases were formed mainly by cracking of decay products of cellulose in the vapour phase and that these reactions can be minimised in the screenheater by fast quenching of these products.

Fourier-transform infrared spectroscopy (FTIR) analysis and visual inspection indicated that the residue obtained below $400{ }^{\circ} \mathrm{C}$ was unconverted cellulose and not char 120 This is in agreement with reported kinetic data 83 which indicate that, below $400{ }^{\circ} \mathrm{C}$, char forming reactions are not significant at reaction times of $1 \mathrm{~s}$ to $5 \mathrm{~s}$. Between 400 and $450{ }^{\circ} \mathrm{C}$, not enough char was recovered for analysis. For conditions of $450{ }^{\circ} \mathrm{C}$ and higher, the yield of char was very low $\left(<0.01 \mathrm{~kg} \mathrm{~kg}^{-1}\right)$ in both the fluidised bed (Figure 4.12) and screen-heater (Figure 4.5A). The low yield of char is in agreement with earlier published data on cellulose pyrolysis 64|193. In conclusion, the conversion of cellulose based on the mass loss was higher than $99 \%$ by weight above $450{ }^{\circ} \mathrm{C}$.

The model I, including the kinetics of Shafizadeh, predicts that the conversion is complete $(>99 \%)$ at $440{ }^{\circ} \mathrm{C}$ and $5 \mathrm{~s}$ holding time. In Figure $4.5 \mathrm{~A}$ these model predictions are plotted. A better fit can be easily obtained by increasing the pre-exponential constant of the rate-limiting mass loss reaction, $k_{2}$ (see Figure $4.5 \mathrm{~A}$ Shafizadeh $k_{2,0}=$ $3.2 \times 10^{14} \mathrm{~s}^{-1} \mathrm{Vs}$. fit $k_{2,0}=2 \times 10^{15} \mathrm{~s}^{-1}$ ). It is worthwhile to mention that the fitted $k_{2}$ and corresponding $E_{2}$ are in agreement with the data calculated by Burnham et al. 217 using the Kissinger's method. As an input, they used the results of the round-robin study of cellulose pyrolysis kinetics as reported by M. Gronli et al. 218 . An activation energy of $\sim 200 \mathrm{~kJ} \mathrm{~mol}^{-1}$ of $k_{2}$, as often experimentally determined 219 and recently supported by density functional theory (DFT) calculation 106/217, describes the measured increase in conversion from nearly zero to almost completion in a temperature range of $75^{\circ} \mathrm{C}$ and reaction time of $<5$ s. Lower activation energies result in a broader temperature range to achieve this. The measured yield of oil was constant after $450{ }^{\circ} \mathrm{C}$.

Figure $4.6 \mathrm{~A}$ to $4.6 \mathrm{D}$ show the $D P$ selectivity. Note that from $400{ }^{\circ} \mathrm{C}$ the cellulose conversion is (nearly) complete, and accordingly selectivity equals yield. The data are quite scattered, which is caused by the uncertainty in the temperature measurement. However, due to a large number of measurements, interesting trends do become clear. For the $\mathrm{T}_{\mathrm{FS}}$ between $370{ }^{\circ} \mathrm{C}$ and $450{ }^{\circ} \mathrm{C}, D P_{1}$ (levoglucosan) is the dominant product 


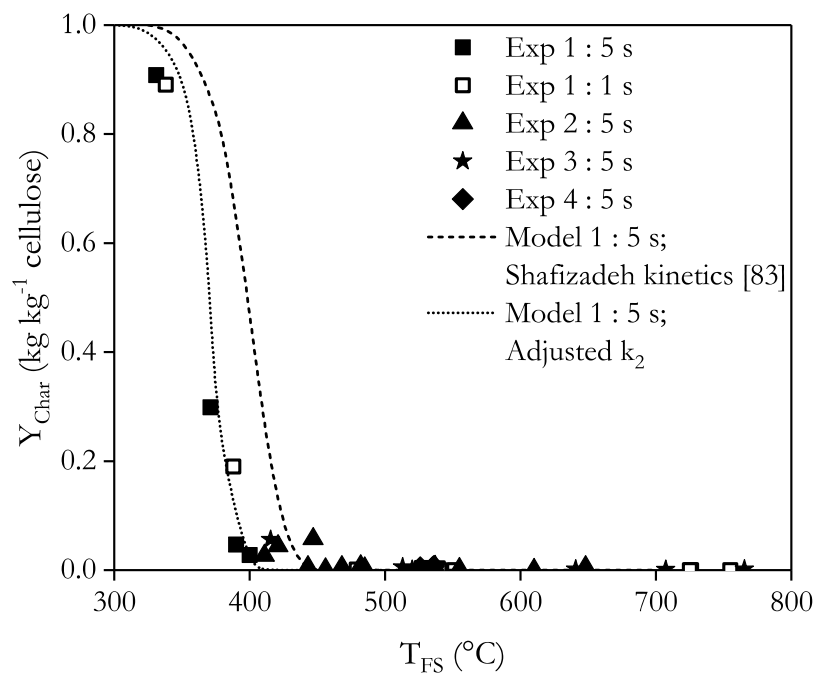

Figure 4.5A: Char yield as a function of $\mathrm{T}_{\mathrm{FS}}$ and different holding time. The data of 4 experimenters are included. The pressure was $0.5 \mathrm{kPa}$

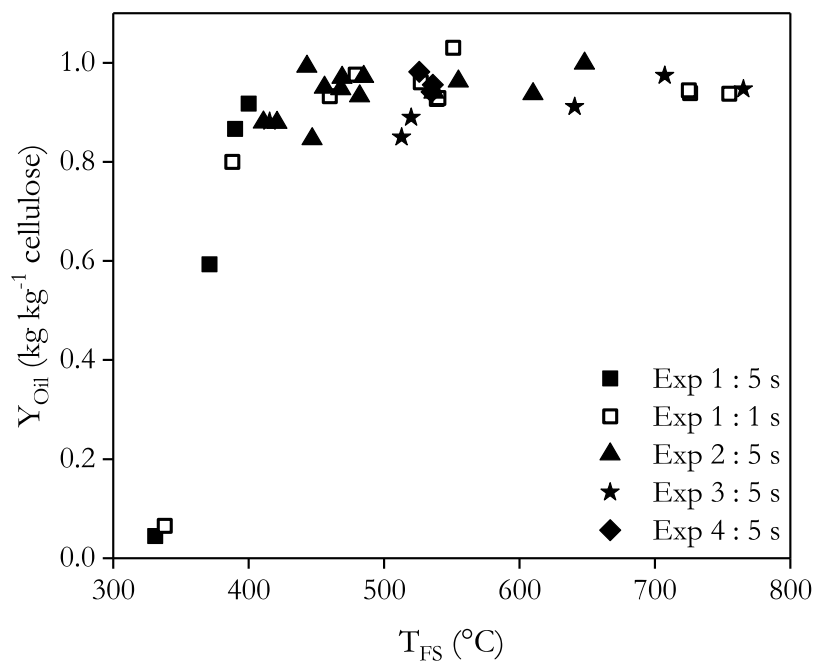

Figure 4.5B: Oil yield as a function of $\mathrm{T}_{\mathrm{FS}}$ and different holding time. The data of 4 experimenters are included. The pressure was $0.5 \mathrm{kPa}$ 
together with $D P_{2}$ and $D P_{1-2}$ (not shown), while at increasing temperature first $D P_{3}$ became dominant followed by $D P_{4}$ (Figure 4.6D), $D P_{5}$ (Figure 4.6D) and $D P_{>5}$ (Figure 4.7 at the expense of $D P_{1}, D P_{2}$ and $D P_{1-2}$, which decreased slightly. The decrease in $D P_{1}$ selectivity at increasing temperature cannot be explained solely by chemistry, as more cracking is expected at higher temperatures leading to more $D P_{1}$. The scatter on $D P_{>5}$, especially above $530{ }^{\circ} \mathrm{C}$, was the largest. Obviously, compounds this large do not have a significant vapour pressure under the studied conditions. Therefore, it is likely that these compounds were ejected from the reacting cellulose which seems to be quite a random process. As for the predictive mathematical models, these physical processes make exact predictions of the oil composition complicated. 


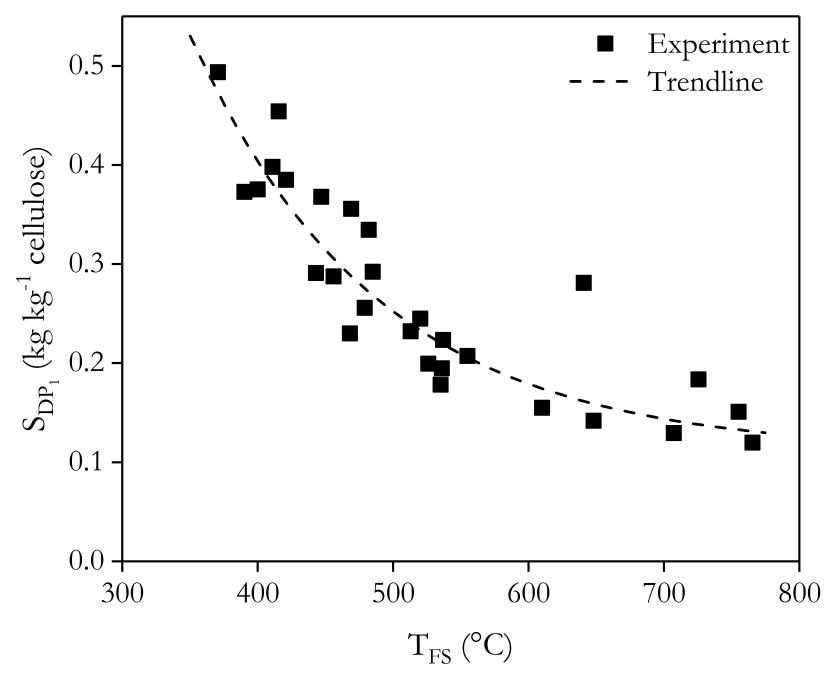

Figure 4.6A: $D P_{1}$ selectivity as a function of $\mathrm{T}_{\mathrm{FS}}$. The pressure was $0.5 \mathrm{kPa}$

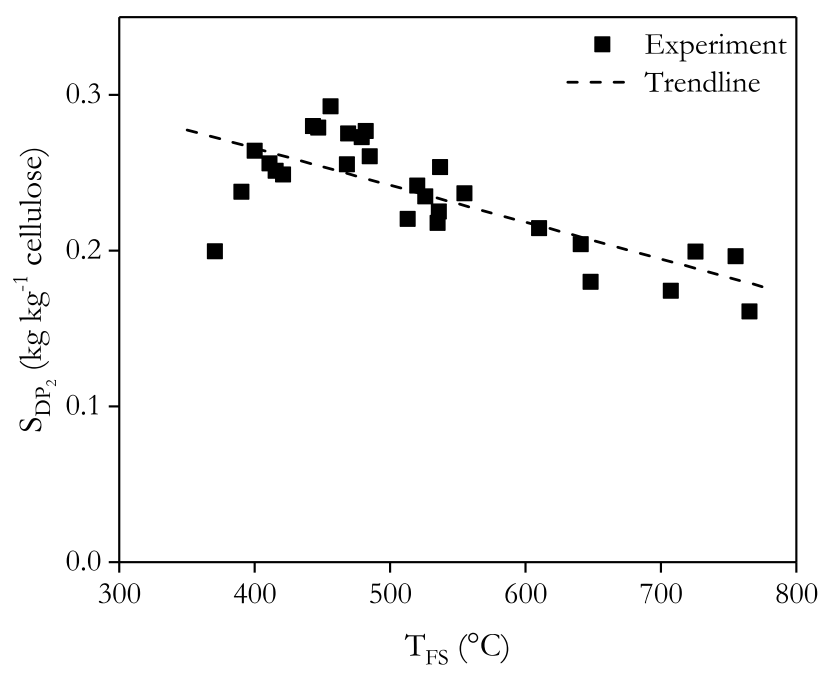

Figure 4.6B: $D P_{2}$ selectivity as a function of $\mathrm{T}_{\mathrm{FS}}$. The pressure was $0.5 \mathrm{kPa}$ 


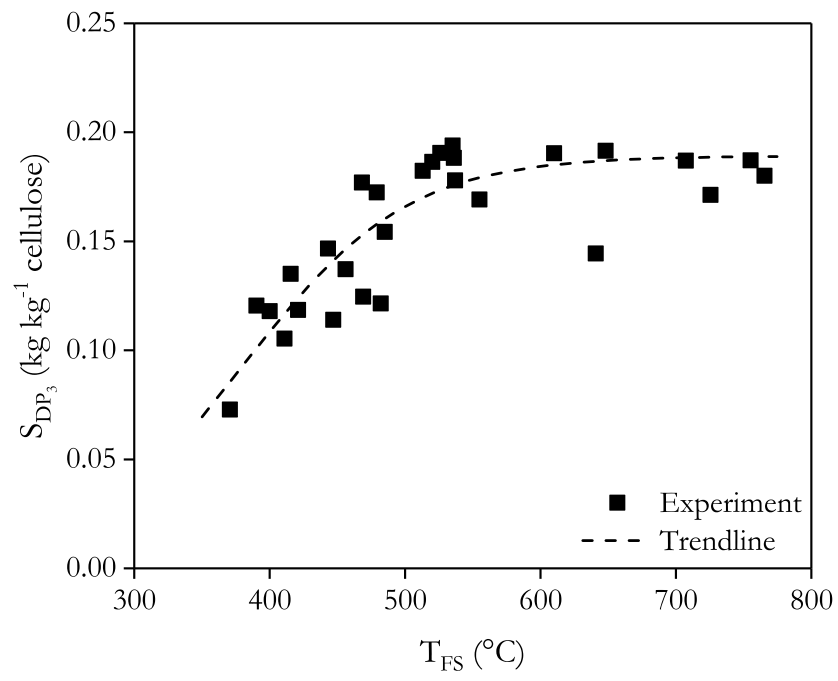

Figure 4.6C: $D P_{3}$ selectivity as a function of $\mathrm{T}_{\mathrm{FS}}$. The pressure was $0.5 \mathrm{kPa}$

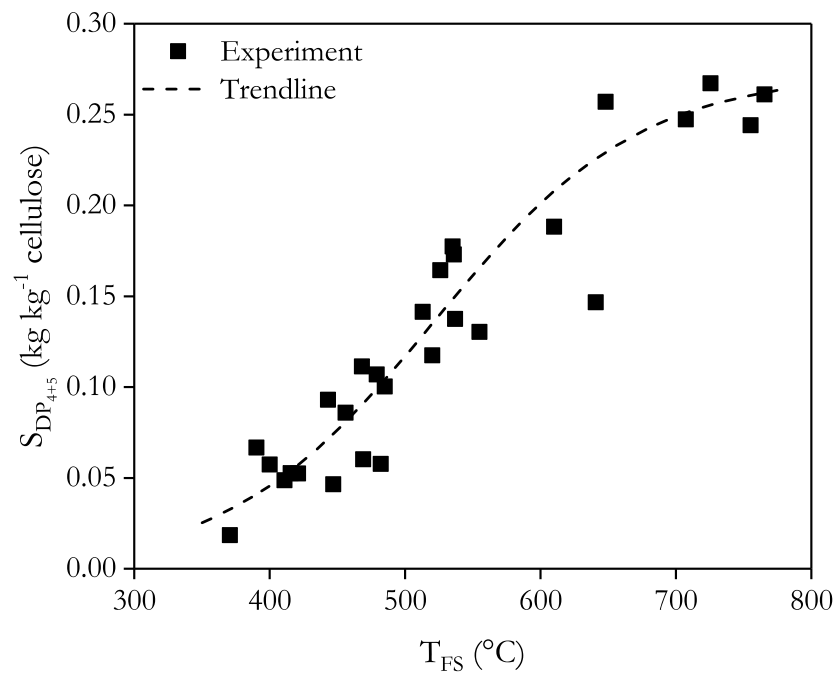

Figure 4.6D: $D P_{4+5}$ selectivity as a function of $\mathrm{T}_{\mathrm{FS}}$. The pressure was $0.5 \mathrm{kPa}$ 
The total yield of sugars, expressed as the recovery of glucose after acid hydrolysis of the oil, remained constant in the temperature range of 420 to $765^{\circ} \mathrm{C}$, see Figure 4.8 To the best of our knowledge, we are the first to report a constant yield of hydrolysable sugar as a function of the pyrolysis temperature in such a broad range. The constant total sugar yield as a function of temperature indicates that the newly developed screen-heater also minimises the secondary reactions of sugars to non-sugar decay products.

Radlein et al.220 also reported a strong effect of temperature on the $D P_{1}$ yield; in their measurements, in an atmospheric fluidised bed, the yield decreased monotonically from $\sim 0.38 \mathrm{~kg} \mathrm{~kg}^{-1}$ at $400{ }^{\circ} \mathrm{C}$ to $\sim 0.15 \mathrm{~kg} \mathrm{~kg}^{-1}$ at $600^{\circ} \mathrm{C}$. They reported a strong decrease in the yield of total sugars from $\sim 0.60 \mathrm{~kg} \mathrm{~kg}^{-1}$ at $400^{\circ} \mathrm{C}$ to $\sim 0.18 \mathrm{~kg} \mathrm{~kg}^{-1}$ at $600{ }^{\circ} \mathrm{C} 220$. Gong et al.178 reported decreasing yields (measured in an atmospheric screen-heater) of $D P_{1}, D P_{2}$ and $D P_{3}$ in the range of 400 to $500{ }^{\circ} \mathrm{C}$ and constant yields between 500 to $700{ }^{\circ} \mathrm{C}$. Also in their case, the yield of total sugars decreased significantly in the range of 400 to $700{ }^{\circ} \mathrm{C}$ (from $\sim 0.6 \mathrm{~kg} \mathrm{~kg}^{-1}$ to $0.35 \mathrm{~kg} \mathrm{~kg}^{-1}$ ) $\stackrel{178}{ }$. Shafizadeh et al. ${ }^{140}$ reported for the slow(er) pyrolysis of cellulose under vacuum a constant oil, levoglucosan and reducing sugar yield between 375 and $500{ }^{\circ} \mathrm{C}$.

As stated before the decrease in $D P_{1}$ yield at increased temperature is unexpected when considering chemistry solely. The higher $D P_{1}$ yield at a lower temperature is explained by the longer time available for cracking of higher $D P$ sugars in/on the reacting sample (in the solid or liquid phase) due to their lower escape rate from the sample. At higher temperature, $D P_{3}$ and larger sugars have a higher escape rate from the sample and hence less time to crack leading to their increased presence in the oil. In an attempt to support this hypothesis, model II was developed. When including the cracking of oligomers on the reacting cellulose and giving the oligomers a lower escape rate than levoglucosan in the model (model II), the measured trend of decreasing $D P_{1}$ and increasing $D P_{\geq 2}$ selectivity as a function of increasing temperature is predicted (see Figure 4.9) by this model. Note that, only the trend is predicted correctly. The quantitative agreement would need a model that includes independently measured or disentangled values for the rate constants of the chemical reactions in/on the particle and escape rates (velocity) of products from the sample.

The observations imply that pyrolysis kinetics, especially those based on the mass loss of cellulose or biomass particles, include both chemistry and mass transfer rates. For instance, at a lower temperature, only low DPs can evaporate as a result of which more bonds have to be broken in the original polymers as compared to higher temperatures, at which also decay products of larger $D P$ can escape. Hence, the definition of Pyle and Zaror of kinetically controlled pyrolysis, which is based on only the ratio the reaction 
rate and heat transfer rate $\frac{60}{}$, needs to be reconsidered.

For temperatures of 550 to $600{ }^{\circ} \mathrm{C}$ the measured $D P_{1}, D P_{3}, D P_{4+5}$ selectivity seem to be unaffected by the final screen temperature (see Figure $4.6 \mathrm{~A}$ to $4.6 \mathrm{D}$. Analysis of the fits shows that these measured DPs are better described by an equation leading to a plateau value at an increased temperature as compared to a monotonic linear increasing or decreasing function. Model II also predicts that the $D P$ yields/selectivity's above a final screen temperature of ca. $550{ }^{\circ} \mathrm{C}$ become constant, as shown in Figure 4.9 This is because the actual reaction temperature becomes constant above this final screen temperature, as also argued by Piskorz et al.192 and Lédé $47|221| 222$. Figure 4.10 shows the average reaction temperature calculated by model I (defined as the average temperature of the sample between $10 \%$ and $90 \%$ conversion, see Eq. 4.7 versus the final temperature of the screens for several cases. Two extreme cases were: A) the screens were heated at a rate of $5000{ }^{\circ} \mathrm{C} \mathrm{s}^{-1}$ and the heat transfer coefficient (screen to sample is $1000 \mathrm{~W} \mathrm{~m}^{-2} \mathrm{~K}^{-1}$ ), and B) the sample is heated with $10000{ }^{\circ} \mathrm{C} \mathrm{s}^{-1}$ (infinite heat transfer coefficient). The parity line represents kinetically controlled pyrolysis which was defined by Pyle et al. 60 as pyrolysis at isothermal conditions. The model predicts that the average reaction temperature is lower than the final temperature of the screens. For case A, this happens at a lower $\mathrm{T}_{\mathrm{FS}}$ in combination with a lower asymptotic reaction temperature as compared to case B. For both extreme cases, above a $\mathrm{T}_{\mathrm{FS}}$ of $550{ }^{\circ} \mathrm{C}$, heat transfer cannot keep up with the reaction rate, and consequently, the conversion is complete within the heating trajectory. This was also observed experimentally by analysis of the pictures/movies taken during conversion. The blue LED, which was connected to the electrodes, lights up when current is passing through the screen (to heat the screen) 120 . The LED in this experiment (cellulose, $0.5 \mathrm{kPa}, \mathrm{T}_{\mathrm{FS}}=610^{\circ} \mathrm{C}$ ) was continuously lighted during the first $121 \mathrm{~ms}$, meaning that the experiment was still in the initial heating pulse 120 . Note that all cellulose has reacted away before $121 \mathrm{~ms}$. This show that the reaction was completed before the screen reached the final screen temperature. 


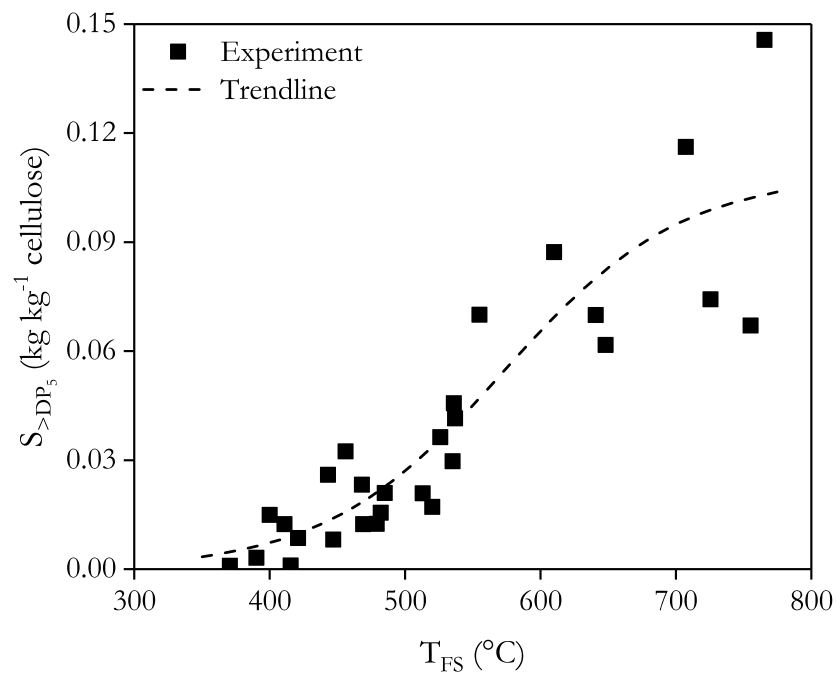

Figure 4.7: $D P_{>5}$ selectivity as a function of $\mathrm{T}_{\mathrm{FS}}$. The pressure was $0.5 \mathrm{kPa}$

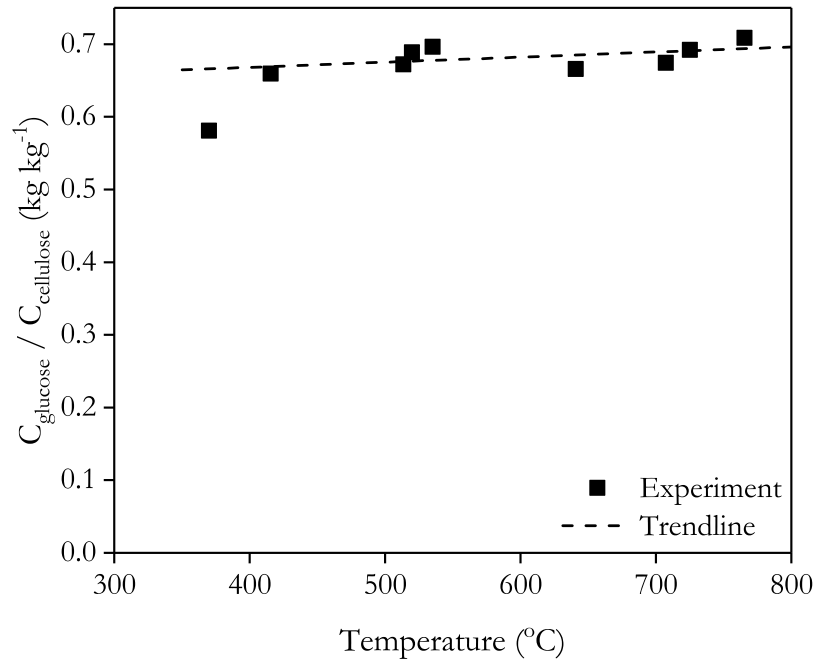

Figure 4.8: Recovery of glucose on a carbon basis after hydrolysis of oils. The pressure was $0.5 \mathrm{kPa}$ 


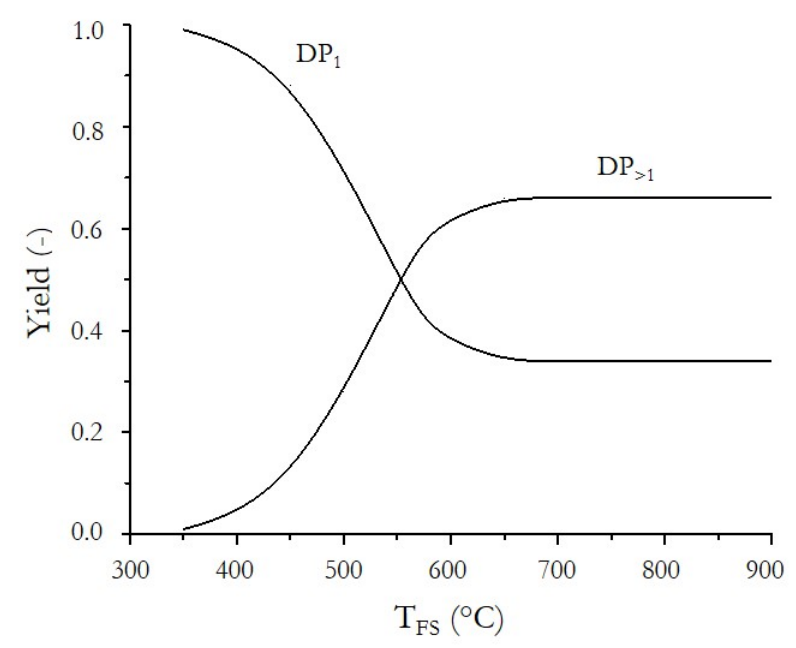

Figure 4.9: Yield predictions using model II for $D P_{1}$ and $D P_{>1}$ as a function of the final screen temperature $\left(\mathrm{T}_{\mathrm{FS}}\right)$

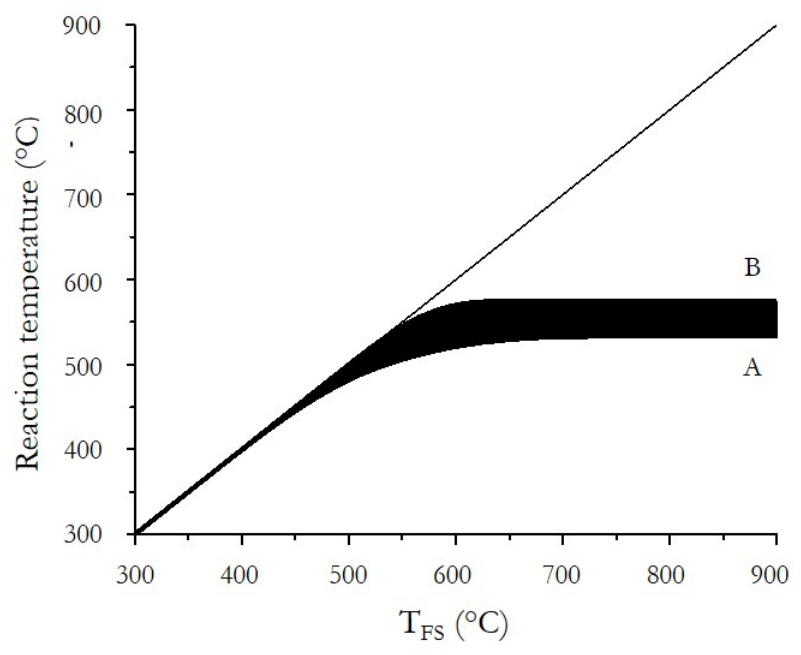

Figure 4.10: Predicted reaction temperature region using the model I as a function of the final screen temperature $\left(\mathrm{T}_{\mathrm{FS}}\right)$. Kinetic constants used of Shafizadeh $\left(k=3.2 \times 10^{14}\right.$ $\mathrm{s}^{-1}$ and $E_{A}=198 \mathrm{~kJ} \mathrm{~mol}^{-1}$ ) 


\subsubsection{Effect of potassium on pyrolysis products}

\section{Potassium impregnation efficiency}

In this part of the work, the concentration of potassium $\left(\mathrm{K}_{2} \mathrm{CO}_{3}\right)$ in cellulose was varied between $1 \mathrm{mg} \mathrm{kg}^{-1}$ and $10000 \mathrm{mg} \mathrm{kg}^{-1}$. Note, $1 \mathrm{mg} \mathrm{kg}^{-1}$ potassium concentration in cellulose, called in the text below, refers to the pure Avicel PH 101 cellulose. The total amount of potassium added to the cellulose, and the actual amount of potassium retained in cellulose after impregnation are presented in Table 4.3 The total amount of potassium retained in cellulose was measured by ion chromatography (IC). The error represents the standard deviations on the mean for three different IC measurements. As can be seen, these values nicely match one another for all three concentrations.

Table 4.3: Potassium content added and detected by IC

\begin{tabular}{lll}
\hline $\begin{array}{l}\text { Added potassium } \\
\mathrm{mg} \mathrm{kg}^{-1}\end{array}$ & $\begin{array}{l}\text { Potassium impregnated in cellulose } \\
\mathrm{mg} \mathrm{kg}^{-1}\end{array}$ & $\begin{array}{l}\text { Error } \\
\%\end{array}$ \\
\hline 100 & 98 & 2.5 \\
1000 & 962 & 3.8 \\
10000 & 9982 & 0.3 \\
\hline
\end{tabular}

\section{Mass balance closure}

The obtained mass balance closure of experiments was between $0.77 \mathrm{~kg} \mathrm{~kg}^{-1}$ and $0.96 \mathrm{~kg} \mathrm{~kg}^{-1}$. The reason for the lower mass balance closure is that water and other light oxygenates were lost during dismantling of the set-up. The mass balance closure was the lowest for the high potassium concentrations. For pyrolysis experiments with a higher concentration of potassium, higher production of water can be expected 62 . The fluidised bed experiments showed that water production increased from $0.11 \mathrm{~kg}$ $\mathrm{kg}^{-1}$ to $0.14 \mathrm{~kg} \mathrm{~kg}^{-1}$ when potassium concentration increased from $1 \mathrm{mg} \mathrm{kg}^{-1}$ to $1000 \mathrm{mg}$ $\mathrm{kg}^{-1}$, respectively. The number of experiments in the screen-heater performed, for each potassium concentration, was at least 6 at $0.5 \mathrm{kPa}$ and 2 at $100 \mathrm{kPa}$. As can be seen, the reproducibility of the experiments was satisfactory, see Figure 4.11 to 4.13 


\section{Lumped product yields}

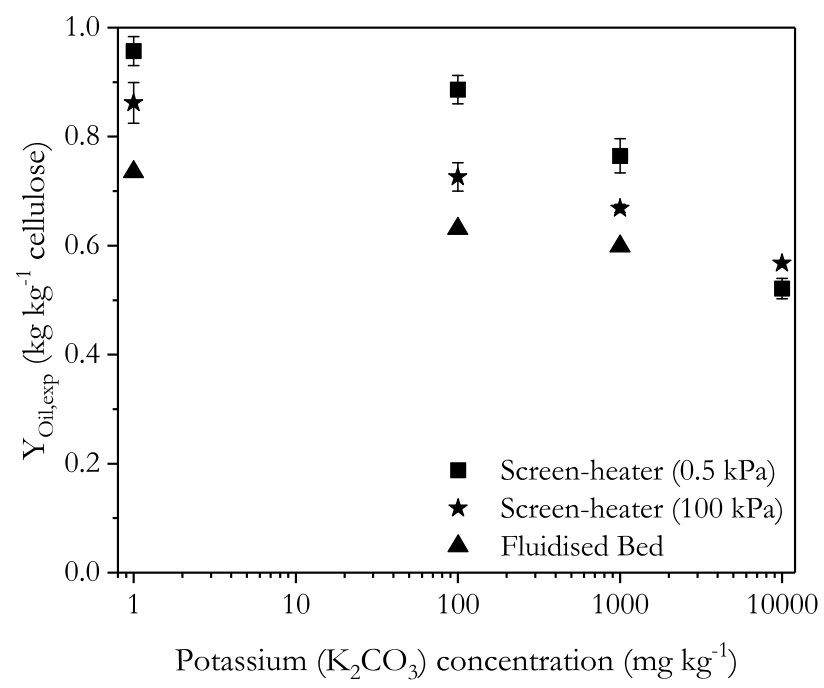

Figure 4.11: Oil yield as a function of potassium concentration in cellulose, in screen-heater and fluidised bed, at the $\mathrm{T}_{\mathrm{FS}}$ of $530{ }^{\circ} \mathrm{C}$

Figure 4.11 (Table B.1 and B.2 in Appendix B shows the oil yield as a function of the potassium concentration (on a logarithmic scale) at $0.5 \mathrm{kPa}$ and $100 \mathrm{kPa}$. The figure includes the data from the screen-heater and fluidised bed experiments. It can be seen that, as an effect of increasing potassium concentration, the oil yield decreased from 0.86 $\mathrm{kg} \mathrm{kg}^{-1}$ to $0.57 \mathrm{~kg} \mathrm{~kg}^{-1}$ at $100 \mathrm{kPa}$. At $0.5 \mathrm{kPa}$ the oil yield decreased from 0.96 to $0.52 \mathrm{~kg}$ $\mathrm{kg}^{-1}$.

A clear difference in oil yield was observed between vacuum and atmospheric pressure experiments at a low concentration of potassium, i.e. up to $1000 \mathrm{mg} \mathrm{kg}^{-1}$. In this range, the oil yield was higher at $0.5 \mathrm{kPa}$ compared to that of $100 \mathrm{kPa}$ experiments. A plausible explanation is that under vacuum the escape rate of pyrolysis products from the hot reacting particle is faster resulting in shorter contact time, or even no contact at all, between the hot products and the potassium. The pyrolysis time at $0.5 \mathrm{kPa}$ is $\sim 79$ ms (see Figure 4.44, which implies a very high product escape rates from the hot reacting particle. Moreover, even in this short pyrolysis time, potassium causes the oil yield to decrease dramatically. When the potassium concentration was further increased to 10000 $\mathrm{mg} \mathrm{kg}^{-1}$ the yield of oil became almost equal at both pressures. It is worthwhile to mention that during pyrolysis in the screen-heater some water insoluble compounds $(<0.12$ $\mathrm{kg} \mathrm{kg}^{-1}$ of the cellulose) were ejected from the screens. In the case of cellulose with $1 \mathrm{mg}$ $\mathrm{kg}^{-1}$ AAEMs, the insoluble fraction turned out to be unconverted white cellulose ${ }^{120}$, 
whereas in the presence of potassium the ejected material had a dark brown colour, indicating that it has been (partially) converted.

For the fluidised bed experiments, a comparable reduction in oil yield was observed with an increase in the potassium concentration in cellulose. The oil yields in the fluidised bed were always lower compared to the screen-heater due to significant vapour phase cracking reactions. Concluding, a significantly higher yield of oil could be obtained as long as - 1) vacuum is applied, and 2) the concentration of potassium $\left(\mathrm{K}_{2} \mathrm{CO}_{3}\right)$ in cellulose is low. At higher AAEMs concentrations, partial removal or passivation of the AAEMs before pyrolysis is mandatory to prevent AAEMs catalysed reactions that lead to low oil and sugar yields.

The effect of potassium $\left(\mathrm{K}_{2} \mathrm{CO}_{3}\right)$ concentration on the gas yield, at two different pressures in the screen-heater and fluidised bed experiments is shown in Figure 4.12 (Table B.1 and B.2 in Appendix B. It can be seen that in the case of the screen-heater more non-condensable gas is formed at higher potassium concentration. However, at both pressures until a potassium concentration of $1000 \mathrm{mg} \mathrm{kg}^{-1}$ the gas yield remained below $0.05 \mathrm{~kg} \mathrm{~kg}^{-1}$ and was even close to zero when the potassium concentration was 1 $\mathrm{mg} \mathrm{kg}{ }^{-1}$. At higher potassium concentration (10000 $\mathrm{mg} \mathrm{kg}^{-1}$ ) the gas yield increased to $0.1 \mathrm{~kg} \mathrm{~kg}^{-1}$ and $0.15 \mathrm{~kg} \mathrm{~kg}^{-1}$ at $0.5 \mathrm{kPa}$ and $100 \mathrm{kPa}$, respectively. Reactions at the particle level, catalysed by potassium, are responsible for the gas production here since the vapour phase reactions were largely suppressed in the screen-heater. The gas produced during screen-heater experiments was mainly composed of $\mathrm{CO}$ and $\mathrm{CO}_{2}$, and their yields are presented in Table B.1 of Appendix B

The fluidised bed experiments revealed that a large amount of the gas was already produced at low potassium concentration $\left(1 \mathrm{mg} \mathrm{kg}^{-1}\right)$, which was produced by vapour phase reactions induced by the long hot vapour residence time ( $\sim 1.6 \mathrm{~s})$. Even at very low potassium concentration $\left(1 \mathrm{mg} \mathrm{kg}^{-1}\right)$ most of the gas is already produced in the vapour phase. At higher concentrations of potassium $\left(\mathrm{K}_{2} \mathrm{CO}_{3}\right)$, the additional amount of gas produced is small.

Figure 4.13 (Table B.1 and B.2 in Appendix B) shows the char yield as a function of potassium $\left(\mathrm{K}_{2} \mathrm{CO}_{3}\right)$ concentration in cellulose, at $0.5 \mathrm{kPa}$ and $100 \mathrm{kPa}$. It was found that for cellulose with $1 \mathrm{mg} \mathrm{kg}^{-1} \mathrm{AAEMs}$, virtually no char was observed on the mesh at both pressures. At $100 \mathrm{mg} \mathrm{kg}^{-1}$ potassium in cellulose, the char yield was still very low. A general trend shows that with an increase in potassium concentration, char yield increased. This observed trend was comparable to the trend observed for the gas yield. The char yield remained below $0.05 \mathrm{~kg} \mathrm{~kg}^{-1}$ until $1000 \mathrm{mg} \mathrm{kg}^{-1}$ potassium concentration at both pressures $(0.5 \mathrm{kPa}$ and $100 \mathrm{kPa})$ and increased steeply to $0.15 \mathrm{~kg} \mathrm{~kg}^{-1}$ for 10000 


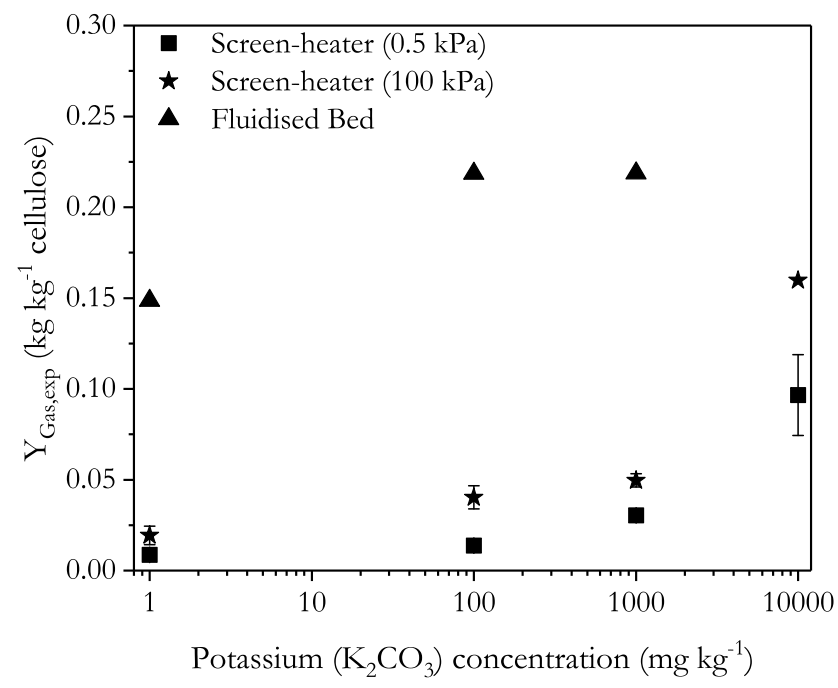

Figure 4.12: Gas yield as a function of potassium concentration in cellulose, in screen-heater and fluidised bed, at the $\mathrm{T}_{\mathrm{FS}}$ of $530{ }^{\circ} \mathrm{C}$

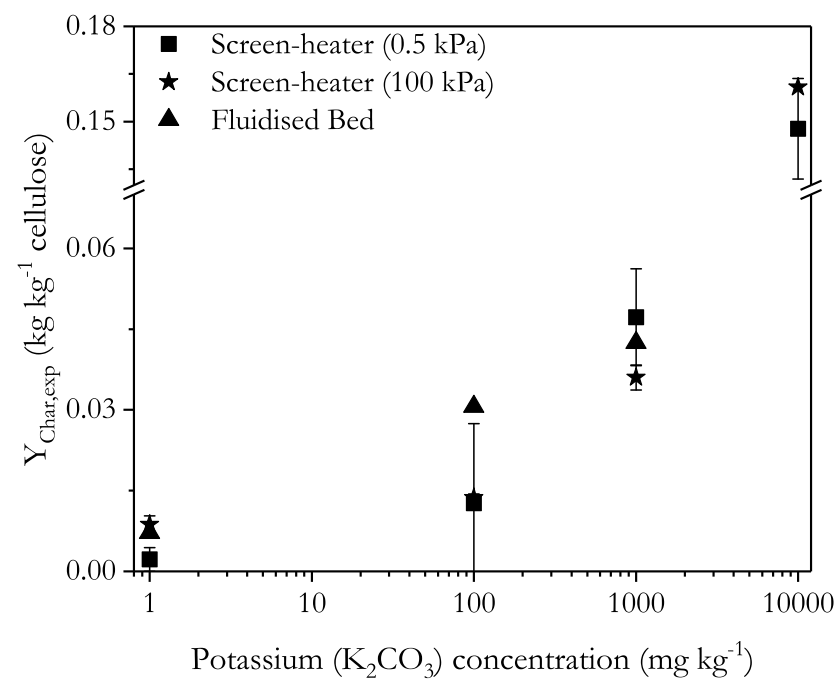

Figure 4.13: Char yield as a function of potassium concentration in cellulose, in screen-heater and fluidised bed, at the $\mathrm{T}_{\mathrm{FS}}$ of $530{ }^{\circ} \mathrm{C}$ 
$\mathrm{mg} \mathrm{kg}{ }^{-1}$ potassium concentration. At the high potassium concentration $\left(10000 \mathrm{mg} \mathrm{kg}^{-1}\right)$, black coloured carbonaceous material was found between the meshes at the end of the experiment. No significant differences were observed between the fluidised bed and screen-heater experiments. Thus, in conclusion, it can be said that the char formation reactions are independent of the escape rate of other components.

\section{Oil Composition}

Figure 4.14A (Table B.3 in Appendix B shows the levoglucosan yield and Figure 4.14B (Table B.3 in Appendix B) shows the glucose recovery as a function of the potassium $\left(\mathrm{K}_{2} \mathrm{CO}_{3}\right)$ concentration in cellulose. Glucose was obtained after the acid hydrolysis of anhydrosugars, varying in the degree of polymerisation, present in the oil. The glucose recovery is expressed as the ratio between the carbon in glucose and carbon in cellulose, see Figure 4.14B The following observations can be made from the data - 1) Levoglucosan (Figure 4.14A) was found to be the major product in fluidised bed experiments and for the screen-heater experiments performed at $100 \mathrm{kPa}$ for a potassium concentration below $1000 \mathrm{mg} \mathrm{kg}^{-1}$. When the potassium concentration was $1000 \mathrm{mg} \mathrm{kg}^{-1}$ or higher no differences in levoglucosan yield was found at $0.5 \mathrm{kPa}$ and $100 \mathrm{kPa}$, for experiments carried out in the screen-heater. Moreover, with an increase in the potassium concentration in cellulose, levoglucosan production decreased, 2) When the vacuum was applied, in the screen-heater experiments, the glucose recovery was highest due to the production of higher $D P$ anhydrosugars (cellobiosan, cellotriosan, etc.). The presence of the bigger anhydrosugars in the oil can be explained by their higher escape rate, at 0.5 $\mathrm{kPa}$, away from the hot zone than at $100 \mathrm{kPa}$, which resulted into less time for bigger anhydrosugars to crack further, for example to levoglucosan. Just like levoglucosan, the recovery of glucose decreased with an increase in the potassium concentration in cellulose and eventually approached zero, even under the extreme conditions applied in the screen-heater.

It is remarkable how fast the potassium catalysed reactions are (milliseconds) and the low concentrations of at which those reactions become destructive to anhydrosugars. Literature shows that with increasing AAEM concentrations in cellulose, the yield of levoglucosan decreased sharply (see Table A.1 in Appendix A. For example, the levoglucosan yields decreased from $0.25 \mathrm{~kg} \mathrm{~kg}^{-1}$ (400 $\mathrm{mg} \mathrm{kg}^{-1}$ ash) to $0.02 \mathrm{~kg} \mathrm{~kg}^{-1}$ (2200 mg $\mathrm{kg}^{-1}$ ash) at $500{ }^{\circ} \mathrm{C}$ and $100 \mathrm{kPa} 223224$. Patwardhan et al. 210 reported constant concentration (not yield) of levoglucosan when the potassium concentration increased from $3000 \mathrm{mg} \mathrm{kg}^{-1}$ to $11800 \mathrm{mg} \mathrm{kg}^{-1}$. Taking into account the oil yield, it is also likely that the levoglucosan yield decreases further as the potassium concentration increased. When 


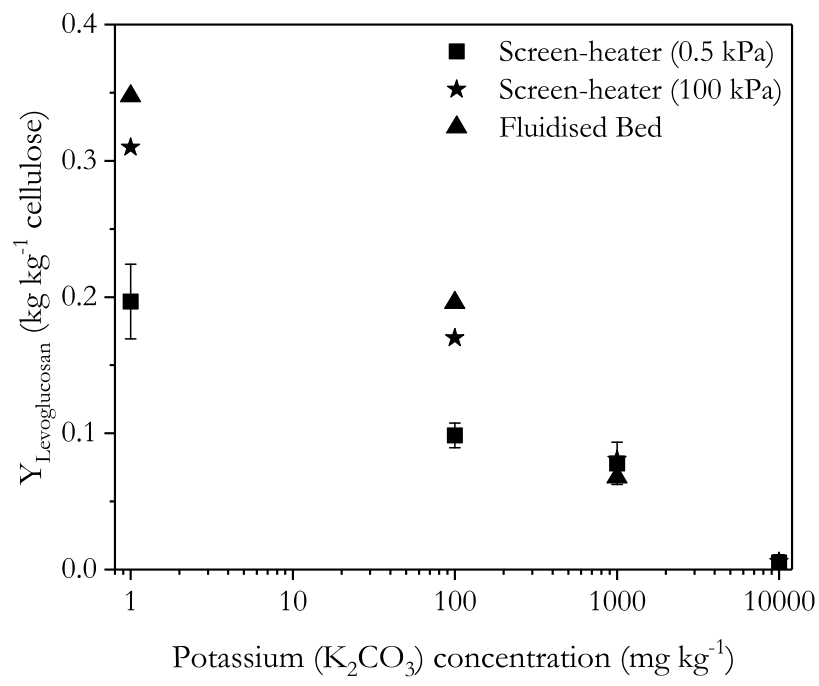

Figure 4.14A: Levoglucosan yield as a function of potassium concentration in cellulose, in screen-heater and fluidised bed, at the $\mathrm{T}_{\mathrm{FS}}$ of $530^{\circ} \mathrm{C}$

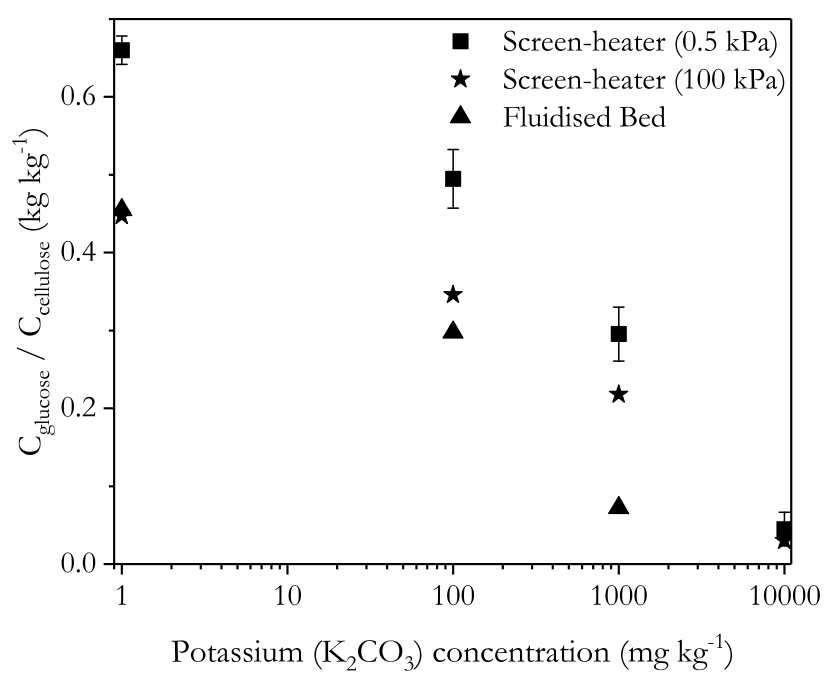

Figure 4.14B: Glucose recovery after hydrolysis of oil as a function of potassium concentration in cellulose, in screen-heater and fluidised bed, at the $\mathrm{T}_{\mathrm{FS}}$ of $530{ }^{\circ} \mathrm{C}$ 
translating these findings to the real biomass, it can be concluded that it is impossible to produce high yields of anhydrosugars from untreated biomass which has typically 10000 $\mathrm{mg} \mathrm{kg}^{-1}$ AAEM. Removal (or passivation) of AAEMs from (or in) the biomass is therefore mandatory.

\section{Levoglucosan pyrolysis}

It was previously shown that levoglucosan could be completely evaporated in vacuum 225 and atmospheric pressure 148 . To obtain more information on the reactions of this important compound, it was pyrolysed in the screen-heater $\left(\mathrm{T}_{\mathrm{FS}}=530^{\circ} \mathrm{C} ; 0.5 \mathrm{kPa}\right.$ and 100 $\mathrm{kPa}$ ). The potassium concentration in the levoglucosan feedstock was $1 \mathrm{mg} \mathrm{kg}^{-1}$ (pure levoglucosan) and $1000 \mathrm{mg} \mathrm{kg}^{-1}$. At both pressures ( $0.5 \mathrm{kPa}$ and $\left.100 \mathrm{kPa}\right)$, levoglucosan without potassium could be completely recovered $\left(\mathrm{R}_{\text {Levoglucosan }}\right)$, see Figure $4.15 \mathrm{~A}$ When potassium was added, only a small amount of gas and char were produced at $0.5 \mathrm{kPa}$, and the oil was solely comprised of levoglucosan. When the pressure was increased to 100 $\mathrm{kPa}$, and the potassium concentration to $1000 \mathrm{mg} \mathrm{kg}^{-1}$, only half of the levoglucosan was recovered (Figure $4.15 \mathrm{~A}$, and noticeable amounts of char and gas were produced (Figure 4.15B). This can again be explained by the faster escape rate of levoglucosan from the hot reacting particle at $0.5 \mathrm{kPa}$ compared to at $100 \mathrm{kPa}$ (factor 10, see Table 4.2). In other words, levoglucosan escaped the hot screens, at $0.5 \mathrm{kPa}$, even before the potassium became catalytically active. Although levoglucosan could be completely evaporated at 100 $\mathrm{kPa}$, in the absence of potassium $\left(1 \mathrm{mg} \mathrm{kg}^{-1}\right)$, only half of the original levoglucosan was recovered in oils obtained from $1000 \mathrm{mg} \mathrm{kg}^{-1}$ potassium infused levoglucosan, pointing again towards very fast catalytic reactions. Note, in the nearly absent vapour phase reactions, destruction of levoglucosan at $100 \mathrm{kPa}$ can solely be ascribed to intra-particle (catalytic) reactions.

\section{Light oxygenates (screen-heater, $530{ }^{\circ} \mathrm{C}$ and $0.5 \mathrm{kPa}$ )}

An important effect of AAEMs on cellulose pyrolysis is the ability to catalyse dehydration and ring fragmentation reactions of the anhydrosugars 2192226. Levoglucosenone was chosen to represent the products of dehydration reactions, while the products of fragmentation reactions are represented by acetol and hydroxyacetaldehyde 121174 . The yields of these compounds, calculated based on three experiments performed under identical conditions, and the corresponding standard deviation on the mean are reported in Table B.6 of Appendix B

The yield of levoglucosenone increased from $0.003 \mathrm{~kg} \mathrm{~kg}^{-1}$ to $0.01 \mathrm{~kg} \mathrm{~kg}^{-1}$ with an increase in the potassium concentration up to $1000 \mathrm{mg} \mathrm{kg}^{-1}$, while no levoglucosenone 


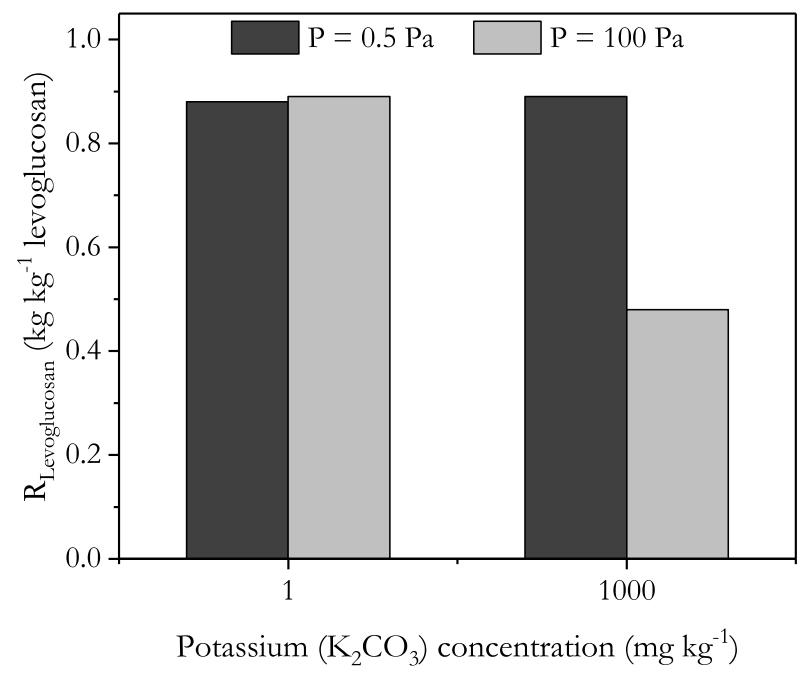

Figure 4.15A: Levoglucosan recovery as a function of potassium concentration in levoglucosan and pressure in screen-heater, at the $\mathrm{T}_{\mathrm{FS}}$ of $530{ }^{\circ} \mathrm{C}$

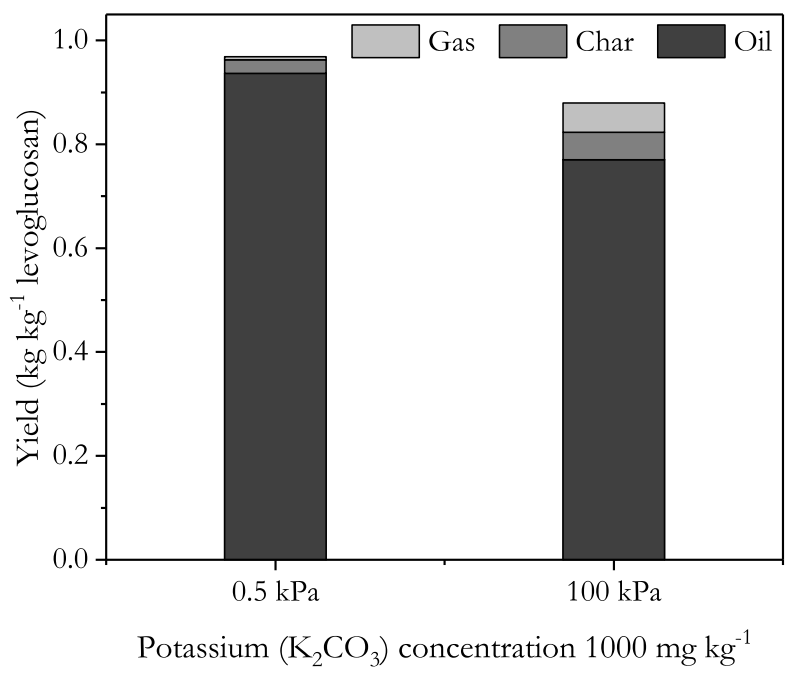

Figure 4.15B: Effect of pressure on oil, char and gas yields at constant potassium concentration in levoglucosan; in screen-heater, at the $\mathrm{T}_{\mathrm{FS}}$ of $530{ }^{\circ} \mathrm{C}$ 
was detected at $10000 \mathrm{mg} \mathrm{kg}^{-1}$ potassium concentration. Levoglucosenone has probably reacted away to form solid residue and/or decomposed to other compounds such as water, gas and light oxygenates. It is worth mentioning that in the case of levoglucosan pyrolysis, no levoglucosenone production was observed. Similar levoglucosenone yields were reported by Zhou et al. 107 in the temperature range between 400 and $600{ }^{\circ} \mathrm{C}$. In the range of $1 \mathrm{mg} \mathrm{kg}^{-1}$ to $1000 \mathrm{mg} \mathrm{kg}^{-1}$ of potassium concentration the acetol yield remained low $\left(<0.0025 \mathrm{~kg} \mathrm{~kg}^{-1}\right)$, and it increased rapidly to $0.02 \mathrm{~kg} \mathrm{~kg}^{-1}$ at $10000 \mathrm{mg} \mathrm{kg}^{-1}$ potassium concentration. Piskorz et al. 223 observed acetol yield of $0.007 \mathrm{~kg} \mathrm{~kg}^{-1}$ for cellulose containing $400 \mathrm{mg} \mathrm{kg}^{-1}$ ash, and it increased $\left(0.032 \mathrm{~kg} \mathrm{~kg}^{-1}\right)$ with an increase in the ash content (2200 $\mathrm{mg} \mathrm{kg}^{-1}$ ash).

In the case of $1 \mathrm{mg} \mathrm{kg}^{-1}$ and $10000 \mathrm{mg} \mathrm{kg}^{-1}$ potassium in cellulose, the hydroxyacetaldehyde yield was $0.11 \mathrm{~kg} \mathrm{~kg}^{-1}$, and it passed through a maximum $\left(0.16 \mathrm{~kg} \mathrm{~kg}^{-1}\right)$ at 100 $\mathrm{mg} \mathrm{kg}^{-1}$ potassium concentration. The yield of hydroxyacetaldehyde reported in the literature lies in the range between $0.016 \mathrm{~kg} \mathrm{~kg}^{-1}$ to $0.16 \mathrm{~kg} \mathrm{~kg}^{-1}$, see Table A.3 in Appendix A The difficulties in determining the hydroxyacetaldehyde yield by gas chromatography have been elaborated in Chapter 3; thus, the direct comparison between the hydroxyacetaldehyde yields reported in this work and the literature is not possible. Nevertheless, principal component analysis (see loading matrix in Section A.3.2 of Appendix A suggests that the yield of hydroxyacetaldehyde is directly proportional to the ash content of cellulose.

In summary, based on the production of levoglucosenone and char, dehydration reactions of anhydrosugars are more pronounced at higher potassium concentrations. Ring fragmentation reactions lead to an unequivocal increase in the gas and acetol yields with an increase in the potassium concentration. The hydroxyacetaldehyde yield was found to be independent of the potassium concentration in cellulose.

\subsubsection{Influence of different anions}

Cellulose was impregnated with different potassium salts $\left(\mathrm{K}_{2} \mathrm{CO}_{3}, \mathrm{KCl}\right.$ or $\left.\mathrm{KOH}\right)$ while keeping the concentration of potassium constant $\left(1000 \mathrm{mg} \mathrm{kg}^{-1}\right)$ to investigate the influence of different anions on the pyrolysis products. All cellulose samples were pyrolysed at $530{ }^{\circ} \mathrm{C}$ and two pressures $(0.5 \mathrm{kPa}$ and $100 \mathrm{kPa})$. Figure $4.16 \mathrm{~A}$ and $4.16 \mathrm{~B}$ (Table B.7 in Appendix B) show the yield of oil, solid residue and gas, at $0.5 \mathrm{kPa}$ and 100 $\mathrm{kPa}$, as a function of the different anions, respectively. The error bars shown in Figure $4.16 \mathrm{~A}$ and $4.16 \mathrm{~B}$ represent the standard deviation on mean, calculated based on 6 and 3 experiments at $0.5 \mathrm{kPa}$ and $100 \mathrm{kPa}$, respectively.

At $0.5 \mathrm{kPa}$, comparable mass balance closures of $\sim 0.84 \mathrm{~kg} \mathrm{~kg}^{-1}$ were obtained. 
However, at $100 \mathrm{kPa}$ the mass balance closure decreased by $0.1 \mathrm{~kg} \mathrm{~kg}^{-1}$ to $0.75 \mathrm{~kg} \mathrm{~kg}^{-1}$. Different anions appeared to have no effect on the mass balance closure (Figure $4.16 \mathrm{~A}$ and 4.16B). The char and gas yields did not differ much between the experiments performed at a given pressure for all three anions. The oil yield decreased when the pressure was increased to $100 \mathrm{kPa}$, which can mainly be attributed to the increasing loss of water and light oxygenates. The obtained oil was analysed for the levoglucosan yield and glucose recovery.

In Figure $4.17 \mathrm{~A}$ to $4.18 \mathrm{~B}$, the levoglucosan yields and the glucose recovery, obtained at $0.5 \mathrm{kPa}$ and $100 \mathrm{kPa}$, are plotted for three different anions. There was almost no effect of pressure on the levoglucosan production, and a small decrease in glucose recovery was observed at $100 \mathrm{kPa}$ compared to at $0.5 \mathrm{kPa}$ for all three different anions. It was observed that $\mathrm{CO}_{3}{ }^{2-}$ was the least active anion in reducing the levoglucosan as well as the hydrolysable anhydrosugar yields, while no significant difference between the catalytic activity of $\mathrm{Cl}^{-}$and $\mathrm{OH}^{-}$was observed. A similar observation was made for the levoglucosan yield by Patwardhan et al. 210 .

DFT calculations suggest that cations can form cation-carbohydrate complexes. In general, cations are more active in forming salt-carbohydrate complex than anions 227 . A theoretical study by Mayes et al. $\stackrel{108}{ }$ shows that distinct anions have a different affinity towards the cation. They also reported that anions are primarily involved in binding with their counter cation and compete with cation-carbohydrate complex reactions instead of influencing cellulose pyrolysis chemistry directly 108 . Nevertheless, more detailed research (experimental and theoretical) is needed to gain a deeper understanding to investigate the role of different anions. 


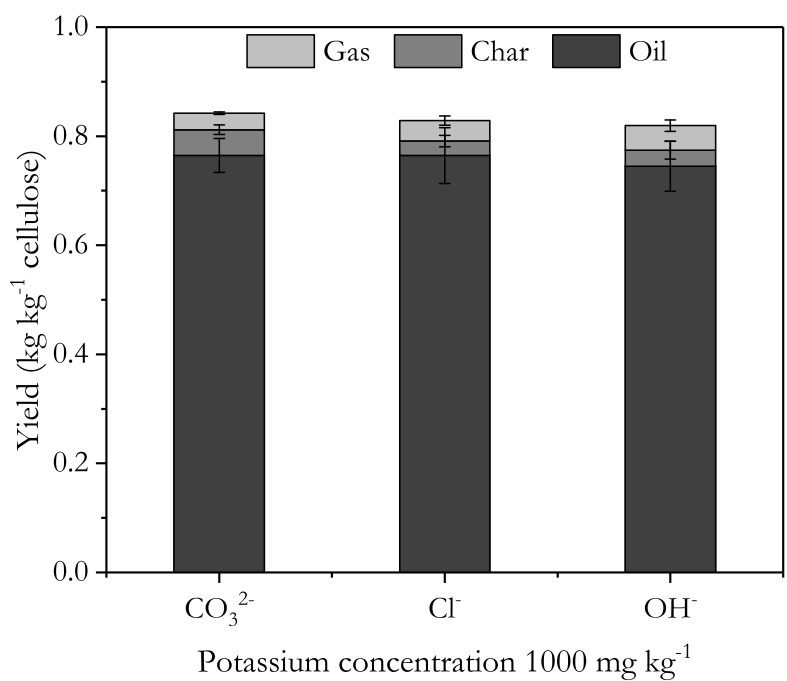

Figure 4.16A: Oil, char and gas yields for different anions with constant potassium concentration. $\mathrm{P}=0.5 \mathrm{kPa}$ and at $\mathrm{T}_{\mathrm{FS}}=530{ }^{\circ} \mathrm{C}$

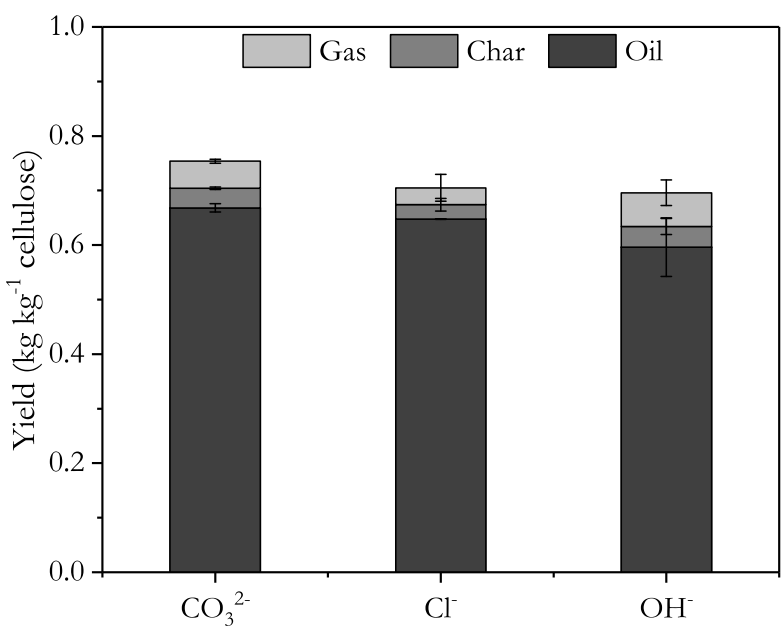

Potassium concentration $1000 \mathrm{mg} \mathrm{kg}^{-1}$

Figure 4.16B: Oil, char and gas yields for different anions with constant potassium concentration. $\mathrm{P}=100 \mathrm{kPa}$ and at $\mathrm{T}_{\mathrm{FS}}=530{ }^{\circ} \mathrm{C}$ 


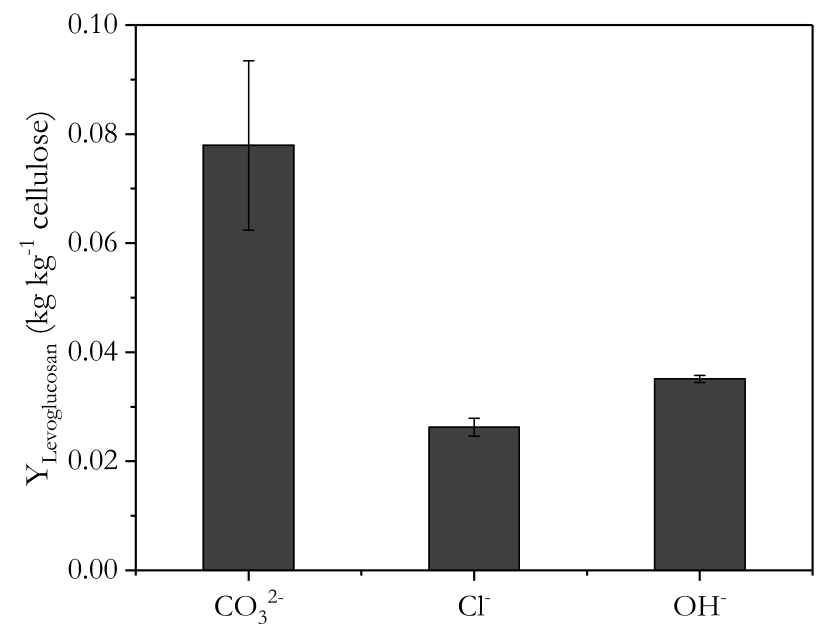

Potassium concentration $1000 \mathrm{mg} \mathrm{kg}^{-1}$

Figure 4.17A: Levoglucosan yield for different anions with constant potassium concentration. $\mathrm{P}=0.5 \mathrm{kPa}$ and at $\mathrm{T}_{\mathrm{FS}}=530^{\circ} \mathrm{C}$

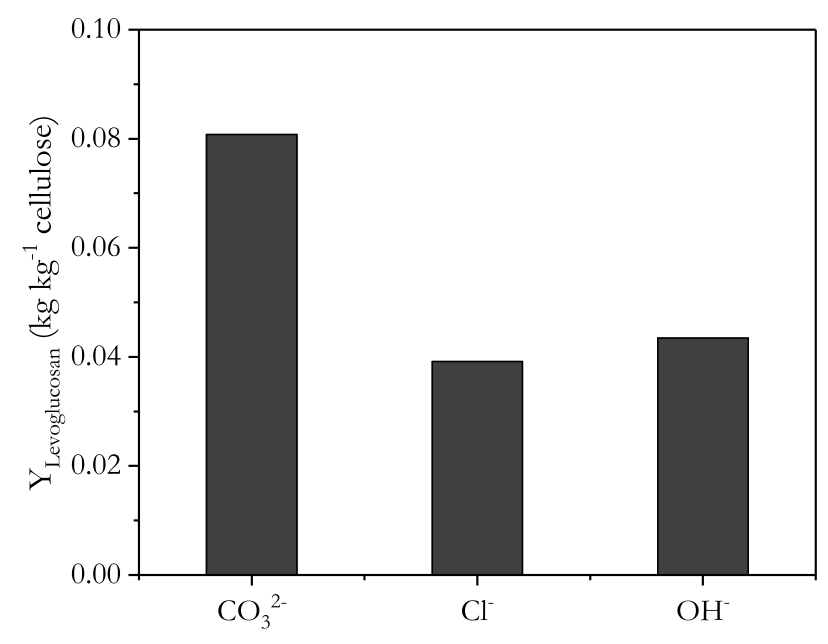

Potassium concentration $1000 \mathrm{mg} \mathrm{kg}^{-1}$

Figure 4.17B: Levoglucosan yield for different anions with constant potassium concentration. $\mathrm{P}=100 \mathrm{kPa}$ and at $\mathrm{T}_{\mathrm{FS}}=530{ }^{\circ} \mathrm{C}$ 


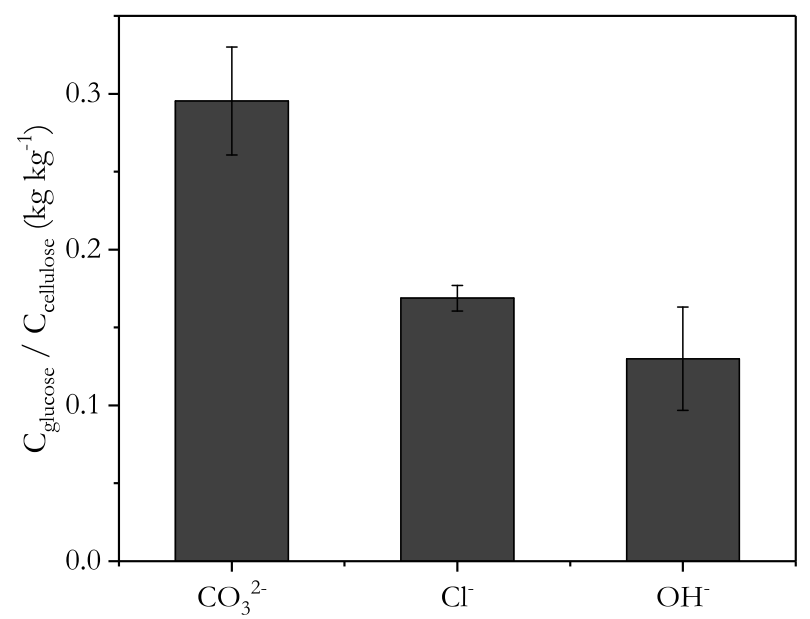

Potassium concentration $1000 \mathrm{mg} \mathrm{kg}^{-1}$

Figure 4.18A: Glucose recovery for different anions with constant potassium concentration. $\mathrm{P}=0.5 \mathrm{kPa}$ and at $\mathrm{T}_{\mathrm{FS}}=530^{\circ} \mathrm{C}$

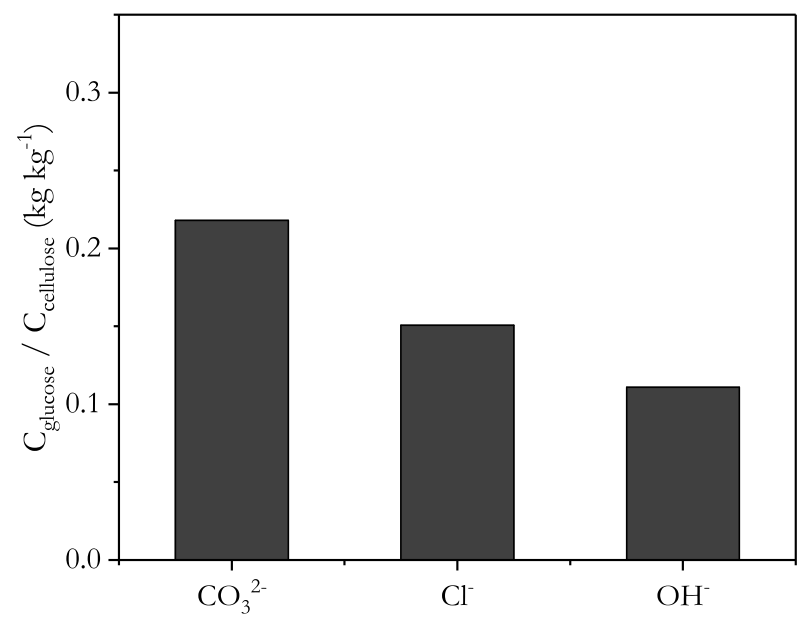

Potassium concentration $1000 \mathrm{mg} \mathrm{kg}^{-1}$

Figure 4.18B: Glucose recovery for different anions with constant potassium concentration. $\mathrm{P}=100 \mathrm{kPa}$ and at $\mathrm{T}_{\mathrm{FS}}=530{ }^{\circ} \mathrm{C}$ 


\subsection{Conclusions}

In the first part of the chapter, the fast pyrolysis of Avicel PH 101 cellulose has been studied in a screen-heater (heating rate $\sim 5000^{\circ} \mathrm{C} \mathrm{s}^{-1}, 0.5 \mathrm{kPa}$ pressure and fast quenching at $\sim-180{ }^{\circ} \mathrm{C}$ ), while varying the temperature and maximising the escape rate of products from the reacting cellulose particle. In the second part, the effects of three different potassium salts on the primary reactions of cellulose pyrolysis are investigated at $530^{\circ} \mathrm{C}$. Also, the obtained results are compared with the pyrolysis, at $100 \mathrm{kPa}$, carried out in the same screen-heater (at lowered escape rate of products) and in a bench scale fluidised bed reactor (increasing the hot vapour residence time).

To the best of our knowledge, we are the first to observe experimentally that it is possible to convert pure cellulose ( $1 \mathrm{mg} \mathrm{kg}^{-1}$ potassium), in the broad temperature range of 370 to $765^{\circ} \mathrm{C}$, into hydrolysable sugars with a high and constant yield $(60 \%-70 \%$ on carbon basis) while producing only a limited amount of light oxygenates and gas. Below $450{ }^{\circ} \mathrm{C}$ solid residue was found, which turned out to be unconverted cellulose, not char. The results indicate that depolymerisation to anhydrosugars $\left(D P_{1}\right.$ to $\left.D P_{>11}\right)$ is a true primary reaction, while gas formation not and that char formation can be, as was already known, avoided. Evidence is accumulating that both the distribution of the produced anhydrosugars and the mass loss rate of cellulose is determined by the interplay between the chemistry, heat and mass transfer at cell wall level above $450{ }^{\circ} \mathrm{C}$. Whereas, below 450 ${ }^{\circ} \mathrm{C}$ and high heating rates, chemistry and mass transfer are the important processes.

The catalytic effects of potassium on cellulose fast pyrolysis are evident, even in the timescale of milliseconds. In screen-heater (at $0.5 \mathrm{kPa}$ ), as a function of potassium concentration, a $\sim 50 \%$ reduction in the oil yield, a significant increase in the gas yield $\left(<0.01\right.$ to $\left.0.15 \mathrm{~kg} \mathrm{~kg}^{-1}\right)$ and a decreased glucose recovery (70\% to almost zero) was observed. These findings show that the destruction of anhydrosugars, by the catalytic activity of potassium, predominantly takes place at the hot reacting particle to produce other products such as water, light oxygenates and gases. Identical char yields obtained in fluidised bed and screen-heater for a given potassium concentration indicate that the char formation reactions are not affected by the escape rate of other products. Generalising, for the low AAEMs content feedstock, reducing pressure, i.e. enhancing the escape rate of products from the hot reacting particle, may improve the oil and sugar yields to a certain extent. However, the removal (or passivation) of AAEMs from (or in) the mineral-rich feedstock, before pyrolysis, is mandatory to obtain high oil and sugar yields. 


\section{Nomenclature}

\begin{tabular}{|c|c|c|}
\hline$A$ & $m^{2}$ & Area available for heat transfer \\
\hline$\alpha$ & $W m^{-2} K^{-1}$ & Heat transfer coefficient \\
\hline$B$ & ${ }^{\circ} \mathrm{C} s^{-1}$ & Heating rate of the screens. \\
\hline$B^{\prime}$ & ${ }^{\circ} \mathrm{C} s^{-1}$ & Cooling rate (measured) of the screens after the holding time \\
\hline$C_{p}$ & $J k g^{-1} K^{-1}$ & Heat capacity of the sample \\
\hline$E_{1}$ & $J \mathrm{~mol}^{-1}$ & Activation energy of reaction 1 \\
\hline$E_{2}$ & $J m o l^{-1}$ & Activation energy of reaction 2 \\
\hline$E_{3}$ & $J m o l^{-1}$ & Equal to $E_{2}$ \\
\hline$E_{4}$ & $J \mathrm{~mol}^{-1}$ & Overall $\mathrm{k}$ lower than $k_{2}$ \\
\hline$\Delta H_{2}$ & $J k g^{-1}$ & the enthalpy of the reaction / evaporation \\
\hline$\Delta H$ & $J k g^{-1}$ & the enthalpy of the evaporation \\
\hline$k_{1,0}$ & $s^{-1}$ & Pre-exponential constant of reaction 1 \\
\hline$k_{2,0}$ & $s^{-1}$ & Pre-exponential constant of reaction 2 \\
\hline$k_{3,0}$ & $s^{-1}$ & $10 \%$ of $k_{2,0}$ (arbitrary choice) \\
\hline$k_{4,0}$ & $s^{-1}$ & Overall k lower than $k_{2}$ \\
\hline$M_{C}$ & $k g$ & the mass of cellulose \\
\hline$M_{C, 0}$ & $k g$ & Initial mass of the cellulose \\
\hline$M_{A C}$ & $k g$ & the mass of active cellulose \\
\hline$M_{A C, 0}$ & $k g$ & Initial mass of the active cellulose \\
\hline$M_{S}$ & $k g$ & the mass of sample \\
\hline$M_{S, 0}$ & $k g$ & Initial mass of the sample \\
\hline$M_{D P_{1}}$ & $k g$ & the mass of $D P_{1}$ \\
\hline$M_{D P_{1}, 0}$ & $k g$ & Initial mass of $D P_{1}$ \\
\hline$M_{D P_{\geq 2}}$ & $k g$ & the mass of $D P_{\geq 2}$ \\
\hline$M_{D P_{\geq 2}, 0}$ & $k g$ & Initial mass of $D P_{\geq 2}$ \\
\hline \multirow[t]{2}{*}{$T_{C}$} & $K$ & Model I: temperature of the sample (cellulose + active cellulose) \\
\hline & & Model II: temperature of the sample (cellulose $+D P_{\geq 2}+D P_{1}$ ) \\
\hline$T_{S}$ & $K$ & Temperature of the screen \\
\hline$T_{C}, 0$ & $K$ & Initial temperature of the sample (cellulose + active cellulose) \\
\hline$T_{S}, 0$ & $K$ & Initial temperature of the screen \\
\hline$T_{s}$ et & $K$ & Set-point of the screen temperature \\
\hline$T_{r}$ & $K$ & the reaction temperature \\
\hline$t_{h}$ & $s$ & Holding time \\
\hline$X$ & - & the conversion on mass basis \\
\hline
\end{tabular}




$\begin{array}{lll}Y_{D P_{1}} & \mathrm{~kg} \mathrm{~kg}^{-1} & \text { The yield of } D P_{1} \text { in oil on cellulose basis } \\ Y_{D P_{\geq 2}} & \mathrm{~kg} \mathrm{~kg}^{-1} & \text { The yield of } D P_{\geq 2} \text { in oil on cellulose basis }\end{array}$




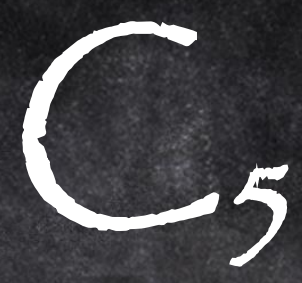

Fast pyrolysis of lignins with different molecular weight:

experiments and modelling

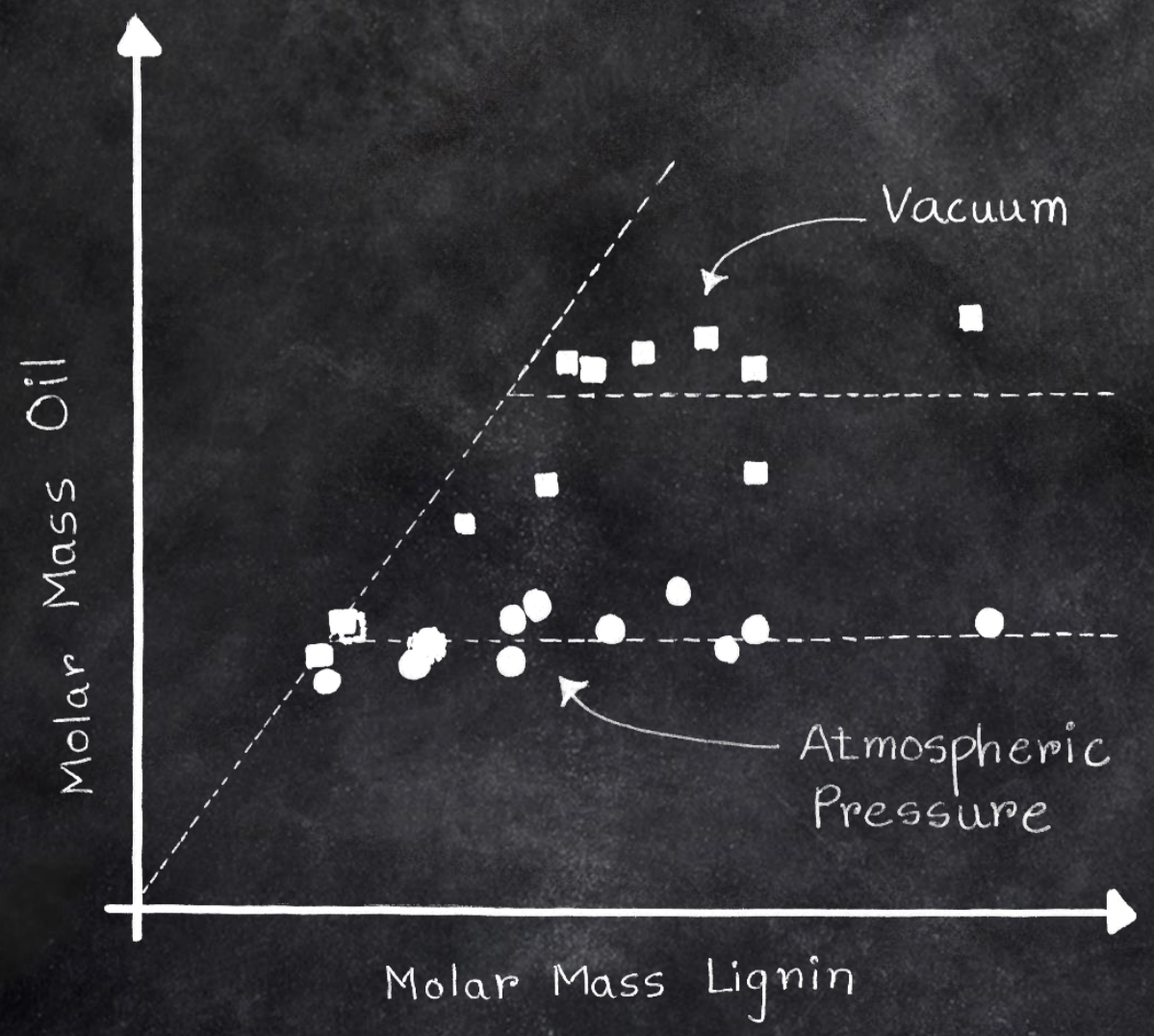




\begin{abstract}
Lignins with number averaged molecular weights between $350 \mathrm{Da}$ and $1900 \mathrm{Da}$ were characterised and subsequently pyrolysed in a screen-heater at pressures of $0.5 \mathrm{kPa}$ and $100 \mathrm{kPa}$ between $425^{\circ} \mathrm{C}$ and $793^{\circ} \mathrm{C}$. Upwards of $530{ }^{\circ} \mathrm{C}$, the temperature turned out to have only a minor influence on the yields and composition of the oils produced. Clear trends were observed as a function of the molecular weight and pressure - 1) at increasing molecular weight of the lignin, the oil yield decreases while yields of char and gas increase, 2) the molecular weight of the oil is lower for oils produced at $100 \mathrm{kPa}$ as compared to the ones obtained at $0.5 \mathrm{kPa}, 3$ ) above a certain molecular weight of the lignins, $\sim 400 \mathrm{Da}$ for $100 \mathrm{kPa}$ and $\sim 800 \mathrm{Da}$ for $0.5 \mathrm{kPa}$, the molecular weight of the oil becomes independent of the molecular weight of the lignin. A mathematical model has been developed, which includes three concurrently occurring processes, viz. cracking and polymerisation reactions and removal, hence mass transport, of unconverted lignin and reaction products from the reaction zone. This model can describe all the trends observed experimentally and provides, after parametrisation, reasonable qualitative predictions of the yield and molecular weight of the oils. Knowledge of the role of the interplay between mass transport and chemistry in the pyrolysis process is further accumulating, and from this the development of lignin valorisation can avail. For instance, it has become clear that in the pyrolysis process the molecular weight of lignin oil, which is an important characteristic for the upgrading of the oil to chemicals and/or fuels, can be steered with the pressure.
\end{abstract}

This chapter is based on:

P.S. Marathe, R.J.M. Westerhof, S.R.A. Kersten, Fast pyrolysis of lignins with different molecular weight: Experiments and modelling, Appl. Energy 236 (2019) 1125-1137. 


\subsection{Introduction}

Lignin is an amorphous, highly cross-linked, hetero-polymer that provides structural integrity and stiffness to plant cell walls 10 . It is the most abundant naturally occurring aromatic polymer and it accounts for $\sim 30 \%$ of all organic carbon in the biosphere $\frac{228}{2}$. Typically, it is burned as a low-value fuel, however, being aromatic in nature, it could be a potential source of mono-aromatics and other value-added chemicals 229, 231.

Lignin is isolated from biomass via several methods such as kraft, organosolv, ball milling, and cold-water precipitation of pyrolytic lignin 14/15/125. The extent to which the structure of native lignin is preserved is controlled by the severity of the isolation method 15]16/232. Milled wood lignin (MWL), obtained by Björkman's method, is considered to represent native lignin most accurately 17 .

Starting in the 1970's, the fast pyrolysis process has been studied extensively to liquefy and depolymerise lignin in various experimental devices $12186 / 233-238$. Aligning the results obtained in the different reactor systems used is difficult. For example, with respect to the production of mono-aromatics yields of up to $20 \%$ were reported in micropyrolysers 239240 , whereas in screen-heaters and fluidised beds typical yields were only 1 to $4 \% 236|241| 242$. Oil yields as high as $80 \%$ were obtained in screen-heaters under vacuum conditions 225|242] while in the other reactors the maximum yield was limited to $40 \%$ 240]241243[244. There is also no consensus on the chemical mechanisms leading to monomers and oligomers. Patwardhan et al. .240 claimed that monomeric compounds are the primary products of lignin pyrolysis and that they polymerise during condensation of the vapours (to oil) to form oligomers. Contrary, Piskorz et al. 52 postulated that oligomers eject from pyrolysing biomass particles, which was later verified experimentally by Small-Angle Neutron Scattering (SANS) analysis by Fratini et al. 53 and by Montoya et al. 55 for lignin, and by Teixeira et al. 54 for cellulose.

Models for lignin pyrolysis range from weight loss kinetic models 27245,248 , lumped component class models 249 251, via population balance calculations over the molecular weight distribution of the reacting lignin 115116 , to models combining a structural description of lignin with the reactivity of linkages between the lignin building blocks 113252 . Weight loss kinetics models are always based on low heating rate data and use experimentally observed yields of volatile species to estimate kinetic parameters to simulate slow pyrolysis of lignin. These models can predict the non-isothermal weight loss of the reacting lignin and yields of volatile species (e.g. gases, methanol). However, they cannot predict the oil yield nor the molecular weight distribution of the oil, which limits their applicability. The lumped class models of Faravelli et al. 250 , Hough et al. $\stackrel{251}{2}$, and Dussan 
et al. 249 use experimentally obtained and/or theoretically (group contribution method and/or density functional theory) calculated kinetic parameters to predict the yields of oil (light and heavy), char, and gas as well as weight loss kinetics. The experimentally obtained kinetic parameters were derived under slow pyrolysis conditions. These models use complex reaction networks, composed of more than a hundred series/parallel primary and/or secondary reactions. As input, the lumped class models use a simplified lignin structure, while the models of Klein et al. 252 and Yanez et al.113253 use the spruce lignin structure proposed by Freudenberg 11 and an artificially generated structure of wheat straw lignin, respectively. In the latter, probabilities of reactions pathways are assigned based on experimental observations as well as theoretical calculations. The model of Klein et al.252 uses empirically obtained kinetic parameters, and their values are used as an initial estimate in the model of Yanez et al.113. These models predict the temporal evolution of the yields of major product fractions and the molecular weight of the liquid and gaseous products. However, they do not capture the influence of mass transfer. The population balance model of Avni et al. $\frac{116}{}$, originally developed for coal pyrolysis, assumes the cracking of weak bonds and transport of volatile products away from the reacting lignin. Interestingly, their model captures the effect of the external pressure on the product yields. Solomon et al.115/116 have described the transport of species by using Fick's law of diffusion, where the diffusion coefficient is a function of pressure, temperature and molecular weight.

This paper aims at advancing the understanding of lignin pyrolysis in order to increase the valorisation of this abundant natural aromatic resource. We assume that, like for cellulose (Chapter 4), the pyrolysis of lignin is controlled by the interplay of chemical reactions taking place in the liquid/solid state and the removal rate of compounds from the reaction zone. If this hypothesis is true, then the product yields and molecular weight distribution of the produced oil depend on the molecular weight (distribution) of the lignin feedstock and the bond type interconnecting the aromatic units. For lignin pyrolysis, the dominant reactions with respect to molecular weight distribution of the oil produced can be generalised into cracking and polymerisation reactions. To investigate this hypothesis, 14 lignins with a mass average molecular weight ranging from 588 to 3596 Da were characterised. Secondly, the lignins were pyrolysed in a screen-heater designed to minimise non-isothermality and to maximise the quenching rate of products (and unconverted lignin) after leaving the reaction zone 119 . Temperatures $\left(425^{\circ} \mathrm{C}\right.$ $\left.-793^{\circ} \mathrm{C}\right)$ and pressures $(0.5 \mathrm{kPa}$ and $100 \mathrm{kPa})$ were varied in order to map the operating window and to further analyse the aforementioned interplay. Finally, the experimental results were compared with a mathematical model including the aforementioned chemical reactions and mass transfer. 
In the literature, numerous studies $232|237| 239|244| 254 \mid 262$ compared the pyrolysis of various lignins which were chosen based on either their source and/or isolation methods, while we are the firsts, to the best of our knowledge, to interpret the results on the basis of the molecular weights of the lignins. The developed population balance model is relatively simple compared to lumped class and linkage reactivity based models and has the easily measurable molecular weight distribution of lignin as the main input. 


\subsection{Lignins}

Physical characteristics such as elemental composition, aromaticity, mass average molecular weight $\left(\left\langle\mathrm{M}_{\mathrm{w}}\right\rangle\right)$, polydispersity values, and content of $\beta$-O-4 linkages present in lignins are presented in Table 5.1 Note, all lignin samples were dried for $12 \mathrm{~h}$ in a vacuum oven $\left(<0.5 \mathrm{kPa}, 20^{\circ} \mathrm{C}\right)$ before any analysis and pyrolysis experiment.

As can be seen, MWL has an oxygen content of 33\% which is considerably higher compared to the other lignins. The oxygen content of the other lignins (i.e. SL, SOL, WSL, PL) is quite comparable. SL has the highest carbon content. Furthermore, all lignins have similar hydrogen $(\sim 6 \%)$, and nitrogen $(<1 \%)$ content. The ash content of all lignins is lower than $5 \mathrm{mg} \mathrm{kg}^{-1}$, and therefore it has assumed that it does not affect the pyrolysis outcome.

In the case of WSL, the ratio of light fraction (L) to a heavy fraction $(\mathrm{H})$ is 1:1, whereas for both pyrolytic lignins it is in the range of 0.65:0.35 (See Table C.1). The molecular weights of light and heavy fractions are presented in Table 5.1 Note, the fractionation experiments were performed twice to check the reproducibility. The standard deviation in the yields of light fractions and heavy fractions, obtained from two separate fractionation experiments, was below $1 \%$ for all fractioned lignins.

As can be seen, the MWL is the heaviest lignin (3596 Da) studied in this work. The $<\mathrm{M}_{\mathrm{w}}>$ of both pyrolytic lignins (PL1 and PL2) is $\sim 9.5$ times lower than the MWL. Three organosolv lignins (SL, SOL and WSL) had their $\left\langle\mathrm{M}_{\mathrm{w}}>\right.$ between $2000 \mathrm{Da}$ and $2500 \mathrm{Da}$. The $\left\langle\mathrm{M}_{\mathrm{w}}>\right.$ of light fractions $(2,5,8,11)$ are notably lower than their parent lignins $(1,4,7,10)$ and much lower than the heavy fractions $(3,6,9,12)$.

The poly-dispersity of 2.5 and high $\left\langle\mathrm{M}_{\mathrm{w}}>\right.$ of MWL, indicates that MWL is mainly composed of high molecular weight compounds originating from native lignin as well as low molecular weight compounds. Organosolv lignins have polydispersity around $\sim 2.1$. The polydispersity values of light fractions $(2,5,8,11)$ are much smaller than the corresponding heavy fractions $(1,4,7,10)$. The $\mathrm{M}_{\mathrm{w}} \mathrm{D}$ of all lignins (VWD response) are presented in Section C.5 of Appendix C

The MWL lignin has the highest abundance of $\beta$-O-4 linkages namely 34.5 per 100 aromatic units. This value is close to the values typically reported for the softwood

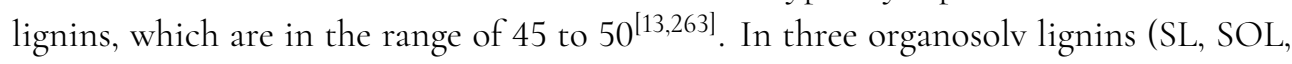
WSL), the abundance of $\beta$-O-4 linkage is in the range from 1.8 to 8.6 per 100 aromatic units. Expectedly, in pyrolytic lignin (10) no traces of $\beta$-O-4 linkages were observed, which is in line with the literature $\frac{126}{10}$. 
In summary, these lignins have the same aromaticity as indicated by their equal $\mathrm{H} / \mathrm{C}$ ratio $(\sim 1.1)$, despite originating from three different isolation processes and differ uniquely in their molecular weights (588 Da to $3596 \mathrm{Da},<\mathrm{M}_{\mathrm{w}}>$ ). Only MWL stands out for having the highest amount of $\beta-\mathrm{O}-4$ linkages, while pyrolytic lignin represents the other end of that spectrum, i.e. no $\beta-\mathrm{O}-4$ linkages. This set of lignins is envisaged to be a powerful tool to test the validity of the hypothesis discussed in the introduction with respect to the influence of the molecular weight (distribution) on the pyrolysis process. 


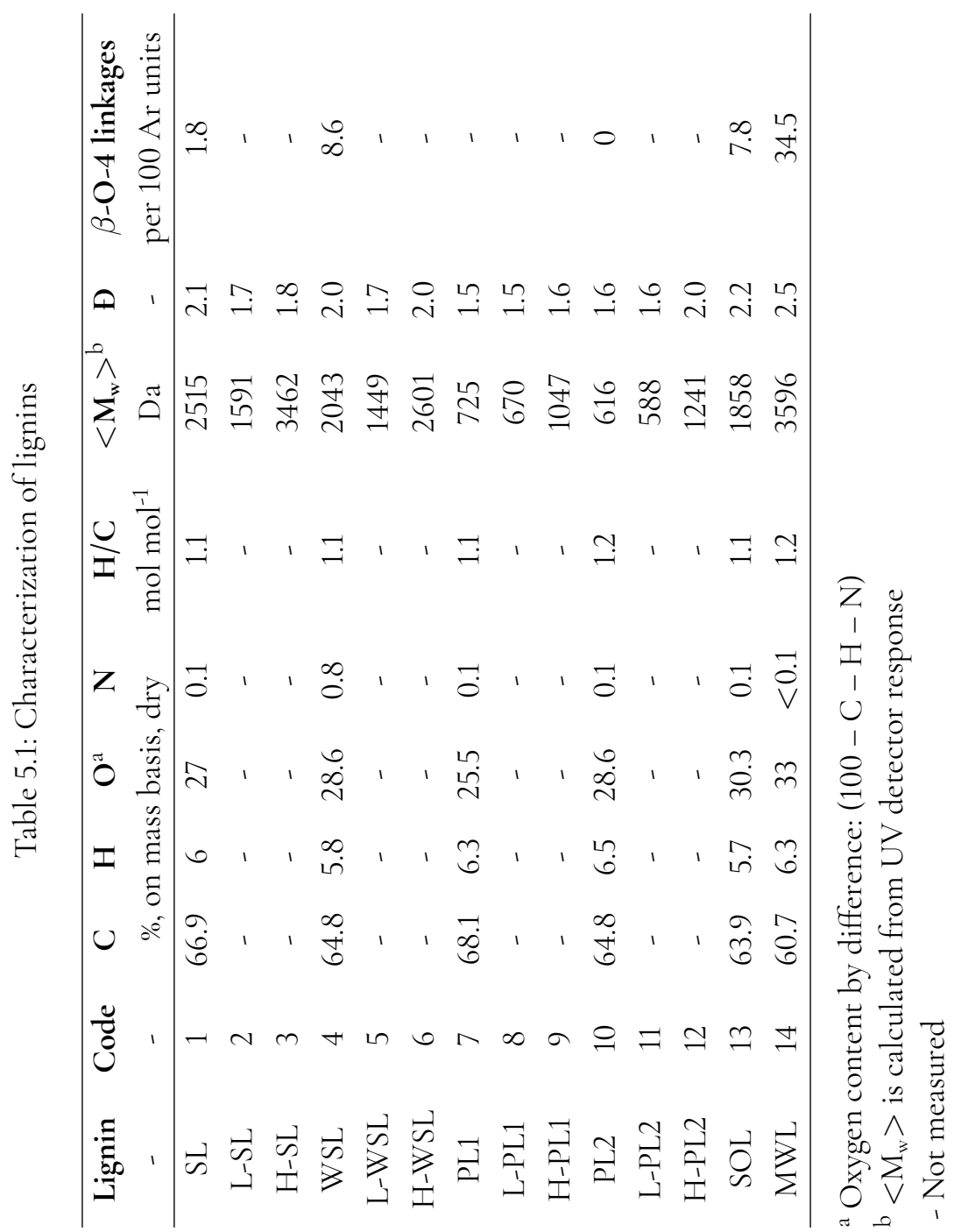




\subsection{Modelling}

The model consists of population balances for the reacting lignin and the produced oil. In Figure 5.1 the model is schematically presented. The population balances are made over segments called $D P_{i}$ where $i$ refers to the number of monomer units out of which the lignin molecules in a segment $D P_{i}$ are build-up. In a segment $D P_{i}$ the lignin molecules are identical linear polymers. The molecular weight of a monomeric unit is set to $200 \mathrm{Da}$ corresponding to the molecular weight of a typical building block alcohol of lignin, i.e. sinapyl alcohol (210 Da).

The following processes are considered for each segment of reacting lignin: cracking reactions, polymerisation reactions and removal (transport) from the reaction zone of unreacted lignin and reaction products. It is assumed that this is the minimal set of reactions and mass transport needed for predicting yields of oil and char and the molecular weight distribution of oil. For these processes experimental proofs are available. Cracking reactions are evident from the yield of lower $D P_{i}$ fractions in the oil as compared to their presence in the feedstock (see Figure C.1A and C.1B. Washing the char with tetrahydrofuran showed a liquid fraction that contained larger molecules than present in the feed (see Figure C.16), hence polymerisation reactions must have taken place. Reactions in the vapour phase outside the particle are excluded by the low hot vapour residence time $(\sim 20 \mathrm{~ms})$. It could be that vapours react while still in/on the hot sample. Therefore, cracking and polymerisation reactions used in the model must be considered as a lumped description of these reactions in the liquid/vapour/solid state of the hot reacting sample. Transport of molecules from the reaction zone is obvious as oil was collected at the cold vessel wall. It is assumed, based on experimental verification ${ }^{120}$, that there are no reactions in the vapour phase and in the oil phase which is condensed on the cold vessel wall. Consequently, for the oil product, only the transport of molecules from the reacting lignin sample is considered. Cracking and mass transport were also included in the population balance model of Solomon et al. ${ }^{[15]}$, though the mass transport was described differently.

The $D P_{i}$ grid ranges from $i=1$ to $i=2 i_{\max }$ with $i_{\max }$ being 50 in the standard simulations $\left(D P_{\max }=10000 \mathrm{Da}\right)$. In the model, the bins between $D P_{\max +1}$ to $2 D P_{\max }$ represent char. The characteristics of the molecules in the char bins are -1$)$ they do not react and 2) they cannot leave the hot reacting lignin. Without these assumptions i.e. without char bins, zero char production is predicted by the model. Summarizing, char is set to be equivalent to the $>D P_{50}$ molecules in the calculation domain. This is a rather a blunt assumption, however, it can be argued that molecules with $D P_{>25}$ will eventually react to char due to their very low likelihood of leaving the reaction zone, 


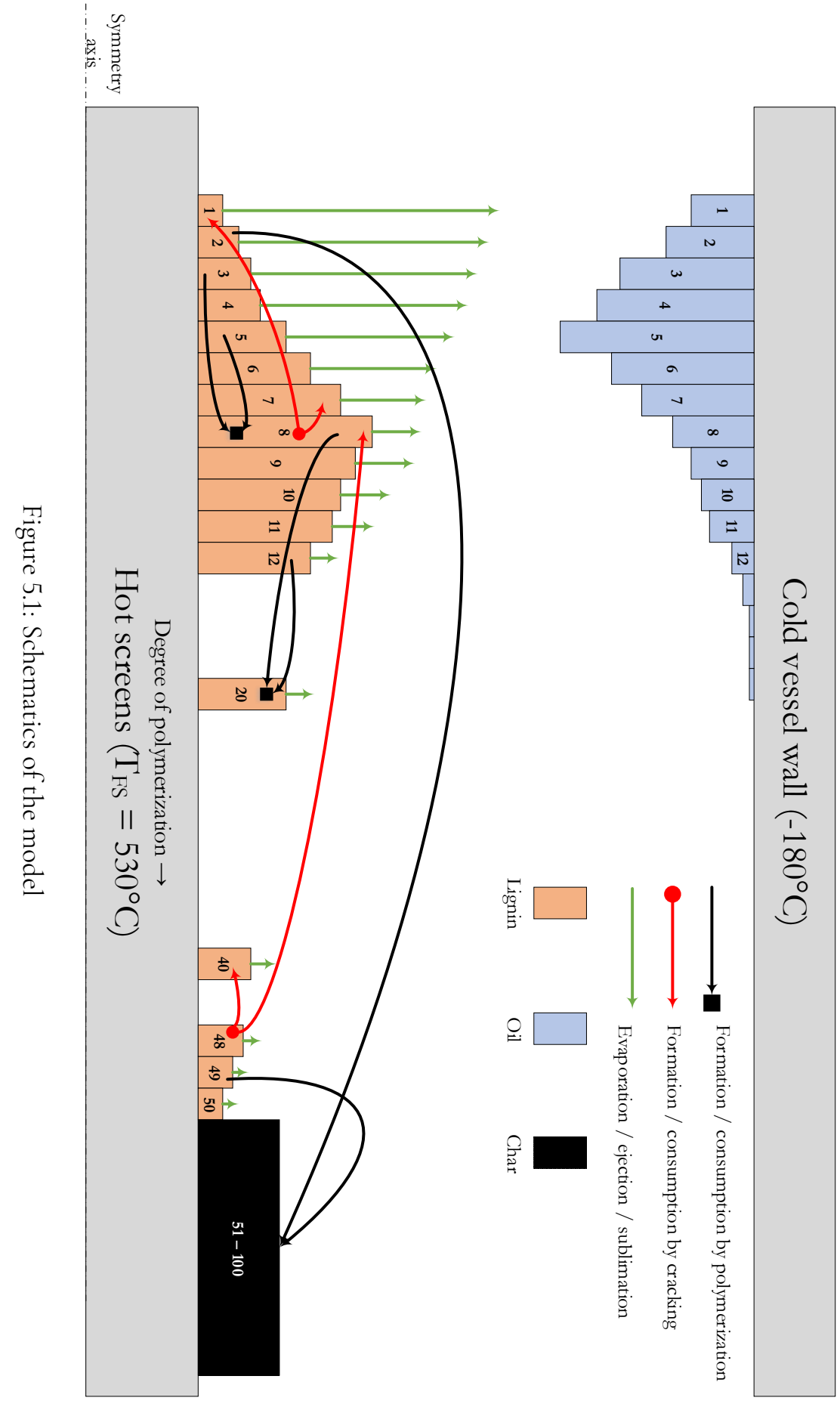


especially for $100 \mathrm{kPa}$ experiments. It should be noted that the molecules in the char bins $\left(D P_{\max +1}\right.$ to $\left.2 D P_{\max }\right)$ have same structure as that of molecules present in the reacting lignin $\left(D P_{i}\right.$ to $\left.D P_{\max }\right)$. The cross-linking reactions of the molecules are not included in the model.

\section{Mole balance:}

The mole balances for the segment $D P_{i}$ of the reacting lignin $\left(C_{i}^{L}\right)$ and oil $\left(C_{i}^{O}\right)$ are given by Eq. 5.1 and Eq. 5.2

$$
\begin{gathered}
\frac{d C_{i}^{L}}{d t}=-E_{i}+K_{i}+P_{i} \\
\frac{d C_{i}^{O}}{d t}=E_{i}
\end{gathered}
$$

Where, $E_{i}$ is the rate of transport of $D P_{i}$ from the reacting lignin to oil, $K_{i}$ is the net rate at which different $D P_{i}$ are formed during cracking reactions, and $P_{i}$ is the net rate at which different $D P_{i}$ are formed during polymerisation reactions. The mathematical description of these three processes will be discussed in following paragraphs.

\section{Transport from the reaction zone:}

It is assumed that a single first order equation can describe these processes:

$$
\begin{gathered}
E_{i}=k_{T, i} C_{i}^{L} \\
k_{T, i}=e^{-A i}+B
\end{gathered}
$$

The exponential term describes the evaporation and/or sublimation rate which is, as the molecular weight and the pressure affect the diffusion coefficient $\frac{115] 116}{}$, higher for lighter molecules and at lower pressure. B is included to allow a fixed, $D P_{i}$ independent, ejection rate. In simulations, the value of $B$ was set to 0.02 and 0 for $0.5 \mathrm{kPa}$ and 100 $\mathrm{kPa}$ experiments, respectively. Transport away from the reaction front is expected to be faster at lower pressure. Instead of using a flux equation for the escape rate, like the film model used by Solomon $\frac{115}{}$, a purely mathematical approach is used (see Eq. 5.3 and Eq. 5.4 that does include the effects described above. This is rationalized by the expectedly very vigorous mass transport under the conditions applied, which is not captured by 
simplified models like the film model. In literature, the transport of species has been described by Darcy's law 295 or modified Clausius-Clapeyron equation 264. Formation of bubbles was observed on the reacting lignin (at $100 \mathrm{kPa}$ ), which points towards vigorous mass transport and to the generation of aerosols (see Figure C.17). For $D P_{\max +1}$ to $2 D P_{\max }$ bins, i.e. for char, the transport rate is set to zero. The green arrows in Figure 5.1 represents $D P_{i}$ dependent transport rates of molecules, highest for $D P_{1}$ and lowest for $D P_{\max }$.

\section{Cracking:}

The following first order reaction describes cracking:

$$
\begin{gathered}
D P_{i} \rightarrow D P_{j}+D P_{i-j} \quad(i>j) \wedge(i>1) \wedge(j>0) \\
R_{K, i}=k_{K} C_{i}^{L}
\end{gathered}
$$

It is assumed that only the bonds connecting the monomer units present in the $D P_{i}$ segment can be cracked. Therefore, the segment $D P_{i}$ can crack in $\frac{(i-1) !}{(i-2) !}=(i-1)$ different ways. It is also assumed that all possibilities of cracking have the same likelihood, i.e. the rate constant $k_{K}$, is the same for all cracking reactions. Under these assumptions the cracking rate $K_{i}^{c}$ of $D P_{i}$ becomes,

$$
K_{i}^{c}=(i-1) R_{K, i}=(i-1) k_{K} C_{i}^{L}
$$

$D P_{i}$ is also formed by cracking reactions. Obviously, $D P_{i}$ can only be formed from a segment $D P_{j}$ with $j>i$. The rate of formation of $D P_{i}$ by cracking is given by:

$$
K_{i}^{f}=2 \sum_{j=i+1}^{i_{\max }} k_{K} C_{j}^{L}
$$

It is set in the model that char $\left(D P_{\max +1}\right.$ to $\left.2 D P_{\max }\right)$ does not crack and therefore the sum in Eq. 58 runs until $i_{\max }$. Eq. 5.7 and Eq. 5.8 are also used by Soloman et al.115. Combing Eq. 5.7 and Eq. 5.8 gives the overall reaction rate of $D P_{i}$ due to cracking: 


$$
\begin{aligned}
K_{i} & =K_{i}^{f}-K_{i}^{c} \\
& =\left\{2 \sum_{j=i+1}^{i_{\max }} k_{K} C_{j}^{L}\right\}-(i-1) k_{K} C_{i}^{L} \\
& =\left\{2 \sum_{j=i+1}^{i_{\max }}\left(\frac{1}{j-1} K_{j}^{c}\right)\right\}-K_{i}^{c}
\end{aligned}
$$

For example, $D P_{1}$ and $D P_{7}$ are formed by consumption of $D P_{8}$ in a cracking reaction, see Figure 5.1

\section{Polymerisation:}

The following second order reaction describes polymerisation:

$$
\begin{gathered}
D P_{j}+D P_{i-j} \rightarrow D P_{i} \quad(i>j) \wedge(i>1) \wedge(j>0) \\
R_{P, i}=k_{P} C_{j}^{L} C_{i-j}^{L}
\end{gathered}
$$

It is assumed that all molecules in segments between $D P_{1}$ to $D P_{\text {max }}$ will polymerize with each other, in all possible combinations, to form polymerisation products which are not bigger than $2 D P_{\max }$. As previously mentioned, the $D P_{\max +1}$ to $2 D P_{\max }$ segments do not take part in polymerisation reactions but will be formed as a product, which represents char. Like in case of cracking, all polymerisation possibilities have the same likelihood i.e. the reaction rate constant, $k_{P}$, is the same for all polymerisation reactions. Thus, the rate of consumption of $D P_{i}$ in polymerisation reactions can be written as follows.

$$
P_{i}^{c}=\left\{\sum_{j=1}^{i_{\max }} k_{P} C_{i}^{L} C_{j}^{L}\right\}+k_{P} C_{i}^{L} C_{j=i}^{L} \quad 1 \leq i \leq i_{\max }
$$

For example, $D P_{3}$ and $D P_{5}$ are consumed in a polymerisation reaction to form $D P_{8}$, see Figure 5.1 Also, $D P_{i}$ will be formed by polymerisation, e.g. $D P_{20}$ is formed as a result of polymerisation reaction between $D P_{8}$ to $D P_{12}$ (Figure 5.1). The rate at which $D P_{i}$ is formed by polymerisation is described by the following equation, in which $k_{P} C_{j}^{L} C_{i-j}^{L}=0$ for all combinations with $(i-j)>D P_{\max }$, i.e. products larger than 
$2 D P_{\max }$ cannot be formed.

$$
P_{i}^{f}= \begin{cases}\sum_{j=1}^{\frac{i-1}{2}} k_{P} C_{j}^{L} C_{i-j}^{L} & \text { if } i \in(2 \mathbb{Z}+1) \wedge \mathbb{Z} \geq 1 \wedge 3 \leq i \leq\left(2 i_{\text {max }}-1\right) ; \\ \sum_{j=1}^{\frac{i}{2}} k_{P} C_{j}^{L} C_{i-j}^{L} & \text { if } i \in 2 \mathbb{Z} \wedge 2 \leq i \leq 2 i_{\text {max }}\end{cases}
$$

The net reaction rate of $D P_{i}$ by polymerisation is given by combining Eq. 5.12 and Eq. 5.13

$$
P_{i}=P_{i}^{f}-P_{i}^{c}
$$

\section{Discretization of GPC chromatogram:}

The way in which $\mathrm{M}_{\mathrm{w}} \mathrm{D}$ of lignin or pyrolysis oil, in terms of $w(\log M)$, is calculated has been described elsewhere 265 .

$$
m(M)_{q}=\frac{w(\log M)}{\ln 10}
$$

Mass corresponding to each molecular weight slice $(q)$ between $1 \mathrm{Da}$ and $10000 \mathrm{Da}$ is calculated and then subsequently discretised into 50 segments of $200 \mathrm{Da}$. The mass fraction of $D P_{i}$ is calculated,

$$
w_{i}=\frac{m_{i}}{\sum_{i=1}^{50} m_{i}}
$$

Note, the $\mathrm{M}_{\mathrm{w}} \mathrm{Ds}$, in terms of mass fractions $\left(w_{i}\right)$, of all lignins and experimentally obtained pyrolysis oils presented in this work (Figure 5.2A Figure $5.2 \mathrm{~B}$ and Figure C.2 to C.15 are calculated by using this procedure. These discretised mass fractions of each $D P_{i}$ segments were converted to corresponding mole fractions by Eq. 5.17 


$$
\omega_{i}=\frac{\frac{w_{i}}{M_{w, D P_{i}}}}{\sum_{i=1}^{50} \frac{w_{i}}{M_{w, D P_{i}}}}
$$

\section{Initial conditions:}

The mole fraction of each $D P_{i}$ is used to calculate the molar concentrations of the $D P_{i}$ 's in the lignin feedstock.

$$
C_{i, \text { feed }}^{L}=\frac{\omega_{i}^{L} N_{\text {total }}}{V_{L}}=\frac{\omega_{i}^{L} \frac{m_{L}}{<M_{n}^{L}>}}{V_{L}}
$$

The molar concentration distribution of the lignin is the initial condition for $C_{i}^{L}$ with $1 \leq i \leq i_{\max }$.

$$
C_{i, t=0}^{L}=C_{i, f e e d}^{L} \quad 1 \leq i \leq i_{\max }
$$

For the char bins, i.e. the segments between $D P_{\max +1}$ to $2 D P_{\max }$

$$
C_{i, t=0}^{L}=0 \quad\left(i_{\max }+1\right) \leq i \leq 2 i_{\max }
$$

Note, the $\mathrm{M}_{\mathrm{w}} \mathrm{D}$ of a lignin sample obtained from the GPC depends on -1) packing material of the column, 2) geometry of column, 3) eluent and its flow rate, and 4) detector type 265-267. At $t=0$ the concentration of each $D P_{i}$ in the oil is zero:

$$
C_{i, t=0}^{O}=0 \quad 1 \leq i \leq i_{\max }
$$

\section{Numerical method:}

The model equations were solved in the coding environment of Matlab ${ }^{\circledR 2017 a}$. The numerical integration was carried out with the built-in ode23tb solver which is especially suited for stiff systems and is based on the trapezoidal rule with a second order backward difference approximation. 


\section{Characteristics of the model:}

The model has two important characteristics:

1. The predictions of $C_{i}^{L}$ and $C_{i}^{O}$ at $t=\infty$ are invariant to the multiplication of the constants $k_{T, i}, k_{P}$ and $k_{K}$ with the same factor (for details see Section C.6.2 in Appendix C.

2. Changing the computational grid by changing the starting point of the char bins (remaining the final grid points) does not influence the predictions after fitting $\frac{k_{T, a v g}}{k_{P}}$ and $\frac{k_{K}}{k_{P}}$ as long as the starting $D P_{i}$ of the char bins corresponds with a mass fraction of zero of that $D P_{i}$ in the lignin feed (for details see Section C.6.2 in Appendix C.

\section{Post-processing:}

The mass fraction and mole fraction of the $D P_{i}$ segments in the oil are given by:

$$
\begin{gathered}
w_{i, c a l, t=\infty}^{O}=\frac{C_{i, t=\infty}^{O} M_{w, D P_{i}}}{\sum_{i=1}^{i_{\max }} C_{i, t=\infty}^{O} M_{w, D P_{i}}} \\
\omega_{i, c a l, t=\infty}^{O}=\frac{\frac{w_{i, c a l, t=\infty}^{O}}{M_{w, D P_{i}}}}{\sum_{i=1}^{i_{\max }} \frac{w_{i, c a l, t=\infty}^{O}}{M_{w, D P_{i}}}}
\end{gathered}
$$

The $<\mathrm{M}_{\mathrm{w}}>$ and $<\mathrm{M}_{\mathrm{n}}>$ of the oil is calculated as follows:

$$
\begin{aligned}
& <M_{w, t=\infty}>=\sum_{i=1}^{i_{\max }} w_{i, c a l, t=\infty}^{O} M_{w, D P_{i}} \\
& <M_{n, t=\infty}>=\sum_{i=1}^{i_{\max }} \omega_{i, c a l, t=\infty}^{O} M_{w, D P_{i}}
\end{aligned}
$$

The oil and char yields are calculated with the following equations: 


$$
\begin{gathered}
Y_{\text {Char }, \text { cal }, t=\infty}=\frac{\sum_{i=i_{\max }+1}^{2 i_{\max }} C_{i, t=\infty}^{L} M_{w, D P_{i}}}{\sum_{i=1}^{i_{\max }} C_{i, t=\infty}^{O} M_{w, D P_{i}}+\sum_{i=i_{\max }+1}^{2 i_{\max }} C_{i, t=\infty}^{L} M_{w, D P_{i}}} \\
Y_{\text {Oil }, \text { cal }, t=\infty}=1-Y_{\text {Char }, \text { cal }, t=\infty}
\end{gathered}
$$

\section{Parameter estimation:}

$$
f_{i}=\sum\left\{\left(w_{i, \exp }^{O}-w_{i, c a l, t=\infty}^{O}\right)^{2}+\left(Y_{\text {Char }, \exp }-Y_{\text {Char }, \text { cal }, t=\infty}\right)^{2}\right\}
$$

As mentioned before, the predictions of $C_{i}^{L}$ and $C_{i}^{O}$ at $t=\infty$ are invariant to multiplication the constants $k_{T, i}, k_{P}$ and $k_{K}$ with the same factor. This in combination with the fact that the experimental method does not allow the determination of the temporal evolution of oil and char yield, instead final yields $(t=\infty)$ are obtained, leads to the restriction that it is not possible to determine all three constants by fitting them to the experimental results. In fact, it is only possible to determine the ratio of the constants, here expressed as $\frac{k_{T, a v g}}{k_{P}}$ and $\frac{k_{K}}{k_{P}}$.

For each lignin, the experimental results were fitted to the model using $\frac{k_{T, a v g}}{k_{P}}$ and $\frac{k_{K}}{k_{P}}$ as parameters. This is called the individual fit procedure. The objective function for this Eq. 5.25 is comprised of -1) the sum of squared difference between the $M_{w} D$ of experimentally obtained oil and calculated, and 2) the squared difference between the experimentally obtained and calculated char yield. Note, as mentioned in Section 5.4.1. some of the volatile products (potential oil) could not be recovered, and therefore, the char yield is used in the minimization routine since it was measured more accurately compared to oil yield. Parameters estimation is carried out with the Matlab in-built optimisation function 1sqnonlin. 95\% confidence intervals for each parameter were determined by the built-in Matlab function nlparci.

$$
g=\sum_{j=1}^{n} f_{j}
$$


In order to estimate a single set of values of $\frac{k_{T, a v g}}{k_{P}}$ and $\frac{k_{K}}{k_{P}}$ per pressure, describing pyrolysis of all lignins studied in this work, the objective function shown in Eq. 5.26 is used, where $n$ represents the number of lignins. This is what is called the total fit procedure. 


\subsection{Experimental results}

\subsubsection{Mass balance closures}

The mass balance closure for individual pyrolysis experiments carried out at 0.5 $\mathrm{kPa}$ was between $0.87 \mathrm{~kg} \mathrm{~kg}^{-1}$ and $0.97 \mathrm{~kg} \mathrm{~kg}^{-1}$, while for $100 \mathrm{kPa}$ experiments a slight decrease in mass closure $\left(0.8 \mathrm{~kg} \mathrm{~kg}^{-1}-0.88 \mathrm{~kg} \mathrm{~kg}^{-1}\right)$ was observed. This decrease can be accounted for the observation that at $100 \mathrm{kPa}$ more pyrolysis products condensed on the gas sampling line, thermocouple, and pressure sensor line instead of on the wall. Light organics (e.g. formic acid, formaldehyde) and water were most likely (partly) lost during gas sampling and during the dismantling of the setup, which explains that the closure was always below $100 \%$. The number of experiments performed for each lignin, under identical conditions, were at least 3. Except, in the case of MWL only two experiments were performed at both pressures because of its limited availability. Reproducibility of the experiments was satisfactory as shown in the Table C.3 The error bars on yields (Figure 5.3A to 5.3C and Figure 5.5) and $\left\langle\mathrm{M}_{\mathrm{n}}\right\rangle$ of the oils (Figure 5.4) represent the standard deviations on the mean.

\subsubsection{Molecular weight distribution of oils at $530{ }^{\circ} \mathrm{C}$}

In Figure 5.2, the $\mathrm{M}_{\mathrm{w}} \mathrm{D}$ of two lignins (11 and 14) and their oils produced at $0.5 \mathrm{kPa}$ and $100 \mathrm{kPa}$ are plotted. Also, model predictions are shown. Because these two lignins are entirely different from each other regarding their $\left\langle\mathrm{M}_{\mathrm{w}}\right\rangle,\left\langle\mathrm{M}_{\mathrm{n}}\right\rangle, \mathrm{M}_{\mathrm{w}} \mathrm{D}$ and $\beta$-O4 linkage content, they were selected to illustrate the observed differences in pyrolysis behaviour. In the case of lignin-11, the $\mathrm{M}_{\mathrm{w}} \mathrm{D}$ of the oils nearly overlapped with the $\mathrm{M}_{\mathrm{w}} \mathrm{D}$ of the parent lignin (Figure 5.2A). On the contrary, a significant shift towards the lower molecular weight region was observed in the $\mathrm{M}_{\mathrm{w}} \mathrm{D}$ for the of lignin-14 oils as compared to the feedstock (Figure 5.2A. For lignin-14, the oil obtained at $0.5 \mathrm{kPa}$ was heavier than the oil obtained at $100 \mathrm{kPa}$.

\subsubsection{Lumped product yields at $530^{\circ} \mathrm{C}$}

In Figure $5.3 \mathrm{~A}$ to $5.3 \mathrm{C}$ oil, char and gas yields are plotted as a function of the $<\mathrm{M}_{\mathrm{n}}>$ of the lignin. At both pressures, a decrease in oil yield was observed with an increase of the $<\mathrm{M}_{\mathrm{n}}>$ of lignin. At $100 \mathrm{kPa}$ lower oil yields were achieved than at 0.5 $\mathrm{kPa}$. This difference in oil yield became wider with an increase in $\left\langle\mathrm{M}_{\mathrm{n}}\right\rangle$ of the lignins. At both pressures, the oil yields obtained for the light fractions $(2,5,11)$ were higher than the yields achieved for their parent lignins $(1,4,10)$ and their respective heavy fractions $(3,6,12)$. For low $<\mathrm{M}_{\mathrm{n}}>$ lignins $(<500 \mathrm{Da})$, high oil yields of up to $0.96 \mathrm{~kg} \mathrm{~kg}^{-1}$ were 


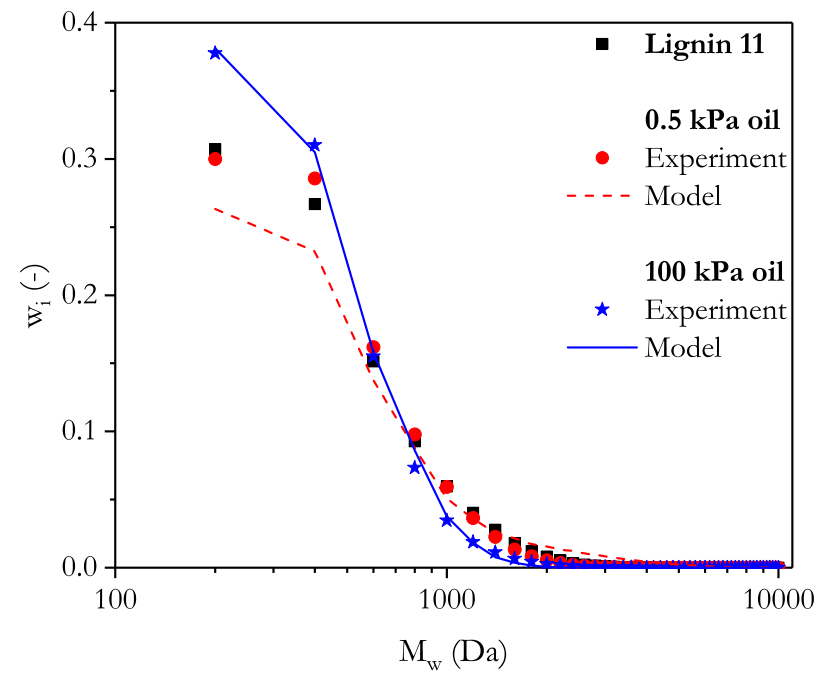

Figure 5.2A: $\mathrm{M}_{\mathrm{w}} \mathrm{D}$ of lignin 11 and its oils

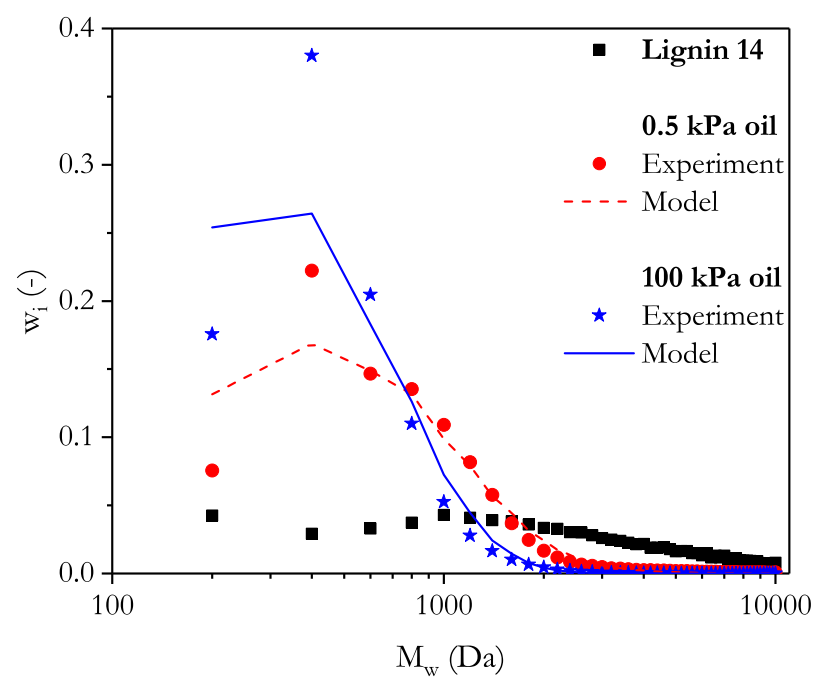

Figure 5.2B: $\mathrm{M}_{\mathrm{w}} \mathrm{D}$ of lignin 14 and its oils 
achieved at $0.5 \mathrm{kPa}$ and decreased to $0.78 \mathrm{~kg} \mathrm{~kg}^{-1}$ at $100 \mathrm{kPa}$. In the case of high $<\mathrm{M}_{\mathrm{n}}>$ lignins (>500 Da), a significant drop in oil yield was observed $\left(0.32 \mathrm{~kg} \mathrm{~kg}^{-1}\right)$ at $100 \mathrm{kPa}$ compared to the $0.5 \mathrm{kPa}$ experiments. In the literature, oil yields of $\sim 0.12 \mathrm{~kg} \mathrm{~kg}^{-1}$ (at $100 \mathrm{kPa}) \stackrel{268}{26}$ and $\sim 0.8 \mathrm{~kg} \mathrm{~kg}^{-1}(\sim 0.5 \mathrm{kPa}) \stackrel{87 / 225242}{ }$ in screen-heater reactors, $\sim 0.55 \mathrm{~kg}$ $\mathrm{kg}^{-1}$ in a tubular reactor 236 , and $\sim 0.40 \mathrm{~kg} \mathrm{~kg}^{-1}$ in a fluidised bed reactor 241244 were reported.

Also at both pressures, the char yield increased with the increase in $\left\langle M_{n}\right\rangle$ of the lignins. For low molecular weight lignins $(<500 \mathrm{Da})$, the char yields were below 0.1 $\mathrm{kg} \mathrm{kg}^{-1}$, while the difference between the char yields obtained at $0.5 \mathrm{kPa}$ and $100 \mathrm{kPa}$ was small. In the case of lignins heavier than $500 \mathrm{Da}$, char yields increased significantly especially for experiments performed at $100 \mathrm{kPa}$. At both pressures, the char yields obtained for the light fractions $(2,5,11)$ were lower than the yields achieved for their parent lignins $(1,4,10)$ and their respective heavy fractions $(3,6,12)$. In the literature, char yields of $\sim 0.75 \mathrm{~kg} \mathrm{~kg}^{-1}$ in TGA $241\left[247269 \mid 270, \sim 0.45 \mathrm{~kg} \mathrm{~kg}^{-1}\right.$ (at $100 \mathrm{kPa}$ ) $\stackrel{268}{26}$ and $\sim 0.12$ $\mathrm{kg} \mathrm{kg}^{-1}(\sim 0.5 \mathrm{kPa})^{225242}$ in screen-heater reactors, $0.22 \mathrm{~kg} \mathrm{~kg}^{-1}(0.5 \mathrm{kPa})$ to $0.35 \mathrm{~kg} \mathrm{~kg}^{-1}$ $(100 \mathrm{kPa})$ in a modified pyroprobe reactor ${ }^{75}, \sim 0.35 \mathrm{~kg} \mathrm{~kg}^{-1}$ in a tubular reactor 236 , and $\sim 0.35 \mathrm{~kg} \mathrm{~kg}^{-1}$ in a fluidised bed reactor 241244 were reported.

Only a small amount of gases $\left(\sim 0.025 \mathrm{~kg} \mathrm{~kg}^{-1}\right)$ were produced for all lignins during pyrolysis at $0.5 \mathrm{kPa}$. A marginal increase, if at all, in gas yield was observed at $100 \mathrm{kPa}$. Gases produced during pyrolysis were mainly $\mathrm{CO}_{2}$ and $\mathrm{CH}_{4}$, while $\mathrm{CO}$ was only present in trace quantities. In literature, at $\sim 530^{\circ} \mathrm{C}$ similar gas yields were obtained by Iatridis et al. 268 and Zhou et al. 242 in screen-heater reactors and by Lou et al. 236 in a tubular reactor . Contrary, gas yields up to $\sim 0.25 \mathrm{~kg} \mathrm{~kg}^{-1}$ and $\sim 0.30 \mathrm{~kg} \mathrm{~kg}^{-1}$ were reported in micro-pyrolysers $240 \mid 271$ and TGA 272 , respectively.

\subsubsection{The average molecular weight of oils at $530{ }^{\circ} \mathrm{C}$}

Figure 5.4 shows the $<M_{n}>$ of the oils as a function of the $<M_{n}>$ of the lignins. At both pressures, the oils obtained from pyrolysis of low $<\mathrm{M}_{\mathrm{n}}>$ lignins ( $<500 \mathrm{Da}$ ) showed no significant reduction in $\left\langle\mathrm{M}_{\mathrm{n}}\right\rangle$ as compared to their parent lignins (data close to parity line). From $\sim 500 \mathrm{Da}$ and above, the oils seemed to have a constant $\left\langle\mathrm{M}_{\mathrm{n}}\right\rangle$ which was independent of the $\left\langle\mathrm{M}_{\mathrm{n}}\right\rangle$ of the lignin. This trend was most clearly observed at $100 \mathrm{kPa}$. At $0.5 \mathrm{kPa}$, larger deviations in molecular weights of oils were observed, which might be explained by the random ejection of molecules from the reacting lignin. It is worth noticing that the yields and the $<\mathrm{M}_{\mathrm{n}}>$ of the oils obtained from lignin 14 (richest in $\beta$-O-4 linkages) do not deviate from the trend as observed for other lignins. 


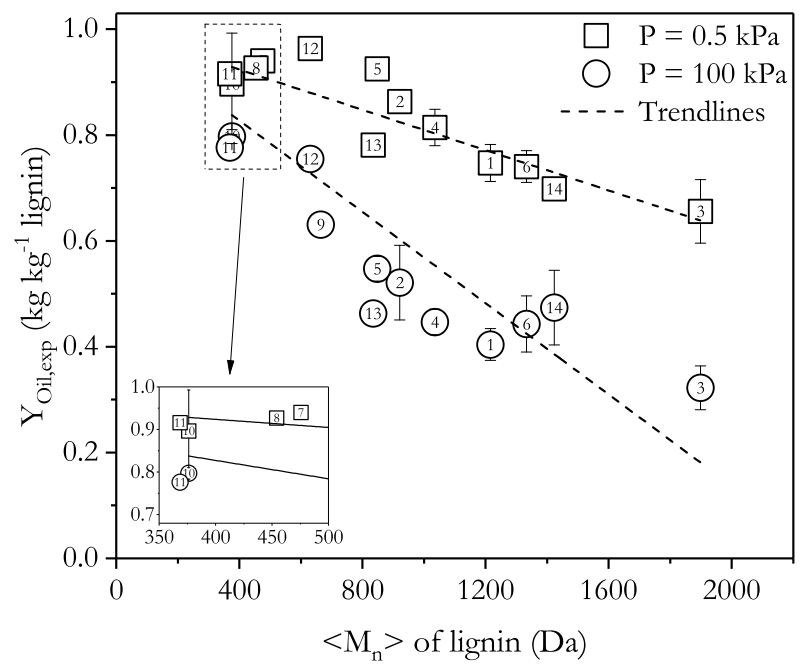

Figure 5.3A: Oil yield as a function of $<M_{n}>$ of the lignins. The numbers in the symbols refer to the lignins listed in Table 5.1

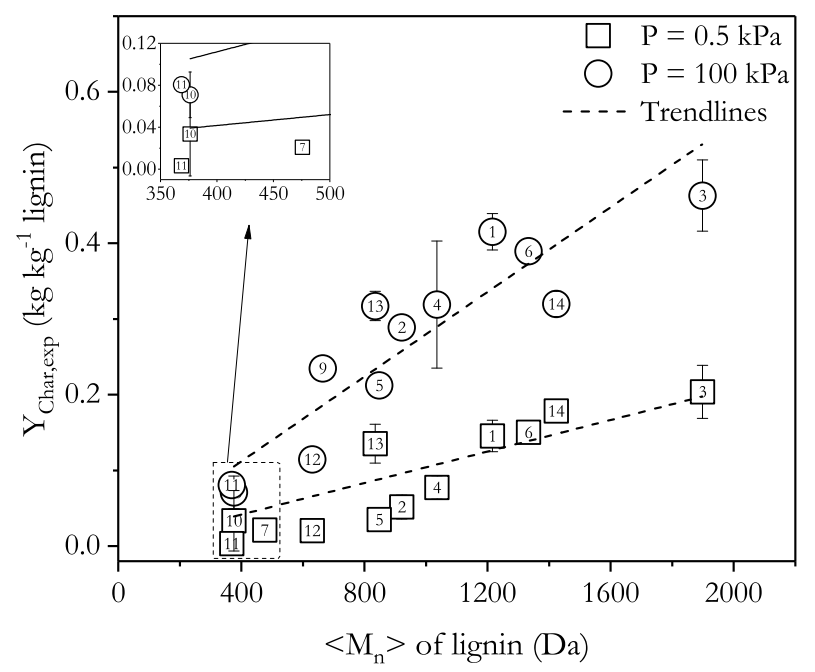

Figure 5.3B: Char yield as a function of $\left\langle\mathrm{M}_{\mathrm{n}}>\right.$ of the lignins. The numbers in the symbols refer to the lignins listed in Table 5.1 


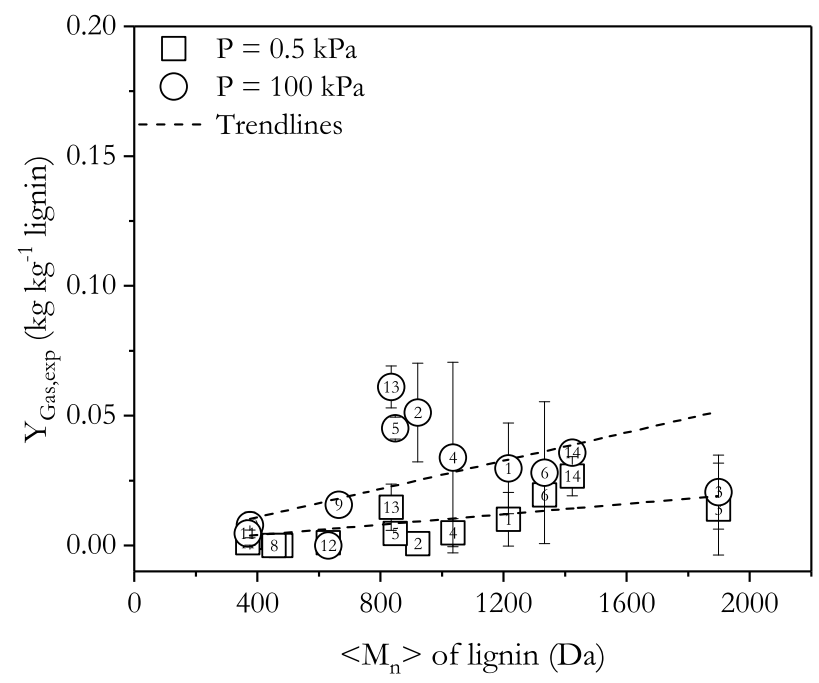

Figure 5.3C: Gas yield as a function of $<\mathrm{M}_{\mathrm{n}}>$ of the lignins. The numbers in the symbols refer to the lignins listed in Table 5.1

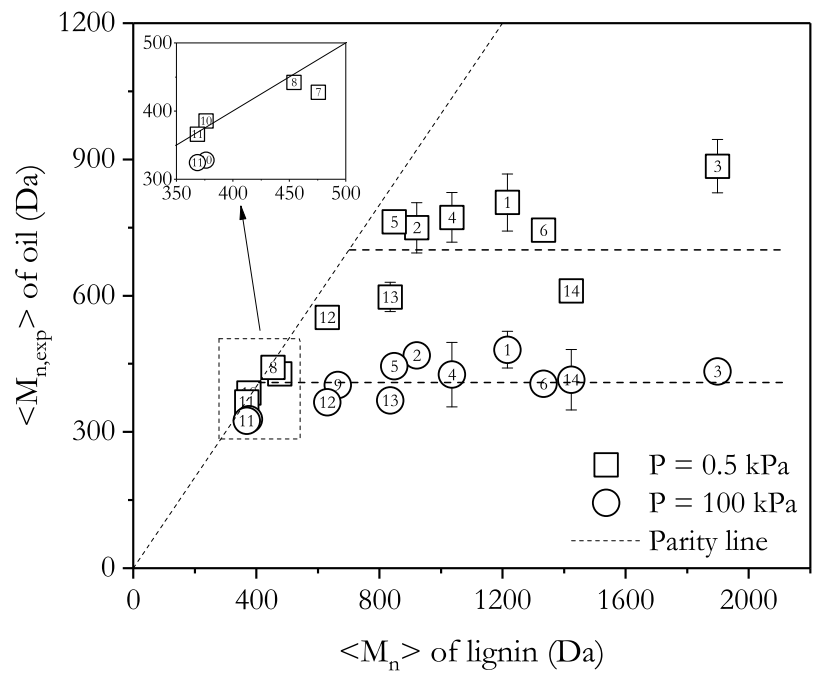

Figure 5.4: Experimentally obtained $<\mathrm{M}_{\mathrm{n}}>$ of oils obtained at $0.5 \mathrm{kPa}$ and $100 \mathrm{kPa}$ as a function of the $<\mathrm{M}_{\mathrm{n}}>$ of the lignins 


\section{Effect of temperature}

Figure 5.5 shows the oil, char and gas yields obtained from the pyrolysis of lignin13 versus the final screen temperature $\left(\mathrm{T}_{\mathrm{FS}}\right)$, at two different pressures. The experiments were carried out in a temperature range between $425^{\circ} \mathrm{C}$ and $793^{\circ} \mathrm{C}$. Figure 5.5 shows that char yield decreased with an increase in $\mathrm{T}_{\mathrm{FS}}$, at both pressures. It can be seen that at $0.5 \mathrm{kPa}$, the maximal amount of gases were produced above the $\mathrm{T}_{\mathrm{FS}}$ of $530{ }^{\circ} \mathrm{C}$ and their yield remained independent of $\mathrm{T}_{\mathrm{FS}}$ after that. At $100 \mathrm{kPa}$, the gas yield was below $0.06 \mathrm{~kg} \mathrm{~kg}^{-1}$ until $530{ }^{\circ} \mathrm{C}$ and thereafter it increased significantly to $0.17 \mathrm{~kg} \mathrm{~kg}^{-1}$ (at 793 $\left.{ }^{\circ} \mathrm{C}\right)$. It can be seen that at $0.5 \mathrm{kPa}, 0.62 \mathrm{~kg} \mathrm{~kg}^{-1}$ of oil yield was achieved at $425^{\circ} \mathrm{C}$ and above $530{ }^{\circ} \mathrm{C}$ it became constant at a value of $\sim 0.8 \mathrm{~kg} \mathrm{~kg}^{-1}$. At $100 \mathrm{kPa}$, the oil yield was independent of $\mathrm{T}_{\mathrm{FS}}$, i.e. it remained constant at $0.46 \mathrm{~kg} \mathrm{~kg}^{-1}-0.49 \mathrm{~kg} \mathrm{~kg}^{-1}$. Similarly, Lou et al. $\stackrel{273}{273}$ observed a constant yield of oil $\left(\sim 0.5 \mathrm{~kg} \mathrm{~kg}^{-1}\right)$ in a wide temperature range. The effect of $T_{F S}$ on the $<M_{n}>$ of oils collected from the pyrolysis of lignin 13 is presented in Figure 5.6, showing independence at $100 \mathrm{kPa}$ and a slight increase with increasing $\mathrm{T}_{\mathrm{FS}}$ at $0.5 \mathrm{kPa}$. A similar trend was observed for pyrolysis of kraft lignin by Ben et al. 274 at $100 \mathrm{kPa}$. 


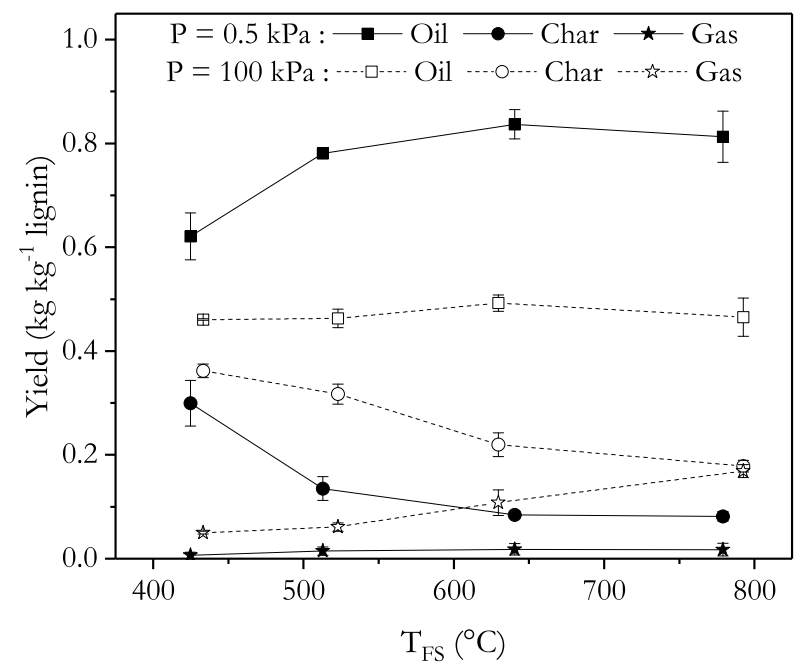

Figure 5.5: Oil, char, and gas yields as a function of the final mesh temperature $\left(\mathrm{T}_{\mathrm{FS}}\right)$ obtained for lignin 13

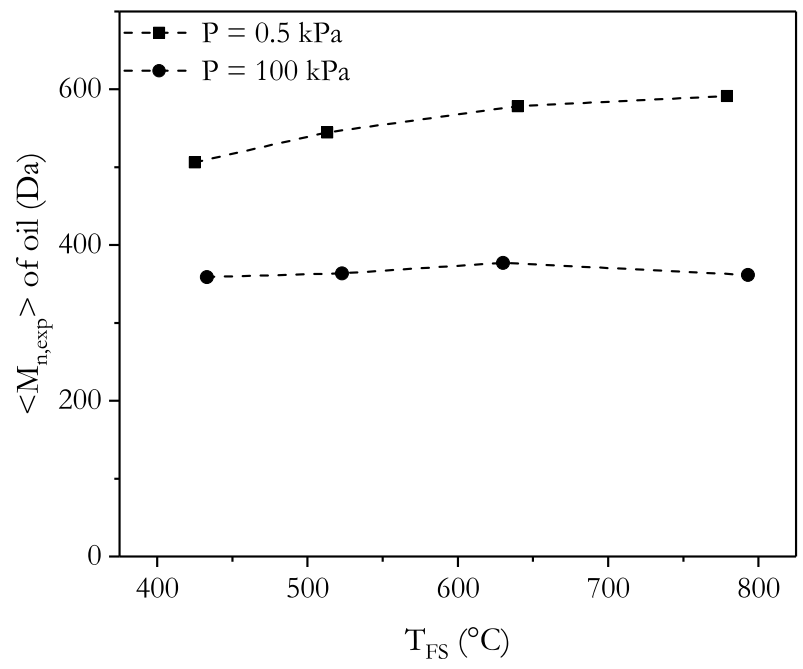

Figure 5.6: $\left\langle\mathrm{M}_{\mathrm{n}}>\right.$ of oil obtained from lignin 13 as a function of $\mathrm{T}_{\mathrm{FS}}$ at $0.5 \mathrm{kPa}$ and 100 $\mathrm{kPa}$ 


\subsection{Discussion}

\subsubsection{Chemical reactions and mass transport}

As mentioned in the introduction, we hypothesize that, like for cellulose (Chapter 4), lignin pyrolysis cannot be described solely by chemical reactions. Instead, there is an interplay of chemistry and mass transport. As previously mentioned, the fact that the oil is collected indicates that mass transport of compounds away from the reaction front is taking place. Due to the influence of pressure on the escape rate - the higher rate at lower pressure - heavier oils are expected at lower pressure. This behaviour was observed in the lignin pyrolysis experiments - lighter oils were collected at $100 \mathrm{kPa}(\sim 400 \mathrm{Da})$ than at $0.5 \mathrm{kPa}(\sim 800 \mathrm{Da})$, see Figure 5.4 At both pressures, the oil yields measured for the low $<\mathrm{M}_{\mathrm{n}}>$ lignins $(<500 \mathrm{Da})$ were high (Figure 5.3A), and no significant change in their $<\mathrm{M}_{\mathrm{n}}>$ was observed compared to the $<\mathrm{M}_{\mathrm{n}}>$ of the parent lignins (Figure 5.4). This indicates that these low $<\mathrm{M}_{\mathrm{n}}>$ lignins are mainly evaporating/sublimating/ejecting while the extent of reactions, in particular, cracking reactions, is limited. On the contrary, for high $<\mathrm{M}_{\mathrm{n}}>$ lignins, the obtained oil yields were (much) higher than the mass fraction of lights in the feed (Figure C.1A and C.1B, and a noticeable decrease in $\left\langle\mathrm{M}_{\mathrm{n}}\right\rangle$ of oils compared to the feedstock (Figure 5.4), affirms the presence of cracking reactions. Because the reactions take place on the reacting lignin (in the liquid and/or solid phase), it is not expected that the pressure influences their rates. At lower pressures, the likelihood of char production decreases (as observed experimentally, see Figure 5.3B) because of the rate of mass transport away from the reacting lignin increases leaving less time for polymerisation. More char (Figure 5.3B and less oil (Figure 5.3A) at increasing $<\mathrm{M}_{\mathrm{n}}>$ can be explained by the fact that heavier molecules have more possibilities (more reactions) to form char in combination with a lower escape rate. Heavier oils at a higher temperature (see Figure 5.6 is not expected when only considering chemical reactions, but can be explained by a higher escape rate of heavy molecules from the reacting sample at higher temperatures.

The main experimental trends can be summarised as -1) the lower the pressure, the higher (or lower) the oil (or char) yield, 2) the lower the pressure, the heavier the collected oil, 3) the heavier the lignin, the higher the char yield, 4) heavier oil at higher temperature all support that pyrolysis of lignin is influenced by the interplay of chemistry and mass transport. It is also clear that the molucalar weight distribution of the lignin is not the only parameter controlling the pyrolysis yields and oil $\mathrm{M}_{\mathrm{w}} \mathrm{D}$. For instance, lignin 5 and 13 having similar $\left\langle\mathrm{M}_{\mathrm{n}}>\right.$ but different oil and gas yields, which may arise from their structural differences. 


\subsubsection{Modelling}

Fitting each lignin individually to the model results in $\frac{k_{T, a v g}}{k_{P}}$ and $\frac{k_{K}}{k_{P}}$ values per lignin that predict the char yield very accurately (Figure 5.7A). For $100 \mathrm{kPa}$ experiments, the predicted $<\mathrm{M}_{\mathrm{n}}>$ of oils also match very well with the experimental values, while they are slightly under-predicted for $0.5 \mathrm{kPa}$ experiments Figure (5.7B). This mismatch in the predictions can be a result of the random ejection of heavier molecules which is difficult to describe. Also, the $\mathrm{M}_{\mathrm{w}} \mathrm{D}$ is predicted fairly well as can be seen in Figure $5.2 \mathrm{~A}$ and $5.2 \mathrm{~B}$ (Figure C.2 to C.15. The range of fitted $\frac{k_{T, \text { avg }}}{k_{P}}$ and $\frac{k_{K}}{k_{P}}$ are listed in Table 5.2 (individual fit), and in Table C.4 in Appendix C they are listed per lignin with their $95 \%$ confidence intervals. As expected $\frac{k_{T, a v g}}{k_{P}}$ is significantly higher at $0.5 \mathrm{kPa}$ due to the higher escape rate at lower pressure. The variation in $\frac{k_{K}}{k_{P}}$ between the pressures is small, which should be the case as this is a ratio of pressure independent reactions. As the range of the parameters is not that large for the individual fits, it has been attempted to fit a single $\frac{k_{T, a v g}}{k_{P}}$ and $\frac{k_{K}}{k_{P}}$ per pressure for all the lignins together, which is referred to as the total fit procedure (see Table 5.2 for the values). This results, on average, in a poor prediction of $\left\langle\mathrm{M}_{\mathrm{n}}>\right.$ and char yield (Figure C.22A and C.22B. However, the macro trends are still predicted.

From the individual fits, it is found that the ratio $\frac{k_{K}}{k_{P}}$ is a function of $\left\langle\mathrm{M}_{\mathrm{n}}>\right.$ of the lignins (Figure C.23) $\frac{k_{K}}{k_{P}}$ decreases with an increase in $\left\langle\mathrm{M}_{\mathrm{n}}\right\rangle$, i.e. larger $D P_{i}$ molecules present in the lignin tend to polymerise faster than described in the original model. No clear relation was observed between the values of $\frac{k_{T, a v g}}{k_{P}}$ and $\left\langle\mathrm{M}_{\mathrm{n}}>\right.$ for $0.5 \mathrm{kPa}$ experiments, while for the $100 \mathrm{kPa}$ experiments the values are independent of $<\mathrm{M}_{\mathrm{n}}>$ of lignins. The fitted $\frac{k_{K}}{k_{P}}$ as a function of $\left\langle\mathrm{M}_{\mathrm{n}}>\right.$ of the lignins together with $\frac{k_{T, \text { avg }}}{k_{P}}$ (see Table 5.2. total fit) are used as input for the model. The predicted char yields and $<\mathrm{M}_{\mathrm{n}}>$ of oils are monotonous in nature and follow the experimentally observed trend (Figure $5.7 \mathrm{C}$ and 5.7D . However, it can be seen that $\left\langle\mathrm{M}_{\mathrm{n}}>\right.$ of oils are under-predicted and char yields are over-predicted at $0.5 \mathrm{kPa}$.

After parameterisation, predicted char yields and $\left\langle\mathrm{M}_{\mathrm{n}}>\right.$ of the oils as a function of temperature match the experimentally obtained values (Figure C.24A and C.24B). It can be seen from Figure C.25A that the values of $\frac{k_{T, a v g}}{k_{P}}$ increase as a function of temperature (especially at $0.5 \mathrm{kPa}$ ) indicating a stronger increase of the mass transport rate with temperature as compared to the polymerisation rate. With the increase in temperature the values of $\frac{k_{K}}{k_{P}}$ increased, while they were similar at both pressures for a any given temperature (Figure C.25B). This indicates that the ratio of reaction rate constants $\left(\frac{k_{K}}{k_{P}}\right)$ is a function of temperature and is not affected by the pressure, as was also assumed. 
Table 5.2: The values of $\frac{k_{T, a v g}}{k_{P}}$ and $\frac{k_{K}}{k_{P}}$ at $0.5 \mathrm{kPa}$ and $100 \mathrm{kPa}$

\begin{tabular}{ccc}
\hline Fit procedure & $\begin{array}{c}\frac{k_{T, \text { avg }}}{k_{P}} \\
\text { mole } \mathrm{m}^{-3}\end{array}$ & $\begin{array}{c}\frac{k_{K}}{k_{P}} \\
\text { mole }^{-3}\end{array}$ \\
\hline Individual fit & $\mathrm{P}=0.5 \mathrm{kPa}$ & 27 to 96 \\
Total fit & 4 to 16 & $39( \pm 0.01)^{\mathrm{b}}$ \\
\hline Individual fit & $10^{\mathrm{a}}( \pm 0.6)^{\mathrm{b}}$ & 24 to 81 \\
Total fit & $\mathrm{P}=100 \mathrm{kPa}$ & $42( \pm 0.3)^{\mathrm{b}}$
\end{tabular}

${ }^{\text {a }}$ Values of $\frac{k_{T, a v g}}{k_{P}}$ used with correlation for model predictions in Figure 5.7C and 5.7D

${ }^{\mathrm{b}}$ Values in parentheses are the $95 \%$ confidence intervals on the ratios

Concluding, after parameterisation of each lignin individually the model describes the experiments very well. However, it is not able to provide good quantitative predictions for all the lignins tested based on a single set of $\frac{k_{T, a v g}}{k_{P}}$ (T and P dependent) and $\frac{k_{K}}{k_{P}}$ (T dependent). This could obviously be explained by the lignins tested being different in other aspects than the $\mathrm{M}_{\mathrm{w}} \mathrm{D}$, e.g. chemical structure. However, including a $\frac{k_{K}}{k_{P}}$ relation accounting for a relatively higher polymerisation rate for larger molecules results in a reasonable qualitative and quantitative description. The model including this relation can be used to predict yields and the $M_{w} D$ of oil based on the $M_{w} D$ of the lignin feedstock. It must, however, be noted that the measured $\mathrm{M}_{\mathrm{w}} \mathrm{D}$ of the feedstock depends on the GPC/SEC machine and method used. As a result, $\frac{k_{T, \text { avg }}}{k_{P}}$ and $\frac{k_{K}}{k_{P}}$ which are obtained by fitting will also depend on the GPC/SEC machine and method.

\subsubsection{Process considerations}

Depolymerisation of lignin is proposed for the production of fuels and platform chemicals $13|233| 238|263| 275 \mid 276$. The results obtained in this paper show that under (very) fast heating conditions and minimal chemical activity in the vapour/gas phase, pressure can steer the molecular weight of the oil. All technical lignins with $\left\langle\mathrm{M}_{n}>>800\right.$ Da result in an $\left\langle M_{n}>\right.$ of the oil that depends on the pressure, but is invariant to the $M_{w} D$ of the feedstock. At atmospheric pressure the oil is rather light, dominated by monomers to trimers, which is beneficial for the production of chemicals. Potentially, high pressure lignin pyrolysis may favour the production of monomers, however, experimental investigation is needed to gain further insights. Light oil comes, however, at the expense of 


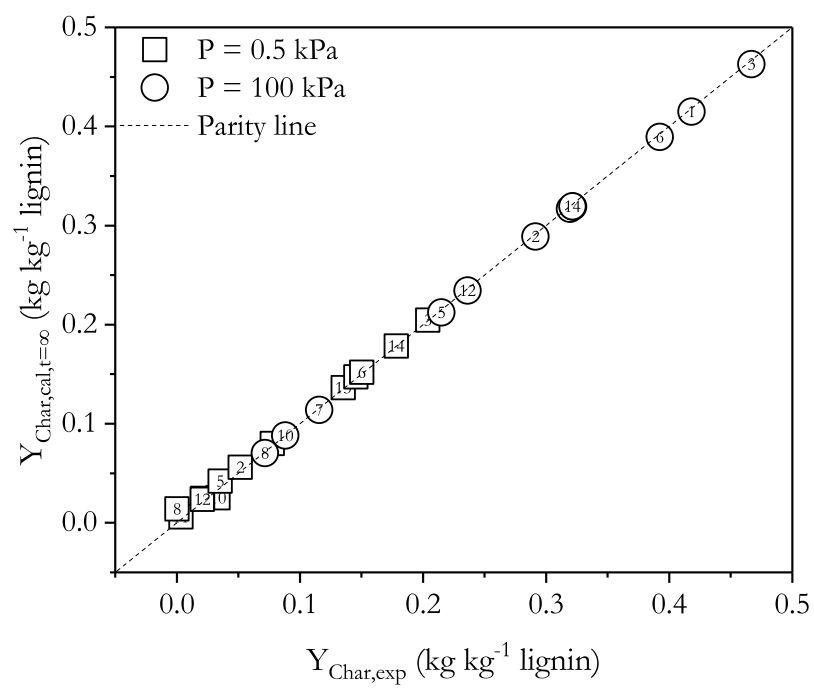

Figure 5.7A: Parity plots in which the experimental char yields are plotted against their predicted values using individual fit procedure

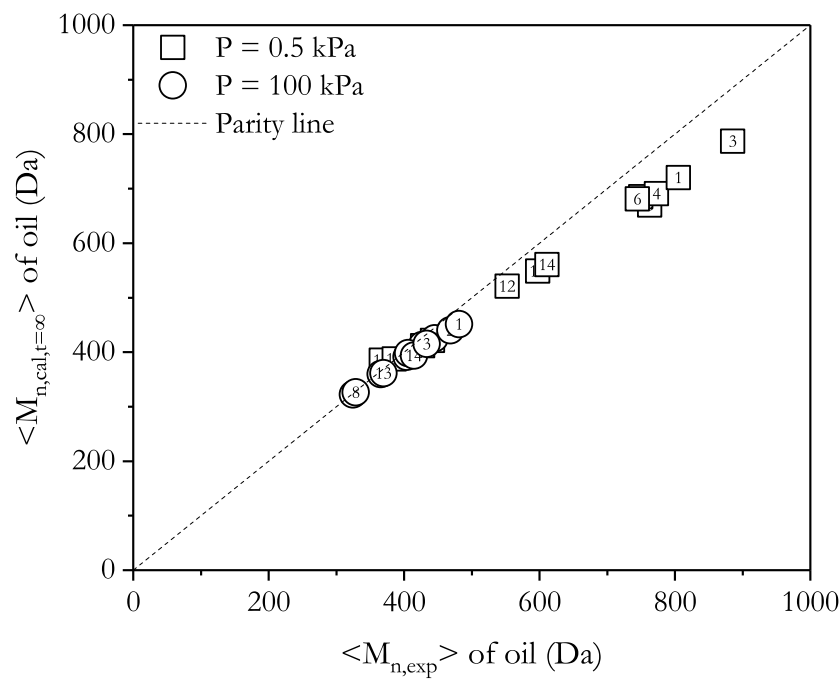

Figure 5.7B: Parity plots in which the experimental $\left\langle\mathrm{M}_{\mathrm{n}}>\right.$ of oils (B) are plotted against their predicted values using individual fit procedure 


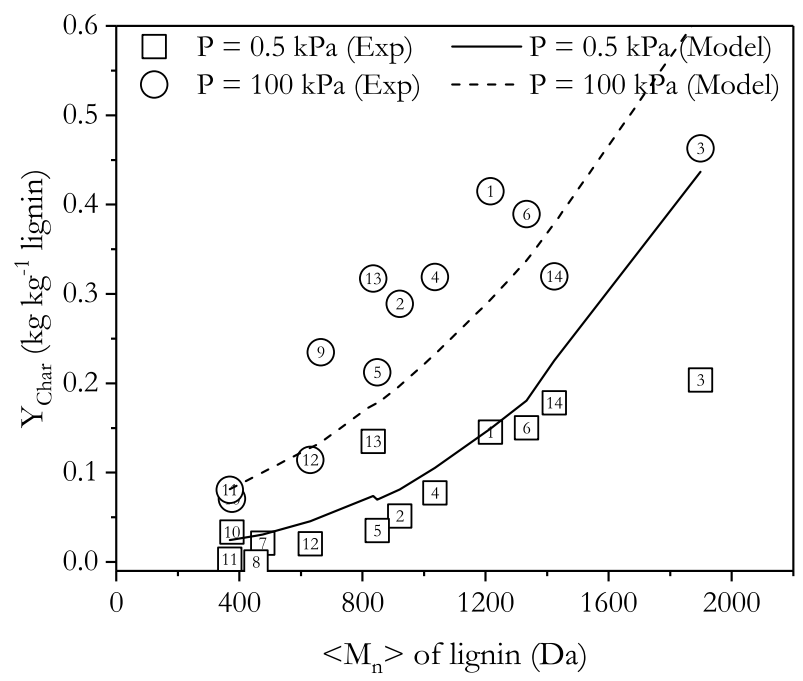

Figure 5.7C: Char yields, experimental and model prediction using the correlation

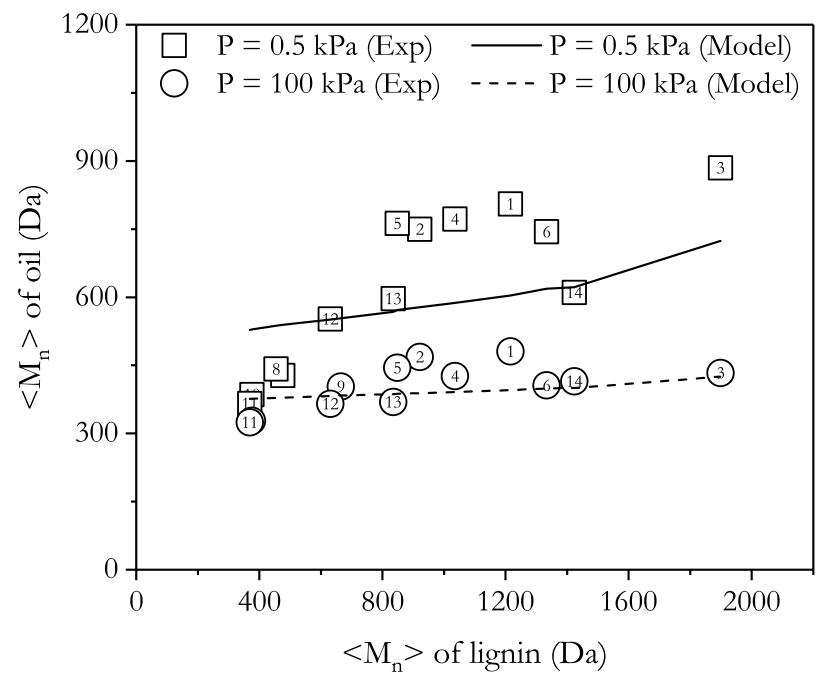

Figure 5.7D: $<\mathrm{M}_{\mathrm{n}}>$ of oils, experimental and model prediction using the correlation 
lower oil yields and higher char yields. Nevertheless, also light oil can also be produced with a yield exceeding $50 \%$ under the tested conditions. There is a clear effect of the $<\mathrm{M}_{\mathrm{n}}>$ of the feedstock and the oil and char yields. If possible, a light feedstock should be selected as this will increase the oil yield. At low pressures, in our case $0.5 \mathrm{kPa}$, the oil is heavier, but its yield is considerably higher. These conditions may be interesting for fuel production. Also a process, in which first as high as possible oil yield is achieved at low pressure followed by further tuning of the product distribution in the vapour/gas phase can be considered. 


\subsection{Conclusions}

In this work, lignins having number averaged molecular weight between $350 \mathrm{Da}$ and 1900 Da were pyrolysed between $425^{\circ} \mathrm{C}$ and $793^{\circ} \mathrm{C}$ and pressures of $0.5 \mathrm{kPa}$ and 100 $\mathrm{kPa}$. It was found that -1 ) With an increase in number averaged molecular weight, oil yield decreased, and char and gas yields increased, 2) At higher pressures (100 kPa) lighter oils were collected than at $0.5 \mathrm{kPa}, 3)$ Above $500 \mathrm{Da}$ (at $100 \mathrm{kPa}$ ) and $1000 \mathrm{Da}$ (at 0.5 $\mathrm{kPa}$ ) the molecular weights of oils became independent of the number averaged molecular weight of the parent lignins, and 4) Heavier oils were collected with an increase in temperature. Based on the gathered experimental evidence of cracking and polymerisation reactions, and mass transport of species from the reacting lignin, a population balance model, which includes these processes, was developed. After parameterisation and by using the molecular weight distribution of lignin as an input, the model predicts all experimentally observed trends. It is noteworthy that the model also predicts the char yields and the number averaged molecular weight of oils reasonably for lignins, for which the $\beta$-O-4 linkage content varies significantly.

The present contribution highlights that during fast pyrolysis of lignin the temperature alone has a limited impact on the oil yield and the number averaged molecular weight of the oils. The molecular weight distribution is one of the most important characteristics of the lignin, which has a significant influence on the pyrolysis product distribution. Modelling results show that heavier molecules tend to polymerise faster than lighter molecules, which results in higher char yields. The pressure, at which the pyrolysis is carried out, is certainly the most influencing process parameter, which alters the transport rate of molecules away from the reaction front, thereby, changing their residence time in the hot reaction zone. It can be considered as the main steering wheel to manipulate the product yields and the number averaged molecular weight of the oils. 


\section{Nomenclature}

A, B

$C_{i}^{L}$

$C_{i, \text { feed }}^{L}$

$C_{i, t=0}^{L}$

$C_{i}^{O}$

$C_{i, t=0}^{O}$

$C_{i, t=\infty}^{O}$

$C_{i, t=\infty}^{L}$

$D P_{i}$

$E_{i}$

$K_{i}$

$k_{T, i}$

$k_{K}$

$k_{P}$

$m(M)_{q}$

$m_{i}$

$m_{L}$

$M_{w, D P_{i}}$

$M_{w}$

$<\mathrm{M}_{\mathrm{n}}>$

$<\mathrm{M}_{\mathrm{w}}>$

$M_{w} D$

$<M_{n}^{L}>$

$<M_{n, t=\infty}^{O}>$

$<M_{w, t=\infty}^{O}>$

$\omega_{i}$

$\omega_{i}^{L}$

$\omega_{i, c a l, t=\infty}^{O}$

$N_{\text {total }}$

$P_{i}$

$R_{K, i}$

$R_{P, i}$

$V_{L}$ mole $m_{L}^{-3}$

mole $m_{L}^{-3}$

mole $m_{L}^{-3}$

mole $m_{L}^{-3}$

mole $m_{L}^{-3}$

mole $m_{L}^{-3}$

mole $m_{L}^{-3}$

mole $m_{L}^{-3} t^{-1}$

mole $m_{L}^{-3} t^{-1}$

$t^{-1}$

$t^{-1}$

mole $m_{L}^{-3} t^{-1}$

$g$

$g$

g

$D a$

Da

$D a$

$D a$

$D a$

$D a$

$D a$

$-$

mole

mole $m_{L}^{-3} t^{-1}$

mole $m_{L}^{-3} t^{-1}$

mole $m_{L}^{-3} t^{-1}$

$m_{L}^{3}$
Parameters used to describe the transport rate of $D P_{i}$

Molar concentrations of $D P_{i}$ in reacting lignin at $t=t$

Molar concentrations of $D P_{i}$ in lignin feedstock

Molar concentrations of $D P_{i}$ in lignin at $t=0$

Molar concentrations of $D P_{i}$ in oil at $t=t$

Molar concentrations of $D P_{i}$ in oil at $t=0$

Molar concentrations of $D P_{i}$ in oil at $t=\infty$

Molar concentrations of $D P_{i}$ in lignin at $t=\infty$

Degree of polymerisation with $i$ number of monomers

Transport rate of $D P_{i}$ from the reacting lignin to cold glass wall at $t=t$

Overall cracking rate of $D P_{i}$ at $t=t$

Evaporation/sublimation/ejection rate constant of $D P_{i}$

First order cracking reaction rate constant

Second order polymerisation reaction rate constant

Mass corresponding to each molecular weight slice $(q)$

Mass corresponding to each $D P_{i}$ obtained after discretization

Total mass of lignin pressed between the two screens

Molecular weight of each $D P_{i}$

Molecular weight

Number average molecular weight

Mass average molecular weight

Molecular weight distribution

$<\mathrm{M}_{\mathrm{n}}>$ of lignin calculated from GPC chromatogram after discretization

Calculated $<\mathrm{M}_{\mathrm{n}}>$ of oil at $t=\infty$

Calculated $<\mathrm{M}_{\mathrm{w}}>$ of oil at $t=\infty$

Mole fraction of each $D P_{i}$

Mole fraction of each $D P_{i}$ present in lignin

Calculated mole fraction of each $D P_{i}$ present in oil at $t=\infty$

Initial number of moles of lignin

Overall polymerisation rate of $D P_{i}$ at $t=t$

Cracking reaction rate of each $D P_{i}$

Polymerisation reaction rate for each $D P_{i}$

Volume of lignin pressed between the two screens 


$\begin{array}{lll}w(\log M)_{q} & - & \begin{array}{l}\text { Molecular weight distribution corresponding to each molecular } \\ \text { weight slice }(q)\end{array} \\ w_{i} & - & \text { Mass fraction of each } D P_{i} \text { in lignin or pyrolysis oils } \\ w_{i, \text { exp }}^{O} & - & \begin{array}{l}\text { Mass fraction of each } D P_{i} \text { present in oil obtained from experi- } \\ \text { ments }\end{array} \\ w_{i, \text { cal }, t=\infty}^{O} & - & \text { Calculated mass fraction of each } D P_{i} \text { present in oil at } t=\infty \\ Y_{\text {Char, exp }} & k g k g_{L}^{-1} & \text { Experimentally obtained char yield } \\ Y_{\text {Char }, \text { cal }, t=\infty} & k g k g_{L}^{-1} & \text { Calculated char yield at } t=\infty \\ Y_{\text {Oil }, \text { cal }, t=\infty} & k g k g_{L}^{-1} & \text { Calculated oil yield at } t=\infty\end{array}$

\section{Superscripts/subscripts}

$\begin{array}{ll}\mathrm{L} & \text { Lignin } \\ \mathrm{O} & \text { Oil } \\ \mathrm{c} & \text { Consumption } \\ \mathrm{f} & \text { Formation }\end{array}$


$\mathrm{C}_{6}$ 


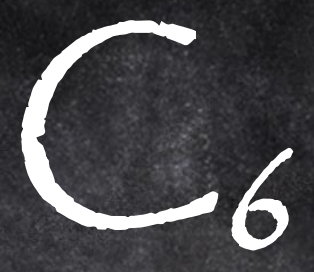

On the effect of ether linkages in lignin on the product yields and the molecular weight of pyrolysis oils using HSQC NMR

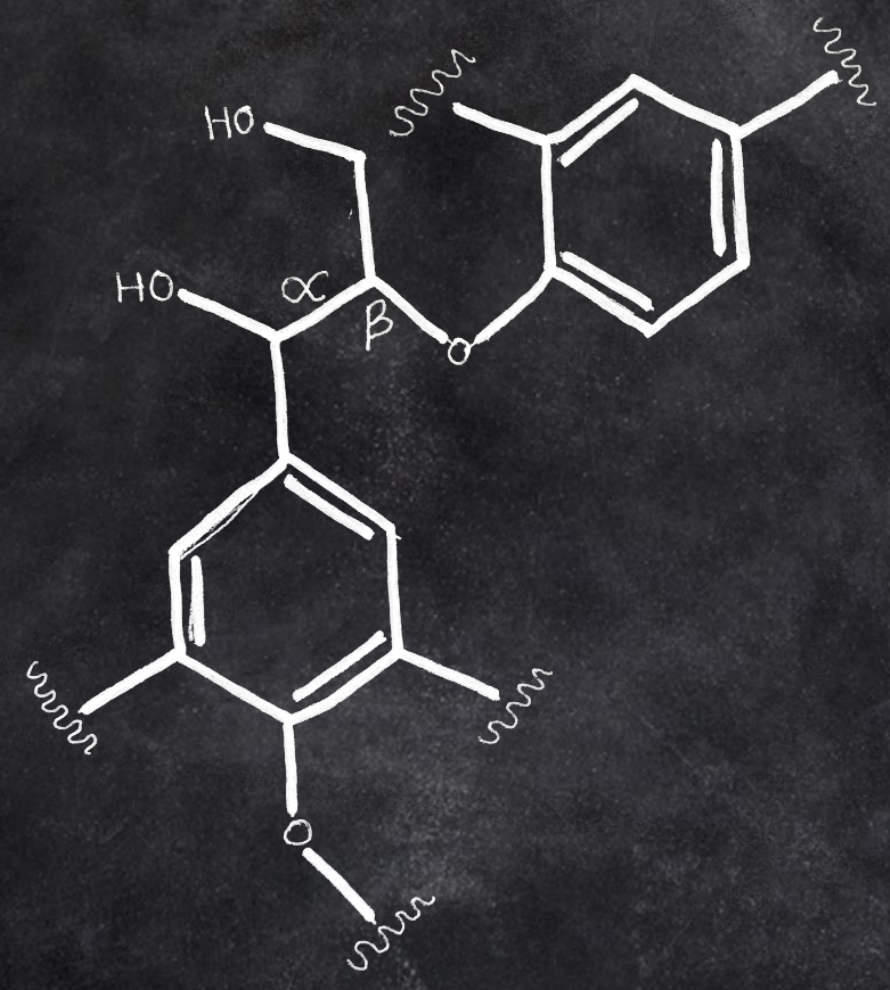




\begin{abstract}
Aromatic units in lignin are connected by ether and carbon linkages. Ether linkages are considered to play an essential role in depolymerisation of lignin by pyrolysis with a goal to obtain high liquid yields and especially high yields of mono-phenolic compounds. In this chapter, five lignins, with the varying number of ether linkages and molecular weights were used as feedstock for experiments in a screen-heater $(0.5 \mathrm{kPa}$ and $100 \mathrm{kPa}$ ) at the $\mathrm{T}_{\mathrm{FS}}$ of $530^{\circ} \mathrm{C}$. The lignin feedstock and their pyrolysis oils were characterised by HSQC NMR to study the effect of ether linkages on the oil and char yields and average molecular weights of the oils. It was demonstrated that a high escape rate (at $0.5 \mathrm{kPa}$ ) of pyrolysis products away from the hot reacting particle, results in oil which still contains a significant amount of molecules with ether linkages. Also, it is shown that the amount of ether linkage in the lignins hardly has any effect on the char and oil yields and the number average molecular weight of the oils.
\end{abstract}




\subsection{Introduction}

The lignin content of biomass varies from 15 to $40 \% 277,279$. Coumaryl, coniferyl, and sinapyl alcohols, the precursors of lignin, are interconnected by various linkages, broadly classified into two types, namely, ether linkages (e.g. $\beta-\mathrm{O}-4, \alpha-\mathrm{O}-4$ ) and carbon linkages (e.g. $\beta-1, \alpha-1,5-5) 13 / 263 / 278 / 280$. Characterisation of the lignin structure using nuclear magnetic resonance (NMR) spectroscopy started in the late 1960s 281,283 and NMR characterisation of pyrolysis oils in the mid-1980s 284 286 . Lately, advancements have been made in characterisation and quantification of linkages in lignin and pyrolysis oils derived from it, using ${ }^{1} \mathrm{H},{ }^{13} \mathrm{C},{ }^{19} \mathrm{~F},{ }^{31} \mathrm{P}$ and HSQC NMR techniques 274/278/287/293. In most of these studies, lignins isolated via different methods and/or source are characterised, from which it is concluded that different isolation methods result in lignins with different amounts of ether bonds due to the destructive nature of the isolation process 293.295 . Note that milled wood lignin, obtained by Björkman's method, is considered to represent native lignin most accurately ${ }^{17}$. In this work, pyrolysis oils obtained under different pyrolysis conditions are qualitatively compared with their feed lignin to identify the structural alterations. It is reported in the literature that the cleavage of ether linkages is a primary decomposition reaction 274 and new aliphatic and aromatic $\mathrm{C}-\mathrm{H}$ linkages are formed by cleavage and rearrangement ether linkages and methoxyl groups, respectively 274 .

In Chapter 5, the oil and char yields and the molecular weight of the oils are interpreted as a function of the molecular weight of lignins. For the depolymerisation of lignin to platform chemicals, inter-unit linkages need to be cleaved, and the formation of new bonds (polymerisation) should be minimised. The main goal of this chapter is to investigate the effect of pyrolysis on the cleavage of ether linkages. Moreover, the effect of the number of ether linkages in lignin on the yields of oil and char and the average molecular mass of oils is investigated. To do so, five different lignins (1,4,10,13 and 14) from Table 5.1 of Chapter 5 , and their corresponding pyrolysis oils, obtained from screen-heater $(0.5 \mathrm{kPa}$ and $100 \mathrm{kPa})$ experiments, were characterised and quantified by HSQC NMR. By varying the pressure during pyrolysis, the escape rate of molecules from the hot reacting particle was varied, which has shown previously to play an important role in the outcome of lignin pyrolysis, see Chapter 5. 


\subsection{Results and discussion}

Five lignins (1,4,10,13 and 14) with varying content of ether linkages were selected from Table 5.1 of Chapter 5 . These lignins and their pyrolysis oils, produced at the $\mathrm{T}_{\mathrm{FS}}$ of $530{ }^{\circ} \mathrm{C}$ in a dedicated screen-heater at two pressures $(0.5 \mathrm{kPa}$ and $100 \mathrm{kPa})$, were characterised by quantitative CMPG-improved HSQC 2D NMR. For the details of the NMR machine settings, see Section 2.4.7 of Chapter 2. Briefly, this method compensates for the influence of ${ }^{1} J_{\mathrm{CH}}$ and $J_{\mathrm{HH}}$ couplings on signal volumes. Two regions of interests were considered: ether linkage region $\left(\delta_{\mathrm{C}} / \delta_{\mathrm{H}} 50-90 / 2.5-5.8\right)$ and building block unit region $\left(\delta_{\mathrm{C}} / \delta_{\mathrm{H}} 90-150 / 5-8.5\right)$.

The $\beta$-aryl ether $(\beta-\mathrm{O}-4, \mathrm{~A})$, phenylcoumaran $(\beta-5, \mathrm{~B})$ and resinol $(\beta-\beta, \mathrm{C})$ are the most important among the inter-unit linkages (marked in red colour), while $\mathrm{p}$ hydroxyphenyl (H), guaiacyl (G) and syringyl (S) are the building blocks of lignin, as shown in Figure 6.1 The cross-peaks representing different ether linkages and building block units were assigned based on the literature 274/293. Note, although the phenylcoumaran (B) and resinol (C) substructures have carbon linkages, they were used to characterise the ether linkages in the respective substructure (Figure 6.1). The distribution of building blocks as a molar percentage and the content of ether linkages per 100 aromatic units were determined by the integration method described by Constant et al. 293 . The reproducibility of the 2D NMR experiments was tested by analysing lignin 4 three times, and the obtained standard deviation on the means for three ether linkages was $\leq 1 \%$. Considering the long measurement time per sample $(\sim 24 \mathrm{~h})$ and the reproducibility of the 2D NMR experiments, other lignins and their oils were analysed only once. Two experimenters integrated the recorded spectrum of each sample, and the average values are reported in Table 6.1

$$
X_{\text {ether }}=1-\frac{A_{A}+A_{B}+A_{C}}{A_{A, 0}+A_{B, 0}+A_{C, 0}} Y_{O i l}
$$

FTIR analysis showed that the $\beta-\mathrm{O}-4$ linkages (at $1120 \mathrm{~cm}^{-1} 296$ ) were absent in the chars obtained from the pyrolysis of lignins (data not shown here). Therefore, the conversion of ether linkages $\left(X_{\text {ether }}\right)$ can be estimated by using Eq. 6.1. where $A_{A, 0}$, $A_{B, 0}$ and $A_{C, 0}$ are the abundance of ether linkages in lignin; $A_{A}, A_{B}$ and $A_{C}$ are the abundance of ether linkages in oil obtained at a given pressure; $Y_{\text {oil }}$ is the oil yield obtained from the pyrolysis of lignin at a given pressure. 

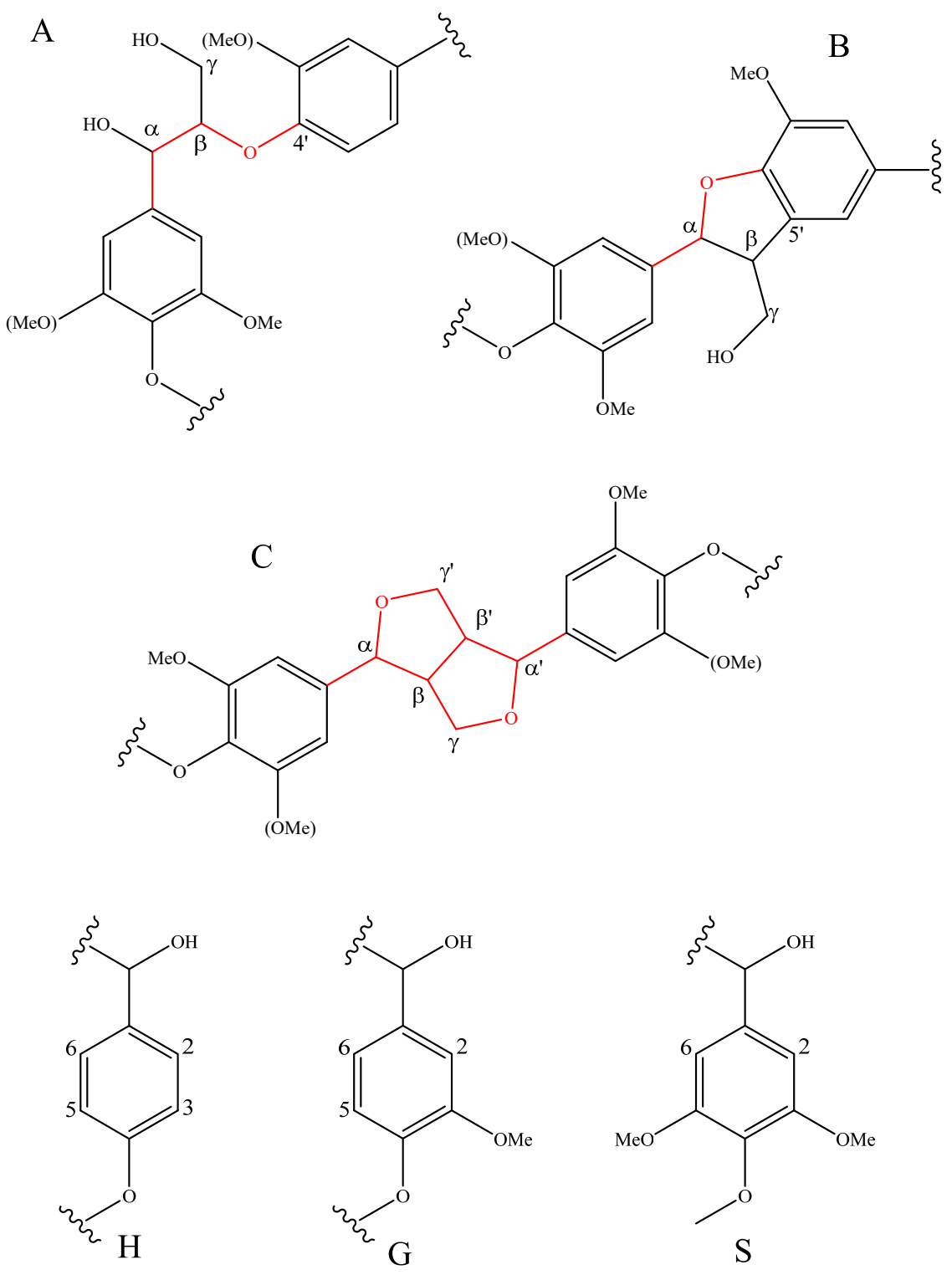

Figure 6.1: Linkages/substructures identified in lignin; $\beta$-aryl ether (A), phenylcoumaran (B), resinol (C), p-hydroxyphenyl (H), guaiacyl (G) and syringyl (S) 


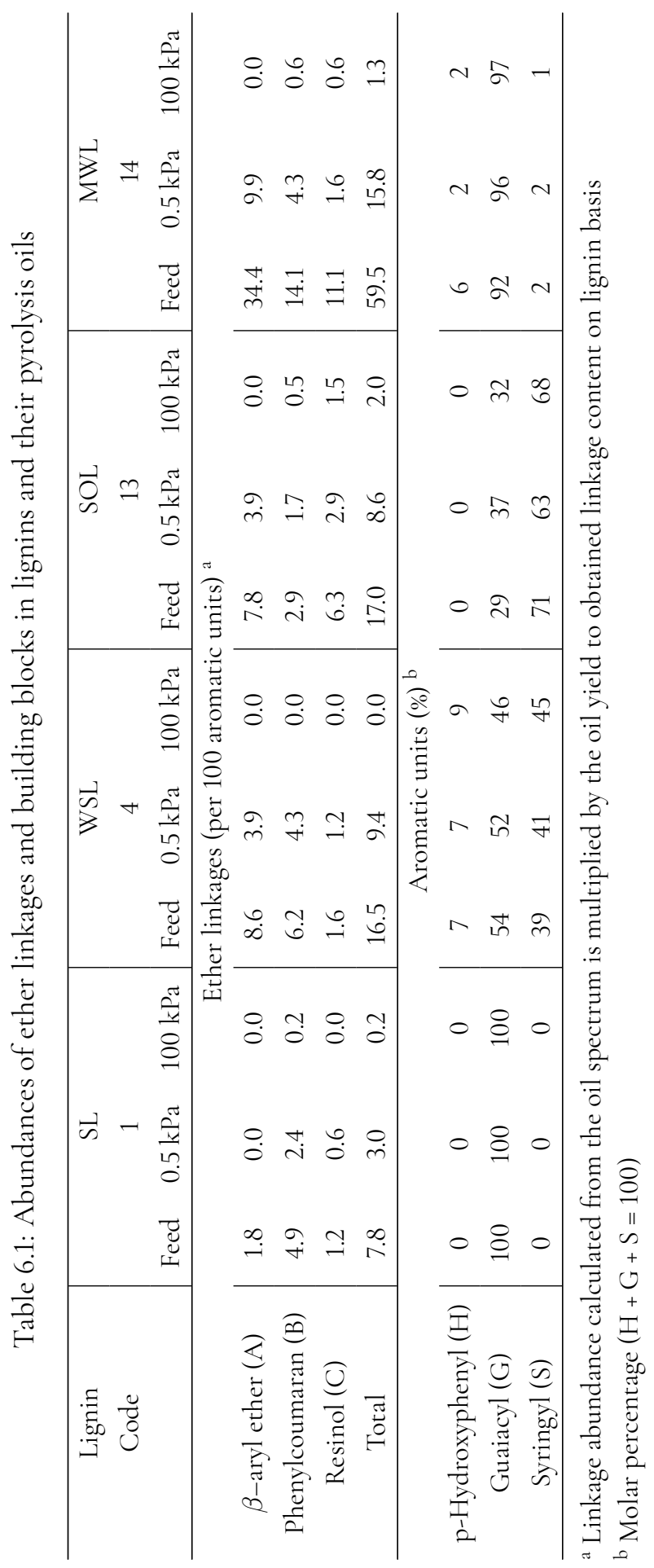


From Table 6.1 it can be seen that lignin 14 has the highest total number of ether linkages among other lignins. The total number of ether linkages are significantly lower in organosolv lignins compared to lignin 14 . The cross peaks of three ether linkages were not observed in the spectrum of pyrolytic lignin (lignin 10), hence, not presented in Figure 6.2 and Table 6.1 Absence of $\beta$-aryl ether, phenylcoumaran and resinol in pyrolytic lignins is reported in the literature $\frac{126 / 286290}{2}$. Like reported in the literature $293 \sqrt[295]{2}$, this result shows that with an increase in the severity of the isolation process, the content of ether linkages in (isolated) lignin decreases.

Figure $6.2 \mathrm{~A}$ presents the conversion of ether linkages during the pyrolysis of four lignins $(1,4,13$ and 14$)$. At $0.5 \mathrm{kPa}$, the conversion of ether linkages was between $43 \%$ to $73 \%$, whereas it was $\sim 96 \%$ at $100 \mathrm{kPa}$. At $0.5 \mathrm{kPa}$, lower conversion of ether linkages can be explained by the rapid removal of molecules containing ether linkages from the hot reaction zone. Otherwise, as a result of the longer residence time of molecules on/in hot reacting particle at $100 \mathrm{kPa}$, nearly all ether linkages were cleaved.

In Figure 6.2B to 6.2D experimentally obtained oil and char yields and the number average molecular weight $\left.\left(<\mathrm{M}_{\mathrm{n}}\right\rangle\right)$ of the oils (per pressure) are plotted as a function of the content of ether linkages in lignins and the pressure during pyrolysis. It can be seen that at both pressures, the product yields and the number average molecular weight of the oils were (nearly) independent of the number of ether linkage in the feedstock lignin.

At $0.5 \mathrm{kPa}$ and $100 \mathrm{kPa}$, the molecular weight distribution $\left(\mathrm{M}_{\mathrm{w}} \mathrm{D}\right)$ of oils obtained from the pyrolysis of lignin 10 overlapped significantly with that of the feedstock, see Figure $5.2 \mathrm{~A}$ in Chapter 5. In other words, during pyrolysis lignin 10 escaped hot screens without undergoing reactions, especially cracking reactions. Consequently, the $\left\langle\mathrm{M}_{\mathrm{n}}>\right.$ of oils, obtained at both pressures, was similar to that of lignin 10, and high oil and low char yields were observed.

The distribution of $\mathrm{p}$-hydroxyphenyl, guaiacyl and syringyl units in lignin vary based on the type of biomass, i.e. softwood, hardwood, grasses 278 . In three softwood lignins studied in this work, i.e. lignin 1 (spruce wood) and lignin 10 and 14 (pinewood), guaiacyl units were predominantly present, see Table 6.1 The cross peaks of all three building blocks were detected in wheat straw lignin (4). A similar observation was made by Constant et al. and Zeng et al. for grass-derived lignins 2932297. Lignin 13, derived from a mixture of three hardwoods, was abundant in syringyl units.

In the literature, it is reported that under pyrolysis conditions, p-hydroxyphenyl and guaiacyl units have a higher tendency for condensation reactions compared to syringyl units $286 / 298$. However, the following trends, contradictory to the literature, were 


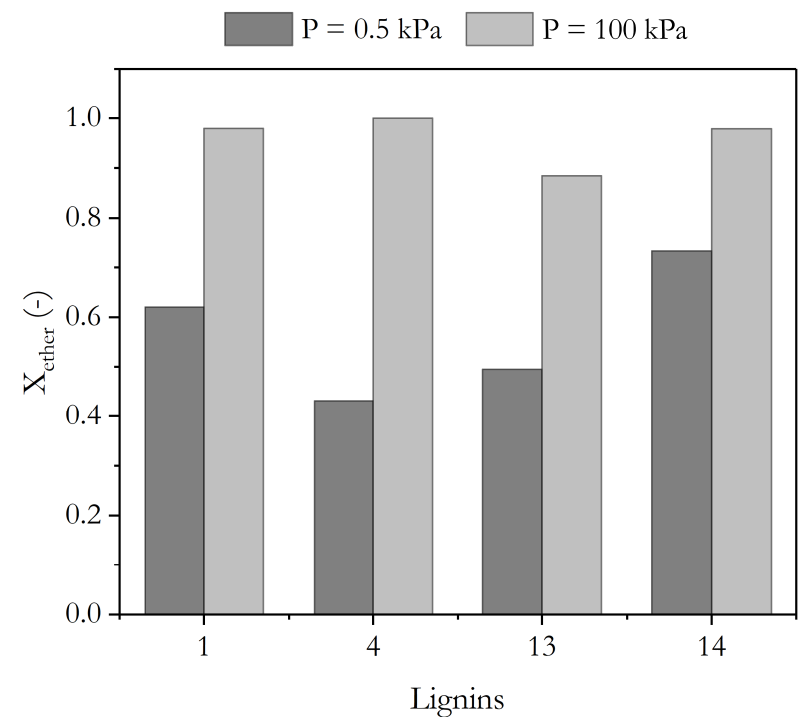

Figure 6.2A: Conversion of ether linkages in different lignins

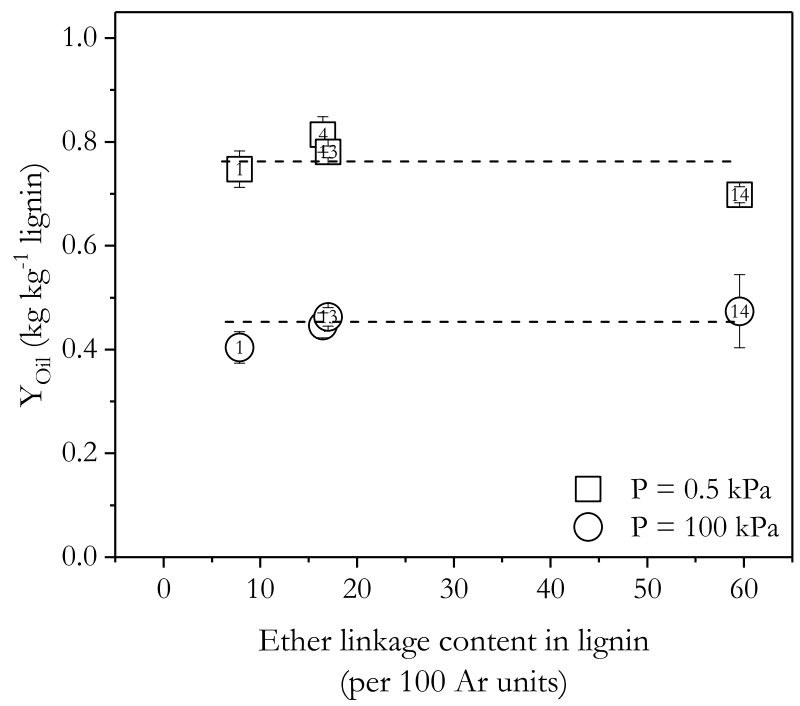

Figure 6.2B: Experimental oil yields against the abundance of ether linkages of lignins 


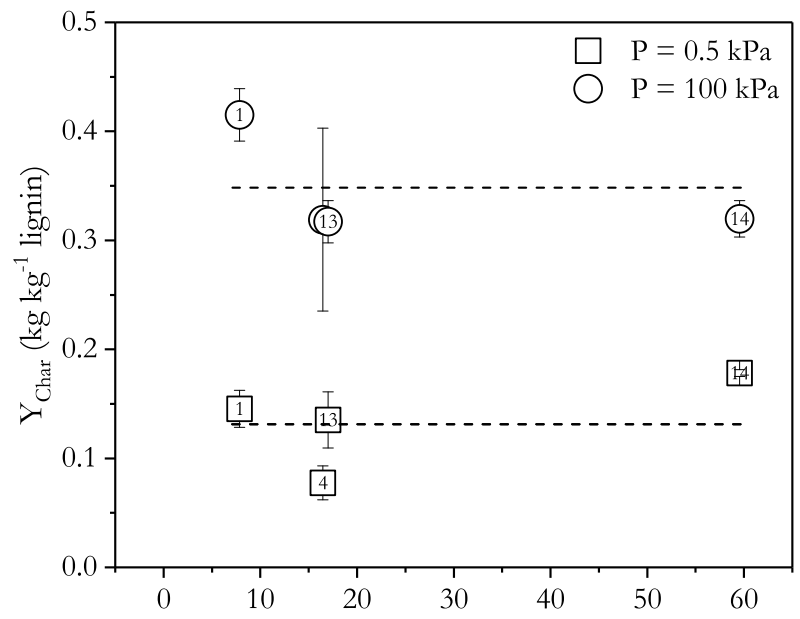

Ether linkage content in lignin (per 100 Ar units)

Figure 6.2C: Experimental char yields against the abundance of ether linkages of lignins

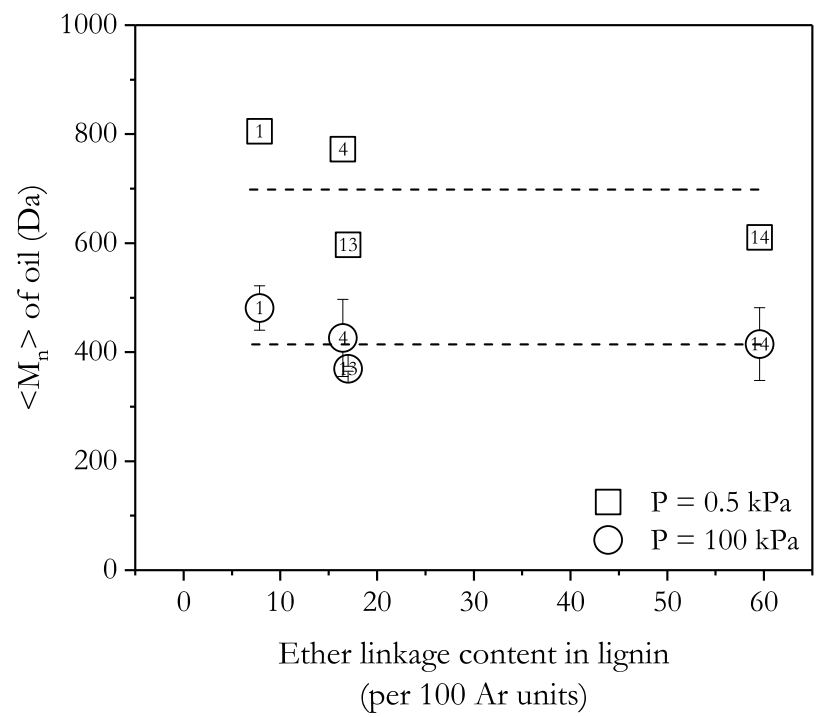

Figure 6.2D: $\left\langle\mathrm{M}_{\mathrm{n}}>\right.$ of oils against the abundance of ether linkages of lignins 
observed: 1) At $0.5 \mathrm{kPa}$ and $100 \mathrm{kPa}$, the molar percentage of guaiacyl units in oil increased for lignin 13 and remained constant for lignin 14, and 2) despite having similar content of guaiacyl units, significantly different char yields were seen for lignin 1 and 14 . A plausible explanation for these difference can be ascribed to the aspects such as the presence of hydroxyl groups at the $\alpha$ or $\beta$ carbon in ether linkage $\frac{299}{20}$ and the reactivity of other linkages/substructures (e.g. cinnamyl alcohol end-groups, ferulate) present in lignin. In the author's opinion, a further experimental investigation is needed to elucidate these observed trends. 


\subsection{Conclusions}

In this chapter, five lignins and their pyrolysis oils obtained in screen-heater at two pressures $(0.5 \mathrm{kPa}$ and $100 \mathrm{kPa})$ were analysed by HSQC NMR. At $0.5 \mathrm{kPa}$, lower conversion of ether linkages was observed $(\sim 60 \%)$ compared to that of observed at 100 $\mathrm{kPa}$, as a result of rapid removal of molecules (containing ether linkages) away from the hot reaction front. The yields of oil and char and the number average molecular weight of oils were found to be independent of the number of ether linkages in the lignin feedstock. 


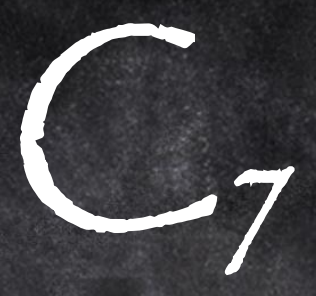

Effect of pressure on the fast pyrolysis of acid-leached bagasse and pine wood: experiments and modelling

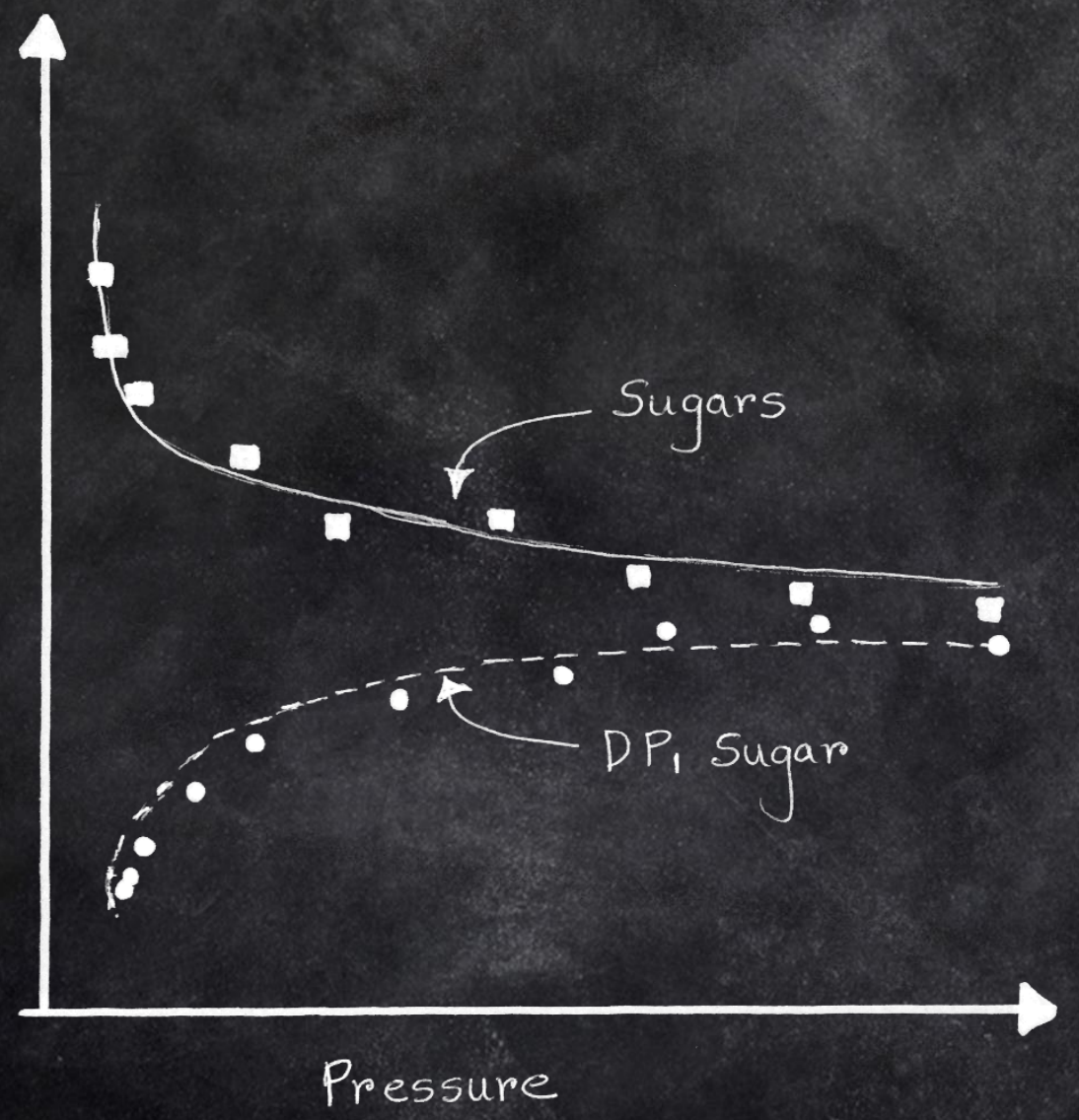




\begin{abstract}
Pyrolysis of acid-leached bagasse has been carried out in the pressure range of 0.005 to $100 \mathrm{kPa}$ in a screen-heater, designed for nearly isothermal operation and rapid quenching of reaction products. At the lowest pressure, i.e. by maximising the escape rate of products away from the hot reaction zone, $73 \%$ of the poly- $\mathrm{C}_{6}$-sugars in the feed were recovered in the liquid product as $\mathrm{C}_{6}$-anhydrosugars $\left(\mathrm{C}_{6} \mathrm{aS}\right)$ with degree of polymerization between 1 and $6\left(D P_{1}-D P_{6}\right)$. A mathematical model, including reactions and mass transfer, was able to predict the measured decrease in the total yield of $\mathrm{C}_{6} \mathrm{aS}$ and the shift to lighter $\mathrm{C}_{6} \mathrm{aS}$ in the $D P$-distribution as a function of increasing pressure. The effect of the hot vapour residence time on the $D P$-distribution of the $\mathrm{C}_{6}$ aS was investigated by pyrolysing in a fluidised bed. At identical pressure and temperature the total yield of $\mathrm{C}_{6}$ aS was the same for the screen-heater and fluidized bed while the $D P$ distribution shifted to $D P_{1}$ as a result of the higher hot vapour residence time in the fluidized bed, which could be described by assuming first order kinetics for all possible cracking reactions of $\mathrm{C}_{6} \mathrm{aS}$ in the vapour phase.
\end{abstract}




\subsection{Introduction}

Fast pyrolysis is a thermochemical conversion processes, in which biomass is converted at $\sim 500{ }^{\circ} \mathrm{C}$ in the absence of oxygen, to form oil, char and gas. Typically, the bio-oil produced is a complex mixture of hundreds of oxygenated organic compounds. A considerable amount of studies has been reported on the production of targeted compounds such as mono-phenols and sugars. For instance, pyrolytic sugars (e.g. glucose, xylose, mannose) can be upgraded to ethanol or platform chemicals 200,203 . In this chapter, we focus on the production of anhydrosugars via pyrolysis of lignocellulosic biomass.

In most previous studies $71|74| 173|174| 300 \mid 301$, fast pyrolysis of biomass was studied in a wide range of reactor temperature $\left(360\right.$ to $650{ }^{\circ} \mathrm{C}$ ) at a constant pressure of 100 $\mathrm{kPa}$. Contrary, only a few accounts are available on the pyrolysis of biomass at reduced pressure $\frac{75|152| 225 \mid 302-308}{30}$, and in most of these studies $225 \mid 302 \sqrt[306 / 308]{30}$ pyrolysis was carried out at a single (reduced) pressure. Amutio et al. 152 studied the effect of pressure $(25 \mathrm{kPa}$ and $100 \mathrm{kPa}$ ) in a continuous conical spouted bed reactor for the pyrolysis of pine wood, from which they showed that the pressure has little effect on the yields of the lumped products liquid (oil), char and gas. They performed pyrolysis of hybrid poplar over a wide range of pressure $(0.4 \text { to } 100 \mathrm{kPa})^{75}$ and quantified monomeric and dimeric anhydrosugars present in the oil. Pecha et al. reported an increase in the $D P_{1}$ (levoglucosan) yield of a factor two, while the yield of larger anhydrosugars diminished with increasing the pressure from 0.4 to $100 \mathrm{kPa}$.

This work aims at advancing the understanding of the role of pressure during the fast pyrolysis of biomass. It is well known that alkali and alkaline earth metals (AAEMs) show strong catalytic activity with respect to the pyrolysis reactions, particularly the decomposition of sugars $61|62| 64|66| 68|136| 153 \mid 309$. In fact, we did not observe a significant effect of pressure on the yields of $D P_{1}-D P_{6} \mathrm{C}_{6}$ aS for pinewood and bagasse with 549 and 5032 ppm AAEMs, respectively (Table D.2 and Table D.4 in Appendix D). Therefore, in order not to be hindered by these catalytic effects acid-leached, hence AAEMs lean, biomass was used in this study.

Like seen in the case of cellulose (Chapter 4) and lignin (Chapter 5), we propose that the competition between mass transport and chemical reactions steers the pyrolysis of biomass with respect to the product slate of sugars. Experimentally obtained yields of $\mathrm{C}_{6} \mathrm{aS}$, obtained in a screen-heater are compared with a mathematical model, which includes chemical reactions and transport of products away from the reaction zone. Additionally, a comparison is made between pyrolysis experiments, performed under the identical conditions, in the screen-heater and a fluidised bed to evaluate the influence 
of hot vapour residence time on the product distribution.

\subsection{Mass balance and reproducibility}

The mass balance closure of acid-leached bagasse (see Table 7.1 for characterisation) pyrolysis experiments, performed in screen-heater in a pressures range between 0.005 to $100 \mathrm{kPa}$, were in the range of 0.86 to $0.93 \mathrm{~kg} \mathrm{~kg}^{-1}$. Pyrolysis of acid-leached pinewood (see Table 7.1 for characterisation) was carried out in a screen-heater $(0.2,55$ and $100 \mathrm{kPa})$ at $485^{\circ} \mathrm{C}$, of which the mass balance closures were in the range between 0.74 to $0.91 \mathrm{~kg} \mathrm{~kg}^{-1}$. An observed decrease in the mass balance closure, with an increase in pressure, can be ascribed to the observation that more pyrolysis products condensed on the gas sampling line, thermocouple, and pressure sensor line instead of on the cold vessel wall. Also, light organic compounds and water were most likely (partly) lost during gas sampling and the dismantling of the setup. Minimally 3 experiments were performed for both feedstock for each condition. Reproducibility of the experiments was satisfactory as shown in Table D.1 and Table D.3 in Appendix D

Because of the limited availability of acid-leached pinewood, only one pyrolysis experiment was performed, at $485^{\circ} \mathrm{C}$ and $55 \mathrm{kPa}$, in the fluidised bed, of which mass balance closure was $0.94 \mathrm{~kg} \mathrm{~kg}^{-1}$. However, its reproducibility was judged by 5 pyrolysis experiments of untreated pinewood in the continuous fluidised bed at $485^{\circ} \mathrm{C}$ and $55 \mathrm{kPa}$. The yields and standard deviation on mean of wet oil, char and gas were $0.62 \mathrm{~kg} \mathrm{~kg}^{-1}( \pm$ $0.01), 0.12 \mathrm{~kg} \mathrm{~kg}^{-1}( \pm 0.01), 0.20 \mathrm{~kg} \mathrm{~kg}^{-1}( \pm 0.01)$. This shows that the reproducibility of experiments was satisfactory. 


\subsection{Modelling}

To interpret the experimentally observed yields of $\mathrm{C}_{6} \mathrm{aS}$ a modified version of our previously developed model for the pyrolysis of lignin (Chapter 5), is used. The schematic representation of the model is presented in Figure 7.1 On/in the particle, $\mathrm{C}_{6} \mathrm{aS}$ depolymerize (red arrows Figure 7.1) to $\mathrm{C}_{6} \mathrm{aS}$ with lower degree of polymerization, react to other products $U$ (purple arrows), or escape from the reaction zone by mass transfer (green arrow). Whether or not $U$ stays on the particle is of no concern for this study. $U$ is a mathematical sink that represents the experimentally observed char, light volatiles and gas. Depolymerisation is assumed to be a first order process, and all reactions have the same likelihood, i.e. the same rate constant $\left(k_{K}\right)$. Decomposition reactions of $\mathrm{C}_{6} \mathrm{aS}$ to $U$ are also assumed to follow first order kinetics and to have the same rate constant $\left(k_{U}\right)$. The transport of $\mathrm{C}_{6} \mathrm{aS}$ by evaporation/sublimation/ejection is described by Eq. 7.1 Note that $k_{T, a v g}$ is a simple average of transport rate of individual escape rates of $\mathrm{C}_{6} \mathrm{aS}$ varying in $D P$ between 1 and 6 , as calculated by Eq. 7.2

$$
\begin{gathered}
k_{T, i}=e^{-A i} \quad 1 \leq i \leq 6 \\
k_{T, \text { avg }}=\frac{\sum_{i=1}^{6} k_{T, i}}{6}
\end{gathered}
$$

It is assumed that $D P_{7}$ is the initial state of the biomass because $\mathrm{C}_{6} \mathrm{aS}$ bigger than $D P_{6}$ were not detected in collected oils (see Section D.2 in Appendix D). Note that the experimental method (in screen-heater) does not allow the determination of the temporal evolution of products. Instead, final yields $(t=\infty)$ are obtained, which leads to the restriction that it is not possible to determine all three constants $\left(k_{T, a v g}, k_{U}\right.$ and $k_{K}$ ) by fitting them to the experimental results. It is only possible to determine the ratio of the constants $\frac{k_{K}}{k_{K}+k_{U}}$ and $\frac{k_{T, a v g}}{k_{K}+k_{U}}$, for details see Section D.3.1 of Appendix D

Vapour phase depolymerisation reactions of $\mathrm{C}_{6} \mathrm{aS}$ are also assumed to be the first order, and all possibilities have the same likelihood, i.e. the same rate constant $k_{V}$. For interpretation of the screen heater experiments only $k_{T, a v g}, k_{U}$ and $k_{K}$ are considerd, while for the fluidized bed $k_{V}$ is included. 


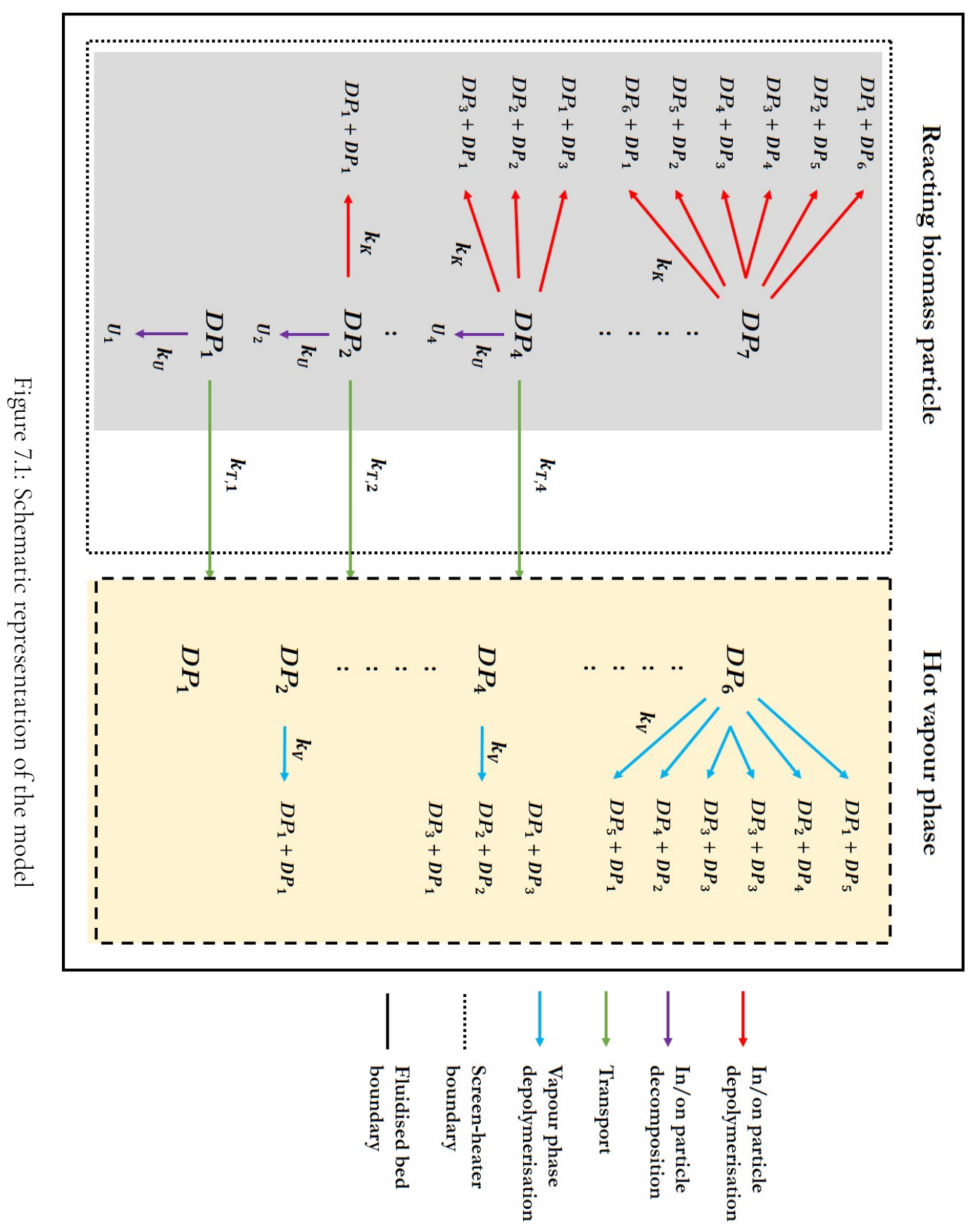




\subsection{Results and discussion}

Table 7.1 shows the total ash content and its composition present in the biomass before and after acid leaching. The values reported in the table are the averages determined based on triplicates. It can be seen that the total ash content of bagasse and pinewood decreased after acid leaching by $68 \%$ and $77 \%$, respectively, while $95 \%$ and $88 \%$ removal of total AAEMs content for bagasse and pinewood was achieved, respectively.

Table 7.1: Total ash content and its composition present in the biomass after acid leaching

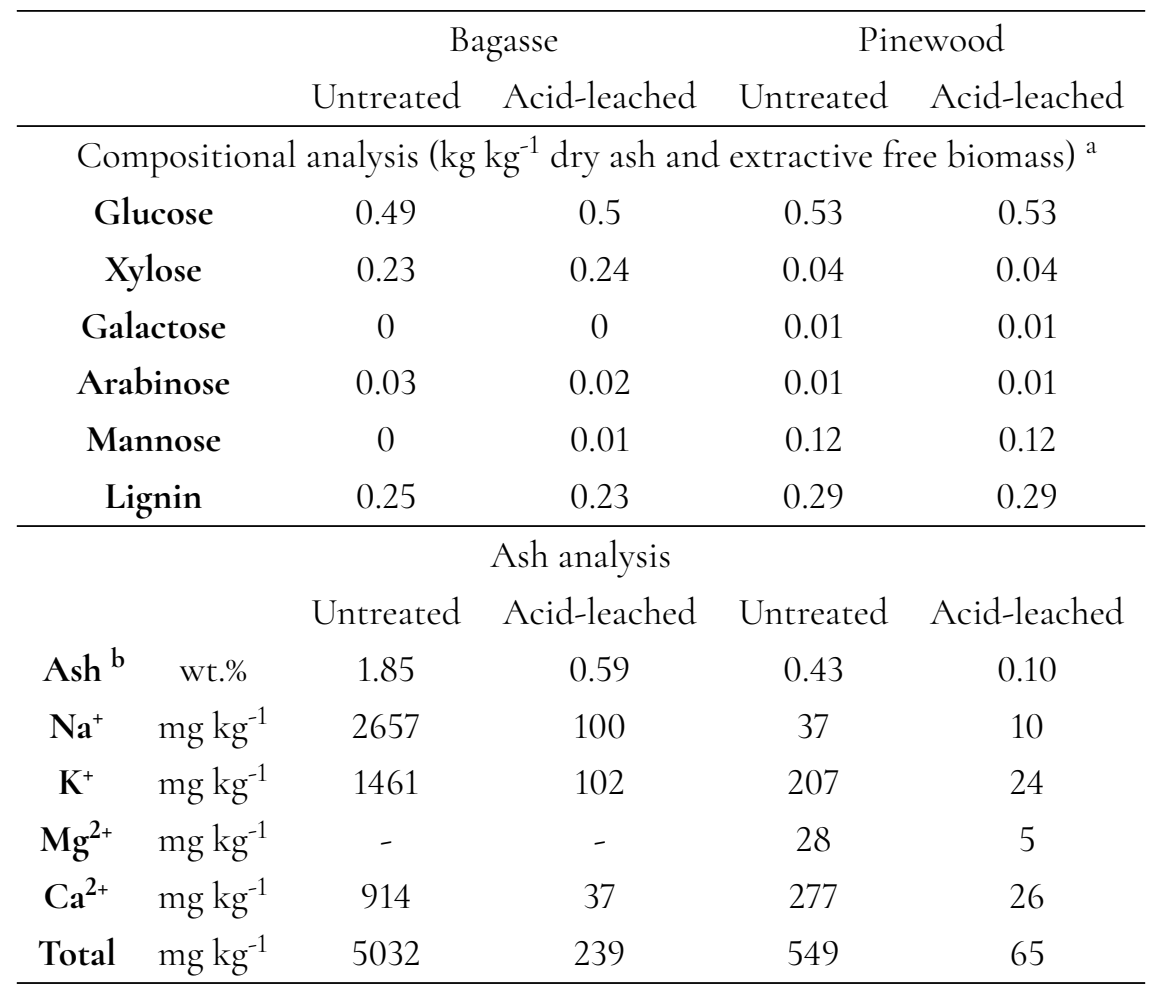

${ }^{a}$ taken from 62

${ }^{\mathrm{b}}$ Including all inorganic materials (metals, Si, etc.)

- Not detected 


\subsubsection{Anhydrosugars}

In this section, the $\mathrm{C}_{6} \mathrm{aS}$ yields obtained from bagasse and pinewood are presented. The HPLC chromatograms of the water-soluble fraction of pyrolysis oil were integrated as described elsewhere ${ }^{120}$. The $D P_{1}$ yields are absolute values, while for $\mathrm{DP}_{\geq 2} \mathrm{C}_{6}$ aS the yields are referred as estimated since minor compounds (partially) co-elute with these bigger $\mathrm{C}_{6} \mathrm{aS}(120$ and Chapter 3$)$. Presence of up to $D P_{6}$ sugars in the oil, obtained from bagasse and pinewood, was confirmed by the direct infusion mass spectrometry (Section D.2 in Appendix D.

It is worth mentioning that from the pyrolysis of Avicel PH 101, $\mathrm{C}_{6}$ aS with $D P$ up to 11 were found in the oil 120|192|193|223|224|310, whereas from biomass, $D P_{6}$ was the biggest detected $\mathrm{C}_{6} \mathrm{aS}$. This difference might be explained the structural differences between the Avicel PH 101 and native cellulose. In this line of reasoning, it takes longer time before $\mathrm{C}_{6} \mathrm{aS}$ can escape the hot reacting particle because of the hindrance created by the lignin present in the cell wall of the biomass particle as compared to Avicel PH 101. As a result of which bigger $\mathrm{C}_{6} \mathrm{aS}$ undergo depolymerisation reactions to form smaller $D P \mathrm{C}_{6}$ aS. Moreover, Avicel PH 101 is one of the purest form of cellulose, and hence its pyrolysis is not affected by lignin or any other contaminant. In the literature, during the pyrolysis of biomass, presence of $\mathrm{C}_{6}$ aS up to $D P_{3}$ in the oil is reported 61|136|142]143, while we are the firsts, to the best of our knowledge, to report the presence of up to $D P_{6} \mathrm{C}_{6}$ aS from the biomass pyrolysis. The presence of bigger $\mathrm{C}_{6} \mathrm{aS}$ (up to $D P_{6}$ ) in biomass-derived oils emphasises the role of random scission of native cellulose, which

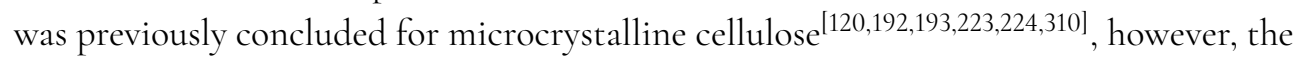
unzipping mechanism, proposed by Golova et al. 311 , still cannot be excluded .

\section{Effect of pressure in screen-heater experiments}

In Figure 7.2 the total yield of $\mathrm{C}_{6} \mathrm{aS}$ (expressed on the fraction of $\mathrm{C}_{6}$ sugars in bagasse) and the mass fraction of $D P_{1}$ in $\mathrm{C}_{6}$ aS are plotted against the pressure. At 0.005 $\mathrm{kPa}, 73 \%$ of $\mathrm{C}_{6}$ sugars from biomass were selectively converted to $\mathrm{C}_{6} \mathrm{aS}$ during pyrolysis. Upon increasing the pressure to $10 \mathrm{kPa}$, the yield of total $\mathrm{C}_{6} \mathrm{aS}$ dropped to the value of $\sim 0.5 \mathrm{~kg} \mathrm{~kg}^{-1}$, and upwards $20 \mathrm{kPa}$ only a small decrease in the yield to $\sim 0.42 \mathrm{~kg} \mathrm{~kg}^{-1}$ was observed. The mass fraction of $D P_{1}$ increased as a function of pressure from 0.13 to $\sim 0.42$. It is worth mentioning that, even at $100 \mathrm{kPa}$, the major fraction of the $\mathrm{C}_{6} \mathrm{aS}$ is composed of $D P_{\geq 2} \mathrm{C}_{6}$ aS. Note that, between 10 and $20 \mathrm{kPa}$, a step change in the yield of $\mathrm{C}_{6} \mathrm{aS}$ (or $D P_{1}$ mass fraction) was observed. Between 20 to $100 \mathrm{kPa}$, the yield of remained (nearly) constant, while the $D P_{1}$ mass fraction increases from 0.32 to $\sim 0.41$. This trend is in line wih the results of Pecha et al. ${ }^{75}$ reported an increase in the $D P_{1}$ 


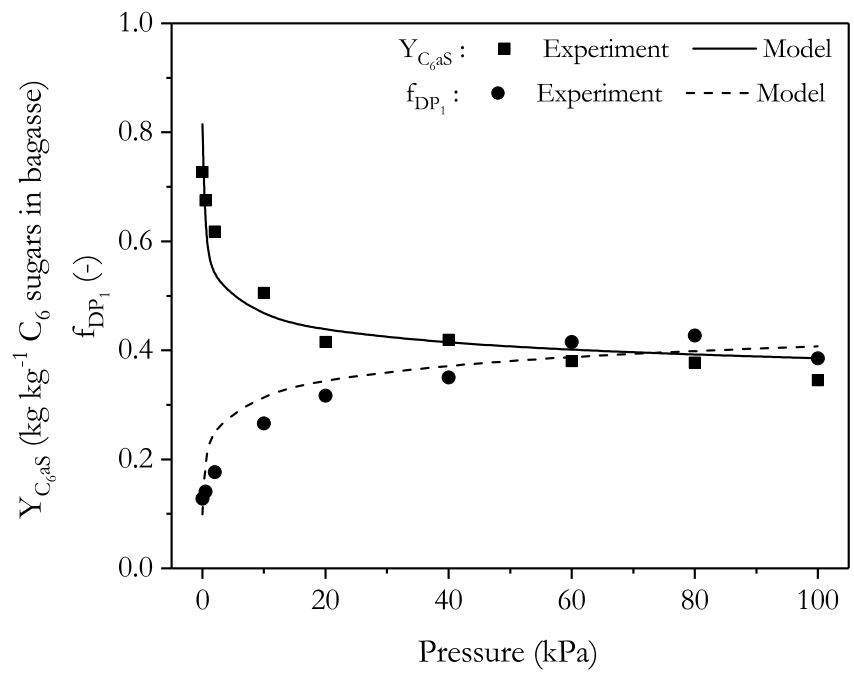

Figure 7.2: $\mathrm{C}_{6} \mathrm{aS}$ yield (on $\mathrm{C}_{6}$ sugars in bagasse) and the mass fraction of $D P_{1}$ in $\mathrm{C}_{6} \mathrm{aS}$, experimental and calculated using the correlation, as a function of pressure; obtained in the screen-heater; $\mathrm{T}_{\mathrm{FS}}=515 \pm 15^{\circ} \mathrm{C}$

(levoglucosan) yield (on poplar wood basis) from $0.06 \mathrm{~kg} \mathrm{~kg}^{-1}$ ( $0.4 \mathrm{kPa}$ ) to $0.1 \mathrm{~kg} \mathrm{~kg}^{-1}$ (100 $\mathrm{kPa}$ ), while the yield of $\mathrm{DP}_{\geq 2} \mathrm{C}_{6} \mathrm{aS}$ diminished. Note, a similar observation was made for acid-leached pinewood, see Table D.5 in Appendix D.

To support the interpretation of the experimentally observed trends the model was used without cracking in the vapour phase, i.e. $k_{V}=0$, which is a valid assumption for the screen-heater $119 \mid 120$. An attempt was made to fit a single $\frac{k_{K}}{k_{K}+k_{U}}$ and $\frac{k_{T, \text { avg }}}{k_{K}+k_{U}}$ for all pressures, which is referred to as the total fit procedure (for values see Table 7.2). This resulted into a poor prediction of the yield of $\mathrm{C}_{6} \mathrm{aS}$ and the $D P_{1}$ mass fraction (see Figure D.10 because the escape rate of $\mathrm{C}_{6} \mathrm{aS}$ is a function of pressure, and hence a single value of $\frac{k_{T, a v g}}{k_{K}+k_{U}}$ cannot capture it.

Next, $\frac{k_{K}}{k_{K}+k_{U}}$ obtained from the total fit procedure was set to a fixed value, which is rationalized by the pressure independence of $k_{K}$ and $k_{U}$ (first order reactions), to obtain $\frac{k_{T, a v g}}{k_{K}+k_{U}}$ per pressure, called as the individual fit procedure. The values of $\frac{k_{T, a v g}}{k_{K}+k_{U}}$ obtained from the individual fit procedure decreased as a function of increasing pressure. The range of fitted $\frac{k_{T, a v g}}{k_{K}+k_{U}}$ (individual fit) is presented in Table 7.2 and in Table D.7 of Appendix D they are listed per pressure with their 95\% confidence intervals. With the fitted $\frac{k_{T, a v g}}{k_{K}+k_{U}}$ as a function of pressure (Figure D.12 and fixed $\frac{k_{K}}{k_{K}+k_{U}}$ (obtained from total fit procedure), the model predicted the experimentally observed trends correctly (Figure 7.2). 
With $\frac{k_{K}}{k_{K}+k_{U}}>0.5$ and fitted $\frac{k_{T, a v g}}{k_{K}+k_{U}}$, the model over predicts the $D P_{1}$ mass fraction. Thus, $\frac{k_{K}}{k_{K}+k_{U}}=0.3$ indicates that the reactions forming other products are always faster than the depolymerisation reactions of $\mathrm{C}_{6} \mathrm{aS}$. Until $10 \mathrm{kPa}$, the mass transport of $\mathrm{C}_{6} \mathrm{aS}$ away from the reaction front is the dominant process, see Figure D.12 In other words, the likelihood of depolymerisation reactions forming smaller DP $\mathrm{C}_{6} \mathrm{aS}$ and other products is small, which consequently results in high yield of $\mathrm{C}_{6} \mathrm{aS}$ and low $D P_{1}$ mass fraction. As shown in Figure D.12, the rate of mass transport at $10 \mathrm{kPa}$ is higher than that at $20 \mathrm{kPa}$, while at $20 \mathrm{kPa}$, the escape rate of $\mathrm{C}_{6}$ aS becomes equal to that of the sum of reactions $\left(\frac{k_{T, a v g}}{k_{K}} \approx 1\right)$. This suggests that, at $20 \mathrm{kPa}$, reactions of $\mathrm{C}_{6} \mathrm{aS}$ proceed at the similar rate (not the same) that of mass transport, whereas at $10 \mathrm{kPa}$ mass transport rate is higher compared to the reaction rates. Thus, as a result of decreased mass transport rate between 10 and $20 \mathrm{kPa}$, a step drop in the yield of $\mathrm{C}_{6} \mathrm{aS}$ (or the $D P_{1}$ mass fraction) was observed. Upwards $20 \mathrm{kPa}, \frac{k_{T, a v g}}{k_{K}+k_{U}}$ was found to be (nearly) constant (Figure D.12, showing no significant change in the escape rate of $\mathrm{C}_{6} \mathrm{aS}$ away from the reacting particle. Thus, in the pressure range between 20 and $100 \mathrm{kPa}$, due to the similar mass transport rate of $\mathrm{C}_{6} \mathrm{aS}$ and likelihood of reactions on/in the reacting particle, a constant yield of $\mathrm{C}_{6}$ aS and $D P_{1}$ mass fraction was observed.

Table 7.2: The values of $\frac{k_{K}}{k_{K}+k_{U}}$ and $\frac{k_{T, a v g}}{k_{K}+k_{U}}$ obtained at a constant $\mathrm{T}_{\mathrm{FS}}$ of $515^{\circ} \mathrm{C}$

\begin{tabular}{ccc}
\hline Fit procedure & $\frac{k_{T, a v g}}{k_{K}+k_{U}}$ & $\frac{k_{K}}{k_{K}+k_{U}}$ \\
& - & - \\
\hline Total fit & $0.7( \pm 0.3)^{\mathrm{a}}$ & $0.3( \pm 0.05)^{\mathrm{a}}$ \\
Individual fit & $1.9( \pm 0.9)^{\mathrm{a}}-0.4( \pm 0.1)^{\mathrm{a}}$ & $0.3^{\mathrm{b}}$ \\
\hline
\end{tabular}

${ }^{\text {a }}$ Values in parentheses are the $95 \%$ confidence intervals

${ }^{\mathrm{b}}$ Value of $\frac{k_{K}}{k_{K}+k_{U}}$ from the total fit procedure used in the individual fit procedure to estimate $\frac{k_{T, a v g}}{k_{K}+k_{U}}$ per pressure 


\section{Effect of hot vapour residence time}

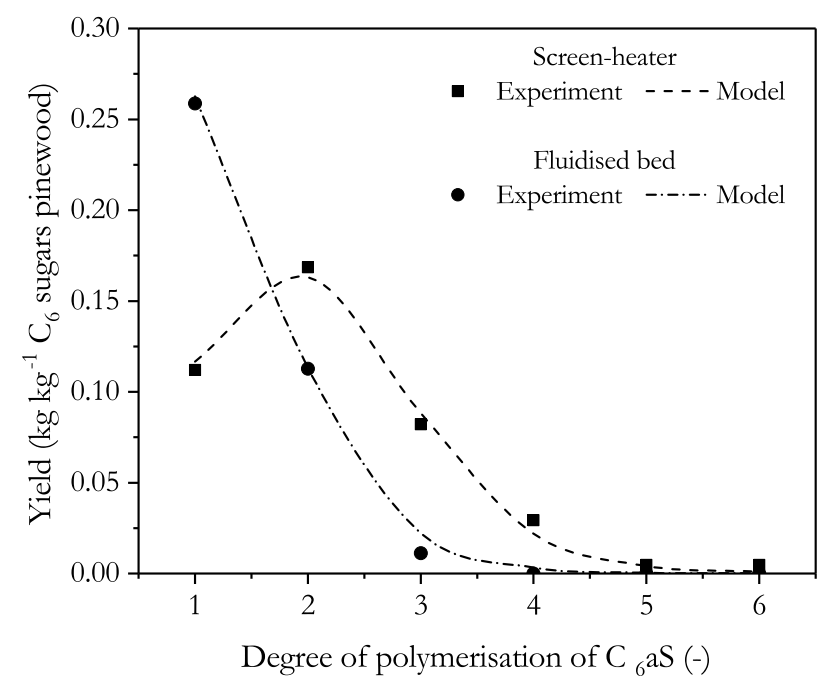

Figure 7.3: DP distribution of anhydrosugar (experimental and calculated) on $\mathrm{C}_{6}$ sugars basis, obtained from pyrolysis of pinewood at $485^{\circ} \mathrm{C}$ and $55 \mathrm{kPa}$ in screen-heater and fluidised bed

Figure 7.3 presents the DP-distribution of obtained from pyrolysis of pinewood at $485^{\circ} \mathrm{C}$ and $55 \mathrm{kPa}$ in screen-heater and fluidised bed. As can be seen that the anhydrosugars present in the fluidised bed oil were predominantly composed of $D P_{1}$ and $\mathrm{DP}_{2}$, while bigger $\mathrm{C}_{6} \mathrm{aS}\left(\mathrm{DP}_{\geq 3}\right)$ were present in small or traces quantities. Contrary, the yield of $D P_{1}$ observed in screen-heater was a factor of $\sim 2$ lower compared to the fluidised bed oils, while the yield of $\mathrm{DP}_{2}$ was highest $\left(\sim 0.17 \mathrm{~kg} \mathrm{~kg}^{-1} \mathrm{C}_{6}\right.$ sugars $)$. The cumulative yield of $\mathrm{DP}_{3}$ and $\mathrm{DP}_{4} \mathrm{C}_{6}$ aS was $\sim 0.1 \mathrm{~kg} \mathrm{~kg}^{-1} \mathrm{C}_{6}$ sugars, and the presence of $\mathrm{DP}_{>4} \mathrm{C}_{6}$ aS was marginal. However, it is important to mention that despite a significant difference in the DP distribution, the total yield of $\mathrm{C}_{6} \mathrm{aS}$ yields from screen-heater and the fluidised bed was $\sim 0.39 \mathrm{~kg} \mathrm{~kg}^{-1} \mathrm{C}_{6}$ sugars.

At identical pressure, it is fair to assume that the mass transport rate of products away from the reacting biomass particle is identical in the screen-heater and fluidised bed. Assuming that, the remarkable difference in the DP-distribution can be ascribed solely to the different hot vapour residence time of products in these two reactors; screen-heater $(\sim 20 \mathrm{~ms})$ and the fluidised $(\sim 1 \mathrm{~s}$,). Since the DP-distribution of $\mathrm{C}_{6} \mathrm{aS}$ in the fluidised bed could not be measured after $\sim 20 \mathrm{~ms}$, the experimentally obtained DP-distribution in screen-heater is used as model input for vapour phase cracking reactions. Fitting the vapour phase cracking reaction rate constant to a value of 
$k_{v}=0.8 \pm 0.1 \mathrm{~s}^{-1}$, accurately predicted the DP-distribution observed in the fluidised bed, see Figure 7.3 Note, for the prediction of $\mathrm{C}_{6} \mathrm{aS}$ DP-distribution of for the screenheater experiment of acid-leached pinewood, shown in Figure 7.3 newly fitted values for acid-leached pinewood of $\frac{k_{T, \text { avg }}}{k_{K}+k_{U}}(0.3 \pm 0.05)$ and $\frac{k_{K}}{k_{K}+k_{U}}(0.1 \pm 0.01)$ were used.

Scott et al. and Graham et al. varied the hot $\left(700{ }^{\circ} \mathrm{C}\right)$ vapour residence time of the products between 30 to $900 \mathrm{~ms}$ during the pyrolysis of cellulose $57 / 312$. They observed that between 30 to $300 \mathrm{~ms}$, the gas yield increased at the expense of liquid products and above $300 \mathrm{~ms}$ the lumped products yields remain constant. Hoekstra et al. performed the pyrolysis of pinewood in a fluidised bed at $500{ }^{\circ} \mathrm{C}$, in which the hot vapour residence time of products was varied between 1.5 to $16.5 \mathrm{~s} \frac{58}{}$. Upwards $\sim 4.5 \mathrm{~s}$, the authors reported no change in the lumped product yields, while the $D P_{1}$ anhydrosugar (levoglucosan) yield was found constant over the entire range of hot vapour residence time. Like reported in previous studies, also in this work, a decrease in the oil yield was seen with increasing hot vapour residence time (Table D.3 in Appendix D); however, a similar yield of $\mathrm{C}_{6} \mathrm{aS}$ was observed in screen-heater and fluidised bed. Gathered experimental evidence shows that bigger $\mathrm{C}_{6} \mathrm{aS}\left(\mathrm{DP}_{22}\right)$ undergo depolymerisation reactions in the hot vapour phase to form smaller DP $\mathrm{C}_{6} \mathrm{aS}$, and reconfirms the previous claim that $D P_{1}$ anhydrosugar is thermally stable in the time scale of a few seconds $\frac{58 / 313}{5}$. These findings also show that the volatile products (e.g. light oxygenated compounds), which can be considered as light oil, are most likely converted to gaseous species in the hot vapour phase leading to lower oil yields in the fluidised bed. 


\subsection{Conclusions}

In this chapter, the effect of pressure on the fast pyrolysis of acid-leached biomass is studied in a dedicated screen-heater (heating rate $\sim 5000{ }^{\circ} \mathrm{C} \mathrm{s}^{-1}$, fast quenching at $\sim$ $180^{\circ} \mathrm{C}, \mathrm{T}_{\mathrm{FS}}=515^{\circ} \mathrm{C}$ ), while varying the system pressure ( 0.005 to $\left.100 \mathrm{kPa}\right)$. It was found that: 1) at the lowest pressure, $73 \%$ of the poly- $\mathrm{C}_{6}$-sugars in the feed were recovered in the liquid product as $\mathrm{C}_{6}$-anhydrosugars $\left(\mathrm{C}_{6} \mathrm{aS}\right)$, while the mass fraction of $D P_{1}$ was only $10 \%, 2)$ With increasing pressure, upwards $20 \mathrm{kPa}$, the yield of $\mathrm{C}_{6} \mathrm{aS}$ was reached a plateau value of $\sim 40 \%$ and shift towards lighter $\mathrm{C}_{6} \mathrm{aS}$ in the DP-distribution was observed. A mathematical model, including depolymerisation and decomposition reactions of $\mathrm{C}_{6} \mathrm{aS}$, and mass transport, could predict, after parameterisation, the effect of pressure on the yield of $\mathrm{C}_{6}$ aS and the $D P_{1}$ mass fraction in the DP-distribution. Modelling results show that the pressure strongly affects the mass transport of products away from the hot reacting particle, consequently, changing the likelihood of chemical reactions.

Pyrolysis (at $485{ }^{\circ} \mathrm{C}$ and $55 \mathrm{kPa}$ ) of pinewood in screen-heater and fluidised bed resulted in the similar yields of $\mathrm{C}_{6} \mathrm{aS}$ with distinctively different DP distribution, the former being richer in $\mathrm{DP}_{32}$ than the latter. As a result of the long hot vapour residence time (screen-heater: $\sim 20 \mathrm{~ms}$ vs fluidised be: $\sim 1 \mathrm{~s}$ ), other volatile species (e.g. light oxygenated compounds) decompose to gas (or water) leading to lower oil yields, and depolymerisation of bigger $\mathrm{C}_{6} \mathrm{aS}\left(\mathrm{DP}_{\geq 2}\right)$ takes place to form lower DP $\mathrm{C}_{6} \mathrm{a}$. 
$\mathrm{C}_{8}$ 


\section{$C_{8}$}

\section{Conclusions and outlook}

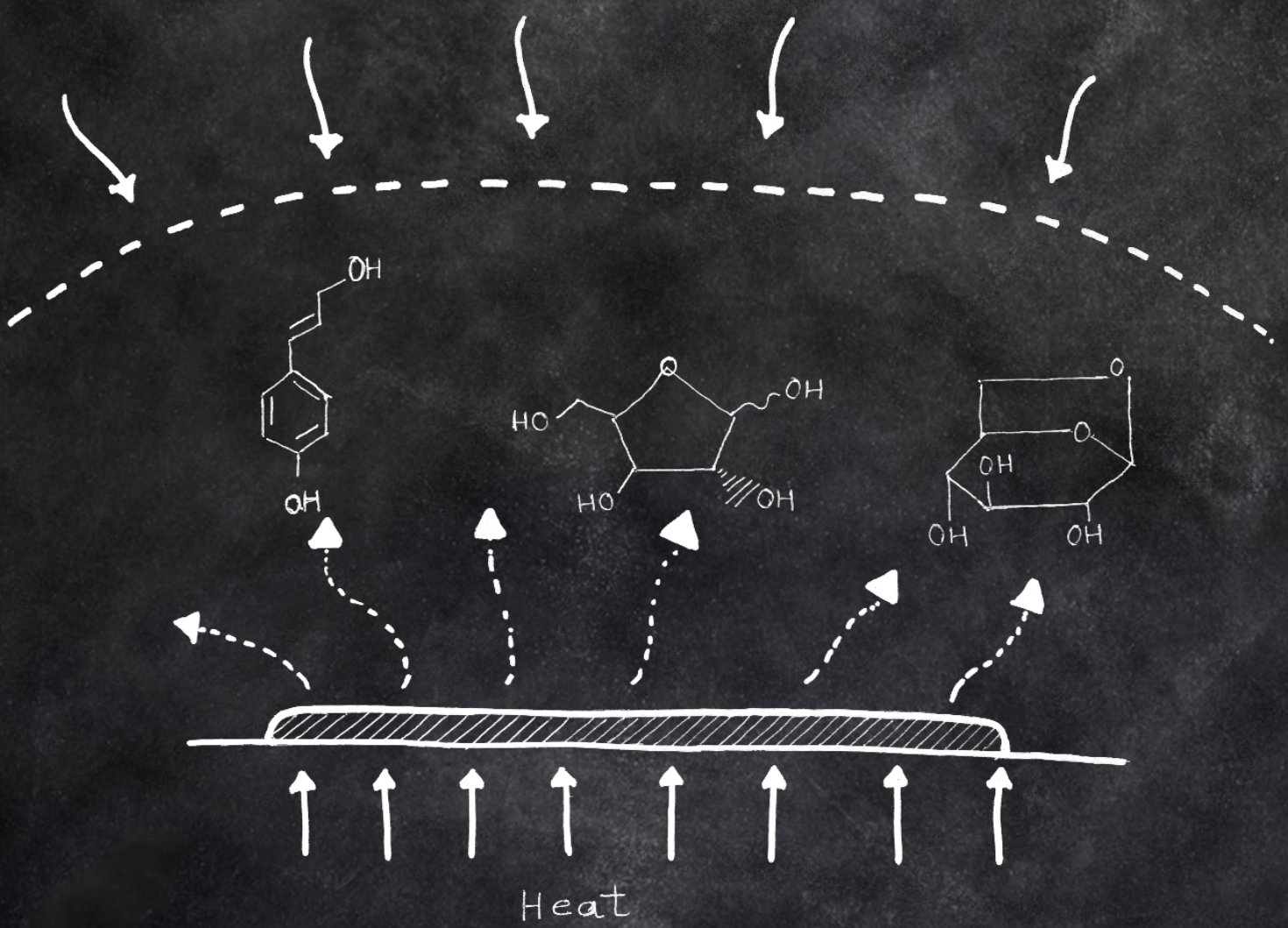


Lignocellulosic biomass, one of the environmentally friendly and renewable resources, is widely recognised as a promising way of addressing the problem of climate change by partially replacing finite fossil-based energy sources. Fast pyrolysis is one of the promising technologies in which lignocellulosic biomass is decomposed, at $\sim 500{ }^{\circ} \mathrm{C}$ and in the absence of oxygen, to produce oil, char and gas. Pyrolysis oil is a complex mixture of organic compounds of different chemical classes such as phenols, aldehydes, anhydrosugars. The pyrolysis of lignocellulosic biomass and its building blocks is governed by the three simultaneously occurring processes, which are 1) chemical reactions (cracking, polymerisation), 2) heat transfer and 3) mass transfer by evaporation, sublimation, random ejection (e.g. aerosols).

A dedicated screen-heater reactor was used, which was designed: 1) to minimise non-isothermality $\left.\left(5000{ }^{\circ} \mathrm{C} \mathrm{s}^{-1}\right), 2\right)$ to minimise reactions inside the reacting particle by maximising the escape rate of products away from the reaction zone, and 3) to minimise reactions outside the reacting particle by minimising hot vapour residence time ( $\sim 20 \mathrm{~ms})$ and fast quenching of the products $\left(\sim-180{ }^{\circ} \mathrm{C}\right)$. Specific tests were performed in a fluidised bed to investigate the effect of hot vapour residence time $(1-2 \mathrm{~s})$. The obtained pyrolysis products were characterised by qualitative and quantitative analysis. Suitability of gas chromatography for quantitative analysis of levoglucosan and hydroxyacetaldehyde was evaluated.

The work presented in this thesis focuses on advancing the current understanding of the chemistry and transport processes, and their interplay during fast pyrolysis of cellulose, lignin and lignocellulosic biomass. Mapping the yields of the building blocks of lignocellulosic biomass, i.e. (anhydro)sugars and aromatics, shall provide deeper insights into the role of the aforementioned interplay.

\section{Anhydrosugars}

The production of anhydrosugars from cellulose (Avicel PH 101) and lignocellulosic biomass was studied under various conditions ( 350 to $765^{\circ} \mathrm{C}$ and 0.005 to 100 $\mathrm{kPa}$ ) to gain an understanding of the underlying interplay between the chemistry and transport processes.

In screen-heater, at $\sim 520^{\circ} \mathrm{C}$, by maximising the escape rate of products $(<0.5 \mathrm{kPa})$ and quick quenching of products $(\sim 20 \mathrm{~ms})$, the anhydrosugar yields obtained from pure cellulose and acid-leached biomass were $85 \mathrm{wt} . \%$ (on cellulose) and $73 \mathrm{wt} . \%$ (on $\mathrm{C}_{6}$ sugars in acid-leached bagasse), respectively. Decreasing the escape rate of products away from the hot reacting particle, i.e. higher pressure during pyrolysis reduced the total yield of anhydrosugars and facilitated the depolymerisation of higher DP anhydrosugars to form smaller ones. For example, cellulose: 70\% (0.5 kPa) to 50\% (100 kPa); acid-leached 
bagasse: $73 \%(0.005 \mathrm{kPa})$ to $40 \%(100 \mathrm{kPa})$

The presence of oligo-anhydrosugars of the degree of polymerisation (DP) up to 6 for acid leached bagasse and even up to 11 for pure cellulose were observed. These finding showed that, at the hot reacting particle, the random chain scission is the dominant mechanism during the fast pyrolysis of pure cellulose and $\mathrm{C}_{6}$ sugars in biomass. However, the role of unzipping mechanism cannot be excluded.

From the pyrolysis of cellulose it was also found that, upwards $550{ }^{\circ} \mathrm{C}$, the depolymerisation reactions become very fast causing the conversion rate to be limited by the heat transfer and due to which the average reaction temperature becomes constant. Consequently, the selectivity of anhydrosugars $\left(\mathrm{DP}_{1}, \mathrm{DP}_{3}\right.$ and $\left.\mathrm{DP}_{4+5}\right)$ was found to be independent of the final screen temperature and the conversion of cellulose was finished in the heating trajectory.

The effect of hot vapour residence time was studied by pyrolysing in the fluidised bed (screen heater: $\sim 20 \mathrm{~ms}$ vs fluidised bed: $1-2 \mathrm{~s}$ ). Note, the heating rate of the sample in both reactors was comparable. At identical pressure and temperature, increasing the hot vapour residence time of volatile products did not decrease the total yield of anhydrosugar. It was found that the bigger anhydrosugars $\left(\mathrm{DP}_{\geq 2}\right)$ depolymerise in the hot vapour phase to form smaller DP anhydrosugars.

The catalytic effects of potassium (for cellulose) and of AAEMs (for biomass) on the sugar production were evident even in the timescale of milliseconds. Consequently, for cellulose, a $\sim 50 \%$ reduction in the oil yield, a significant increase in the gas yield $\left(<0.01\right.$ to $\left.0.15 \mathrm{~kg} \mathrm{~kg}^{-1}\right)$ and a decrease in glucose recovery (70 \% to almost zero) were observed. Pyrolysis at reduced pressure, i.e. by fast removal of products from the hot reaction zone, can improve the sugar yields only for low AAEMs content feedstock $(\sim 0.01$ wt.\%). Therefore, a pre-treatment step is mandatory for AAEMs rich feedstock $(>0.1$ wt.\%) if the aim is to produce sugars.

It can be said that the fast pyrolysis behaviour of pure cellulose (Avicel PH 101) and the $\mathrm{C}_{6}$ sugars in lignocellulosic biomass are similar in multiple aspects.

Oudenhoven et al. have shown that by pyrolysing acid-leached biomass in a fluidised bed at $480{ }^{\circ} \mathrm{C}$, sugar recovery up to $40 \%$ can be achieved ${ }^{71}$. In this work, acidleached biomass particles of $\sim 80 \mu \mathrm{m}$ (no capillaries 314 ) were pyrolysed in screen-heater at $515^{\circ} \mathrm{C}$ with reduced pressure $(0.005 \mathrm{kPa})$, i.e. maximised escape rate of products away from the hot reacting particle. Consequently, $\sim 50 \%$ sugar recovery has been achieved from the pyrolysis of biomass. A further increase in pyrolysis temperature would reduce sugar recovery 71 . Therefore, in the author's view, improving sugar recovery from 
biomass beyond $50 \%$ will be challenging.

\section{Phenolic compounds}

The production of phenolic compounds was studied from isolated lignin. For the investigation, lignins isolated via cold water precipitation of pyrolysis oil, organolsolv process and milled wood process were used. The molecular weights of isolated lignins were between 350 and $1900 \mathrm{Da}$, and the number of ether linkages varied between 0 to 60 per 100 aromatic units.

In this work, $3.5 \mathrm{wt}$.\% yield of mono-phenolic compounds was achieved from sigma organosolv lignin in a screen-heater $\left(420^{\circ} \mathrm{C}\right.$ and $\left.100 \mathrm{kPa}\right)$, whereas for milled wood lignin (richest in ether linkages) it was $<1 \mathrm{wt} . \%$. It was found that due to the influence of pressure on the mass transport rate, at higher pressure lighter oils $(\sim 400 \mathrm{Da})$ and lower pressure heavier oils $(\sim 800 \mathrm{Da})$ were collected. At any given pressure, lighter molecules rapidly escape from the hot reacting particle, restricting the extent of cracking reactions, thereby, hindering the production of mono-phenolic compounds $\left(\mathrm{DP}_{1}\right)$. The molecular weight distribution was found to be one of the important characteristics of the lignin feedstock. Modelling results showed that the heavier molecules tend to polymerise faster than lighter molecules. HSQC NMR analysis of lignins and its oils showed that the yields of oil and char and the number average molecular weight of oils were found to be independent of the number of ether linkages in the lignin feedstock. The system pressure was identified as the main steering wheel to manipulate the product yields and the molecular weight distribution of the oils.

In the literature, it is considered that the pyrolysis of lignin follows the radical mechanism and the radicals formed during pyrolysis supposedly favour different reaction pathways, e.g. hydrogen abstraction to form mono-phenolic compound or termination to form a heavy molecule. These radical reactions can take place in/on the hot reacting particle or outside, i.e. in the (hot) vapour phase, or during oil recovery. However, from the experimental results of this thesis, no conclusions can be drawn regarding these radical reactions. Further research is needed to get deeper insights into the competing reaction pathways. New insights can be gained by: 1) adding radical stabilising agent during lignin pyrolysis which may prevent unwanted coupling reactions of radicals, 2) in situ NMR/EPR lignin pyrolysis shall provide real-time occurring changes in lignin structure as well as in the radical concentrations.

It appears that, under the pyrolysis conditions studied in this work, the production of dimeric, trimeric (or bigger) phenolic compounds is being favoured over mono- 
phenolic compounds. This raises the question of whether fast pyrolysis of lignin is the way forward for the production of mono-phenolic compounds. Solely from the perspective of the mono-phenolic compound yields obtained from the fast pyrolysis of lignin, other options appear more lucrative. Rahimi et al. showed that lignin could be converted to $52 \%$ mono-phenolic compounds by oxidation of $\beta-\mathrm{O}-4$ linkages followed by cleavage with formic acid 315 . Shuai et al. have shown that the addition of formaldehyde during biomass pre-treatment produces lignin, which can be converted to $78 \%$ mono-phenolic compounds via hydrogenolysis 316 .

\section{Main message}

The fast pyrolysis of lignocellulosic biomass and its building blocks is undoubtedly governed by the interplay between the chemistry, heat transfer and mass transfer. As already known, high heating rates $\left(5000{ }^{\circ} \mathrm{C} \mathrm{s}^{-1}\right)$ of the sample are required to maximise the production of oil. The hot vapour residence time $(1-2 \mathrm{~s})$ does not affect the total anhydrosugar yields, however, it affects the DP distribution of anhydrosugars. The molecular weight (distribution) of isolated lignins is one of the important parameter, which has a significant influence on the pyrolysis product distribution. Below $500{ }^{\circ} \mathrm{C}$, the temperature of the pyrolysis was found to have a significant impact on the yields of oil and the composition of the oil. Upwards $550{ }^{\circ} \mathrm{C}$, the reactions become very fast, causing conversion rate to be limited by the heat transfer rate, consequently making the actual reaction temperature constant. Resultantly, a further increase in temperature does not affect the yield of oil and its composition. The system pressure is the key parameter, which alters the residence time of products in/on the hot reacting particle, thereby, providing a means to steer the yields and composition of the products of pyrolysis. 
$\mathrm{C}_{8}$ 
Appendices

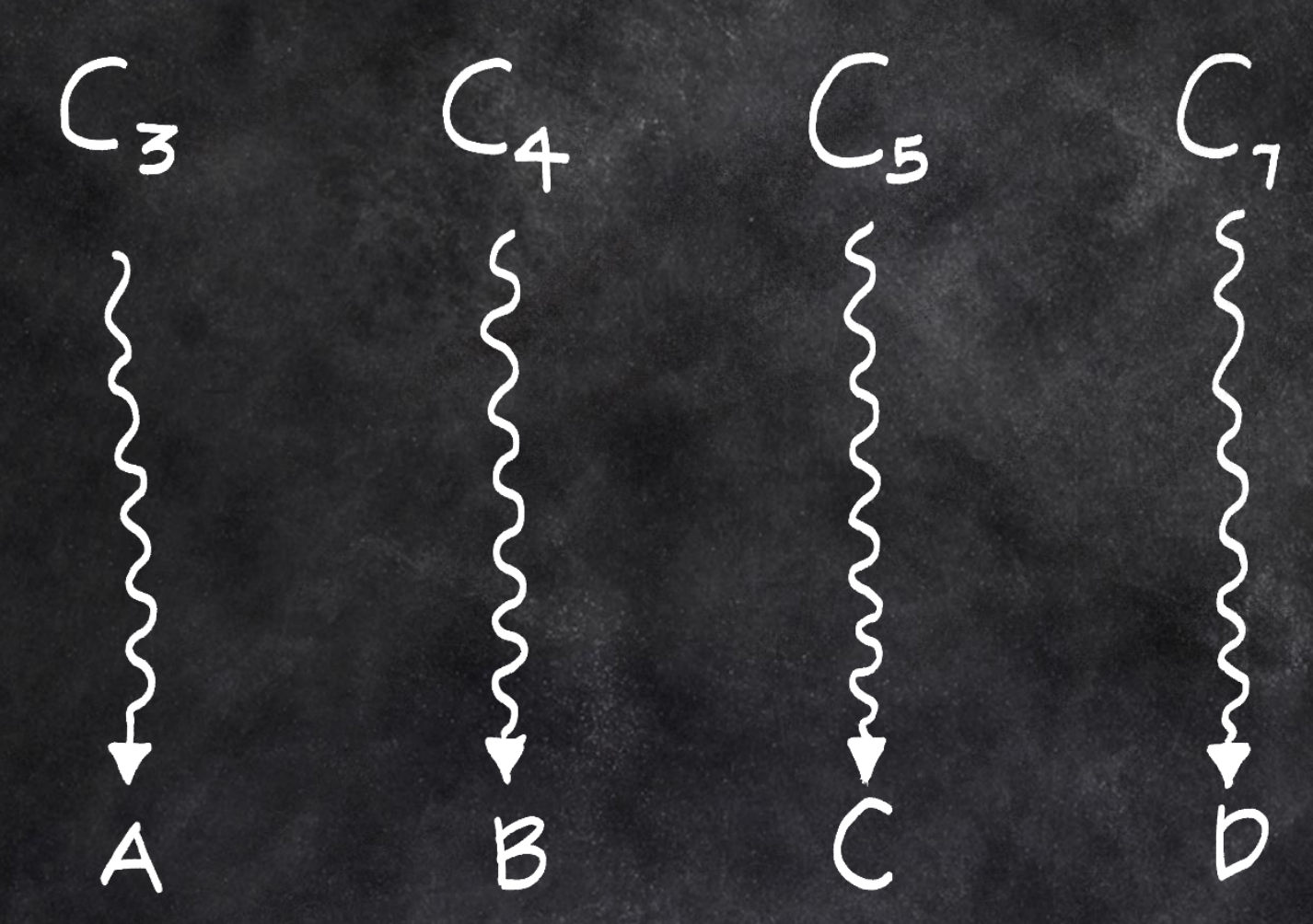


$\mathrm{C}_{8}$ 


\section{A}

Supporting information for Chapter 3 

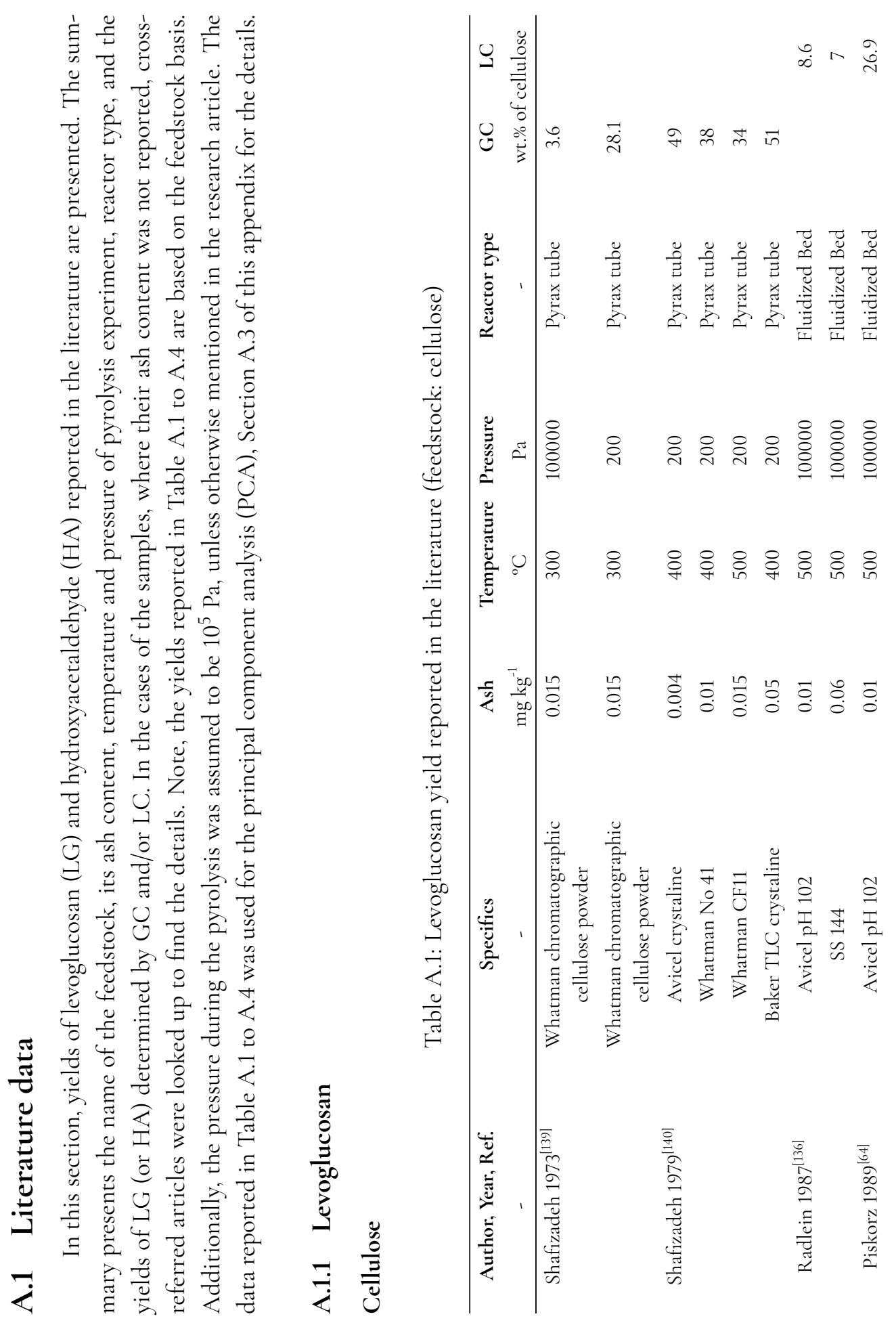
$\wedge m \stackrel{\infty}{\infty} \stackrel{\infty}{+}$

ㄱํำㅇำ

ㅇำ

iु่ ₹

$\stackrel{2}{3}$

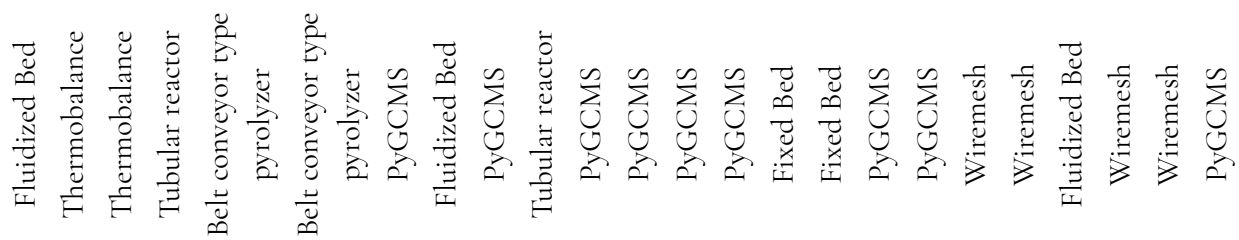

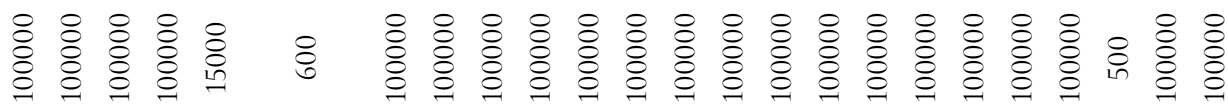

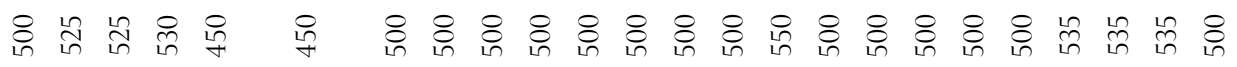

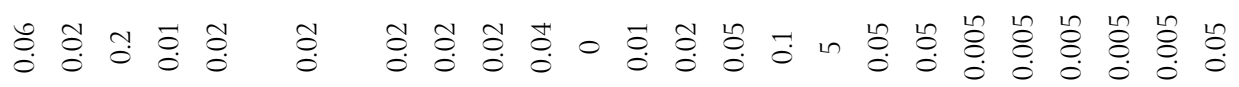

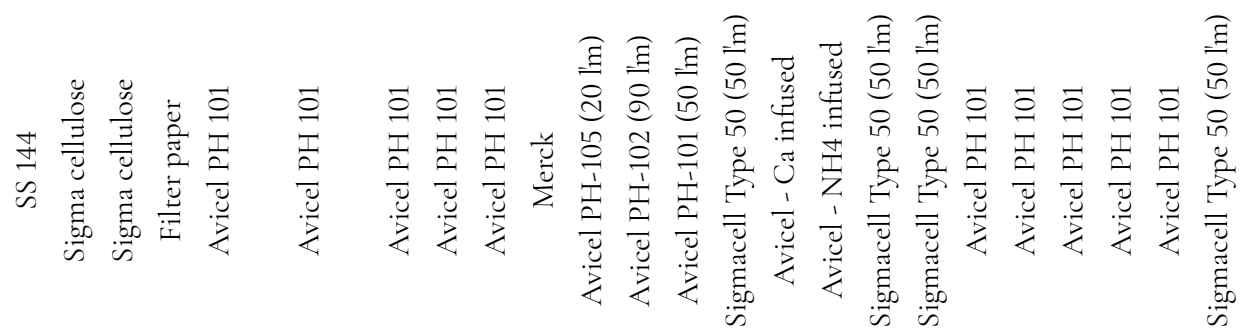

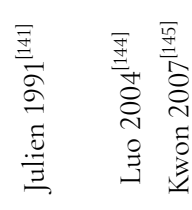

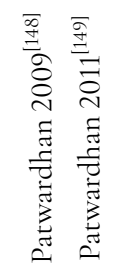

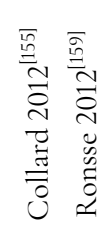

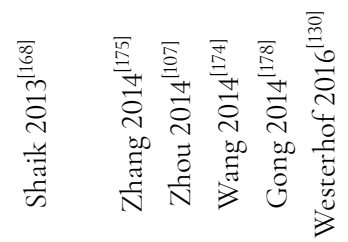

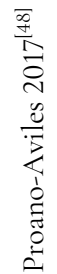


负

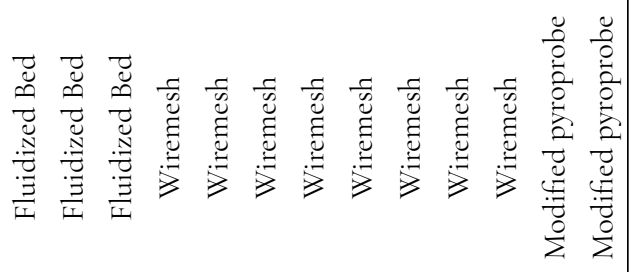

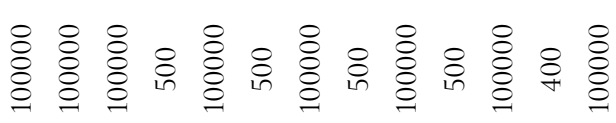

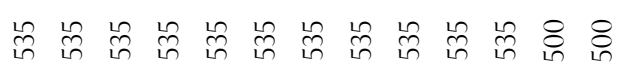

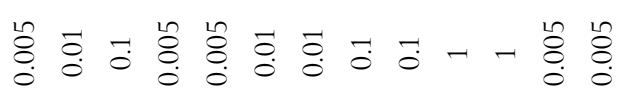

A

$\overrightarrow{0} \overrightarrow{0} \overrightarrow{0} \overrightarrow{0} \overrightarrow{0} \overrightarrow{0} \overrightarrow{0} \overrightarrow{0} \overrightarrow{0} \overrightarrow{0} \overrightarrow{0} \overrightarrow{0}$

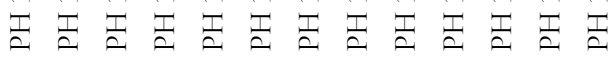

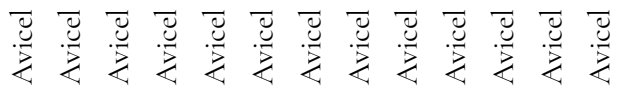

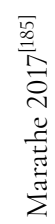

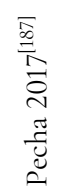




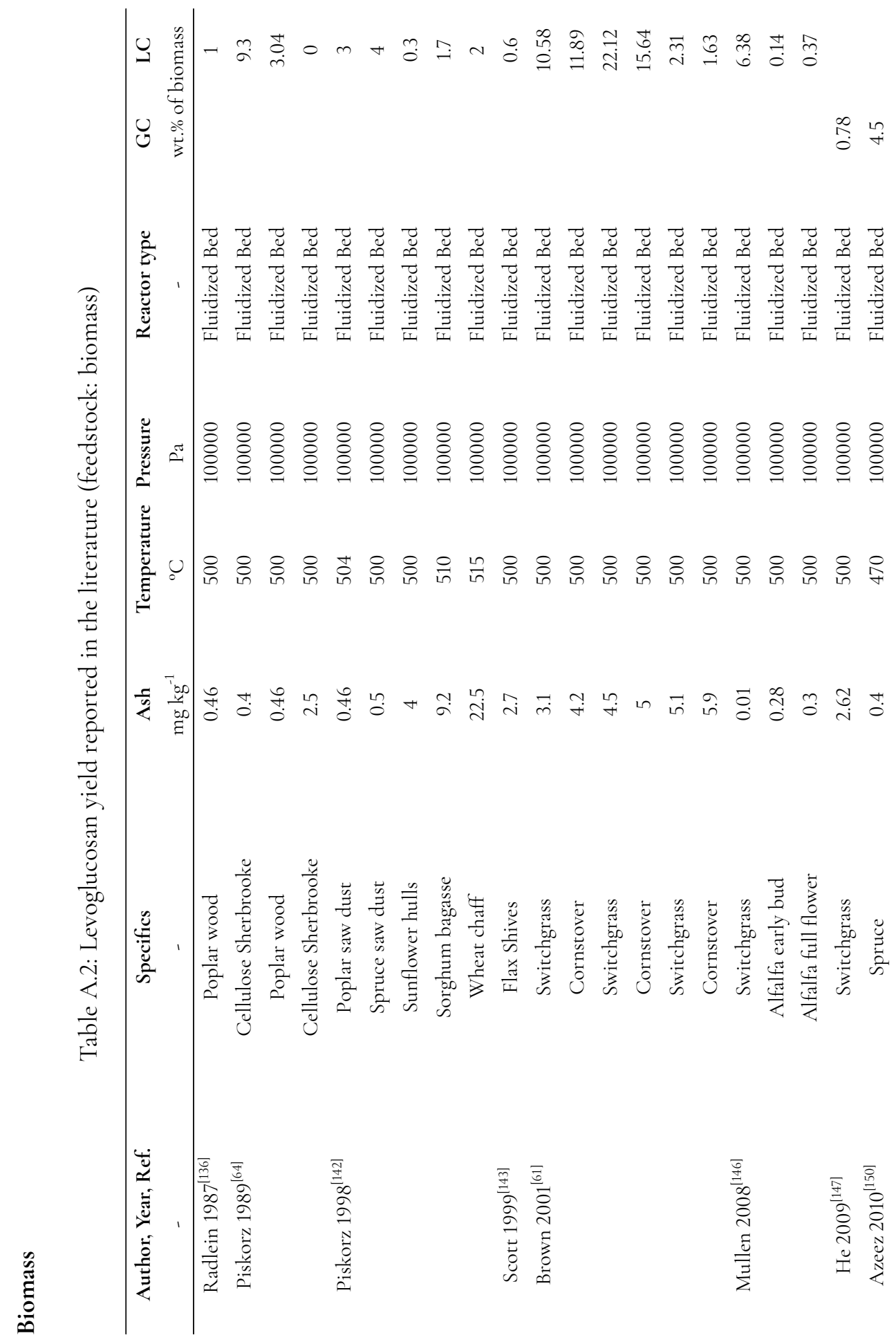




$$
\text { 十莫娄 }
$$

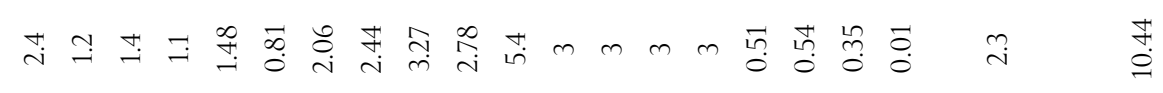

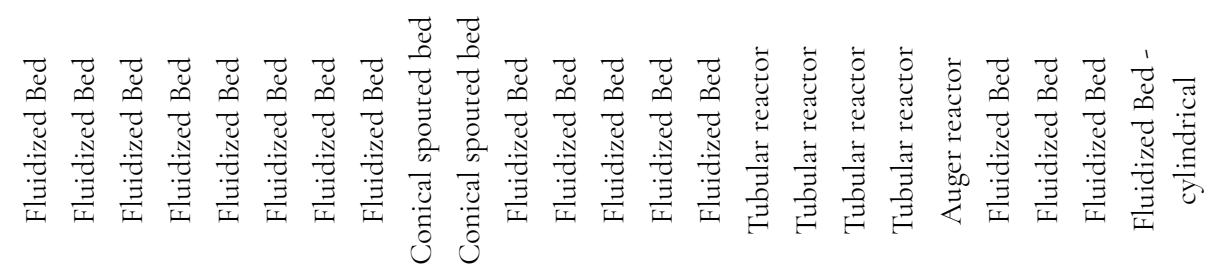

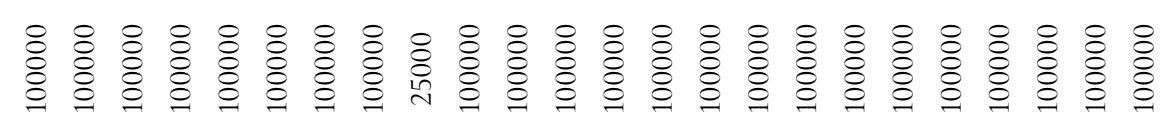

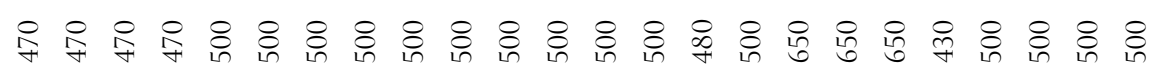

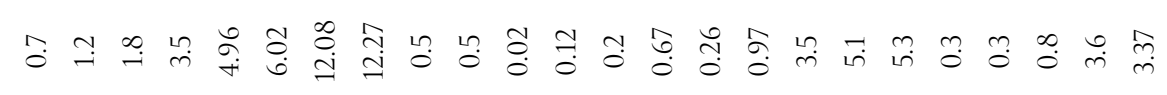

A

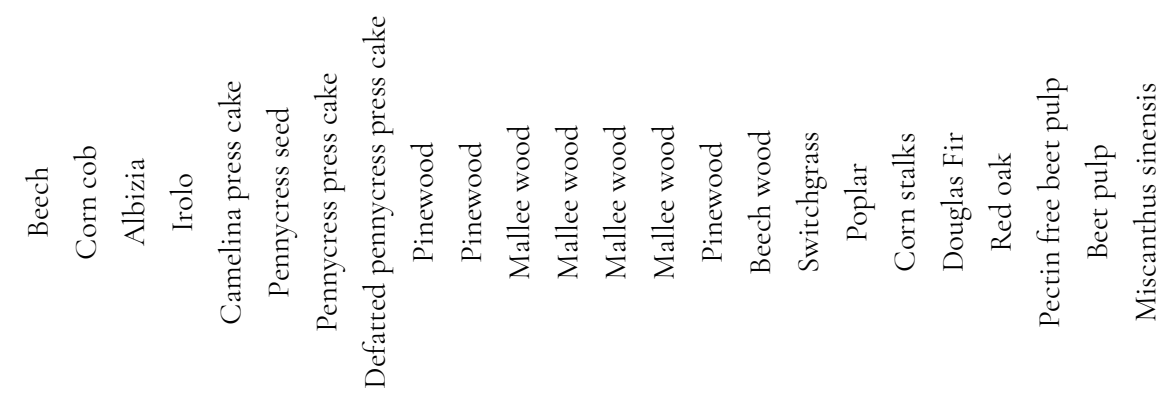

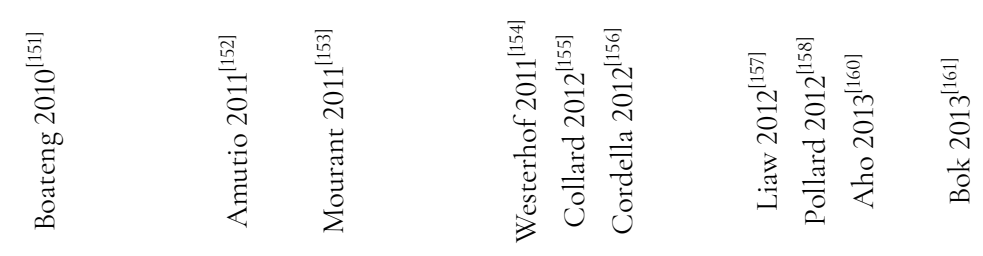




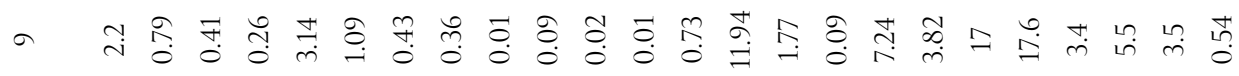

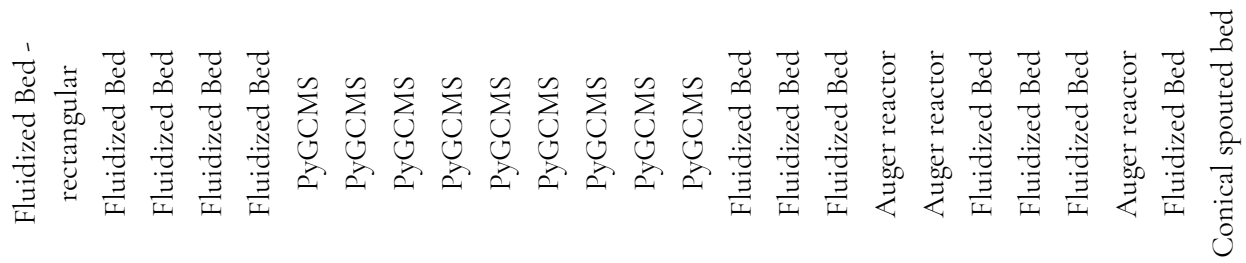

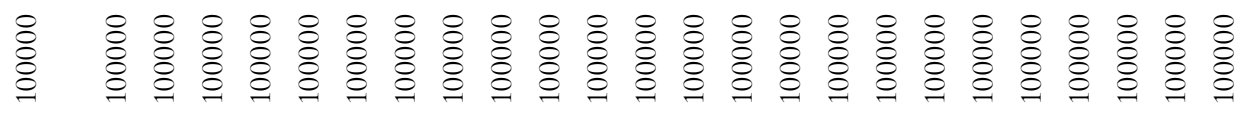

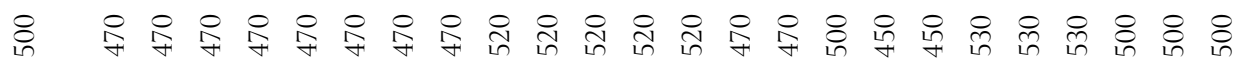

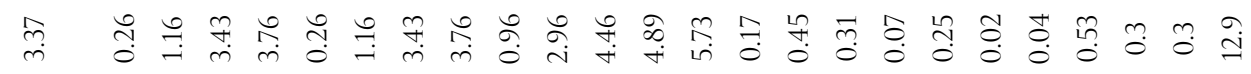

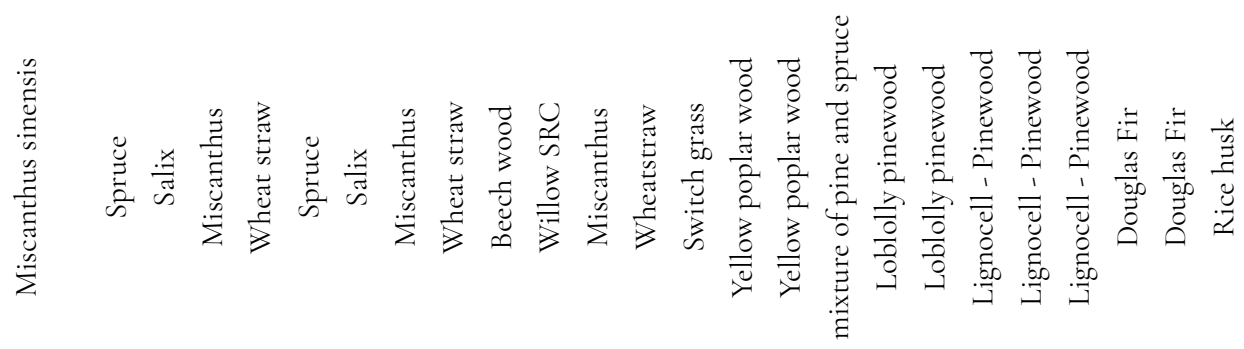

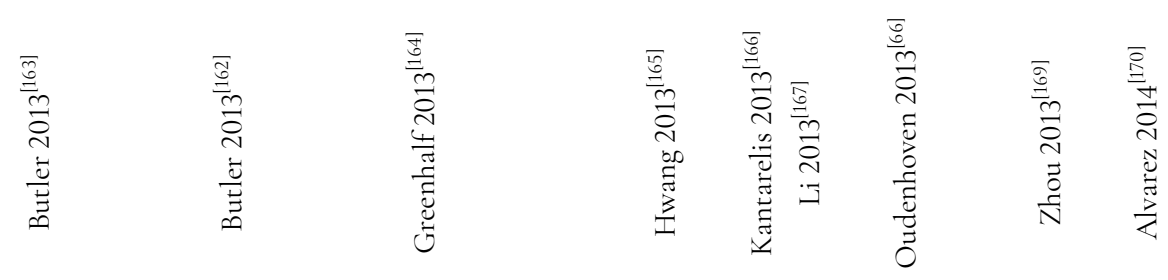




\section{ㄱํำ}

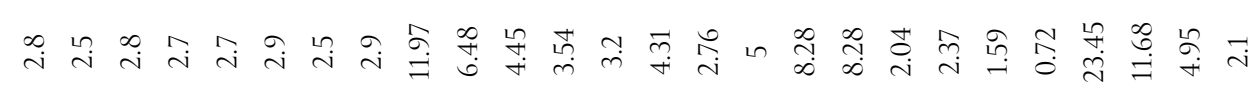

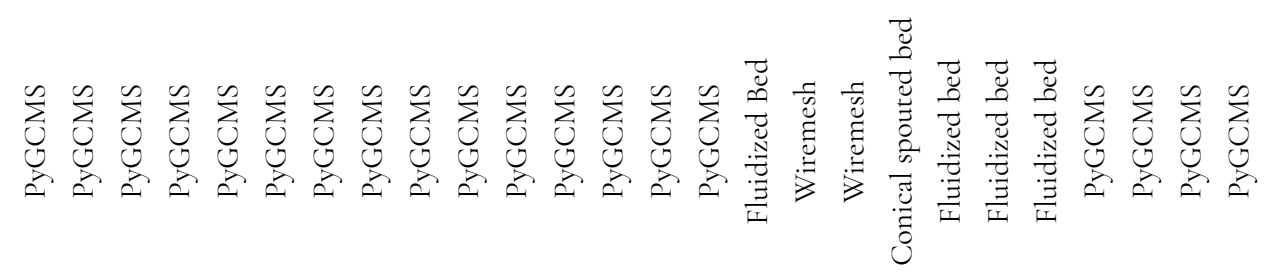

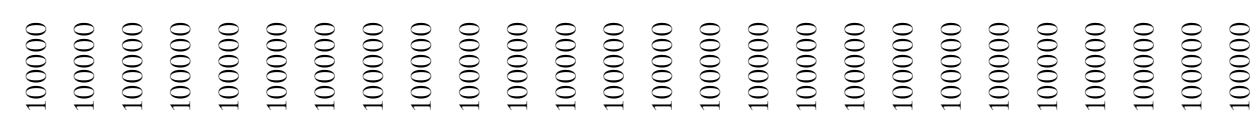

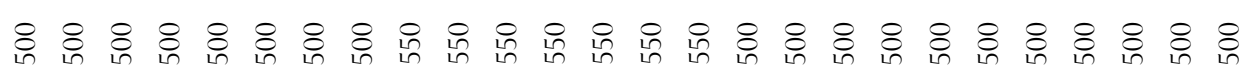

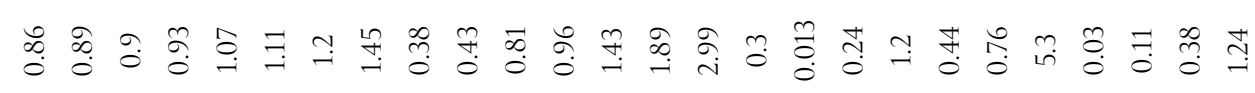

A

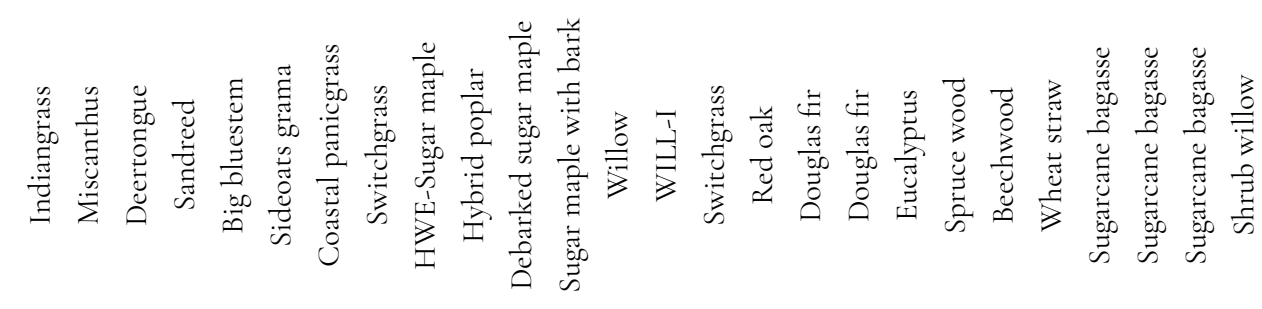

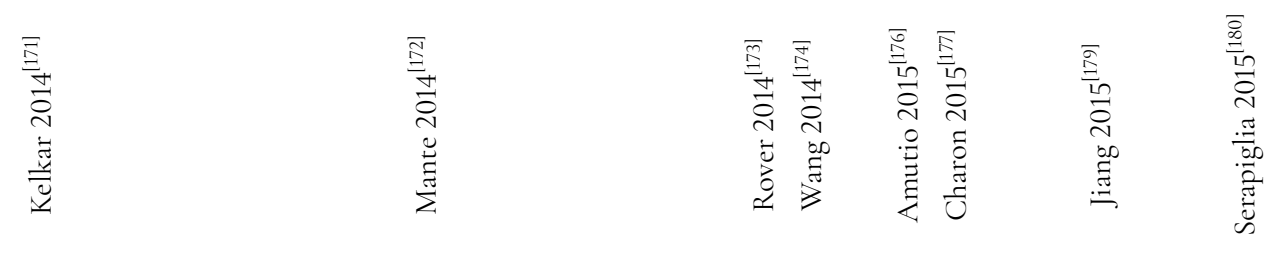




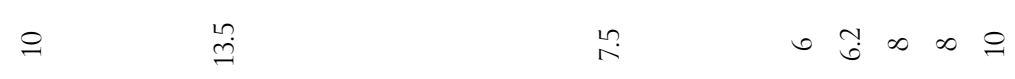

đֶ讠

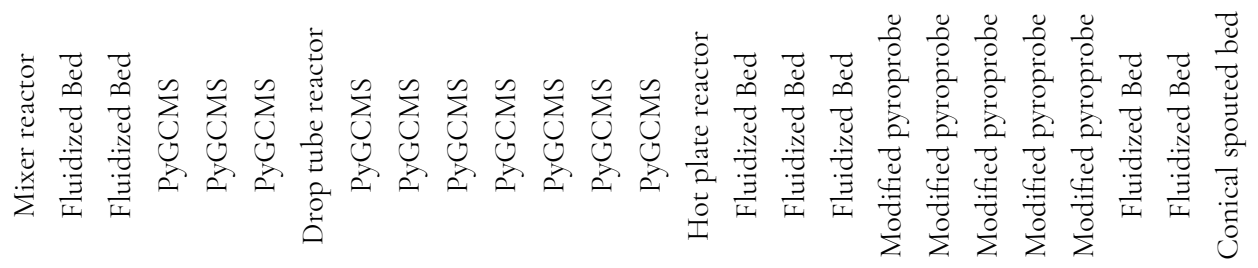

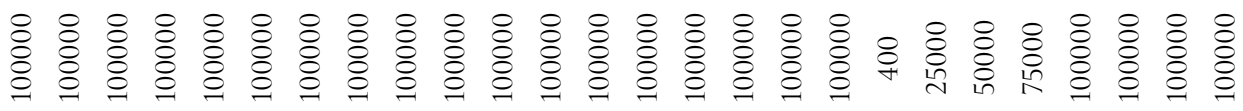

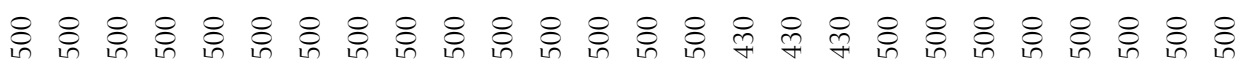

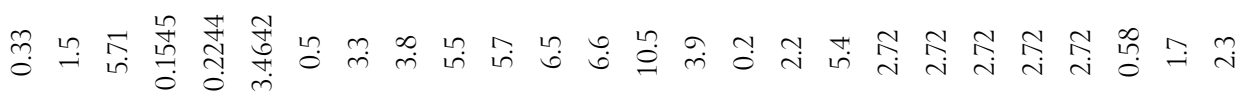

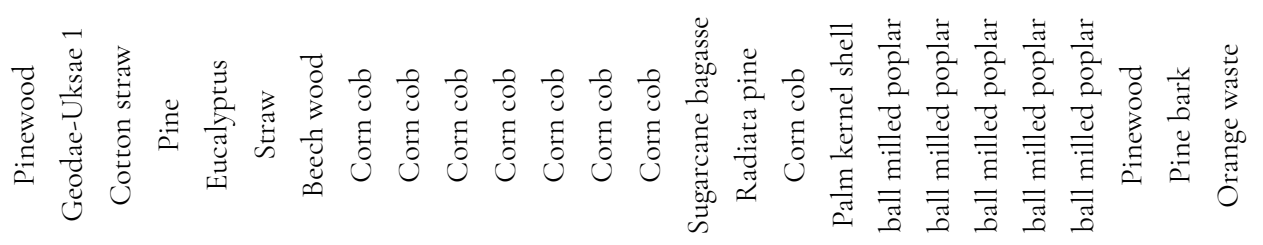

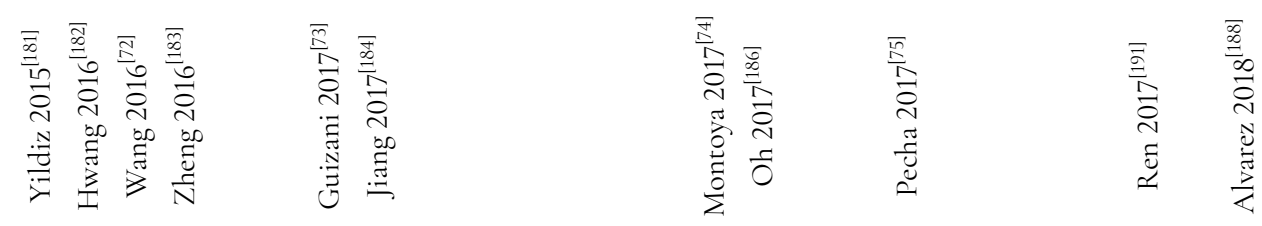




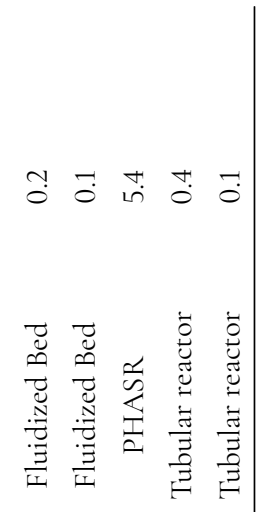

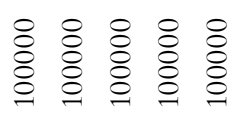

윤유뉴

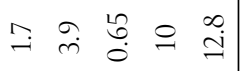

A

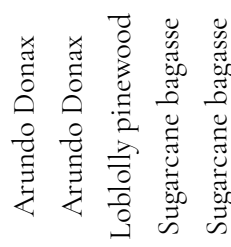

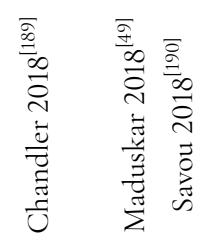




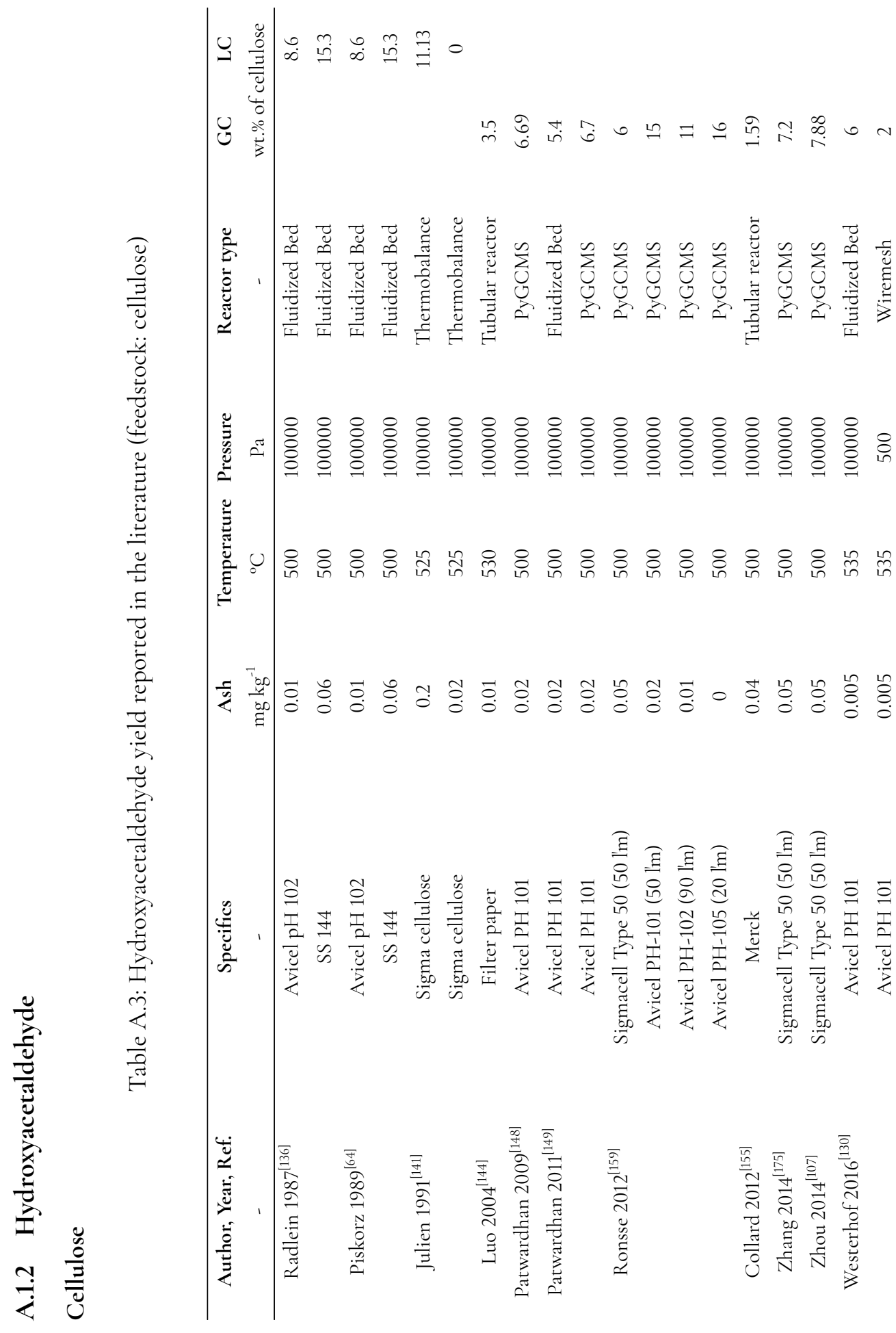




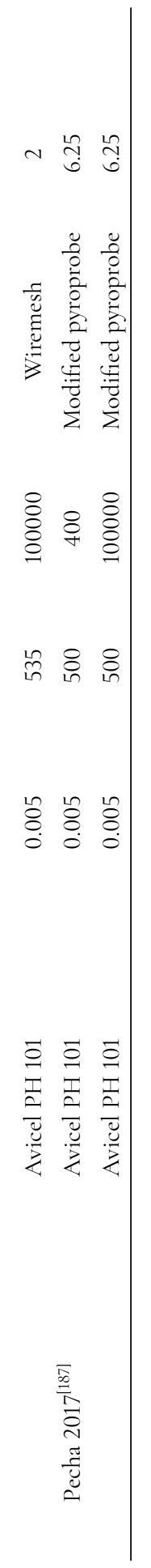




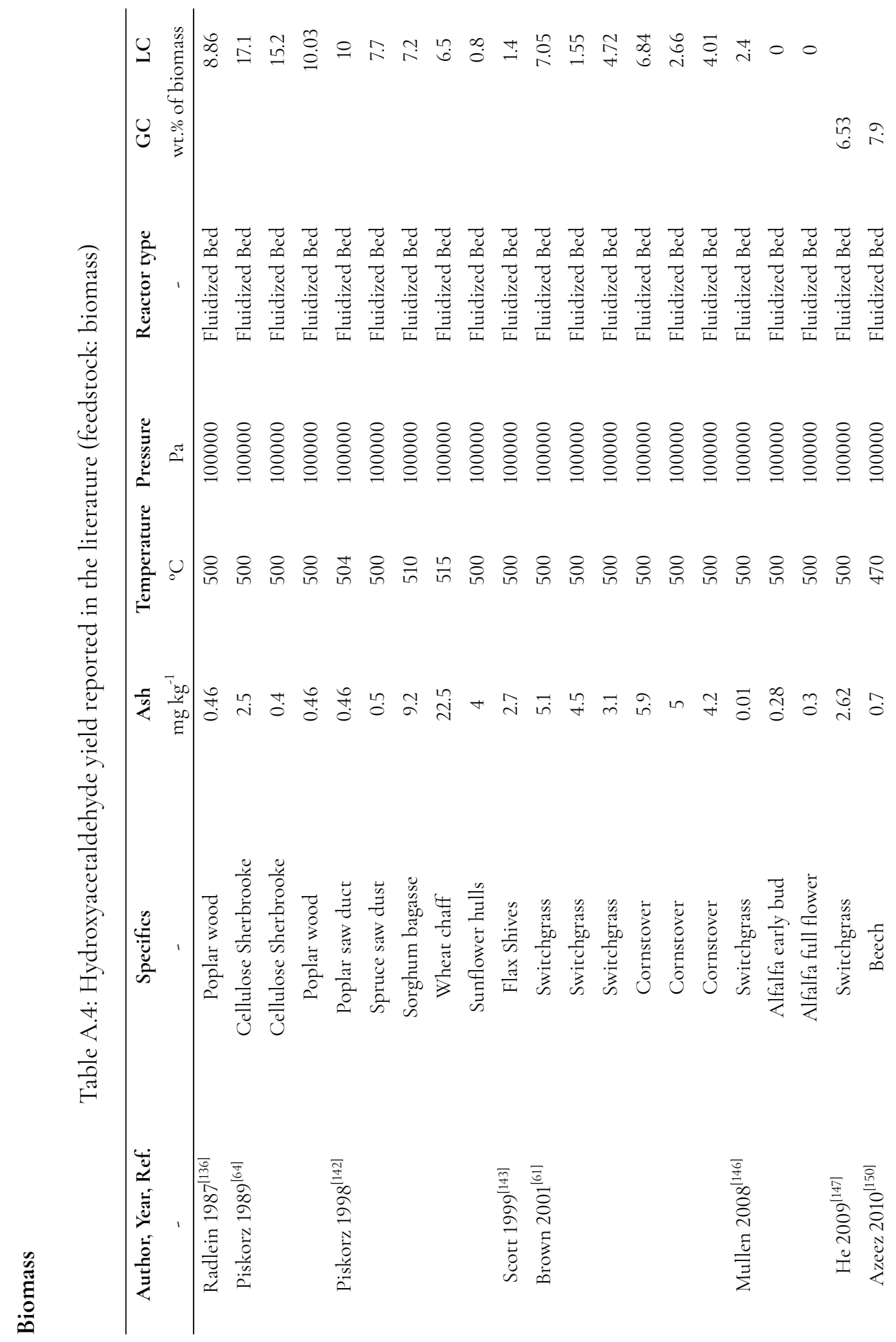




$$
\stackrel{+}{\pi}
$$

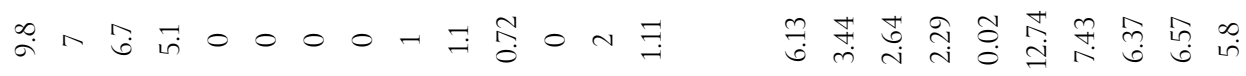

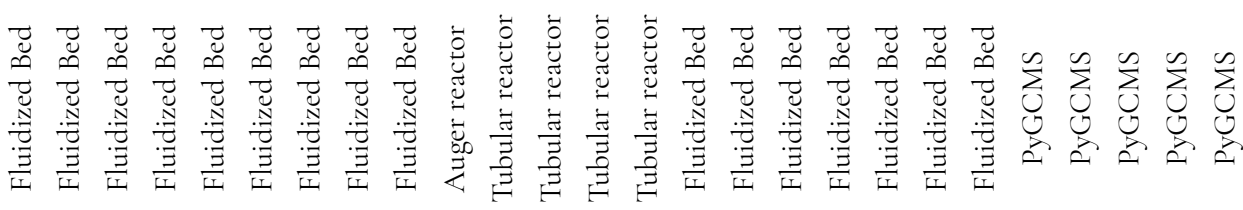

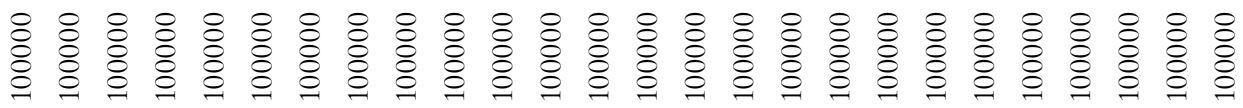

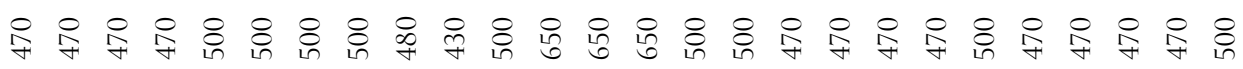

サ. 냉

A

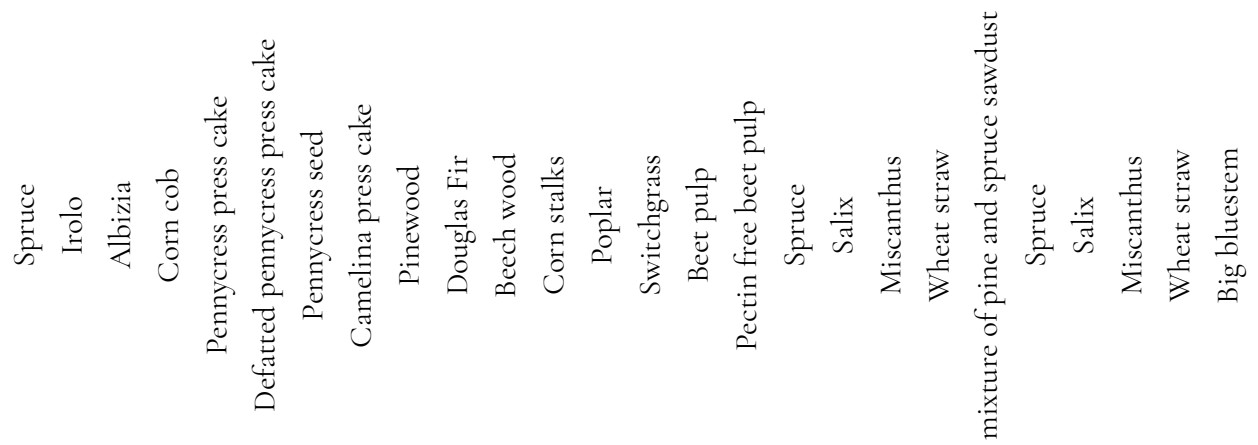

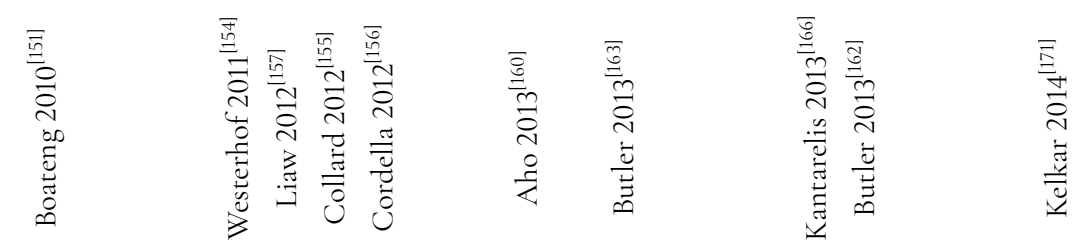




\section{$\stackrel{8}{8}$}

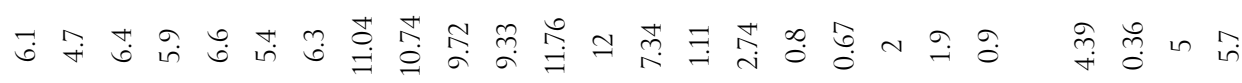

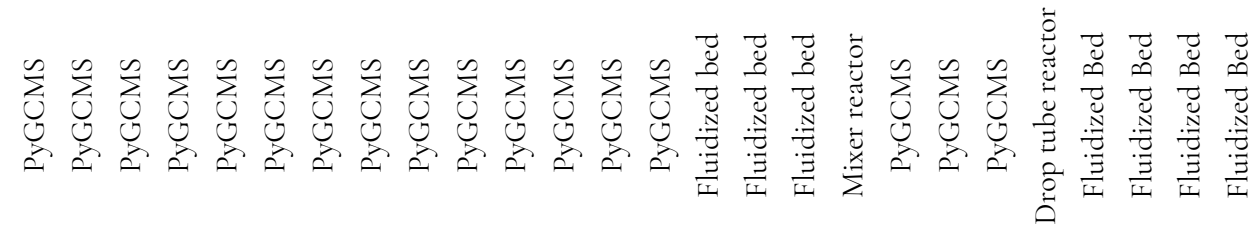

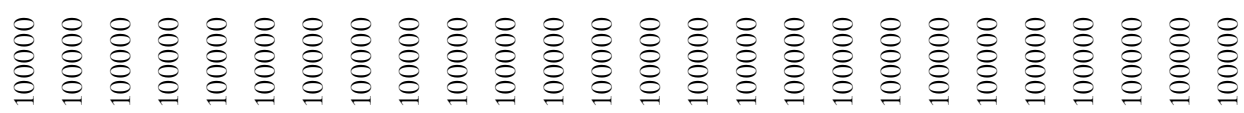

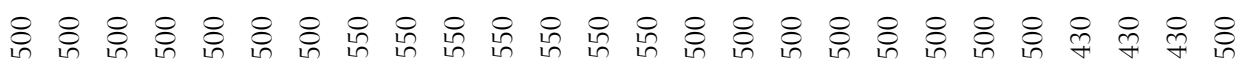

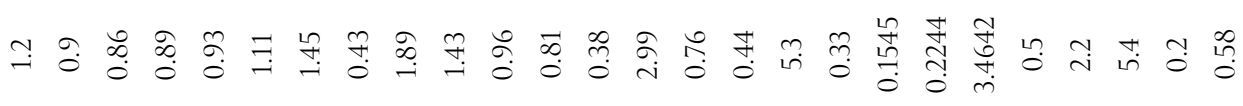

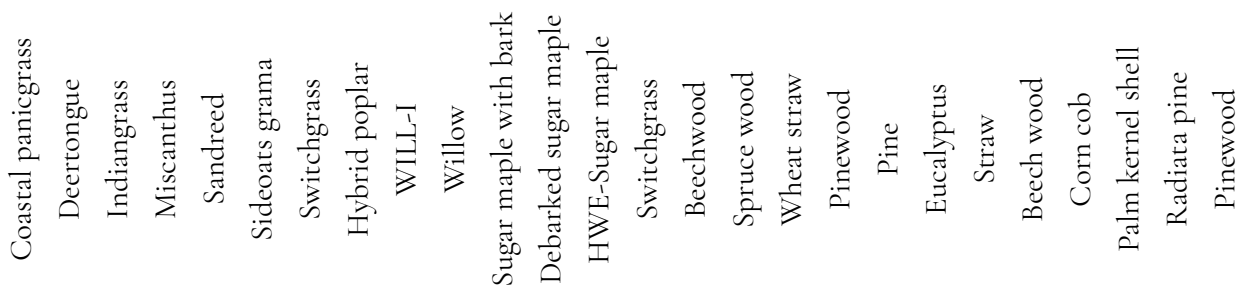

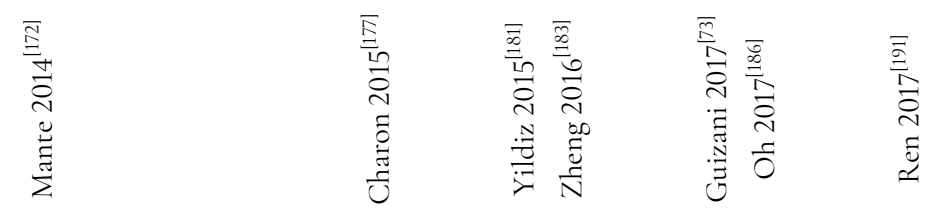




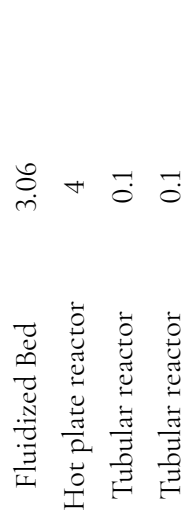

$\begin{array}{llll}8 & 8 & 8 & 8 \\ 8 & 0 & 0 & 0 \\ \circ & 0 & 0 & 0 \\ 0 & 0 & 0 & 0\end{array}$

๖

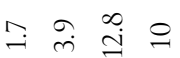

A

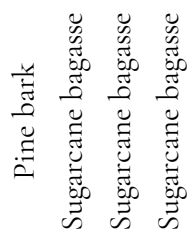

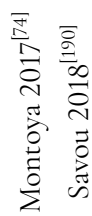




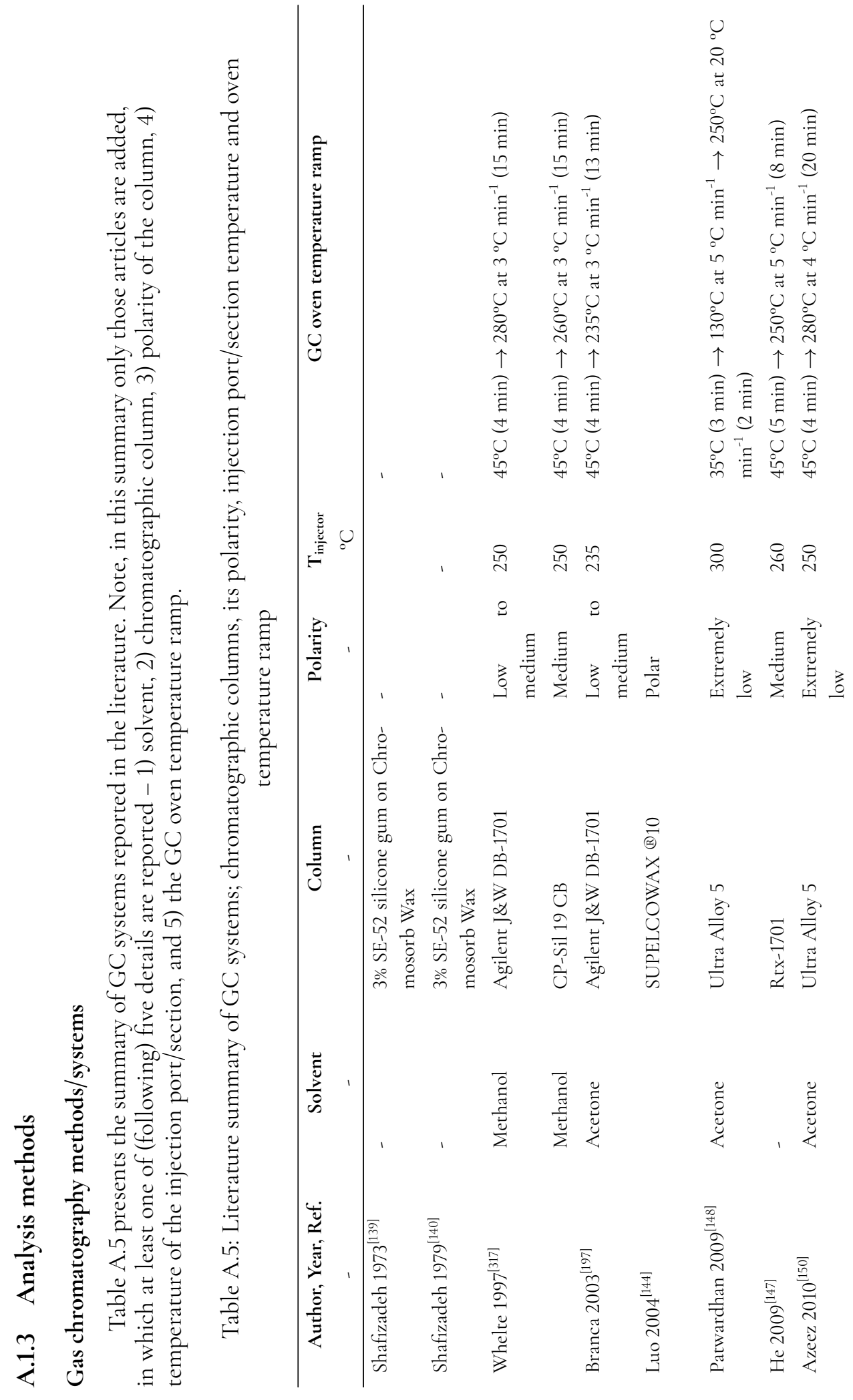




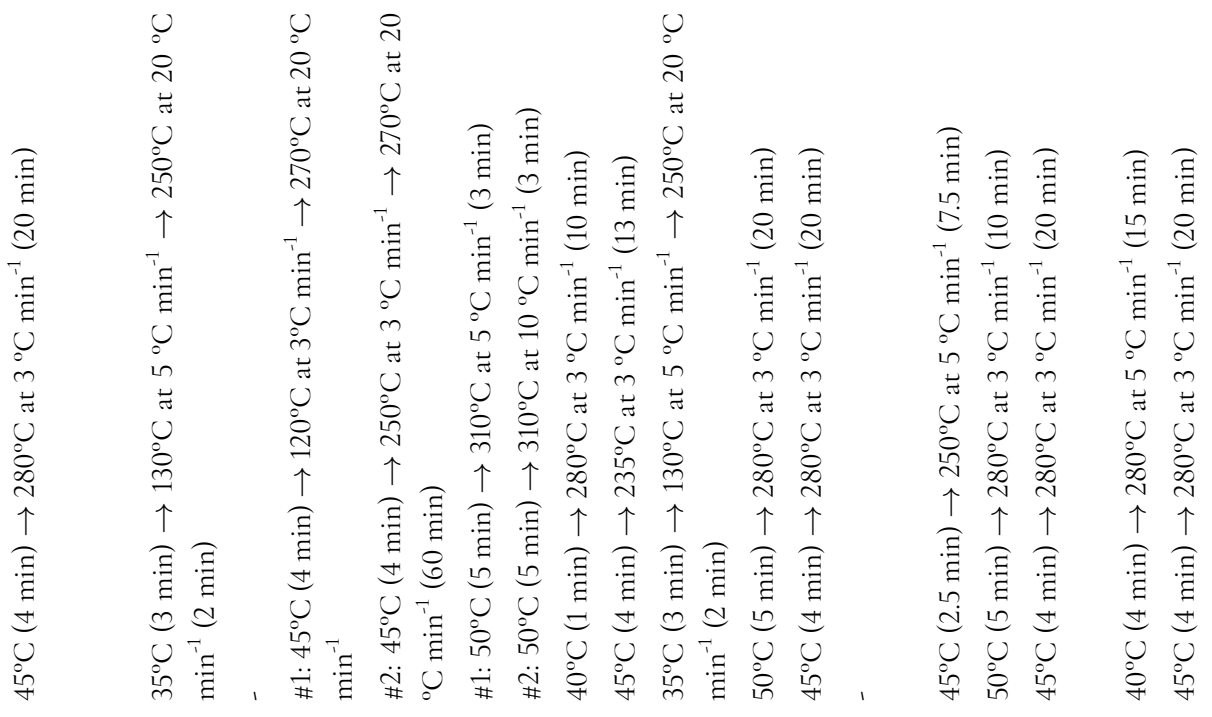

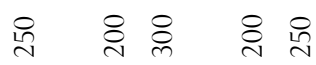

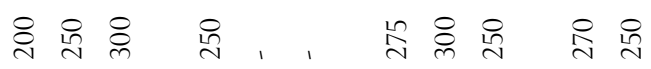

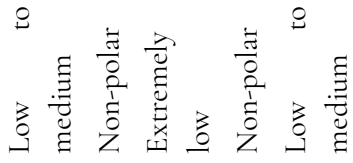

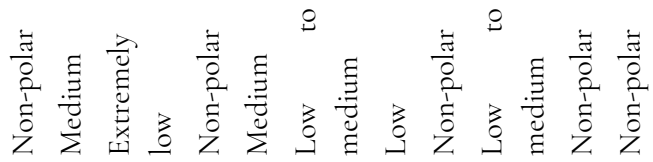

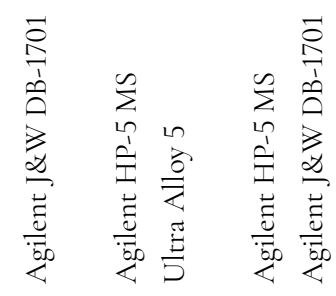

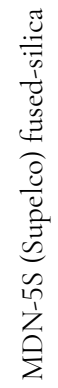

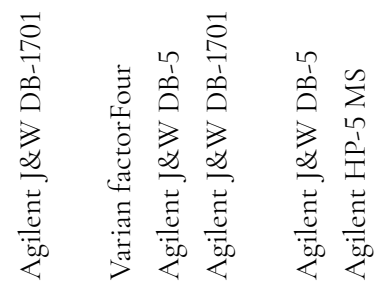

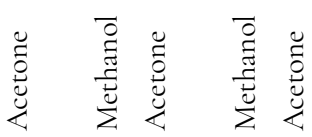
動章

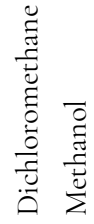

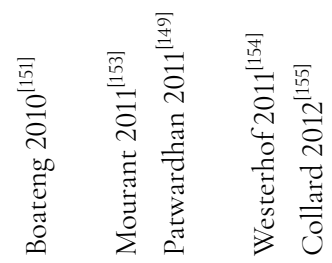
圈圈署 翼最

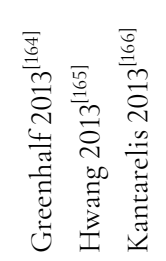<smiles>O=C(S)C1CCC1</smiles> 


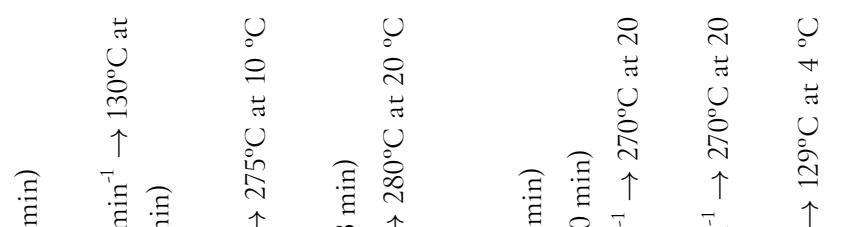

(1)

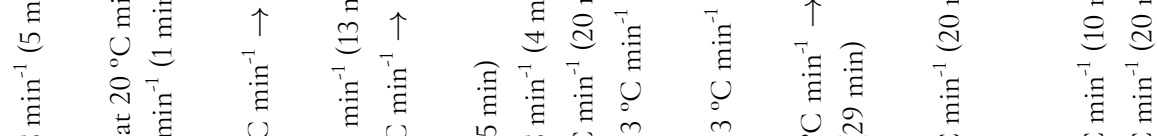

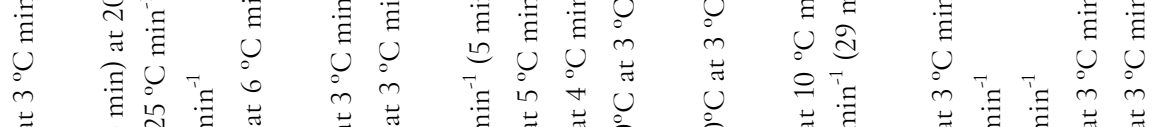

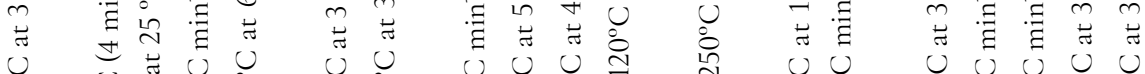

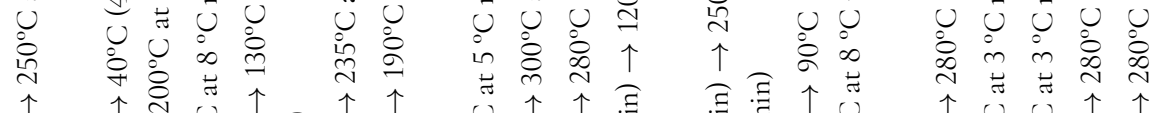

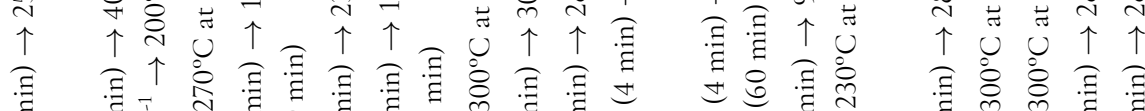

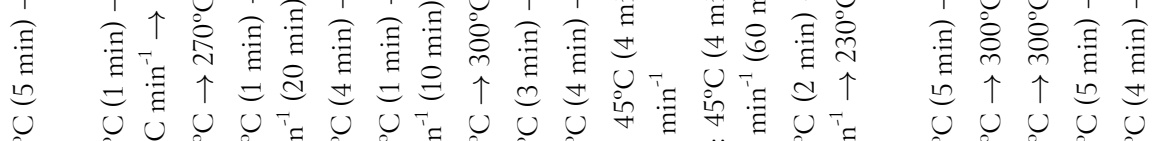

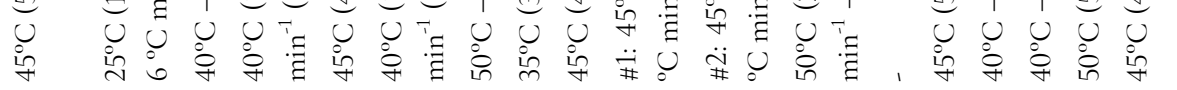

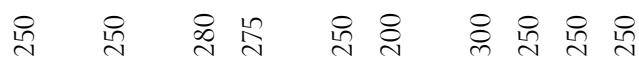

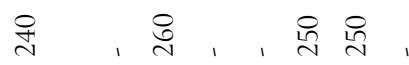

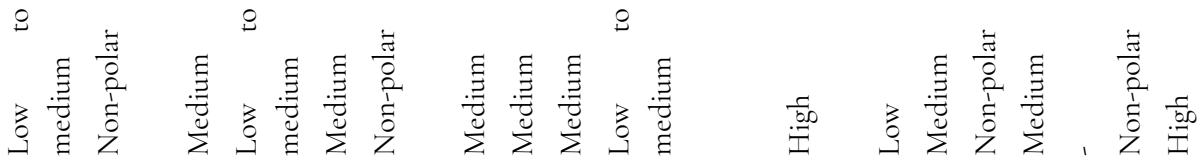

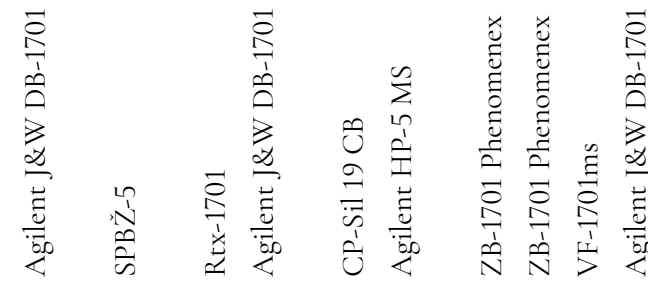

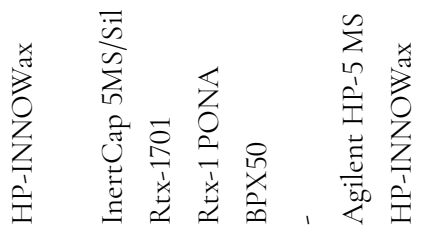

毫畜

$\sqrt{\underline{1} \frac{1}{2}}$

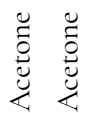

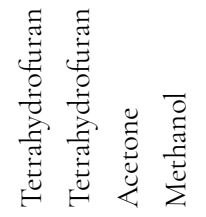

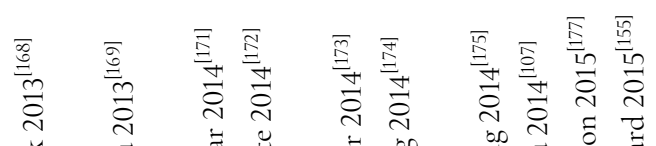

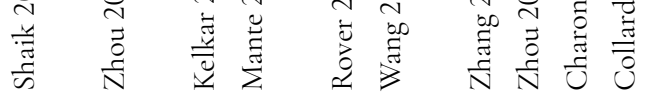

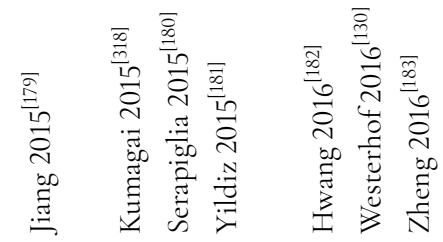




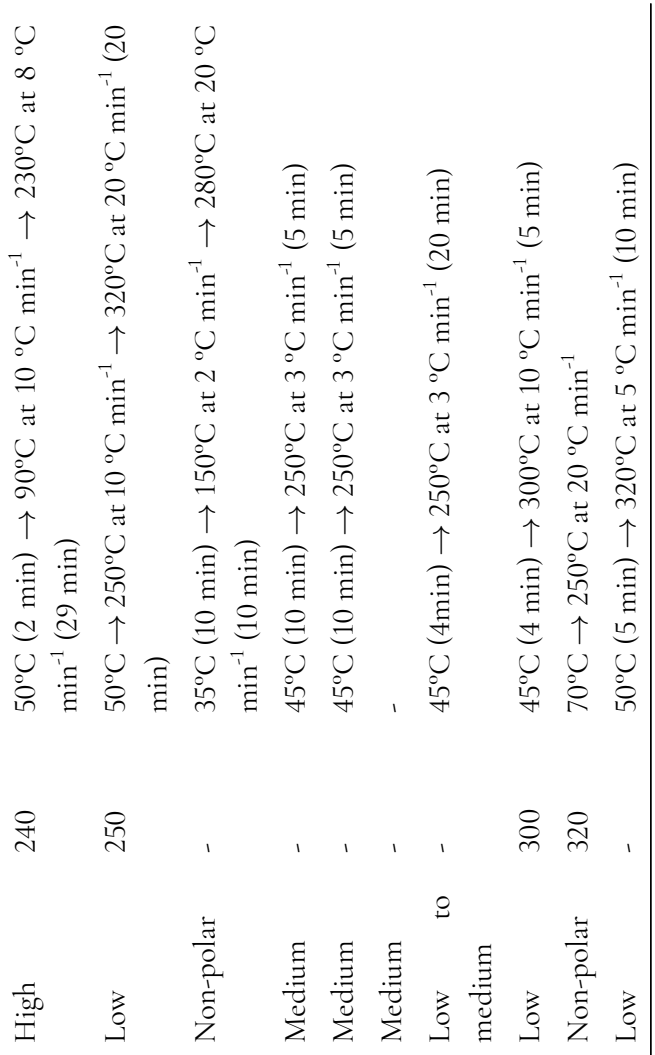

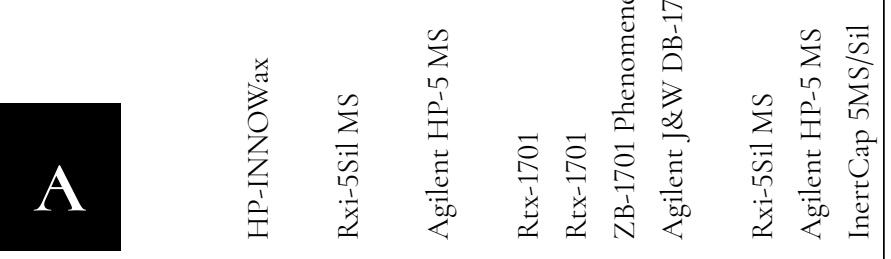<smiles>C1CCC1</smiles>

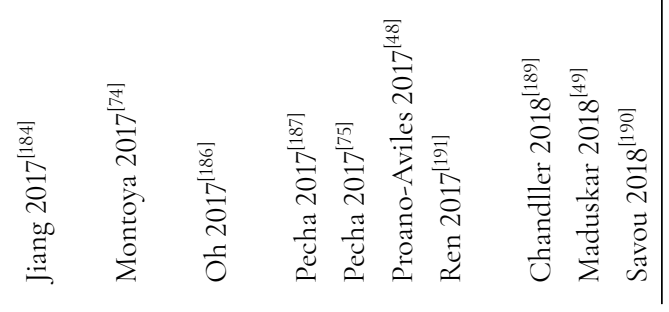




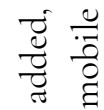

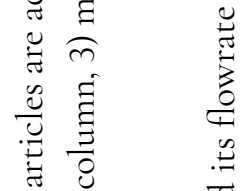

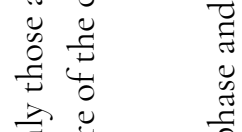

至

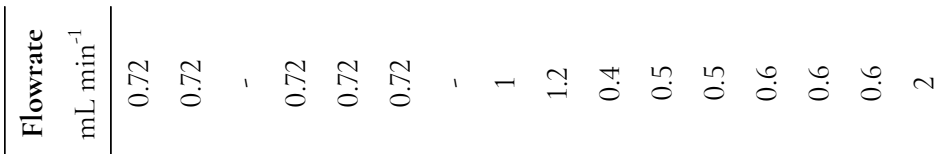

䖾

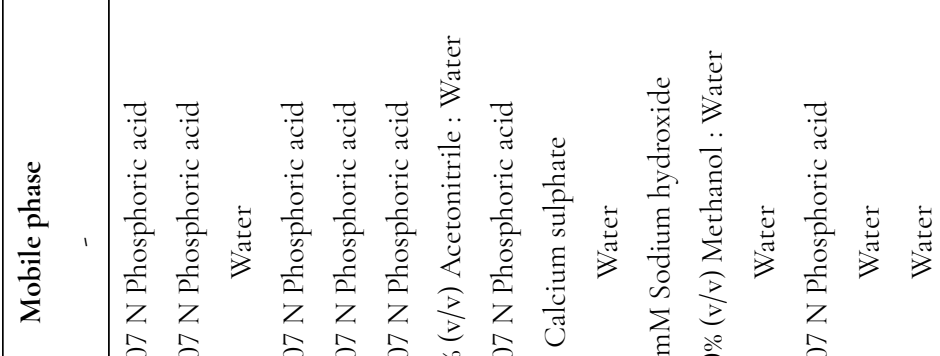

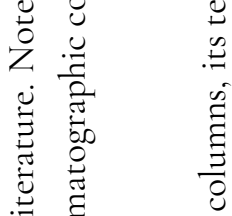

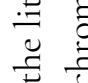

Э

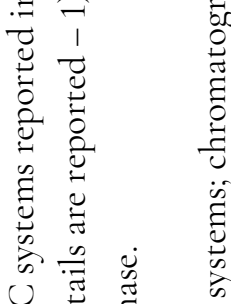

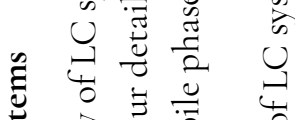

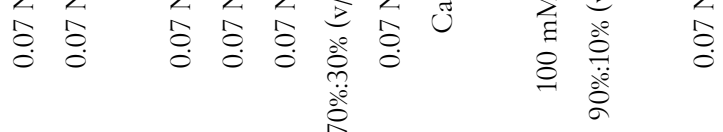

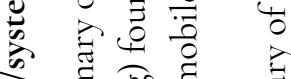

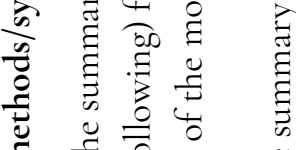

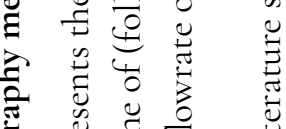

की

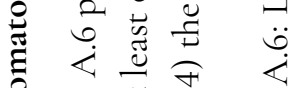

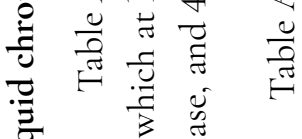

$\frac{1}{8} 0$ 는

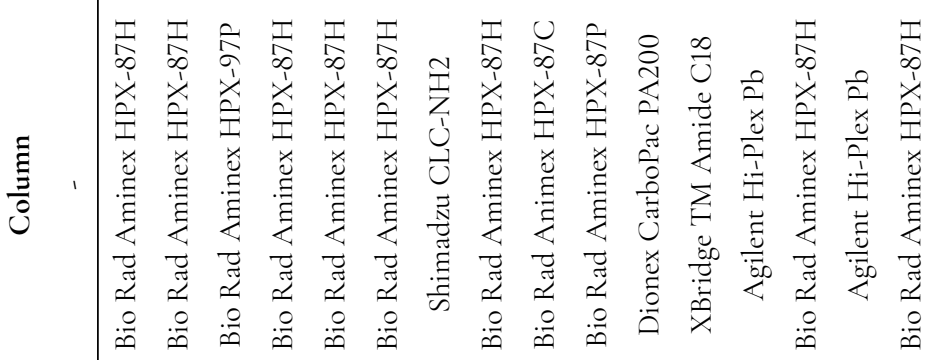

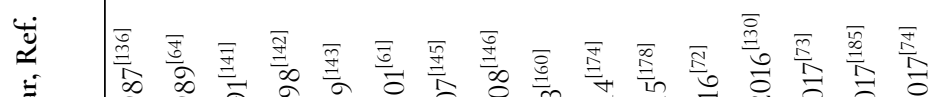

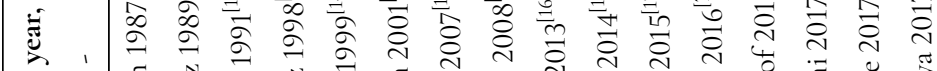

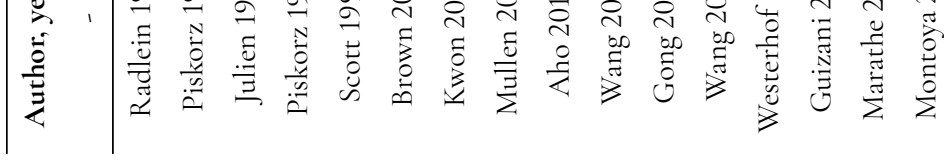




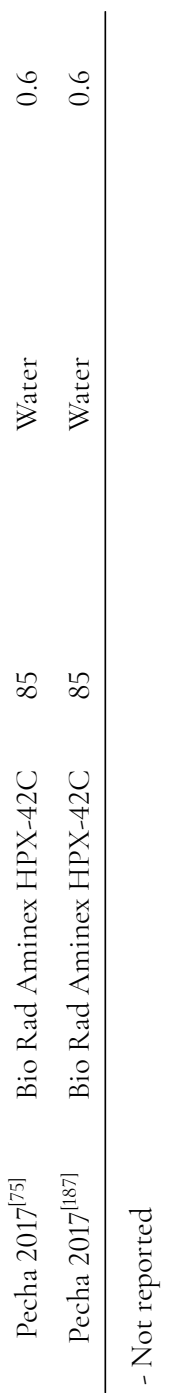




\section{A.2 Welch's $t$-test}

As reported in the Table A.1 to A.4 the yields of LG and HA were determined by either gas GC or by LC. For the yields of both compounds (LG and HA), obtained from cellulose and biomass, and determined by GC and LC, population means were calculated. Subsequently, Welch's $t$-test was used to find whether the two populations, i.e. all yields determined by GC (population 1) and by LC (population 2), have equal means. The $t$-test and $p$-values were determined by using Matlab 2017a inbuilt function ttest2.

\section{A.3 Principal component analysis (PCA)}

\section{A.3.1 Procedure}

Table A.7: Example of transformed data set used for PCA

\begin{tabular}{|c|c|c|c|c|c|}
\hline $\begin{array}{l}\text { Yield } \\
\text { wt. } \%\end{array}$ & $\begin{array}{c}\text { Ash } \\
\mathrm{mg} \mathrm{kg-1}\end{array}$ & $\begin{array}{c}\text { Temperature } \\
{ }^{\circ} \mathrm{C}\end{array}$ & $\begin{array}{c}\text { Pressure } \\
\mathrm{Pa}\end{array}$ & $\begin{array}{c}\text { Reactor type } \\
-\end{array}$ & Analytical technique \\
\hline 8.6 & 0.01 & 500 & 100000 & 1 & 2 \\
\hline 15.3 & 0.062 & 500 & 100000 & 1 & 2 \\
\hline . & . & . & - & . & . \\
\hline . & . & . & . & . & . \\
\hline 6.25 & 0.005 & 500 & 400 & 2 & 1 \\
\hline 6.25 & 0.005 & 500 & 100000 & 2 & 1 \\
\hline
\end{tabular}

Principal component analysis (PCA) was used to identify the dominant factors affecting the yields of both species (LG and HA) reported in the literature. For PCA, it was assumed that the yields $(\mathrm{Y})$ of the species was affected by five factors - 1) Ash content (A), 2) Temperature (T), 3) Pressure (P), 4) Reactor type (R), and 5) Analytical technique (AT). Note, no distinction is made between individual cellulose (or biomass) samples, and it was assumed that their heterogeneity is captured by their ash content. For each reactor type a unique integer code (starting from 1) was assigned. Similarly, for GC and LC numeric codes 1 and 2 were assigned, respectively. For PCA, data reported in the Table A.3 was transformed into Table A.7 Similarly, Table A.1. Table A.2 and Table A.4 were also transformed. PCA was carried out in Matlab 2017a by using in built function pca.

In order to take into account the large numerical differences in the data, each 
variable in the transformed tables, was scaled by using following equation,

$$
z=\frac{x-\mu}{\sigma}
$$

Where $z$ is the scaled value, $x$ is the original value, $\mu$ is the mean of the population and $\sigma$ is the standard deviation of the population.

\section{A.3.2 Loading matrices}

Below are the loading matrices obtained for LG and HA, from both feedstock (cellulose and biomass).

Cellulose - Levoglucosan

\begin{tabular}{c|cccccc} 
& $Y$ & $A$ & $T$ & $P$ & $R$ & $A T$ \\
\hline$Y$ & 1.00 & -0.31 & -0.18 & -0.01 & -0.18 & -0.46 \\
$A$ & & 1.00 & 0.06 & 0.07 & -0.14 & -0.11 \\
$T$ & & & 1.00 & 0.33 & 0.15 & 0.44 \\
$P$ & & & & 1.00 & -0.16 & -0.06 \\
$R$ & & & & & 1.00 & 0.16 \\
$A T$ & & & & & & 1.00
\end{tabular}

Cellulose - Hydroxyacetaldehyde

\begin{tabular}{c|cccccc} 
& $Y$ & $A$ & $T$ & $P$ & $R$ & $A T$ \\
\hline$Y$ & 1.00 & 0.27 & -0.49 & 0.24 & -0.52 & 0.29 \\
$A$ & & 1.00 & 0.05 & 0.20 & 0.04 & 0.44 \\
$T$ & & & 1.00 & -0.21 & 0.56 & 0.00 \\
$P$ & & & & 1.00 & -0.22 & 0.19 \\
$R$ & & & & & 1.00 & -0.36 \\
$A T$ & & & & & & 1.00
\end{tabular}


Biomass - Levoglucosan

\begin{tabular}{c|cccccc} 
& $Y$ & $A$ & $T$ & $P$ & $R$ & $A T$ \\
\hline$Y$ & 1.00 & -0.16 & 0.03 & -0.07 & 0.01 & 0.22 \\
$A$ & & 1.00 & 0.12 & 0.03 & 0.06 & 0.08 \\
$T$ & & & 1.00 & 0.01 & 0.41 & -0.05 \\
$P$ & & & & 1.00 & 0.00 & -0.22 \\
$R$ & & & & & 1.00 & -0.23 \\
$A T$ & & & & & & 1.00
\end{tabular}

Biomass - Hydroxyacetaldehyde

Note, the pressure was excluded from PCA since it was constant throughout the dataset, see Table A.4

\begin{tabular}{c|ccccc} 
& $Y$ & $A$ & $T$ & $R$ & $A T$ \\
\hline$Y$ & 1.00 & -0.25 & 0.02 & 0.11 & 0.13 \\
$A$ & & 1.00 & 0.11 & -0.03 & 0.11 \\
$T$ & & & 1.00 & 0.51 & -0.01 \\
$R$ & & & & 1.00 & -0.48 \\
$A T$ & & & & & 1.00
\end{tabular}




\section{A.4 Pure compound calibration}

\section{A.4.1 Levoglucosan}

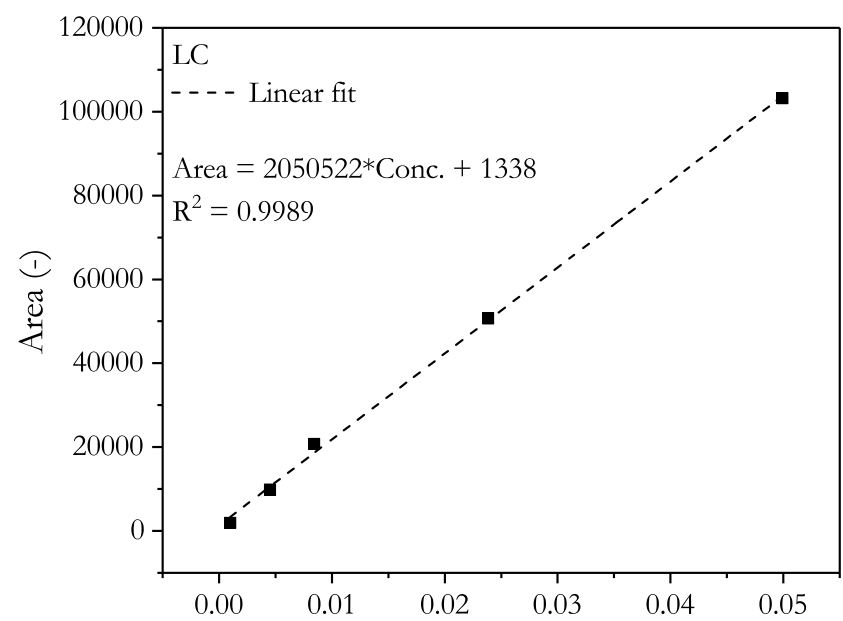

Concentration (g levoglucosan $\mathrm{g}^{-1}$ mixture)

Figure A.1A: Levoglucosan (LG) calibration on LC

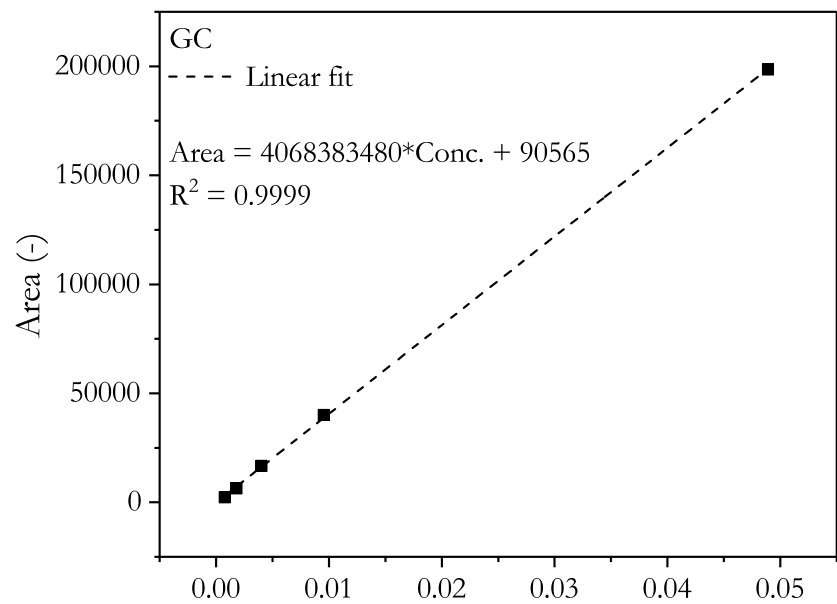

Concentration ( $\mathrm{g}$ levoglucosan $\mathrm{g}^{-1}$ mixture)

Figure A.1B: Levoglucosan (LG) calibration on GC 


\section{A.4.2 Hydroxyacetaldehyde}

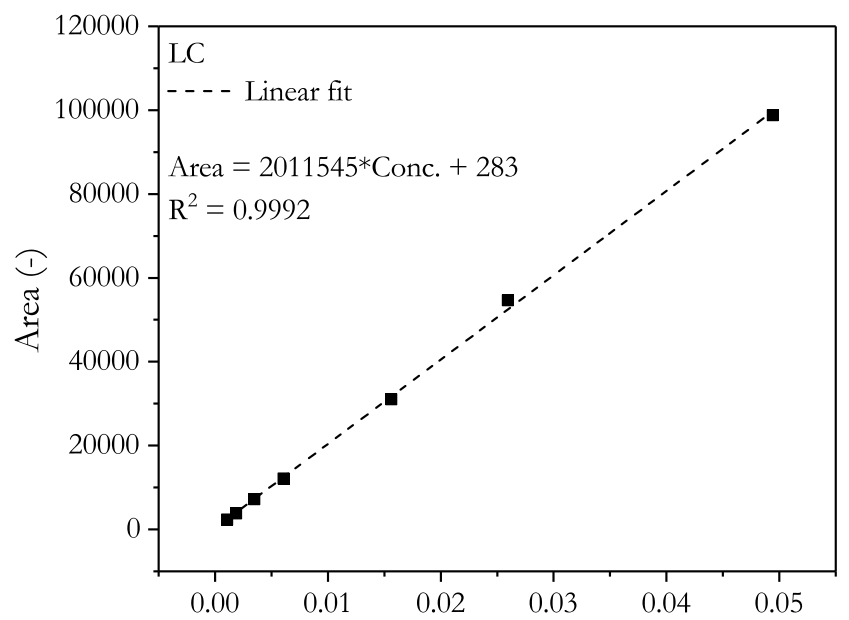

Concentration (g hydroxyacetaldehyde $\mathrm{g}^{-1}$ mixture)

Figure A.2A: Hydroxyacetaldehyde (HA) calibration on LC

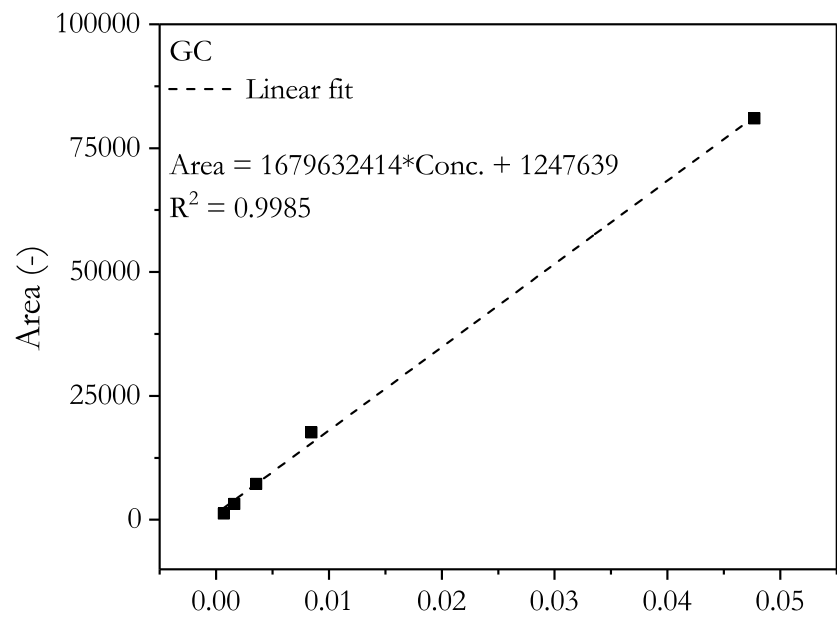

Concentration (g hydroxyacetaldehyde $\mathrm{g}^{-1}$ mixture)

Figure A.2B: Hydroxyacetaldehyde (HA) calibration on GC 


\section{A.4.3 Retention time}

In Table A.8. the retention time of levoglucosan (LG) and hydroxyacetaldehyde (HA) in GC and LC systems are presented.

Table A.8: Retention time of levoglucosan (LG) and hydroxyacetaldehyde (HA) in GC and LC

\begin{tabular}{ccc}
\hline Compound & GC & LC \\
& \multicolumn{2}{c}{$\min$} \\
\hline LG & 55.5 & 31.2 \\
HA & 6.4 & 16.25 \\
\hline
\end{tabular}

\section{A.5 Proof of cellobiosan depolymerisation}

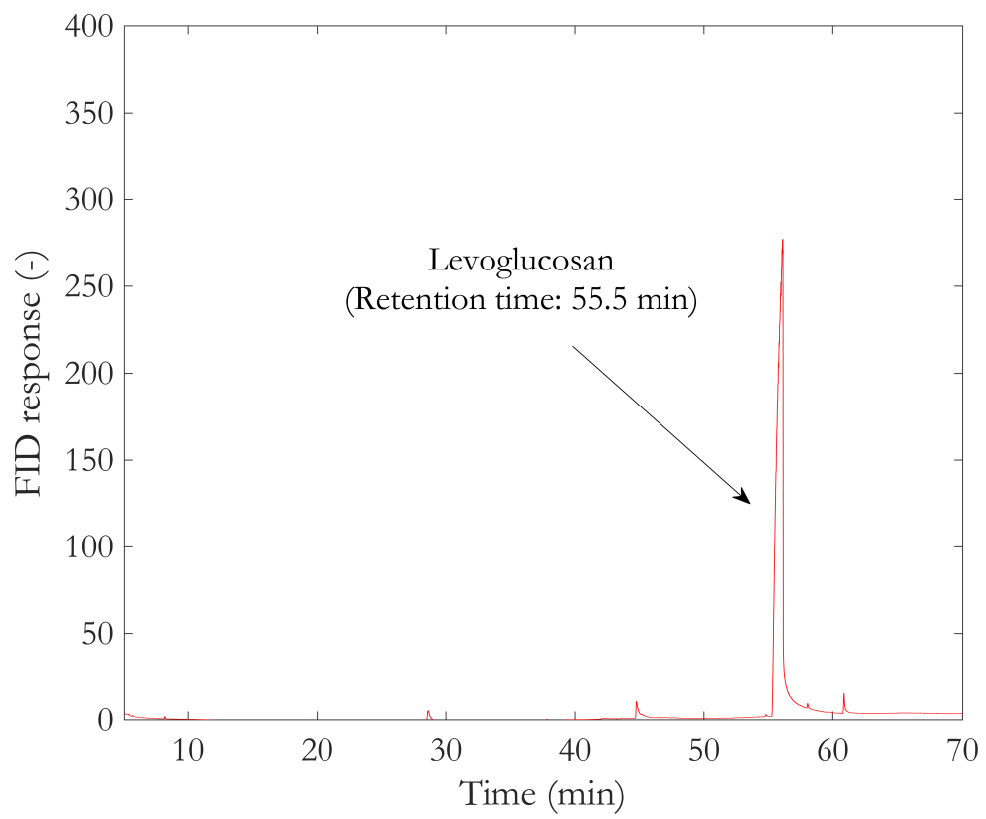

Figure A.3: Chromatogram recorded by FID after injecting a cellobiosan solution

Cellobiosan, diluted in methanol, was injected into the GC and the chromatogram recorded by the FID is presented in Figure A.3 Presence of levoglucosan in the chromatogram was confirmed by comparing the retention time of the standard. The concentration of cellobiosan in methanol was 1.4 wt.\%. In Table A.9 the mass (and moles) 
of cellobiosan and levoglucosan before (and after) GC analysis, and conversion of cellobiosan are presented. Conversion of cellobiosan is estimated based on the assumption that cellobiosan only reacts to levoglucosan.

Table A.9: Mass (and moles) of cellobiosan and levoglucosan before (and after) GC analysis and conversion of cellobiosan

\begin{tabular}{ccccc}
\hline & Unit & Cellobiosan & Levoglucosan & Methanol \\
\hline Molar mass & $\mathrm{g} \mathrm{mole}^{-1}$ & 324 & 162 & 32 \\
Before GC analysis & $\mathrm{g}$ & 0.087 & 0 & 6.0269 \\
& mole & 0.00027 & & \\
After GC analysis & $\mathrm{g}$ & 0 & 0.024 & \\
& mole & & 0.000150 & \\
Conversion & $\%$ & 28 & & \\
\hline
\end{tabular}

\section{A.6 Isolation, identification and quantification}

\section{A.6.1 Method: Proton Nuclear magnetic resonance ( ${ }^{1} \mathrm{H}$ NMR)}

${ }^{1} \mathrm{H}$ NMR spectra were recorded on a Bruker Avance II $600 \mathrm{MHz}$ NMR spectrometer $(14.1 \mathrm{~T})$, using a $5 \mathrm{~mm}$ triple nucleus TXI ${ }^{1} \mathrm{H}_{-}{ }^{13} \mathrm{C} /{ }^{15} \mathrm{~N} /{ }^{2} \mathrm{H}$ probe and Avance III 400 MHz NMR spectrometer (9.4 T) provided with a broadband BBFO probe. Both spectrometers are equipped with a $z$ gradient coil, producing a maximum gradient strength of 50 gauss $\mathrm{cm}^{-1}$.

\section{A.6.2 Isolation}

Figure A.4 presents the LC chromatograms (RI detector) of the water-soluble fraction of pyrolysis oils obtained from the cellulose (pure and $1000 \mathrm{mg} \mathrm{kg}^{-1}$ potassium infused) at $530{ }^{\circ} \mathrm{C}$ in a fluidized bed. Note, spectra in Figure A.4 are shown for the qualitative comparison only. It can be seen that with an increase in the potassium concentration in cellulose, anhydrosugars disappeared and a peak (retention time: $16.25 \mathrm{~min}$, highlighted in the gray area) became prominent, referred as unknown in Figure A.4

In order to identify and eliminate the possibility of co-elution of more than one compound at the same retention time, the unknown peak was isolated from the pyrolysis oil by the following procedure. The concentrated solution (40 wt.\%) of oil in deionised water was prepared and was injected into LC. Because of the dead volume of the LC system, the sample was collected from the waste tubing line after the delay of $1.6 \mathrm{~min}$ 


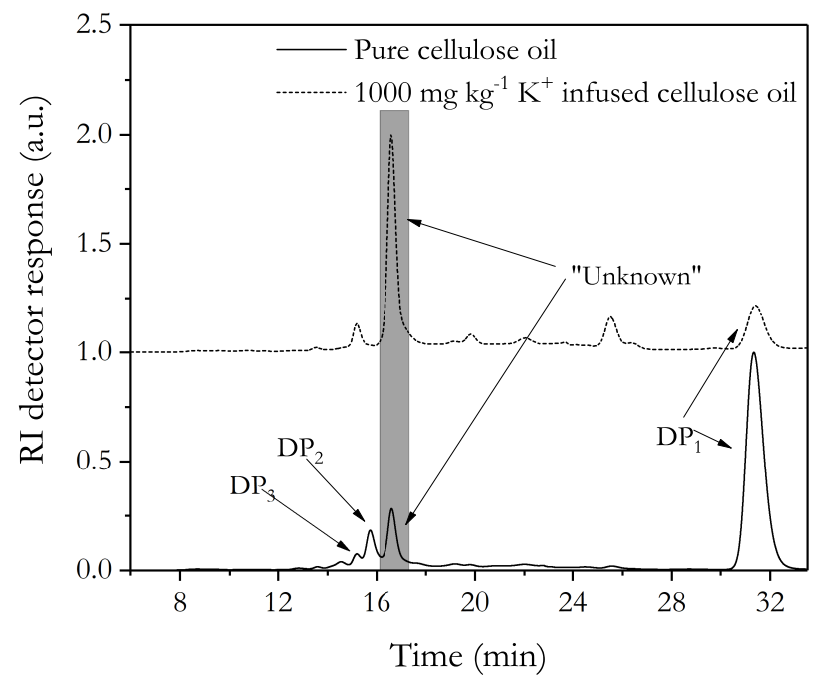

Figure A.4: LC chromatograms of oils obtained from cellulose (pure and $1000 \mathrm{mg} \mathrm{kg}^{-1}$ potassium infused) pyrolysed in a fluidised bed at $530{ }^{\circ} \mathrm{C}$

(between $17.3 \mathrm{~min}$ and $18.8 \mathrm{~min}$ ). Isolated unknown compound(s) was reanalysed by LC to confirm the isolation. After that, deionised water from isolated fraction was removed by purging dry nitrogen $(\sim 4 \mathrm{~h})$ until dry crystalline solids were precipitated. Precipitated solids were dissolved in deuterium oxide $\left(\mathrm{D}_{2} \mathrm{O}\right)$ and were subsequently analysed by the ${ }^{1} \mathrm{H}$ NMR) spectroscopy.

\section{A.6.3 Identification}<smiles>O=CCO</smiles>

(A)

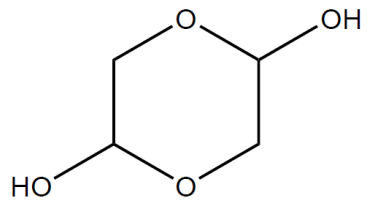

(B)<smiles>OCC(O)O</smiles>

(C)

Figure A.5: Chemical structures of A) Hydroxyacetaldehyde, B) Glycolaldehyde dimer, and C) Ethane-1, 1, 2-triol 
The ${ }^{1} \mathrm{H}$-NMR spectrum (Figure A.6 shows two main intense peaks corresponding with the compound of interest, which was isolated by using LC. In the spectrum, traces of other compounds (small peaks) can be observed. The peak at $9.59 \mathrm{ppm}$ corresponds with the aldehydic proton (Figure A.5-A) and the peak at $4.4 \mathrm{ppm}$ corresponds with $\mathrm{CH} 2$ protons (Figure A.5.A). However, the intensity of these peaks is 11 times smaller than the intense peaks. The more intense peaks match with the structure showed in Figure A.5. B as it will be explained below. The first mentioned peaks in the ${ }^{1} \mathrm{H}$ NMR) spectrum suggest the presence of hydroxyacetaldehyde, but mainly the dimeric structure (Figure A.5.B).

To unequivocally assign the intense peaks with the dimeric structure, homonuclear and heteronuclear 2D NMR experiments were acquired. ${ }^{1} \mathrm{H},{ }_{1}^{1} \mathrm{H}$-COSY NMR spectrum below (Figure A.7) shows correlation between $\mathrm{CH}_{2}$ and $\mathrm{CH}$ corresponding to the dimeric structure. Excluding the small peak at $4.4 \mathrm{ppm}$ that does not show any correlation peak, according with the expected for the glycolaldehyde structure.

Heteronuclear correlation, ${ }^{1} \mathrm{H},{ }^{13} \mathrm{C}$ HSQC NMR spectrum is shown in Figure A.8 The correlation peaks indicate unequivocally the assignation to the dimeric structure. Due to the edition of peaks in the HSQC pulse sequence acquired, it was possible to differentiate peaks due to $\mathrm{CH}_{2}$ and $\mathrm{CH}$, present at the dimeric and no at the monomeric structure. Since HSQC is an inverse NMR technique, also the correlation due to trace peaks were observed.

Finally, to prove the assignment of the peaks through NMR, we acquired spectra of glycolaldehyde in $\mathrm{D}_{2} \mathrm{O}$ and methanol-d4. For the spectrum in $\mathrm{D}_{2} \mathrm{O}$ we were able to identify the same situation observed in the isolated peak. However, in the case of methanol-d4 the chemical shift observed matches better with the structure shown in Figure A.5-C. Note that the multiplicity observed in the methanol-d4 spectrum is similar to the dimeric structure, however, the chemical shift is different. In methanol-d4 are misfit, due to different environment (because of the solvent) and also to different structure. Therefore, non-aqueous conditions lead to dimeric structure and methanolic conditions can lead to triol structure (see Figure A.5-C). However, in all of the spectra the monomeric glycolaldehyde is observed in a ratio approximated to 1:10 (or even higher). 


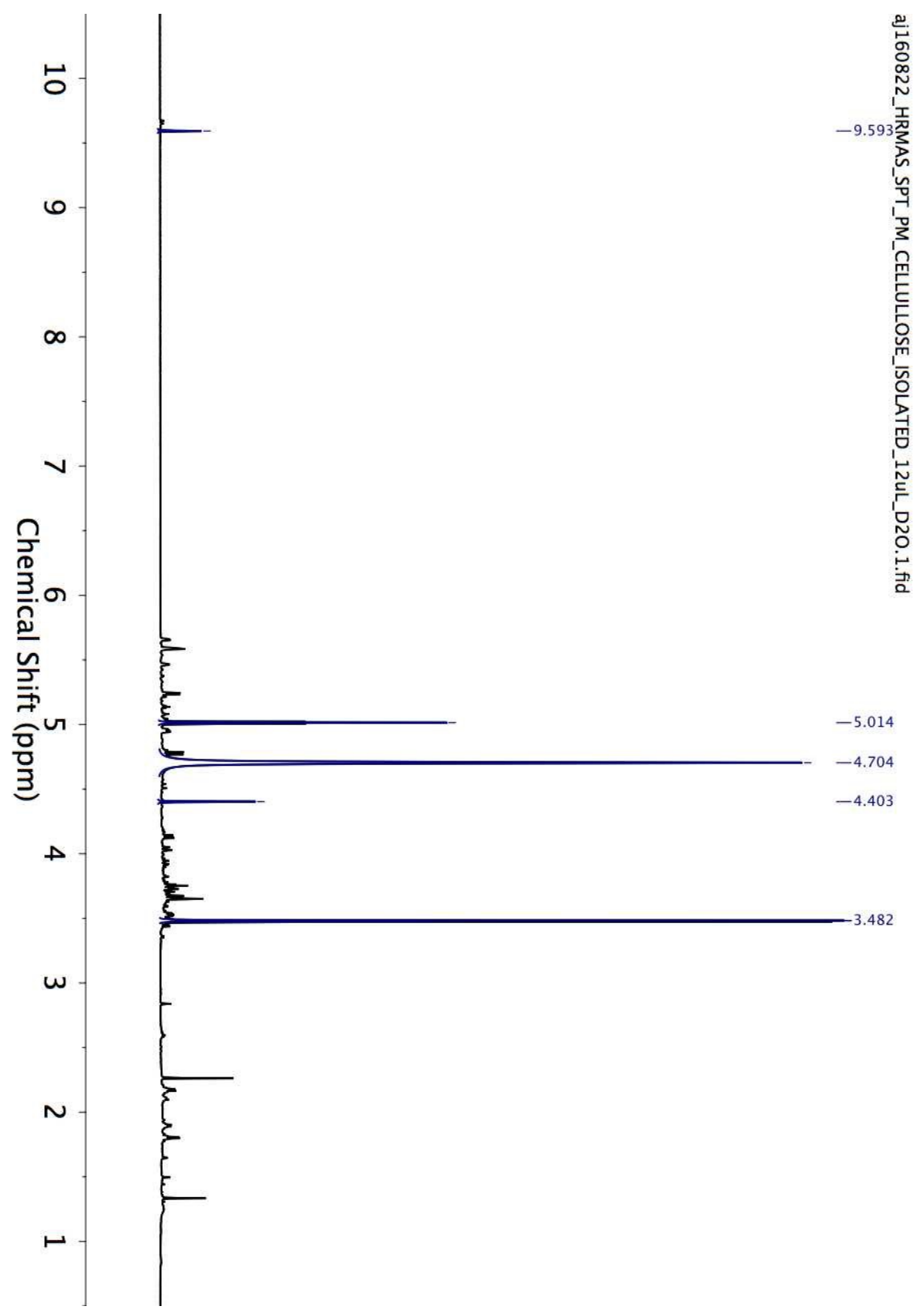

Figure A.6: ${ }^{1} \mathrm{H}$ NMR spectra of isolated peak in $\mathrm{D}_{2} \mathrm{O}$

${ }^{1} \mathrm{H}$ NMR: $\left(600 \mathrm{MHz}, \mathrm{D}_{2} \mathrm{O}\right) \delta 9.59(\mathrm{~s}, 1 \mathrm{H}), 5.01(\mathrm{t}, \mathbf{J}=\mathbf{5 . 1} \mathrm{Hz}, \mathbf{1 H}), 4.403(\mathrm{~s}, 2 \mathrm{H}), 3.48(\mathrm{~d}$, $\mathrm{J}=5.1 \mathrm{~Hz}, 2 \mathrm{H})$ 


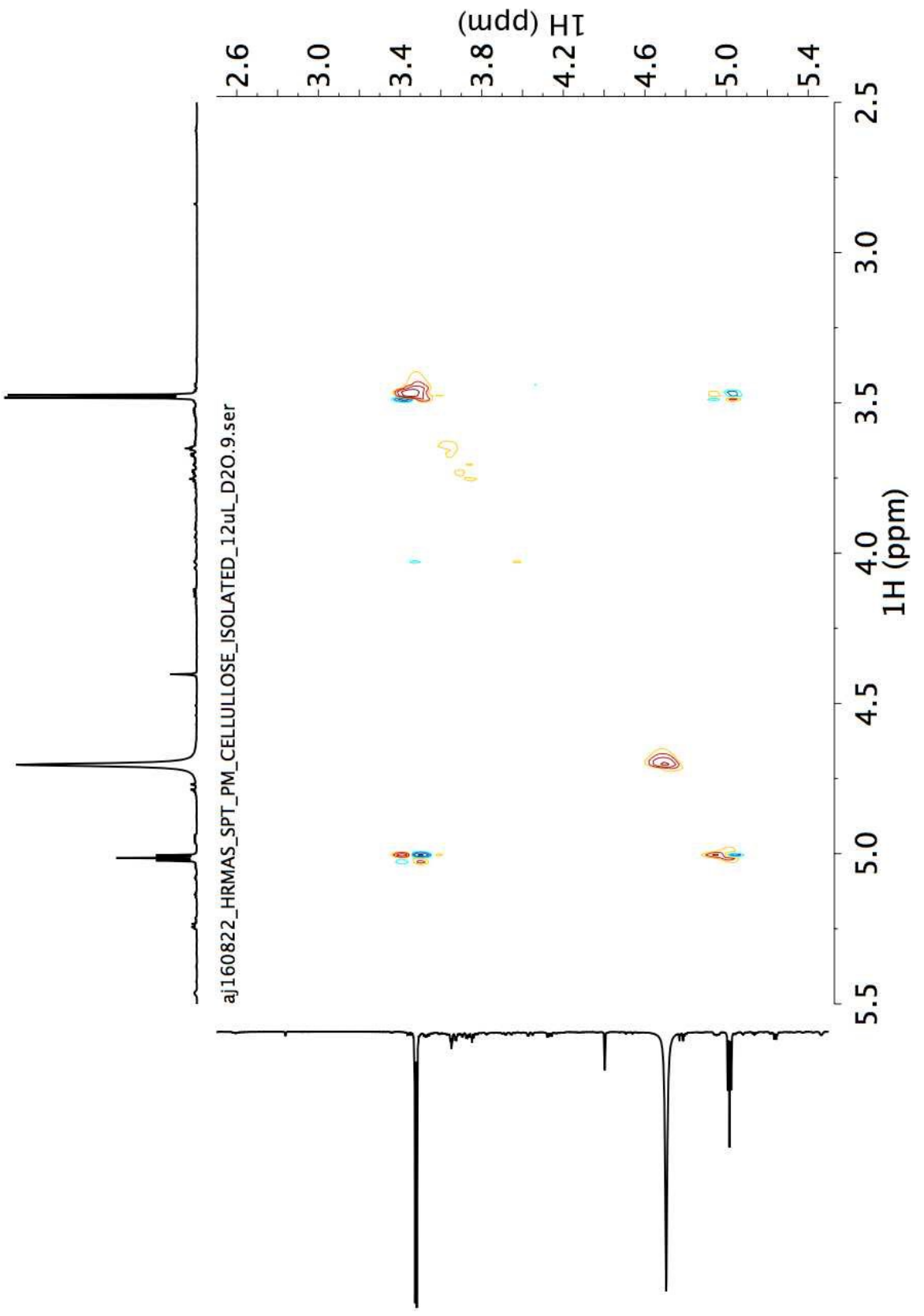

Figure A.7: ${ }^{1} \mathrm{H},{ }^{1} \mathrm{H}-\mathrm{COSY}$ NMR spectrum. ${ }^{1} \mathrm{H},{ }^{1} \mathrm{H}-\mathrm{COSY}\left(600 \mathrm{MHz}, \mathrm{D}_{2} \mathrm{O}\right)$ showed the correlation peaks between 5.01 and 3.48 ppm 

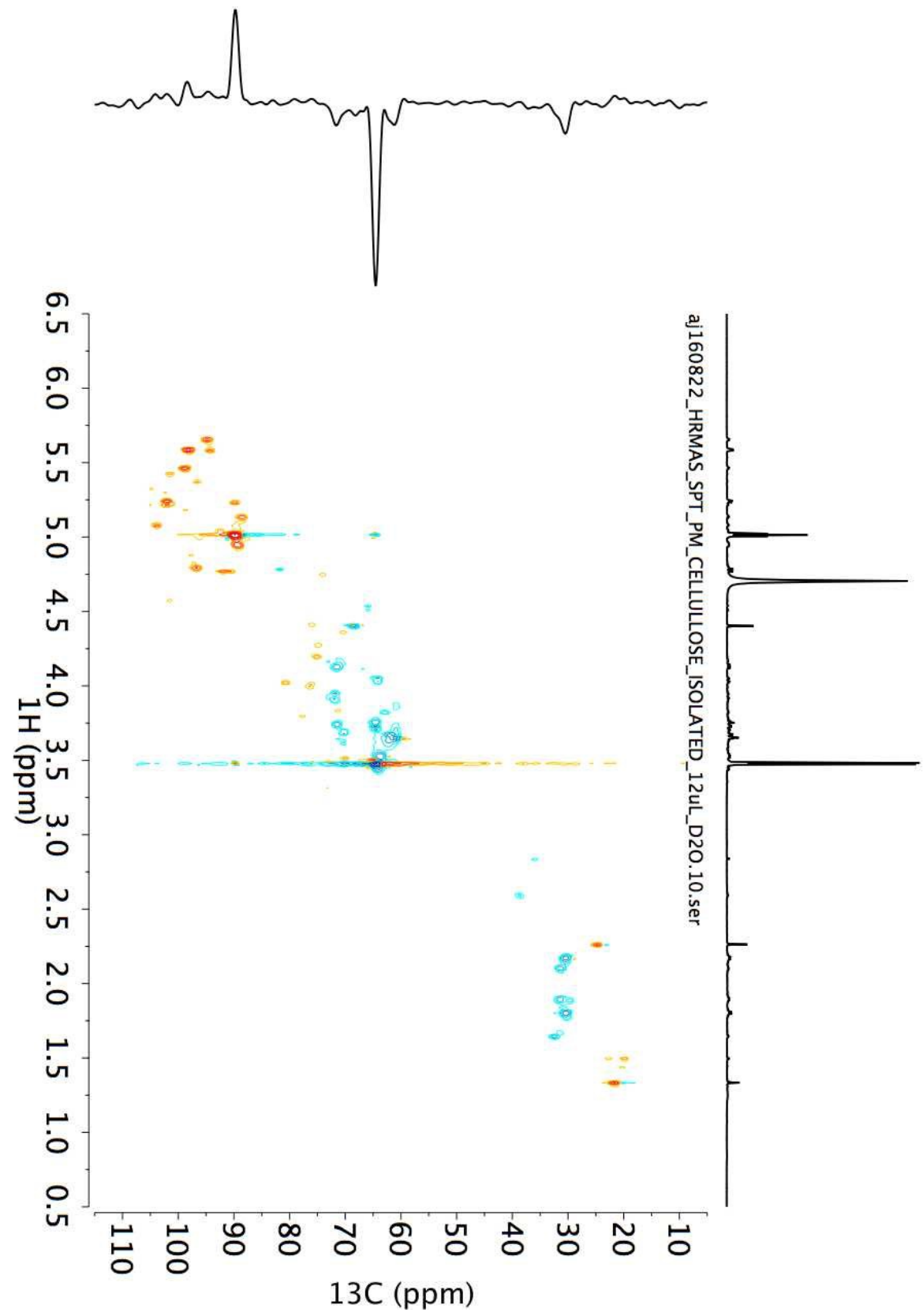

Figure A.8: ${ }^{1} \mathrm{H},{ }^{13} \mathrm{C}-\mathrm{HSQC}$ NMR spectrum of isolated peak in $\mathrm{D}_{2} \mathrm{O} .{ }^{1} \mathrm{H},{ }^{13} \mathrm{C}-\mathrm{HSQC}:{ }^{1} \mathrm{H}$ NMR $\left(600 \mathrm{MHz}, \mathrm{D}_{2} \mathrm{O}\right)$ and ${ }^{13} \mathrm{C}$ NMR $\left(151 \mathrm{MHz}, \mathrm{D}_{2} \mathrm{O}\right)$ showed the following proton-carbon correlation peaks: 5.01 and $89.75,3.48$ and 64.64 


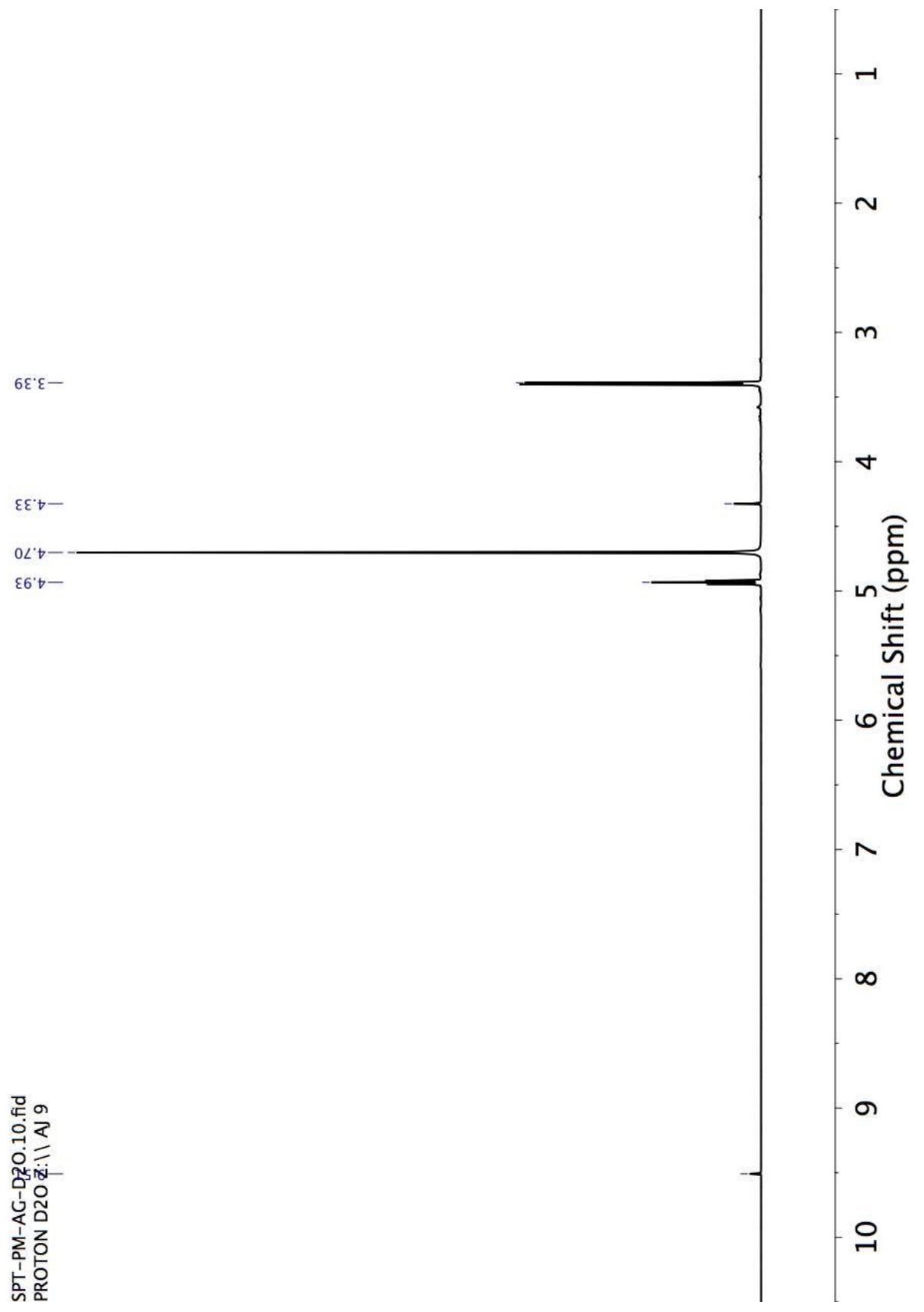

Figure A.9: In $\mathrm{D}_{2} \mathrm{O}:{ }^{1} \mathrm{H}$ NMR $\left(400 \mathrm{MHz}, \mathrm{D}_{2} \mathrm{O}\right) \delta 4.93(\mathrm{t}, 1 \mathrm{H}), 4.70\left(\mathrm{D}_{2} \mathrm{O}, 4.33(\mathrm{~s}, 2 \mathrm{H})\right.$, $3.39(\mathrm{~d}, 2 \mathrm{H})$ 


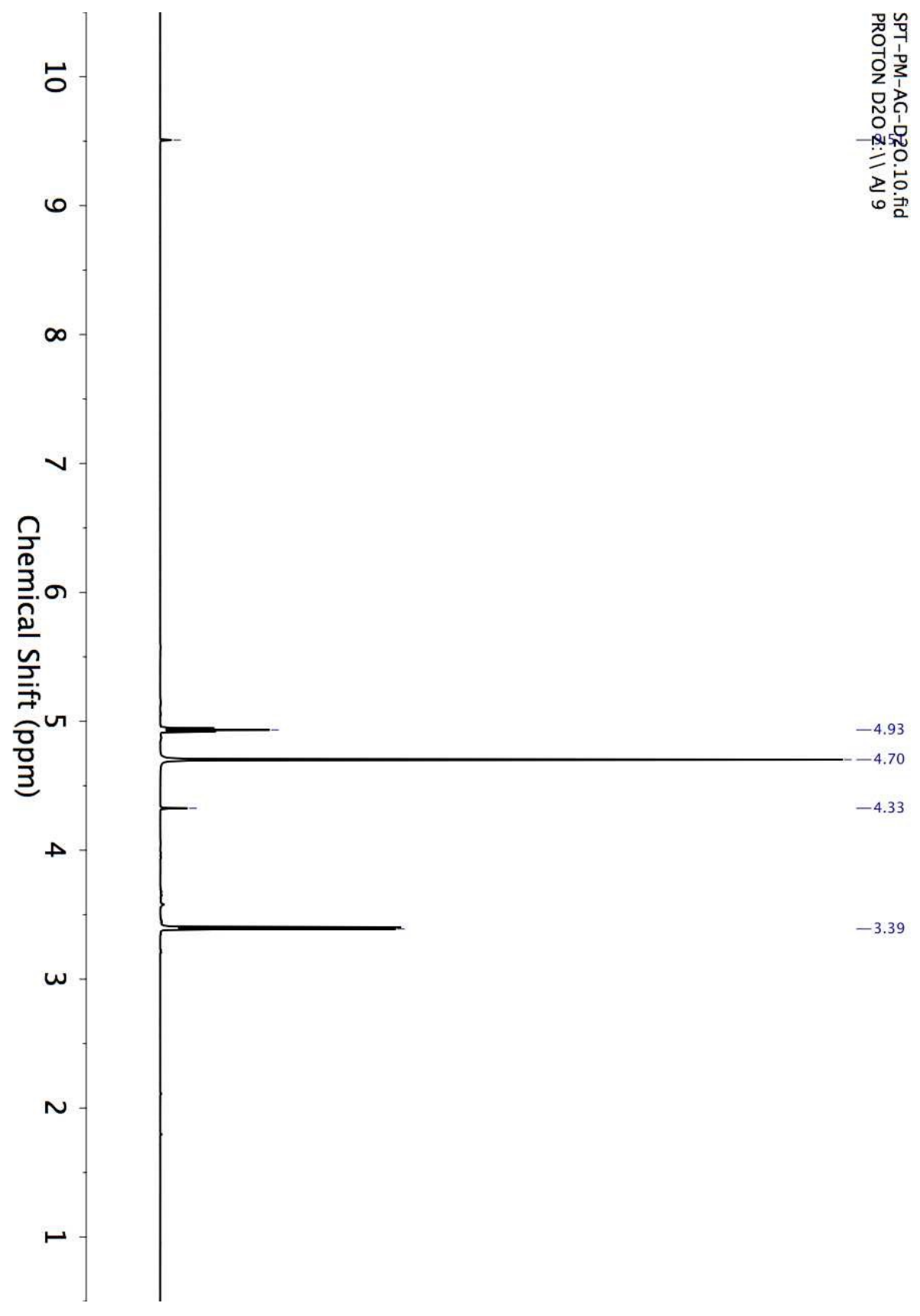

Figure A.10: In Methanol-d4: ${ }^{1} \mathrm{H}$ NMR (400 MHz, MeOD) $\delta 5.59(\mathrm{~s}, 2 \mathrm{H}), 4.90\left(\mathrm{D}_{2} \mathrm{O}\right.$, $4.54(\mathrm{t}, 1 \mathrm{H}), 3.46(\mathrm{~d}, 2 \mathrm{H}), 3.33$. Note, $\mathrm{H}_{2} \mathrm{O}$ peak arising from the solvent (MeOD). 


\section{A.6.4 Quantification}

It can be seen from Figure A.4 that hydroxyacetaldehyde (in dimer form) partially overlapped cellobiosan peak, especially in the oils obtained from pure cellulose. Thus, in order to quantify the hydroxyacetaldehyde yield following integration procedure was followed. Figure A.11A shows the LC chromatogram of the hydroxyacetaldehyde (in dimer form), of which retention time is $16.25 \mathrm{~min}$ (maximum). Because of the fact that no other compound elutes after hydroxyacetaldehyde (see Figure A.4) following integration method was developed and used. The peak was integrated into two separate parts, namely right area (RA) and left area (LA). From a seven point calibration (see Figure A.2A it was found that the ratio between the RA and LA is $\sim 1.6$ and was independent of hydroxyacetaldehyde concentration, see Figure A.11B Thus, for oils only RA was determined and LA was computed using the ratio ( $\mathrm{LA}=\mathrm{RA} / 1.6)$. The total area under the peak was determined by adding RA and LA, which was used for the quantification of the hydroxyacetaldehyde.

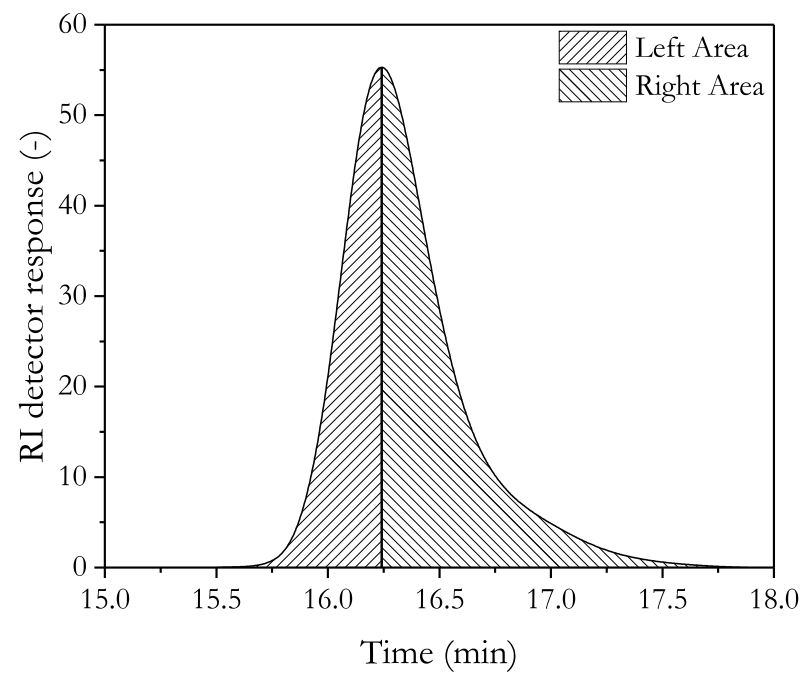

Figure A.11A: LC chromatogram of hydroxyacetaldehyde 


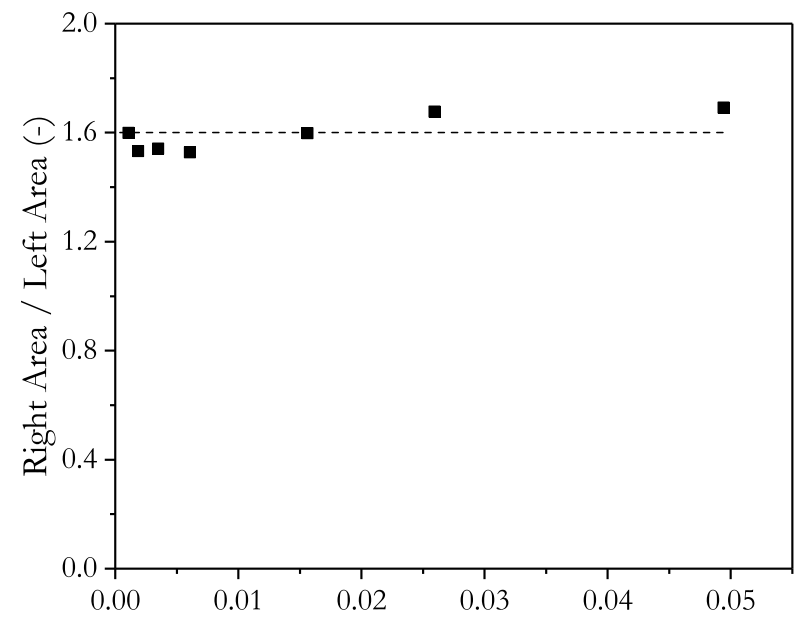

Hydroxyacetaldehyde concentration ( $\mathrm{g} \mathrm{g}^{-1}$ mixture)

Figure A.11B: The ratio between right area (RA) and left area (LA) as a function of hydroxyacetaldehyde concentration

\section{A.7 Examples of GC chromatogranm}

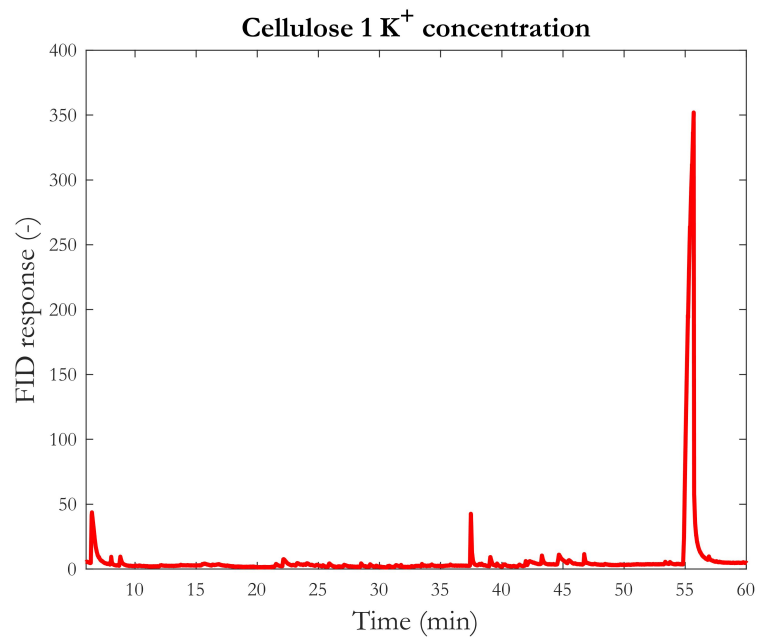

Figure A.12A: GC chromatograms of cellulose $\left(1 \mathrm{mg} \mathrm{kg}^{-1} \mathrm{~K}^{+}\right)$derived oil recorded by FID 


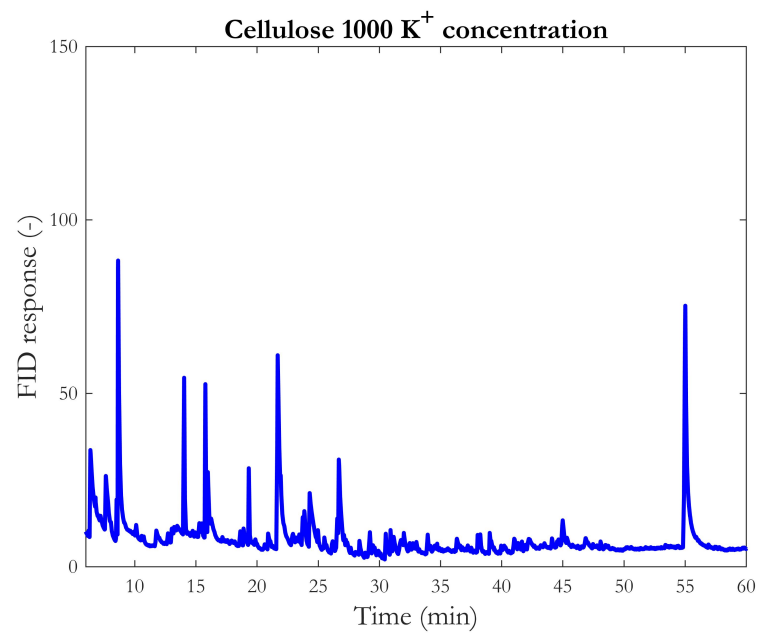

Figure A.12B: GC chromatograms of cellulose $\left(1000 \mathrm{mg} \mathrm{kg}^{-1} \mathrm{~K}^{+}\right)$derived oil recorded by FID

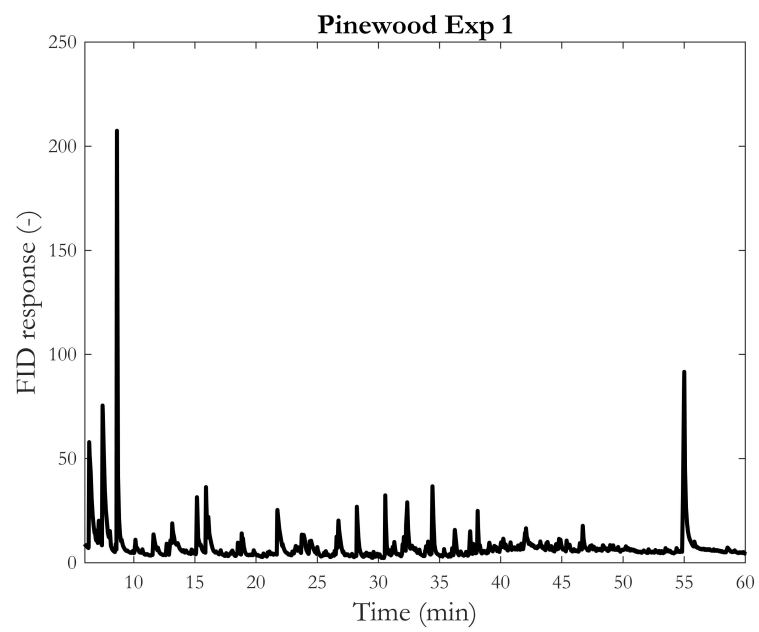

Figure A.12C: GC chromatograms of biomass derived oil (Exp 1) recorded by FID 
A 


\section{B}

Supporting information for Chapter 4 


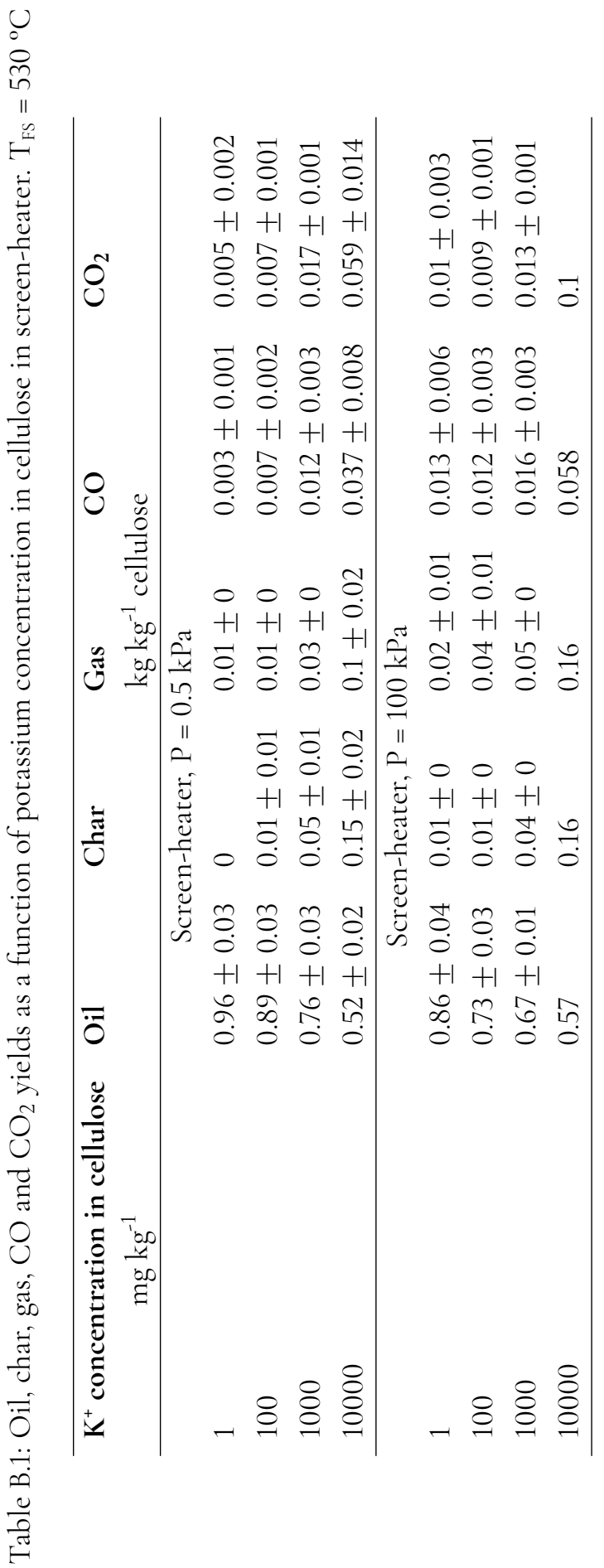


Table B.2: Oil, char and gas yields as a function of potassium concentration in cellulose in fluidised bed. $\mathrm{T}_{\mathrm{FS}}=530{ }^{\circ} \mathrm{C}$

\begin{tabular}{cccc}
\hline $\begin{array}{c}\mathbf{K}^{+} \text {concentration in cellulose } \\
\mathrm{mg} \mathrm{kg}^{-1}\end{array}$ & $\begin{array}{c}\text { Oil } \\
\mathrm{kg} \mathrm{kg}^{-1}\end{array}$ & $\begin{array}{c}\text { Char } \\
\text { cellulose }\end{array}$ & $\begin{array}{c}\text { Gas } \\
1\end{array}$ \\
\hline 100 & 0.73 & 0.01 & 0.12 \\
1000 & 0.63 & 0.03 & 0.24 \\
& 0.60 & 0.04 & 0.22 \\
\hline
\end{tabular}

Table B.3: Levoglucosan yield and glucose recovery after hydrolysis of oil, as a function of potassium concentration in cellulose; in screen-heater and fluidized bed. $\mathrm{T}_{\mathrm{FS}}=530$ ${ }^{\circ} \mathrm{C}$

\begin{tabular}{ccc}
\hline $\begin{array}{c}\mathbf{K}^{+} \text {concentration in cellulose } \\
\mathrm{mg} \mathrm{kg}^{-1}\end{array}$ & $\begin{array}{c}C_{\text {Glucose }} \\
C_{\text {Cellulose }} \\
\mathrm{kg} \mathrm{kg}^{-1}\end{array}$ & $\begin{array}{c}\text { Levoglucosan } \\
\text { cellulose }\end{array}$ \\
\hline \multicolumn{4}{c}{ Screen-heater, $\mathrm{P}=0.5 \mathrm{kPa}$} \\
1 & $0.66 \pm 0.02$ & $0.2 \pm 0.03$ \\
100 & $0.49 \pm 0.04$ & $0.1 \pm 0.01$ \\
1000 & $0.3 \pm 0.03$ & $0.08 \pm 0.02$ \\
10000 & $0.04 \pm 0.02$ & $0.01 \pm 0.01$ \\
\hline \multicolumn{4}{c}{ Screen-heater, $\mathrm{P}=100 \mathrm{kPa}$} \\
1 & 0.45 & 0.31 \\
100 & 0.35 & 0.17 \\
1000 & 0.22 & 0.08 \\
10000 & 0.03 & 0.01 \\
\hline \multicolumn{3}{c}{ Fluidized Bed Reactor } \\
100 & 0.45 & 0.35 \\
1000 & 0.30 & 0.20 \\
\hline \multicolumn{4}{c}{0.07} & 0.07 \\
\hline
\end{tabular}


Table B.4: Levoglucosan recovery $\left(\mathrm{R}_{\text {Levoglucosan }}\right)$ as a function of potassium concentration in levoglucosan and pressure in screen-heater. $\mathrm{T}_{\mathrm{FS}}=530{ }^{\circ} \mathrm{C}$

\begin{tabular}{|c|c|}
\hline $\begin{array}{c}\mathrm{K}^{+} \text {concentration in levoglucosan } \\
\mathrm{mg} \mathrm{kg}^{-1}\end{array}$ & $\begin{array}{c}\mathbf{R}_{\text {Levoglucosan }} \\
\mathrm{kg} \mathrm{kg}^{-1} \text { levoglucosan }\end{array}$ \\
\hline \multicolumn{2}{|c|}{ Screen-heater, $\mathrm{P}=0.5 \mathrm{kPa}$} \\
\hline 1 & 0.88 \\
\hline 1000 & 0.89 \\
\hline \multicolumn{2}{|c|}{ Screen-heater, $\mathrm{P}=100 \mathrm{kPa}$} \\
\hline 1 & 0.89 \\
\hline 1000 & 0.48 \\
\hline
\end{tabular}

Table B.5: Effect of pressure on oil, char and gas yields at constant potassium concentration in levoglucosan in screen-heater. $\mathrm{T}_{\mathrm{FS}}=530{ }^{\circ} \mathrm{C}$

\begin{tabular}{cccc}
\hline $\mathbf{P}$ & Oil & $\begin{array}{c}\text { Char } \\
\text { kg kg-1 levoglucosan }\end{array}$ \\
$\mathrm{kPa}$ & \multicolumn{3}{c}{ Gas } \\
\hline \multicolumn{4}{l}{ Levoglucosan $+1000 \mathrm{mg} \mathrm{kg}^{-1}$ potassium } \\
$<0.5$ & $0.94 \pm 0.05$ & $0.03 \pm 0$ & $0.01 \pm 0$ \\
100 & $0.77 \pm 0.03$ & $0.05 \pm 0.01$ & $0.06 \pm 0.02$ \\
\hline
\end{tabular}

Table B.6: Levoglucosenone, acetol and hydroxyacetaldehyde yields as a function of potassium concentration in cellulose in screen-heater. $\mathrm{T}_{\mathrm{FS}}=530{ }^{\circ} \mathrm{C}$ and $\mathrm{P}=0.5 \mathrm{kPa}$

\begin{tabular}{cccc}
\hline $\begin{array}{c}\mathbf{K}^{+} \text {concentration in cellulose } \\
\mathrm{mg} \mathrm{kg}^{-1}\end{array}$ & Levoglucosenone & $\begin{array}{c}\text { Acetol } \\
\mathrm{kg} \mathrm{kg}^{-1} \text { cellulose }\end{array}$ & Hydroxyacetaldehyde \\
\hline 1 & $0.002 \pm 0$ & $0.002 \pm 0.001$ & $0.11 \pm 0.01$ \\
100 & $0.003 \pm 0$ & $0.002 \pm 0$ & $0.16 \pm 0.01$ \\
1000 & $0.01 \pm 0.001$ & $0.002 \pm 0$ & $0.14 \pm 0.01$ \\
10000 & 0 & $0.023 \pm 0.001$ & $0.12 \pm 0.01$ \\
\hline
\end{tabular}




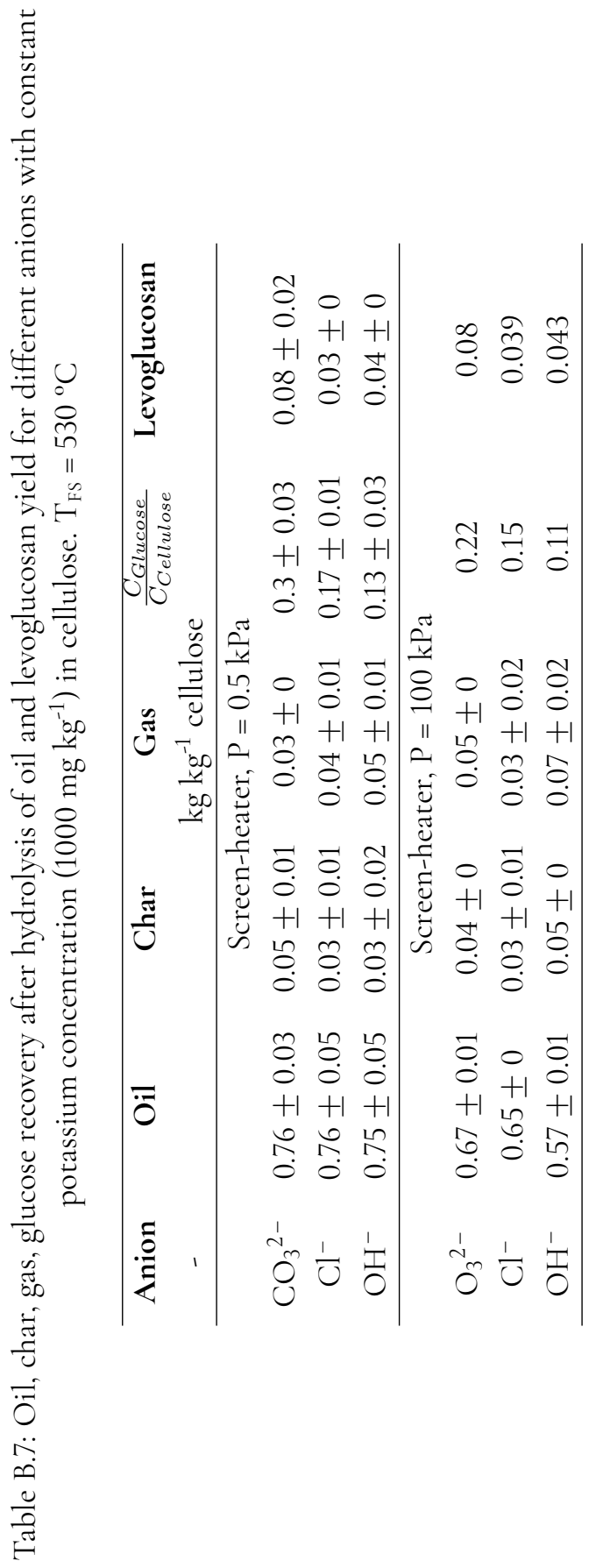




\section{C}

Supporting information for Chapter 5 


\section{C.1 Fractionation efficiencies}

Fractionation experiment efficiencies for different lignins are presented in Table C.1

Table C.1: Fractionation efficiencies of lignin

\begin{tabular}{ccc}
\hline Lignin & Code & $\mathrm{L}: \mathrm{H}$ \\
- & - & $\mathrm{kg}: \mathrm{kg}$ \\
\hline SL & 1 & $0.41: 0.59$ \\
WSL & 4 & $0.5: 0.5$ \\
PL1 & 7 & $0.66: 0.34$ \\
PL2 & 10 & $0.63: 0.37$ \\
\hline
\end{tabular}

\section{C.2 Effect of temperature}

Table C.2 presents the lumped product yields obtained from the lignin 13 as a function of $\mathrm{T}_{\mathrm{FS}}$.

Table C.2: Oil, char and gas yields, $\left\langle\mathrm{M}_{\mathrm{w}}>\right.$ and polydispersity values of oils obtained at the $\mathrm{T}_{\mathrm{FS}}$ of $530{ }^{\circ} \mathrm{C}$

\begin{tabular}{|c|c|c|c|c|c|}
\hline $\mathrm{T}_{\mathrm{FS}}$ & $Y_{\text {Oil,exp }}$ & $Y_{\text {Char,exp }}$ & $Y_{\text {Gas,exp }}$ & $<\mathbf{M}_{\mathrm{w}, \exp }>$ & Đ \\
\hline${ }^{\circ} \mathrm{C}$ & \multicolumn{3}{|c|}{ wt.\% on lignin } & $\mathrm{Da}$ & - \\
\hline \multicolumn{6}{|c|}{$\mathrm{P}=0.5 \mathrm{kPa}$} \\
\hline 425 & $62 \pm 5$ & $30 \pm 4$ & $1 \pm 1$ & 736 & 1.5 \\
\hline 513 & $78 \pm 1$ & $14 \pm 2$ & $1 \pm 1$ & 804 & 1.5 \\
\hline 640 & $84 \pm 3$ & $8 \pm 1$ & $2 \pm 1$ & 874 & 1.5 \\
\hline 779 & $81 \pm 5$ & $8 \pm 1$ & $2 \pm 1$ & 952 & 1.6 \\
\hline \multicolumn{6}{|c|}{$\mathrm{P}=100 \mathrm{kPa}$} \\
\hline 433 & $46 \pm 0.2$ & $36 \pm 1$ & $5 \pm 0.3$ & 440 & 1.2 \\
\hline 523 & $46 \pm 2$ & $32 \pm 2$ & $6 \pm 1$ & 454 & 1.2 \\
\hline 630 & $49 \pm 2$ & $22 \pm 2$ & $11 \pm 2$ & 500 & 1.3 \\
\hline 793 & $47 \pm 4$ & $18 \pm 1$ & $17 \pm 1$ & 494 & 1.4 \\
\hline
\end{tabular}









\section{C.4 Oil yield as a function of lights in the feed}

Figure C.1A and C.1B presens the experimental oil yields as a function of the mass fractions of lights in the lignins. Lights were defined as: $D P_{\leq 4}$ for $0.5 \mathrm{kPa}$ and $D P_{\leq 2}$ for $100 \mathrm{kPa}$. The boundaries of the mass fraction in the lignins were chosen because the $<\mathrm{M}_{\mathrm{n}}>$ of oils obtained at $0.5 \mathrm{kPa}$ was $\sim 800 \mathrm{Da}$ and at $100 \mathrm{kPa}$ was $\sim 400 \mathrm{Da}$, see Figure 5.4 in Chapter 5.

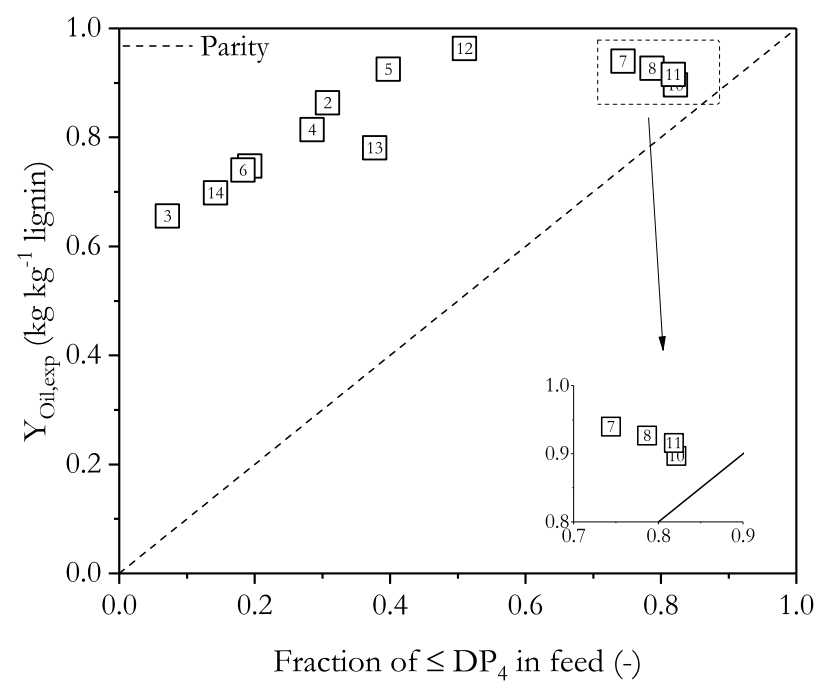

Figure C.1A: Experimental oil yield as a function of the mass fractions of lights $\left(\leq D P_{4}\right)$ in the lignins at $0.5 \mathrm{kPa}$ 


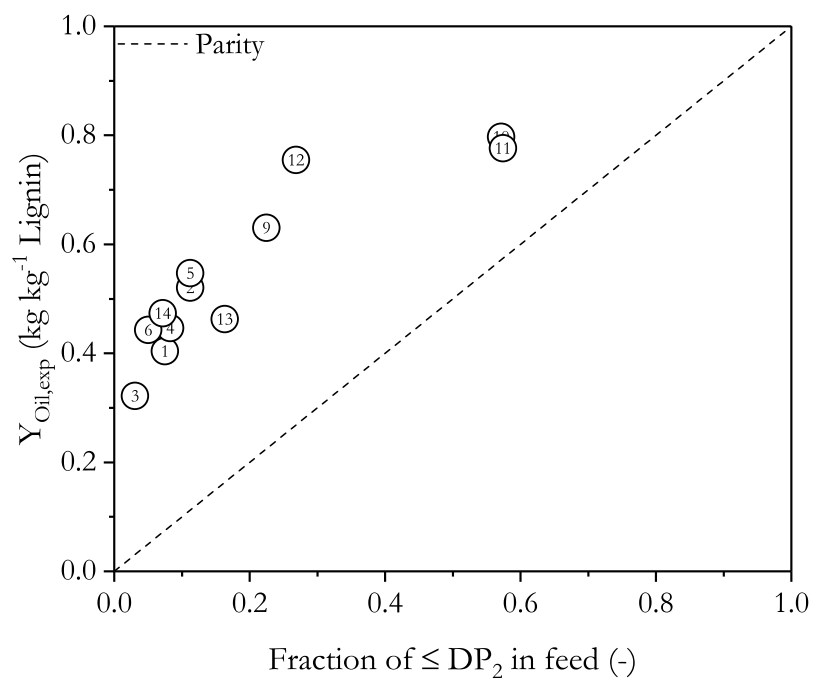

Figure C.1B: Experimental oil yield as a function of the mass fractions of lights in the lignins at $100 \mathrm{kPa}$

\section{C.5 $\quad \mathrm{M}_{\mathrm{w}} \mathrm{D}$ plots of all lignins}

The $\mathrm{M}_{\mathrm{w}} \mathrm{D}$ of all lignin and their oils (experiment and model) are shown in Figure C.2 to Figure C.15 For model predictions, parameters obtained from the individual fit procedure are used. 


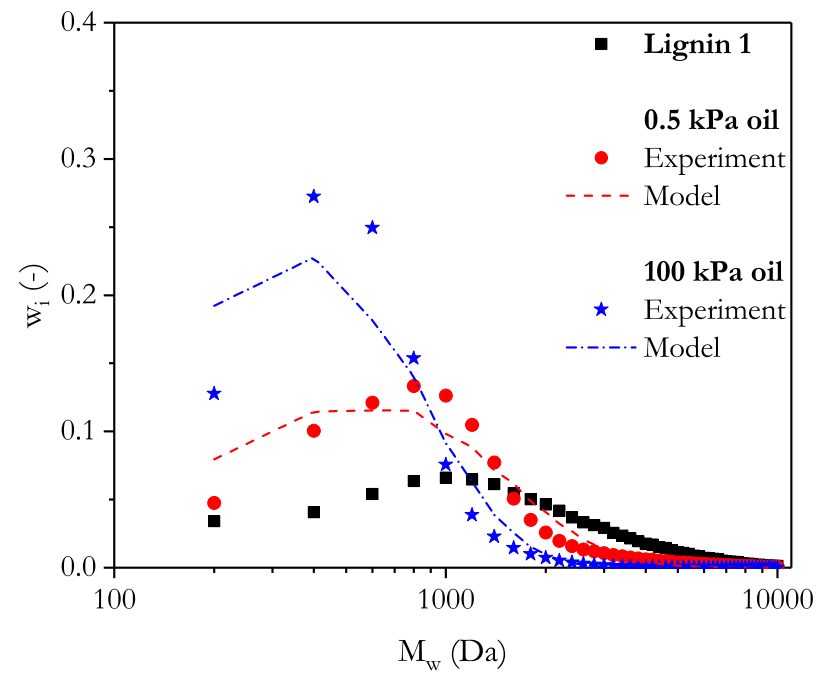

Figure C.2: $\mathrm{M}_{\mathrm{w}} \mathrm{D}$ of lignin 1 and its oils

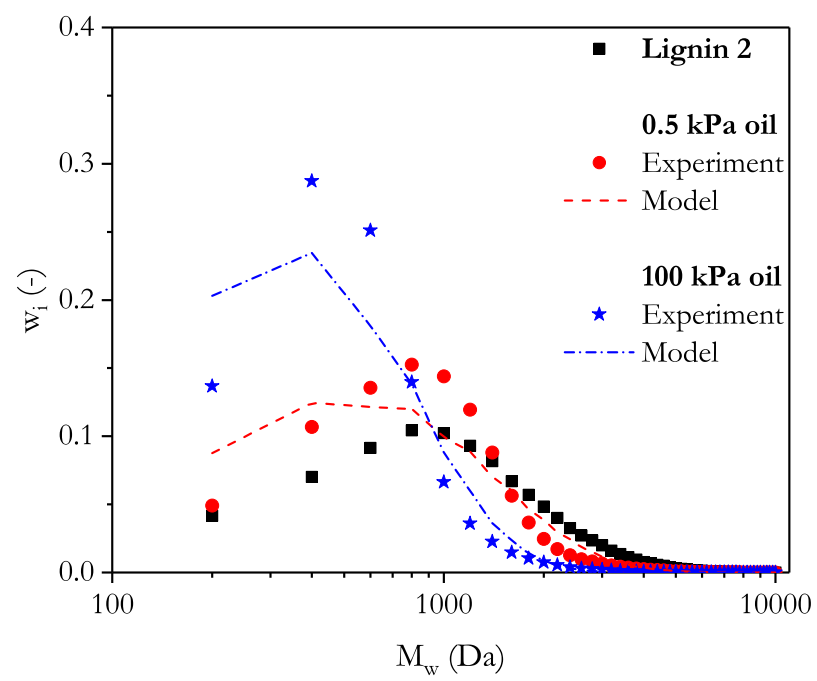

Figure C.3: $\mathrm{M}_{\mathrm{w}} \mathrm{D}$ of lignin 2 and its oils 


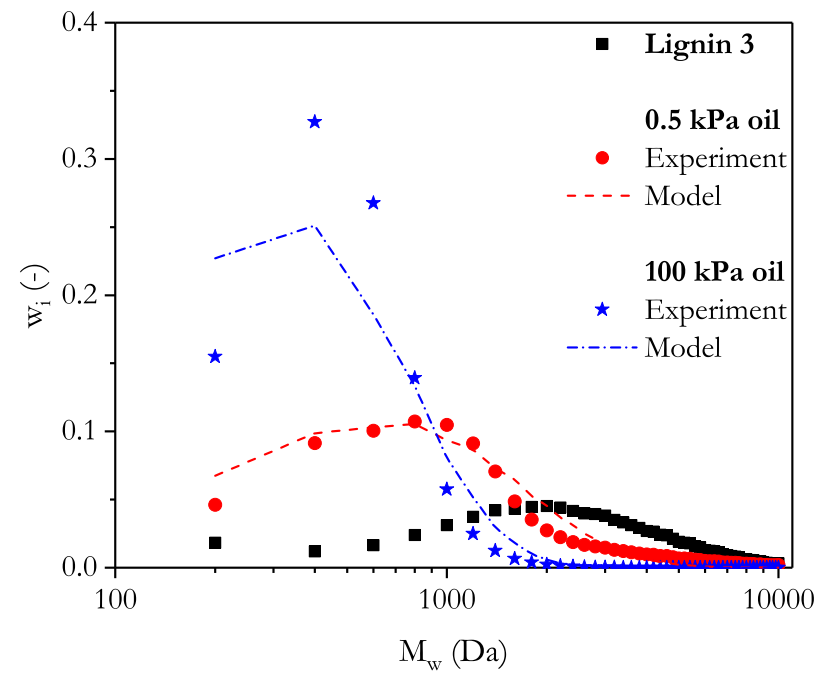

Figure C.4: $\mathrm{M}_{\mathrm{w}} \mathrm{D}$ of lignin 3 and its oils

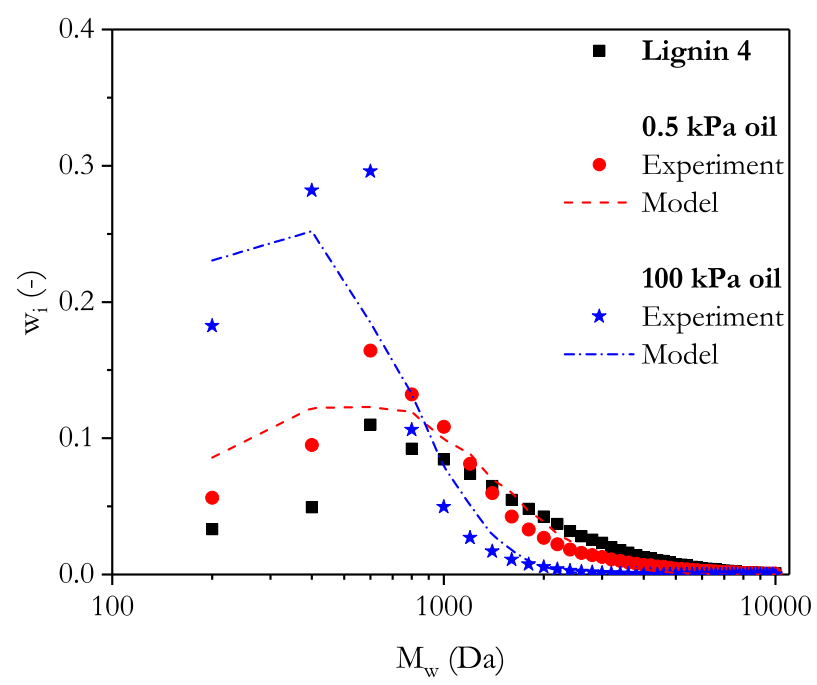

Figure C.5: $\mathrm{M}_{\mathrm{w}} \mathrm{D}$ of lignin 4 and its oils 


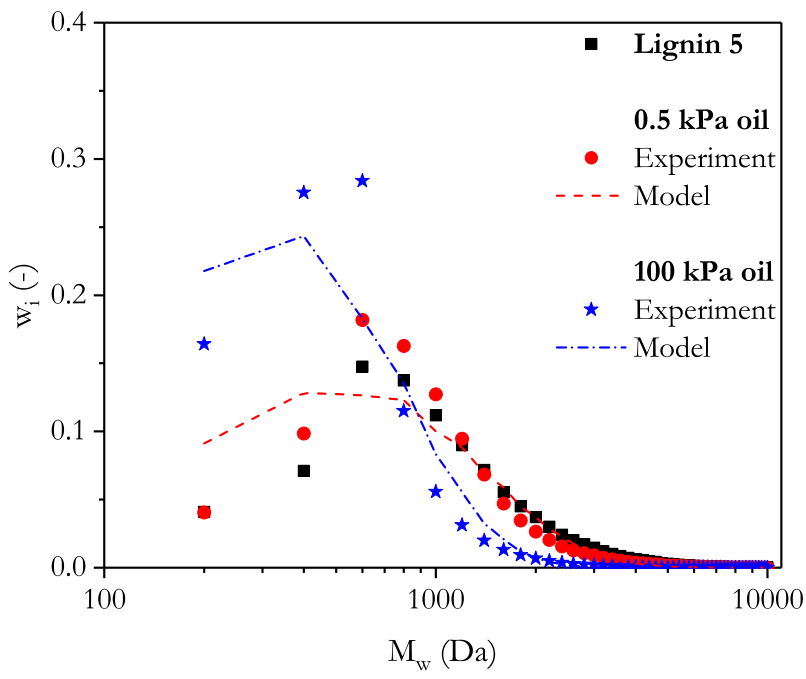

Figure C.6: $\mathrm{M}_{\mathrm{w}} \mathrm{D}$ of lignin 5 and its oils

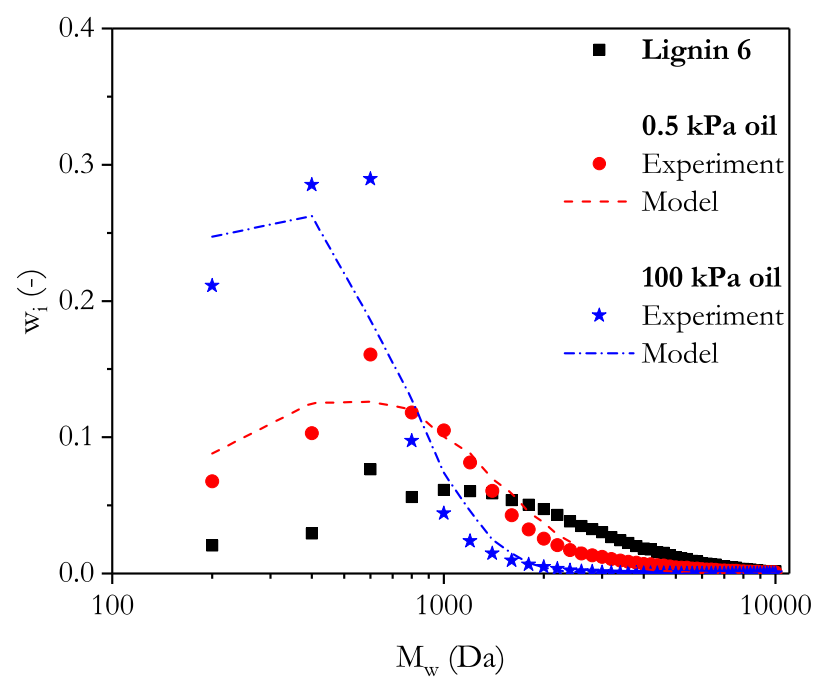

Figure C.7: $\mathrm{M}_{\mathrm{w}} \mathrm{D}$ of lignin 6 and its oils 


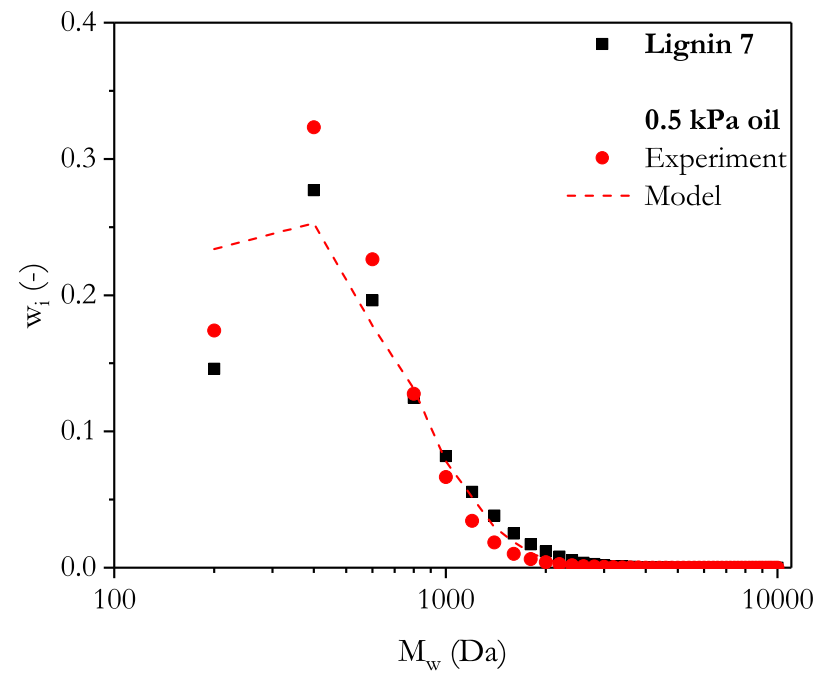

Figure C.8: $\mathrm{M}_{\mathrm{w}} \mathrm{D}$ of lignin 7 and its oil

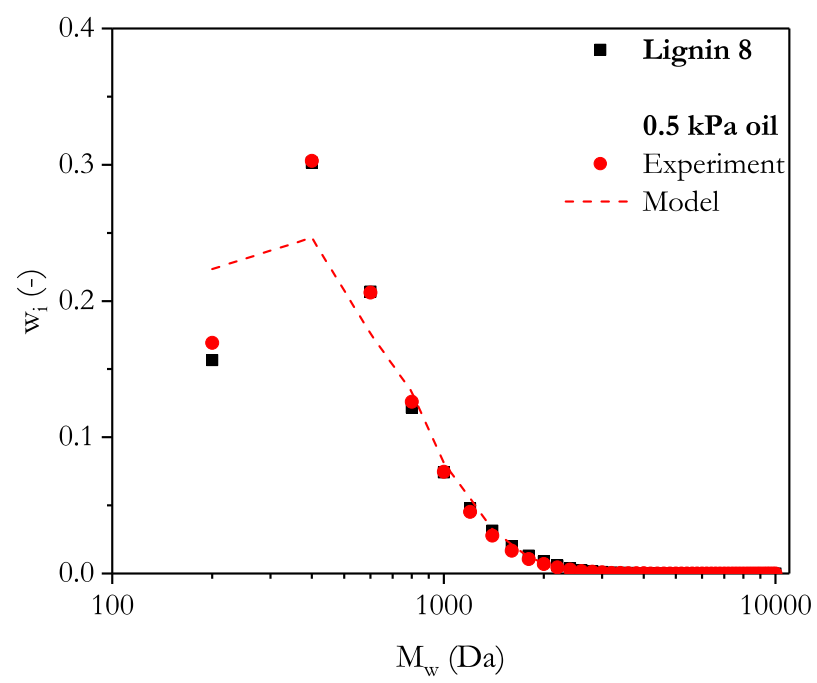

Figure C.9: $\mathrm{M}_{\mathrm{w}} \mathrm{D}$ of lignin 8 and its oil 


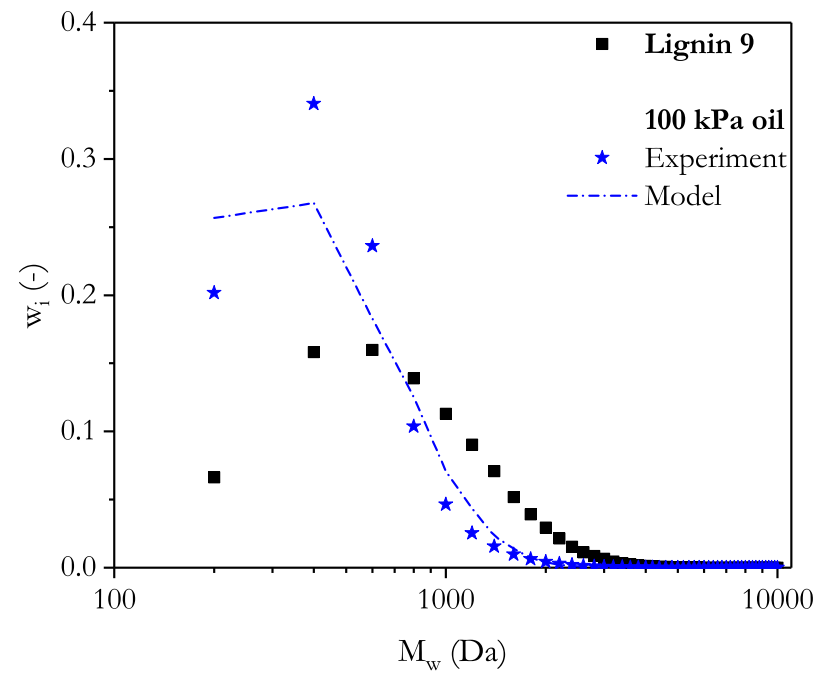

Figure C.10: $M_{w} D$ of lignin 9 and its oil

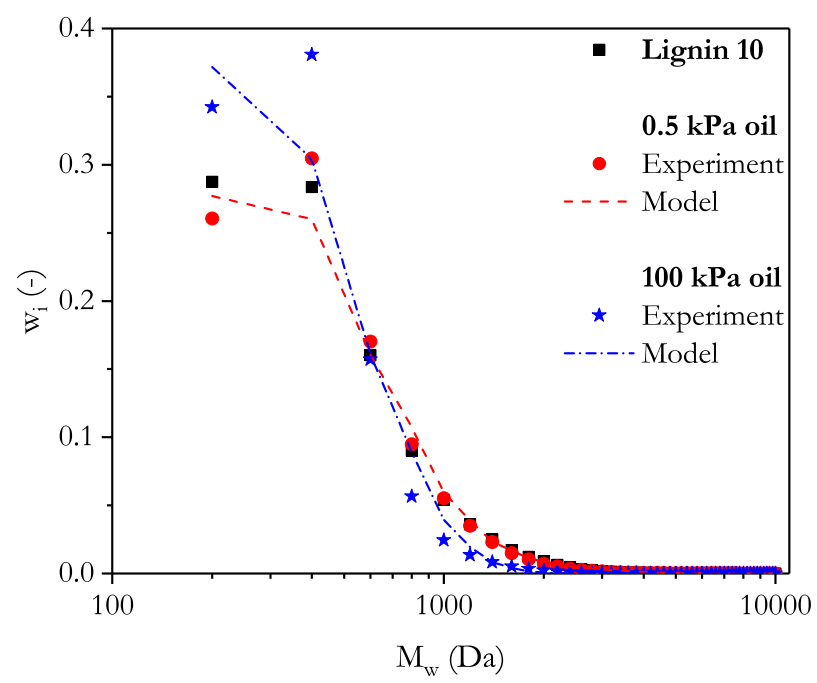

Figure C.11: $\mathrm{M}_{\mathrm{w}} \mathrm{D}$ of lignin 10 and its oils 


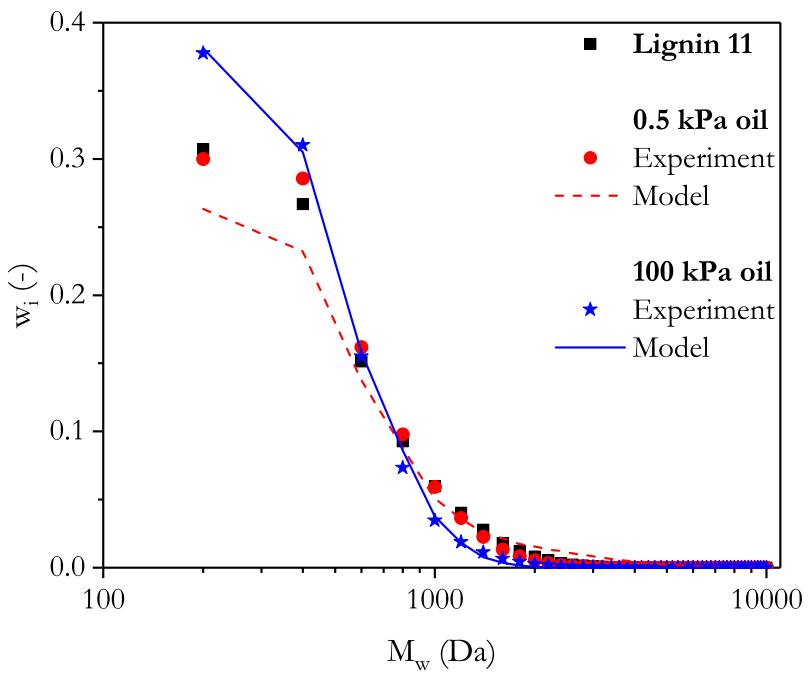

Figure C.12: $\mathrm{M}_{\mathrm{w}} \mathrm{D}$ of lignin 11 and its oils

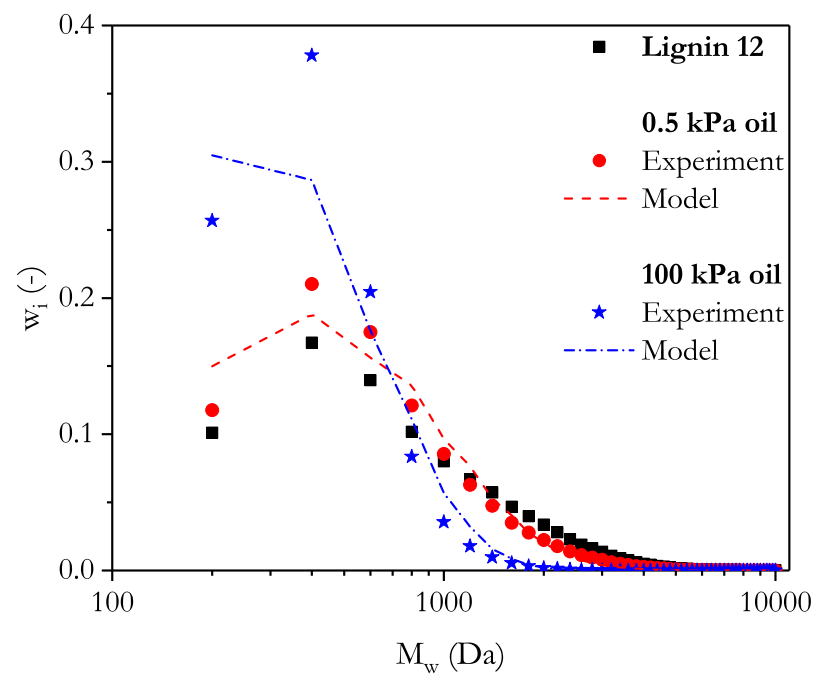

Figure C.13: $\mathrm{M}_{\mathrm{w}} \mathrm{D}$ of lignin 12 and its oils 


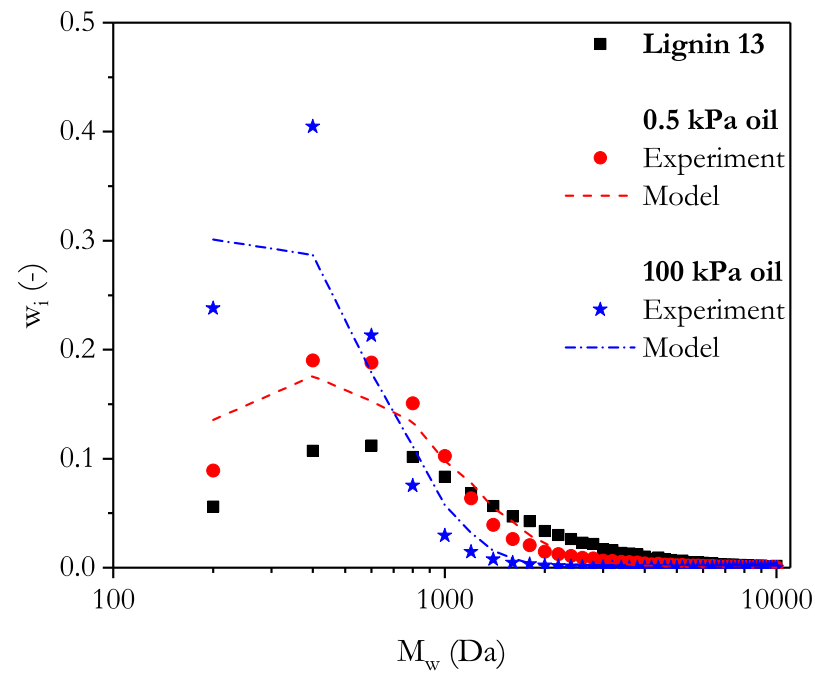

Figure C.14: $\mathrm{M}_{\mathrm{w}} \mathrm{D}$ of lignin 13 and its oils

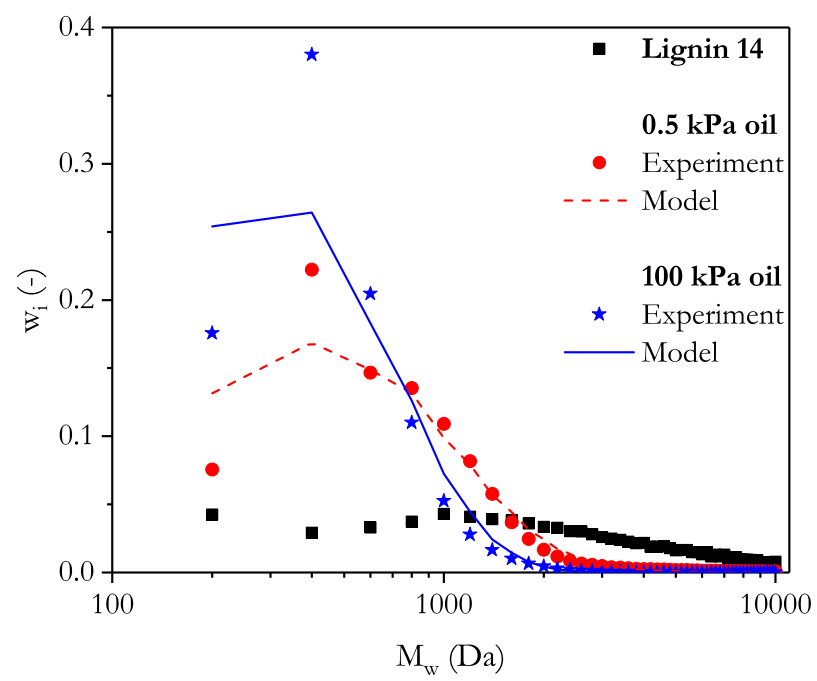

Figure C.15: $\mathrm{M}_{\mathrm{w}} \mathrm{D}$ of lignin 14 and its oils 


\section{C.6 Model}

\section{C.6.1 Experimental proof of polymerisation and bubble formation}

The char, obtained from the pyrolysis of lignin 1, trapped between the screens was washed with THF. Figure C.16 presents the $\mathrm{M}_{\mathrm{w}} \mathrm{D}$ of the THF soluble fraction of the char and the lignin 1. Note, the response of THF soluble fraction of char has been scaled to that of lignin 1 for comparison purpose only. However, it is worth mentioning that no

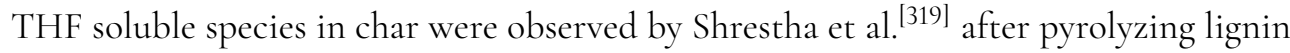
at $400{ }^{\circ} \mathrm{C}$.

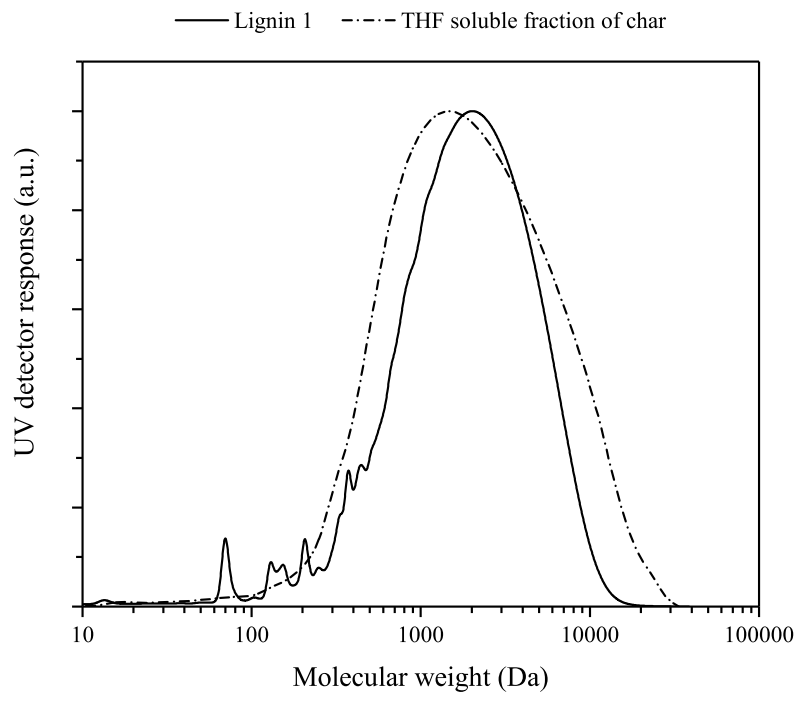

Figure C.16: $\mathrm{M}_{\mathrm{w}} \mathrm{D}$ of lignin 1 and tetrahydrofuran soluble fraction of its char obtained at $100 \mathrm{kPa}$ 
Figure C.17 shows the formed bubbles in the lignin melt during the pyrolysis of lignin 13 at $530^{\circ} \mathrm{C}$ and at $100 \mathrm{kPa}$.

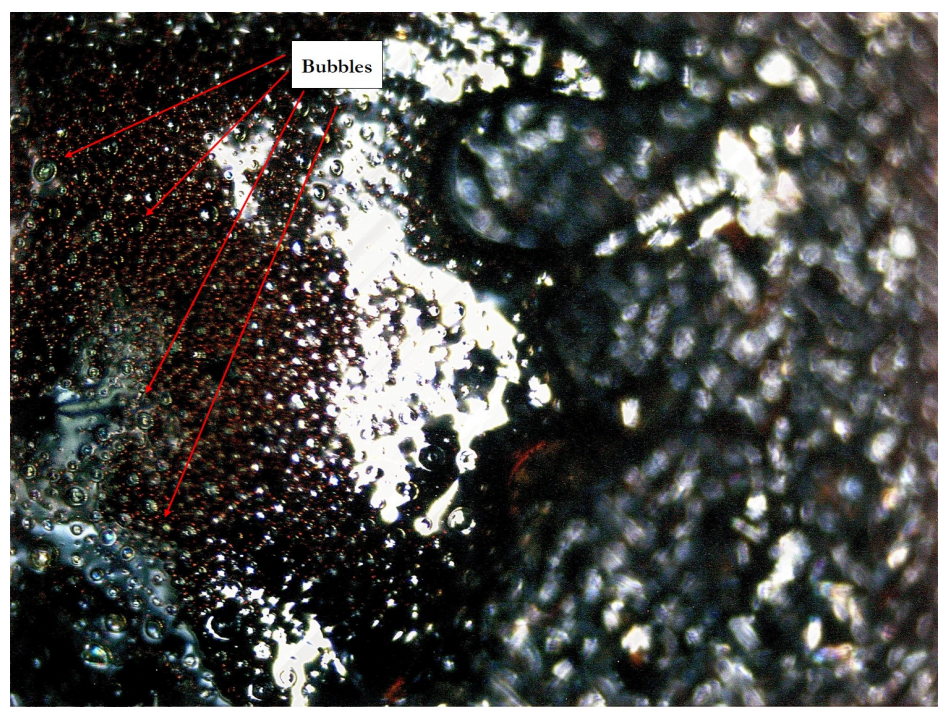

Figure C.17: Formed bubbles in the lignin melt during the pyrolysis of lignin 13 at 530 ${ }^{\circ} \mathrm{C}$ and at $100 \mathrm{kPa}$ 


\section{C.6.2 Model characteristics}

Invariant predictions: Multiplying rate constants with the same factor

Lignin pyrolysis (excluding gas formation reactions) can be simplified to two parallel first and second order reactions, as shown in Figure C.18

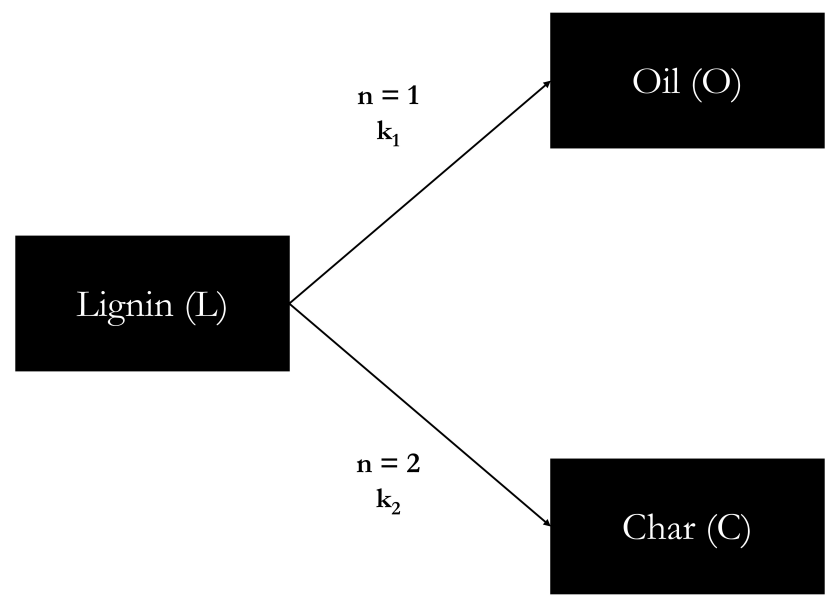

Figure C.18: Schematic representation of lignin pyrolysis; oil (O) and char (C) formation reactions are of $1^{\text {st }}$ and $2^{\text {nd }}$ order, respectively

Rate equations for lignin, oil and char are as follows, where $k_{1}$ is a sum of transport rate constant and cracking rate constant and $k_{2}$ represents the polymerisation rate constant.

$$
\begin{gathered}
\frac{d C_{L}}{d t}=-k_{1} C_{L}-k_{2} C_{L}^{2} \\
\frac{d C_{O}}{d t}=k_{1} C_{L} \\
\frac{d C_{C}}{d t}=k_{2} C_{L}^{2}
\end{gathered}
$$

Analytical solutions of Eq. C.1. Eq. C.2 and Eq. C.3 with $C_{L}(0)=C_{L, 0}$, $C_{O}(0)=0$ and $C_{C}(0)=0$, respectively, are as follows, 


$$
\begin{gathered}
C_{L}=\frac{k_{1} C_{L, 0}}{e^{k_{1} t}\left(k_{1}+k_{2} C_{L, 0}\right)-k_{2} C_{L, 0}} \\
C_{0}=\frac{k_{1}}{k_{2}}\left\{\ln \left(\frac{e^{k_{1} t}\left(k_{1}+k_{2} C_{L, 0}\right)-k_{2} C_{L, 0}}{k_{1}}-k_{1} t\right)\right\} \\
C_{C}=C_{L, 0}-C_{L}-C_{O}
\end{gathered}
$$

at $t \rightarrow \infty$

$$
Y_{\text {Char }}=1+\frac{k_{1}}{k_{2} C_{L, 0}} \ln \left(\left|\frac{k_{1}}{k_{1}+k_{2} C_{L, 0}}\right|\right)
$$

As can be seen from the char yield formula (Eq. C.7), at $\mathrm{t}=\infty$ the char yield is only a function of the ratios of the rate constants, i.e. $k_{1}$ and $k_{2}$, for a given initial concentration of lignin $\left(C_{L, 0}\right)$. Thus, transport of molecules, cracking reactions and polymerisation reactions are interdependent and hence predictions remain unaffected when all rates $\left(k_{T, a v g}, k_{K}, k_{P}\right)$ are multiplied by a same factor. The different processes occurring during lignin pyrolysis should be compared based on rate ratios, i.e. $\frac{k_{T, a v g}}{k_{P}}$ and $\frac{k_{K}}{k_{P}}$. Simulations were carried out for atmospheric pressure experiments of lignin 4 to demonstrate this characteristic for the full model described in the Chapter 5, see Figure C.19A and C.19B Note, as the value of multiplication factor increased, population balance equations reached faster to steady state solution. 


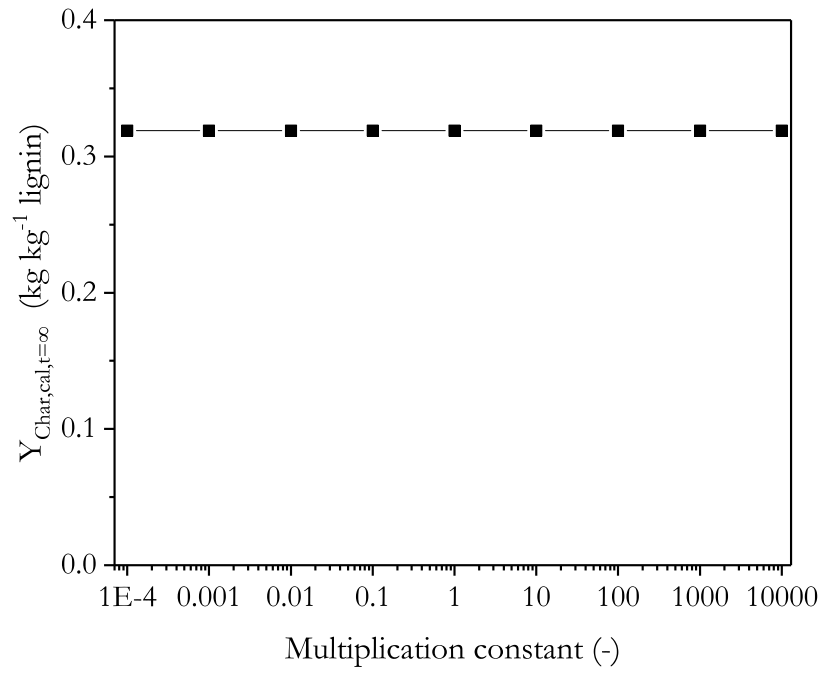

Figure C.19A: Effect of multiplication factor on the calculated char yield

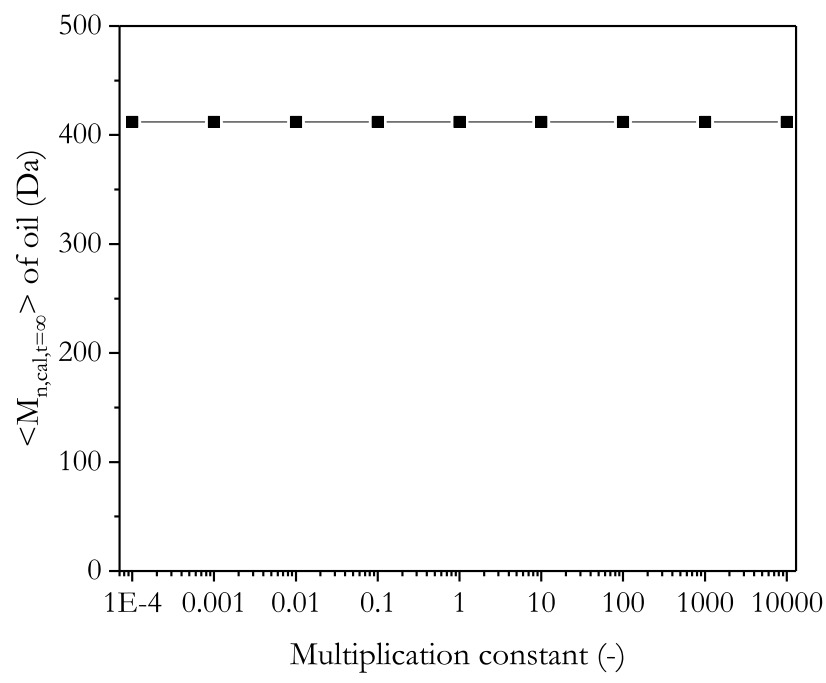

Figure C.19B: Effect of multiplication factor on the calculated $<M_{n}>$ of oils 


\section{Length of computational grid}

One of the parameters in the model is the length of whole grid, i.e. $D P_{1}$ to $2 D P_{\max }$. In all standard simulations the value of the $i_{\max }$ was set at $50\left(\mathrm{DP}_{\max }=\right.$ $10000 D a$ ), thereby, the char bins were between $\left(D_{\max }+1\right)$ to $2 D P_{\max }$. However, it can be argued that molecules bigger than $\mathrm{DP}_{>25}$, being not present in the oil (especially at $100 \mathrm{kPa}$ ), can be treated as a char. Hence, a sensitivity analysis was carried out to investigate the effect grid length on the model predictions i.e. char yield and the $\left\langle\mathrm{M}_{\mathrm{n}}>\right.$ of the oil. In these simulations the length of whole grid $\left(\mathrm{DP}_{1}\right.$ to $\left.2 D P_{\max }\right)$ was varied between 50 to 100 . For example, for $i_{\max }=25$, the computational grid ended at 50 and char bins were between $\mathrm{DP}_{26}$ to $\mathrm{DP}_{50}$. During this analysis, a set of parameters was estimated for each whole grid, i.e. 50. Simulations were carried out for lignin 1 , at 0.5 $\mathrm{kPa}$ and $100 \mathrm{kPa}$.

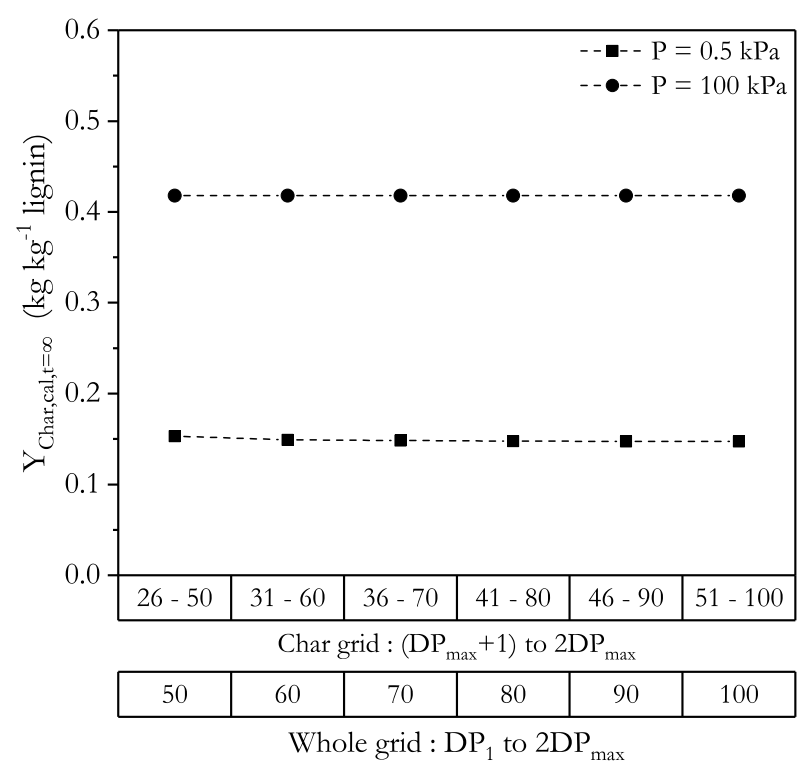

Figure C.20A: Effect of grid length on the calculated char yield 


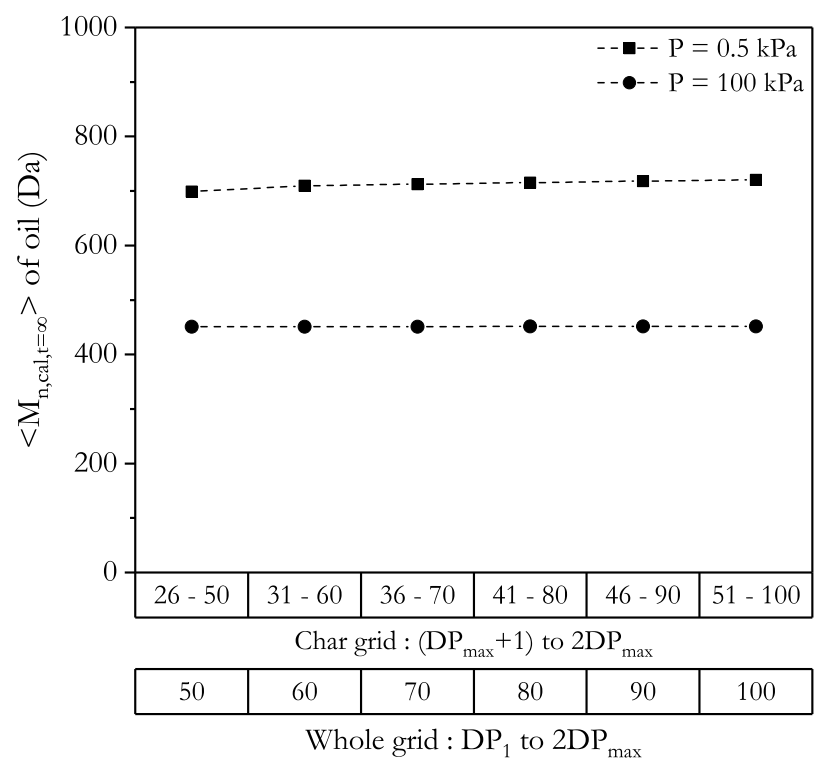

Figure C.20B: Effect of grid length on the calculated $<M_{n}>$ of oils

At both pressures, the predicted char yields are independent of the grid length and match accurately with the experimental values, i.e. $0.15 \mathrm{~kg} \mathrm{~kg}^{-1}(0.5 \mathrm{kPa})$ and $0.42 \mathrm{~kg} \mathrm{~kg}^{-1}$ $(100 \mathrm{kPa})$, see Figure C.20A Similarly, the predicted $\left\langle\mathrm{M}_{\mathrm{n}}\right\rangle$ of the oils remain constant as a function of the grid length at both pressures, see Figure C.20B As the length of the computational grid decreases, an increase in the values of $\frac{k_{T}, a v g}{k_{P}}$ and $\frac{k_{K}}{k_{P}}$ was observed. It can be seen that at $0.5 \mathrm{kPa}$ the values of $\frac{k_{K}}{k_{P}}$ are higher than for $100 \mathrm{kPa}$ and they increase proportionally. The transport rate becomes increasingly dominant over polymerisation for smallest char grid of 25 bins (26-50), especially for $0.5 \mathrm{kPa}$ experiments (see Figure C.21A and C.21B. 


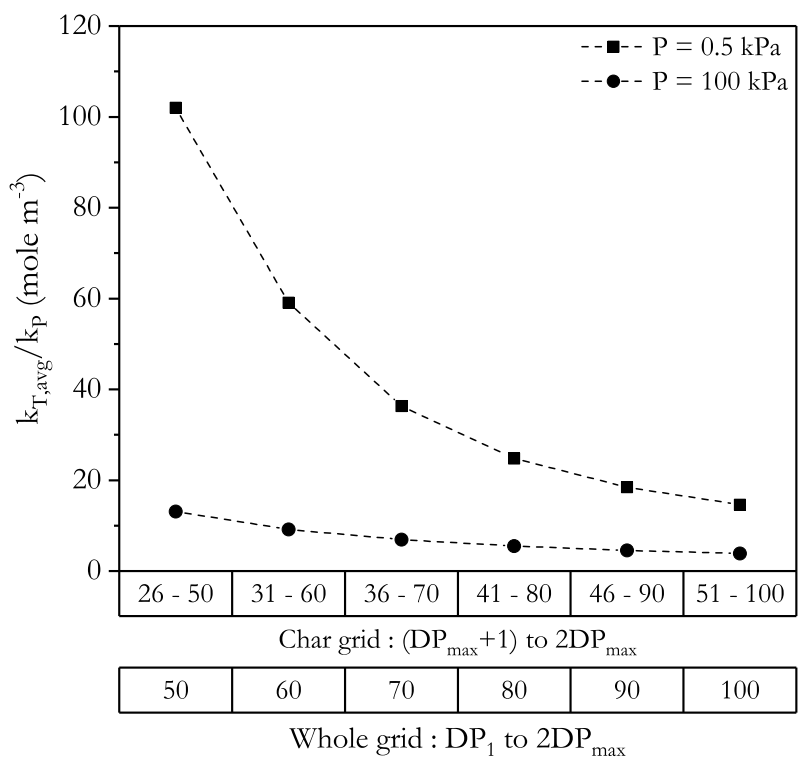

Figure C.21A: Effect of grid length on $\frac{k_{T, a v g}}{k_{P}}$

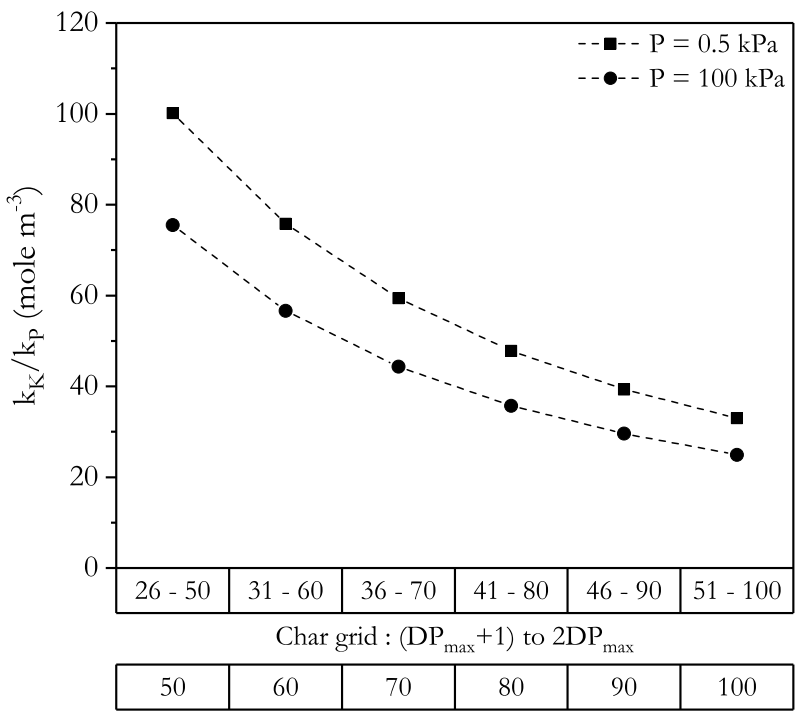

Whole grid : $\mathrm{DP}_{1}$ to $2 \mathrm{DP}_{\max }$

Figure C.21B: Effect of grid length on $\frac{k_{K}}{k_{P}}$ 


\section{C.6.3 Individual fit procedure}

The values of $\frac{k_{T, a v g}}{k_{P}}$ and $\frac{k_{K}}{k_{P}}$ for each lignin obtained from the individual fit procedure for $0.5 \mathrm{kPa}$ and $100 \mathrm{kPa}$ experiments are presented below in Table C.4 It also presents the $95 \%$ confidence intervals of the ratios.

Table C.4: Values of $\frac{k_{T, a v g}}{k_{P}}$ and $\frac{k_{K}}{k_{P}}$ for each lignin obtained from the individual fit procedure

\begin{tabular}{cc|cc|cc}
\hline \multicolumn{2}{c|}{ Pressure } & \multicolumn{2}{c|}{$\mathbf{P}=\mathbf{0 . 5} \mathbf{~ k P a}$} & \multicolumn{2}{c}{$\mathbf{P}=\mathbf{1 0 0} \mathbf{~ k P a}$} \\
Lignin & Code & $\frac{k_{T, a v g}}{k_{P}}$ & $\frac{k_{K}}{k_{P}}$ & $\frac{k_{T, a v g}}{k_{P}}$ & $\frac{k_{K}}{k_{P}}$ \\
- & $\#$ & ${\text { mole } \mathrm{m}^{-3}}^{\text {mole }^{-3}}$ & ${\text { mole } \mathrm{m}^{-3}}^{\text {mole } \mathrm{m}^{-3}}$ \\
\hline SL & 1 & $15 \pm 2$ & $33 \pm 3$ & $4 \pm 0.4$ & $25 \pm 3$ \\
L-SL & 2 & $16 \pm 4$ & $47 \pm 7$ & $4 \pm 0.5$ & $35 \pm 4$ \\
H-SL & 3 & $16 \pm 2$ & $27 \pm 1$ & $3 \pm 0.7$ & $24 \pm 3$ \\
WSL & 4 & $15 \pm 3$ & $43 \pm 5$ & $3 \pm 0.9$ & $35 \pm 4$ \\
L-WSL & 5 & $16 \pm 6$ & $52 \pm 11$ & $4 \pm 0.4$ & $43 \pm 5$ \\
H-WSL & 6 & $13 \pm 1$ & $35 \pm 3$ & $3 \pm 0.4$ & $30 \pm 3$ \\
PL1 & 7 & $4 \pm 1$ & $87 \pm 25$ & - & - \\
L-PL1 & 8 & $5 \pm 1$ & $96 \pm 35$ & - & - \\
H-PL1 & 9 & - & - & $3 \pm 0.5$ & $44 \pm 5$ \\
PL2 & 10 & $5 \pm 0.2$ & $92 \pm 11$ & $2 \pm 0.3$ & $81 \pm 8$ \\
L-PL2 & 11 & $4 \pm 0.4$ & $38 \pm 4$ & $5 \pm 3$ & $55 \pm 0.04$ \\
H-PL2 & 12 & $10 \pm 1$ & $74 \pm 11$ & $3 \pm 0.01$ & $65 \pm 7$ \\
SOL & 13 & $8 \pm 1$ & $43 \pm 4$ & $2 \pm 0.8$ & $39 \pm 4$ \\
MWL & 14 & $9 \pm 0.8$ & $40 \pm 3$ & $3 \pm 0.6$ & $37 \pm 4$ \\
\hline
\end{tabular}




\section{C.6.4 Model predictions with total fit procedure}

The char yields and the $\left\langle\mathrm{M}_{\mathrm{n}}>\right.$ of oils predicted using the total fit procedure are presented in Figure C.22A and C.22B respectively.

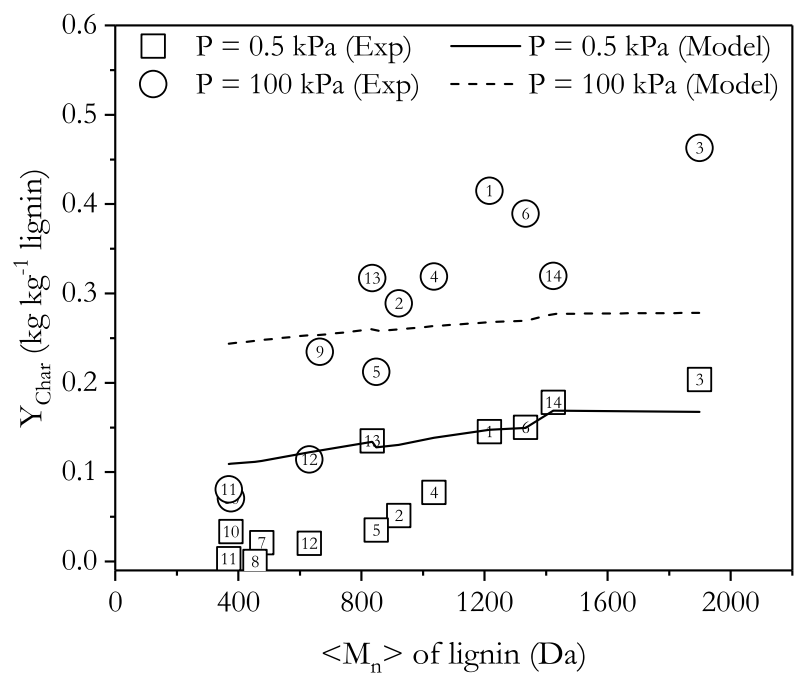

Figure C.22A: Char yields, experimental and calculated from total fit procedure, as a function of the $<\mathrm{M}_{\mathrm{n}}>$ of the lignins

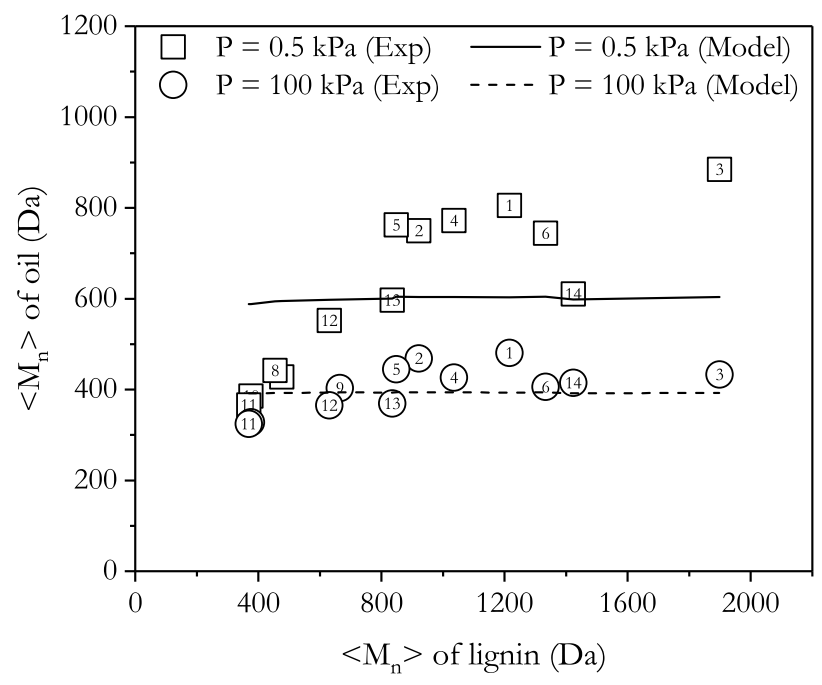

Figure C.22B: $<M_{n}>$ of oils, experimental and calculated from total fit procedure, as a function of the $\left\langle\mathrm{M}_{\mathrm{n}}>\right.$ of the lignins 


\section{C.6.5 Correlation between $\frac{k_{K}}{k_{P}}$ and $<\mathbf{M}_{\mathbf{n}}>$ of lignins}

The relation between $\frac{k_{K}}{k_{P}}$ and $\left\langle\mathrm{M}_{\mathrm{n}}>\right.$ of lignins obtained from the individual fits is presented in Figure C.23 Also, the coefficient of determination $\left(\mathrm{R}^{2}\right)$ and the values of slope and intercept of the linear fit are shown.

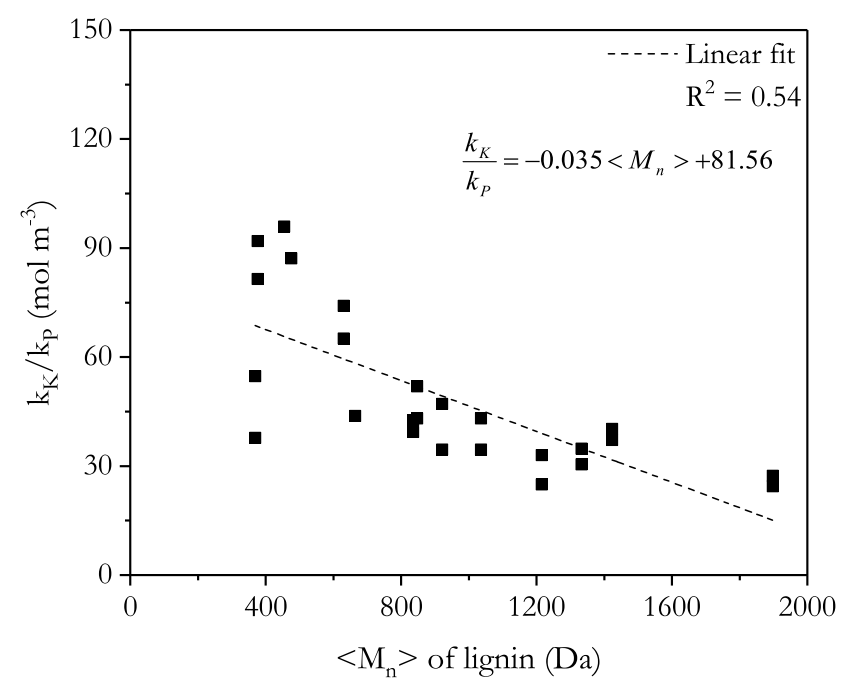

Figure C.23: Correlation between $\frac{k_{K}}{k_{P}}$ and $<\mathrm{M}_{\mathrm{n}}>$ of lignins

C.6.6 Effect of $\mathrm{T}_{\mathrm{FS}}$ on the model predictions, and $\frac{k_{T, a v g}}{k_{P}}$ and $\frac{k_{K}}{k_{P}}$

The parity plots (Figure C.24A and C.24B) of the experimental char yields (A) and $<\mathrm{M}_{\mathrm{n}}>$ of oils (B) are plotted against their predicted values obtained as a function of $\mathrm{T}_{\mathrm{FS}}$, at $0.5 \mathrm{kPa}$ and $100 \mathrm{kPa}$.

The values of $\frac{k_{T, a v g}}{k_{P}}$ and $\frac{k_{K}}{k_{P}}$ obtained, after parameterization, as function of $\mathrm{T}_{\mathrm{FS}}$ are presented in the Figure C.25A and C.25B. respectively. 


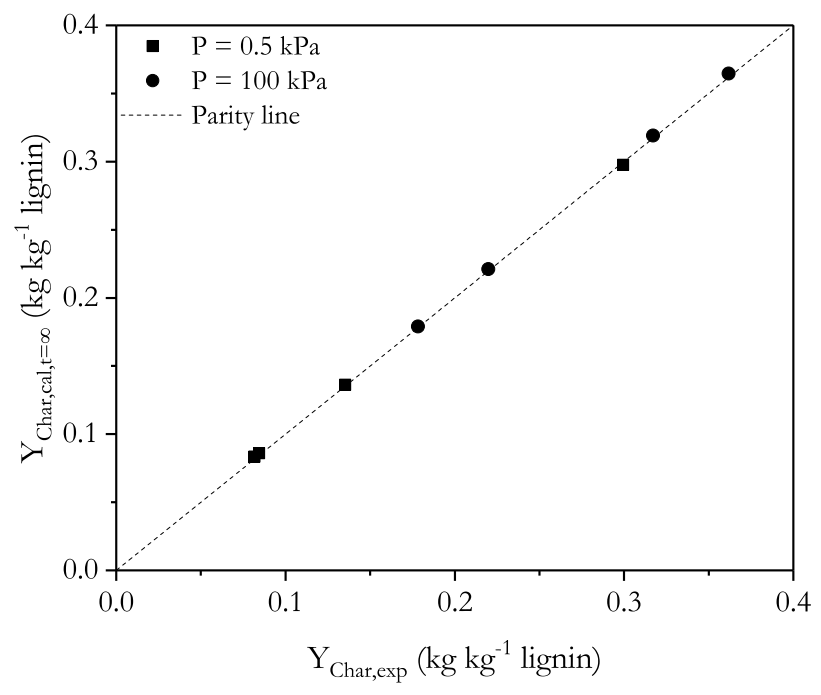

Figure C.24A: Parity plots in which the experimental char yields are plotted against their predicted values obtained as a function of $\mathrm{T}_{\mathrm{FS}}$

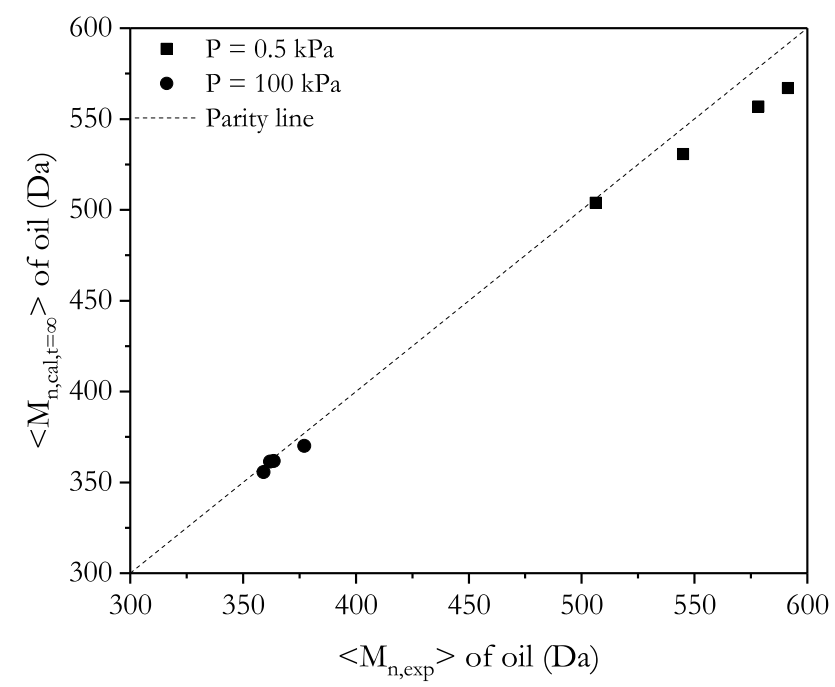

Figure C.24B: Parity plots in which the experimental $\left\langle\mathrm{M}_{\mathrm{n}}>\right.$ of oils are plotted against their predicted values obtained as a function of $\mathrm{T}_{\mathrm{FS}}$ 


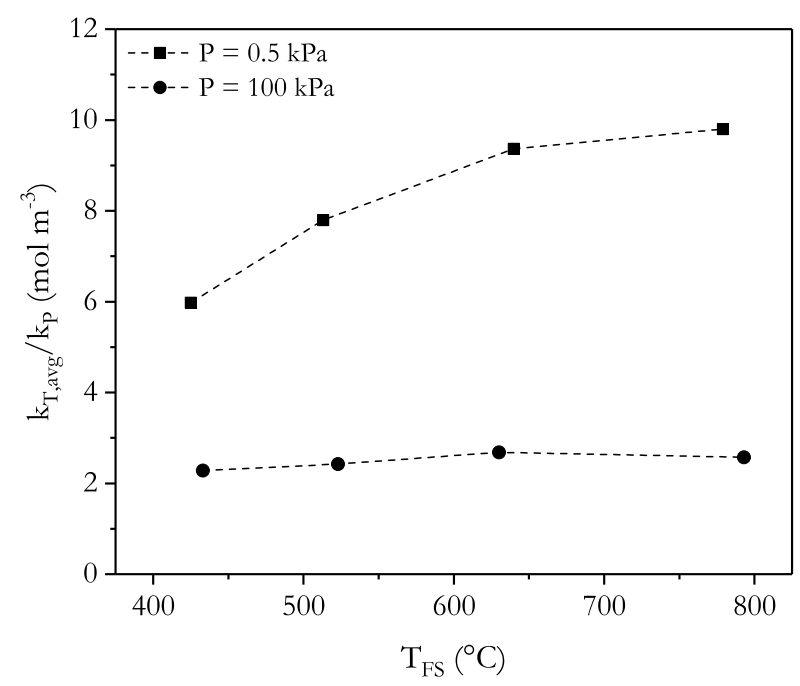

Figure C.25A: The values of $\frac{k_{T, a v g}}{k_{P}}$ as a function of $\mathrm{T}_{\mathrm{FS}}$

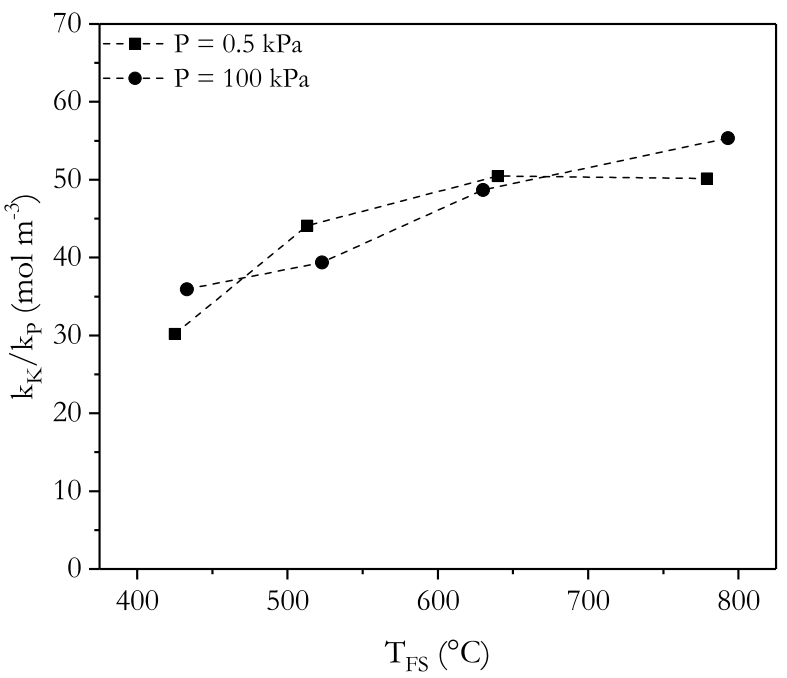

Figure C.25B: The values of $\frac{k_{K}}{k_{P}}$ as a function of $\mathrm{T}_{\mathrm{FS}}$ 
C 


\section{D}

Supporting information for Chapter 7 


\section{D.1 Experimental data}

Each data point reported in Table D.1 to Table D.4 is an average of minimum three experiments. The calculated standard deviation on the mean is also presented. The data reported in Table D.3 and Table D.5 for acid-leached pinewood in fluidised bed is based on a single experiment because of the limited availability of the feedstock.

\section{Bagasse}

Table D.1: Yields of oil, char, gas, water-insoluble compounds (WIS) obtained from pyrolysis of acid-leached bagasse as a function of pressure in screen-heater $\left(\mathrm{T}_{\mathrm{FS}}=515 \pm\right.$ $\left.10{ }^{\circ} \mathrm{C}\right)$

\begin{tabular}{ccccc}
\hline $\begin{array}{c}\text { Pressure } \\
\mathrm{kPa}\end{array}$ & $\mathrm{Y}_{\text {Oil }}$ & \multicolumn{4}{c}{$\mathrm{Y}_{\text {Char }}$} & $\mathrm{Y}_{\text {Gas }}$ & $\mathrm{Y}_{\mathrm{wIIS}_{\mathrm{IS}}}$ \\
wt.\% on d.a.f. bagasse \\
\hline $0.005 \pm 0.00$ & $91.3 \pm 1.2$ & $4.6 \pm 0.2$ & $0.5 \pm 0.0$ & $17.2 \pm 1.6$ \\
$0.2 \pm 0.03$ & $85.6 \pm 2.0$ & $5.0 \pm 0.4$ & $0.5 \pm 0.1$ & $15.6 \pm 2.3$ \\
$2 \pm 0.03$ & $87.9 \pm 0.5$ & $3.5 \pm 0.1$ & $3.2 \pm 0.6$ & $22.1 \pm 0.5$ \\
$10 \pm 2.5$ & $91 \pm 3$ & $3 \pm 0$ & $3 \pm 0$ & $14 \pm 0.2$ \\
$21 \pm 1.08$ & $78.7 \pm 2.3$ & $9.3 \pm 1.4$ & $1.9 \pm 0.4$ & $11.8 \pm 2.2$ \\
$38 \pm 0.30$ & $78.5 \pm 2.7$ & $9.0 \pm 1.6$ & $2.5 \pm 0.8$ & $17.7 \pm 1.3$ \\
$60 \pm 0.10$ & $81.5 \pm 2.9$ & $8.7 \pm 1.5$ & $2.3 \pm 0.3$ & $18.2 \pm 1.3$ \\
$81 \pm 1.01$ & $79.4 \pm 1.4$ & $7.4 \pm 0.5$ & $2.9 \pm 0.8$ & $17.6 \pm 1.2$ \\
$101 \pm 1.39$ & $72.8 \pm 2.4$ & $8.2 \pm 0.9$ & $4.7 \pm 0.3$ & $13.3 \pm 2.9$ \\
\hline
\end{tabular}


Table D.2: Yield of $\mathrm{C}_{6}$ anhydrosugars $\left(\mathrm{C}_{6} \mathrm{a} S\right)$ and $\mathrm{DP}_{1}$ mass fraction obtained from pyrolysis of acid-leached bagasse as a function of pressure in screen-heater $\left(\mathrm{T}_{\mathrm{FS}}=515 \pm\right.$ $\left.10{ }^{\circ} \mathrm{C}\right)$

\begin{tabular}{ccccccccccc}
\hline \multicolumn{2}{c}{ Feedstock } & \multicolumn{4}{c}{ Untreated bagasse } & \multicolumn{5}{c}{ Acid-leached bagasse } \\
$\begin{array}{c}\text { Pressure } \\
\mathrm{kPa}\end{array}$ & \pm & $\mathrm{Y}_{\mathrm{C}_{6} \mathrm{aS}}$ & \pm & $\mathrm{f}_{\mathrm{DP}_{1}}$ & \pm & $\mathrm{Y}_{\mathrm{C}_{6} \mathrm{aS}}$ & \pm & $\mathrm{f}_{\mathrm{DP}_{1}}$ & \pm \\
\hline $5 \times 10^{-3}$ & 0.00 & 25.2 & 0.2 & 0.08 & 0.0 & 73 & 3 & 0.13 & 0.01 \\
0.2 & 0.03 & 16.4 & 1.3 & 0.06 & 0.3 & 67 & 2 & 0.14 & 0.00 \\
2 & 0.03 & 22.0 & 2.9 & 0.05 & 0.3 & 62 & 2 & 0.18 & 0.00 \\
10 & 2.5 & - & - & - & - & 51 & 3 & 0.27 & 0.01 \\
20 & 1.08 & 10.2 & 0.9 & 0.10 & 0.3 & 42 & 2 & 0.32 & 0.00 \\
40 & 0.30 & 10.3 & 1.3 & 0.11 & 0.5 & 42 & 1 & 0.35 & 0.01 \\
60 & 0.10 & 6.8 & 2.2 & 0.15 & 0.1 & 38 & 1 & 0.42 & 0.00 \\
80 & 1.01 & 8.5 & 1.2 & 0.14 & 0.1 & 38 & 2 & 0.43 & 0.01 \\
100 & 1.39 & 8.1 & 0.8 & 0.15 & 0.0 & 35 & 1 & 0.39 & 0.00 \\
\hline
\end{tabular}

\section{Pinewood}

Table D.3: Yields of oil, char, gas and water-insoluble compounds (WIS) obtained from pyrolysis of acid-leached pinewood as a function of pressure in screen-heater and fluidised bed $\left(\mathrm{T}=485^{\circ} \mathrm{C}\right)$

\begin{tabular}{|c|c|c|c|c|}
\hline $\begin{array}{c}\text { Pressure } \\
\mathrm{kPa}\end{array}$ & $\mathrm{Y}_{\mathrm{Oil}}$ & $\begin{array}{c}\mathrm{Y}_{\text {Char }} \\
\text { wt.\% on } \mathrm{d}\end{array}$ & $\begin{array}{c}\mathrm{Y}_{\mathrm{Gas}} \\
\text { f. bagasse }\end{array}$ & $\mathrm{Y}_{\mathrm{WIS}}$ \\
\hline \multicolumn{5}{|c|}{ Screen-heater } \\
\hline $0.3 \pm 0.01$ & $83.7 \pm 1.4$ & $7.1 \pm 2.2$ & $0.5 \pm 0.0$ & $10.2 \pm 0.8$ \\
\hline $55 \pm 0.05$ & $76.2 \pm 1.3$ & $8.9 \pm 0.0$ & $1.5 \pm 0.2$ & $12.7 \pm 0.9$ \\
\hline $100 \pm 1.3$ & $63.6 \pm 2.0$ & $8.2 \pm 0.1$ & $2.1 \pm 0.1$ & $9.0 \pm 1.0$ \\
\hline \multicolumn{5}{|c|}{ Fluidised bed } \\
\hline 55 & 62 & 12 & 19 & 7.9 \\
\hline
\end{tabular}




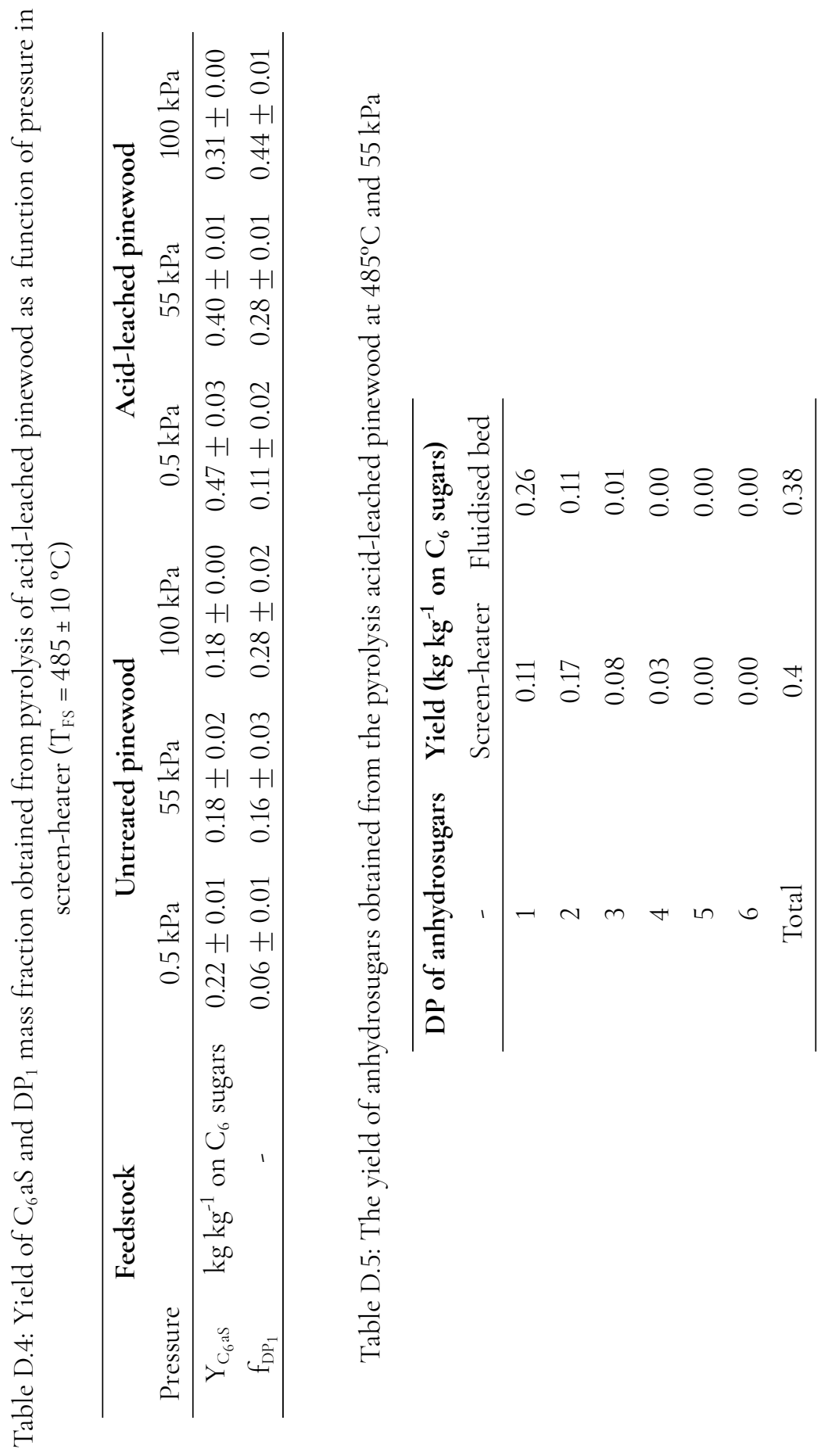




\section{D.2 Direct infusion mass spectrometry}

In this section, direct infusion mass spectrometry of water-soluble fraction of biooils and fingerprinting $\left(\mathrm{MS}^{2}\right)$ of anhydrosugars is presented. For the details of the method see Section 2.4.5 in Chapter 2.

Table $D .6$ presents the molar mass $(\mathrm{m} / \mathrm{z})$ and $\mathrm{NH}^{4+}\left(\right.$ or $\left.\mathrm{Na}^{+}\right)$adduct molar mass corresponding to different DPs, which were found in the oil as well as in $\mathrm{MS}^{2}$ spectra. Different DPs found in the spectra are highlighted in a red ellipse, see Figure D.1 to Figure D.3

Table D.6: Molar mass (m/z) and $\mathrm{NH}^{4+}\left(\right.$ or $\left.\mathrm{Na}^{+}\right)$adduct molar mass corresponding to different DPs

\begin{tabular}{ccccc}
\hline DP & Name & Molar mass or $\mathbf{m} / \mathbf{z}$ & DP with $\mathbf{N H}^{4+}$ & DP with $\mathbf{~ a}^{+}$ \\
- & - & Da & Da & Da \\
\hline 1 & Levoglucosan & 162 & 180 & 185 \\
2 & Cellobiosan & 324 & 342 & \\
3 & Cellotriosan & 486 & 504 & \\
4 & Cellotetrasan & 648 & 666 & \\
5 & Cellopentasan & 810 & 828 & \\
6 & Cellohexasan & 972 & 990 & \\
\hline
\end{tabular}




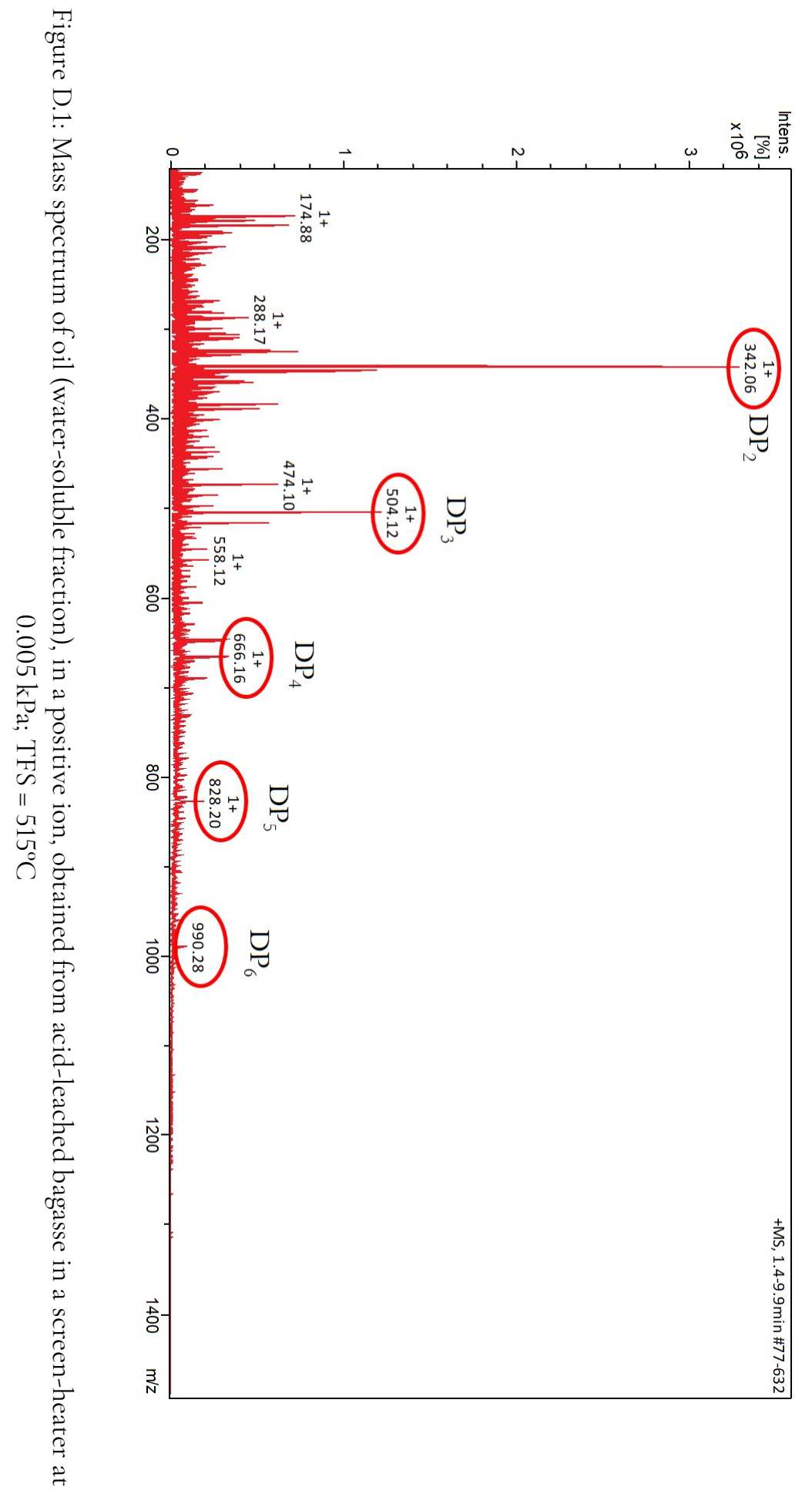




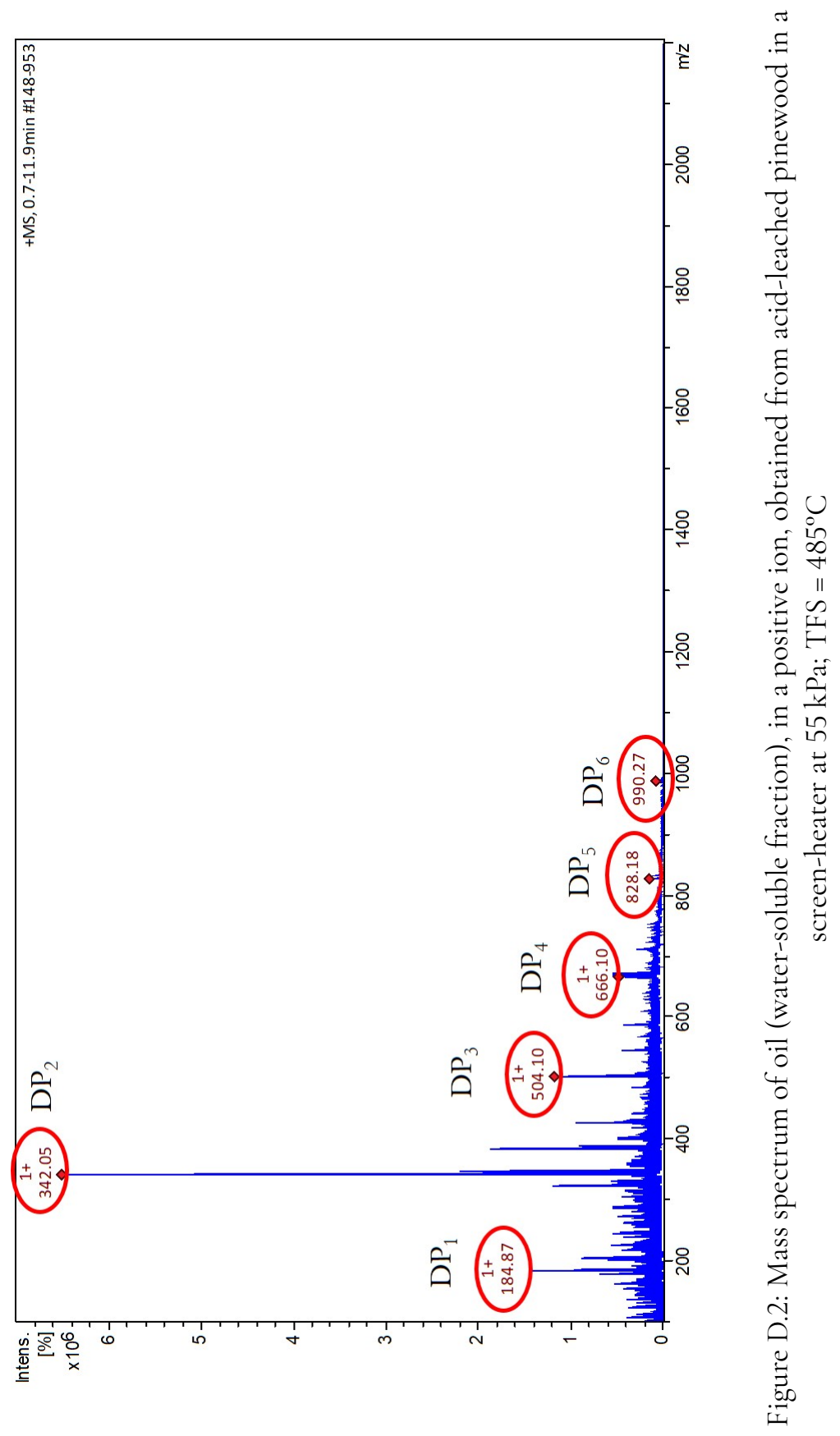




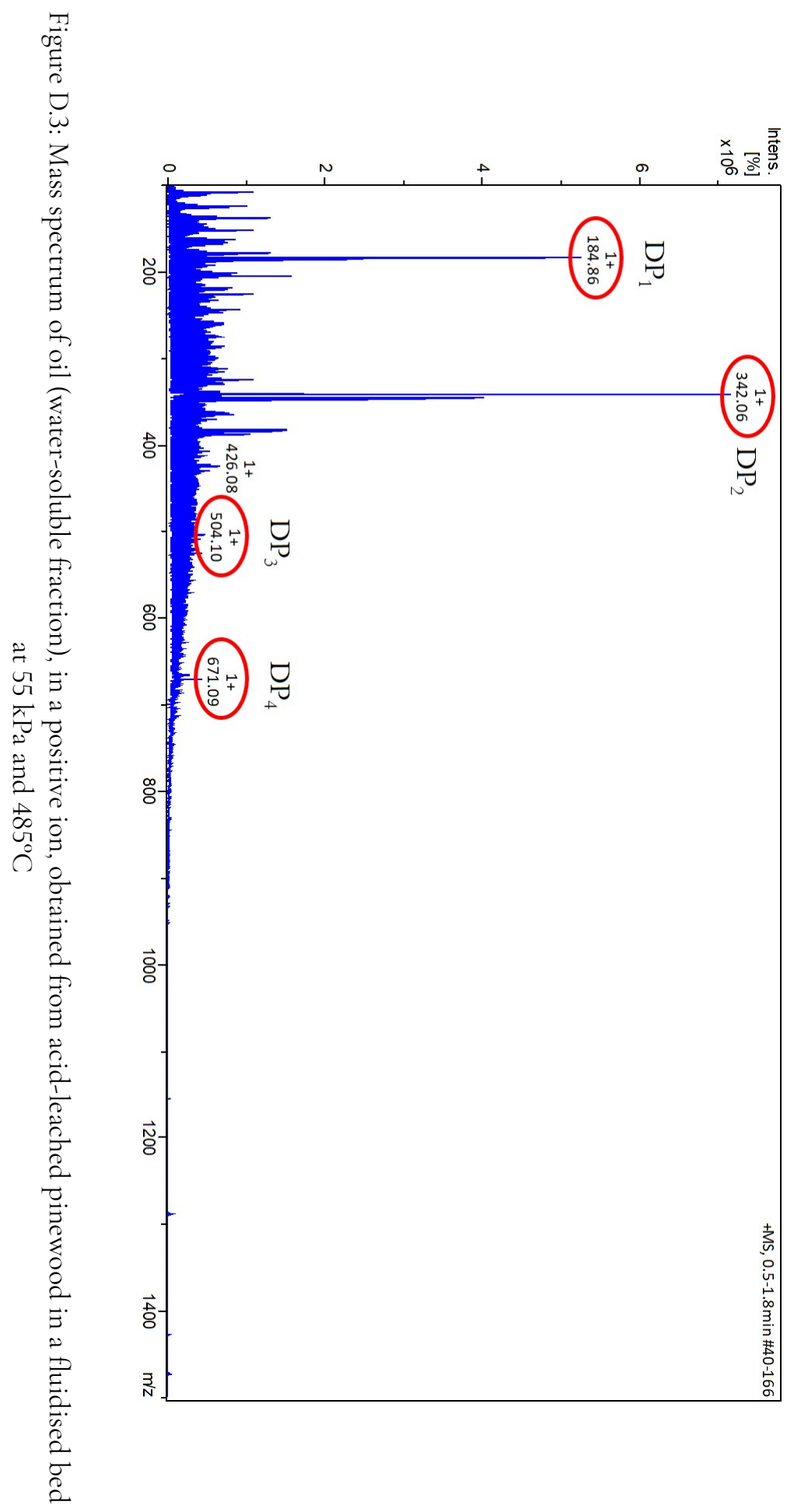




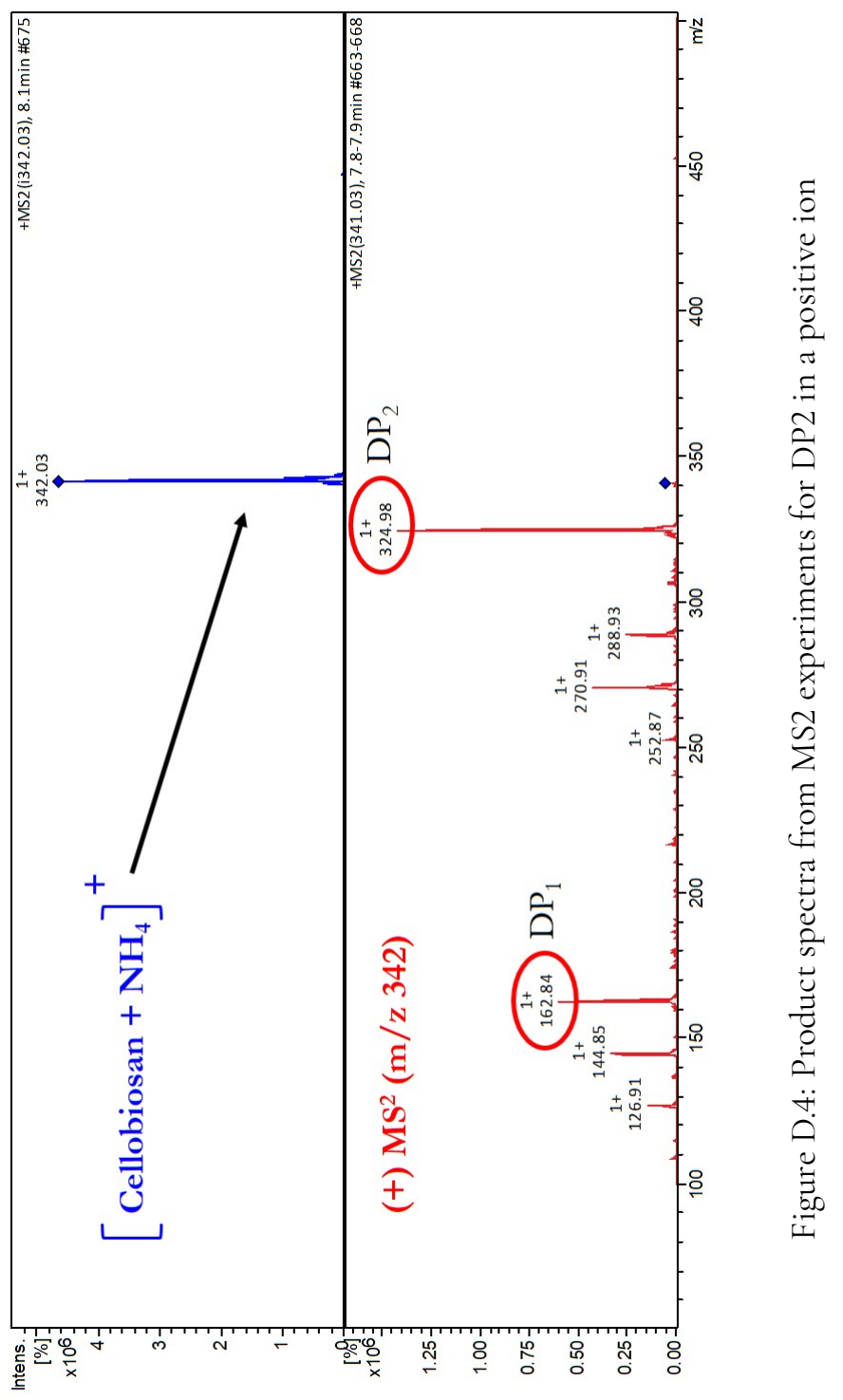




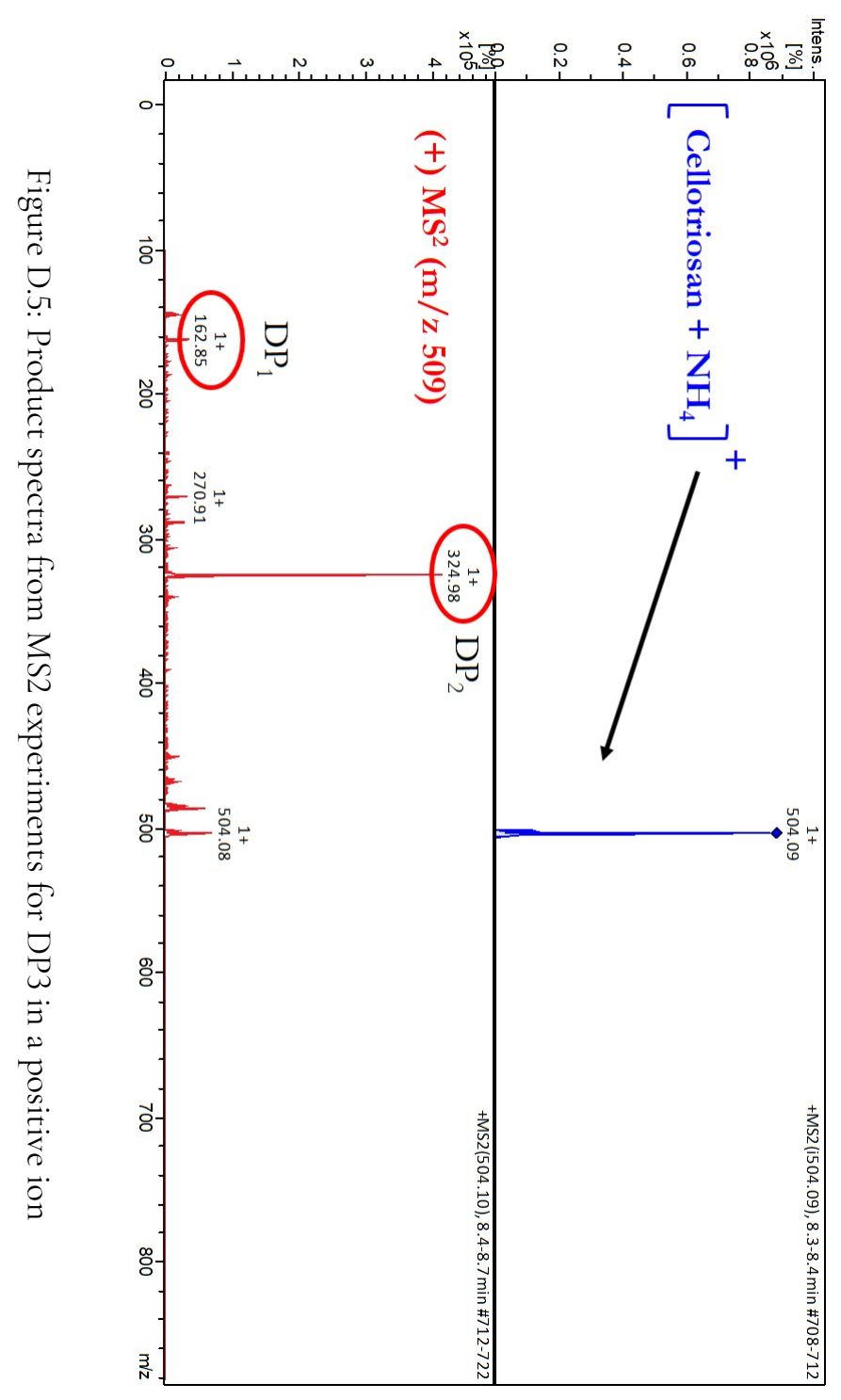




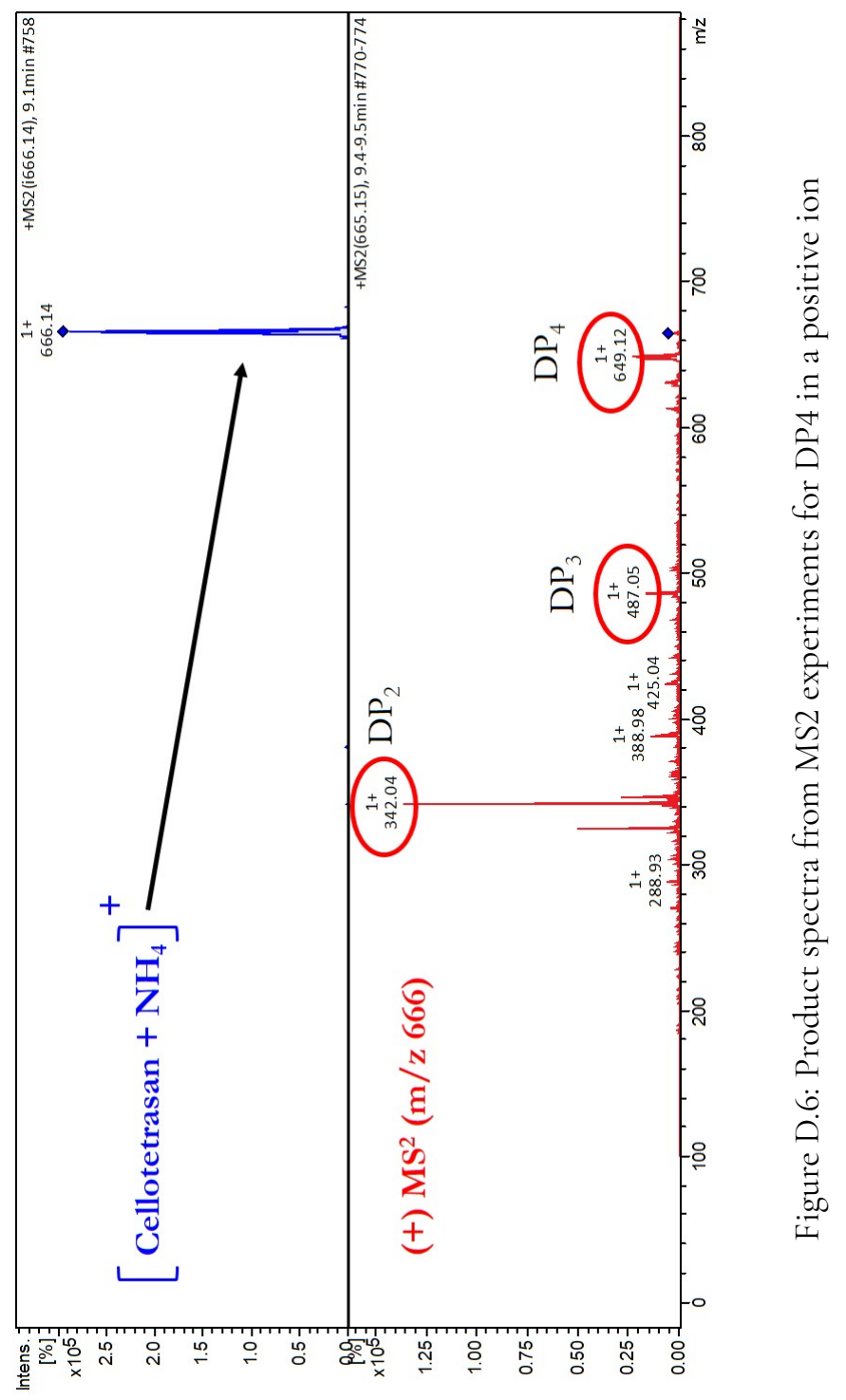




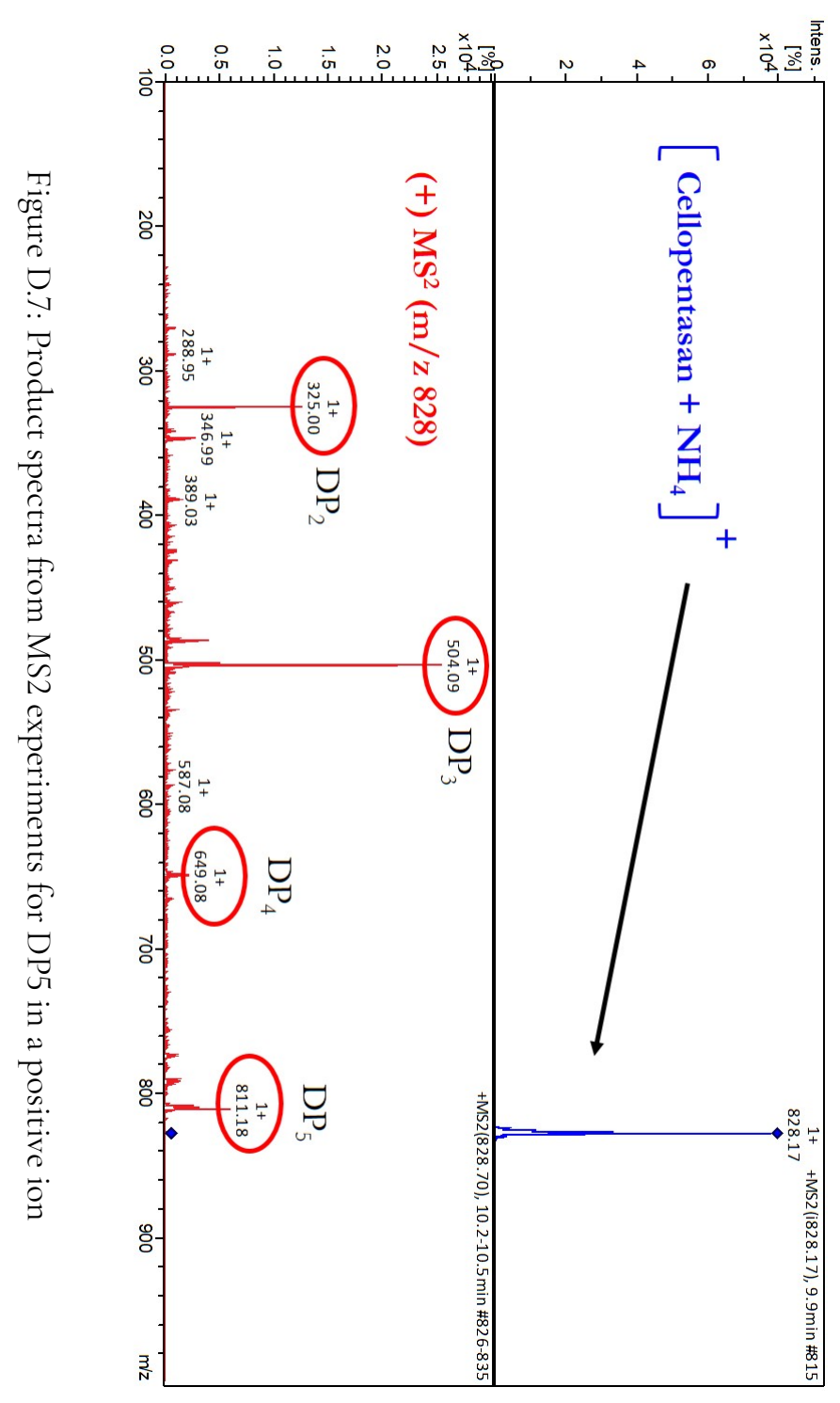




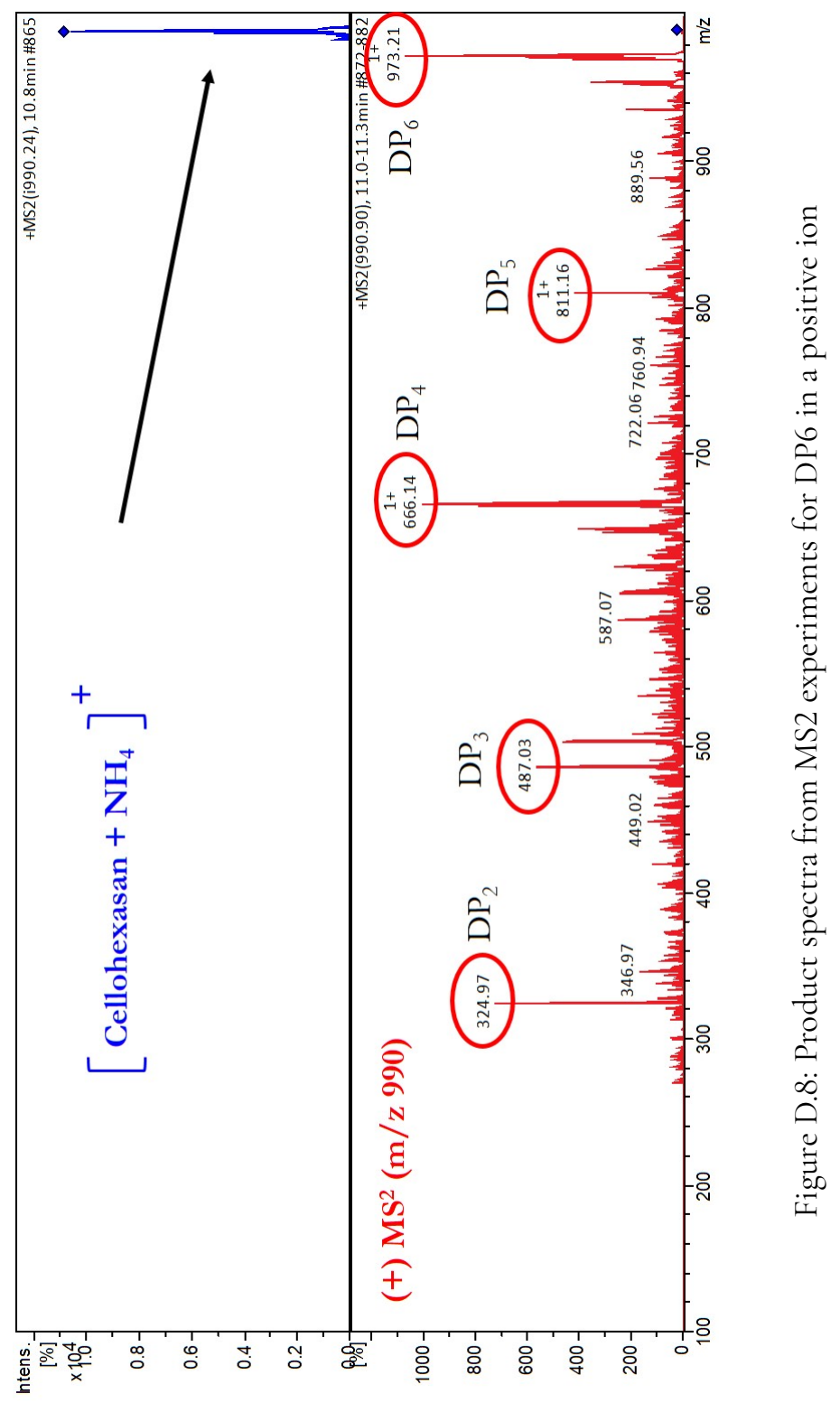




\section{D.3 Model description}

\section{D.3.1 Model characteristic}

Pyrolysis of $\mathrm{C}_{6}$ sugars in biomass can be simplified to three series-parallel first order reactions, as shown in Figure D.9

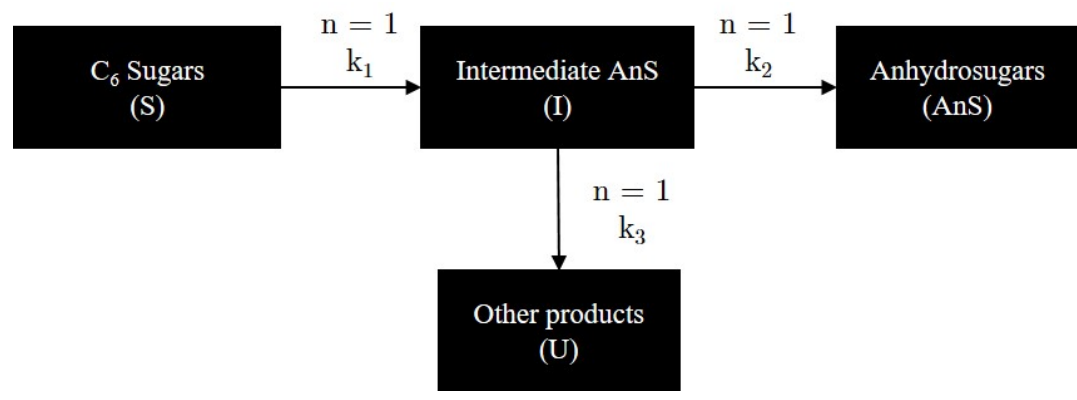

Figure D.9: Schematic representation of $\mathrm{C}_{6}$ sugars (in biomass) pyrolysis

Rate equations for $\mathrm{C}_{6}$ sugars (S), intermediate $\mathrm{C}_{6} \mathrm{aS}$ (I), $\mathrm{C}_{6} \mathrm{aS}$ (AnS) and other products (U) are as follows, where $k_{1}$ is a depolymerisation rate constant, $k_{2}$ represents mass transport rate of $\mathrm{C}_{6} \mathrm{aS}$ away from the reaction front, and $k_{3}$ is the rate constant for decomposition reactions.

$$
\begin{gathered}
\frac{d C_{S}}{d t}=-k_{1} C_{S} \\
\frac{d C_{I}}{d t}=k_{1} C_{S}-k_{2} C_{I}-k_{3} C_{I} \\
\frac{d C_{A n S}}{d t}=k_{2} C_{I} \\
\frac{d C_{U}}{d t}=k_{3} C_{I}
\end{gathered}
$$

Analytical solutions of Eq. D.1, Eq. D.2 Eq. D.3 and Eq. D.4 with $C_{S}(0)=$ $C_{S, 0}, C_{I}(0)=0, C_{A n S}(0)=0$ and $C_{U}(0)=0$, respectively, are as follows,

$$
C_{S}=C_{S, 0} e^{-k_{1} t}
$$




$$
\begin{gathered}
C_{I}=\frac{k_{1} C_{S, 0}}{k_{2}+k_{3}-k_{1}}\left(e^{-k_{1} t}-e^{-\left(k_{2}+k_{3}\right) t}\right) \\
C_{A n S}=\frac{k_{1} C_{S, 0}}{k_{2}+k_{3}-k_{1}}\left(\frac{e^{-\left(k_{2}+k_{3}\right) t}}{k_{2}+k_{3}}-\frac{e^{-k_{1} t}}{k_{1}}\right)+\frac{k_{2}}{k_{2}+k_{3}} \\
C_{U}=C_{S, 0}-C_{S}-C_{I}-C_{A n S}
\end{gathered}
$$

at $t \rightarrow \infty$

$$
Y_{A n S}=\frac{k_{2}}{k_{2}+k_{3}}
$$

From Eq. D.9 it can be seen that, at steady state, the yield of $\mathrm{C}_{6} \mathrm{aS}$ is only a function of the mass transport rate of anhydrosugars $\left(k_{2}\right)$ and decomposition rate constant $\left(k_{3}\right)$. It is important to note that this analytical solution only computes the yield of $\mathrm{C}_{6} \mathrm{aS}$.

The experimental method does not allow the determination of the temporal evolution of products. Instead, final yields $(t=\infty)$ are obtained, leads to the restriction that it is not possible to determine all three constants $\left(k_{T, a v g}, k_{U}\right.$ and $\left.k_{K}\right)$ by fitting them to the experimental results. Since the aim is to predict both the yield of $\mathrm{C}_{6}$ aS and the mass fraction of $\mathrm{DP}_{1}$ in $\mathrm{C}_{6} \mathrm{aS}$, inclusion of depolymerisation reaction rate constant $\left(k_{K}\right)$ becomes necessary. Therefore, it was decided that the different processes occurring during the pyrolysis of $\mathrm{C}_{6}$ sugars should be compared based on $\frac{k_{K}}{k_{K}+k_{U}}$ and $\frac{k_{T \text {,avg }}}{k_{K}+k_{U}}$. 


\section{D.3.2 Description}

\section{Particle level}

\section{Mass balance}

The mass balances for $\mathrm{DP}_{1}$ to $\mathrm{DP}_{7}$ and other products $(U)$ are presented below.

$$
\begin{gathered}
\frac{d m_{D P_{i}}^{P}}{d t}=\left(K_{i}^{f}-K_{i}^{c}\right)-E_{i}-U_{i} \quad 1 \leq i \leq 6 \\
\frac{d m_{D P_{i}}^{P}}{d t}=K_{i}^{c} \quad i=7 \\
\frac{d U}{d t}=\sum_{i=1}^{6} U_{i} \\
\frac{d m_{D P_{i}}^{O}}{d t}=E_{i} \quad 1 \leq i \leq 6
\end{gathered}
$$

\section{Transport}

The transport of $\mathrm{C}_{6} \mathrm{aS}$, by evaporation/sublimation/ejection, is described by a single first order equation.

$$
\begin{array}{cc}
E_{i}=k_{T, i} m_{D P_{i}}^{P} & 1 \leq i \leq 6 \\
k_{T, i}=e^{-A i} & 1 \leq i \leq 6
\end{array}
$$

\section{Depolymerisation}

Depolymerisation is assumed to be a first order process, and all possibilities have the same likelihood, i.e. the rate constant $k_{K}$, is the same for all depolymerisation reactions. Note that the $D P_{1}$ segment do not depolymerise further.

$$
\begin{array}{cc}
K_{i}^{f}=k_{K} 2 \sum_{j=i+1}^{7} \frac{i}{j} m_{D P_{j}}^{P} & 1 \leq i \leq 6 \\
K_{i}^{c}=k_{K}(i-1) m_{D P_{i}}^{P} & 1 \leq i \leq 6
\end{array}
$$




\section{Decomposition}

Decomposition reaction of each $\mathrm{C}_{6} \mathrm{aS}$ assumed to follow first order kinetics, and all decomposition reactions have the same rate constant, $k_{U}$. Furthermore, it is assumed that once the other products are formed, they do not take part in any reactions and remain at the reacting particle.

$$
U_{i}=k_{U} m_{D P_{i}}^{P} \quad 1 \leq i \leq 6
$$

\section{Initial conditions}

The initial masses of $\mathrm{C}_{6}$ aS $\left(D P_{1}\right.$ to $\left.D P_{6}\right)$ on the hot reacting particle and in the oil are,

$$
m_{D P_{i}, t=0}^{P}=m_{D P_{i}, t=0}^{O}=0 \quad 1 \leq i \leq 6
$$

The fraction of $\mathrm{C}_{6}$ sugars present in bagasse or pinewood is used as an initial mass of $D P_{7}$, see Table 1 .

$$
m_{D P_{i}, t=0}^{P}=f_{C_{6}} \quad i=7
$$

The mass fraction of other products is

$$
U_{t=0}=0
$$

\section{Post-processing}

Eq. D.19 and Eq. D.20 calculate the yield of $\mathrm{C}_{6} \mathrm{aS}$ and the mass fraction of DP1 in $\mathrm{C}_{6} \mathrm{aS}$, respectively.

$$
\begin{gathered}
Y_{C_{6} a S, c a l, t=\infty}=\frac{\sum_{i=1}^{6} m_{D P_{i}, t=\infty}^{O}}{m_{D P_{7}, t=0}^{P}} \\
f_{D P_{1}, c a l, t=\infty}=\frac{m_{D P_{1}, t=\infty}^{O}}{\sum_{i=1}^{6} m_{D P_{i}, t=\infty}^{O}}
\end{gathered}
$$




\section{Parameter estimation}

$$
h_{j}=\sum\left\{\left(f_{D P_{1}, \exp }-f_{D P_{1}, c a l, t=\infty}\right)^{2}+\left(Y_{C_{6} a S, \exp }-Y_{C_{6} a S, c a l, t=\infty}\right)^{2}\right\}
$$

$$
g=\sum_{j=1}^{n} h_{j}
$$

The objective function for this (Eq. D.21) is comprised of - 1) the sum of the squared difference between the experimentally obtained and calculated mass fraction of $\mathrm{DP}_{1}$, and 2) the squared difference between the experimentally obtained and calculated $\mathrm{C}_{6} \mathrm{aS}$ yield.

At a constant temperature, parameters $k_{U}$ and $k_{K}$ are constant and are independent of pressure. To estimate a single value of $\frac{k_{K}}{k_{K}+k_{U}}$ over the entire pressure range, the objective function shown in Eq. D.22 is used where $n$ represents each pressure; this is called the total fit procedure. The experimental results obtained at each pressure were fitted to the model, with $\frac{k_{K}}{k_{K}+k_{U}}$ the value obtained from the total fit procedure, to obtain $\frac{k_{T, a v g}}{k_{K}+k_{U}}$ using the objective function shown in Eq. D.21 This called the individual fit procedure. Parameters estimation is carried out with the Matlab built-in optimisation function lsqnonlin. 95\% confidence intervals for each parameter were determined by the built-in Matlab function nlparci. 
Hot vapour phase

Mass balance

$$
\frac{d m_{D P_{i}}^{V}}{d t}=k_{V}\left[2 \sum_{j=i+1}^{6} \frac{i}{j} m_{D P_{i}}^{V}-(i-1) m_{D P_{i}}^{V}\right] \quad 1 \leq i \leq 6 \quad \text { (Eq. D.23) }
$$

\section{Initial conditions}

Since the DP distribution of $\mathrm{C}_{6} \mathrm{aS}$ in the fluidised bed could not be measured after $\sim 20 \mathrm{~ms}$, the DP distribution of experimentally obtained in screen-heater is used as initial conditions.

$$
\begin{aligned}
& m_{D P_{1}, t=0}^{V}=0.112 \\
& m_{D P_{2}, t=0}^{V}=0.169 \\
& m_{D P_{3}, t=0}^{V}=0.082 \\
& m_{D P_{4}, t=0}^{V}=0.029 \\
& m_{D P_{5}, t=0}^{V}=0.005 \\
& m_{D P_{6}, t=0}^{V}=0.005
\end{aligned}
$$

\section{Numerical method}

The model equations were implemented in the coding environment of Matlab ${ }^{\circledR 2017 a .}$ The numerical integration was carried out with the built-in ode45 solver which is based on the explicit Runge-Kutta method. 


\section{Parameter estimation}

$$
h=\sum\left(m_{D P_{i}, \exp }^{V}-m_{D P_{i}, c a l, t=\infty}^{V}\right)^{2}
$$

The objective function for this Eq. D.24 is comprised of the sum of the squared difference between the experimentally obtained (in fluidised bed) and calculated masses of $\mathrm{DP}_{1}$ to $\mathrm{DP}_{6}$. The experimental DP distribution of $\mathrm{C}_{6} \mathrm{aS}$ was fitted to the model to obtain the value of $k_{V}$. Parameters estimation is carried out with the Matlab in-built optimisation function 1sqnonlin. 95\% confidence interval for $k_{V}$ was determined by the built-in Matlab function nlparci.

\section{Results}

\section{Total fit procedure}

The $\mathrm{C}_{6} \mathrm{aS}$ yield (on $\mathrm{C}_{6}$ sugars in acid-leached bagasse) and the mass fraction of $\mathrm{DP}_{1}$ in $\mathrm{C}_{6} \mathrm{aS}$ predicted using the total fit procedure are presented in Figure D.10

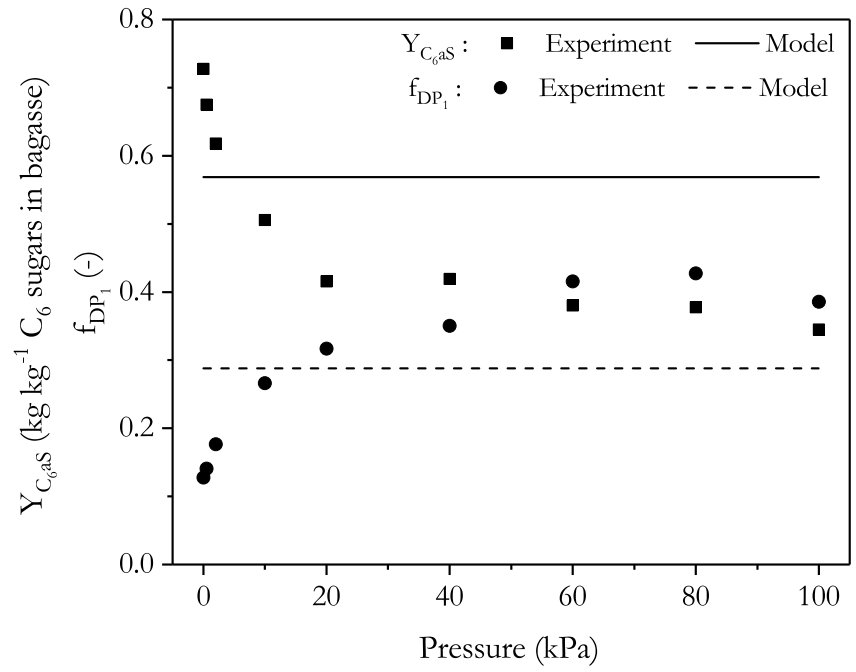

Figure D.10: $\mathrm{C}_{6} \mathrm{aS}$ yield (on $\mathrm{C}_{6}$ sugars in acid-leached bagasse) and the mass fraction of $\mathrm{DP}_{1}$ in $\mathrm{C}_{6} \mathrm{aS}$, experimental and calculated using the total fit procedure, as a function of pressure 


\section{Individual fit procedure}

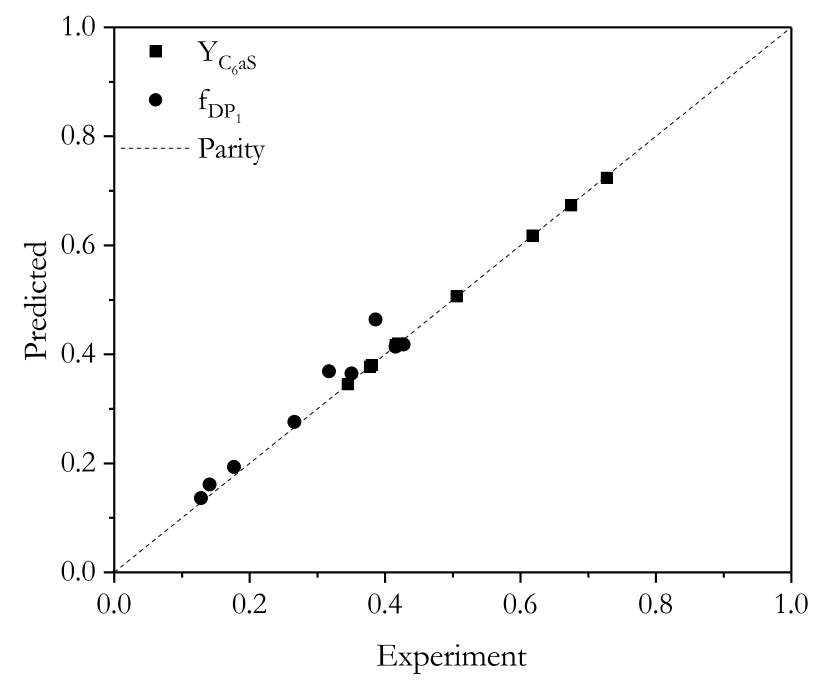

Figure D.11: Parity plot in which the experimental $\mathrm{C}_{6}$ aS yield (on $\mathrm{C}_{6}$ sugars in acid-leached bagasse) and the mass fraction of $\mathrm{DP}_{1}$ are plotted against their predicted values using individual fit procedure

Parity plot of the experimental $\mathrm{C}_{6}$ aS yield (on $\mathrm{C}_{6}$ sugars in acid-leached bagasse) and the mass fraction of $\mathrm{DP}_{1}$ against their predicted values using individual fit procedure are presented in Figure D.11 The values of $\frac{k_{T, a v g}}{k_{K}+k_{U}}$ per pressure obtained using the individual fit procedure are presented in Table D.7

Table D.7: Values of $\frac{k_{T, a v g}}{k_{K}+k_{U}}$ per pressure obtained using the individual fit procedure

\begin{tabular}{cc}
\hline $\begin{array}{c}\text { Pressure } \\
\mathrm{kPa}\end{array}$ & $\frac{k_{T, a v g}}{k_{K}+k_{U}}$ \\
\hline 0.005 & - \\
0.5 & $1.9 \pm 0.9$ \\
2 & $1.2 \pm 0.5$ \\
10 & $0.8 \pm 0.2$ \\
20 & $0.5 \pm 0.2$ \\
40 & $0.5 \pm 0.1$ \\
60 & $0.4 \pm 0.1$ \\
80 & $0.4 \pm 0.1$ \\
100 & $0.4 \pm 0.1$ \\
\hline
\end{tabular}


Correlation between $\frac{k_{T, a v g}}{k_{K}+k_{U}}$ and pressure

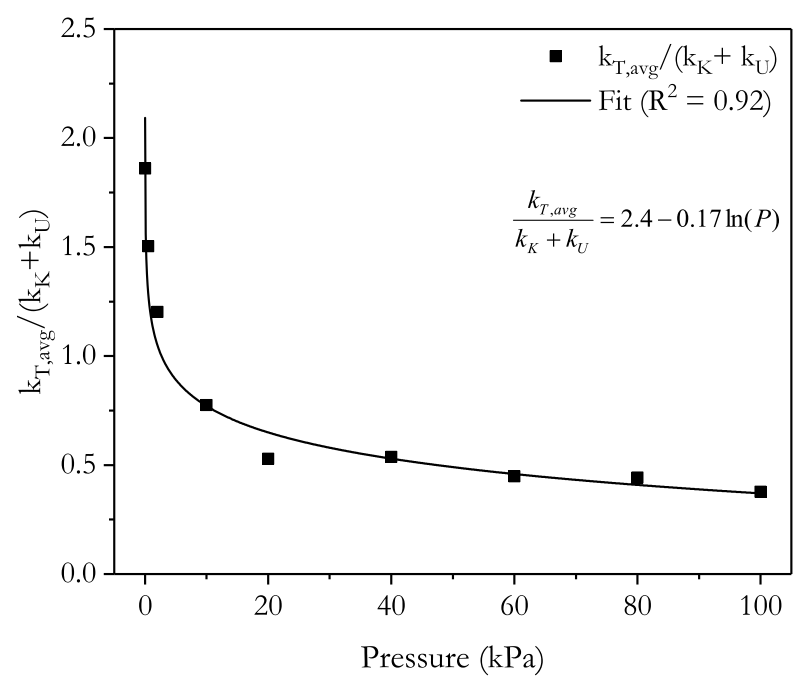

Figure D.12: Values of $\frac{k_{T, a v g}}{k_{K}+k_{U}}$ obtained using individual fit procedure as a function of the pressure with fixed $\frac{k_{K}}{k_{K}+k_{U}}$ obtained from total fit procedure 


\section{Nomenclature}

A

$C_{S}$

$C_{S, 0}$

$C_{A n S}$

$C_{A n S, 0}$

$C_{I}$

$C_{I, 0}$

$C_{U}$

$C_{U, 0}$

$E_{i}$

$f_{C_{6}}$

$f_{D P_{1}, e x p}$

$f_{D P_{1}, c a l, t=\infty}$

$K_{i}$

$k_{1}, k_{3}$

$k_{2}$

$k_{T, i}$

$k_{K}$

$k_{U}$

$k_{V}$

$m_{D P_{i}}^{P}$

$m_{D P_{i}, t=0}^{P}$

$m_{D P_{i}}^{O}$

$m_{D P_{i}, t=0}^{O}$

$m_{D P_{i}, t=\infty}^{O}$

$m_{D P_{i}}^{V}$

$m_{D P_{i}, \exp }^{V}$

$m_{D P_{i}, c a l, t=\infty}^{V}$

$U_{i}$ mole $m^{-3}$

mole $m^{-3}$

mole $\mathrm{m}^{-3}$

mole $\mathrm{m}^{-3}$

mole $m^{-3}$

mole $m^{-3}$

mole $m^{-3}$

mole $m^{-3}$

$k g s^{-1}$

$k g s^{-1}$

$s^{-1}$

$s^{-1}$

$s^{-1}$

$s^{-1}$

$s^{-1}$

$s^{-1}$

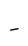

$$
\text { - }
$$

$$
\text { - }
$$$$
\text { - }
$$$$
\text { - }
$$$$
\text { - }
$$$$
-
$$$$
k g s^{-1}
$$

Parameter used to describe the transport rate of $\mathrm{DP}_{\mathrm{i}}$

Molar concentration of $\mathrm{C}_{6}$ carbohydrates in simplified model at $t=t$

Molar concentration of $\mathrm{C}_{6}$ carbohydrates in simplified model at $t=0$

Molar concentration of $\mathrm{C}_{6} \mathrm{aS}$ in simplified model at $t=t$

Molar concentration of $\mathrm{C}_{6} \mathrm{aS}$ in simplified model at $t=0$

Molar concentration of intermediate $\mathrm{C}_{6} \mathrm{aS}$ in simplified model at $t=t$

Molar concentration of intermediate $\mathrm{C}_{6} \mathrm{aS}$ in simplified model at $t=0$

Molar concentration of other products in simplified model at $t=t$

Molar concentration of other products in simplified model at $t=0$

Transport rate of $\mathrm{DP}_{\mathrm{i}}$ from the reacting particle to cold glass wall at $t=t$

Fraction of $\mathrm{C}_{6}$ sugars in biomass

Experimentally obtained mass fraction of $\mathrm{DP}_{1}$ in $\mathrm{C}_{6} \mathrm{aS}$

Calculated mass fraction of $\mathrm{DP}_{1}$ in $\mathrm{C}_{6} \mathrm{aS}$ at $t=\infty$

Overall depolymerisation rate of $\mathrm{DP}_{\mathrm{i}}$ at $t=t$

First order rate constants reactions in simplified model

First order rate constants of transport in simplified model

Evaporation/sublimation/ejection rate constant of $\mathrm{DP}_{\mathrm{i}}$

First order depolymerisation rate constant

First order decomposition rate constant

First order vapour phase depolymerisation rate constant

Mass fraction of $\mathrm{DP}_{\mathrm{i}}$ at the reacting particle at $t=t$

Mass fraction of $\mathrm{DP}_{\mathrm{i}}$ at the reacting particle at $t=0$

Mass fraction of $\mathrm{DP}_{\mathrm{i}}$ at the cold glass wall at $t=t$

Mass fraction of $\mathrm{DP}_{\mathrm{i}}$ at cold glass wall at $t=0$

Mass fraction of $\mathrm{DP}_{\mathrm{i}}$ at cold glass wall at $t=\infty$

Mass fraction of $\mathrm{DP}_{\mathrm{i}}$ in the hot vapour phase at $t=t$

Experimentally obtained mass fraction of $\mathrm{DP}_{\mathrm{i}}$ in the hot vapour phase

Mass fraction of $\mathrm{DP}_{\mathrm{i}}$ in the hot vapour phase at $t=\infty$

Overall decomposition rate of $\mathrm{DP}_{\mathrm{i}}$ at $t=t$ 


$\begin{array}{lll}Y_{C_{6} a S, \exp } & \mathrm{kg} \mathrm{kg}^{-1} & \text { Experimentally obtained yield of } \mathrm{C}_{6} \text { aS } \\ Y_{C_{6} a S, \text { cal }, t=\infty} & \mathrm{kg} \mathrm{kg}^{-1} & \text { Calculated yield of } \mathrm{C}_{6} \text { aS at } t=\infty\end{array}$

\section{Superscripts}

c

Consumption

f

Formation 
D 
References

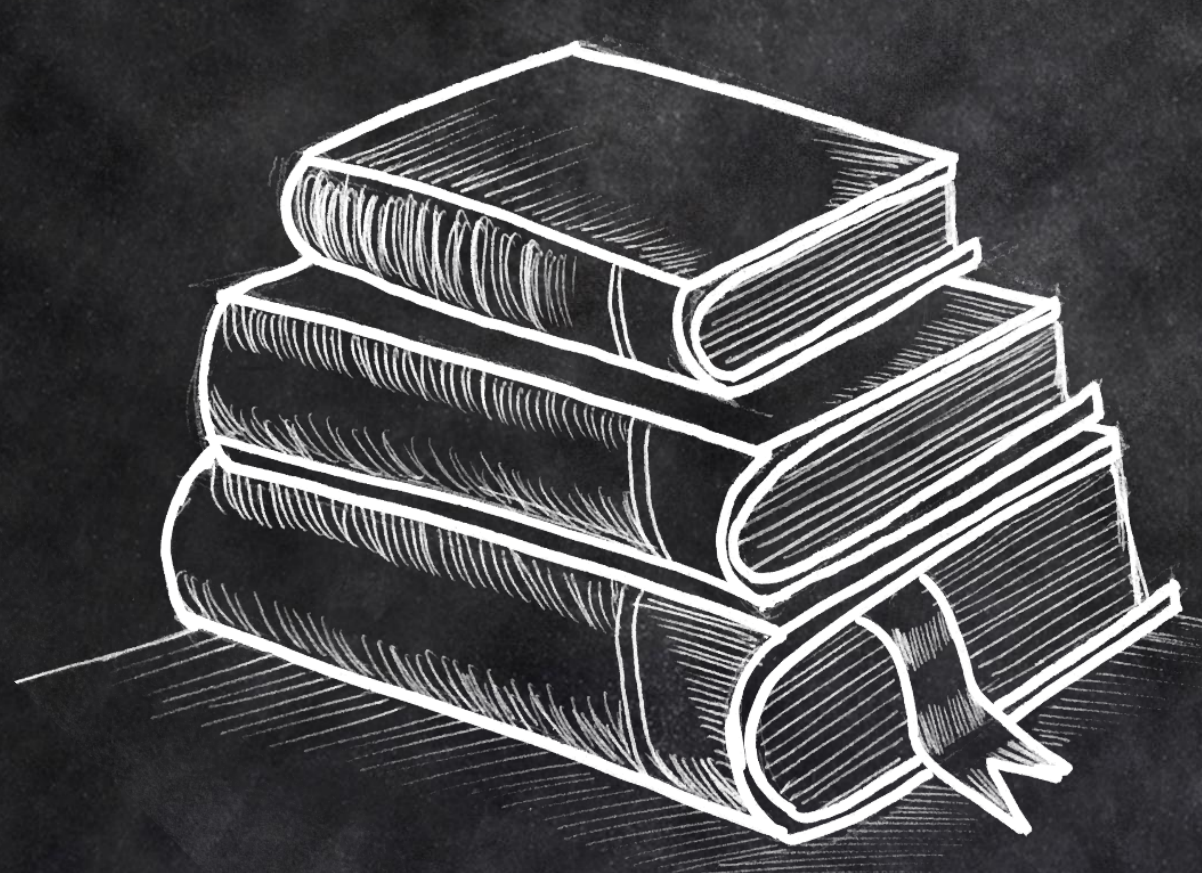




\section{References}

[1] World energy outlook 2016. Tech. rep. International Energy Agency, 2016.

[2] B. J. M. de Vries, D. P. van Vuuren, and M. M. Hoogwijk. "Renewable energy sources: Their global potential for the first-half of the 21st century at a global level: An integrated approach". Energy Policy 35.4 (2007), pp. 2590-2610. DOI: 10.1016/j . enpol . 2006. 09.002

[3] A. Angelis-Dimakis, M. Biberacher, J. Dominguez, et al. "Methods and tools to evaluate the availability of renewable energy sources". Renewable and Sustainable Energy Reviews 15.2 (2011), pp. 1182-1200. DOI: $10.1016 /$ j.rser.2010.09.049

[4] C. di Blasi. "Modeling chemical and physical processes of wood and biomass pyrolysis". Progress in Energy and Combustion Science 34.1 (2008), pp. 47-90. DOI: 10.1016/j . pecs . 2006.12 .001

[5] W. van Swaaij, S. Kersten, and W. Palz. Biomass power for the world. 1st. Vol. 6. PAN STANFORD PUB, 6, 2015. 760 pp.

[6] E. Commision. 2019. URL: https : //ec . europa.eu/eurostat/data/database (visited on 04/08/2019).

[7] H. H. Nimz, U. Schmitt, E. Schwab, et al. "Wood". Ullmann's Encyclopedia of Industrial Chemistry. American Cancer Society, 2000. DOI: 10.1002/14356007.a28_305

[8] D. E. Brown. "Lignocellulose hydrolysis". Philosophical Transactions of the Royal Society of London. Series B, Biological Sciences 300.1100 (1983), pp. 305-322.

[9] D. Mohan, C. U. Pittman, and P. H. Steele. "Pyrolysis of Wood/Biomass for Bio-oil: A Critical Review”. Energy \& Fuels 20.3 (2006), pp. 848-889. DOI: 10.1021/ef 0502397

[10] R. Rowell. Handbook Of Wood Chemistry And Wood Composites. 2005. DoI: 10 . $1201 /$ b12487

[11] A. C. N. Karl Freudenberg. Constitution and Biosynthesis of Lignin. Molecular Biology, Biochemistry and Biophysics Molekularbiologie, Biochemie und Biophysik. SpringerVerlag Berlin Heidelberg, 1968, p. 132.

[12] E. Adler. "Lignin chemistry-past, present and future". Wood Science and Technology 11.3 (1977), pp. 169-218. DOI: 10.1007/bf00365615

[13] J. Zakzeski, P. C. A. Bruijnincx, A. L. Jongerius, et al. "The Catalytic Valorization of Lignin for the Production of Renewable Chemicals". Chemical Reviews 110.6 (2010), pp. 3552 3599. DOI: $10.1021 / \operatorname{cr} 900354 \mathrm{u}$

[14] F. E. Brauns and D. A. Brauns. The Chemistry of Lignin. 1952, p. 808. DOI: 10.1016/b9781-4832-2779-5.50005-5

[15] A. Björkman. "Studies on finely divided wood. part 1. extraction of lignin with neutral solvents". Sven Papperstidn 59 (1956), pp. 477-485. 
[16] J. Wildschut, A. T. Smit, J. H. Reith, et al. "Ethanol-based organosolv fractionation of wheat straw for the production of lignin and enzymatically digestible cellulose". Bioresource Technology 135.0 (2013), pp. 58-66. DOI: 10.1016/j . biortech.2012.10.050

[17] M. Fasching, P. Schröder, R. P. Wollboldt, et al. "A new and facile method for isolation of lignin from wood based on complete wood dissolution". Holzforschung 62.1 (2008). DOI: $10.1515 / \mathrm{hf} .2008 .003$

[18] S. V. Vassilev, D. Baxter, L. K. Andersen, et al. "An overview of the chemical composition of biomass”. Fuel 89.5 (2010), pp. 913-933. DOI: 10.1016/j.fuel.2009.10.022

[19] S. V. Vassilev, D. Baxter, L. K. Andersen, et al. "An overview of the organic and inorganic phase composition of biomass". Fuel 94 (2012), pp. 1-33. DOI: 10.1016/j .fuel. 2011. 09.030

[20] P. McKendry. "Energy production from biomass (part 1): overview of biomass". Bioresource Technology 83.1 (2002), pp. 37-46. DOI: 10.1016/s0960-8524(01)00118-3

[21] J. L. Easterly and M. Burnham. "Overview of biomass and waste fuel resources for power production". Biomass and Bioenergy 10.2-3 (1996), pp. 79-92. DOI: 10 . 1016 / 0961 9534(95)00063-1

[22] D. Tillman. "Biomass cofiring: the technology, the experience, the combustion consequences". Biomass and Bioenergy 19.6 (2000), pp. 365-384. DOI: 10 . 1016 / s0961 9534(00)00049-0

[23] A. Bridgwater, S. Czernik, J. Diebold, et al. Fast pyrolysis of biomass: a handbook. CPL Press, 14, 2008. 196 pp.

[24] G. Centi and R. A. van Santen. Catalysis for renewables: from feedstock to energy production. John Wiley \& Sons, 2008.

[25] W. N. Rowlands, A. Masters, and T. Maschmeyer. "The Biorefinery-Challenges, Opportunities, and an Australian Perspective". Bulletin of Science, Technology \& Society 28.2 (2008), pp. 149-158. DOI: $10.1177 / 0270467607313960$

[26] F. Goudriaan and D. Peferoen. "Liquid fuels from biomass via a hydrothermal process". Chemical Engineering Science 45.8 (1990), pp. 2729-2734. DOI: 10.1016/0009-2509(90) 80164-a

[27] F. Behrendt, Y. Neubauer, M. Oevermann, et al. "Direct liquefaction of biomass". Chemical Engineering \& Technology 31.5 (2008), pp. 667-677. DOI: 10.1002/ceat . 200800077

[28] S. Kumar, J.-P. Lange, G. V. Rossum, et al. "Liquefaction of Lignocellulose: Process Parameter Study To Minimize Heavy Ends". Industrial \& Engineering Chemistry Research 53.29 (2014), pp. 11668-11676. DOI: $10.1021 /$ ie501579v

[29] A. Bridgwater. "Review of fast pyrolysis of biomass and product upgrading". Biomass and Bioenergy 38 (2012), pp. 68-94. DOI: 10.1016/j.biombioe.2011.01.048

[30] T. Bridgwater. "Challenges and Opportunities in Fast Pyrolysis of Biomass: Part I". Johnson Matthey Technology Review 62.1 (2018), pp. 118-130. DOI: 10.1595/205651318x696693 
[31] F. R. Amin, Y. Huang, Y. He, et al. "Biochar applications and modern techniques for characterization". Clean Technologies and Environmental Policy 18.5 (2016), pp. 1457-1473. DOI: $10.1007 / \mathrm{s} 10098-016-1218-8$

[32] S. Czernik and A. V. Bridgwater. "Overview of Applications of Biomass Fast Pyrolysis Oil”. Energy \& Fuels 18.2 (2004), pp. 590-598. DoI: 10.1021/ef034067u

[33] B. V. de Beld, E. Holle, and J. Florijn. "The use of pyrolysis oil and pyrolysis oil derived fuels in diesel engines for CHP applications". Applied Energy 102 (2013), pp. 190-197. DOI: $10.1016 / \mathrm{j}$.apenergy . 2012.05.047

[34] G. van Rossum, S. R. A. Kersten, and W. P. M. van Swaaij. "Staged Catalytic Gasification/Steam Reforming of Pyrolysis Oil". Industrial \& Engineering Chemistry Research 48.12 (2009), pp. 5857-5866. DOI: 10.1021/ie900194j

[35] L. Moens, S. K. Black, M. D. Myers, et al. "Study of the Neutralization and Stabilization of a Mixed Hardwood Bio-Oil”. Energy \& Fuels 23.5 (2009), pp. 2695-2699. Dor: 10 . $1021 /$ ef 8009266

[36] J. Wildschut, F. H. Mahfud, R. H. Venderbosch, et al. "Hydrotreatment of Fast Pyrolysis Oil Using Heterogeneous Noble-Metal Catalysts". Industrial \& Engineering Chemistry Research 48.23 (2009), pp. 10324-10334. DOI: 10.1021/ie9006003

[37] F. de Miguel Mercader, M. Groeneveld, S. Kersten, et al. "Production of advanced biofuels: Co-processing of upgraded pyrolysis oil in standard refinery units". Applied Catalysis B: Environmental 96.1-2 (2010), pp. 57-66. DOI: 10.1016/j.apcatb.2010.01.033

[38] R. K. Sharma and N. N. Bakhshi. "Catalytic upgrading of biomass-derived oils to transportation fuels and chemicals". The Canadian Journal of Chemical Engineering 69.5 (1991), pp. 1071-1081. DOI: $10.1002 /$ cjce.5450690505

[39] T. P. Vispute, H. Zhang, A. Sanna, et al. "Renewable Chemical Commodity Feedstocks from Integrated Catalytic Processing of Pyrolysis Oils". Science 330.6008 (2010), pp. 12221227. DOI: $10.1126 /$ science. 1194218

[40] E. F. Iliopoulou, K. S. Triantafyllidis, and A. A. Lappas. "Overview of catalytic upgrading of biomass pyrolysis vapors toward the production of fuels and high-value chemicals". Wiley Interdisciplinary Reviews: Energy and Environment 8.1 (2018), e322. DOI: 10 .1002/ wene.322

[41] R. Venderbosch and W. Prins. "Fast pyrolysis technology development". Biofuels, Bioproducts and Biorefining 4.2 (2010), pp. 178-208. DOI: 10.1002/bbb. 205

[42] J. A. Garcia-Nunez, M. R. Pelaez-Samaniego, M. E. Garcia-Perez, et al. "Historical Developments of Pyrolysis Reactors: A Review”. Energy \& Fuels 31.6 (2017), pp. 5751-5775. DOI: $10.1021 /$ acs . energyfuels.7b00641

[43] E. Butler, G. Devlin, D. Meier, et al. "A review of recent laboratory research and commercial developments in fast pyrolysis and upgrading". Renewable and Sustainable Energy Reviews 15.8 (2011), pp. 4171-4186. DOI: 10.1016/j.rser.2011.07.035 
[44] BTG-BTL. Mega-order from finland for dutch energy technology. 2019. URL: https : / / www . btg-btl . com/en / company / news / news / article ? id=134 (visited on 04/05/2019).

[45] G. SriBala, H.-H. Carstensen, K. M. V. Geem, et al. "Measuring biomass fast pyrolysis kinetics: State of the art". Wiley Interdisciplinary Reviews: Energy and Environment 8.2 (2018), e326. DOI: $10.1002 /$ wene. 326

[46] R. Narayan and M. J. Antal. "Thermal Lag, Fusion, and the Compensation Effect during Biomass Pyrolysist". Industrial \& Engineering Chemistry Research 35.5 (1996), pp. 17111721. DOI: $10.1021 /$ ie950368i

[47] J. Lédé. "Biomass Pyrolysis: Comments on Some Sources of Confusions in the Definitions of Temperatures and Heating Rates". Energies 3.4 (2010), pp. 886-898. DOI: 10.3390/ en3040886

[48] J. Proano-Aviles, J. K. Lindstrom, P. A. Johnston, et al. "Heat and Mass Transfer Effects in a Furnace-Based Micropyrolyzer". Energy Technology 5.1 (2017), pp. 189-195. DOI: 10. 1002/ente.201600279

[49] S. Maduskar, G. G. Facas, C. Papageorgiou, et al. "Five Rules for Measuring Biomass Pyrolysis Rates: Pulse-Heated Analysis of Solid Reaction Kinetics of Lignocellulosic Biomass. On the Challenges Facing the Handling of Solid Biomass Feedstocks". ACS Sustainable Chemistry \& Engineering 6.1 (2018), pp. 1387-1399. DOI: 10.1021/acssuschemeng. $7 \mathrm{~b} 03785$

[50] J. Lédé. "Cellulose pyrolysis kinetics: An historical review on the existence and role of intermediate active cellulose". Journal of Analytical and Applied Pyrolysis 94 (2012), pp. 1732. DOI: $10.1016 / \mathrm{j} \cdot$ jaap.2011.12.019

[51] V. Mamleev, S. Bourbigot, M. L. Bras, et al. "The facts and hypotheses relating to the phenomenological model of cellulose pyrolysis". Journal of Analytical and Applied Pyrolysis 84.1 (2009), pp. 1-17. DOI: $10.1016 / j \cdot j$ jaap. 2008.10.014

[52] J. Piskorz, P. Majerski, and D. Radlein. "Pyrolysis of Biomass-Aerosol Generation: Properties, Applications, and Significance for Process Engineers". Biomass Conference of the Americas, 4th. Biomass: A Growth Opportunity in Green Energy and Value-Added Products, Elsevier Science, Oxford, UK, Oakland California. 1999, pp. 1153-1159.

[53] E. Fratini, M. Bonini, A. Oasmaa, et al. "SANS Analysis of the Microstructural Evolution during the Aging of Pyrolysis Oils from Biomass". Langmuir 22.1 (2006), pp. 306-312. DOI: $10.1021 / 1 \mathrm{a} 051990 \mathrm{a}$

[54] A. R. Teixeira, K. G. Mooney, J. S. Kruger, et al. "Aerosol generation by reactive boiling ejection of molten cellulose”. Energy \& Environmental Science 4.10 (2011), p. 4306. DOI: 10.1039/c1ee01876k

[55] J. Montoya, B. Pecha, F. C. Janna, et al. "Micro-explosion of liquid intermediates during the fast pyrolysis of sucrose and organosolv lignin". Journal of Analytical and Applied Pyrolysis 122 (2016), pp. 106-121. DOI: $10.1016 / \mathrm{j} \cdot \mathrm{jaap} .2016 .10 .010$ 
[56] O. Boutin, M. Ferrer, and J. Lédé. "Radiant flash pyrolysis of cellulose-Evidence for the formation of short life time intermediate liquid species". Journal of Analytical and Applied Pyrolysis 47.1 (1998), pp. 13-31. DOI: 10.1016/s0165-2370(98)00088-6

[57] R. G. Graham, M. A. Bergougnou, and B. A. Freel. "The kinetics of vapour-phase cellulose fast pyrolysis reactions". Biomass and Bioenergy 7.1-6 (1994), pp. 33-47. DOI: 10 . 1016/ 0961-9534(94)00045-u

[58] E. Hoekstra, R. J. M. Westerhof, W. Brilman, et al. "Heterogeneous and homogeneous reactions of pyrolysis vapors from pine wood”. AIChE Journal 58.9 (2011), pp. 2830-2842. DOI: 10.1002 /aic. 12799

[59] M. B. Pecha, J. I. M. Arbelaez, M. Garcia-Perez, et al. "Progress in understanding the four dominant intra-particle phenomena of lignocellulose pyrolysis: chemical reactions, heat transfer, mass transfer, and phase change". Green Chemistry (2019). DOI: 10.1039/ c9gc00585d

[60] D. Pyle and C. Zaror. "Heat transfer and kinetics in the low temperature pyrolysis of solids". Chemical Engineering Science 39.1 (1984), pp. 147-158. DOI: 10 . 1016 / 0009 2509(84)80140-2

[61] R. C. Brown, D. Radlein, and J. Piskorz. "Pretreatment Processes to Increase Pyrolytic Yield of Levoglucosan from Herbaceous Feedstocks". ACS Symposium Series. Ed. by J. J. Bozell. ACS Symposium Series. Washington, DC: American Chemical Society, 2001, pp. 123-132. DOI: $10.1021 / \mathrm{bk}-2001-0784$.ch010

[62] S. R. G. Oudenhoven, R. J. M. Westerhof, and S. R. A. Kersten. "Fast pyrolysis of organic acid leached wood, straw, hay and bagasse: improved oil and sugar yields". Journal of Analytical and Applied Pyrolysis 116 (2015), pp. 253-262. DOI: 10.1016/j · jaap. 2015. 09.003

[63] S. Turn, C. Kinoshita, D. Ishimura, et al. Leaching of alkalis in biomass using banagrass as a prototype herbaceous species. Tech. rep. NREL/SR-510-35433. National Renewable Energy Laboratory, 1997.

[64] J. Piskorz, D. S. A. G. Radlein, D. S. Scott, et al. "Pretreatment of wood and cellulose for production of sugars by fast pyrolysis". Journal of Analytical and Applied Pyrolysis 16.2 (1989), pp. 127-142. DOI: 10.1016/0165-2370(89)85012-0

[65] G. F. David, V. H. Perez, O. R. Justo, et al. "Effect of acid additives on sugarcane bagasse pyrolysis: production of high yields of sugars". Bioresource Technology 223 (2017), pp. 74 83. DOI: $10.1016 / \mathrm{j}$.biortech.2016.10.051

[66] S. R. G. Oudenhoven, R. J. M. Westerhof, N. Aldenkamp, et al. "Demineralization of wood using wood-derived acid: towards a selective pyrolysis process for fuel and chemicals production". Journal of Analytical and Applied Pyrolysis 103 (2013), pp. 112-118. DOI: 10.1016/j.jaap.2012.10.002

[67] L. Rodríguez-Machín, L. E. Arteaga-Pérez, J. Vercruysse, et al. "Py-GC/MS based analysis of the influence of citric acid leaching of sugarcane residues as a pretreatment to fast pyrolysis". Journal of Analytical and Applied Pyrolysis 134 (2018), pp. 465-475. DOI: 10 . $1016 / j \cdot j a a p .2018 .07 .013$ 
[68] N. Kuzhiyil, D. Dalluge, X. Bai, et al. "Pyrolytic sugars from cellulosic biomass". ChemSusChem 5.11 (2012), pp. 2228-2236. DOI: 10.1002/cssc. 201200341

[69] D. L. Dalluge, T. Daugaard, P. Johnston, et al. "Continuous production of sugars from pyrolysis of acid-infused lignocellulosic biomass". Green Chem. 16.9 (2014), pp. 41444155. DOI: $10.1039 / \mathrm{c4gc00602j}$

[70] N. Kuzhiyil and R. Brown. "Temperature dependence of levoglucosan yield from fast pyrolysis of acid infused biomass". Biofuels 5.2 (2014), pp. 123-127. DOI: $10.4155 / \mathrm{bfs}$. 13.72

[71] S. R. G. Oudenhoven, C. Lievens, R. J. M. Westerhof, et al. "Effect of temperature on the fast pyrolysis of organic-acid leached pinewood: the potential of low temperature pyrolysis". Biomass and Bioenergy 89 (2016), pp. 78-90. DOI: 10 . 1016/ j . biombioe. 2015.12 .019

[72] J. Wang, Q. Wei, J. Zheng, et al. "Effect of pyrolysis conditions on levoglucosan yield from cotton straw and optimization of levoglucosan extraction from bio-oil". Journal of Analytical and Applied Pyrolysis 122 (2016), pp. 294-303. DOI: 10.1016/j · jaap. 2016. 09.013

[73] C. Guizani, S. Valin, J. Billaud, et al. "Biomass fast pyrolysis in a drop tube reactor for bio oil production: Experiments and modeling”. Fuel 207 (2017), pp. 71-84. DOI: 10.1016/ j.fuel.2017.06.068

[74] J. Montoya, B. Pecha, D. Roman, et al. "Effect of temperature and heating rate on product distribution from the pyrolysis of sugarcane bagasse in a hot plate reactor". Journal of Analytical and Applied Pyrolysis 123 (2017), pp. 347-363. DOI: 10.1016/j . jaap. 2016. 11.008

[75] M. B. Pecha, E. Terrell, J. I. Montoya, et al. "Effect of Pressure on Pyrolysis of Milled Wood Lignin and Acid-Washed Hybrid Poplar Wood". Industrial \& Engineering Chemistry Research 56.32 (2017), pp. 9079-9089. DOI: 10.1021/acs . iecr.7b02085

[76] B. Kamm, M. Kamm, M. Schmidt, et al. "Lignocellulose-based chemical products and product family trees". Biorefineries-Industrial Processes and Products. Wiley-VCH Verlag GmbH, 2008, pp. 97-149. DOI: 10.1002/9783527619849.ch20

[77] K. Sipilä, E. Kuoppala, L. Fagernäs, et al. "Characterization of biomass-based flash pyrolysis oils". Biomass and Bioenergy 14.2 (1998), pp. 103-113. DOI: 10 . 1016 / s09619534(97) 10024-1

[78] M. Garcia-Perez, A. Chaala, H. Pakdel, et al. "Characterization of bio-oils in chemical families”. Biomass and Bioenergy 31.4 (2007), pp. 222-242. DOI: 10.1016/j . biombioe. 2006.02 .006

[79] P. K. Kanaujia, Y. Sharma, U. Agrawal, et al. "Analytical approaches to characterizing pyrolysis oil from biomass". TrAC Trends in Analytical Chemistry 42 (2013), pp. 125-136. DOI: $10.1016 /$ j.trac.2012.09.009 
[80] S. Papari and K. Hawboldt. "A review on the pyrolysis of woody biomass to bio-oil: Focus on kinetic models". Renewable and Sustainable Energy Reviews 52 (2015), pp. 1580-1595. DOI: $10.1016 /$ j.rser.2015.07.191

[81] A. Anca-Couce. "Reaction mechanisms and multi-scale modelling of lignocellulosic biomass pyrolysis". Progress in Energy and Combustion Science 53 (2016), pp. 41-79. DOI: 10.1016/ j.pecs.2015.10.002

[82] S. Hameed, A. Sharma, V. Pareek, et al. "A review on biomass pyrolysis models: Kinetic, network and mechanistic models". Biomass and Bioenergy 123 (2019), pp. 104-122. DOI: 10.1016/j.biombioe.2019.02.008

[83] A. G. W. Bradbury, Y. Sakai, and F. Shafizadeh. "A kinetic model for pyrolysis of cellulose”. Journal of Applied Polymer Science 23.11 (1979), pp. 3271-3280. DOI:10.1002/app. 1979.070231112

[84] F. Thurner and U. Mann. "Kinetic investigation of wood pyrolysis". Industrial \& Engineering Chemistry Process Design and Development 20.3 (1981), pp. 482-488. DOI: 10 . $1021 /$ i200014a015

[85] M. J. Antal. "Effects of reactor severity on the gas-phase pyrolysis of cellulose- and kraft lignin-derived volatile matter". Industrial \& Engineering Chemistry Product Research and Development 22.2 (1983), pp. 366-375. DOI: 10.1021/i300010a039

[86] J. Antal MichaelJerry. "Biomass Pyrolysis: A Review of the Literature Part 2-Lignocellulose Pyrolysis". Advances in Solar Energy. Ed. by K. Böer and J. Duffie. Springer US, 1985. Chap. 4, pp. 175-255. DOI: 10.1007/978-1-4613-9951-3_4

[87] T. R. Nunn, J. B. Howard, J. P. Longwell, et al. "Product compositions and kinetics in the rapid pyrolysis of milled wood lignin". Industrial \& Engineering Chemistry Process Design and Development 24.3 (1985), pp. 844-852. DOI: 10.1021/i200030a054

[88] S. Ward and J. Braslaw. "Experimental weight loss kinetics of wood pyrolysis under vacuum". Combustion and Flame 61.3 (1985), pp. 261-269. DOI: 10.1016/0010-2180(85) 90107-5

[89] M. Samolada and I. Vasalos. "A kinetic approach to the flash pyrolysis of biomass in a fluidized bed reactor”. Fuel 70.7 (1991), pp. 883-889. Dor: 10.1016/0016-2361(91) 90200-t

[90] R. S. Miller and J. Bellan. "A Generalized Biomass Pyrolysis Model Based on Superimposed Cellulose, Hemicelluloseand Liqnin Kinetics". Combustion Science and Technology 126.1-6 (1997), pp. 97-137. DOI: 10.1080/00102209708935670

[91] J. Reina, E. Velo, and L. Puigjaner. "Kinetic Study of the Pyrolysis of Waste Wood". Industrial \& Engineering Chemistry Research 37.11 (1998), pp. 4290-4295. DOI: 10 . 1021/ ie980083g

[92] C. H. Bamford, J. Crank, D. H. Malan, et al. "The combustion of wood. Part I". Mathematical Proceedings of the Cambridge Philosophical Society 42.02 (1946), p. 166. DOI: 10 . $1017 / \mathrm{s} 030500410002288 \mathrm{x}$ 
[93] H.-C. Kung. "A mathematical model of wood pyrolysis". Combustion and Flame 18.2 (1972), pp. 185-195. DOI: $10.1016 / \mathrm{s} 0010-2180$ (72)80134-2

[94] B. Fredlund. "Modelling of heat and mass transfer in wood structures during fire". Fire Safety Journal 20.1 (1993), pp. 39-69. DOI: 10.1016/0379-7112(93)90011-e

[95] C. Di Blasi. "Heat, momentum and mass transport through a shrinking biomass particle exposed to thermal radiation". Chemical Engineering Science 51.7 (1996), pp. 1121-1132.

[96] M. C. Melaaen and M. G. Grønli. "Modelling and Simulation of Moist Wood Drying and Pyrolysis". Developments in Thermochemical Biomass Conversion: Volume 1 / Volume 2. Ed. by A. V. Bridgwater and D. G. B. Boocock. Dordrecht: Springer Netherlands, 1997, pp. 132-146. DOI: 10.1007/978-94-009-1559-6_10

[97] J. Larfeldt, B. Leckner, and M. C. Melaaen. "Modelling and measurements of the pyrolysis of large wood particles". Fuel 79.13 (2000), pp. 1637-1643. Dor: 10 . 1016 / s0016 2361(00)00007-7

[98] M. G. Grønli and M. C. Melaaen. "Mathematical Model for Wood Pyrolysis - Comparison of Experimental Measurements with Model Predictions". Energy \& Fuels 14.4 (2000), pp. 791-800. DOI: $10.1021 /$ ef990176q

[99] A. Janse, R. Westerhout, and W. Prins. "Modelling of flash pyrolysis of a single wood particle". Chemical Engineering and Processing: Process Intensification 39.3 (2000), pp. 239252. DOI: $10.1016 / \mathrm{s} 0255-2701$ (99)00092-6

[100] M. J. Hagge and K. M. Bryden. "Modeling the impact of shrinkage on the pyrolysis of dry biomass". Chemical Engineering Science 57.14 (2002), pp. 2811-2823. DOI: 10 . 1016/ s0009-2509(02) 00167-7

[101] S. Bandyopadhyay, R. Chowdhury, and G. K. Biswas. "Transient behavior of a coconut shell pyrolyzer: a mathematical analysis". Industrial \& Engineering Chemistry Research 35.10 (1996), pp. 3347-3355. DOI: 10.1021/ie950695q

[102] B. Peters, E. Schröder, and C. Bruch. "Measurements and particle resolved modelling of the thermo- and fluid dynamics of a packed bed". Journal of Analytical and Applied Pyrolysis 70.2 (2003), pp. 211-231. DOI: 10.1016/s0165-2370(02)00133-x

[103] B. Wagenaar, W. Prins, and W. van Swaaij. "Flash pyrolysis kinetics of pine wood". Fuel Processing Technology 36.1-3 (1993), pp. 291-298. DOI: 10 . 1016 / 0378-3820(93 ) 90039-7

[104] D. Lathouwers and J. Bellan. "Yield Optimization and Scaling of Fluidized Beds for Tar Production from Biomass". Energy \& Fuels 15.5 (2001), pp. 1247-1262. DOI: 10 . $1021 /$ ef010053h

[105] H. Gerhauser, S. C. Generalis, R. A. Hague, et al. "CFD for the modelling of entrainment in fluidised bed fast pyrolysis of biomass". Progress in Thermochemical Biomass Conversion. Ed. by A. V. Bridgwater. Blackwell Science Ltd, 2001, pp. 1281-1295. DOI: 10 . 1002/ 9780470694954.ch106

[106] H. B. Mayes and L. J. Broadbelt. "Unraveling the Reactions that Unravel Cellulose". The Journal of Physical Chemistry A 116.26 (2012), pp. 7098-7106. DOI: 10.1021/jp300405x 
[107] X. Zhou, M. W. Nolte, H. B. Mayes, et al. "Experimental and Mechanistic Modeling of Fast Pyrolysis of Neat Glucose-Based Carbohydrates. 1. Experiments and Development of a Detailed Mechanistic Model". Industrial \& Engineering Chemistry Research 53.34 (2014), pp. 13274-13289. DOI: $10.1021 /$ ie502259w

[108] H. B. Mayes, M. W. Nolte, G. T. Beckham, et al. "The Alpha-Bet(a) of Salty Glucose Pyrolysis: Computational Investigations Reveal Carbohydrate Pyrolysis Catalytic Action by Sodium Ions". ACS Catalysis 5.1 (2015), pp. 192-202. DOI: 10.1021/cs501125n

[109] S. Wang, B. Ru, H. Lin, et al. "Degradation mechanism of monosaccharides and xylan under pyrolytic conditions with theoretic modeling on the energy profiles". Bioresource Technology 143 (2013), pp. 378-383. DOI: 10.1016/j.biortech.2013.06.026

[110] X. Zhou, W. Li, R. Mabon, et al. "A mechanistic model of fast pyrolysis of hemicellulose". Energy \& Environmental Science 11.5 (2018), pp. 1240-1260. DOI:10.1039/c7ee03208k

[111] J. M. Younker, A. Beste, and A. Buchanan. "Computational study of bond dissociation enthalpies for lignin model compounds: Beta-5 Arylcoumaran". Chemical Physics Letters 545 (2012), pp. 100-106. DOI: 10.1016/j.cplett.2012.07.017

[112] T. Elder and A. Beste. "Density functional theory study of the concerted pyrolysis mechanism for lignin models". Energy \& Fuels 28.8 (2014), pp. 5229-5235. DOI: 10 . $1021 /$ ef5013648

[113] A. J. Yanez, P. Natarajan, W. Li, et al. "Coupled Structural and Kinetic Model of Lignin Fast Pyrolysis”. Energy \& Fuels 32.2 (2018), pp. 1822-1830. DOI: 10.1021/acs . energyfuels . 7 b03311

[114] X. Wang, S. R. A. Kersten, W. Prins, et al. "Biomass Pyrolysis in a Fluidized Bed Reactor. Part 2: Experimental Validation of Model Results". Industrial \& Engineering Chemistry Research 44.23 (2005), pp. 8786-8795. DOI: 10.1021/ie050486y

[115] P. R. Solomon and H.-H. King. "Tar evolution from coal and model polymers: Theory and experiments". Fuel 63.9 (1984), pp. 1302-1311. DoI: 10.1016/0016-2361 (84)904411

[116] E. Avni, R. W. Coughlin, P. R. Solomon, et al. "Mathematical modelling of lignin pyrolysis”. Fuel 64.11 (1985), pp. 1495-1501. DOI: 10.1016/0016-2361(85)90362-x

[117] F. Mahdi, A. Hassanpour, and F. Muller. "An investigation on the evolution of granule formation by in-process sampling of a high shear granulator". Chemical Engineering Research and Design 129 (2018), pp. 403-411. DOI:10.1016/j . cherd.2017.10.038

[118] L. Passauer, T. Hallas, E. Bäucker, et al. "Biodegradation of Hydrogels from Oxyethylated Lignins in Model Soils”. ACS Sustainable Chemistry \& Engineering 3.9 (2015), pp. 19551964. DOI: 10.1021 /acssuschemeng. 5b00139

[119] E. Hoekstra, W. P. M. van Swaaij, S. R. A. Kersten, et al. "Fast pyrolysis in a novel wiremesh reactor: design and initial results". Chemical Engineering Journal 191 (2012), pp. 4558. DOI: $10.1016 /$ j.cej.2012.01.117 
[120] S. R. G. Oudenhoven. "Improving the selectivity of pyrolysis by pyrolytic acid leaching of biomass: the role of AAEMs, anhydrosugar production and process design \& evaluation". PhD thesis. University of Twente, 2016. DOI: 10.3990/1.9789036541381

[121] Z. Wang, A. G. McDonald, R. J. M. Westerhof, et al. "Effect of cellulose crystallinity on the formation of a liquid intermediate and on product distribution during pyrolysis". Journal of Analytical and Applied Pyrolysis 100 (2013), pp. 56-66. DOI: 10.1016/j · jaap. 2012.11 .017

[122] J. Rojas, A. Lopez, S. Guisao, et al. "Evaluation of several microcrystalline celluloses obtained from agricultural by-products". Journal of Advanced Pharmaceutical Technology \& Research 2.3 (2011), p. 144. DOI: 10.4103/2231-4040.85527

[123] A. Sluiter, B. Hames, R. Ruiz, et al. Determination of ash in biomass. Tech. rep. NREL/TP510-42622. National Renewable Energy Laboratory, 2008.

[124] A. Sluiter, B. Hames, R. Ruiz, et al. Determination of sugars, byproducts, and degradation products in liquid fraction process samples. Tech. rep. NREL/TP-510-42623. National Renewable Energy Laboratory, 2008.

[125] B. Scholze and D. Meier. "Characterization of the water-insoluble fraction from pyrolysis oil (pyrolytic lignin). part i. PY-GC/MS, FTIR, and functional groups". Journal of Analytical and Applied Pyrolysis 60.1 (2001), pp. 41-54. DOI: 10.1016/s0165-2370(00) 00110-8

[126] B. Scholze, C. Hanser, and D. Meier. "Characterization of the water-insoluble fraction from fast pyrolysis liquids (pyrolytic lignin)". Journal of Analytical and Applied Pyrolysis 58-59.0 (2001), pp. 387-400. DOI: 10.1016/s0165-2370(00)00173-x

[127] R. W. Thring, E. Chornet, J. Bouchard, et al. "Evidence for the heterogeneity of glycol lignin". Industrial \& Engineering Chemistry Research 30.1 (1991), pp. 232-240. DOI: 10 . 1021/ie00049a036

[128] R. W. Thring and S. L. Griffin. "The heterogeneity of two canadian kraft lignins". Canadian Journal of Chemistry 73.5 (1995), pp. 629-634. DOI:10.1139/v95-081

[129] E. Alsbou and B. Helleur. "Direct Infusion Mass Spectrometric Analysis of Bio-oil Using ESI-Ion-Trap MS”. Energy \& Fuels 28.1 (2013), pp. 578-590. DOI: 10.1021/ef4018288

[130] R. J. M. Westerhof, S. R. G. Oudenhoven, P. S. Marathe, et al. "The interplay between chemistry and heat/mass transfer during the fast pyrolysis of cellulose". Reaction Chemistry \& Engineering 1.5 (2016), pp. 555-566. DOI: 10.1039/c6re00100a

[131] H. Koskela, I. Kilpeläinen, and S. Heikkinen. "Some aspects of quantitative 2d NMR". Journal of Magnetic Resonance 174.2 (2005), pp. 237-244. DOI: 10.1016/j • jmr . 2005. 02.002

[132] T. Funazukuri, R. R. Hudgins, and P. L. Silveston. "Product distribution in pyrolysis of cellulose in a microfluidized bed". Journal of Analytical and Applied Pyrolysis 9.2 (1986), pp. 139-158. DOI: $10.1016 / 0165-2370(86) 85004-5$ 
[133] R. H. Furneaux and F. Shafizadeh. "Pyrolytic production of 1,6-anhydro- $\beta$-d-mannopyranose". Carbohydrate Research 74.1 (1979), pp. 354-360. DOI: 10 . 1016 / s0008-6215(00) 84794-1

[134] H. Kawamoto, Y. Ueno, and S. Saka. "Thermal reactivities of non-reducing sugars in polyether-Role of intermolecular hydrogen bonding in pyrolysis". Journal of Analytical and Applied Pyrolysis 103 (2013), pp. 287-292. DOI: 10.1016/j.jaap.2012.08.009

[135] S. Matsuoka, H. Kawamoto, and S. Saka. "What is active cellulose in pyrolysis? An approach based on reactivity of cellulose reducing end". Journal of Analytical and Applied Pyrolysis 106 (2014), pp. 138-146. DOI: 10.1016/j · jaap.2014.01.011

[136] D. Radlein, J. Piskorz, A. Grinshpun, et al. "Fast pyrolysis of pre-treated wood and cellulose". Prepr. Pap., Am. Chem. Soc., Div. Fuel Chem 12.1 (1987), pp. 39-49. Dor: 10.1016/ 0165-2370 (87) 80013-x

[137] M. Sajdak, M. Chrubasik, and R. Muzyka. "Chemical characterisation of tars from the thermal conversion of biomass by $1 \mathrm{D}$ and 2D gas chromatography combined with silylation". Journal of Analytical and Applied Pyrolysis 124 (2017), pp. 426-438. DOI: 10.1016/ j.jaap.2017.02.027

[138] C. Tessini, M. Vega, N. Müller, et al. "High performance thin layer chromatography determination of cellobiosan and levoglucosan in bio-oil obtained by fast pyrolysis of sawdust". Journal of Chromatography A 1218.24 (2011), pp. 3811-3815. DOI: 10 . 1016 / j . chroma.2011.04.037

[139] F. Shafizadeh and Y. L. Fu. "Pyrolysis of cellulose". Carbohydrate Research 29.1 (1973), pp. 113-122. DOI: $10.1016 / \mathrm{s} 0008-6215(00) 82074-1$

[140] F. Shafizadeh, R. H. Furneaux, T. G. Cochran, et al. "Production of levoglucosan and glucose from pyrolysis of cellulosic materials". Journal of Applied Polymer Science 23.12 (1979), pp. 3525-3539. DOI: 10.1002/app.1979.070231209

[141] S. Julien, E. Chornet, P. K. Tiwari, et al. "Vacuum pyrolysis of cellulose: Fourier transform infrared characterization of solid residues, product distribution and correlations". Journal of Analytical and Applied Pyrolysis 19.0 (1991), pp. 81-104. DOI: 10.1016/01652370(91)80036-8

[142] J. Piskorz, P. Majerski, D. Radlein, et al. "Fast pyrolysis of sweet sorghum and sweet sorghum bagasse". Journal of Analytical and Applied Pyrolysis 46.1 (1998), pp. 15-29. DOI: 10.1016/s0165-2370(98)00067-9

[143] D. S. Scott, P. Majerski, J. Piskorz, et al. "A second look at fast pyrolysis of biomass the RTI process". Journal of Analytical and Applied Pyrolysis 51.1-2 (1999). Ed. by T. editor, pp. 23-37. DOI: $10.1016 / \mathrm{s} 0165-2370(99) 00006-6$

[144] Luo, Wang, Liao, et al. "Mechanism Study of Cellulose Rapid Pyrolysis". Industrial \& Engineering Chemistry Research 43.18 (2004), pp. 5605-5610. DOI: 10.1021/ie030774z 
[145] G. J. Kwon, D. Y. Kim, S. Kimura, et al. "Rapid-cooling, continuous-feed pyrolyzer for biomass processing. Preparation of levoglucosan from cellulose and starch". Journal of Analytical and Applied Pyrolysis 80.1 (2007), pp. 1-5. DOI: 10.1016/j · jaap. 2006.12. 012

[146] C. A. Mullen and A. A. Boateng. "Chemical Composition of Bio-oils Produced by Fast Pyrolysis of Two Energy Crops”. Energy \& Fuels 22.3 (2008), pp. 2104-2109. DOI: 10 . 1021/ef700776w

[147] R. He, X. P. Ye, B. C. English, et al. "Influence of pyrolysis condition on switchgrass biooil yield and physicochemical properties". Bioresource Technology 100.21 (2009), pp. 53055311. DOI: $10.1016 /$ j.biortech.2009.02.069

[148] P. R. Patwardhan, J. A. Satrio, R. C. Brown, et al. "Product distribution from fast pyrolysis of glucose-based carbohydrates". Journal of Analytical and Applied Pyrolysis 86.2 (2009), pp. 323-330. DOI: $10.1016 /$ j.jaap.2009.08.007

[149] P. R. Patwardhan, D. L. Dalluge, B. H. Shanks, et al. "Distinguishing primary and secondary reactions of cellulose pyrolysis". Bioresource Technology 102.8 (2011), pp. 52655269. DOI: $10.1016 /$ j.biortech.2011.02.018

[150] A. M. Azeez, D. Meier, J. Odermatt, et al. "Fast Pyrolysis of African and European Lignocellulosic Biomasses Using Py-GC/MS and Fluidized Bed Reactor”. Energy \& Fuels 24.3 (2010), pp. 2078-2085. DOI: 10.1021/ef9012856

[151] A. A. Boateng, C. A. Mullen, and N. M. Goldberg. "Producing Stable Pyrolysis Liquids from the Oil-Seed Presscakes of Mustard Family Plants: Pennycress (Thlaspi arvense L.) and Camelina (Camelina sativa)". Energy \& Fuels 24.12 (2010), pp. 6624-6632. DOI: 10.1021/ef $101223 a$

[152] M. Amutio, G. Lopez, R. Aguado, et al. "Effect of Vacuum on Lignocellulosic Biomass Flash Pyrolysis in a Conical Spouted Bed Reactor". Energy \& Fuels 25.9 (2011), pp. 3950_ 3960. DOI: $10.1021 /$ ef $200712 \mathrm{~h}$

[153] D. Mourant, Z. Wang, M. He, et al. "Mallee wood fast pyrolysis: Effects of alkali and alkaline earth metallic species on the yield and composition of bio-oil". Fuel 90.9 (2011), pp. 2915-2922. DOI: $10.1016 /$ j.fuel.2011.04.033

[154] R. J. M. Westerhof, D. W. F. Brilman, M. Garcia-Perez, et al. "Fractional Condensation of Biomass Pyrolysis Vapors". Energy \& Fuels 25.4 (2011), pp. 1817-1829. DOI: 10.1021/ ef2000322

[155] F.-X. Collard, J. Blin, A. Bensakhria, et al. "Influence of impregnated metal on the pyrolysis conversion of biomass constituents". Journal of Analytical and Applied Pyrolysis 95 (2012), pp. 213-226. DOI: $10.1016 / \mathrm{j} \cdot \mathrm{jaap} .2012 .02 .009$

[156] M. Cordella, C. Torri, A. Adamiano, et al. "Bio-oils from biomass slow pyrolysis: A chemical and toxicological screening”. Journal of Hazardous Materials 231-232 (2012), pp. 26-35. DOI: $10.1016 / \mathrm{j} \cdot \mathrm{jhazmat} .2012 .06 .030$ 
[157] S.-S. Liaw, S. Zhou, H. Wu, et al. "Effect of pretreatment temperature on the yield and properties of bio-oils obtained from the auger pyrolysis of Douglas fir wood". Fuel 103 (2013), pp. 672-682. DOI: 10.1016/j.fuel.2012.08.016

[158] A. S. Pollard, M. R. Rover, and R. C. Brown. "Characterization of bio-oil recovered as stage fractions with unique chemical and physical properties". Journal of Analytical and Applied Pyrolysis 93.0 (2012), pp. 129-138. DOI: 10.1016/j · jaap.2011.10.007

[159] F. Ronsse, D. Dalluge, W. Prins, et al. "Optimization of platinum filament micropyrolyzer for studying primary decomposition in cellulose pyrolysis". Journal of Analytical and Applied Pyrolysis 95 (2012), pp. 247-256. DOI: 10.1016/j · jaap.2012.02.015

[160] A. Aho, M. Käldström, N. Kumar, et al. "Pyrolysis of beet pulp in a fluidized bed reactor". Journal of Analytical and Applied Pyrolysis 104 (2013), pp. 426-432. DOI: 10 . 1016 / j . jaap.2013.06.002

[161] J. P. Bok, H. S. Choi, J. W. Choi, et al. "Fast pyrolysis of Miscanthus sinensis in fluidized bed reactors: Characteristics of product yields and biocrude oil quality". Energy 60 (2013), pp. 44-52. DOI: $10.1016 / \mathrm{j}$. energy . 2013.08.024

[162] E. Butler, G. Devlin, D. Meier, et al. "Characterisation of spruce, salix, miscanthus and wheat straw for pyrolysis applications". Bioresource Technology 131 (2013), pp. 202-209. DOI: $10.1016 /$ j.biortech.2012.12.013

[163] E. Butler, G. Devlin, D. Meier, et al. "Fluidised bed pyrolysis of lignocellulosic biomasses and comparison of bio-oil and micropyrolyser pyrolysate by GC/MS-FID”. Journal of Analytical and Applied Pyrolysis 103 (2013), pp. 96-101. DOI: 10.1016/j · jaap. 2012. 10.017

[164] C. E. Greenhalf, D. J. Nowakowski, A. B. Harms, et al. "A comparative study of straw, perennial grasses and hardwoods in terms of fast pyrolysis products". Fuel 108 (2013), pp. 216-230. DOI: $10.1016 /$ j.fuel.2013.01.075

[165] H. Hwang, S. Oh, T.-S. Cho, et al. "Fast pyrolysis of potassium impregnated poplar wood and characterization of its influence on the formation as well as properties of pyrolytic products". Bioresource Technology 150 (2013), pp. 359-366. DOI: 10.1016/j . biortech. 2013.09 .132

[166] E. Kantarelis, W. Yang, and W. Blasiak. "Production of Liquid Feedstock from Biomass via Steam Pyrolysis in a Fluidized Bed Reactor". Energy \& Fuels 27.8 (2013), pp. 4748 4759. DOI: $10.1021 /$ ef $400580 \mathrm{x}$

[167] Q. Li, P. H. Steele, F. Yu, et al. "Pyrolytic spray increases levoglucosan production during fast pyrolysis". Journal of Analytical and Applied Pyrolysis 100 (2013), pp. 33-40. DOI: 10 . $1016 / j \cdot$ jaap.2012.11.013

[168] S. M. Shaik, P. N. Sharratt, and R. B. H. Tan. "Influence of selected mineral acids and alkalis on cellulose pyrolysis pathways and anhydrosaccharide formation". Journal of Analytical and Applied Pyrolysis 104.0 (2013), pp. 234-242. DOI: $10.1016 / \mathrm{j}$. jaap. 2013. 07.010 
[169] S. Zhou, D. Mourant, C. Lievens, et al. "Effect of sulfuric acid concentration on the yield and properties of the bio-oils obtained from the auger and fast pyrolysis of Douglas Fir". Fuel 104.0 (2013), pp. 536-546. DOI: 10.1016/j.fuel.2012.06.010

[170] J. Alvarez, G. Lopez, M. Amutio, et al. "Bio-oil production from rice husk fast pyrolysis in a conical spouted bed reactor". Fuel 128 (2014), pp. 162-169. DoI: $10.1016 / \mathrm{j}$. fuel. 2014.02 .074

[171] S. Kelkar, Z. Li, J. Bovee, et al. "Pyrolysis of North-American grass species: Effect of feedstock composition and taxonomy on pyrolysis products". Biomass and Bioenergy 64 (2014), pp. 152-161. DOI: 10.1016/j.biombioe.2014.03.032

[172] O. D. Mante, S. P. Babu, and T. E. Amidon. "A comprehensive study on relating cell-wall components of lignocellulosic biomass to oxygenated species formed during pyrolysis". Journal of Analytical and Applied Pyrolysis 108 (2014), pp. 56-67. DOI: 10.1016/j · jaap. 2014.05 .016

[173] M. R. Rover, P. A. Johnston, L. E. Whitmer, et al. "The effect of pyrolysis temperature on recovery of bio-oil as distinctive stage fractions". Journal of Analytical and Applied Pyrolysis 105 (2014), pp. 262-268. DOI: $10.1016 / \mathrm{j} \cdot \mathrm{jaap} .2013 .11 .012$

[174] Z. Wang, S. Zhou, B. Pecha, et al. "Effect of Pyrolysis Temperature and Sulfuric Acid During the Fast Pyrolysis of Cellulose and Douglas Fir in an Atmospheric Pressure Wire Mesh Reactor". Energy \& Fuels 28.8 (2014), pp. 5167-5177. DOI: 10.1021/ef500999z

[175] J. Zhang, M. W. Nolte, and B. H. Shanks. "Investigation of Primary Reactions and Secondary Effects from the Pyrolysis of Different Celluloses". ACS Sustainable Chemistry \& Engineering 2.12 (2014), pp. 2820-2830. DOI: $10.1021 / \mathrm{sc500592v}$

[176] M. Amutio, G. Lopez, J. Alvarez, et al. "Fast pyrolysis of eucalyptus waste in a conical spouted bed reactor". Bioresource Technology 194 (2015), pp. 225-232. DOI: $10.1016 / \mathrm{j}$. biortech.2015.07.030

[177] N. Charon, J. Ponthus, D. Espinat, et al. "Multi-technique characterization of fast pyrolysis oils". Journal of Analytical and Applied Pyrolysis 116 (2015), pp. 18-26. DOI: 10.1016/ j.jaap.2015.10.012

[178] X. Gong, Y. Yu, X. Gao, et al. "Formation of Anhydro-sugars in the Primary Volatiles and Solid Residues from Cellulose Fast Pyrolysis in a Wire-Mesh Reactor". Energy \& Fuels 28.8 (2014), pp. 5204-5211. DOI: 10.1021/ef501112q

[179] L. Jiang, A. Zheng, Z. Zhao, et al. "Obtaining fermentable sugars by dilute acid hydrolysis of hemicellulose and fast pyrolysis of cellulose". Bioresource Technology 182 (2015), pp. 364-367. DOI: $10.1016 /$ j.biortech.2015.01.032

[180] M. J. Serapiglia, C. A. Mullen, L. B. Smart, et al. "Variability in pyrolysis product yield from novel shrub willow genotypes". Biomass and Bioenergy 72 (2015), pp. 74-84. DOI: 10.1016/j.biombioe.2014.11.015

[181] G. Yildiz, F. Ronsse, R. Venderbosch, et al. "Effect of biomass ash in catalytic fast pyrolysis of pine wood". Applied Catalysis B: Environmental 168-169 (2015), pp. 203-211. DOI: 10.1016/j.apcatb.2014.12.044 
[182] J. G. Hwang, H. C. Park, J. W. Choi, et al. "Fast pyrolysis of the energy crop "GeodaeUksae 1" in a bubbling fluidized bed reactor". Energy 95 (2016), pp. 1-11. DOI:10.1016/ j.energy.2015.11.049

[183] A. Zheng, K. Zhao, L. Jiang, et al. "Bridging the Gap between Pyrolysis and Fermentation: Improving Anhydrosugar Production from Fast Pyrolysis of Agriculture and Forest Residues by Microwave-Assisted Organosolv Pretreatment". ACS Sustainable Chemistry \& Engineering 4.9 (2016), pp. 5033-5040. DOI: 10.1021/acssuschemeng.6b01416

[184] L. Jiang, N. Wu, A. Zheng, et al. "Comprehensive Utilization of Hemicellulose and Cellulose To Release Fermentable Sugars from Corncobs via Acid Hydrolysis and Fast Pyrolysis". ACS Sustainable Chemistry \& Engineering 5.6 (2017), pp. 5208-5213. DOI: 10.1021/ acssus chemeng.7b00561

[185] P. S. Marathe, S. R. G. Oudenhoven, P. W. Heerspink, et al. "Fast pyrolysis of cellulose in vacuum: The effect of potassium salts on the primary reactions". Chemical Engineering Journal 329 (2017), pp. 187-197. DOI: 10.1016/j.cej.2017.05.134

[186] S.-J. Oh, G.-G. Choi, and J.-S. Kim. "Production of acetic acid-rich bio-oils from the fast pyrolysis of biomass and synthesis of calcium magnesium acetate deicer". Journal of Analytical and Applied Pyrolysis 124 (2017), pp. 122-129. DOI: 10.1016/j · jaap. 2017. 01.032

[187] M. B. Pecha, J. I. Montoya, F. Chejne, et al. "Effect of a Vacuum on the Fast Pyrolysis of Cellulose: Nature of Secondary Reactions in a Liquid Intermediate". Industrial \& Engineering Chemistry Research 56.15 (2017), pp. 4288-4301. DOI: 10 . 1021 /acs . iecr . $7 \mathrm{~b} 00476$

[188] J. Alvarez, B. Hooshdaran, M. Cortazar, et al. "Valorization of citrus wastes by fast pyrolysis in a conical spouted bed reactor". Fuel 224 (2018), pp. 111-120. DOI: 10.1016/ j.fuel.2018.03.028

[189] D. S. Chandler and F. L. P. Resende. "Effects of warm water washing on the fast pyrolysis of Arundo Donax". Biomass and Bioenergy 113 (2018), pp. 65-74. DOI: 10 . 1016 / j . biombioe.2018.03.008

[190] V. Savou, G. Grause, S. Kumagai, et al. "Pyrolysis of sugarcane bagasse pretreated with sulfuric acid". Journal of the Energy Institute (2018). DOI: $10.1016 / \mathrm{j} \cdot \mathrm{joei} .2018 .06$. 003

[191] X. Ren, J. Meng, J. Chang, et al. "Effect of blending ratio of loblolly pine wood and bark on the properties of pyrolysis bio-oils". Fuel Processing Technology 167 (2017), pp. 43-49. DOI: $10.1016 /$ j.fuproc. 2017.06 .025

[192] J. Piskorz, P. Majerski, D. Radlein, et al. "Flash pyrolysis of cellulose for production of anhydro-oligomers". Journal of Analytical and Applied Pyrolysis 56.2 (2000), pp. 145-166. DOI: $10.1016 / \mathrm{s} 0165-2370(00) 00089-9$

[193] J. Lédé, F. Blanchard, and O. Boutin. "Radiant flash pyrolysis of cellulose pellets: products and mechanisms involved in transient and steady state conditions". Fuel 81.10 (2002), pp. 1269-1279. DOI: $10.1016 / \mathrm{s} 0016-2361(02) 00039-\mathrm{x}$ 
[194] C. I. Stassinopoulou and C. Zioudrou. "A study of the dimeric structures of glycolaldehyde solutions by NMR". Tetrahedron 28.5 (1972), pp. 1257-1263. DOI: 10.1016/s00404020(01)93550-1

[195] D. K. Shen and S. Gu. "The mechanism for thermal decomposition of cellulose and its main products". Bioresource Technology 100.24 (2009), pp. 6496-6504. DOI: 10.1016/j. biortech.2009.06.095

[196] J. P. Diebold. A Review of the Chemical and Physical Mechanisms of the Storage Stability of Fast Pyrolysis Bio-Oils. Report. National Renewable Energy Laboratory, 2000, pp. 780795.

[197] C. Branca, P. Giudicianni, and C. Di Blasi. "GC/MS Characterization of Liquids Generated from Low-Temperature Pyrolysis of Wood”. Industrial \& Engineering Chemistry Research 42.14 (2003), pp. 3190-3202. DOI: 10.1021/ie030066d

[198] T. Sfetsas, C. Michailof, A. Lappas, et al. "Qualitative and quantitative analysis of pyrolysis oil by gas chromatography with flame ionization detection and comprehensive two-dimensional gas chromatography with time-of-flight mass spectrometry". Journal of Chromatography A 1218.21 (2011), pp. 3317-3325. DOI: 10.1016/j . chroma . 2010.10. 034

[199] J. Lian, S. Chen, S. Zhou, et al. "Separation, hydrolysis and fermentation of pyrolytic sugars to produce ethanol and lipids". Bioresource Technology 101.24 (2010), pp. 9688 9699. DOI: $10.1016 /$ j.biortech.2010.07.071

[200] L. Luque, R. Westerhof, G. V. Rossum, et al. "Pyrolysis based bio-refinery for the production of bioethanol from demineralized ligno-cellulosic biomass". Bioresource Technology 161 (2014), pp. 20-28. DOI: $10.1016 /$ j.biortech.2014.03.009

[201] J. M. R. Gallo, D. M. Alonso, M. A. Mellmer, et al. "Production and upgrading of 5hydroxymethylfurfural using heterogeneous catalysts and biomass-derived solvents". Green Chem. 15.1 (2013), pp. 85-90. DOI: 10.1039/c2gc36536g

[202] J. C. B. D. J. D. J. A. Gärtner Christian A Serrano-Ruiz. "Catalytic upgrading of biooils by ketonization". ChemSusChem 2.12 (2009), pp. 1121-1124. DOI: 10. 1002/cssc . 200900178

[203] X. Hu and C.-Z. Li. "Levulinic esters from the acid-catalysed reactions of sugars and alcohols as part of a bio-refinery". Green Chemistry 13.7 (2011), p. 1676. DOI: 10.1039/ c1gc15272f

[204] Z. Yang, Z. Bai, H. Sun, et al. "Biomass pyrolysis liquid to citric acid via 2-step bioconversion”. Microbial Cell Factories 13.1 (2014). DOI: 10.1186/s12934-014-0182-4

[205] L. C. C. Rivière. La Cellulose - et les éthers cellulosiques. Ed. by Beranger. Ch. Beranger, 1920.

[206] J. Lédé. "Chapter 2. Primary Reactions of Cellulose Pyrolysis". Green Chemistry Series. Royal Society of Chemistry, 2017, pp. 12-36. DOI: $10.1039 / 9781788010245-00012$ 
[207] S. Kersten and M. Garcia-Perez. "Recent developments in fast pyrolysis of ligno-cellulosic materials". Current Opinion in Biotechnology 24.3 (2013), pp. 414-420. DOI: 10.1016/j . copbio.2013.04.003

[208] M. S. Mettler, D. G. Vlachos, and P. J. Dauenhauer. "Top ten fundamental challenges of biomass pyrolysis for biofuels". Energy \& Environmental Science 5.7 (2012), p. 7797. DOI: $10.1039 / \mathrm{c} 2 \mathrm{ee} 21679 \mathrm{e}$

[209] A. Kilzer K.J. Broido. "Speculations on the nature of cellulose pyrolysis". Pyrodynamics 2 (1965), pp. 151-163.

[210] P. R. Patwardhan, J. A. Satrio, R. C. Brown, et al. "Influence of inorganic salts on the primary pyrolysis products of cellulose". Bioresource Technology 101.12 (2010), pp. 46464655. DOI: $10.1016 / \mathrm{j}$. biortech.2010.01.112

[211] T. Hosoya, H. Kawamoto, and S. Saka. "Cellulose-hemicellulose and cellulose-lignin interactions in wood pyrolysis at gasification temperature". Journal of Analytical and Applied Pyrolysis 80.1 (2007), pp. 118-125. DOI: $10.1016 / \mathrm{j} \cdot \mathrm{jaap} .2007 .01 .006$

[212] J. Zhang, Y. S. Choi, C. G. Yoo, et al. "Cellulose-Hemicellulose and Cellulose-Lignin Interactions during Fast Pyrolysis". ACS Sustainable Chemistry \& Engineering 3.2 (2015), pp. 293-301. DOI: $10.1021 / \mathrm{sc500664h}$

[213] T. J. Haas, M. R. Nimlos, and B. S. Donohoe. "Real-Time and Post-reaction Microscopic Structural Analysis of Biomass Undergoing Pyrolysis". Energy \& Fuels 23.7 (2009), pp. 3810_ 3817. DOI: $10.1021 /$ ef $900201 \mathrm{~b}$

[214] O. Boutin, M. Ferrer, and J. Lédé. "Flash pyrolysis of cellulose pellets submitted to a concentrated radiation: experiments and modelling". Chemical Engineering Science 57.1 (2002), pp. 15-25. DOI: $10.1016 /$ s0009-2509(01)00360-8

[215] T. E. Toolbox. Specific Heat of common Substances. 2019.

[216] V. Oja and E. M. Suuberg. "Vapor Pressures and Enthalpies of Sublimation ofd-Glucose,dXylose, Cellobiose, and Levoglucosan”. Journal of Chemical \& Engineering Data 44.1 (1999), pp. 26-29. DOI: $10.1021 /$ je980119b

[217] A. K. Burnham, X. Zhou, and L. J. Broadbelt. "Critical Review of the Global Chemical Kinetics of Cellulose Thermal Decomposition”. Energy \& Fuels 29.5 (2015), pp. 29062918. DOI: $10.1021 /$ acs . energyfuels.5b00350

[218] M. Grønli, M. J. Antal, and G. Várhegyi. "A Round-Robin Study of Cellulose Pyrolysis Kinetics by Thermogravimetry". Industrial \& Engineering Chemistry Research 38.6 (1999), pp. 2238-2244. DOI: 10.1021/ie980601n

[219] Y.-C. Lin, J. Cho, G. A. Tompsett, et al. "Kinetics and Mechanism of Cellulose Pyrolysis". The Journal of Physical Chemistry C 113.46 (2009), pp. 20097-20107. DOI: 10 . 1021 / jp906702p

[220] G. C. Grassi and H. A Zibetta, eds. Control of selectivity in the fast pyrolysis of cellulose. Elsevier, 1991, pp. 643-649. 
[221] J. Lédé. "Reaction temperature of solid particles undergoing an endothermal volatilization. Application to the fast pyrolysis of biomass". Biomass and Bioenergy 7.1-6 (1994), pp. 49-60. DOI: $10.1016 / 0961-9534(94) 00046-v$

[222] J. Lede, J. P. Diebold, G. V. C. Peacocke, et al. "The Nature and Properties of Intermediate and Unvaporized Biomass Pyrolysis Materials". Developments in Thermochemical Biomass Conversion: Volume 1/Volume 2. Ed. by A. V. Bridgwater and D. G. B. Boocock. Dordrecht: Springer Netherlands, 1997, pp. 27-42. DOI: 10.1007/978-94-009-1559-6_2

[223] J. Piskorz, D. Radlein, and D. S. Scott. "On the mechanism of the rapid pyrolysis of cellulose". Journal of Analytical and Applied Pyrolysis 9.2 (1986), pp. 121-137. DOI: 10 . 1016/0165-2370(86)85003-3

[224] D. Radlein, J. Piskorz, and D. Scott. "Fast pyrolysis of natural polysaccharides as a potential industrial process". Journal of Analytical and Applied Pyrolysis 19 (1991), pp. 41-63. DOI: $10.1016 / 0165-2370$ (91)80034-6

[225] E. Hoekstra, W. P. M. Van Swaaij, S. R. A. Kersten, et al. "Fast pyrolysis in a novel wiremesh reactor: Decomposition of pine wood and model compounds". Chemical Engineering Journal 187.0 (2012), pp. 172-184. DOI: 10.1016/j.cej.2012.01.118

[226] G. N. Richards. "Glycolaldehyde from pyrolysis of cellulose". Journal of Analytical and Applied Pyrolysis 10.3 (1987), pp. 251-255. DOI: 10.1016/0165-2370(87)80006-2

[227] H. B. Mayes, J. Tian, M. W. Nolte, et al. "Sodium Ion Interactions with Aqueous Glucose: Insights from Quantum Mechanics, Molecular Dynamics, and Experiment". The Journal of Physical Chemistry B 118.8 (2014), pp. 1990-2000. DOI: 10.1021/jp409481f

[228] W. Boerjan, J. Ralph, and M. Baucher. "Lignin Biosynthesis". Annual Review of Plant Biology 54.1 (2003), pp. 519-546. DOI: 10.1080/10409230391036757

[229] D. Stewart. "Lignin as a base material for materials applications: Chemistry, application and economics". Industrial Crops and Products 27.2 (2008), pp. 202-207. DOI: 10.1016/ j.indcrop. 2007.07 .008

[230] B. M. Upton and A. M. Kasko. "Strategies for the Conversion of Lignin to High-Value Polymeric Materials: Review and Perspective”. Chemical Reviews 116.4 (2016), pp. 22752306. DOI: $10.1021 /$ acs . chemrev.5b00345

[231] J. R. Collett, J. M. Billing, P. A. Meyer, et al. "Renewable diesel via hydrothermal liquefaction of oleaginous yeast and residual lignin from bioconversion of corn stover". Applied Energy 233-234 (2019), pp. 840-853. DOI: 10.1016/j . apenergy .2018.09.115

[232] S. Wang, B. Ru, H. Lin, et al. "Pyrolysis behaviors of four lignin polymers isolated from the same pine wood". Bioresource Technology 182 (2015), pp. 120-127. DOI: 10.1016/j . biortech.2015.01.127

[233] C. Amen-Chen, H. Pakdel, and C. Roy. "Production of monomeric phenols by thermochemical conversion of biomass: a review". Bioresource Technology 79.3 (2001), pp. 277299. DOI: $10.1016 / \mathrm{s} 0960-8524(00) 00180-2$ 
[234] D.-1. Guo, S.-b. Wu, B. Liu, et al. "Catalytic effects of $\mathrm{NaOH}$ and $\mathrm{Na} 2 \mathrm{CO} 3$ additives on alkali lignin pyrolysis and gasification”. Applied Energy 95 (2012), pp. 22-30. DOI: 10 . 1016/j . apenergy.2012.01.042

[235] H. Kawamoto. "Lignin pyrolysis reactions". Journal of Wood Science 63.2 (2017), pp. 117132. DOI: $10.1007 / \mathrm{s} 10086-016-1606-z$

[236] R. Lou, S. Wu, and G. Lyu. "Quantified monophenols in the bio-oil derived from lignin fast pyrolysis". Journal of Analytical and Applied Pyrolysis 111 (2015), pp. 27-32. DOI: 10 . $1016 / \mathrm{j} \cdot$ jaap.2014.12.022

[237] D. J. McClelland, A. H. Motagamwala, Y. Li, et al. "Functionality and molecular weight distribution of red oak lignin before and after pyrolysis and hydrogenation". Green Chemistry 19.5 (2017), pp. 1378-1389. DOI:10.1039/c6gc03515a

[238] M. P. Pandey and C. S. Kim. "Lignin Depolymerization and Conversion: A Review of Thermochemical Methods". Chemical Engineering \& Technology 34.1 (2011), pp. 29-41. DOI: 10.1002/ceat. 201000270

[239] G. Jiang, D. J. Nowakowski, and A. V. Bridgwater. "Effect of the Temperature on the Composition of Lignin Pyrolysis Products". Energy \& Fuels 24.8 (2010), pp. 4470-4475. DOI: $10.1021 /$ ef $100363 \mathrm{c}$

[240] P. R. Patwardhan, R. C. Brown, and B. H. Shanks. "Understanding the Fast Pyrolysis of Lignin”. ChemSusChem 4.11 (2011), pp. 1629-1636. DOI: 10.1002/cssc. 201100133

[241] P. J. de Wild, W. J. J. Huijgen, and H. J. Heeres. "Pyrolysis of wheat straw-derived organosolv lignin". Journal of Analytical and Applied Pyrolysis 93 (2012), pp. 95-103. DOI: 10 . $1016 / j \cdot j a a p .2011 .10 .002$

[242] S. Zhou, M. Garcia-Perez, B. Pecha, et al. "Effect of the Fast Pyrolysis Temperature on the Primary and Secondary Products of Lignin”. Energy \& Fuels 27.10 (2013), pp. 5867-5877. DOI: $10.1021 /$ ef 4001677

[243] D. Li, C. Briens, and F. Berruti. "Improved lignin pyrolysis for phenolics production in a bubbling bed reactor - Effect of bed materials". Bioresource Technology 189 (2015), pp. 714. DOI: $10.1016 / \mathrm{j}$.biortech.2015.04.004

[244] D. J. Nowakowski, A. V. Bridgwater, D. C. Elliott, et al. "Lignin fast pyrolysis: Results from an international collaboration". Journal of Analytical and Applied Pyrolysis 88.1 (2010), pp. 53-72. DOI: $10.1016 /$ j.jaap. 2010.02.009

[245] L. Burhenne, J. Messmer, T. Aicher, et al. "The effect of the biomass components lignin, cellulose and hemicellulose on TGA and fixed bed pyrolysis". Journal of Analytical and Applied Pyrolysis 101 (2013), pp. 177-184. DoI: 10.1016/j·jaap.2013.01.012

[246] M. G. Grønli, G. Várhegyi, and C. Di Blasi. "Thermogravimetric Analysis and Devolatilization Kinetics of Wood". Industrial \& Engineering Chemistry Research 41.17 (2002), pp. 42014208. DOI: $10.1021 /$ ie0201157

[247] G. Jiang, D. J. Nowakowski, and A. V. Bridgwater. "A systematic study of the kinetics of lignin pyrolysis". Thermochimica Acta 498.1 (2010), pp. 61-66. DOI: 10 . 1016/ j . tca . 2009.10 .003 
[248] S. Lotfi, R. Mollaabbasi, and G. S. Patience. "Kinetics of softwood kraft lignin inert and oxidative thermolysis". Biomass and Bioenergy 109 (2018), pp. 239-248. DOI: 10 . 1016/ j.biombioe.2017.11.011

[249] K. Dussan, S. Dooley, and R. F. D. Monaghan. "A model of the chemical composition and pyrolysis kinetics of lignin”. Proceedings of the Combustion Institute (2018).

[250] T. Faravelli, A. Frassoldati, G. Migliavacca, et al. "Detailed kinetic modeling of the thermal degradation of lignins". Biomass and Bioenergy 34.3 (2010), pp. 290-301.

[251] B. R. Hough, D. T. Schwartz, and J. Pfaendtner. "Detailed Kinetic Modeling of Lignin Pyrolysis for Process Optimization". Industrial \& Engineering Chemistry Research 55.34 (2016), pp. 9147-9153. DOI: 10.1021/acs.iecr.6b02092

[252] M. T. Klein and P. S. Virk. "Modeling of Lignin Thermolysis". Energy \& Fuels 22.4 (2008), pp. 2175-2182. DOI: $10.1021 /$ ef800285f

[253] A. J. Yanez, W. Li, R. Mabon, et al. "A Stochastic Method to Generate Libraries of Structural Representations of Lignin”. Energy \& Fuels 30.7 (2016), pp. 5835-5845. DOI: 10 . 1021/acs.energyfuels.6b00966

[254] O. Faix, D. Meier, and I. Grobe. "Studies on isolated lignins and lignins in woody materials by pyrolysis-gas chromatography-mass spectrometry and off-line pyrolysis-gas chromatography with flame ionization detection". Journal of Analytical and Applied Pyrolysis 11 (1987), pp. 403-416. DOI: 10.1016/0165-2370(87)85044-1

[255] C. Saiz-Jimenez and J. W. de Leeuw. "Pyrolysis-gas chromatography-mass spectrometry of isolated, synthetic and degraded lignins". Organic Geochemistry 6 (1984), pp. 417-422. DOI: $10.1016 / 0146-6380$ (84)90064-0

[256] E. Jakab, O. Faix, F. Till, et al. "Thermogravimetry/mass spectrometry study of six lignins within the scope of an international round robin test". Journal of Analytical and Applied Pyrolysis 35.2 (1995), pp. 167-179. DOI: 10.1016/0165-2370(95)00907-7

[257] M. C. Terrón, M. L. Fidalgo, G. C. Galletti, et al. "Pyrolysis-gas chromatography-mass spectrometry of milled wood lignin of two Chilean woods naturally decayed by Ganoderma australe, Phlebia chrysocrea and a brown-rot fungus". Journal of Analytical and Applied Pyrolysis 33 (1995), pp. 61-75. DOI: 10.1016/0165-2370(94)00861-t

[258] S. Beis, S. Mukkamala, N. Hill, et al. "Fast pyrolysis of lignins". BioResources. 2010th ser. 5 (2010), pp. 1408-1424.

[259] J. Chu, W. Jiang, and S. Wu. "Depolymerization Characteristics during the Pyrolysis of Two Industrial Lignins”. BioResources. 2017th ser. 12.4 (2017), pp. 7241-7254.

[260] S. Wang, H. Lin, B. Ru, et al. "Comparison of the pyrolysis behavior of pyrolytic lignin and milled wood lignin by using TG-FTIR analysis". Journal of Analytical and Applied Pyrolysis 108 (2014), pp. 78-85. DOI: $10.1016 / \mathrm{j} \cdot$ jaap. 2014.05.014

[261] J. Zhang, K. H. Kim, Y. S. Choi, et al. "Comparison of Fast Pyrolysis Behavior of Cornstover Lignins Isolated by Different Methods". ACS Sustainable Chemistry \& Engineering 5.7 (2017), pp. 5657-5661. DOI: 10.1021/acssuschemeng. 7b01393 
[262] L. Zhang, K. Chen, and L. Peng. "Comparative Research about Wheat Straw Lignin from the Black Liquor after Soda-Oxygen and Soda-AQ Pulping: Structural Changes and Pyrolysis Behavior". Energy \& Fuels 31.10 (2017), pp. 10916-10923. DOI: 10 . 1021 /acs . energyfuels.7b01786

[263] R. Rinaldi, R. Jastrzebski, M. T. Clough, et al. "Paving the Way for Lignin Valorisation: Recent Advances in Bioengineering, Biorefining and Catalysis". Angewandte Chemie International Edition 55.29 (2016), pp. 8164-8215. DOI: 10.1002/chin.201636254

[264] A. Dufour, B. Ouartassi, R. Bounaceur, et al. "Modelling intra-particle phenomena of biomass pyrolysis". Chemical Engineering Research and Design 89.10 (2011), pp. 2136-2146. DOI: $10.1016 / \mathrm{j}$. cherd.2011.01.005

[265] E. Hoekstra, S. R. A. Kersten, A. Tudos, et al. "Possibilities and pitfalls in analyzing (upgraded) pyrolysis oil by size exclusion chromatography (SEC)". Journal of Analytical and Applied Pyrolysis 91.1 (2011), pp. 76-88. DOI: 10.1016/j · jaap.2011.01.006

[266] S. Baumberger, A. Abaecherli, M. Fasching, et al. "Molar mass determination of lignins by size-exclusion chromatography: towards standardisation of the method". Holzforschung 61.4 (2007), p. 459. DOI: $10.1515 / \mathrm{HF} .2007 .074$

[267] R. J. A. Gosselink, A. Abächerli, H. Semke, et al. "Analytical protocols for characterisation of sulphur-free lignin". Industrial Crops and Products 19.3 (2004), pp. 271-281. DOI: 10.1016/j.indcrop.2003.10.008

[268] B. Iatridis and G. R. Gavalas. "Pyrolysis of a Precipitated Kraft Lignin". Industrial \& Engineering Chemistry Product Research and Development 18.2 (1979), pp. 127-130. DOI: 10 . 1021/i360070a010

[269] C. Di Blasi. "Comparison of semi-global mechanisms for primary pyrolysis of lignocellulosic fuels". Journal of Analytical and Applied Pyrolysis 47.1 (1998), pp. 43-64.

[270] H. Yang, R. Yan, H. Chen, et al. "Characteristics of hemicellulose, cellulose and lignin pyrolysis”. Fuel 86.12 (2007), pp. 1781-1788. DOI: 10.1016/j.fuel.2006.12.013

[271] J. A. Caballero, R. Font, and A. Marcilla. "Pyrolysis of Kraft lignin: yields and correlations". Journal of Analytical and Applied Pyrolysis 39.2 (1997), pp. 161-183. DOI: 10.1016/ s0165-2370(96)00965-5

[272] K. Raveendran, A. Ganesh, and K. C. Khilar. "Pyrolysis characteristics of biomass and biomass components". Fuel 75.8 (1996), pp. 987-998. DOI: 10.1016/s0016-2361 (96) 00158-5

[273] R. Lou and S.-b. Wu. "Products properties from fast pyrolysis of enzymatic/mild acidolysis lignin”. Applied Energy 88.1 (2011), pp. 316-322. DOI: 10 . 1016/ j . apenergy . 2010.06 .028

[274] H. Ben and A. J. Ragauskas. "NMR characterization of pyrolysis oils from kraft lignin". Energy \& Fuels 25.5 (2011), pp. 2322-2332. DOI: 10.1021/ef2001162

[275] A. Demirbas. "Biomass resource facilities and biomass conversion processing for fuels and chemicals". Energy Conversion and Management 42.11 (2001), pp. 1357-1378. 
[276] A. J. Ragauskas, G. T. Beckham, M. J. Biddy, et al. "Lignin Valorization: Improving Lignin Processing in the Biorefinery". Science 344.6185 (2014), pp. 1246843-1246843. DOI: 10 . $1126 /$ science. 1246843

[277] K. V. Sarkanen. Lignins. Occurrence, Formation, Structure and Reactions. Wiley-Interscience, 1971.

[278] C. Heitner, D. Dimmel, and J. Schmidt, eds. Lignin and Lignans: Advances in Chemistry. ST LUCIE PR, 11, 2010. 683 pp.

[279] E. Novaes, M. Kirst, V. Chiang, et al. "Lignin and Biomass: A Negative Correlation for Wood Formation and Lignin Content in Trees". PLANT PHYSIOLOGY 154.2 (2010), pp. 555-561. DOI: $10.1104 /$ pp.110.161281

[280] R. Parthasarathi, R. A. Romero, A. Redondo, et al. "Theoretical Study of the Remarkably Diverse Linkages in Lignin". The Journal of Physical Chemistry Letters 2.20 (2011), pp. 2660_ 2666. DOI: $10.1021 / j z 201201 \mathrm{q}$

[281] t. Higuchi. "Bamboo lignin and its biosynthesis". Wood Research : Report of the Institute of Wood Research (Translated) 48 (1969).

[282] H.-m. Chang, E. B. Cowling, and W. Brown. "Comparative Studies on Cellulolytic Enzyme Lignin and Milled Wood Lignin of Sweetgum and Spruce”. Holzforschung 29.5 (1975), pp. 153-159. DOI: $10.1515 / \mathrm{hfsg} .1975 .29 .5 .153$

[283] H. H. Nimz and H.-D. Lüdemann. "Kohlenstoff-13-NMR-Spektren von Ligninen, 6. Ligninund DHP-Acetate". Holzforschung 30.2 (1976), pp. 33-40. DOI: 10.1515/hfsg. 1976. 30.2 .33

[284] J. F. Haw and T. P. Schultz. "Carbon-13 CP/MAS NMR and FT-IR Study of Low-Temperature Lignin Pyrolysis". Holzforschung 39.5 (1985), pp. 289-296. DOI: 10.1515/hfsg. 1985. 39.5.289

[285] J. I. Hedges, G. L. Cowie, J. R. Ertel, et al. "Degradation of carbohydrates and lignins in buried woods". Geochimica et Cosmochimica Acta 49.3 (1985), pp. 701-711. DOI: 10.1016/ 0016-7037 (85) 90165-6

[286] D. S. Radlein, J. Piskorz, and D. S. Scott. "Lignin derived oils from the fast pyrolysis of poplar wood". Journal of Analytical and Applied Pyrolysis 12.1 (1987), pp. 51-59. DOI: 10.1016/0165-2370(87)80014-1

[287] D. Ibarra, M. I. Chávez, J. Rencoret, et al. "Lignin Modification duringEucalyptus globulusKraft Pulping Followed by Totally Chlorine-Free Bleaching: A Two-Dimensional Nuclear Magnetic Resonance, Fourier Transform Infrared, and Pyrolysis-Gas Chromatography/Mass Spectrometry Study". Journal of Agricultural and Food Chemistry 55.9 (2007), pp. 3477-3490. DOI: $10.1021 / j f 063728 t$

[288] H. Ben and A. J. Ragauskas. "NMR Characterization of Pyrolysis Oils from Kraft Lignin". Energy \& Fuels 25.5 (2011), pp. 2322-2332. DOI: 10.1021/ef2001162

[289] H. Ben and A. J. Ragauskas. "Comparison for the compositions of fast and slow pyrolysis oils by NMR characterization”. Bioresource Technology 147 (2013), pp. 577-584. DOI: 10 . 1016/j.biortech.2013.07.151 
[290] M. Fortin, M. M. Beromi, A. Lai, et al. "Structural Analysis of Pyrolytic Lignins Isolated from Switchgrass Fast-Pyrolysis Oil”. Energy \& Fuels 29.12 (2015), pp. 8017-8026. DOI: 10.1021/acs.energyfuels.5b01726

[291] N. Hao, H. Ben, C. G. Yoo, et al. "Review of NMR Characterization of Pyrolysis Oils". Energy \& Fuels 30.9 (2016), pp. 6863-6880. DOI: 10.1021/acs . energyfuels .6b01002

[292] H. Ben and J. R. F. III. "In-depth investigation on quantitative characterization of pyrolysis oil by 31P NMR". RSC Advances 6.21 (2016), pp. 17567-17573. DOI: 10 . $1039 /$ c5ra23939g

[293] S. Constant, H. L. J. Wienk, A. E. Frissen, et al. "New insights into the structure and composition of technical lignins: a comparative characterisation study". Green Chemistry 18.9 (2016), pp. 2651-2665. DOI: 10.1039/c5gc03043a

[294] A. S. Jaeaeskelaeinen, Y. Sun, D. S. Argyropoulos, et al. "The effect of isolation method on the chemical structure of residual lignin". Wood Science and Technology 37.2 (2003), pp. 91-102. DOI: $10.1007 / \mathrm{s} 00226-003-0163-y$

[295] A. Guerra, I. Filpponen, L. A. Lucia, et al. "Comparative Evaluation of Three Lignin Isolation Protocols for Various Wood Species". Journal of Agricultural and Food Chemistry 54.26 (2006), pp. 9696-9705. DOI: 10.1021/jf062433c

[296] A.-A. M. A. Nada, M. A. Yousef, K. A. Shaffei, et al. "Infrared spectroscopy of some treated lignins". Polymer Degradation and Stability 62.1 (1998), pp. 157-163. DOI: 10 . 1016/s0141-3910(97)00273-5

[297] J. Zeng, G. L. Helms, X. Gao, et al. "Quantification of Wheat Straw Lignin Structure by Comprehensive NMR Analysis". Journal of Agricultural and Food Chemistry 61.46 (2013), pp. 10848-10857. DOI: $10.1021 / j f 4030486$

[298] O. Faix, E. Jakab, F. Till, et al. "Study on low mass thermal degradation products of milled wood lignins by thermogravimetry-mass-spectrometry". Wood Science and Technology 22.4 (1988), pp. 323-334. DOI: 10.1007/bf00353322

[299] Y. S. Choi, R. Singh, J. Zhang, et al. "Pyrolysis reaction networks for lignin model compounds: unraveling thermal deconstruction of $\beta-\mathrm{O}-4$ and $\alpha-\mathrm{O}-4$ compounds". Green Chemistry 18.6 (2016), pp. 1762-1773. DOI: 10.1039/c5gc02268a

[300] M. Garcia-Perez, S. Wang, J. Shen, et al. "Effects of Temperature on the Formation of Lignin-Derived Oligomers during the Fast Pyrolysis of Mallee Woody Biomass". Energy \& Fuels 22.3 (2008), pp. 2022-2032. DOI: 10.1021/ef7007634

[301] S.-S. Liaw, Z. Wang, P. Ndegwa, et al. "Effect of pyrolysis temperature on the yield and properties of bio-oils obtained from the auger pyrolysis of Douglas Fir wood". Journal of Analytical and Applied Pyrolysis 93 (2012), pp. 52-62. DOI: 10.1016/j · jaap . 2011. 09.011

[302] C. Roy, B. D. Caumia, and H. Pakdel. "Preliminary Feasibility Study of the Biomass Vacuum Pyrolysis Process". Research in Thermochemical Biomass Conversion. Springer Netherlands, 1988, pp. 585-596. DOI: 10.1007/978-94-009-2737-7_45 
[303] H. Pakdel, C. Roy, C. Amen-Chen, et al. "Phenolic compounds from vacuum pyrolysis of wood wastes". The Canadian Journal of Chemical Engineering 75.1 (1997), pp. 121-126. DOI: $10.1002 /$ cjce. 5450750119

[304] M. Garcia-Perez, A. Chaala, H. Pakdel, et al. "Vacuum pyrolysis of softwood and hardwood biomass". Journal of Analytical and Applied Pyrolysis 78.1 (2007), pp. 104-116. DOI: $10.1016 / \mathrm{j} \cdot \mathrm{jaap} .2006 .05 .003$

[305] M. Garcia-Perez, A. Chaala, and C. Roy. "Vacuum pyrolysis of sugarcane bagasse". Journal of Analytical and Applied Pyrolysis 65.2 (2002), pp. 111-136. DOI: 10 . 1016 / s01652370(01)00184-x

[306] T. R. Nunn, J. B. Howard, J. P. Longwell, et al. "Product compositions and kinetics in the rapid pyrolysis of sweet gum hardwood". Industrial \& Engineering Chemistry Process Design and Development 24.3 (1985), pp. 836-844. DOI:10.1021/i200030a053

[307] N. Chen, J. Ren, Z. Ye, et al. "Study on vacuum pyrolysis of coffee industrial residue for bio-oil production". IOP Conference Series: Earth and Environmental Science 59 (2017), p. 012065. DOI: $10.1088 / 1755-1315 / 59 / 1 / 012065$

[308] Y. M. Ju, K. C. Oh, K. Y. Lee, et al. "Performance Analysis of a Vacuum Pyrolysis System". Journal of Biosystems Engineering 43.1 (2018), pp. 14-20.

[309] D. S. Scott, L. Paterson, J. Piskorz, et al. "Pretreatment of poplar wood for fast pyrolysis: rate of cation removal". Journal of Analytical and Applied Pyrolysis 57.2 (2001), pp. 169-176. DOI: $10.1016 / \mathrm{s} 0165-2370(00) 00108-\mathrm{x}$

[310] A. D. Pouwels, G. B. Eijkel, P. W. Arisz, et al. "Evidence for oligomers in pyrolysates of microcrystalline cellulose". Journal of Analytical and Applied Pyrolysis 15 (1989), pp. 71-84. DOI: $10.1016 / 0165-2370(89) 85023-5$

[311] O. P. Golova. "Chemical Effects of Heat on Cellulose". Russian Chemical Reviews 44.8 (1975), pp. 687-697. DOI:10.1070/rc1975v044n08abeh002369

[312] D. S. Scott, J. Piskorz, M. A. Bergougnou, et al. "The role of temperature in the fast pyrolysis of cellulose and wood". Industrial \& Engineering Chemistry Research 27.1 (1988), pp. 8-15. DOI: $10.1021 /$ ie00073a003

[313] T. Hosoya, H. Kawamoto, and S. Saka. "Different pyrolytic pathways of levoglucosan in vapor-and liquid/solid-phases". Journal of Analytical and Applied Pyrolysis 83.1 (2008), pp. 64-70. DOI: $10.1016 / \mathrm{j} \cdot$ jaap.2008.06.008

[314] R. J. M. Westerhof, H. S. Nygård, W. P. M. van Swaaij, et al. "Effect of Particle Geometry and Microstructure on Fast Pyrolysis of Beech Wood". Energy \& Fuels 26.4 (2012), pp. 2274-2280. DOI: $10.1021 /$ ef 201688n

[315] A. Rahimi, A. Ulbrich, J. J. Coon, et al. "Formic-acid-induced depolymerization of oxidized lignin to aromatics". Nature 515.7526 (2014), pp. 249-252. DOI:10.1038/nature13867

[316] L. Shuai, M. T. Amiri, Y. M. Questell-Santiago, et al. "Formaldehyde stabilization facilitates lignin monomer production during biomass depolymerization". Science 354.6310 (2016), pp. 329-333. DOI: 10.1126/science.aaf7810 
[317] S. Wehlte, D. Meier, J. Moltran, et al. "The Impact of Wood Preservatives on the Flash Pyrolysis of Biomass". Developments in Thermochemical Biomass Conversion: Volume 1/Volume 2. Ed. by A. V. Bridgwater and D. G. B. Boocock. Dordrecht: Springer Netherlands, 1997, pp. 206-219. DOI: 10.1007/978-94-009-1559-6_15

[318] S. Kumagai, R. Matsuno, G. Grause, et al. "Enhancement of bio-oil production via pyrolysis of wood biomass by pretreatment with H2SO4". Bioresource Technology 178 (2015), pp. 76-82. DOI: 10.1016/j.biortech.2014.09.146

[319] B. Shrestha, Y. le Brech, T. Ghislain, et al. "A multitechnique characterization of lignin softening and pyrolysis". ACS Sustainable Chemistry \& Engineering 5.8 (2017), pp. 6940_ 6949. DOI: $10.1021 /$ acssuschemeng.7b01130 




\section{Acknowledgement}

The journey of my $\mathrm{PhD}$, in the last four and a half years, was full of ups and downs, a lot of fun and self-enriching. To quote Sir Isaac Newton "... If I have seen further it is by standing on the shoulders of Giants." Hence, I would like to acknowledge people who have directly or indirectly helped me in shaping up this work.

Sascha, first of all, thanks a lot for giving me the opportunity to pursue this $\mathrm{PhD}$ work. I remember our first meeting on $5^{\text {th }}$ January 2015, when you gave me your first advice - "If you don't know something, just accept that as a fact, so you can learn.". To this day, I have sincerely tried to follow that thought and will continue to do so. I have learnt a lot from you on various levels. I must admit writing was not my strong suit, however, with your guidance and feedback, this work has been materialised. It was fun (not always) to discuss the same figures over and over again to refine the hypothesis. When I moved to Europe in 2011, I was afraid of mathematics, and today, I can proudly put that behind me. Thank you for pushing me in that direction by giving me the opportunity to be your student assistant in a reactor design course. Roel (Gen. PyRoel), thanks a lot for supervising me on a daily basis (on some instances hourly basis) during this whole journey of my PhD. I always admired your critical thinking about the results and your clear feedback. It was fun learning from you on how to operate the pilot plant unit. I learnt a lot of experimental skills with your guidance. I enjoyed our long conversations about pyrolysis, geopolitics, economics and of course, food. Thank you, Sascha and Roel, for your advice, time (on some occasions even at midnight) and faith in me without which this was impossible to achieve.

I would like to express my sincere gratitude to my graduation committee for accepting the invitation to judge my work and taking the time to read the same. I look forward to having a fruitful and constructive discussion on the $13^{\text {th }}$ of September 2019.

This work was financially supported by the Netherland's Organisation for Scientific Research (NWO), The Netherlands to which I am grateful.

A special thanks to Benno, Johan, the late Karst, and Ronald for their excellent technical support. Without you, it would not have been possible to perform all my experiments successfully. I enjoyed working with you all in the pleasant atmosphere of HDL with coffee and cakes. Erna, thank you for making sure that the analytical equipment was up and running. Thank you for allowing me to learn LC-MS with you in Bremen, Germany. Thank you, Yvonne, for taking care of all the paperwork which was essential in this journey. Thank you, especially for booking time in Sascha's agenda whenever I 
needed.

This work wouldn't have been materialised without the contribution of all the students. Ivar, Tom, Peter, Miranti, Pau, Tesfalidet, Rustam, Thomas, Julia and Alessandro, I enjoyed the time working with you all, and I express my sincere gratitude to you.

Stijn, thank you very much for guiding me through the heaps of pyrolysis literature in my initials days when I had no clue about what pyrolysis was, and also for introducing me to the "smelly" world of pyrolysis in my first week itself. I remember many conversions about pyrolysis, photography, food, and enjoyed speaking in Dutch with you on (almost) every Dutch Wednesdays until you were in the SPT.

I would like to thank the rest of the SPT staff, Wim and Wim, Jean-Paul, Louis, Boelo, Caroline and Henk. Pilar, thanks a lot for helping me out with the last experiments in the screen heater and for fun conversations. Alberto, without your NMR expertise I couldn't have shown some of the exciting results, thanks a ton!

Bert, thank you for giving me the opportunity to work at the Suster BV on the Eastman project, and I look forward to doing my best.

Dear pigeon from South Africa (Surika), I got to know you first when you visited SPT for your internship in 2015, and since then it has been an interesting journey for us from being colleagues to friends. We enjoyed eating carrot cakes, cheesecakes and pancakes at home, in Doppio, and almost everywhere. Thank you for joining us to innumerable day trips, and the fun we had exploring different cities. I appreciate that you took me annoying you in the right sense, and now you have the "premium" access to avenge the same. Also, thanks for safeguarding my noodles from Dortmund to Enschede :P. This year alone we biked together roughly $80 \mathrm{~km}$, and I hope in the future we will cross the $100 \mathrm{~km}$ mark. I wish one day I visit Kruger Park with you. I must admit that you replicate pigeon sound very well. Thank you for making me the delicious Bunny Chow, apple cake and moist melk taart muffins, and always listening to my frustrations about work. I wish you all the very best in the last year of your PhD and hope to attend your defence soon. Thimo, I enjoyed our discussions not only about biomass but also about politics, programming and social sciences. Also, your journey from being a student of mine to a friend and a paranymph has been interesting. Thank you for being there to discuss pyrolysis in the university hallways and while cycling back home from work. I really appreciate your gift of Klompen, which will remain as a unique Dutch souvenir with me forever. Special thanks to your father for exchanging the boots to my size. Although I never mentioned this before, we share the love for peanut butter. Looking forward to more mini-golf sessions (at which you are really good). I wish you success for your 
$\mathrm{PhD}$ and future career. I would like to express my sincere thanks to both of you, Surika and Thimo, for going through the chapters of my thesis and sharing your constructive feedback.

Lisette, I cannot thank you enough for all the things you have done for me throughout this journey. I remember when you rescued me from the "Dark" Christmas of 2015. We shared a lot of happy moments including cooking sessions (paneer, pasta, 6-layered cakes, samosa, etc.), biking, to a small extent PS4 gaming, day trips to all the corners of the Netherlands (and also in Germany), and of course Christmas markets. I definitely look forward to tasting your version of Glühwein this year. Thank you for being a part of the joyous occasion of my wedding in India. Thanks to you and Fred for helping us in filling out tax forms, driving us to IKEA and to many more destinations. Also, thank you for introducing Prachi and me to the traditional Dutch Christmas dinner. I hope we cherish our friendship in the upcoming years. I wish you both success with everything. Dear Ehsan, thank you for the unlimited gaming experience (probably we spent more than 100 hours on Mortal Combat, Call of Duty, Ghost Recon, Far Cry), Iranian-Indian cooking evenings, last moment decided day trips, long discussions about the history of Asia and science, and giving me the honour of being your paranymph. I truly enjoyed our visit to the Iranian and Persian Garden Exhibition in Bonn, Germany. I hope that we continue visiting Ganesha and explore many more eateries. I admire your passion for being a perfectionist, for example, you were determined to resolve a mismatch of 0.5 $\mathrm{mm}$ on your thesis cover even when it was not a concern. I appreciate your love towards "high quality" stuff, and I hope you become "Richie Rich" in the future to build your collection. Thank you for helping us out on difficult days. I wish you all the best in future endeavours. Sam, thanks for being a good friend with whom I could have healthy conversations and giving me the honour of being your paranymph on the D-Day. Thank you for introducing me to Nthabi and Simi. I hope we will meet soon in Terneuzen as well as in Ghent to have a good time. I wish all three of you the best for the future.

Cindy, thanks for the Chinese food workshop at your place, letting me taste your algae and honouring me to be your paranymph. I wish you and your family the best for the future, and I look forward to visiting your restaurant someday. Chiel (toyo), thank you for being the amazing neighbour in the office. Dion, it was nice to have a discussion about lignin with you time to time, and helping me out with the translation, thanks! Gerardo, I always enjoyed talking to you and was amazed to see that you could finish a glass of beer in almost two seconds. You are a great friend, thanks! Juraj, you are (probably will be) the dancer of SPT and hitting the floor with you was fun. I also enjoyed conversations on various topics with you, thanks mate! 
Marek and Sandra, I do remember our nice day trip to Soesterberg Dutch Military Museum, and we also enjoyed some gaming together, thank you! Maria, I am grateful to you for teaching me GPC, which was very useful during this work, and enjoyed working with you in my early days at the SPT, thanks! Martijn, thank you for analysing my high priority HPLC samples which ended up in Chapter 7 of this thesis. Martin (Jackson), I enjoyed our small conversations during lunch and coffee breaks on the whole range of subjects. I learned a few tricks of Matlab and LATEX from you while typesetting this thesis. Thanks man! Oh yes, also thanks for not showing the bloopers of my colour knowledge. Natalia, till date, I am still surprised how you managed to make brownies from kidney beans. Thanks for having nice conversations with me and sharing your noodle salad recipe. I wish you and Kasper all the best for the future. Özge, I really enjoyed our trip to Dortmund Christmas market. You are a wonderful person, friend and researcher, and it was nice that we could collaborate in our work.

Pavlina, thanks for helping me out in getting lignin samples from ECN and checking work pyrolysis in Greek script. Rick, thanks for showing me Matlab tricks to debug my code. I wish you all the best for the last phase of your PhD. Shushil, I always enjoyed talking with you in Hindi about Indian politics. Thanks for making me a delicious dinner just an evening before your defence in 2015. Thomas, the analysis of a few of my samples in your GC was really crucial for two chapters in this thesis, thanks for helping me out! Tomas, thanks for answering my all Matlab queries, introducing me to your "Chocolate Drawer" in the office and giving me paaseitjes even when we were almost nine months away from Easter. Vincent, I enjoyed supervising and correcting ACRE exams with you. You were too generous in giving points! Hartstikke (not Hardstikke :P) bedankt for reading one of the chapters of my thesis and helping me out with Matlab! Varsha, it is good to have a friend from your motherland in a foreign country! You have always been an encouraging and supporting friend of mine, thank you! I am also very thankful to Anne, Angelo, Daniele, Linonel, Lucia, Maarten, Michel, Muthia, Qian, Rens, Rik, Urmi, Vahideh, Xiaohua and Yordi, whom I met during my stay at SPT. Robert, I really appreciate your help in working out the analysis of pyrolysis oils on LC-MS, thanks a lot !

Lisette, Surika, Varsha, Chiel, Dion, Gerardo, Martin, Stijn and Thomas, thank you very much guys for joining my wedding in India, all of you made it really special. I hope you had a good time exploring India.

Manas, thank you for helping me out with the housing contract even before I started my PhD officially. All the best for the final phase of your PhD. Vikram, thank you for keeping me company in Calslaan 1 in the first six months of 2015. Together with 
Manas and you, we had many meals together. Anvar, thank you for having good conversations in Calslaan 1 on various topics. Praneeth, I enjoyed small chats with you every now and then with a cup of coffee, thanks! Special thanks to Pramodji and Aadhar team (Navin-Mitwa, Kartikeya-Harshita, Shantanu, Poorvi, etc.) for involving me in Dandiya and Enschede marathon event. Tushar and Anupriya, thank you for keeping us company and celebrating all the festivals with us. Good luck with your future adventures.

I have no words to express my gratitude to Aai and Baba throughout the journey of my education. I was never inclined to go outside India to pursue higher studies, however, with your trust in me, I am at this stage of completing my studies. Thank you for always being there to listen to my jibber-jabber and supporting me through the difficult times. Special thanks to Aai for translating the English summary of this thesis into Marathi. Tai, Vihaan and Swapneel, thanks a lot for keeping me motivated by having timely video calls, regularly sending me photos of various events back home. Kaka and Kaku (Buche), through your video calls, you always supported me throughout the journey of $\mathrm{PhD}$. Hope to see you soon. I am forever indebted to Shri Damle kaka and P.P. Shri Aanandswami for your continued support and guidance during this whole journey.

Prachi, I cannot thank you enough for putting up with my frustrations, encouraging and motivating me on tough days, and for understanding me when I was working late in the evenings (or sometimes a whole night). Without your support and love, I couldn't have overcome the challenges, which I faced, especially in the last phase of this journey. I look forward to enjoying many more adventures with you in the upcoming years. 



\section{List of publications}

\section{Publications}

[1] R.J.M. Westerhof, S.R.G. Oudenhoven, P.S. Marathe, M. Engelen, M. Garcia-Perez, Z. Wang, S.R.A. Kersten, The interplay between chemistry and heat/mass transfer during the fast pyrolysis of cellulose, Reaction Chemistry \& Engineering 1 (2016) 555-566, DOI: 10.1039/C6RE00100A

[2] P.S. Marathe, S.R.G. Oudenhoven, P.W. Heerspink, S.R.A. Kersten, R.J.M. Westerhof, Fast pyrolysis of cellulose in vacuum: The effect of potassium salts on the primary reactions, Chem. Eng. J. (Lausanne) 329 (2017) 187-197,

DOI: 10.1016/j.cej.2017.05.134

[3] P.S. Marathe, R.J.M. Westerhof, S.R.A. Kersten, Fast pyrolysis of lignins with different molecular weight: Experiments and modelling, Appl. Energy 236 (2019) 1125-1137, DOI: 10.1016/j.apenergy.2018.12.058

[4] P.S. Marathe, A. Juan, X. Hu, R.J.M. Westerhof, S.R.A. Kersten, Evaluating quantitative determination of levoglucosan and hydroxyacetaldehyde in bio-oils by gas and liquid chromatography, J. Anal. Appl. Pyrolysis (2019),

DOI: 10.1016/j.jaap.2019.02.010

[5] M. Pala, P.S. Marathe, X. Hu, F. Ronsse, W. Prins, S.R.A. Kersten, J.P. Lange, R.J.M. Westerhof, Recycling of product gas does not affect fast pyrolysis oil yield and composition (Manuscript submitted)

[6] P.S. Marathe, R.J.M. Westerhof, S.R.A. Kersten, Effect of pressure on the fast pyrolysis of acid-leached bagasse and pine wood: experiments and modelling (Manuscript in preparation) 


\section{Poster presentation}

[1] P.S. Marathe, S.R.G. Oudenhoven, R.J.M. Westerhof, S.R.A. Kersten, Effect of Alkali and Alkaline Earth Metals (AAEMs) on Cellulose Pyrolysis, European Biomass Conference and Exhibition 2016, Amsterdam, The Netherlands

[2] P.S. Marathe, T.C. Derks, R.J.M. Westerhof, S.R.A. Kersten, Effect of Pressure on Fast Pyrolysis of Untreated and Acid Leached Bagasse, National Process Technology Symposium 2018, Enschede, The Netherlands

\section{Oral presentation}

[1] P.S. Marathe, A. Juan, R.J.M. Westerhof, S.R.A. Kersten, The interplay between chemistry and heat/mass transfer during pyrolysis of lignin, Pyro2018, Kyoto, Japan 


\section{About the author}

Pushkar was born on $16^{\text {th }}$ August 1988 in Mumbai, India, where he attended secondary school. After the conclusion of schooling in 2004, he went to the Bharati Vidyapeeth Institute of Technology (BVIT), New Mumbai and obtained a Diploma in Chemical Engineering in 2007.

Pushkar obtained Bachelors in Chemical Engineering in 2010 from the University of Mumbai. During bachelor studies, he did an internship at the Indian Institute of Technology, Bombay (IITB) on the topic 'Reactive Distillation' under the guidance of Prof. Dr S.M. Mahajani.

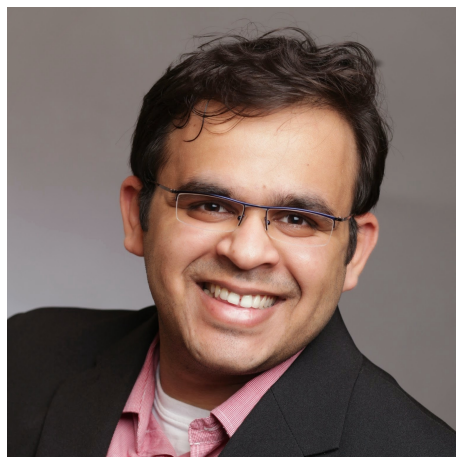

He worked as a Research Assistant at the Institute of Chemical Technology, Matunga (ICT) on the research project titled - Novel solvents for $\mathrm{CO}_{2}$ capture from flue gas, under the guidance of Assoc. Prof. Dr P.D. Vaidya for 9 months (January to September 2011).

Pushkar started his master's studies in 2011 at the Technical University of Dortmund, Germany (TUD). During his master's studies, he had an opportunity to work as a Process Intern at the Electrolysis Division of the ThyssenKrupp Uhde GmbH, Dortmund and Bayer MaterialScience, Leverkusen. The M.Sc. was concluded in October 2014 with the thesis titled - Investigations on the effectiveness of latent heat storage by hybrid adsorbent-PCM particles, under the guidance of Prof. Dr D.W. Agar.

Since January 2015 he started working as a PhD student at the University of Twente on the NWO Research project titled - Fundamentals of Fast Pyrolysis, under the guidance of Prof. Dr S.R.A. Kersten and Dr R.J.M. Westerhof. The work performed during his $\mathrm{PhD}$ is written down in this thesis. 


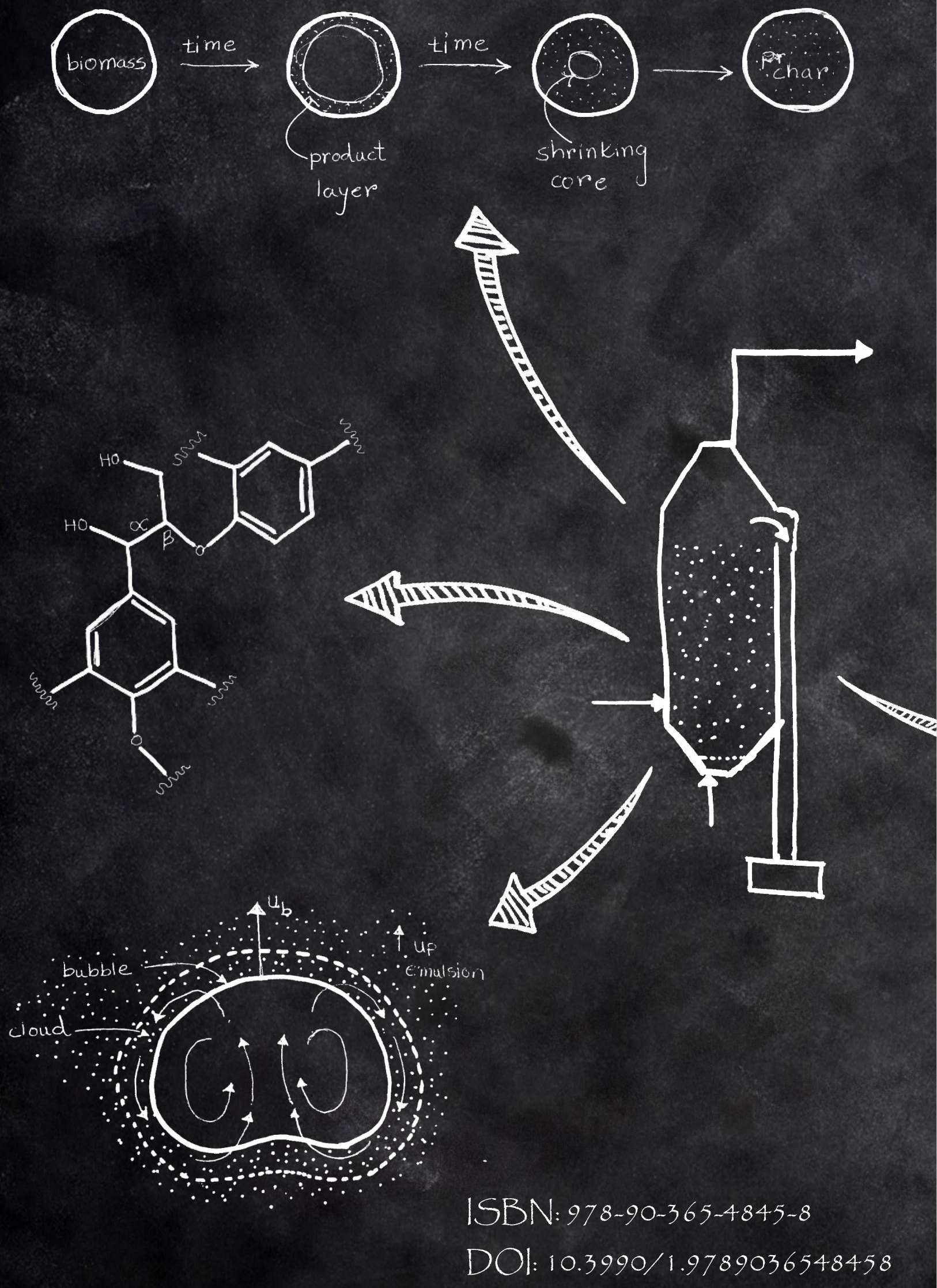

